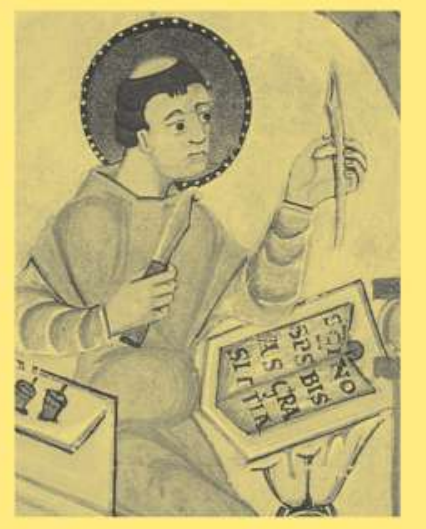

Kultur, Wissenschaft,

Literatur

Beiträge zur

Mittelalterforschung

Band 38

Judith Lange / Eva Rothenberger /

Martin Schubert (Hrsg.)

Die Kolmarer Liederhandschrift und ihr Umfeld

Forschungsimpulse 
Der vorliegende Sammelband zur Kolmarer Liederhandschrift (München, BSB, Cgm 4997) widmet sich der überlieferungs- und kulturgeschichtlichen Stellung dieser herausragendsten und umfangreichsten Meisterliederhandschrift sowie ihrem Verhältnis zu den übrigen Codices der rheinisch-schwäbischen Gruppe der Liederhandschriften. Der Band vereint verschiedene Aspekte aus den Bereichen der Überlieferungs- und Wirkungsgeschichte sowie der Kulturgeschichte des Meistergesangs. Im Fokus stehen die textuellen und melodischen Kunstformen der Kolmarer Liederhandschrift, die Textualität der überlieferten Lieder sowie das facettenreiche geistliche Liedgut der Handschrift.

Prof. Dr. Martin Schubert, Dr. Eva Rothenberger und Dr. Judith Lange sind in der Germanistischen Mediävistik an der Universität Duisburg-Essen tätig. Ihre Forschungsschwerpunkte sind Editionsphilologie, mittelalterliche Lyrik und Mittelalterrezeption (Schubert), mittelhochdeutsche und frühneuhochdeutsche Marienlyrik, Liturgie und Volkssprache sowie Meistergesang (Rothenberger) und Töne des Sangspruchdichters Regenbogen, Genderkonstruktionen in der mittelhochdeutschen Epik sowie Interpunktionsforschung (Lange). 
Die Kolmarer Liederhandschrift und ihr Umfeld 


\section{KULTUR, WISSENSCHAFT, LITERATUR BEITRÄGE ZUR MITTELALTERFORSCHUNG}

Herausgegeben von Thomas Bein

BAND 38 


\author{
Judith Lange / Eva Rothenberger / \\ Martin Schubert (Hrsg.)
}

\title{
Die Kolmarer Liederhandschrift und ihr Umfeld
}

Forschungsimpulse 


\title{
Bibliografische Information der Deutschen Nationalbibliothek
}

Die Deutsche Nationalbibliothek verzeichnet diese Publikation in der Deutschen Nationalbibliografie; detaillierte bibliografische Daten sind im Internet über http://dnb.d-nb.de abrufbar.

\author{
Abbildung auf dem Umschlag: \\ Notker Balbulus als Schreiber. \\ ,Mindener' Tropar. Um 1025. Berlin theol. lat. quart. 11. \\ Abdruck mit freundlicher Genehmigung von: \\ Bibl. Jagiellońska, Krakau.
}

Die frei zugängliche Open-Access-Publikation des vorliegenden Titels wurde mit Mitteln des Publikationsfonds der Universitätsbibliothek

Duisburg-Essen ermöglicht.

\author{
ISSN 1615-665X \\ ISBN 978-3-631-77842-5 (Print) \\ E-ISBN 978-3-631-85613-0 (E-PDF) \\ E-ISBN 978-3-631-85614-7 (EPUB) \\ DOI $10.3726 / \mathrm{b} 18479$
}

PETER LANG

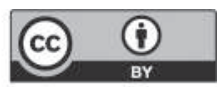

Open Access: Dieses Werk ist lizenziert unter einer Creative

Commons Namensnennung 4.0 Internationalen Lizenz (CC-BY). Weitere Informationen: https://creativecommons.org/licenses/by/4.0/

(C) Judith Lange / Eva Rothenberger / Martin Schubert (Hrsg.), 2021

Peter Lang - Berlin · Bern · Bruxelles · New York ·

Oxford $\cdot$ Warszawa $\cdot$ Wien

Diese Publikation wurde begutachtet.

www.peterlang.com 


\section{Inhalt}

Vorwort

Judith Lange, Eva Rothenberger und Martin Schubert

Einleitung 9

\section{Textuelle und melodische Kunstformen in der Kolmarer}

Liederhandschrift

Horst Brunner

Leich, Hort, Parat, Reihen, Tanz. Artifizielle Lieder in der Kolmarer

Liederhandschrift

Lorenz Welker

Reyen in der Kolmarer Liederhandschrift. Gattungscharakteristika und Kontext in musikhistorischer Perspektive

Stefan Rosmer

Die Töne der Kolmarer Liederhandschrift. Versuch zu den melodischen Formen, Strophenstrukturen und der Schichtung des Bestands 103

\section{Überlieferung und Textualität}

\section{Michael Baldzuhn}

nachsenger und Fremdtext-Verwertung. Barauffüllung und

Wiederverwendung alter Sangspruchstrophen im neuen Meisterlied

Sophie Knapp und Holger Runow

Kopieren - Kompilieren - Kreieren. Aspekte der Überlieferung und Textualität am Beispiel des Frauenlobcorpus der Kolmarer Liederhandschrift

Nils Hansen

„gräulich verderbt“ und „übel zugerichtet“? Überlieferungstreue und Bearbeitungstendenzen der Kolmarer Liederhandschrift am Beispiel von Liedern in Tönen Konrads von Würzburg 
Anabel Recker

Der Cgm 1019 im Kontext der rheinisch-schwäbischen Meisterliederhandschriften. Mit einer Analyse der Konkordanzen zur Kolmarer Liederhandschrift

\section{Geistliches Lied und theologische Reflexion in $\mathrm{k}$}

Felix Prautzsch

Die Meisterschaft des Laien? Zum ästhetischen und theologischen Anspruch im Meistergesang

Johannes Janota

Die Bibelversifikationen in der Kolmarer Liederhandschrift

Simone Loleit

neyn, da zweyent sich die mer - Zum Zusammenhang von Antijudaismus, christologischer Schriftauslegung und Allegorese in Regenbogens

Der juden krieg

\section{Die Metapoetik der Meisterlieder bis 1520}

Johannes Rettelbach

Ist imandt hie der mit mir singen welle? Überblick über die Elemente metapoetischer Meisterlieder 1430 bis 1520

Register 


\section{Vorwort}

Dieser Band, der die aktuelle Forschung zu einer der wichtigsten mittelalterlichen Handschriften zusammenzubringen versucht, geht zurück auf einen Workshop, der am 3. und 4. September 2018 an der Universität Duisburg-Essen veranstaltet wurde. Die Veranstaltung, die federführend von Eva Rothenberger und Judith Lange organisiert und konzipiert wurde, widmete sich, wie die Ausschreibung besagte, unter interdisziplinärer Perspektive „der überlieferungsund kulturgeschichtlichen Stellung der Kolmarer Liederhandschrift sowie ihrem Verhältnis zu anderen großen Meisterliederhandschriften“. Die facettenreichen Vorträge beleuchteten verschiedene Aspekte aus den Bereichen der Überlieferungs- und Wirkungsgeschichte, der Philologie und Editionswissenschaft, der Musikwissenschaft und der Kulturgeschichte des Meistergesangs.

$\mathrm{Zu}$ danken ist der Deutschen Forschungsgemeinschaft, welche den besagten Workshop im Rahmen des DFG-Projekts „Edition der in Regenbogens Langem Ton überlieferten Lieder" finanzierte. Die frei zugängliche Open-Access-Publikation des vorliegenden Titels wurde mit Mitteln des Publikationsfonds der Universitätsbibliothek Duisburg-Essen ermöglicht. Vor allem danken wir den Beiträgerinnen und Beiträgern für ihre Referate und Diskussionen sowie für die Ausarbeitung der Druckfassungen für diesen Sammelband. Für die nächsten Jahre, in denen sich die Erforschung der Kolmarer Liederhandschrift sicher noch immens vertiefen wird, hoffen wir, einen nützlichen Baustein beigetragen zu haben.

Essen, im Januar 2021

J. L., E. R., M. S. 



\section{Judith Lange, Eva Rothenberger und Martin Schubert}

\section{Einleitung}

\section{I. $\mathrm{Zu}$ diesem Band}

Die in diesem Band versammelten Beiträge widmen sich weitestgehend drei großen Themenbereichen:* den Kunstformen in der Kolmarer Liederhandschrift (1), der Überlieferung und Textualität (2) sowie dem geistlichem Liedgut (3). Hinzu gesellt sich der Beitrag Johannes Rettelbachs, der versucht, das metapoetische Liedgut der Meistersinger zu analysieren und zu klassifizieren (4).

\section{Textuelle und melodische Kunstformen in der Kolmarer Liederhandschrift}

Die Autoren Horst Brunner, Lorenz Welker und Stefan Rosmer widmen sich jeweils den textuellen und/oder melodischen Kunstformen der Kolmarer Liederhandschrift. Dabei bleibt Brunner ganz fokussiert auf die Texte der zweiten Lage der Handschrift, während Welker und Rosmer für ihre Überlegungen die Parallelüberlieferung der analysierten Töne (Rosmer/Welker) sowie zeitnahe form- und/oder namensgleiche Lieder und Melodien aus Frankreich und Großbritannien (Welker) mit einbeziehen.

Horst Brunners Beitrag reflektiert über diejenigen Lieder, die sich zu Beginn der Handschrift versammelt finden und sich vom übrigen Liedgut der Handschrift ihrer Form nach unterscheiden. Nach einer ausführlichen Beschreibung der unter dem Schlagwort „artifiziell“ versammelten Liedtypen Leich, Hort, Parat, Reihen und Tanz untersucht Brunner dieses, Sondergut' auf seine kunstfertige ,Gemachtheit' hin. Neben Liedern, die allein durch ihren großen Umfang schon eine Sonderstellung einnehmen, werden unter den Bezeichnungen Parat, Reihen, Tanz und Leich besonders jene Lieder versammelt, deren Produktion das Kunstvermögen der Autoren sowohl hinsichtlich ihrer metrischen als auch ihrer sprachlichen Gestalt auf besondere Weise herausforderte.

Lorenz Welker befasst sich in seinem Beitrag mit einem spezifischen der von Brunner als „artifiziell“ bezeichneten Liedtypen, dem Reihen, und geht der Frage nach deren gattungstypischer (melodischer und textueller) Gestalt

* In dieser gemeinsam erstellten Einleitung geht Teil I auf Judith Lange zurück, Teil II auf Eva Rothenberger, Teil III auf Martin Schubert. 
nach. Welker rückt die Reihen aufgrund ihrer Texte in die Nähe des ,Tanzes', da sowohl Reihen als auch Tanz von einem Anführer, der die Bewegung vorgibt, geleitet werden. Ein Vergleich der musikalischen Form der fünf in der zweiten Lage aufgezeichneten Reihen mit ihren Parallelüberlieferungen zeigt, dass die Melodieführung der k-Versionen sich im Vergleich zur Parallelüberlieferung konsequent als schlichter erweist. In einem zweiten Schritt nimmt Welker, nach einer vorangehenden Definition des Reihenbegriffs unter Einbezug der gängigen Musiklexika und mhd. Wörterbücher, den Gattungskontext und mögliche Charakteristika des Liedtypus in den Blick. Im Vergleich mit Quellen aus dem englisch- und französischsprachigen Raum weist Welker nach, dass es spezifische Gattungscharakteristika des „deutschen Reihen“ gegeben haben muss, die sich unserem heutigen Blick in weiten Teilen entziehen.

Stefan Rosmer widmet sich - in der Rolle eines Impulsgebers für weitere Forschung - den Melodien in k, die bis in die jüngere Forschung zur Musik hinein kaum eine Rolle einnahmen. Auf eine Skizze der bisherigen Forschung über die Musik mittelalterlicher deutschsprachiger Musiktexte folgt eine eingehende Betrachtung der in k überlieferten Töne (d. h. hier Notationen), um diese hinsichtlich einer möglichen zeitlichen Schichtung miteinander zu vergleichen. Rosmer kommt zu dem Schluss, dass die Töne in $\mathrm{k}$ keineswegs so homogen sind wie bisher angenommen. Er erarbeitet anhand zweier Beispielanalysen die Arbeitshypothese zweier „Typen oder Modelle der musikalischen Gestaltung eines Tons, denen sich der Großteil der untersuchten Töne zuordnen lässt“ (S. 128). Dabei kommt Rosmer zu dem Ergebnis, dass die beiden Gruppen (A. und B. genannt) zeitliche Schichtung markieren: Während sich in Gruppe A. (von einer Ausnahme abgesehen) nur unechte Töne und Töne von Autoren versammeln, die nach 1350 produktiv waren, finden sich unter B. alle anderen altüberlieferten Töne sowie unechte Töne und ein „sicher junger Ton von Albrecht Lesch“ (S. 129).

\section{2. Überlieferung und Textualität}

Der Überlieferung einzelner Texte und Korpora sowie dem produktiven Umgang mit bereits vorhandenem Liedmaterial durch Fremdtext- und Fremdtonverwender oder durch die k-Schreiber A und B widmen sich die Beiträge Michael Baldzuhns, des Autorenduos Sophie Knapp und Holger Runow sowie Nils Hansens. Anhand des Frauenlob-Korpus (Knapp/Runow) und anhand des Konrad von Würzburg-Korpus (Hansen) wird zum einen der generellen Qualität der in k überlieferten Lieder und zum anderen den vorhandenen Formen und Ausprägungen redaktioneller Eingriffe nachgespürt. Anabel Recker 
beschäftigt sich mit ähnlichen Fragestellungen, indem sie die Überlieferungszusammenhänge der Gruppe der sog. rheinisch-schwäbischen Liederhandschriften beleuchtet. Besonderes Augenmerk legt die Autorin dabei auf die etwas ältere fränkische Meisterliedersammlung Cgm 1019 und ihre Konkordanzen zu k.

Den Reigen der Beiträge, die sich mit der Textüberlieferung innerhalb der Kolmarer Liederhandschrift beschäftigen, eröffnet die umfangreiche Materialsammlung Michael Baldzuhns. Baldzuhn befasst sich mit jenen Strophenkonglomeraten, die sich aus, unechten' und ,echten' Strophen zusammensetzen, und geht der Frage nach, welche Überlieferungsreflexe hinter den Ergänzungen junger Strophen stehen. Unterteilte die Forschung bislang in ,Auffüllung und ,Zusammenstellung' und folgte einem produktionsästhetischen, auf die Konvention ungerader Strophenzahlen der Bare fokussierten Erklärungsansatz, versucht Baldzuhn, die Zusammenstellung prozessorientiert (im Rahmen einer „Übergangsphase obligater Mehrstrophigkeit“ [S. 138]) und „um seiner selbst willen“" (S. 139) zu untersuchen. Auf Basis des Kolmarer Liedmaterials erarbeitet Baldzuhn vier Grundtypen der Wiederverwendung/Fremdtext-Verwertung durch meisterliche nachsenger.

Auch Sophie Knapp und Holger Runow widmen sich den Formen des produktiven Umgangs mit bereits vorhandenen Strophen und Liedern und analysieren diese anhand der Lieddubletten innerhalb des Frauenlob-Korpus in k. Neben Fällen von Dubletten, hinter denen mit hoher Wahrscheinlichkeit Versehen im Abschreibeprozess stecken, weisen Runow und Knapp nach, dass einzelne Strophen durchaus kreativ in neue Barzusammenhänge (z. T. in Verbindung mit altüberlieferten und/oder ,echten' Einzelstrophen) eingefügt sind und sich „eine spezifische Art produktiv gestaltender Redaktion, nämlich [eine] punktuelle Anpassung an [das neue] Umfeld beobachten lässt" (S. 213). Dabei ist, so die Autoren, nie pauschal zu urteilen, sondern jeder mehrfach überlieferte Bar, jede mehrfach abgeschriebene Strophe oder Strophenteile bedürfen einer separaten Untersuchung und Bewertung.

Nils Hansen beschäftigt sich, ausgehend von älteren kritischen Stimmen dazu, mit Fragen der Überlieferungstreue der in $\mathrm{k}$ überlieferten Lieder und Strophen Konrads von Würzburg; im besonderen Fokus stehen auch hier Lieder, die in $\mathrm{k}$ als Dubletten vorliegen. Akribisch vergleicht Hansen die in $\mathrm{k}$ überlieferten Texte mit der heute noch auf uns gekommenen Altüberlieferung vor allem im Cpg 350 (D) sowie in der Großen Heidelberger Liederhandschrift C. Neben der Frage, wie altüberliefertes Material in k präsentiert wird, möchte Hansen Hinweisen darauf nachspüren, „welche Art von Vorlagen die Redaktoren der Handschrift verarbeiteten und wie sie mit diesen umgingen“ (S. 222). 
Er kommt zu dem Schluss, dass das Korpus durchaus unterschiedliche Formen und Ausprägungen der Bearbeitung aufweist, es sich bei einem Großteil der vorgenommenen Änderungen allerdings um Eingriffe handelt, die den Auftakt herstellen oder das Versmaß in meistersingerischer Manier ,bessern'. Hansen stellt eine Spannbreite von Bearbeitungstendenzen fest, zu der auch die recht getreue Übernahme alter Quellen zählt.

In einen größeren Überlieferungskontext wird die Kolmarer Liederhandschrift durch Anabel Recker gestellt. Sie untersucht den Cgm 1019 (Sigly y) und seine Konkordanzen zu k im Kontext der Gruppe der rheinisch-schwäbischen Liederhandschriften, zu welchen beide Handschriften zählen. Recker spürt den Verwandtschaftsverhältnissen der Handschriften untereinander nach, um Aufschluss darüber zu erhalten, woher die Schreiber von k das Material für ihre Kollektion bezogen und ob möglicherweise Kontaktpunkte zwischen einzelnen meistersingerischen Produktionszentren bestanden. Für den Cgm 1019 hält Recker nach ihrer Analyse fest, dass dieser ein dezidiert meisterliches Profil aufweist: „Die Datierung, die Verortung in Franken, die weltliche inhaltliche Ausrichtung, das spezifisch meistersingerliche Sondergut - all diese Merkmale machen ein Entstehungsumfeld, in dem meisterlicher Gesang produktiv ausgeübt wurde, plausibel“ (S. 273). Zudem kann Recker anhand der festgestellten Konkordanzen das Vorhandensein gemeinsamer Vorlagen für k und y zumindest sehr wahrscheinlich machen.

\section{Geistliches Lied und theologische Reflexion in $\mathbf{k}$}

Ganz unterschiedlichen Schwerpunkten widmen sich die drei Aufsätze zum geistlichen Liedgut in k. Während Felix Prautzsch geistliche Lieder der Kolmarer Liederhandschrift auf diesen inhärente Ausformungen einer Laientheologie hin untersucht, entwickelt Johannes Janota ein Klassifikationsmodell für vorreformatorische, quasi prototypische Bibelversifikationen. Simone Loleit wiederum nimmt mit dem ,Judenkrieg' ein Lied in den Blick, in dem sich ein starker Antijudaismus manifestiert, und spürt textimmanenten Gründen hierfür nach.

Von Karl Stackmanns Diktum von der, Meisterschaft der Laien` ausgehend, widmet sich Felix Prautzsch dem ästhetischen und theologischen Anspruch im Meistergesang und speziell dessen Repräsentation in der Kolmarer Liederhandschrift. Prautzsch geht der Frage nach, worin sich der laientheologische Anspruch der meister des 14. und 15. Jahrhunderts in den Texten selbst niederschlägt und wie sich die institutionellen Rahmenbedingungen und inhaltlichen Aspekte zum spezifischen literarisch-ästhetischen Medium gesungener 
Dichtung verhalten. Herausgestellt wird die Bedeutung der Meister des 14. und 15. Jahrhunderts und ihrer vorreformatorischen Laienbildung als Wegbereiter des späteren reformatorischen Meistergesangs und dessen theologischen Anspruchs. Prautzsch attestiert schon dem frühen Meistergesang eine "gleichermaßen ästhetische wie theologische“ (S. 311) Meisterschaft, die sich auf der Suche nach eigenen Formen und literarisch-künstlerischen Ausdrucksmitteln befindet (S. 311). Als zentrales Motiv führen auch die Texte der Kolmarer Liederhandschrift dabei immer wieder eine göttliche Inspiration für ihre Kunst an, die im Selbstlegitimierungsprozess der frühen Meister die höchste Stellung einnimmt.

Johannes Janota bietet eine systematische Sichtung der vorreformatorischen Bibelversifikationen; einer Gattung, die sich im Eigentlichen erst nach der Reformation und durch Hans Sachs zu einem eigenen Typus formiert. Janota analysiert die quasi prototypischen Bibelversifikationen der Kolmarer Liederhandschrift hinsichtlich ihrer poetischen Faktur und spürt vorhandenen Ansätzen zur Gruppenbildung nach. Maßgebende Faktoren der vergleichenden Analyse sind zum einen die verwendeten Töne, zum anderen die Nähe zum Bibeltext, denn „zwischen intendierter Textnähe und raffender Paraphrase [eröffnet sich] ein breites Spektrum an Gestaltungsmöglichkeiten [...], die vielleicht Ansätze für typische Textmuster zeigen“ (S. 316). Anhand der sieben Versifikationen der Kolmarer Liederhandschrift gelingt es Janota, zu zeigen, dass schon die vorreformatorischen Bibelversifikationen als feste Größe beschrieben werden können, die einem Prototypen gleich die Basis für den späteren ,festen Typus' der Reformationszeit begründen.

Simone Loleit geht dem Zusammenhang von Antijudaismus, christologischer Schriftauslegung und Allegorese im ,Judenkrieg' in Regenbogens Langem Ton nach. Die Textgrundlage der Analyse bildet dabei die strophenreiche k-Fassung des häufig und bis in die Strophenebene hinein extrem variantenreich überlieferten Liedes. Loleit erarbeitet dabei in Form zweier Leitfragen die Gründe für die abgebildete Aggressivität sowie die Gründe für die (Un-)Verzichtbarkeit der Figur des Juden als Adressat.

\section{Die Metapoetik der Meisterlieder bis $\mathbf{1 5 2 0}$}

Den Abschluss des Sammelbandes bildet Johannes Rettelbachs äußerst umfangreiche überblicksartige Sichtung der metapoetischen Meisterlieder der Liederhandschriften bis 1520 und ihrer poetologisch-selbstreflexiven Elemente. Als metapoetisch versteht Rettelbach dabei all solche Lieder, „die sich mit Voraussetzungen, Regeln, Geschichte und Wirkungen des Gesanges 
auseinandersetzen, ferner Aufschluss über den Ablauf von Veranstaltungen geben, bei denen mehrere Singer zugegen sind und nacheinander singen" (S. 373). Systematisch ordnet Rettelbach das gesichtete Material nach inhaltlichen und thematischen Gesichtspunkten.

\section{Forschungsüberblick zur Handschrift}

Die langjährige Forschung zur Kolmarer Liederhandschrift (München, Bayerische Staatsbibliothek, Cgm 4997; Sigle k [vormals t]), die im Folgenden in wichtigen Etappen chronologisch nachgezeichnet werden soll, ${ }^{1}$ bezeugt zum einen den außergewöhnlichen Stellenwert der besagten Meisterliedersammlung - hier ist etwa an das systematische und bis dahin nicht belegte Ordnungsprinzip der Texte nach Tonautoren zu denken, ${ }^{2}$ an den Einbezug von Autoren, die nicht der Meisterliedtradition zuzurechnen sind, sowie an die regelmäßige Melodieaufzeichnung ${ }^{3}$ und die Bedeutung der Kolmarer Liederhandschrift als „die wichtigste Quelle für die Melodieüberlieferung zur

1 Handschriftenbeschreibung bei Karin Schneider: Die deutschen Handschriften der Bayerischen Staatsbibliothek München. Die mittelalterlichen Handschriften aus Cgm 4001-5247. Wiesbaden 1996 (Catalogus codicum manuscriptorum Bibliothecae Monacensis V,7), S. 423-444. Zusammenfassend zur Handschrift und Forschung siehe die Überblicksdarstellungen (Neuestes zuerst): Gisela Kornrumpf: Kolmarer Liederhandschrift. In: Killy Literaturlexikon. Autoren und Werke des deutschsprachigen Kulturraumes. 2., vollständig überarbeitete Auflage. Hg. von Wilhelm Kühlmann u. a. Bd. 6. Berlin, New York 2009, S. 608-610; Michael Baldzuhn: Vom Sangspruch zum Meisterlied. Untersuchungen zu einem literarischen Traditionszusammenhang auf der Grundlage der Kolmarer Liederhandschrift. Tübingen 2002 (Münchener Texte und Untersuchungen 120), S. 23-33; Lorenz Welker: Kolmarer Liederhandschrift. Beschreibung, Datierung, Notierung, Herkunft. In: Die Musik in Geschichte und Gegenwart. 2., neubearbeitete Ausgabe. Hg. von Ludwig Finscher. Sachteil. Bd. 5 (1996), Sp. 450-455; Burghart Wachinger: ,Kolmarer Liederhandschrift'. In: ${ }^{2}$ VL 5 (1985), Sp. 27-39.

2 Siehe Gisela Kornrumpf: Die Kolmarer Liederhandschrift. Bemerkungen zu Plan, Provenienz und Funktion. In: Gisela Kornrumpf: Vom Codex Manesse zur Kolmarer Liederhandschrift. Aspekte der Überlieferung, Formtraditionen, Texte. Bd. 1: Untersuchungen. Tübingen 2008 (Münchener Texte und Untersuchungen 133), S. 257-274 [zuerst: Die Kolmarer Liederhandschrift. Bemerkungen zur Provenienz. In: Ja muz ich sunder riuwe sin. Festschrift für Karl Stackmann zum 15. Februar 1990. Hg. von Wolfgang Dinkelacker, Ludger Grenzmann und Werner Höver. Göttingen 1990, S. 155-169].

3 Vgl. Baldzuhn 2002 (Anm. 1), S. 27-28. 
deutschen Dichtung des Mittelalters. ${ }^{\text {" }}$ Zum anderen zeigt sich, dass nach wie vor grundlegende Forschungsfragen, insbesondere hinsichtlich der Entstehungszusammenhänge von $\mathrm{k}$, der frühen Geschichte der Handschrift bis zur Mitte des 16. Jahrhunderts ${ }^{5}$ sowie ihrer Vorlagenbindung nach wie vor weitgehend offen sind. Ein Meilenstein bei der Texterschließung der Kolmarer Liederhandschrift ist das von Horst Brunner und Burghart Wachinger herausgegebene ,Repertorium der Sangsprüche und Meisterlieder des 12. bis 18. Jahrhunderts', das den Textbestand der gesamten Handschrift liedweise, nach Tönen und Tonautoren geordnet (samt Initien, Strophenbestand, Parallelüberlieferung) erschließt. ${ }^{6}$ Lagen Abbildungen der Handschrift lange Zeit lediglich als Schwarz-weiß-Faksimiles vor, ist die Handschrift seit 2018 als farbiges Volldigitalisat frei zugänglich. ${ }^{7}$

Die Erforschung der Kolmarer Liederhandschrift, die sich seit dem Jahr 1857 im Besitz der Bayerischen Staatsbibliothek München befindet, setzt im 19. Jahrhundert mit ersten Beschreibungen ${ }^{8}$ und einem Vergleich mit der verwandten ,Donaueschinger Liederhandschrift' (Karlsruhe, Landesbibliothek, Cod. Donaueschingen 120) ein. ${ }^{9}$ Bereits Friedrich von der Hagen erwägt aufgrund

4 Welker 1996 (Anm. 1), Sp. 454.

5 Siehe Kornrumpf 2008 (Anm. 2), S. 257.

6 Siehe Repertorium der Sangsprüche und Meisterlieder des 12. bis 18. Jahrhunderts. Hg. von Horst Brunner und Burghart Wachinger. Bd. 1: Einleitung. Überlieferung. Tübingen 1994 [RSM], S. 205-209.

7 Vgl. Die Kolmarer Liederhandschrift der Bayerischen Staatsbibliothek München (cgm 4997). In Abb. hg. von Ulrich Müller, Franz Viktor Spechtler und Horst Brunner. 2 Bde. Göppingen 1976 (Litterae 35,1-2); Die Colmarer Liederhandschrift. Faksimile-Ausgabe ihrer Melodien. Hg. von Friedrich Gennrich. Langen bei Frankfurt 1967 (Summa musicae medii aevi 18); das von der Bayerischen Staatsbibliothek bereitgestellte Farbdigitalisat ist verfügbar unter: urn: nbn: de: bvb:12-bsb00105055-7 [letzter Zugriff 9.11.2020].

8 Eine erste erschließbare, aber nicht mehr erhaltene formale Beschreibung erfuhr k durch den Basler Buchhändler Georg, der die Kolmarer Handschrift nach München verkaufte. Siehe Michael Baldzuhn: Blattverluste im Suchensinn-Korpus der „Kolmarer Liederhandschrift“. In: Zeitschrift für deutsche Philologie 119 (2000), S. 427-433, hier S. 429 mit Anm. 12.

9 Siehe Karl Bartsch: Meisterlieder der Kolmarer Handschrift. Stuttgart 1862 (Bibliothek des Literarischen Vereins in Stuttgart 68) [Nachdruck Norderstedt 2016]; Paul Runge: Die Sangesweisen der Colmarer Handschrift und die Liederhandschrift Donaueschingen. Leipzig 1896. Reprografischer Nachdruck Hildesheim 1965, S. 1-89 
des - seiner Form nach jedoch fingierten - Provenienzeintrags im Register (fol. 3r) eine Herkunft aus Mainz ${ }^{10}$ und formuliert die Hypothese eines möglichen Entstehungszusammenhangs mit einer dort ansässigen, freilich historisch nicht greifbaren Meistersingergesellschaft. ${ }^{11}$

Eine erste eingehendere formale Beschreibung der Kolmarer Liederhandschrift liefert Karl Bartsch im Jahr 1862: diese umfasst eine kurze Vorstellung von $\mathrm{k}$ und den damals beiden im selben Band zusammengebundenen Handschriften, ${ }^{12}$ ein Liedverzeichnis in Auszügen sowie den Abdruck ausgewählter Lieder. Außerdem schließt sich die Beobachtung an, dass die Handschrift von mehreren Händen stamme, wobei bereits Bartsch von einem „ursprüngliche[n] schreiber ${ }^{\text {"13 }}$ spricht und damit ggf. bereits von einem Hauptschreiber ausgeht.

Eine Identifizierung des sich in der ausführlichen Beischrift zweier Lieder im Unerkannten Ton nennenden magist [er] scilicet scriptor[] der Kolmarer Liederhandschrift (fol. 492ra) mit Nestler von Speyer findet sich erstmals bei Karl Goedeke im Jahr 1870. Goedeke stützt seine Argumentation auf eine durch Hans Sachs vorgenommene Tonzuschreibung an Nestler von Speyer im mgq 414 (Berlin, Staatsbibliothek). ${ }^{14}$

(zu k); S. 153-156 (zum Verhältnis zwischen der Kolmarer und der Donaueschinger Liederhandschrift).

$10 \mathrm{k}$, fol. 3r: Dis bich vn daffel ist der xii Meister gediecht vn ist ob vi<i> hundert jaren zů mecz im di̊m $<$ ge>legen vn in der lieberyg. Zitiert nach Horst Brunner und Johannes Rettelbach: Der vrsprung des maystergesangs. Eine Schulkunst aus dem frühen 16. Jahrhundert und die Kolmarer Liederhandschrift. In: Zeitschrift für deutsches Altertum und deutsche Literatur 114 (1985), S. 221-240, hier S. 234. - Das sogenannte ,Buch von Mainz', das ein Meisterlied des 16. Jahrhunderts erwähnt, wurde durch die Meistersinger des 16. Jahrhunderts, aber auch durch die moderne Forschung (vgl. Hans Ellenbeck, Bert Nagel) zum Teil mit der Kolmarer Liederhandschrift gleichgesetzt. Welche Rolle in diesem Zusammenhang die auf fol. $3 \mathrm{r}$ befindliche Notiz im Register von k spielt, ist unklar. Siehe ebd., S. 234-235 mit Anm. 37; Hans Ellenbeck: Die Sage vom Ursprung des Deutschen Meistergesangs. Diss. Bonn 1911, S. 56f. und bei Bert Nagel: Meistersang. Stuttgart 1962 (Sammlung Metzler 12), S. 25 (beides zitiert nach Brunner/Rettelbach).

11 Von der Hagen: Die Kolmarische Sammlung von Minne- und Meisterliedern. In: Museum für altdeutsche Literatur und Kunst 2 (1811), S. 146-225, hier S. 149.

12 Neben k München, BSB, Cgm 4998 und 4999.

13 Vgl. Bartsch 1862 (Anm. 9), S. 4.

14 Vgl. Karl Goedeke: Zur Geschichte des Meistergesanges. In: Germania. Vierteljahrsschrift für deutsche Altertumskunde 15 (1870), S. 197-202, hier S. 200. Goedeke nutzt die zweite Blattzählung von $\mathrm{k}$ und gibt dementsprechend fol. 478 an. 
Die Beobachtung, dass zwei Schreiber an der Herstellung der Kolmarer Liederhandschrift beteiligt waren, findet sich erstmals 1954 bei Rudolf Genseke; ${ }^{15}$ eine dritte Hand ließe sich nach Genseke mitunter vermuten, jedoch auch als Variante einer der beiden Haupthände beurteilen. Durch Schriftbestimmung kann bereits Genseke den Codex auf die Mitte des 15. Jahrhunderts datieren und den Schreiber A als den Hauptredaktor der Handschrift ausmachen. ${ }^{16}$ Die Schriftenanalyse führt Genseke schließlich zur Hypothese, dass k „in einer Schreiberwerkstätte und von A und B ziemlich gleichzeitig geschrieben worden ist. ${ }^{\text {"17 }}$ Anhand der Wasserzeichenbestimmung sowie der bereits durch Emil Pflug erfolgten Sprachbestimmung als rheinfränkisch ${ }^{18}$ schließt Genseke eine teils in der älteren Forschung vermutete Herkunft der Handschrift aus Bayern aus. ${ }^{19}$

Karl Stackmann hält in seiner Edition zu Heinrich von Mügeln aus dem Jahr 1959 fest, dass die Kolmarer Liederhandschrift in mehreren Etappen entstanden sein müsse und nicht einer einzigen Vorlage entstammen könne; auf der Grundlage der Wasserzeichenbestimmung nach Briquet setzt Stackmann ungefähr 1470 als terminus post quem für die Entstehung von $\mathrm{k}$ an. ${ }^{20}$ Anders als die Vorgenannten liest Stackmann die vorhandenen Schriftunterschiede als

15 Vgl. Frieder Schanze: Meisterliche Liedkunst zwischen Heinrich von Mügeln und Hans Sachs. Bd. I: Untersuchungen. München 1983 (Münchener Texte und Untersuchungen 82), S. 39, Anm. 20.

16 Rudolf Genseke: Die Kolmarer Handschrift und ihre Bedeutung für den deutschen Meistergesang. Diss. masch. Tübingen 1954, S. 9-15. - Zu Gensekes Argumentation eines terminus ante quem (1462), die sich auf den vermeintlich politischen Inhalt eines Liedes in Klingsors Schwarzem Ton stützt, siehe kritisch Horst Brunner: Die alten Meister. Studien zu Überlieferung und Rezeption der mittelhochdeutschen Sangspruchdichter im Spätmittelalter und in der frühen Neuzeit. München 1975, S. 69, Anm. 2.

17 Genseke 1954 (Anm. 16), S. 15.

18 Vgl. ebd., S. 11; bezogen auf Emil Pflug: Suchensinn und seine Dichtungen. Breslau 1908 (Germanistische Abhandlungen 32), S. 15.

19 Vgl. Genseke 1954 (Anm. 16), S. 8-9; bezogen auf Edward Schröder: Kleinere Dichtungen Konrads von Würzburg. Bd. 3: Die Klage der Kunst. Berlin 1926; Helmuth Thomas: Untersuchungen zur Überlieferung der Spruchdichtung Frauenlobs. Leipzig 1939 (Palaestra 217).

20 Vgl. Die kleineren Dichtungen Heinrichs von Mügeln. Erste Abteilung: Die Spruchsammlung des Göttinger Cod. Philos. 21. 1. Teilband: Einleitung, Text der Bücher I-IV. Hg. von Karl Stackmann. Berlin 1959 (Deutsche Texte des Mittelalters 50), S. LXV-XCV (zu k insgesamt); hier S. LXXXVI, LXXII. 
Varianz einer einzigen Hand. ${ }^{21}$ Zwar bewertet er den Eintrag über die angebliche Aufbewahrung des Codex in Mainz (fol. 3r) als Legende, dennoch hält Stackmann eine Herkunft der Liederhandschrift aus der Gegend um Mainz aufgrund westmitteldeutscher Dialektmerkmale für möglich. ${ }^{22}$

In seinem 1960 publizierten Aufsatz ,Aufbau und Entstehung des cgm 4997 bietet Heinrich Husmann eine ausführliche Beschreibung der einzelnen Lagen, der Wasserzeichen sowie der Foliierung. Husmann spricht sich gegen Stackmanns Hypothese einer einzigen Hand aus und vermutet über Schreiber A und $B$ hinausgehend mehrere Nachtragshände. ${ }^{23}$ Zwar nimmt Husmann verschiedene Vorlagen von $\mathrm{k}$ an, die sich anhand zahlreicher Umstellungen von Lagen und Einzelblättern nachvollziehen ließen, dennoch erwägt er einen der Handschrift zugrundeliegenden Gesamtplan, dessen Konzeption womöglich seitens einer dritten Person, etwa durch den Leiter des Skriptoriums oder den Auftraggeber, nachträglich geändert wurde. ${ }^{24}$

Ursula Aarburg bietet in einem Beitrag von 1961 ein die Töne und Leichs der Kolmarer Liederhandschrift listendes Verzeichnis, welches das Inhaltsverzeichnis von Karl Bartsch weiterführt und jeweils vermerkt, ob und in welchem Umfang Melodieaufzeichnung vorhanden ist. ${ }^{25}$

In Horst Brunners Studie ,Die alten Meister', die sich der Spätüberlieferung der Sangspruchdichtung, vornehmlich der Formgeschichte sowie der Rezeption ,alter Töne durch die Meistersinger bis in die Frühe Neuzeit, widmet, nimmt die Kolmarer Liederhandschrift eine prominente Stellung ein. So geht Brunner detailliert auf die Geschichte der Handschrift inklusive der teils kritischen Beurteilung von $\mathrm{k}$ durch die Meistersinger des 16. Jahrhunderts ein. Brunner schließt Mainzer Provenienz nicht aus und hält eine gezielte Sammlung als umfassendes Kompendium der alten Meister für möglich (mit Ausnahme des

21 Vgl. ebd., S. LXXXVI. Die Monografie Gensekes mit der dort vertretenen These zweier Hände lag ihm, wie Schanze darlegt, nicht vor. Vgl. Schanze 1983 (Anm. 15), S. 39, Anm. 20.

22 Vgl. Die kleineren Dichtungen Heinrichs von Mügeln, S. LXX; siehe ausführlicher S. XC-XCII.

23 Vgl. Heinrich Husmann: Aufbau und Entstehung des cgm 4997 (Kolmarer Liederhandschrift). In: Deutsche Vierteljahrsschrift für Literaturwissenschaft und Geistesgeschichte 34 (1960), S. 189-243, hier S. 197 und 240.

24 Vgl. ebd., S. 239-243 und S. 197.

25 Vgl. Ursula Aarburg: Verzeichnis der im Kolmarer Liedercodex enthaltenen Töne und Leiche. In: Festschrift Heinrich Besseler zum sechzigsten Geburtstag. Hg. vom Institut für Musikwissenschaft der Karl-Marx-Universität. Leipzig 1961, S. 127-136. 
genannten Tons von Nestler und zweier Nürnberger Töne tradiert k keine neu geschaffenen Töne von Zeitgenossen). Besonders aufschlussreich im Hinblick auf die Tradierung alter Töne ist Brunners Entdeckung eines Auszugs aus der Kolmarer Liederhandschrift in einer nach Nürnberg weisenden Faszikelsammlung (Weimar, Herzogin Anna Amalia Bibliothek, Fol. 421) aus dem 17./frühen 18. Jahrhundert. ${ }^{26}$

In diesem Forschungskontext steht auch die 1993 durch Johannes Rettelbach vorgelegte Studie zum Tönegebrauch von Sangspruchdichtern und Meistersingern, die sich unter anderem anhand der Kolmarer Liederhandschrift dezidiert mit der formalen Rezeption der Töne unter den Aspekten der Fortführung bekannter Tonschemata, der Weiterentwicklung neuer Tonschemata aus bekanntem Material sowie der Adaptation einzelner Elemente in späteren Tönen auseinandersetzt. ${ }^{27}$

Die Monografie ,Die Kolmarer Liederhandschrift', die Christoph Petzsch im Jahr 1978 vorlegte, befasst sich ausführlich mit Entstehung und Geschichte der Handschrift. Petzsch, der k nach Mainz lokalisiert, vertritt die These, die Handschrift sei im Kontext der erzbischöflichen Kanzlei „zum Zweck der Überwachung" entstanden.$^{28}$ Auf diese Weise korrigiert er - nicht zuletzt, da eine Mainzer Singschule im 15. Jahrhundert nicht nachweisbar ist - seine zuvor

26 Vgl. Brunner 1975 (Anm. 16), zur Kolmarer Liederhandschrift v. a. S. 68-171, hier S. 83; der besagte Auszug aus $k$ findet sich in Heft 32 des Schreibers Benedict Watt; vgl. ebd., S. 84-94.

27 Johannes Rettelbach: Variation - Derivation - Imitation. Untersuchungen zu den Tönen der Sangspruchdichter und Meistersinger. Tübingen 1993 (Frühe Neuzeit 14).

28 Christoph Petzsch: Die Kolmarer Liederhandschrift. Entstehung und Geschichte. München 1978, S. 49. Insbesondere Frieder Schanze 1983 (Anm. 15), S. 56, bezieht Stellung gegen die von Petzsch vertretene These: „Denn welchen Nutzen hätte es für einen Zensor gehabt, wenn er diejenigen Texte, an denen er möglicherweise Anstoß nahm, irgendwo unter der Masse der völlig unbedenklichen Lieder einordnete und sie dort eher versteckte anstatt sie hervorzuheben? Und wozu hätte er Melodien aufzeichnen sollen, wo es ihm doch nur um Texte gehen konnte?" Auch Walter Röll stellt in seiner Rezension zur Monografie Christoph Petzsch’ eine Entstehung in einer Kanzlei in Frage und plädiert aufgrund des ,routinierten' und der Notenaufzeichnung fähigen Schreibers für einen Entstehungszusammenhang in geistlichen Schreibstuben. Vgl. Walter Röll: Müller, Ulrich; Spechtler, Franz Viktor; Brunner, Horst (Hg.): Die Kolmarer Liederhandschrift der Bayerischen Staatsbibliothek München; Petzsch, Christoph: Die Kolmarer Liederhandschrift. Entstehung und Geschichte. In: Beiträge zur Geschichte der deutschen Sprache und Literatur 102 (1980), S. 284-291, hier S. 289. 
geäußerte Einschätzung, k sei als ein Reproduktionshandbuch einer Meistersingergesellschaft anzusehen. ${ }^{29}$

Entscheidende Erkenntnisse und Modifizierungen älterer Forschungsmeinungen zur Handschrift liefert Frieder Schanze in seiner Monografie ,Meisterliche Liedkunst zwischen Heinrich von Mügeln und Hans Sachs' Anfang der 1980er-Jahre. Auf der Grundlage der seit 1961 erschienenen Wasserzeichenkartei Piccards kann Schanze die Datierung der Kolmarer Liederhandschrift auf die Jahre 1459 bis 1462 eingrenzen sowie die These eines schrittweisen Anwachsens aufgrund von Einschüben und Umordnungen weiter untermauern. ${ }^{30}$ Dieses allmähliche Entstehen der Handschrift spricht laut Schanze gegen eine Auftragsarbeit und für einen privaten Entstehungszusammenhang im Umfeld eines interessierten Sammlers. ${ }^{31}$ Aufgrund der Wasserzeichenbestimmung brachte Schanze auch eine neue Hypothese zum Entstehungsort ins Spiel: In Verbindung mit der Identifizierung des Schreibers A mit Nestler von Speyer erwägt Schanze die Möglichkeit, dass k im Raum Speyer entstanden sein könnte, und stützt diese Vermutung durch die rheinfränkische Schreibsprache mit ihren elsässischen Einschlägen; der Eintrag auf fol. 3r, der die Handschrift an die Sage vom Ursprung des Meistergesangs in der Zeit Kaiser Ottos des Großen anbindet, verdiene kein Vertrauen und könne daher auch nicht auf eine Mainzer Provenienz schließen lassen. ${ }^{32}$

Das durch Horst Brunner und Johannes Rettelbach edierte Lied Der ursprung des maystergesangs in Frauenlobs Langem Ton warf erneut die Frage nach der Provenienz von $\mathrm{k}$ auf. Anders als Frieder Schanze werten Brunner und Rettelbach den Eintrag auf fol. 3r sowie die Erwähnung eines ,Buches von Mainz' in

29 Vgl. Schanze 1983 (Anm. 15), S. 55; bezogen auf: Christoph Petzsch: Der magister scilicet scriptor der Kolmarer Liederhandschrift, sein , unerkannter Ton' und nochmals zur Frage der Meistergesangsreform. In: Die Musikforschung 26 (1973), S. 445-473, hier S. 458; ders.: Die Rubriken der Kolmarer Liederhandschrift. In: Zeitschrift für deutsche Philologie 93 (1974), S. 88-116, hier S. 113.

30 Vgl. Schanze 1983 (Anm. 15), S. 48; 40-41; zu k insgesamt S. 35-86.

31 Vgl. ebd., S. 58-59.

32 Vgl. ebd., S. 49-52. Entschieden gegen die von Schanze vorsichtig formulierte Hypothese einer Speyerer Provenienz stellt sich Christoph Petzsch in seinem 1988 veröffentlichten Artikel zu Wasserzeichen und Provenienz von k. Petzsch zeigt sich kritisch gegenüber Schanzes Versuch einer Lokalisierung sowie Datierungseingrenzung anhand des Schreibstoffes und beharrt auf seiner These einer Mainzer Provenienz. Vgl. Christoph Petzsch: Wasserzeichen und Provenienz der ,Kolmarer Liederhandschrift' (Cgm 4997). In: Zeitschrift für deutsches Altertum und deutsche Literatur 117 (1988), S. 201-210, hier S. 204, 206. 
Strophe VI des besagten Meisterliedes nicht als bloße legendenhafte Überformung. Eine Entstehung der Handschrift in Mainz oder zumindest deren dortige Aufbewahrung bis zum Erwerb der Handschrift durch Jörg Wickram im Jahr 1546 lässt sich laut Brunner und Rettelbach zwar ebenso wenig wie andere Hypothesen zur Herkunft der Handschrift beweisen, sei aber auch nach wie vor nicht auszuschließen. ${ }^{33}$

Gisela Kornrumpf ist es vor allem zu verdanken, dass die naturwissenschaftlichmedizinische Sammelhandschrift Cod. M III 3 (Salzburg, Universitätsbibliothek) für das Forschungsumfeld der Kolmarer Liederhandschrift entdeckt wurde. In ihrer zuerst im Jahre 1990 publizierten Untersuchung, die 2008 um bibliografische Hinweise und ein Nachwort ergänzt nochmals erschien, kann Kornrumpf nachweisen, dass zwei der Schreiber des besagten Codex mit jenen von $\mathrm{k}$ identisch sind, wobei die Gewichtung der Schreibleistung umgekehrt ist: Anders als in k ist B als Hauptschreiber des in Salzburg aufbewahrten Codex auszumachen. ${ }^{34}$ Zwar ließe sich weder für die eine noch die andere Handschrift eine Lokalisierung in Speyer oder Umgebung belegen, dennoch weise auch Cod. M III 3 in diese Gegend: Zum einen stammt der erste historisch identifizierbare Besitzer der Handschrift aus Speyer, wobei sich freilich nicht klären lässt, ob dieser die medizinische Sammlung in Auftrag gab oder selbst käuflich erwarb; zum anderen weisen einige der überlieferten Textautoren in die Speyerer Umgebung. ${ }^{35}$ Anders als Frieder Schanze erwägt Kornrumpf für beide Handschriften einen Auftraggeber, etwa einen ,adligen Liebhaber ' meisterlicher Liedkunst, denn „Leuten ihres Standes lag auch das Interesse an Himmels- und Heilkunde in Prosa nicht fern, davon

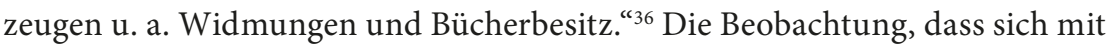

33 Vgl. Brunner/Rettelbach 1985 (Anm. 10), S. 234-235.

34 Vgl. Kornrumpf 2008 (Anm. 2), S. 270. Die in einer Rezeptsammlung präsente Erwähnung eines Schreibers ,des anderen Buches' (Nr. 29; fol. 171 va) ließe sich nach Kornrumpf (ebd., S. 271) unter Vorbehalt als Hinweis auf Schreiber A und somit auf die Kolmarer Liederhandschrift, die sich zum Entstehungszeitpunkt von Cod. M III 3 bereits in der Schlussphase ihrer Entstehung befand, verstehen.

35 Vgl. ebd., S. 266-268. Die durch Franz Viktor Spechtler formulierte Vermutung, der vorgeschaltete Kalender weise in die Diözese Speyer, müsste nach Kornrumpf, S. 267, erst noch näher untersucht werden; bezogen auf Franz Spechtler: Eine bisher unbekannte Handschrift des, Mönchs von Salzburg' in der Salzburger Studienbibliothek. In: Mitteilungen der Gesellschaft für Salzburger Landeskunde 102 (1962), S. 35-49, hier S. 41.

36 Kornrumpf 2008 (Anm. 2), S. 271. Die Hypothese, dass es sich bei der Kolmarer Liederhandschrift um eine Auftragsarbeit handelt, ließe sich laut Kornrumpf auch mit 
wenigen Ausnahmen keine Doppelungen in beiden Handschriften finden lassen - obwohl die medizinische Sammlung durchaus Reimpaargedichte enthält und etliche thematisch passende Meisterlieder aus k zur Verfügung gestanden hätten -, untermauert nach Kornrumpf die These einer Anfertigung beider Handschriften für ein- und denselben, offensichtlich laikalen Auftraggeber. ${ }^{37}$ Im Nachwort der Untersuchung (modifizierender Zusatz gegenüber der Erstveröffentlichung) räumt Kornrumpf ein, dass der von Schanze erwogene private Hintergrund von k eventuell plausibler als die Hypothese einer Auftragsarbeit sei. Nichtsdestotrotz werde laut Kornrumpf ein Austausch mit Auftraggebern und Meisterlieddichtern stattgefunden haben, die zum einen Quellen, zum anderen Liedkompetenz vermittelten. ${ }^{38}$

Die von Bernhard Schnell im Jahre 1993 erschienene Analyse der besagten medizinischen Handschrift verdeutlicht nochmals die Parallelen zu k: Für beide Handschriften, die in ihrem Layout übereinstimmen, ließe sich ein allmähliches Anwachsen konstatieren. ${ }^{39}$ Entstehungsort und -zeit des Salzburger Codex grenzt Schnell auf der Grundlage des durch Kornrumpf identifizierten Erstbesitzers sowie einer überlieferten Liste von Speyerer Maßen und Gewichten auf "Speyer um 1460“ ein. ${ }^{40}$ Im Mittelpunkt der Untersuchung steht die These, dass die beiden Schreiber A und B ausgebildete und zugleich literarisch tätige Wundärzte gewesen seien; so verschränke sich auch die Bezeichnung magister scilicet scriptor in k letzten Endes mit dem

dem „persönlichen Engagement, von dem die Sammlung so offensichtlich geprägt ist", gut vereinbaren. Ebd., S. 272.

37 Vgl. ebd.

38 Vgl. ebd., S. 274. An anderer Stelle meint Kornrumpf dazu: „Demzufolge wird A (Nestler) die K. L. aus eigenem Antrieb oder auf Bitten anderer Kenner der meisterl. Liedkunst, jedenfalls nicht als reines Auftragswerk in Angriff genommen haben." Kornrumpf 2009 (Anm. 1), S. 608-610, hier S. 609.

39 Vgl. Bernhard Schnell: Medizin und Lieddichtung. Zur medizinischen Sammelhandschrift Salzburg M III 3 und zur Kolmarer Liederhandschrift. In: Archiv für das Studium der neueren Sprache und Literaturen 230 (1993), S. 261-278, hier S. 264, 268-270. Darüber hinaus weise das Arbeitsprogramm beider Handschriften auf ,das bewußte Sammeln des verfügbaren Wissens der Zeit und zwar bei hohem Qualitätsanspruch." Ebd., S. 276.

40 Vgl. ebd., S. 264, S. 276. Bereits Franz Spechtler nennt als terminus post quem das Jahr 1460 und erwägt Speyerer Provenienz. Vgl. Spechtler 1962 (Anm. 36), S. 39-40. 
Salzburger Codex: magister sei die gelehrte Sprachform für die Bezeichnung des Arztes als meister. ${ }^{41}$

Einen wesentlichen Beitrag zu den Schichtungen von Überlieferung und Textgebrauch von $\mathrm{k}$ leistet Michael Baldzuhn in seiner 2002 veröffentlichten und auf seine Dissertation aus dem Jahr 1996 zurückgehenden Studie ,Vom Sangspruch zum Meisterlied'. Ausgehend von der Identifizierung altbezeugter Einzelstrophen sowie Strophen in noch unfester Gruppierung, die der Barbildung vorausgehen, gelingt es Baldzuhn, die Überlieferungsschichten der Handschrift herauszuschälen und den Schluss zu ziehen, dass in $\mathrm{k}$,eher mehrere verschiedene Quellen geringeren als wenige Vorlagen größeren Umfangs verarbeitet wurden [...]. ${ }^{\times 2}$ Die Kolmarer Liederhandschrift erscheint zusammen mit weiteren Aspekten - beispielsweise der systematischen Auszeichnung von Mehrstrophigkeit in den Rubriken - als ein Zeugnis jener frühen Meisterliederhandschriften, die eine Rückbesinnung auf die ältere Gattungsgeschichte verschriftlichten. ${ }^{43}$

Das von Ursula Aarburg und noch von Lorenz Welker angemerkte Forschungsdesiderat einer mangelnden Neuedition der erstmals von Runge vorgelegten Melodien aus $\mathrm{k}^{44}$ erbrachten Horst Brunner und Karl-Günther Hartmann im Jahr 2010. Die Monografie ,Spruchsang. Die Melodien der Sangspruchdichter des 12. bis 15. Jahrhunderts'vereint insgesamt 225 Melodien, darunter diejenigen der Spruchtöne aus $\mathrm{k}^{45}$

41 Vgl. Schnell 1993 (Anm. 40), S. 277. Die These, die Kompilatoren der Handschrift seien ausgebildete Wundärzte, macht Schnell an Anlage und Inhalt der Handschrift, einigen Schreiberaussagen im Ich-Modus sowie an den in den Texten greifbaren medizinischen Verfahren fest. Vgl. ebd., S. 271-276.

42 Baldzuhn 2002 (Anm. 1), S. 495.

43 Vgl. ebd., S. 497; 500-501. Verlorenen Blättern (einer Lage, eines Doppelblattes oder von drei Einzelblättern) im Kolmarer Suchensinn-Korpus spürt Baldzuhn nach in: Baldzuhn 2000 (Anm. 8), S. 427-433.

44 Vgl. Welker 1996 (Anm. 1), Sp. 454; Ursula Aarburg: Art. Kolmarer Liederhandschrift. In: Die Musik in Geschichte und Gegenwart. Allgemeine Enzyklopädie der Musik. Hg. von Friedrich Blume. Bd. 7. Kassel 1958, Sp. 1415-1419.

45 Spruchsang. Die Melodien der Sangspruchdichter des 12. bis 15. Jahrhunderts. Hg. von Horst Brunner und Karl Günther Hartmann. Kassel u. a. 2010 (Monvmenta monodica medii aevi 6). Siehe aus der älteren Forschung speziell zur Notation in $\mathrm{k}$ bspw. Burkhard Kippenberg: Der Rhythmus im Minnesang. Eine Kritik der literarund musikhistorischen Forschung mit einer Übersicht über die musikalischen Quellen. München 1962 (Münchener Texte und Untersuchungen 3), z. B. S. 72-75. 
Neben ihrer kodikologischen Erfassung wurde die Kolmarer Liederhandschrift in Teilen auch editorisch erschlossen. Erste Textausgaben, die sich auf ausgewählte Lieder konzentrieren, wurden im 19. Jahrhundert vorgelegt. Friedrich von der Hagen beschränkt sich 1811 auf die Mitteilung weniger Lieder aus der Feder Konrads von Würzburg. Eine umfangreichere Teilausgabe der überlieferten Meisterlieder aus k legt Karl Bartsch 1862 vor, der knapp über zweihundert Liedtexte in normalisiertem Mittelhochdeutsch wiedergibt. Einige Jahre später folgt die Teilausgabe der Melodien durch Paul Runge. ${ }^{46}$ Die 1965 veröffentlichte Studie Durward Poynters zur Poetologie der frühen Meistersinger gibt auf der Basis der Ausgabe von Bartsch ausgewählte Meisterlieder aus $\mathrm{k}$ wieder (121 Lieder). ${ }^{47}$ An dieser Stelle zu erwähnen ist auch die editorische Erschließung der Heidelberger Handschrift cpg 680 durch Elisabeth Wunderle, die aufgrund der inhaltlichen und metrischen Textqualität meist die Kolmarer Liederhandschrift als Leithandschrift heranzieht. ${ }^{48}$ In neuerer Zeit werden Lieder aus $\mathrm{k}$ in Studien, die sich auf Einzeltexte beschränken oder auf bestimmte Tonkorpora konzentrieren, editorisch erschlossen. ${ }^{49}$

46 Siehe von der Hagen 1811 (Anm. 11); Bartsch 1862 (Anm. 9); Runge 1896 (Anm. 9).

47 Vgl. Durward S. Poynter: The Poetics of the Early Meistersänger as Reflected in the Kolmarer Handschrift (Cgm, 4997). Diss. masch. Los Angeles 1965.

48 Elisabeth Wunderle: Die Sammlung von Meisterliedern in der Heidelberger Handschrift cpg 680. Edition und Kommentar. Göppingen 1993 (Göppinger Arbeiten zur Germanistik 584).

49 Vgl. beispielsweise (Neuestes zuerst; Publikationen, die Einzellieder als Anhang der Untersuchung edieren, bleiben an dieser Stelle unberücksichtigt) Franziska Wenzel: Meisterschaft im Prozess. Der Lange Ton Frauenlobs - Texte und Studien. Mit einem Beitrag zu vormoderner Textualität und Autorschaft. Berlin 2012; Holger Runow: Rumelant von Sachsen. Edition - Übersetzung - Kommentar. Berlin, New York 2011 (Hermaea N.F. 121); Der Marner. Lieder und Sangsprüche aus dem 13. Jahrhundert und ihr Weiterleben im Meistersang. Einführung, Übersetzung und Stellenkommentar. Hg., eingeleitet, erläutert und übersetzt von Eva Willms. Berlin, New York 2008; Geistliche Gesänge des deutschen Mittelalters. Melodien und Texte handschriftlicher Überlieferung bis um 1530. Bd. 2: Gesänge E-H (Nr. 173-330). In Verbindung mit Mechthild Sobiela-Caanitz, Cristina Hospenthal und Max Schiendorfer hg. von Max Lütolf. Kassel u. a. 2004 (Das deutsche Kirchenlied II,2); Sangsprüche in Tönen Frauenlobs. Supplement zur Göttinger Frauenlob-Ausgabe. Hg. von Jens Haustein und Karl Stackmann. 2 Bde. Göttingen 2000 (Abhandlungen der Akademie der Wissenschaften in Göttingen. Philologisch-historische Klasse. Folge 3, 232); Ulrike-Marianne Schulz: Liebe, Ehe und Sexualität im vorreformatorischen Meistersang. Texte und Untersuchungen. Göppingen 1995 (Göppinger Arbeiten zur Germanistik 624). - Im Rahmen zweier DFG-Projekte werden Lieder in Regenbogen-Tönen 


\section{Zur materialen Gestalt der Kolmarer Liederhandschrift}

\section{Kurzkatalogisat}

Ein Kurzkatalogisat der Kolmarer Liederhandschrift sieht heutzutage ungefähr so aus: ${ }^{50}$

\section{München, Bayerische Staatsbibliothek, Cgm 4997 - Kolmarer}

Liederhandschrift $(k)$

Papier - 854 Blätter - 29,3 x 20,0 cm - südrheinfränkisch ${ }^{51}$ (Speyer?) - um 1460

Äußere Gestalt: Drei Foliierungen, ${ }^{52}$ zitiert wird die letzte (um $1860^{53}$ ) 1-853 (Zählfehler bei 631 und 631a, das $a$ nachträglich zugefügt). Kleinere Schaltblätter und Papierschäden. ${ }^{54} 131$ leere Seiten. ${ }^{55}$ - Verschiedene Wasserzeichen um $1460 .^{56}$ - Lagen: ursprüngliche Sexternionen mit zahlreichen

an der Universität Duisburg-Essen editorisch aufbereitet und sowohl digital (über http://www.ldm-digital.de/) als auch in Printform zur Verfügung gestellt: „Edition der in Regenbogens ,Langem Ton` überlieferten Lieder“ (Förderphase: Sommer 2015 bis Herbst 2020); „Edition der in Regenbogens ,Brief- und Grundweise` und ,Grauem Ton` überlieferten Lieder“ (Projektbeginn Mai 2021) [jeweils Projektleiter Martin Schubert, wissenschaftliche Mitarbeiterinnen Judith Lange, Eva Rothenberger]. Die Regenbogen zugeschriebenen Töne werden im Rahmen des Dissertationsprojektes von Nils Hansen erschlossen, sodass in absehbarer Zeit alle echten und zugeschriebenen Töne Regenbogens editorisch erschlossen sein werden.

50 Das Katalogisat beruht natürlich im Wesentlichen auf Schneider 1996 (Anm. 1) und auf dem Handschriftencensus: www.handschriftencensus.de/6355 (eingesehen am 25. 10. 2020).

51 Siehe zur Sprachbestimmung die gründlichste Zusammenstellung (zum MügelnKorpus, fast ausschließlich Schreiber A) bei Stackmann 1959 (Anm. 20), S. XC-XCII; Die weltlichen Lieder des Mönchs von Salzburg. Texte und Melodien. Hg. von Christoph März (MTU 114), Tübingen 1999, S. 97f.; siehe die Zusammenstellung weiterer Literaturverweise bei Baldzuhn 2002 (Anm. 1), S. 25. Die Sprachuntersuchung wäre auf Grundlage umfangreicher Transkriptionen fortzuführen; vgl. Stackmann, S. XC: „Vielleicht, daß man eines Tages, wenn die ganze Hs. untersucht ist, besseres Material zur Hand hat."

52 Synopse der Zählungen bei Stackmann 1959 (Anm. 20), S. LXXIX-LXXXIII; Husmann 1960 (Anm. 23).

53 Wachinger 1985 (Anm. 1), Sp. 27.

54 Genauer bei Schneider 1996 (Anm. 1), S. 423.

55 Aufstellung bei Schneider 1996 (Anm. 1), S. 424.

56 Analyse bei Schanze 1983 (Anm. 15), S. 36-41; Schneider 1996 (Anm. 1), S. 424. 
Erweiterungen. ${ }^{57}$ - Schriftraum: ab 19r meist rund 21,0 x 14,0 cm. - Zweispaltig mit kleineren einzeiligen Partien. ${ }^{58}$ - 34-44 Zeilen. - Schrift: Bastarda zweier sich abwechselnder Hände; beide auch im 'Speyrer Kompendium' (Salzburg, Universitätsbibl., Cod. M III 3)..$^{59}$ Schreiber A (Register der Meisterlieder; die meisten Melodiestrophen in Noten und Text; gesamte Redaktion) vermutlich identisch mit Nestler von Speyer. ${ }^{60}$ Abbreviaturen (Nasalstrich, $r$-Haken) und Diakritika ( $e$ und Punkte über Vokalen für Umlaut; teils Punkte über $u$ als Vokalindex). ${ }^{61}$ Nachträge des 16 . Jhs. ${ }^{62}$ - Melodien in deutscher gotischer Choralnotation (Hufnagelnotation) im Fünfliniensystem. ${ }^{63}$ - 19ra mehrfarbige Deckfarbeninitiale; rotschwarze Initialen. - Einband von 1589, restauriert, ${ }^{64}$ dunkelbrauner Kalblederüberzug mit Streicheisenlinien, Rollen- und Einzelstempeln; je fünf ziselierte Messingbeschläge; die beiden Schließen fehlen; ${ }^{65}$ vorne eingeprägt Alt Gesang Bvch und Datum 1589.

57 Lagenplan bei Schneider 1996 (Anm. 1), S. 424; detaillierte Übersicht bei Husmann 1960 (Anm. 23), S. 194-238.

58 Dies sind fol. 1r-29v (Register, Nachträge; Melodieeintrag zu Frauenlobs Marienleich und Überzartem Ton), fol. 534rv (halbes Einzelblatt zur Ergänzung; vgl. u. bei Anm. 203), fol. 588v Zeile 1-5 (Schluss der ersten Strophe eines Liedes in Boppes Hofton, ${ }^{1}$ Bop/1/543, wahrscheinlich irrtümlich über beide Spalten geschrieben). Vgl. die Nachweise bei Schneider 1996 (Anm. 1), S. 424.

59 Siehe www.handschriftencensus.de/5238 (mit Lit. und Link zum Handschriftendigitalisat); ausführliche Beschreibung: Anna Jungreithmayr unter Mitarbeit von Josef Feldner und Peter H. Pascher: Die deutschen Handschriften des Mittelalters der Universitätsbibliothek Salzburg (Österreichische Akademie der Wissenschaften, phil.-hist. Klasse, Denkschriften 196; Veröffentlichungen der Kommission für Schrift- und Buchwesen des Mittelalters III,2). Wien 1988, S. 193-209. Bei der Händetrennung S. 193 werden Schreiber A und B nicht geschieden, sondern zu Hand 2 zusammengefasst; Trennung von A und B bei Kornrumpf 2008 (Anm. 2), S. 265 f. Zum Bezug zu k ebd., S. 264-273; Schnell 1993 (Anm. 39).

60 Schneider 1996 (Anm. 1), S. 424; Schanze 1983 (Anm. 15), S. 53f.; Wachinger 1985 (Anm. 1), Sp. 32f.; Burghart Wachinger: Nestler von Speyer. In: ${ }^{2}$ VL 6 (1987), Sp. $905-$ 907.

61 Stackmann 1959 (Anm. 20), S. LXXXVII-LXXXIX.

62 Siehe ebd., S. LXXII-LXXIV; Brunner 1975 (Anm. 16), S. 74-77; Petzsch 1978 (Anm. 28), S. 168f. zu Einträgen Wickrams und S. 188-201 zu Einträgen ab 1546. Ergänzend zu Petzschs Beitrag siehe Röll 1980 (Anm. 28), S. 286-291.

63 Schneider 1996 (Anm. 1), S. 424; Welker 1996 (Anm. 1).

64 Dies könnte bei der Restaurierung von 1958 geschehen sein, die Husmann 1960 (Anm. 23), S. 190 erwähnt.

65 Schneider 1996 (Anm. 1), S. 424; Stackmann 1959 (Anm. 20), S. LXXXVIf. 
Herkunft: Die Frühzeit der Handschrift ist unsicher; einige Indizien für Entstehung in Speyer. ${ }^{66}$ Abhängigkeit von der Ursprungssage des Meistergesangs verrät ein mystifizierender Eintrag auf 3r (Ende 15./Anfang 16. Jh.) über die siebenhundertjährige Verwendung des Codex in Mainz, der Hypothesen zur Entstehung in Mainz angeregt hat. ${ }^{67}$ Auf Aufbewahrung in Mainz könnte $z u$ Maincz ... ein buch hindeuten, das in der Schulkunst Der vrsprung des maystergesangs (frühes 16. Jh.) erwähnt wird ${ }^{68} \mathrm{Um} 1485$ bildet k eine Vorlage der in der südlichen Ortenau (Kloster Wonnental bei Emmendingen?) geschriebenen ,Donaueschinger Liederhandschrift' (Karlsruhe, Landesbibl., Cod. Donaueschingen 120). ${ }^{69}$ Am 21. Dez. 1546 von Jörg Wickram in Schlettstadt (Séléstat, $40 \mathrm{~km}$ westlich von Emmendingen) gekauft für die Einrichtung der Kolmarer Singschule (Eintrag 16r ${ }^{70}$ ). Entleihungen nach Augsburg um 1550-1553 (18r) und Straßburg 1590-1591 (18rv und rückwärtiger Spiegel). ${ }^{71} 1571$ in Kolmar durch Adam Puschmann benutzt (18r). 1789 als in Kolmar befindlich gemeldet; die Handschrift lag ,in der Zunftstube der Colmarer Schuster“; ;2 dann eine Weile verschollen; 1857 durch einen Basler Buchhändler an die Hof- und

66 Vgl. grundlegend zum Folgenden Schneider 1996 (Anm. 1), S. 425 und Wachinger 1985 (Anm. 1), Sp. 37. Zu den Kenntnissen siehe Stackmann 1959 (Anm. 20), S. LXXII: „wir wissen, wenn wir ehrlich sind, über die ersten 70 Jahre in der Geschichte der Hs. überhaupt nichts“; ähnlich Brunner 1975 (Anm. 16), S. 70. Hinweise auf Speyer bei Schanze 1983 (Anm. 15), S. 51 anhand der Verbreitungsgebiete der Wasserzeichen; weitere bei Kornrumpf 2008 (Anm. 2), S. 260-268; vgl. Schneider 1996 (Anm. 1), S. 425.

67 Datierung des Eintrags nach Schneider 1996 (Anm. 1), S. 425. Zum Eintrag siehe Schneider 1996 (Anm. 1), S. 425; Stackmann 1959 (Anm. 20), S. LXVI-LXX; Husmann 1960 (Anm. 23), S. 191-193; Petzsch 1978 (Anm. 28), S. 23-32; Röll 1980 (Anm. 28), S. 287f.; Schanze 1983 (Anm. 15), S. 49f. (mit klarer Kritik an der Zuverlässigkeit des Eintrags); Wachinger 1985 (Anm. 1), Sp. 32; Brunner/Rettelbach 1985 (Anm. 10), S. 234. Zur eventuellen Entstehung in Mainz siehe Stackmann S. LXX; energisch dafür Petzsch 1978 (Anm. 28), S. 23-47; abwägend Brunner/Rettelbach, S. $235 f$.

68 Brunner/Rettelbach 1985 (Anm. 10), Abdruck S. 223-227; Vers 137 und 143. Zur Datierung ebd., S. 228-230.

69 Schneider 1996 (Anm. 1), S. 425; Brunner 1975 (Anm. 16), S. 70; Wachinger 1985 (Anm. 1), Sp. 34f.

70 Siehe Stackmann 1959 (Anm. 20), S. LXXII; Petzsch 1978 (Anm. 28), S. 164-207; Wachinger 1985 (Anm. 1), Sp. 37.

71 Siehe Stackmann 1959 (Anm. 20), S. LXXII-LXXIV zu den Entleihungen und den an verschiedenen Stellen eingetragenen Versen von Nutzern des 16. Jh.s.

72 Wachinger 1985 (Anm. 1), Sp. 38. Nachweise bei Stackmann 1959 (Anm. 20), S. LXXV; vgl. Kornrumpf 2008 (Anm. 2), S. 257. 
Staatsbibliothek München verkauft (1v). ${ }^{73}$ Eine beigebundene 26-seitige Straßburger Meisterliedersammlung (von 1582-1591) wurde in München entfernt und als Cgm 4999 separat aufgestellt. ${ }^{74}$

\section{Inhalt: ${ }^{75}$}

1r-2v Nachträge von Claus Bentz (2v; Mitte 16. Jh.), VaterunserAuslegung und Ave-Maria-Paraphrase ${ }^{76}$

$3 \mathrm{r}-15 \mathrm{v} \quad$ Register der Meisterlieder

$16 \mathrm{r}-18 \mathrm{v} \quad$ Einträge des 16. Jh.s

19ra-853ra ,Kolmarer Liederhandschrift': 5 Leichs, ca. 935 Strophenlieder mit zusammen ca. 4380 Strophen in 107 Tönen. ${ }^{77}$ Rückwärtiger Spiegel: Reimpaargedicht des Straßburger Bürgers Martin Breun, 1591.

Abb.: Farbdigitalisat der Bayerischen Staatsbibliothek (s. o. Anm. 7).

Literatur: www.handschriftencensus.de/6355 (eingesehen am 25. 10. 2020); Schneider 1996 (wie Anm. 1); Wachinger 1985 (wie Anm. 1), Sp. 27-39; vgl. weiter die Übersicht oben in Abschnitt II.

\section{Schreiber A und Schreiber B}

Diese karge Auflistung bildet einen Codex nur höchst unvollständig ab, der ganze Bände von Forschung füllt. An jeder Stelle könnte die Kurzbeschreibung unschwer in die Tiefe erweitert werden; dies sei nur ansatzweise an zwei Beispielen angerissen: den Schreiberpersonen und der materialen Struktur der Schreibprozesse.

Bei den beiden Schreibern der Kolmarer Liederhandschrift ist deutlich, dass Schreiber A eine wichtigere Funktion einnimmt. Er war offenbar „für die

73 Stackmann 1959 (Anm. 20), S. LXXV-LXXVIII; Petzsch 1978 (Anm. 28), S. 208-243 (jeweils mit Indizien für die Übergangszeit).

74 Petzsch 1978 (Anm. 28), S. 185-188; vgl. zur Handschrift RSM Bd. 1 (Anm. 6), S. 210f.

75 Detaillierte Auflistung bei Schneider 1996 (Anm. 1), S. 426-444.

76 Siehe Peter Appelhans: Untersuchungen zur spätmittelalterlichen Mariendichtung. Die rhythmischen mittelhochdeutschen Mariengrüße. Heidelberg 1970 (Germanische Bibliothek, Dritte Reihe), S. 45f.; Burghart Wachinger: ,Gegrüßet sistu ane we. In: ${ }^{2}$ VL 2 (1980), Sp. 1136f. Vgl. zum Eintrag Husmann 1960 (Anm. 23), S. 190; Stackmann 1959 (Anm. 20), S. LXXIV.

77 Vgl. Wachinger 1985 (Anm. 1), Sp. 27. Siehe genaue Auflistung bei Schneider 1996 (Anm. 1), S. 427-444 und im RSM Bd. 1 (Anm. 6), S. 205-209. 
Disposition und die Endredaktion verantwortlich " ${ }^{78}$ was daran zu erkennen ist, dass er nicht nur die meisten Melodiestrophen sowie fast alle Noten eintrug, sondern auch das Register und ganz überwiegend „die organisatorischen Anweisungen, Hinweise auf nachträgliche Materialumstellungen, auf Fortset-

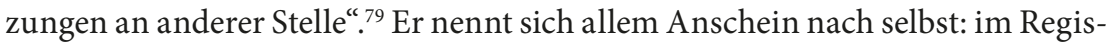
ter scriptor[] huius libri (fol. 9r) sowie magist[er] scilicet scriptor[] huius libri (fol. 492r) beim Eintrag eines Lieds zu den 72 Namen Marias im Unerkannten Ton, der in der Nürnberger Tradition Nestler von Speyer zugeordnet ist. ${ }^{80}$ Die Rubrik zum Lied stellt den magister scilicet scriptor als Tonerfinder und Dichter dar, ${ }^{81}$ der sein eigenes Lied hier einbringt. Das Lied ist nicht nur durch die Rubrik hervorgehoben, sondern auch dadurch, dass Schreiber A in der Melodienotation besondere Formen der Rhythmisierung verwendet. ${ }^{82}$ Angesichts der Ordnungsleistung des Schreibers A fällt auf, dass dieses Lied innerhalb des Marner-Korpus steht und damit die sonstige Tonautorordnung unterläuft. Möglich ist aber, dass der Schreiber durch eine vorhergehende Notiz (fol. 490r) angeregt wurde, dass der Marner einen Ton nur einmal benutzt habe, und danach sein eigenes Beispiel für einen solchen Ton einrückte. ${ }^{83}$ Dass der eigene Ton auf diese Art im Codex ,versteckt' erscheint, könnte ostentatives Zeichen von Bescheidenheit sein, das durch den Registereintrag wieder relativiert wird.

Die größte Wahrscheinlichkeit besteht, dass der Schreiber A und Nestler von Speyer identisch sind. ${ }^{84}$ Horst Brunner und Johannes Rettelbach wiesen zwar

78 Kornrumpf 2008 (Anm. 2), S. 260. Schnell 1993 (Anm. 39), S. 261 nennt ihn ebenfalls „Redaktor“; vgl. Husmann 1960 (Anm. 23), S. 197. Baldzuhn 2002 (Anm. 1), S. 25 nennt Schreiber B den „Gehilfe[n] des Hauptredaktors A“.

79 Baldzuhn 2002 (Anm. 1), S. 25.

80 Beide Belegstellen bei Schanze 1983 (Anm. 15), S. 52f.; Schnell 1993 (Anm. 39), S. 261. Der Beleg von fol. 492r bei Husmann 1960 (Anm. 23), S. 220; Petzsch 1973 (Anm. 29), S. 445f.; Röll 1980 (Anm. 28), S. 217; Wachinger 1987 (Anm. 60), Sp. $905 f$. Das Lied auf fol. 492r ist RSM ${ }^{1} \mathrm{Nestl} / 1 \mathrm{a}$; siehe Gisela Kornrumpf: ,Zweiundsiebzig Namen Marias‘. In: ${ }^{2}$ VL 11 (2004), Sp. 1698-1709, hier Sp. 1703f.; Text bei Thomas Cramer: Die kleineren Liederdichter des 14. und 15. Jahrhunderts. Bd. 2. München 1978, S. 399-403; Abdruck der Melodie bei Petzsch 1973 (Anm. 29), S. 459f. Zur Nürnberger Tradition vgl. Wachinger 1985 (Anm. 1), Sp. 33.

81 Kornrumpf 2008 (Anm. 2), S. 260.

82 Welker 1996 (Anm. 1), Sp. 452 nennt die Markierung von Längen durch gedoppelte Puncta und Kürzen durch Minimakauden im Abgesang.

83 Petzsch 1978 (Anm. 28), S. 258; Röll 1980 (Anm. 28), S. 221; Wachinger 1985 (Anm. 1), Sp. $33 \mathrm{f}$.

84 Wachinger 1987 (Anm. 60), Sp. 906; Wachinger 1985 (Anm. 1), Sp. 33; ebd. Auseinandersetzung mit der Frage, ob k an dieser Stelle Autograph ist oder Übernahme aus 
darauf hin, dass ein Namenszusatz "von Speyer" am ehesten naheliege, wenn eine Person gerade nicht in ihrer Heimatstadt wirkte; ${ }^{85}$ aber Frieder Schanze hat bereits das Argument angeführt, dass der Namenszusatz gerade nicht in k überliefert ist und also auch, etwa aus Nürnberger Sicht, einen Bürger Speyers bezeichnen könne. ${ }^{86}$

Hand B füllte die Strophen nach den Melodiestrophen ein und steuerte insgesamt einen großen Schreibanteil bei. In seiner geläufigen Schrift wurde die Hand „vermutlich eines Berufsschreibers ${ }^{\text {“87 }}$ gesehen; allein von $\mathrm{k}$ ausgehend, könnte man vermuten, dass er für Schreiber A arbeitete. ${ }^{88}$ Die für die Lokalisierung der Handschrift eigentlich wichtige genauere Beschreibung der Schreibsprache ist leider erschwert: zum einen haben die Schreiber offenbar versucht, allzu dialektale Formen zu vermeiden, ${ }^{89}$ zum anderen ist das vorhandene Material bislang nur bruchstückhaft erfasst. ${ }^{90}$ Hinzu kommt der undeutliche Einfluss einer Vielzahl von Vorlagen und die bislang nur vage Unterscheidung der dialektalen Formen bei Schreiber A und B. ${ }^{91}$

Ein schwerwiegendes Indiz für die Arbeit der beiden Schreiber ist die Identifikation eines weiteren Bandes dieser beiden Hände, die Gisela Kornrumpf gelungen ist. ${ }^{92}$ Das große medizinische 'Speyrer Kompendium ${ }^{93}$ gehört, wie Bernhard Schnell betont, „zu den bedeutendsten deutschsprachigen Medizinhandschriften des Mittelalters. Sein Stellenwert in der Medizingeschichte ist durchaus vergleichbar mit dem, den die Kolmarer Liederhandschrift in der Literaturgeschichte einnimmt. ${ }^{\text {"94 }}$ Das Kompendium enthält unter anderem

einer Vorlage (Husmann 1960 [Anm. 23], S. 219f. und Röll 1980 [Anm. 28], S. 220 vermuteten Abschrift aus einer Vorlage mit Marginalien). Die Mehrheit sieht hier Autograph.

85 Brunner/Rettelbach 1985 (Anm. 10), S. 237.

86 Schanze 1983 (Anm. 15), S. 54, Anm. 57.

87 Schneider 1996 (Anm. 1), S. 424.

88 Vgl. Wachinger 1985 (Anm. 1), Sp. 37: er sieht Schreiber A ,in einer Position, in der er einen zweiten Schreiber beschäftigen konnte.“

89 Stackmann 1959 (Anm. 20), S. XC; Baldzuhn 2002 (Anm. 1), S. 24.

90 Wachinger 1985 (Anm. 1), Sp. 32; Kornrumpf 2008 (Anm. 2), S. 260f.; Kornrumpf 2009 (Anm. 1), S. 609; Baldzuhn 2002 (Anm. 1), S. 24. Vgl. o. Anm. 51; weiterhin bleibt eine umfassende Untersuchung anhand einer größeren Textbasis ein Desiderat.

91 Kornrumpf 2009 (Anm. 1), S. 608; Kornrumpf 2008 (Anm. 2), S. 260.

92 Siehe Kornrumpf 2008 (Anm. 2), S. 264.

93 Salzburg, Universitätsbibl., Cod. M III 3; siehe oben Anm. 59.

94 Schnell 1993 (Anm. 39), S. 262. Vgl. ebd. S. 265 zum hohen Anteil (ca. 90\%) medizinischen Fachschrifttums, während Randthemen wie ,Tier' und ,Garten' nur gelegentlich vorkommen. 
einen Eintrag, der auf den 13. 9. 1460 datiert ist (fol. 445ra) ${ }^{95}$ und mehrere Hinweise auf Speyer. ${ }^{96}$ Im Vergleich der beiden Handschriften fallen diese Merkmale auf:

- Beide Handschriften zeigen Hinweise auf das Anwachsen während der Arbeit. ${ }^{97}$ Offenbar sollte jede der beiden Handschriften auf ihrem Gebiet eine große Summe ziehen und war als längeres ,work in progress' geplant. ${ }^{98}$

- In beiden Fällen wurde das Sammelgebiet während des Fortgangs erweitert. Offenbar strömte während der Arbeit weiteres Material hinzu; „es dürfte aus den verschiedensten Vorlagen stammen. ${ }^{\text {"99 }}$ Änderungen im Konzept führten zu Um- und Beiheftungen. Dies hängt zusammen mit der „von beiden Schreibern praktizierte[n] Technik der Anlagerung, die sich aus der Aufschlüsselung der beteiligten Hände und den bewußt angelegten Freiräumen [...] noch zum Teil ablesen läßt“. ${ }^{100}$ Schanze hat in seinem Fazit zur Entstehung von $\mathrm{k}$ drei Punkte benannt, die Bernhard Schnell ganz genauso für das ,Speyrer Kompendium' ansetzt: Die jeweilige Handschrift ist „Ergebnis eines mehrschichtigen Arbeitsprozesses“, bei deren Anfang „der Redaktor noch gar keine genaue Vorstellung von der endgültigen Gestalt der Handschrift besaß“; schließlich: „Erst im Verlauf der Arbeit wuchs die Sammlung in Dimensionen, die der Sammler zu Beginn ganz offenkundig nicht eingeplant hatte. ${ }^{\text {"101 }}$

- Die Ausstattung der beiden Codices ist vergleichbar: zweispaltige Anlage, rubrizierte Überschriften und Zwischentexte, Gliederung durch verschiedenfarbige Lombarden. ${ }^{102}$ Beide Handschriften sind übergreifend

95 Kornrumpf 2008 (Anm. 2), S. 266; Schnell 1993 (Anm. 39), S. 264.

96 Zusammengestellt bei Kornrumpf 2008 (Anm. 2), S. 266f.; Schnell 1993 (Anm. 39), S. 264. Zur Geschichte der Hs. siehe Schnell, S. $264 \mathrm{f}$.

97 Kornrumpf 2008 (Anm. 2), S. 269. Siehe unten Anm. 148 u. ö. zu den verschiedenen Papiersorten in k.

98 Vgl. Kornrumpf 2008 (Anm. 2), S. 268.

99 Wachinger 1985 (Anm. 1), Sp. 34 zu k. Schnell 1993 (Anm. 39), S. 266-268 unterscheidet beim ,Speyrer Kompendium“ zehn Textkorpora, die „nicht nach einem ,Gesamtplan` abfolgen“ (S. 268), wobei er das erste Textkorpus (fol. 11ra-82rb bzw. die Lagen I bis V, also fol. 7-86) als zentralen Block einstuft.

100 Schnell 1993 (Anm. 39), S. 263 zum ,Speyrer Kompendium'. Ebd., S. 276 zum Vergleich: „Im Arbeitsprogramm und in der Arbeitsweise der beiden Schreiber läßt sich völlige Übereinstimmung feststellen.“

101 Schanze 1983 (Anm. 15), S. 40f.; zitiert bei Schnell 1993 (Anm. 39), S. 270.

102 Schnell 1993 (Anm. 39), S. 264. 
erschlossen: durch das Register in k, durch Querverweise im ,Speyrer Kompendium. ${ }^{103}$ Eine Besonderheit des ,Speyrer Kompendiums' sind medizinische Demonstrationszeichnungen (Aderlassmann), die sich auf zwei zugefügten Pergamentdoppelblättern befinden. ${ }^{104}$ Ein wesentlicher Unterschied der Handschriften ist das Format: Während k mit 29,3 x $20 \mathrm{~cm}$ und 854 Blättern eine „fast quaderförmige Gestalt ${ }^{\text {“105 }}$ aufweist, ist das ,Speyrer Kompendium' mit 40,8 x 29,4 cm und 518 Blättern zum einen deutlich größer, zum anderen eher wie ein Buch geformt; ${ }^{106}$ darauf wird noch zurückzukommen sein.

- Auffällig dicht beieinander liegen die Datierungen der beiden Bücher über die Wasserzeichenanalyse: 1459-1462 bei k; ${ }^{107} 1457-1462$ beim ,Speyrer Kompendium ' ${ }^{108}$ wozu auch die genannte Datierung auf 1460 (fol. 445ra) passt.

- Ein Unterschied in der materialen Gestalt besteht darin, dass bei vergleichbarem Vorgehen $\mathrm{k}$ aus zahlreichen verschiedenen Papieren zusammengestellt ist, ${ }^{109}$ während das ,Speyrer Kompendium' nur eine einzige Papiersorte verwendet. ${ }^{110}$ Heinrich Husmann vermutete für $\mathrm{k}$, dass der Papiervorrat während der Arbeit erschöpft war und daher andere Papiersorten herangezogen wurden. ${ }^{111}$ Der Befund der Medizinhandschrift könnte darauf deuten, dass der letztlich angestrebte Gesamtumfang früher klar war (worauf auch

103 Ebd., S. 263 zum Verweissystem im ,Speyrer Kompendium'.

104 Ebd., S. 264, der auf die fehlende Beschriftung der Zeichnungen verweist: „Entweder wurden die beiden Demonstrationszeichnungen erst beim Binden des Kodex - vielleicht mit der ersten Pergamentlage - eingefügt, oder es fehlt, aus welchen Gründen auch immer, ein Arbeitsschritt, d. h. das Buch war, als es gebunden wurde, noch nicht ganz fertig."

105 Kornrumpf 2008 (Anm. 2), S. 257; Kornrumpf 2009 (Anm. 1), S. 608: „quaderförmige Gestalt“; Welker 1996 (Anm. 1), Sp. 450: „nahezu kubische Gestalt“; nach der Beschreibung von Karl Felix Halm von 1857 (gedruckt bei Petzsch 1978 [Anm. 28], S. 224) „ein wahres Monstrum“.

106 Entsprechend der Größe verfügt der Einband von k nur über vier erhabene Bünde, das ,Speyrer Kompendium' über fünf. Bei letzterem liegt, anders als bei k, noch „[z]eitgleicher" Einband (Jungreithmayr 1988 [Anm. 59], S. 193) vor; doch hilft das Muster aus Streicheisenlinien nicht zur Identifizierung der Buchbinderwerkstatt.

107 Schanze 1983 (Anm. 15), S. 48.

108 Schnell 1993 (Anm. 39), S. 263.

109 Husmann 1960 (Anm. 23), S. 193 u. ö.; vgl. die detaillierte Wasserzeichenanalyse bei Schanze 1983 (Anm. 15), S. 36-41.

110 Schnell 1993 (Anm. 39), S. 263.

111 Husmann 1960 (Anm. 23), S. 193. 
das größere Format weisen könnte) oder dass von Beginn an eine höhere Geldsumme in das Projekt investiert wurde, so dass ein größerer Papiervorrat gekauft werden konnte. Vielleicht war es aufgrund des größeren Formats des ,Speyrer Kompendiums' tunlich, zeitig zueinanderpassendes Papier zu besorgen. Die Vorstellung aber, dass das ,Speyrer Kompendium' dann auch gründlicher vorausgeplant sein könnte, wird durch die verschlungene Genese konterkariert.

- Obwohl sich die Sammelbereiche teils überschneiden - das ,Speyrer Kompendium' erfasst auch Verstexte, die in sein weiteres Spektrum passen -, kommen Dubletten zwischen den Bänden fast gar nicht vor, wie Gisela Kornrumpf hervorgehoben hat. ${ }^{112}$ Der einzige Fall ist das ,Goldene ABC' des Mönchs von Salzburg (k fol. 653vb-657ra, Schreiber A; Salzburg fol. 418r419r, Schreiber B). Da die beiden Aufzeichnungen wohl auf verschiedene Vorlagen zurückgehen, nimmt Kornrumpf an, dass die codexübergreifende Dublette unbeabsichtigt und unbemerkt unterlief. ${ }^{13}$

- Während k deutlich vom Schreiber A dominiert wird, scheint B im ,Speyrer Kompendium ' die koordinierende Person zu sein. ${ }^{114}$ Man kann daraus, wie Gisela Kornrumpf, den Schluss ziehen, dass jeder Schreiber ein Projekt führte und sie sich wechselseitig unterstützten. ${ }^{115}$

Trotz der üppigen Hinterlassenschaft der beiden Schreiber finden sich kaum Indizien, die über ihr Schreibzeugnis hinausweisen. Offenbar ist die geläufigere Schrift von Schreiber B; darum wurde in ihm zunächst ein Berufsschreiber vermutet. ${ }^{116}$ Bei Schreiber A finden wir Latein- und Notenkenntnisse sowie einen exzellenten Überblick über Sangspruch und Meistergesang; ${ }^{117}$ aufgrund

112 Kornrumpf 2008 (Anm. 2), S. 272. Jeder Band für sich enthält Einzeltexte mehrfach. Schnell 1993 (Anm. 39), S. 268f. und 273 sieht die gelegentlichen Dubletten innerhalb des ,Speyrer Kompendiums' nicht nur als Irrtümer, sondern auch als Streben nach größtmöglicher Komplettheit.

113 Kornrumpf 2008 (Anm. 2), S. 273.

114 Zum Anteil von Schreiber B am ,Speyrer Kompendium' siehe Kornrumpf 2008 (Anm. 2), S. 265f.; Schnell 1993 (Anm. 39), S. 262.

115 Kornrumpf 2008 (Anm. 2), S. 271.

116 Vgl. oben Anm. 87.

117 Auf der Einstellungsseite ist bei Schreiber A wohl auch eine gewisse Marienfrömmigkeit zu konstatieren, wenn er als einziges eigenes Werk in k ein Marienlob einträgt und bekräftigt, dass er wegen der hohen Würde Marias kein anderes Lied in diesem Ton gedichtet habe; vgl. Petzsch 1973 (Anm. 29), S. 464. Der Befund taugt als Persönlichkeitsmerkmal nur bedingt. 
der Lateinkenntnisse und des Umstands, dass er anscheinend einen zweiten Schreiber beschäftigte, dachte Wachinger bei ihm „am ehesten an einen Beamten oder Kleriker" ${ }^{118}$ Christoph Petzsch hält ihn, angesichts der Professionalität im Bereich des Meistergesangs, sogar für einen „überdurchschnittlich instruierte[n] Kleriker". ${ }^{\text {"19 }}$

Diese Einschätzung wird durch das ,Speyrer Kompendium' relativiert. Bernhard Schnell sieht in den Schreibern zwei „ausgebildete Wundärzte“,120 was er auf die in Auswahl und Zusammenstellung nachgewiesene Sachkenntnis im medizinischen Sammelkodex und auf die enthaltenen Selbstreferenzen zurückführt. Wenn an mehreren Stellen auf die beiden schriber verwiesen wird, die Rezepte ausprobiert und Menschen geheilt hätten, ${ }^{121}$ dann ist deutlich, dass sie sich hier als professionelle Ärzte inszenieren. Dabei werden Rezepte, Wirkungsbeteuerung und eigene Erfahrungswerte zur Überzeugung der Rezipienten zusammengestellt, wie etwa am Rezept bei Nabelbruch zu erkennen: ${ }^{122}$

Item do einem kinde der nabel gebrochen ist: So solt du nemmen güntzel, und hat brün bletter. Vnd sude die in luterm wasser vnd tü ym des wassers in daz bat. Vnd binde ym des crütes als warm über den nabel so dü es nyder legest. Vnd tu es dicke; so me, so besser. Wann es ist war vnd wart versucht an des schribers kinden der daz ander buch geschrieben hat.

Dass in dem ,Schreiber des anderen Buchs' der Schreiber A als Betreuer von k zu sehen sein dürfte, ${ }^{123}$ ist sehr plausibel. Der Passus setzt erstens voraus, dass der Rezipient das andere Buch identifizieren kann und dass es nur ein solches Buch gibt. Er wendet sich also an einen imaginierten Leser, der beide Werke vor sich hat. Wenn wir k als das Projekt von A und das ,Speyrer Kompendium' als Projekt von B ansehen, dann wäre damit das Hauptwerk von beiden einigermaßen komplett. Die Wendung könnte bedeuten, dass Schreiber B davon ausging, beide Bücher würden bei einem gemeinsamen Leser landen: also eventuell einem Auftraggeber, der beide mit einer Aufgabe jahrelang in zwei Bereichen

118 Wachinger 1985 (Anm. 1), Sp. 37.

119 Petzsch 1978 (Anm. 28), S. 120; die Stellungnahme steht allerdings im Zusammenhang mit seiner übergreifenden These; vgl. u. Anm. 205.

120 Schnell 1993 (Anm. 39), S. 271, ebenso S. 276; Kornrumpf 2008 (Anm. 2), S. 274.

121 Nachweise bei Schnell 1993 (Anm. 39), S. 275.

122 ,Speyrer Kompendium' (vgl. Anm. 59), fol. 171va, Abkürzungen aufgelöst und Interpunktion zugefügt; Satztrennung nach der Rubrizierung der Handschrift. Die letzten zwei Halbsätze auch bei Kornrumpf 2008 (Anm. 2), S. 271, und Schnell 1993 (Anm. 39), S. 275 zitiert.

123 Kornrumpf 2008 (Anm. 2), S. 271. 
beschäftigt hätte, ${ }^{124}$ die sie mit Bravour erfüllten. Ebenso könnte es sich aber auch um eine Wendung an die Nachwelt handeln, also unter anderem an uns, an diejenigen, die beide Bücher vergleichen und den inneren Zusammenhang erkennen.

Nun erfährt man auch daraus nicht viel mehr über die Personen der Schreiber. Aus dem zitierten Eintrag und ähnlichen von Schnell besprochenen Stellen lässt sich schließen, dass der eine Schreiber Frau und Kinder hatte; ${ }^{125}$ er war also zumindest kein zölibatär lebender Kleriker. In dem Eintrag oben wird der schriber nur als Angehöriger der Patienten angeführt, an anderen Stellen aber auch als Anwender von Heilverfahren. Es ist unstrittig, dass hier persönliche medizinische Kompetenz überzeugend suggeriert wird. Schnells Hinweis auf Ärzte als Literaten wurde seither dankbar aufgegriffen. ${ }^{126}$

Schnell erwähnt, dass das verwendete magister für den Kompilator ein Ausdruck für ,Arzt' sein kann: ${ }^{127}$ Beim Schreiber A in k wäre dann magister scilicet scriptor huius libri nicht als, Arzt dieses Buchs' zu übersetzen, sondern als ,Arzt - und Schreiber dieses Buchs'. Im nichtmedizinischen Kontext von k ist es aber eher unwahrscheinlich, dass Benutzer hier auf die Bedeutung ,Arzt' statt des naheliegenden ,Meisters` verfallen wären. Schnell nimmt weiter an, es habe sich um Wundärzte gehandelt, nicht um studierte Ärzte mit Universitätsabschluss (physici), „die sich in der Regel in der Latinität bewegten““ ${ }^{128}$ Dies bleibt aber offen, solange wir nichts über die Zielgruppe und ein etwaiges Vermittlungsbemühen der Redaktoren wissen. Das Kompendium ist schon in sich ein Unikum und könnte also auch einen singulären Umschlag in die Volkssprache repräsentieren. Ein volkssprachiges Kompendium hätte auch ein studierter Arzt in solcher Form erstellt. Mit der Frage nach dem Zielpublikum ist die nach der Funktion der beiden Codices berührt, die weiter unten noch einmal angesprochen wird.

124 Ebd., S. 271f. bringt das bedenkenswerte Argument, dass z. B. ein adliger Liebhaber von Meisterkunst k in Auftrag gegeben habe; wenn beide Bände für den gleichen Auftraggeber vorgesehen waren, erklärte dies die Vermeidung von codexübergreifenden Dubletten.

125 Dies betont auch Welker 1996 (Anm. 1), Sp. 453.

126 Schnell 1993 (Anm. 39), S. 262; Baldzuhn 2002 (Anm. 1), S. 29, erkennt darin die "Zuordnung zu einem bekannten Autorentypus“.

127 Schnell 1993 (Anm. 39), S. 277.

128 Ebd., S. 276. 


\section{Materiale Struktur und Bestandsschichtung von $\mathbf{k}$}

Die Kolmarer Liederhandschrift bietet ein breites Spektrum meisterlicher Lieddichtung, wobei Geistliches dominiert; in den weltlichen Liedern findet sich häufig Kunstthematik (etwa als Inszenierung meisterlichen Wettstreits), zudem Sittenlehre, Frauenpreis, Scherzhaftes und Ständelehre; dazwischen stehen gelegentlich längere Erzählungen in Strophenform (,Lorengel', ,Veronica II'); sortiert wurde nach Tonautoren und Tönen in zeitgenössischen Zuschreibungen. ${ }^{129}$ Gisela Kornrumpf hat hervorgehoben, dass die Lieder überwiegend aus dem späten 14. und der ersten Hälfte des 15. Jahrhunderts stammen, dass ein großer Teil der Texte, aber nur wenige Töne Unica sind und dass zwei Leichs und rund 540 Strophen, also ein knappes Achtel des Gesamtbestands, aus der Zeit vor 1350 entstammen. ${ }^{130}$ Die Auswahl des Tönerepertoires zeigt konservative Züge, die sich etwa vom Nürnberger Gebrauch der Zeit unterscheiden, und könnte mit dem für den rheinischen Meistergesang bezeugten Gebrauch zusammenhängen, nur die Töne alter Meister anzuerkennen. ${ }^{131}$ Von allen anderen Meisterliederhandschriften des 15. Jahrhunderts unterscheidet $\mathrm{k}$ sich durch die Ordnung nach Tonmeistern und Tönen, durch die Melodieaufzeichnung und durch den breiteren Fokus, etwa die Aufnahme von Reihen, Parat und Leichs. ${ }^{132}$

Die beschriebene Spannbreite stand nicht von vornherein fest, und Indizien für den Sammelprozess sind noch am materialen Zeugnis der Handschrift ablesbar, wie es häufiger bei umfangreichen Sammelhandschriften festzustellen ist. Dass ein Anwachsen der Sammlung in k von vornherein geplant war, wird dadurch unterstrichen, dass bei wichtigen Autoren und bei reich überlieferten Tönen je neue Lagen beginnen, ${ }^{133}$ was Ergänzungen erleichterte, solange der Band nicht gebunden war. Durch Tonanfänge am Lagenanfang reservierte man zugleich Freiseiten am Lagenende, um die Option von Ergänzungen offenzuhalten; ${ }^{134}$ ähnlich sind auch im ,Speyrer Kompendium` Freiräume

129 Wachinger 1985 (Anm. 1), Sp. 28f.

130 Ebd., Sp. 27f., unter Berufung auf Kornrumpf.

131 Brunner 1975 (Anm. 16), S. 80-83; Wachinger 1985 (Anm. 1), Sp. 36.

132 Brunner 1975 (Anm. 16), S. 165-171; Wachinger 1985 (Anm. 1), Sp. 36f. Siehe zur Besonderheit dieser Textgruppe im vorliegenden Band Horst Brunner (S. 53-69) und Lorenz Welker (S. 71-101).

133 Husmann 1960 (Anm. 23), S. 194 und 239.

134 Vgl. zum ähnlichen Vorgehen in der,Großen Heidelberger Liederhandschrift': Wernfried Hofmeister: Der Mut zur Lücke: Auf den Spuren von Textnachträgen in der Manessischen Liederhandschrift. Ein Beitrag zu einer 'Überlieferungs-Philologie' 
reserviert. ${ }^{135}$ Über die Bestandsschichtung im Band sind wir bisher, trotz einiger wichtiger Beiträge, nur bruchstückhaft informiert. Bereits die Betrachtung des Blattbestands und seiner nachweisbaren Veränderungen, die im Folgenden im Zentrum stehen, liefert zahlreiche Indizien für die Genese des Codex.

Im Ergebnis sind Ersteintrag und Nachträge auf vielfältige Weise miteinander verwoben. Ähnlich wie andere der großen Handschriften Spuren von Änderungen im Sammelkonzept zeigen, zum Beispiel durch Umordnung bereits geschriebener Seiten, ${ }^{136}$ finden sich solche auch in $\mathrm{k}$. Hier ist durch die alte Foliierung eine frühe Blattversetzung dokumentiert; ${ }^{137}$ anfangs war dies die Reihenfolge:

des Mittelalters. In: Entstehung und Typen mittelalterlicher Lyrikhandschriften. Akten des Grazer Symposions 13.-17. Oktober 1999. Hg. von Anton Schwob und Andràs Vizkelety unter Mitarbeit von Andrea Hofmeister-Winter. Bern u. a. 2001 (JIG A 52), S. 79-106; Martin Schubert: Sprechende Leere. Lücke, Loch und Freiraum in der Großen Heidelberger Liederhandschrift. In: Editio 22, 2008, S. 118-138.

135 Siehe Kornrumpf 2008 (Anm. 2), S. 270: Die Freiräume seien vielleicht für Weiterführung durch künftige Benutzer gedacht gewesen und wurden von den Händen 3 und 4 auch so genutzt. Schnell 1993 (Anm. 39), S. 263: die leeren Seiten seien Teil der „Technik der Anlagerung“', S. 268: man sehe dies an den „leer gebliebenen Blättern, Spalten und Leerräumen [...] oder an der Praxis, neue Abschnitte erst in der zweiten Spalte zu beginnen."

136 Siehe etwa Gisela Kornrumpf: Die Anfänge der Manessischen Liederhandschrift. In: Deutsche Handschriften 1100-1400. Oxforder Kolloquium 1985. Hg. von Volker Honemann und Nigel F. Palmer. Tübingen 1988, S. 279-296 [erweiterter Wiederabdruck in Kornrumpf 2008 (Anm. 2), S. 1-31]; Gisela Kornrumpf: Der Grundstock der 'Jenaer Liederhandschrift' und seine Erweiterung durch Randnachträge. In: Die 'Jenaer Liederhandschrift'. Codex - Geschichte - Umfeld. Hg. von Jens Haustein und Franz Körndle unter Mitwirkung von Wolfgang Beck und Christoph Fasbender. Berlin, New York 2010, S. 39-79.

137 Siehe zu den Foliierungen und den folgenden Zahlen Schneider 1996 (Anm. 1), S. 423; Husmann 1960 (Anm. 23), S. 195. - Die dritte Foliierung ist modern; ich nutze sie hier zum Vergleich, da sie nicht die Fehler der zweiten Foliierung enthält, die nach der Umordnung entstand und weitgehend parallel zur dritten verläuft. Im Folgenden werden die Lagen anhand der dritten Foliierung benannt; auf Lagenzählung in k verzichte ich, da hierzu konkurrierende Systeme umlaufen. 


\section{Zählung 3. Zählung}

fol. [fehlt] 19-31

13-537 94-693

$538-682 \quad 706-853$

683-732 32-83
Frauenlob: Marienleich und Überzarter Ton Langer Ton Frauenlobs (...) Schwarzer Ton Klingsors

Stolles Alment (...) Sanfter Ton des Harder

Artifizielle Lieder (Reihen, Parat, Leichs)

Damit ist deutlich, dass sich der Teil mit den artifiziellen Liedern zum Zeitpunkt der ersten Zählung am Ende des bis dahin Gesammelten befand. Mit der Entscheidung, diese fünf Lagen weit nach vorne zu ziehen und nach der ersten Textlage mitten ins Frauenlob-Korpus einzurücken, wird wohl die besondere Wertschätzung dieser Liedformen unterstrichen. ${ }^{138}$ Husmann hat plausibel gemacht, dass der Eintrag auf fol. 43v Dyß ist frauwenlobs taugenhort oder sin slosshort vnd solt davorn nach sim leich sten in der ursprünglichen Anordnung noch sinnvoller gewesen wäre, weil dann ein Verweis vom alten Folio 694 nach 1 erfolgt wäre; die Feststellung solcher Querbezüge konnte auch Anregung für die Umordnung sein. ${ }^{139}$ Von den alten Folien 1-12 sind keine Zahlen der ersten Zählung zu finden, diese Blätter dürften aber, wie in der Tabelle angedeutet, in den heutigen fol. 19-31 vorliegen, ${ }^{140}$ die dann den ursprünglichen prächtigen Eingang ins Frauenlob-Korpus bildeten.

138 Husmann 1960 (Anm. 23), S. 196 und 241; Schanze 1983 (Anm. 15), S. 40. Ebd., Anm. 21 kritisiert Schanze Husmanns Vorstellung, die Umordnung sei auf eine weitere Person zurückzuführen, und vermutet eher Sinnesänderung des Redaktors. Vgl. zu dieser Textgruppe oben Anm. 132.

139 Husmann 1960 (Anm. 23), S. 197.

140 Zusammen 13 Blätter aufgrund des Schaltzettels fol. 29 (vgl. unten Anm. 161). Husmann 1960 (Anm. 23), S. 195 setzt sich mit Stackmann auseinander, der diese Lage für spät hielt, weil sie die rote (zweite) Zählung I-XII trägt, die erst nach der Umordnung eingetragen wurde; siehe Stackmann 1959 (Anm. 20), S. LXXXIII: „Der alte Anfang ist bei der letzten Redaktion ausgeschieden worden." Husmann nahm an, dass diese ursprünglich erste Lage in erster Zählung in roten lateinischen Ziffern und der Rest in schwarzen arabischen Ziffern geschrieben war; das ist aber höchst unwahrscheinlich, da ab dem heutigen fol. 32 die roten Ziffern ab XIII, die erst nach der Umordnung datieren, ohne erkennbaren Unterschied fortfahren. Wahrscheinlicher ist, dass die erste Lage ursprünglich nicht foliiert war, weil ihre Position im Einband selbstverständlich schien. Der Umstand, dass nur die ersten beiden Prachtformen einspaltig geschrieben sind (fol. 19r-29v, vgl. o. Anm. 58) weist auf eine frühe Entstehungsphase. Schanze 1983 (Anm. 15), S. 42, Anm. 26: „Die ältere 
Die kleine Tabelle zeigt augenfällig, dass die heutigen Folien 1-18, die die Register und diverse Nachträge enthalten, in der ersten Zählung nicht berücksichtigt waren. ${ }^{141}$ Auch belegt die Aufstellung an den Scharnierstellen die neuen Folien ohne alte Entsprechung (fol. 84-93, 694-705), die also Erweiterungen nach der Umstellung sind. ${ }^{142}$ Ebenso lässt sich vermuten, dass nach der Umstellung noch Seiten hinzugekommen sind, da fol. 13-537 der ersten Zählung 525 Blätter erfasst und fol. 94-693 der zweiten 600 Blätter. Die Rechnung ist, aufgrund der mehrfach inkohärenten Zählung, allerdings nicht exakt. ${ }^{143}$ In der ersten Zählung sind insgesamt 40 Blatt mit Behelfszählungen wie 387a- $h$ markiert, was auf frühe Zufügungen deuten kann, aber auch als Korrektur von Zählfehlern gedeutet werden könnte. ${ }^{144}$ Unter den 37 Folien, die keine erste Foliierung tragen, sind die Zufügungen nach dieser Foliierung zu suchen. ${ }^{145}$

Bei diesen Rechnungen fällt zweierlei ins Auge. Zum einen ist der heutige Schluss des Codex, also der Teil, der oben bei Stolles Alment beginnt, seit der

Foliierung fehlt in der ersten Lage, sie beginnt aber in Lage 7 mit der Zahl 13 und setzt damit die Anfangsposition der ersten Lage voraus."

141 Vgl. Schneider 1996 (Anm. 1), S. 423. Das Register wurde nach der Umordnung angelegt, blieb aber auch in der zweiten Paginierung ungezählt, wohl aus praktischen Gründen, weil die Paginierung des Textteils Voraussetzung der Registerarbeit war. Schanze 1983 (Anm. 15), S. 41, Anm. 24, weist darauf hin, dass das Register, obwohl spät geschrieben, auf der ältesten Papiersorte steht: „Die erste Lage $\left(\mathrm{O}^{1-}\right.$ Papier mit nachträglich eingeschobenem B-Papier), der zuletzt geschriebene Teil der Handschrift, muß schon früh für das Inhaltsverzeichnis reserviert worden sein“; vgl. dazu Husmann 1960 (Anm. 23), S. 193.

142 Fol. 84-93: Muskatblut, auf P-Papier (siehe Schanze 1983 [Anm. 15], S. 37) und fol. 694-705: ,Stubenkrieg' und div. ,Wartburgkrieg'Texte und Lorengel, auf $\mathrm{O}^{3}$-und $\mathrm{O}^{5}$-Papier (ebd. S. 39). Fol. 84-93 sind nur Teil einer Lage, zudem am Ende der ersten Ordnung; sie könnten zuvor auch unnummeriert geblieben sein.

143 Die Position dieser Blätter muss man aus den bisherigen Übersichten bei Husmann 1960 (Anm. 23) und Schanze 1983 (Anm. 15), S. 35-52 zusammensuchen.

144 Zählprobleme der ersten Zählung bei fol. 122-134 (40a-l), 172-175 (81a-d), 419-430 (310a-l), 485-488 (358I-358 $\left.{ }^{I V}\right), 519-527(387 a-h), 589 f$. (446a-b). Erkennbar ist die Korrektur eines vorhergehenden Fehlers bei fol. 419-430, da sowohl bei fol. 417 als auch bei 431 die erste Zählung mit „309“ beginnt.

145 Nicht in der ersten Zählung erfasst sind die fol. 1-18 (Register, oben nicht mitgezählt), 29, 71/78 (einziger Fall in den Lagen der artifiziellen Lieder; vgl. dazu unten bei Anm. 196), 84-93, 162, 190, 304, 305, 321, 591, 645/660, 670/671, 685/688, 694705; weder in der ersten noch der zweiten Zählung paginiert wurden fol. 71, 450 und 534 . 
ersten Foliierung in seiner Blattzahl unverändert. ${ }^{146}$ Zum anderen war das heutige letzte Blatt, fol. 853, bereits vor der Umordnung vorhanden. Das bedeutet: Die zahlreichen Ergänzungen nach der Umordnung, die viele zusätzliche Blätter erforderten, wurden sämtlich einsortiert; es gibt kein ergänztes Blatt am Schluss. Zwar hat Michael Baldzuhn gezeigt, dass zum Zeitpunkt der Registererstellung am Ende noch mindestens drei Blatt folgten, die im Register auf fol. $14 \mathrm{v}$ angezeigt werden und sechs Suchensinn-Lieder enthielten, ${ }^{147}$ doch diese Seiten sind heute verloren. So wie sich der Band jetzt präsentiert, scheint er seit der Umordnung am Ende nicht mehr gewachsen zu sein, sondern ausschließlich im Inneren.

Dass im jetzt hinteren Teil weniger ergänzt wurde, belegt auch der Teil ab Stolles Alment, in den keine zusätzlichen Blätter mehr eingelegt wurden. Auch wenn hier noch viele Nachträge hinzukamen, waren offenbar die reservierten Freiräume ausreichend. Ob das Interesse, zusätzliches Material aufzutreiben, in dieser Tongruppe geringer war, wäre noch zu überlegen. Jedenfalls zeigt die Position von fol. 853, dass allem Anschein nach mit der Umordnung das Tonrepertoire der Sammlung für vollständig angesehen wurde: Es gab kein Bestreben mehr, neue Töne am Ende zu ergänzen.

Grundlage weiterer Überlegungen zur Genese der Handschrift sind die Lagen- und Wasserzeichenanalysen bei Heinrich Husmann und Frieder Schanze. Husmann unterschied bereits drei Sorten Papier, die er nach ihren Motiven O-, B- und P-Wasserzeichen nannte (Ochsenkopf, Berg, Buchstabe P), und erkannte, dass der ursprüngliche Bestand im O-Papier zu sehen sei. ${ }^{148}$ Erste Erweiterungen sah er auf Mischungen von O- und P-Papier; das B-Papier sah er erst nach der Umordnung im Einsatz. ${ }^{149}$ Diese Unterscheidung half ihm, spätere Blattzufügungen zu isolieren. So konnte er beispielsweise feststellen, dass eine Reihe Doppelblätter des B-Papiers nach der ersten und vor der zweiten Foliierung eingelegt wurden. ${ }^{150}$ Für die Anbringung der (ersten) Foliozählung

146 Rechnerisch scheint bei den obigen Zahlen die neue Foliierung drei Blatt mehr zu umfassen (148 statt 145 Blatt); dies liegt aber nur an drei Foliierungsfehlern der alten Zählung: 550 und 636 sind je zweimal vergeben, ein ungezähltes Blatt nach 584; siehe Husmann 1960 (Anm. 23), S. 232f. und 236.

147 Siehe Baldzuhn 2000 (Anm. 8), S. 427f.; S. 428 Nachweise der sechs Lieder anhand der Initien im Register.

148 Husmann 1960 (Anm. 23), S. 190, 193 u. ö.

149 Ebd., S. 203.

150 Ebd., S. 199; es handelt sich um fol. 645/660, 670/671, 685/688, 808, 809, 810/813, $811 / 812$. 
vermutet Husmann, dass diese wohl im Fortschreiben eingetragen wurde, da sie im Allgemeinen mit der Hand im Text wechselt. ${ }^{151}$ Bei den Ergänzungen wurden teils ganze Lagen ergänzt. ${ }^{152}$

Darüber hinausgehend hat Schanze sechs verschiedene Sorten des OWasserzeichens unterschieden. ${ }^{153}$ Er stellt fest, dass die von ihm als $\mathrm{O}^{1}$ - und $\mathrm{O}^{2}$-Wasserzeichen benannten Papiere für die ursprünglichen Lagen verwendet wurden und dass $\mathrm{O}^{3}$-Papiere erst im nächsten Schritt als ganze Lagen zugefügt wurden, $\mathrm{O}^{4}$ und $\mathrm{O}^{5}$ wieder später. ${ }^{154}$ Er kann damit nachweisen, dass bei Tönen wie Frauenlobs Würgendrüssel, Regenbogens Grauem Ton oder Marners Langem Ton eine oder zwei Lagen für Nachträge ergänzt wurden; in Regenbogens Langem Ton umfasst die Ergänzung gar fünf ganze Lagen (fol. 369-430). ${ }^{155}$ Auch die in ältere Lagen eingelegten $\mathrm{O}^{3}$-Blätter können damit als Zufügungen identifiziert werden. Bei der Betrachtung dieser Verhältnisse verweist Schanze auf Indizien für die Auswertung umfangreicher Quellen in früheren Stadien und zahlreicher Einzelquellen zu späterer Zeit. ${ }^{156}$ Husmanns These, die Handschrift sei aus zwei bis drei Hauptquellen kompiliert, wies Schanze mit guten Gründen zurück. ${ }^{157}$

Auf diesen Grundlagen sind also mindestens drei Phasen der Entstehung zu unterscheiden: die Erstellung der ersten Sammlung nebst ihren Erweiterungen und der ersten Foliierung; die Phase der Umordnung, mit folgenden Erweiterungen; und die zweite Foliierung/Erstellung des Registers sowie einige spätere Zufügungen. Innerhalb der Phasen sind teils Arbeitsschritte zu unterscheiden. Eine genauere Analyse der Schichtung eines einzelnen Bestands hat zuerst Karl Stackmann für das Korpus Heinrich von Mügeln vorgenommen, ${ }^{158}$ das eine Niederschrift der ersten Phase mit einigen Erweiterungen repräsentiert. Stackmann hat detailliert gezeigt, wie neues Material Änderungen in mehreren Schritten - er zählt bis zu fünf - hervorrief. ${ }^{159}$

151 Husmann 1960 (Anm. 23), S. 206.

152 Ebd., S. 240 mit Beispielen.

153 Schanze 1983 (Anm. 15), S. 36.

154 Ebd., S. 41.

155 Ebd.

156 Siehe ebd., S. 42 zur längeren Passage von Schreiber A in Frauenlobs Langem Ton; S. 44 zu den Nachträgen in Regenbogens Briefweise, ebenfalls von Schreiber A.

157 Husmann 1960 (Anm. 23), S. 241-243; Schanze 1983 (Anm. 15), S. 40; vgl. Baldzuhn 2002 (Anm. 1), S. 23.

158 Stackmann 1959 (Anm. 20), S. LXXXIV-LXXXVI; vgl. Baldzuhn 2002 (Anm. 1), S. 24.

159 Stackmann 1959 (Anm. 20), S. LXXXIVf.: In der Lage fol. 589-606 wurde ein Doppelblatt (Wasserzeichen ,P`) so eingelegt, dass der hintere Teil (fol. 604) eine Ergänzung 
a) Die Ursammlung und ihre Erweiterungen. Mit 19r beginnt die ursprünglich erste Lage der Sammlung, was sich auch in der erläuternden Rubrik äußert: Hie volget gesang der meinster geticht. Zum ersten in meinster Heinrich frauwenlobs tönen die nacheinander gent vnd die ersten genotiert et sic de aliis. ${ }^{160}$ Hier wurde also eine Gebrauchsanweisung vorangestellt, die sowohl den Gesamtinhalt umschrieb (der meinster geticht) und die Tonautor- und Tonordnung erläutert als auch die Beigabe von Noten zur jeweils ersten Strophe eines Tons. ${ }^{161}$

Frauenlob und Regenbogen als die tönereichsten Meister stehen am Anfang; diese Lieder umfassen heute zusammen ca. 45\% des Bestands. ${ }^{162}$ Danach kommen der Marner, Konrad von Würzburg, der Kanzler, Boppe und Heinrich von Mügeln (siehe oben). Eingeschoben in diesen Teil ist der durch Nachträge angeschwollene Eintrag zum Mönch von Salzburg. ${ }^{163}$ Danach folgen die Meister, die vor allem durch einen Ton vertreten sind: Reinmar von Zweter, Reinmar von Brennenberg, Alter und Junger Stolle, Ehrenbote, Wolfram, Walther, Tugendhafter Schreiber, Ungelehrter, Heinrich von Ofterdingen, Rumelant, Anker, Mülich von Prag, Tannhäuser, der Liebe von Giengen, Meffrid und der Junge Meißner. ${ }^{164}$ Zum Abschluss folgen einige Meister des späteren 14. und des 15. Jahrhunderts: Suchensinn, Peter von Arberg, Lesch und Harder. ${ }^{165}$ Die Gruppe von artifiziellen Liedern stand ursprünglich am Ende.

Die Differenzierung von Arbeitsschritten anhand des $\mathrm{O}^{1}$ - und $\mathrm{O}^{3}$-Papiers hat Schanze, ungefähr bis fol. 600, ausführlich dargestellt. ${ }^{166}$ Isoliert man den

aufnehmen konnte, dafür aber nicht reichte, so dass von fol. 604vb auf 609vb gesprungen wurde (Verweis 604vb: am funften plat); der vordere Teil des Doppelblatts (fol. 591) wurde mit späteren Nachträgen verfüllt usw. Vgl. zur Stelle Schanze 1983 (Anm. 15), S. 47, der allerdings annimmt, dass fol. 591/604 „später, nach der zweiten Foliierung“ zugefügt wurde. Ebenso wie fol. 589/606 und 590/605 ist dieses Doppelblatt in die erste Foliierung eingepflegt: Fol. 591 trägt zwar keine Zahl, 604 aber schon. Alle diese Ergänzungen im Mügeln-Korpus gehören damit zur ersten Phase.

160 Fol. 19r, zit. bei Husmann 1960 (Anm. 23), S. 196; Röll 1980 (Anm. 28), S. 216.

161 Husmann 1960 (Anm. 23), S. 196. Diese Lage, ursprünglich ein Sexternio, wurde durch das zugefügte halbe Blatt fol. 29 erweitert, wohl weil zunächst der Eintrag des Abgesangs zum Überzarten Ton vergessen worden war; siehe Husmann 1960 (Anm. 23), S. 194f. mit Lagenplan.

162 Wachinger 1985 (Anm. 1), Sp. 30.

163 Ebd.

164 Ebd., Sp. $30 f$.

165 Ebd., Sp. 31.

166 Schanze 1983 (Anm. 15), S. 42-47. 
Kernbestand der Handschrift als das $\mathrm{O}^{1}$-Papier, dann umfasste dieser kaum die Hälfte des Bandes. ${ }^{167}$ Im Folgenden zeigt sich, „daß ein ursprünglicher Plan nicht aufgegeben wurde; aber Akzentverschiebungen im Sammelinteresse zogen doch beträchtliche Modifikationen nach sich “. ${ }^{168}$ Das $\mathrm{O}^{3}$-Papier ist bereits vor der ersten Foliierung im damals hinteren Teil der Handschrift mehrfach verwendet worden: die umgestellten Lagen mit den artifiziellen Liedern bestehen weitgehend aus $\mathrm{O}^{3}$-Papier, mit gelegentlichen späteren Einfügungen (B- und P-Papier). Daraus ließe sich folgern, dass der ursprüngliche Papiervorrat schon vor der Umordnung zur Neige ging. ${ }^{169}$

Die größeren Modifikationen lassen sich an vielen Einzelstellen über die Foliierungen erkennen. Fol. 519-526 ( $\mathrm{O}^{3}$-Papier), mit dem 40strophigen ,Ave Maria' in der Morgenweise Konrads von Würzburg, ${ }^{170}$ sind in der ersten Zählung als 387a-387h gezählt und dürften also nach dieser Zählung zugefügt sein: ${ }^{171}$ die Anpassung mit Buchstaben belegt zudem, dass dies vor der zweiten Zählung geschah ${ }^{172}$ es handelt sich also um eine Ergänzung der ersten Phase.

Teils umfangreiche Ergänzungen und Umordnungen führen teils zu sonderbaren Befunden. ${ }^{173}$ Vor allem das Fortarbeiten in nicht-linearer Form, mit Textsprüngen quer durch den Codex, erschwert den Überblick. Die Lage fol. 118-138 umfasst 21 Blätter, davon zehn Doppelblätter, die recht zusammengeflickt erscheinen. ${ }^{174}$ Das innerste Doppelblatt fol. 128/129 mit dem Tannton Frauenlobs scheint in den fortlaufenden Text eines Liedes im Langen Ton

167 Kornrumpf 2008 (Anm. 2), S. 258: „kaum die Hälfte“; Kornrumpf 2009 (Anm. 1), S. 608: „weniger als die Hälfte“; Baldzuhn 2002 (Anm. 1), S. 24: „nicht einmal die Hälfte“.

168 Kornrumpf 2008 (Anm. 2), S. 258.

169 Husmann 1960 (Anm. 23), S. 203 nennt die letzte Lage der artifiziellen Lieder (heute fol. 82-93) „eine sehr spät erst nachträglich ,eingeschobene‘ bzw. angefügte Lage“, was sich aber auf die Zeit vor der Umordnung bezieht.

$170{ }^{1}$ KonrW/6/100b.

171 Husmann 1960 (Anm. 23), S. 222 mit Lagenplan.

172 Siehe zu den Papieren Schanze 1983 (Anm. 15), S. 38. Irritierenderweise ist dieser Quaternio aus $\mathrm{O}^{3}$-Papier zum Quinio vervollständigt, und zwar durch ein umgelegtes Doppelblatt aus P-Papier, das mit den gleichen Foliozahlen wie die anrainenden Blätter versehen wurde: Es folgen jetzt 387, 387, 387a- $h, 388,388$ (heute fol. 517-528).

173 Siehe z. B. zur Reorganisation der Lagen fol. 139-154 und 155-165 (Ausschneiden von vorhandenen Seiten mit anderen Tönen und Versetzung nach hinten, um Raum für Nachträge zu schaffen; vor der ersten Foliierung) Husmann 1960 (Anm. 23), S. 203-205 und Schanze 1983 (Anm. 15), S. 43f.

174 Siehe den Lagenplan bei Husmann 1960 (Anm. 23), S. 202. 
Frauenlobs inseriert, der jetzt von fol. $127 \mathrm{v}$ auf $130 \mathrm{r}$ springt. ${ }^{175}$ Die alte Zählung beweist aber, dass dieses Doppelblatt $\left(\mathrm{O}^{3}\right.$-Papier) älter ist und in Wirklichkeit die heutigen fol. 122-127 und ihre Gegenblätter 130-134 ( $\mathrm{O}^{4}$-Papier) jünger sind und statt eines hier nicht mehr vorhandenen Doppelblatts eingesetzt wurden. ${ }^{176}$ Die elf Blätter enthalten vielfältige Zufügungen zu Frauenlobs Langem Ton, die hier als Nachtrag noch der ersten Phase unterkamen. Ein Lied in Frauenlobs Würgendrüssel läuft korrekt über die Lagengrenze von fol. 117v auf 118r. Bei den nachgetragenen Liedern im Langen Ton springt die Aufzeichnung aber von fol. $115 \mathrm{v}$ auf $122 \mathrm{r} .{ }^{177}$ Der Nachtrag verfüllte nicht einfach Leerräume, denn 119vb-121v sind bis heute leer. Es scheint, dass die Schreiber nach der ersten Foliierung einen Senio geschrieben hatten, der an 115v angeschlossen hätte, ohne zu bemerken, dass eine Fortsetzung der Lage sowie die folgende Lage bereits vorlagen. Das Problem lösten sie, indem sie ihren Senio in die folgende Lage integrierten, wodurch eine riesige Lage entstand, dabei die Paginierung durch Buchstaben einpassten (fol. 40a-40l) und den Benutzern mehrfache Sprünge zumuteten.

b) Die Umordnung und die folgenden Erweiterungen. Mit der Umordnung der artifiziellen Lieder begann eine neue Phase in der Erstellung des Codex, die durch weitere Ergänzungen im Inneren geprägt ist. Auch hier wurde dem zuströmenden Material in erfindungsreicher, teils schwer nachvollziehbarer Weise begegnet. Es folgen wenige Beispiele.

Beim Ergänzen auf ursprünglich freigehaltenen Seiten wurden auch jetzt diverse Sprünge ausgeführt. Ein Lied im Hofton Muskatbluts beginnt auf fol. 93v. Unten auf der Seite wird durch Such daz überige vnd me muscatblut an dem clxxj blat nach fr[auwenlobs] leit ton auf die Fortsetzung auf fol. 192r verwiesen. ${ }^{178}$ Die Lage fol. 82-93 bildete vor der Umordnung das Ende der Handschrift;

$175{ }^{1} \mathrm{Frau} / 29 / 1 \mathrm{a}$ und ${ }^{1} \mathrm{Frau} / 2 / 548$; siehe den Verweis auf $127 \mathrm{v}$ : ker vmb ij bletter.

176 Dieses Doppelblatt, das die 1. Zählung 41/44 tragen müsste, vermutet Husmann 1960 (Anm. 23), S. 203 im Doppelblatt fol. 141/152, da er auf fol. 141 eine gestrichene 44 ausmacht. Das Doppelblatt müsste nach Husmann versetzt worden sein, bevor es beschrieben wurde, wobei aber offen bleibt, warum die Schreiber ein leeres Doppelblatt versetzten und umnummerierten, wenn sie an gleicher Stelle neue leere Doppelblätter einlegten und neu nummerierten.

177 Siehe fol. 115v: such uber vj bletter Cij; „102“ ist die zweite Paginierung von fol. 122. Husmann 1960 (Anm. 23), S. 203 erkennt hier Korrektur von Cij aus xla („40a“), was die entsprechende Zählung der ersten Paginierung wäre.

$178{ }^{1}$ Musk/1/11e. Siehe Husmann 1960 (Anm. 23), S. 200 und RSM (Anm. 6), Bd. 4, S. 385. Bei Klaus Jürgen Seidel: Der Cgm 379 der Bayerischen Staatsbibliothek und 
mit diesem Eintrag wurde also die ursprüngliche Sammlung von artifiziellen Formen noch einmal erweitert, indem der bereits vorhandene MuskatblutEintrag fortgesetzt wurde, wahrscheinlich nach der Umordnung. In der ersten Foliierung sind in der Lage fol. 82-93 nur fol. 82 und 83 foliiert; das erste ist $\mathrm{O}^{3}$-Papier, das zweite bereits, wie die vier inneren Doppelblätter, P-Papier. Muskatbluts Hofton wurde auf den inneren P-Folien begonnen (also wohl zu einem relativ späten Zeitpunkt), läuft über die letzten beiden $\mathrm{O}^{3}$-Blätter und springt dann auf weiteres $\mathrm{O}^{3}$-Papier knapp 100 Blätter weiter hinten. Der Verweis auf 192r gehort hinfur nach dem lxxiij blat ließe sich auch so deuten, dass er eine fehlerhafte Einordnung zurechtrücken solle. Unklar bleibt, wieso nach fol. 93 keine weiteren Blätter eingelegt wurden - schließlich befindet sich hier ein Lagenende. Eine weitere Option könnte sein, dass zu einem weit fortgeschrittenen Zeitpunkt der Beschreibstoff knapp wurde und man auf bislang freigehaltene Blätter zurückgriff. Dann aber fällt auf, dass zahlreiche freie Seiten zwischen den beiden Sprungstellen nicht genutzt wurden. ${ }^{179}$ Da die Fortsetzung des Muskatblut-Lieds mitten in einer Lage nach zwei leeren Blättern steht, ließe sich nur argumentieren, dass die Schreiber an allen Stellen noch Raum für Ergänzungen reservieren wollten und erst hier genug Platz fanden, um sowohl Freiraum als auch Nachtrag unterzubringen.

Husmann teilt den sonderbaren Fall mit, dass die Strophe 22 des Winsbecken zweimal in der Sammlung eingetragen ist und dabei jeweils an der gleichen Stelle einen Seitenumbruch enthält. ${ }^{180} \mathrm{Ihm}$ war dies aufgefallen, weil bei dem einen Übergang (fol. 743v-744r) eine Reklamante steht, die auf die Variante hinter dem anderen Übergang (fol. 817v-818r) verweist. Mit dieser Strophe beginnt ein Teil der Vaterlehre, der über 42 Strophen hin in der Handschrift doppelt eingetragen ist (fol. 744ra-747rb; fol. 817ra-821va). Husmann geht nun, aufgrund von kleinen Inhaltsvarianten, davon aus, dass Schreiber B hier zwei Vorlagen zum Winsbecken hatte und beide aufnehmen wollte. ${ }^{181}$ Daraus zieht er den Schluss, dass der Schreiber fol. 744-817, also sechs Lagen, einfügte, weil

das „Augsburger Liederbuch“ von 1454. Augsburg 1972, S. 744-746 wird das Lied nebst der Schreibervermerke abgedruckt, aber nicht auf die sonderbare Aufzeichnungsform eingegangen.

179 Siehe Schneider 1996 (Anm. 1), S. 424: fol. 120-121, 129v, 135, 138, 154v, 156v, 159v$160 \mathrm{v}, 165 \mathrm{v}, 185 \mathrm{v}, 187 \mathrm{v}, 190-191$.

180 Husmann 1960 (Anm. 23), S. 233, mit Textabdruck beider Strophen; siehe zur Stelle RSM ${ }^{1}$ Winsb/1n. Die Passage mag hier etwas ausführlicher besprochen werden; sie wird bei Schanze 1983 (Anm. 15), S. 42-47 nicht behandelt.

181 Husmann 1960 (Anm. 23), S. 233f. 
er vorhatte, beide Fassungen hintereinander zu bieten. Immerhin enthalten diese Lagen ein Dutzend andere Töne, ${ }^{182}$ deren neue Position erläuterungsbedürftig war. Husmann erwägt, ob die Reihung alter Meister in einer Vorlage den Schreiber angeregt habe, diese vorzuziehen und die andere Vorlage, die mehr jüngere Meister enthielt, vorerst zurückzustellen. ${ }^{183}$ Diese Umstellung müsste noch vor der ersten Foliierung geschehen sein.

Der völlig blödsinnige Vorgang, parallele Texte nicht nacheinander aufzunehmen, sondern über 70 Folien mitten in eine Strophe $\mathrm{zu}$ inserieren, wird dadurch allerdings nicht erklärt. Auch bleibt offen, wie der Seitenumbruch an der genau gleichen Stelle zustande kam; aus dem bloßen Vorhandensein zweier Vorlagen ist der Vorgang nicht erklärbar. Zu erkennen ist am Seitenende von fol. 817v, dass beim Anfang von Strophe 22 sechs Zeilen in drei gepresst sind und auf den unteren und rechten Margin hinausgeschrieben wurde. An dieser Stelle wurde also der Anschluss passend gemacht, weil er zum folgenden fol. 818r gehören sollte, das bereits geschrieben war. Husmann scheint mir den Status der Textvarianten zu hoch einzustufen: Die beiden Vorlagen hätten nicht nur die gleiche Auswahl von Winsbecke-Strophen ${ }^{184}$ bieten, sondern diese auch noch in annähernd gleicher Formulierung enthalten müssen. Die Winsbecke-Ausgabe vermeldet, dass die Strophen hier „parallel überliefert" seien; sie „stimmen fast durchwegs genau überein. ${ }^{“ 185}$ Dieses Verhältnis ist seit Leitzmanns Untersuchung von 1888 dokumentiert. ${ }^{186}$

Bei der Durchsicht der 42 doppelten Strophen konnte ich keine wesentlichen Inhaltsvarianten entdecken, sondern nur iterierende Formen wie das von Husmann bemerkte wunne/selde (744ra/818ra) ${ }^{187}$ oder Einzelfehler. ${ }^{188}$ Der Text läuft

182 Siehe RSM, Bd. 1 (Anm. 6), S. 208f. und das Digitalisat der Handschrift.

183 Husmann 1960 (Anm. 23), S. 234.

184 Also Str. 22-37, 39-42, 44, 45, 50, 52, 53, 55, 56, 65-78, 80; siehe RSM (Anm. 6), Bd. 5, S. 571.

185 Winsbeckische Gedichte nebst Tirol und Fridebrant. Hg. von Albert Leitzmann. 3., neubearbeitete Auflage von Ingo Reiffenstein. Tübingen 1962 (Altdeutsche Textbibliothek 9), S. VIII und XI. Vgl. auch S. X: „Ein wichtiges Kriterium für die Zusammengehörigkeit einzelner Hss. ist die Strophenanordnung.“

186 Albert Leitzmann: Zur Kritik und Erklärung des Winsbeken und der Winsbekin. In: Beiträge zur Geschichte der deutschen Sprache und Literatur 13, 1888, S. 248 277, hier S. 254: In der Beschreibung des zweiten Eintrags überwiegen „(ganz) wie oben“ (12x) und „Sonst wie oben“ (24x).

187 Husmann 1960 (Anm. 23), S. 233.

188 Wie in Str. 70: 746va gewalt/820vb gestalt. Fehler bei der Rubrizierung in Str. 75: 747ra Min (!) kraft/821rb Din kraft. 
vielmehr auffällig parallel. Auch besondere Dialektmerkmale stehen überwiegend identisch. ${ }^{189}$ Varianz findet sich in der Rubrik zu den Strophen 65-80: Einmal steht $x v$ lieder in dem selben done (746ra), das andere Mal Item xv lieder aber in dem selben done (820rb). Dieser Unterschied dürfte darauf zurückzuführen sein, dass die Rubriken unabhängig von der Vorlage jeweils ad hoc neu gesetzt wurden. Beweisend für die Nutzung der gleichen Vorlage dürfte ein Bindefehler der beiden Niederschriften in Strophe 29 sein: Der Vers daz er yt obe lige soll sich reimen auf lobe : klobe : dobe (744va/818va; graphematisch identisch). In beiden Fällen hat der Schreiber den Fehler im Fortschreiben bemerkt, wohl beim Auftreten der Reime, und durch rote Doppelstriche Wortumstellung zu lige obe angedeutet. Der Schreiber dürfte bei der zweiten Abschrift ein Déjà-vu erlebt haben.

Damit entfällt das Argument, eine zweite Überlieferung habe zu Dubletten angeregt. Naheliegender als Husmanns Konstrukt ${ }^{190}$ ist die These, dass Schreiber B die Vorlage umfassend abschrieb, aber dann die Lage fol. 818-829 verlegte und die gleiche Vorlage irrtümlich ein zweites Mal kopierte. Als später die fehlende Lage wiederauftauchte, war sie zwar zu schade zum Wegwerfen, begann aber mitten in einer Strophe. Also quetschte der Schreiber den Strophenanfang, den er auf $743 \mathrm{v}$ nachschlagen konnte, ${ }^{191}$ auf ein freigebliebenes Lagenende und gab durch die Rubrik ein ander lere dez vaters (fol. 817vb) eine notdürftige Rechtfertigung, dass hier, gleich nach Suchensinn-Strophen, plötzlich erneut Winsbecke folgte. Husmanns Versuche, Vorlagen zu isolieren, waren auch an dieser Stelle nicht überzeugend.

189 Fol. 744ra/818ra: plegen; 744rb/818rb: driegen; 744va/818va verdüst (= vertuost); $745 \mathrm{vb} / 820 \mathrm{ra}$ dünt (= tuont) usw.

190 Husmann 1960 (Anm. 23), S. 233 druckt die Strophe 22 einmal als Rekonstruktion der ersten Niederschrift, also fol. 743v/818r, sowie einmal als umgekehrte Kombination (817v/744r) der beiden Strophenteile. Letztere haben aber nie zusammengehört, wie schon die Reklamante auf 817v beweist; es liegt hier kein „Abdruck von Str. 22 in beiden Versionen“ (RSM [Anm. 6)], Bd. 5, S. 571) vor. Mit dem Indiz doppelter Abschrift aus gleicher Vorlage werden auch Husmanns weitergehende Folgerungen zu zwei großen Vorlagen für k (S. 243) noch hinfälliger.

191 Husmann 1960 (Anm. 23), S. 238 vermutet, dass der zweite Anfang von Str. 22, „wie die Varianten zeigen, nicht nach dem vorn vorhandenen Stück, sondern gerade nach der anderen Vorlage“ erfolgt. Sein Abdruck beider Fassungen S. 233 zeigt aber, wie minimal die Unterschiede sind (jogent/jugent; dogent/tugend; enweiß nit/weyß nit; in rechtem ee/in rechter ee). Dies überschreitet nicht das, was an Schreibereingriffen üblich ist und bei mehrfachem Kopieren Abweichungen erzeugt. 
c) Die Registererstellung und spätere Erweiterungen. Das Register (fol. 3r$15 v$ ) wurde auf (in der 2. Zählung) ungezählten Blättern vorangestellt. Dabei blieben Blätter frei (fol. 16r-18v), die später beschrieben wurden. Offenbar nutzte der Schreiber zunächst zwei Ternios. ${ }^{192}$ Husmann weist überzeugend darauf hin, dass der Schreiber offenbar vor der Mitte des zweiten Ternios feststellte, dass der Raum nicht reichen würde, und zwei weitere Doppelblätter einlegte; ${ }^{193} \mathrm{ab}$ dem Übergang auf die Zusatzblätter mit fol. 9r schreibt er die Tonautornamen größer, weil er nun keinen Raum mehr sparen muss. ${ }^{194}$

Grundlage des Registers ist die zweite, rote Foliierung in römischen Ziffern $I-V I I I^{C} X X X I X$. Sie wurde nach der Umordnung erstellt, zu einem späten Zeitpunkt, denn sie zählt fast alle Blätter. Sie macht einige Zählfehler, die für die meisten Unterschiede zur dritten Foliierung verantwortlich sind. Bei den wenigen Blättern, die in der zweiten Foliierung ungezählt blieben - nämlich fol. 71, 450, 534 - kann man sich nun fragen, ob sie beim Eintrag der Ziffern überschlagen wurden oder noch gar nicht vorlagen. Da diese drei Blätter auch keine Ziffern der ersten Paginierung enthalten, wäre es ein sonderbarer Zufall, wenn zuvor ergänzte Blätter nun gewissermaßen durch Überblättern hervorgehoben wurden; bei 450 und 534 kann aber auch der Umstand, dass dies keine vollständigen Blätter sind, veranlasst haben, dass sie vom Redaktor nicht gezählt wurden. ${ }^{195}$ Jedes der drei Blätter zeigt im Detail einen anderen Befund:

- Fol. 71 bildet mit fol. 78 ein Doppelblatt. Fol. 78 trägt eine Ziffer der zweiten Paginierung - allerdings identisch mit dem vorhergehenden fol. 77 als $l v i i{ }^{196}$ Das deutet darauf hin, dass die zweite Zählung abgeschlossen war, als das Doppelblatt eingelegt wurde, und dass noch ein Versuch gemacht wurde, es in die bestehende Zählung zu integrieren. Husmann macht wahrscheinlich, dass das Doppelblatt (mit späterem B-Papier) hinzugenommen wurde, um auf fol. 78r das Ende eines Liedes in Muskatbluts Fröhlichem Ton aufzunehmen, das auf 77v anfängt. ${ }^{197}$ Dann dürfte der Eintrag des Roten Tons des Zwinger auf 79r zu dieser Zeit bereits vorgelegen haben, denn offenbar konnte nicht in der Lage vorangeschrieben werden. Fol. 78v blieb dabei frei.

192 Mit den fol. (ungezählt) und 1-5; 6-8 und 13-15.

193 Fol. 9-12.

194 Husmann 1960 (Anm. 23), S. 191; Lagenplan S. 190.

195 So Husmann 1960 (Anm. 23), S. 217.

196 Siehe ebd., S. 199 mit Lagenplan.

197 ' Musk/3/3b; siehe Husmann 1960 (Anm. 23), S. 199. 
Für ein weiteres Lied in Muskatbluts Fröhlichem Ton ${ }^{198}$ nutzte der Schreiber auch das neue Gegenblatt 71, das bereits genau so eingelegt war: er begann den Eintrag auf 70v und führte ihn bis 71v. Er konnte wohl erkennen, dass das freie fol. $78 \mathrm{v}$ diesen Text nicht aufnehmen konnte, und wich auf die alternative Stelle aus, die aber noch vor der Melodienotation des Tons liegt (siehe fol. 70v: Der ton stet hiennach. liiii). Im Register stehen zunächst die umliegenden Lieder eingetragen; das Lied des hinteren Nachtrags steht auf dem unteren Rand und wird über ein rotes Kreuz als Verweiszeichen diesen zugefügt. ${ }^{199}$ Das Lied des vorderen Nachtrags, das ins Umfeld dieses Eintrags gehört, gelangte nicht mehr ins Register. ${ }^{200}$ Der durch die Blattfolge angezeigte Umstand, dass die beiden Lieder nachträglich zugefügt wurden, wird einmal durch die Zufügung im Register, einmal durch die Auslassung bestätigt.

- Fol. 450, ein kleineres Einzelblatt, wurde mitten in ein Lied eingeschaltet. Es enthält die vierte und fünfte Strophe zu einem Lied in Marners Langem Ton, dessen dritte Strophe ebenfalls auf fol. 449v steht, sowie ein dreistrophiges Lied im gleichen Ton. ${ }^{201}$ Im Register auf $8 \mathrm{v}$ steht das vervollständigte Lied; in der Spalte mit der Angabe der Zahl der Strophen ist eine iij getilgt und durch eine $v$ ersetzt. ${ }^{202}$ Der Zuwachs um zwei Strophen wurde also nachträglich im Register vermerkt; das auf dem gleichen Blatt eingetragene dreistrophige Lied wurde nicht im Register repräsentiert.

- Fol. 534 ist ein halbes Einzelblatt, das laut Beischrift zugefügt wurde, um ein dreistrophiges Lied in Konrads Hofton durch eine erste und fünfte Strophe zu ergänzen. ${ }^{203} \mathrm{Da}$ im Register das Lied als fünfstrophig, mit dem Initium der nachgetragenen ersten Strophe, eingetragen ist, ${ }^{204}$ lag diese Ergänzung bei der Registererstellung schon vor.

$198{ }^{1}$ Musk/3/5b.

199 Fol. 3r, letzte beiden Zeilen: lvij (rote Blattzahl nach der zweiten Paginierung) Ich wil gen dysem mey ( $\left.{ }^{1} \mathrm{Musk} / 3 / 1 \mathrm{n}\right)$ und Item ich wil ein krenczlin buwen ( $\left.{ }^{1} \mathrm{Musk} / 3 / 3 \mathrm{~b}\right)$.

200 Dieser Befund ist unsicher, da auf dieser Seite des Registers (fol. 3r) der Eintrag zur Aufbewahrung der Handschrift in Mainz Zeilen des Registers verdeckt.

$201{ }^{1}$ Marn/7/502a, 4. und 5. Str., und ${ }^{1}$ Marn/7/504; siehe RSM (Anm. 6), Bd. 4, S. $296 f$.

202 Fol. 8v: iijc $x x x v$ (Rubrum der Pagina, entspricht fol. 449) Sung ich den luten mine (über getilgtem yre) lied (getilgtes Rubrum der Strophenanzahl, dann:) v. In der letzten Tilgung schimmern noch drei senkrechte Hasten durch; das schließende $j$ ist eindeutig.

$203{ }^{1}$ KonrW/7/504a, siehe RSM (Anm. 6), Bd. 4, S. 212.

204 Fol. 9v: Vil cluge meinster sprechent daz sie nemme michel wunder $v$ (Rubrum $v$ für die Anzahl der Strophen). Der Raum vor der Spalte, in dem sonst die Blattzahl 
Die auf den Blättern verteilten drei Befunde - Zufügung vor der Registererstellung, Zufügung mit nachträglicher Korrektur im Register, Zufügung ohne Aufnahme ins Register - zeigen, dass die Sammeltätigkeit auch nach Abschluss des Registers fortgesetzt wurde; teils mit Einpflege ins Register, teils ohne.

Kommen wir zum Vergleich der beiden Buchblöcke zurück, der Kolmarer Liederhandschrift und des ,Speyrer Kompendiums‘. Die verwendeten vielfältigen Papiersorten sowie die einen normalen Buchblock sprengende Blattzahl von $\mathrm{k}$ weisen darauf hin, dass hier letztlich mehr zusammengebunden wurde, als bei Beginn des Projekts vorauszusehen war. Dass beim ,Speyrer Kompendium' von vornherein ein größeres Format genutzt und genügend Papier besorgt wurde, könnte vermuten lassen, dass der angestrebte Umfang von vornherein bekannt war. Das wäre aber nur möglich gewesen, wenn die zu verarbeitenden Vorlagen bereits vorgelegen hätten. Die vorliegenden Erweiterungen und Ergänzungen machen dies unwahrscheinlich. Entweder hat der magister des ,Speyrer Kompendiums' seinen Band von vornherein großzügiger geplant, oder er hat aus dem bereits fortgeschrittenen Parallelprojekt gefolgert, dass ein größerer Puffer sinnvoll wäre. Beiden Projekten sind offenbar reiche Quellen und Vorlagen zugeflossen, und die beiden Schreiber haben so für zwei ganz verschiedene Fachbereiche die großen Summen ihrer Zeit gezogen.

Ziemlich schleierhaft ist bislang, für welchen Gebrauch und für welches Zielpublikum die beiden Schreiber die voluminösen Codices zusammenstellten. Dass $\mathrm{k}$ als eine Art Nachschlagewerk für eine Meistersingschule benutzt wurde, ergibt sich folgerichtig aus seiner Anlage; doch ist völlig unsicher, ob ein solcher Gebrauch von vornherein intendiert war. ${ }^{205}$ Dass der Band zum praktischen Gebrauch zum Singen und Lesen, zum Nachschlagen - erstellt wurde, ist ersichtlich; ebenso, dass er außerdem zweifach ,repräsentativ' ist: Er vertritt einen historischen Gattungsquerschnitt, und er macht etwas her. $\mathrm{Zu}$ gerne wüsste man, ob er aufgrund

steht, ist leer, also wird man die Zahl der darüberstehenden Strophe ${ }^{1}$ KonrW/7/503a übernehmen: $v^{c} x i x$, also die zweite Zählung des dem eingeschobenen Blatt vorhergehenden fol. 533.

205 Welker 1996 (Anm. 1), Sp. 454 geht davon aus, dass der „Entstehungskontext der Hs. nicht innerhalb einer Meistersingergesellschaft zu suchen sein" dürfte. Zu der bei Petzsch 1978 (Anm. 28), S. 48-84 ausgeführten These, die Handschrift sei von einer geistlichen Behörde zum Zwecke der Überwachung (also Zensur) erstellt worden, genügt die berechtigte Kritik bei Schanze 1983 (Anm. 15), S. 55f.; vgl. Wachinger 1985 (Anm. 1), Sp. 35. 
des privaten Interesses zweier Einzelgänger entstand, ${ }^{206}$ welche alles aufbewahren wollten, dessen sie habhaft wurden, oder ob ein Sammler und Auftraggeber solches Interesse an Fachleute delegierte. ${ }^{207}$

Die letzten Sätze kann man, wenn man „Singen“ durch „Heilen“ ersetzt, ebenso für das ,Speyrer Kompendium ' formulieren. Hinweise auf einen Mäzen oder Auftraggeber fehlen in beiden Bänden. Die Vorstellungen, die wir uns vom praktischen Gebrauch der beiden Sammlungen machen, sind vage. Aus dem Inhalt abgeleitet, wird man an „ein an der Medizin interessiertes Publikum “ im einen Fall, ${ }^{208}$ an ,am Sangspruch und Meistergesang Interessierte im anderen Fall denken müssen. Für die Meister beider Bücher gilt, was Schanze zum Schreiber A in k bemerkt hat: dass hier jemand „seiner eigenen Leidenschaft in exzessiver Weise und mit großer Kennerschaft frönte und [...] dafür weder Mühe noch auch Kosten scheute “. ${ }^{209}$ Das gilt unabhängig davon, ob eigenes oder fremdes Geld in das Projekt investiert wurde.

206 Schanze 1983 (Anm. 15), S. 57 vermutet einen „rein privaten Hintergrund“ für k; dem folgend nimmt Wachinger 1985 (Anm. 1), Sp. 37 die „private Sammlung eines Liebhabers" an; Schnell 1993 (Anm. 39), S. 277 überträgt Schanzes Vermutung auf das ,Speyrer Kompendium:

207 Kornrumpf 2009 (Anm. 1), S. 609 nimmt an, dass Schreiber A die Handschrift „aus eigenem Antrieb oder auf Bitten anderer Kenner der meisterl. Liedkunst, jedenfalls nicht als reines Auftragswerk" erarbeitete.

208 Schnell 1993 (Anm. 39), S. 270f., Zitat S. 270, umreißt das mögliche Publikum des ,Speyrer Kompendiums', das von unausgebildeten Heilern über Bader, Barbiere, Apotheker, Wundärzte und andere bis zu studierten Medizinern reicht. Das, Speyrer Kompendium ' scheint sich an einen ,astromedizinisch interessierten Hausvater" zu richten, wie Kornrumpf 2008 (Anm. 2), S. 269 (mit einem Begriff von Gundolf Keil) feststellt.

209 Schanze 1983 (Anm. 15), S. 58. Schanze führt hier zwar noch als Kostenpunkt „die Beschäftigung eines Schreibers“ an, doch sollte man sich das Verhältnis jetzt wohl als gegenseitige Unterstützung bei beiden Projekten vorstellen. 



\title{
Horst Brunner
}

\section{Leich, Hort, Parat, Reihen, Tanz Artifizielle Lieder in der Kolmarer Liederhandschrift}

Gisela Kornrumpf gewidmet zum 5. August 2018

\begin{abstract}
The Kolmarer Liederhandschrift includes, very much at the beginning, a collection of highly artificial songtypes (Leich, Hort, Parat/Barant, Reihen and Tanz). These six quires, which originally formed the end of the codex, have been moved here in the process of making the book. In form, these songs differ remarkably from the Meisterlieder making up the main body of the manuscript. This article describes in detail the artificial songtypes and analyses their elaborate construction in meter, form and style. It is argued that the scribes of the Kolmarer Liederhandschrift recognized the outstanding profile of the subcollection and therefore moved it to its new position.
\end{abstract}

Über ihr ,normales' meistersingerliches Tönerepertoire hinaus überliefert die Kolmarer Liederhandschrift bekanntlich mehrere Liedarten, die in anderen Meisterliedercodices des 15. und frühen 16. Jahrhunderts nur sehr vereinzelt begegnen. ${ }^{1} \mathrm{Zu}$ diesem ,Sondergut ${ }^{\mathrm{t}}$ gehören die vier großen geistlichen

1 Ausgaben: Die Kolmarer Liederhandschrift der Bayerischen Staatsbibliothek München (cgm 4997). In Abbildung hg. von Ulrich Müller, Franz Viktor Spechtler und Horst Brunner. 2 Bde. Göppingen 1976 (Litterae 35); Meisterlieder der Kolmarer Handschrift. Hg. von Karl Bartsch. Stuttgart 1862, Neudruck 1962; Die Sangesweisen der Colmarer Handschrift und die Liederhandschrift Donaueschingen. Hg. von Paul Runge. Leipzig 1896, Neudruck 1965; Die kleineren Liederdichter des 14. und 15. Jahrhunderts. Hg. von Thomas Cramer. 4 Bde. München 1977-1985; André Schnyder: Das geistliche Tagelied des späten Mittelalters und der frühen Neuzeit. Tübingen, Basel 2004 (Bibliotheca Germanica 45); GGdM = Geistliche Gesänge des deutschen Mittelalters. Melodien und Texte handschriftlicher Überlieferung bis um 1530. 8 Bde. Hg. von Max Lütolf et al. Kassel u. a. 2004-2019. - RSM = Repertorium der Sangsprüche und Meisterlieder des 12. bis 18. Jahrhunderts. 16 Bde. Hg. von Horst Brunner und Burghart Wachinger. Tübingen 1986-2009. - Grundlegende Literatur zum Thema, auf die ich hier nur pauschal hinweise: Christoph Petzsch: Frühlingsreien als Vortragsform und seine Bedeutung im Bîspel. In: DVjs 45 (1971), S. 35-79; Horst Brunner: Die alten Meister. Studien zu Überlieferung und Rezeption der mittelhochdeutschen Sangspruchdichter im Spätmittelalter und in der 
Leichs: Frauenlobs Marienleich und sein (hier unter dem Namen Regenbogen tradierter) Kreuzleich, der Frauenlob zugeschriebene Tougenhort eines unbekannten Autors und der aus einem geistlichen Tagelied und dem eigentlichen Leich bestehende Hort Peters von Reichenbach, dazu das nicht in der Leich-, sondern in der Sequenztradition stehende Goldene ABC des Mönchs von Salzburg; ferner sind hierher zu zählen die drei geistlichen Tagweisen Peters von Arberg sowie der Cisiojanus und das Nacht- und das Taghorn des Mönchs von Salzburg - letztere sind ebenso wie das Goldene ABC aus einer speziellen Quelle mit Liedern des Mönchs in die Handschrift geraten; außerhalb der Kolmarer Handschrift findet sich vereinzelt unter der Überschrift In des münchis von Salzpurg daghorn (Bl. 336r) lediglich ein anonymes Marienlied (RSM ${ }^{1}$ Mönch/8/2), abgefasst in einer Variante des Tons, in der von Hans Sachs 1517/ 18 geschriebenen Berliner Meistersingerhandschrift Mgq 414.

Zum ,Sondergut' der Handschrift gehören noch weitere Lieder. Der Textteil - voraus geht ein ausführliches Inhaltsverzeichnis - beginnt, wie in einer Überschrift angekündigt, mit den Tönen des im Meistergesang am höchsten angesehenen ,Alten Meisters' Frauenlob. An erster Stelle steht der Marienleich, es folgt der unechte, komplizierte und sehr lange Überzarte Ton. Die FrauenlobReihe wird dann zunächst unterbrochen. Der Redaktor der Handschrift, der Schreiber A, den wir mit dem aus späteren Quellen bezeugten Nestler von Speyer identifizieren, über den man freilich gar nichts weiß, hat, als die Arbeit an der Handschrift so gut wie beendet war, bekanntlich eine Umorganisation vorgenommen: er zog die sechs letzten Lagen des noch ungebundenen Buches nach vorn und ordnete sie nach der 1 . Lage ein. ${ }^{2}$ Man kann dies an der ursprünglichen Blattzählung sehen, die nun geändert wurde, vor allem aber vermerkte er den Sachverhalt im Inhaltsverzeichnis. Mit Bezug auf den voranstehenden Marienleich Frauenlobs liest man hier: Jtem ander leich, Reyen, Barant nacheinander

frühen Neuzeit. München 1975 (MTU 54); Frieder Schanze: Meisterliche Liedkunst zwischen Heinrich von Mügeln und Hans Sachs. 2 Bde. München 1983/84 (MTU 82/83); Johannes Rettelbach: Variation - Derivation - Imitation. Untersuchungen zu den Tönen der Sangspruchdichter und Meistersinger. Tübingen 1993 (Frühe Neuzeit 14); Michael Baldzuhn: Vom Sangspruch zum Meisterlied. Untersuchungen zu einem literarischen Traditionszusammenhang auf der Grundlage der Kolmarer Liederhandschrift. Tübingen 2002 (MTU 120); Gisela Kornrumpf: Vom Codex Manesse zur Kolmarer Liederhandschrift. Aspekte der Überlieferung, Formtraditionen, Texte. Bd. 1: Untersuchungen. Tübingen 2008 (MTU 133). - Gisela Kornrumpf bin ich für Hinweise dankbar verbunden.

2 Zum Aufbau der zweiten Lage vgl. den Beitrag von Lorenz Welker in diesem Band, besonders S. 72 . 
in allerley meystertonen (Bl. 3r). Es folgen (1) Harder, Goldener Schilling in der Chorweise; (2) Harder, Goldener Reihen; (3) Lesch, Goldener Reihen; (4) Peter von Sachs, Barantton; (5) Mülich von Prag, Reihen; (6) Ps.-Frauenlob, Gekrönter Reihen; (7) Ps.-Konrad von Würzburg, Reihen (ohne Melodie); (8) Ps.-Konrad von Würzburg, Goldenes Reihel; (9) Ps.-Frauenlob, Tougenhort oder Schloßhort; (10) Peter von Reichenbach, Hort; (11) Ps.-Neidhart, Fraß; (12) Tannhäuser, Ludeleich; (13) Zwinger, Hort im Roten Ton. Auf den Ludeleich und Zwingers Hort folgen jeweils Texte und Töne des jüngsten in der Handschrift namentlich vertretenen Spruchautors Muskatblut, mit denen die Handschrift ursprünglich geendet hätte, anschließend geht mit der 7. Lage die Reihe der Töne Frauenlobs weiter.

Wie ist diese Umordnung zu verstehen? Der Redaktor bemerkte, dass die Liedgruppe, die ihm offenbar mit einer - uns unbekannten - Vorlage zugekommen war, nicht in den üblichen Ablauf der nach den Tonautoren geordneten Handschrift passte, sondern dass es sich um besondere Lieder - nicht Töne! - handelte, die seiner Ansicht nach eher zu dem den Codex eröffnenden, formal und hinsichtlich des Umfangs den regelrechten Tönen fernstehenden Marienleich Frauenlobs gestellt werden mussten. Manche der ,besonderen' Lieder finden sich vereinzelt auch in anderen Meistersingerhandschriften, waren also dieser Tradition nicht völlig fremd; gehäuft, als eigene Gruppe, treten sie jedoch ausschließlich hier auf. Gemeinsam ist vielen von ihnen die anspruchsvolle Kompliziertheit ihrer Strophenformen, teilweise auch deren Umfang, der sie von den üblichen Tönen des Meistersingerrepertoires unterscheidet; manche zeichnen sich auch durch eine besonders große Strophenzahl aus. Ich bezeichne die Texte, die ich im Folgenden genauer bespreche, als artifizielle Lieder. Die Strophenformen der betreffenden Lieder waren nicht weithin gebräuchlich, sie wurden vielmehr für ein ganz bestimmtes Lied eigens geschaffen und standen oft neben Tönen des gleichen Autors, die im üblichen Rahmen des Meistergesangs blieben und mehrfache oder auch vielfache Verwendung fanden. Das schloss zwar nicht völlig aus, dass gelegentlich der Autor selbst oder weitere Dichter sich des ,besonderen' Schemas bedienten - das blieb jedoch die Ausnahme.

Es empfiehlt sich, die in den Überschriften verwendeten Liedtypenbezeichnungen, die sich vereinzelt auch bei weiteren Liedern der Handschrift finden, detailliert durchzugehen: Leich, Hort, Parat (Barant ist eine sprachliche Nebenform mit westoberdeutscher Nasalierung ${ }^{3}$ ), Reihen - dazu kommt noch, nicht in der Eröffnungsgruppe, die Bezeichnung Tanz.

3 Vgl. Frühneuhochdeutsche Grammatik. Hg. von Oskar Reichmann und Klaus-Peter Wegera. Tübingen 1993 (Sammlung kurzer Grammatiken Germanischer Dialekte), L 62,4 . 
Leich/Hort: Unter, Leich'verstand man seit dem späten 12. Jahrhundert die durchkomponierte, in Versikel gegliederte Groß- und Prunkform der Lieddichter; unter den professionellen Spruchdichtern haben sich Walther von der Vogelweide, Reinmar von Zweter, Tannhäuser, der Wilde Alexander, Konrad von Würzburg, Herman Damen und Frauenlob ihrer bedient. ${ }^{4}$ Die Typenbezeichnung findet sich in der Kolmarer Handschrift in der Überschrift von Frauenlobs Marienleich: Diß ist unser frauwen leich oder der guldin flügel (Bl. 19r), ferner in der Überschrift des weiter hinten stehenden, hier fälschlich Regenbogen zugeschriebenen Frauenlobschen Kreuzleichs: Diß ist Regenbogen geticht dez heiligen cruczes leich (Bl. 291r). Als synonyme Bezeichnung der Großform taucht in der Kolmarer Handschrift allerdings auch die Bezeichnung ,Hort ${ }^{c}$ auf, die in diesem Zusammenhang wohl soviel bedeutet wie "gesammelte Kostbarkeiten, etwas Erlesenes ". ${ }^{5}$ Als Horte erscheinen in der Handschrift, die hier codex unicus ist, zunächst einmal zwei große Leichs. An erster Stelle der Frauenlob in der Überschrift zu Unrecht zugeschriebene Tougenhort, zu dem angemerkt ist: [...] vnd solt da vorn nach sim leich sten (Bl. 43va). Es handelt sich um den Marienleich eines unbekannten Autors in der Nachfolge von Frauenlobs Marienleich, mit 912 Verszeilen der längste bekannte Leich überhaupt, entstanden wohl in der ersten Hälfte oder um die Mitte des 14. Jahrhunderts. ${ }^{6}$ Ferner gehört hierher der Hort des sonst unbekannten Mitteldeutschen Peter von Reichenbach, der vermutlich ebenfalls in der ersten Hälfte oder um die Mitte des 14. Jahrhunderts gedichtet und komponiert wurde. Der nähere Blick zeigt, dass unter der Überschrift Dyß peter von richenbachs hort (Bl. 60ra) zwei unterschiedliche Texte zusammengefügt sind, nämlich ein in komplizierten, langen Strophen gedichtetes geistliches Tagelied ${ }^{7}$ - die Liebenden, gemeint sind Leib und Seele, sollen vor dem Jüngsten Gericht geweckt werden - und der eigentliche Leich, in dem der erste Teil von Frauenlobs Kreuzleich nachgeahmt wird, bei dem es sich also ebenfalls um einen geistlichen Text handelt. ${ }^{8}$ Die Zusammenstellung der beiden Texte, des Tageliedes und des Leichs, unter einer

4 Vielleicht auch der Zwinger, vgl. ${ }^{2}$ VL 10 (1999), Sp. 1632-1634 (Johannes Rettelbach), hier Sp. 1633.

$5 \quad$ Vgl. DWb Bd. 10, Sp. 1835.

6 Vgl. ${ }^{2}$ VL 9 (1995), Sp. 992f. (Horst Brunner).

7 Vgl. ${ }^{2}$ VL 7 (1989), Sp. 450 (Horst Brunner): „Der Text besteht aus drei je 37zeiligen Strophen in der ungewöhnlichen Form einer Doppelkanzone (AAB/CCB)“.

8 Vgl. zu diesem Lied auch den Beitrag Johannes Janotas in diesem Band (S. 313-337), der das Bar hinsichtlich seiner Bedeutung als Bibelversifikation betrachtet. 
gemeinsamen Überschrift kann auf einem Versehen beruhen, das geistliche Wecklied könnte aber auch als Einleitung zum Leich verstanden worden sein, so dass die Bezeichnung ,Hort hier für die Zusammenstellung zweier, erlesener' Texte stehen könnte.

Man muss davon ausgehen, dass die Form des großen Leichs spätestens um die Mitte des 14. Jahrhunderts aus dem Typenrepertoire der Sangspruchdichter verschwunden war. Die Kolmarer Handschrift spiegelt somit einen zur Zeit ihrer Entstehung um 1460 längst überholten Zustand des Repertoires. Die manchmal als Leich angesehene Großdichtung des Mönchs von Salzburg, das umfangreiche geistliche ,Goldene ABC', das in der zweiten Hälfte des 14. Jahrhunderts entstanden und ebenfalls in der Handschrift enthalten ist, gehört nicht in den Traditionszusammenhang des deutschen Leichs, sondern in den der (phänomenologisch freilich verwandten) lateinischen Sequenz. Die Dichtung wird in der Kolmarer Handschrift weder als Leich noch als Hort bezeichnet. $^{9}$

Indes fanden die Bezeichnungen ,Leich' und ,Hort' in der Handschrift auch Anwendung auf Strophenlieder. Deren Gemeinsamkeit besteht in ihrer anspruchsvollen Vielstrophigkeit. Als Leich bezeichnet wird der 13-strophige Goldene Schilling ( $\left.{ }^{1} \mathrm{Hardr} / 1 / 1\right)$ des in das späte 14. Jahrhundert gehörenden Harder, abgefasst in einer schlichten 11-zeiligen Strophenform, ein Lied, in dem die Inkarnation in metaphorischen Verkleidungen umschrieben wird; ferner erscheint unter der Überschrift Li̊deleich die Bearbeitung eines Tannhäuserliedes ( ${ }^{1}$ Tanh $\left.4 / 1 c\right)$, das in der sicher originalnäheren Hs. C nur drei Strophen hat - in der Kolmarer Handschrift wurde die ursprünglich zwanzigzeilige Strophenform durch Weglassen des Refrains auf 15 Zeilen verkürzt, die Strophenzahl indes auf 11 erweitert. ,Hort' heißen (auch im späteren Meistergesang ${ }^{10}$ ) in der Handschrift außerdem weitere vielstrophige Lieder. 7 Strophen in einem fünfzehnzeiligen Ton hat Zwingers Hort im Roten Ton ( $\left.{ }^{1} \mathrm{Hardr} / 1 / 1\right)$, über den es im Register heißt: Dez zwingers rotten don stet hie [nämlich in der Anfangsgruppe] von des hordes wegen (Bl. 3r); Thema des Liedes ist die Passion Christi. Zwinger ist schlecht bezeugt, die Forschung datiert ihn in die Zeit um 1300. Weitere als Hort bezeichnete Texte in der Kolmarer Handschrift - nicht in der

9 Vgl. Horst Brunner: Tradition und Innovation im Bereich der Liedtypen um 1400. Beschreibung und Versuch der Erklärung. Zuerst 1983, revidierter Wiederabdruck in: Horst Brunner: Annäherungen. Studien zur deutschen Literatur des Mittelalters und der Frühen Neuzeit. Berlin 2008 (Philologische Studien und Quellen 210), S. 246-263, hier S. $256 f$.

10 Vgl. Brunner 1975 (Anm. 1), S. 158, Anm. 305. 
Eröffnungsgruppe - haben 13 ( ${ }^{1}$ Wartb/1/502-504), 14 ( $\left.{ }^{1} \mathrm{Frau} / 8 / 507\right), 25$ ( ${ }^{1}$ Regb/ 2/2,5,6), 53 ( $\left.{ }^{1} \mathrm{Frau} / 23 / 3\right)$ und 71 ( ${ }^{1} \mathrm{HeiMü/110-181)} \mathrm{Strophen} \mathrm{-} \mathrm{letzterer} \mathrm{Text} \mathrm{ist}$ der als Tuom, d. h. Dom, bezeichnete große Marienpreis Heinrichs von Mügeln. Man wird angesichts dieser Terminologie nicht daran zweifeln können, dass in den anspruchsvollen vielstrophigen Strophenliedern die Vorstellung vom Leich als einer Großform weiterlebte, auch wenn diese selbst längst außer Gebrauch gekommen war. ${ }^{11}$

Den Bezeichnungen Barant/Parat und Tanz begegnet man in der Kolmarer Handschrift vereinzelt, häufiger finden sich als Reihen benannte Lieder. ,Barant', wie erwähnt eine Nebenform der in Meistersingerhandschriften öfter anzutreffenden Bezeichnung,Parat', erscheint in der Überschrift zu einem Lied des weiter nicht bekannten Peter von Sachs: Dyß ist ein Barant ton her peter von Saßen (Bl. 38r). Das Wort bedeutet in diesem Zusammenhang nach Lexers Mittelhochdeutschem Wörterbuch nichts anderes als ,Kunststück'.12 Und um ein Kunststück handelt es sich bei diesem Ton in der Tat. ${ }^{13}$ In der Kolmarer Handschrift findet sich zunächst ein Peter von Sachs zugeschriebenes artifizielles dreistrophiges Marienlied Maria gnuchtig/zuchtig ( ${ }^{1}$ PeterS/1), dann wird mitgeteilt, der Autor habe das Lied dem in der zweiten Hälfte des 14. Jahrhunderts wirkenden Mönch von Salzburg zugeschickt, der mit einem gleichfalls dreistrophigen, jedoch lateinischen Marienlob O Maria/pia im gleichen Ton geantwortet habe ( ${ }^{1}$ Mönch/10/1). Auf diesen Text folgt dann noch, ebenfalls in diesem Ton, ein anonymes Minnelied mit Natureingang Man sicht louber/ touber ( ${ }^{1}$ PeterS/3). Außerhalb der Kolmarer Handschrift sind noch zwei weitere lateinische Lieder in dem offenbar beliebten, äußerst anspruchsvollen Ton überliefert, der auch, leicht variiert, von Oswald von Wolkenstein (Kl 42) benutzt wurde. Gisela Kornrumpf konnte nachweisen, dass nicht Peter von Sachs Erfinder des Tones war, sondern dass dieser erstmals bereits in der ersten Hälfte des 14. Jahrhunderts für das deutsche Herbst-Minnelied Man sicht

11 Vgl. ,Hort' im Stichwortregister des RSM, Bd. 15.

12 Vgl. auch Christoph Petzsch: Parat-(Barant-)Weise, Bar und Barform. Eine terminologische Studie. In: Archiv für Musikwissenschaft 28 (1971), S. 33-43; Kurt Gärtner: Wer parat welle lernen, der uar in diese tauernen. Eine Zech- und Spielrede aus der ersten Hälfte des 14. Jahrhunderts. In: Beiträge zur weltlichen und geistlichen Lyrik des 13. bis 15. Jahrhunderts. Hg. von Kurt Ruh und Werner Schröder. Berlin 1973, S. 84-97.

13 Vgl. Walter Röll: Vom Hof zur Singschule. Überlieferung und Rezeption eines Tones im 14.-17. Jahrhundert. Heidelberg 1976. 
leuber/teuber eines unbekannten Autors verwendet wurde. ${ }^{14}$ Um einen Eindruck vom Kunstanspruch des Tons zu vermitteln, zitiere ich dessen 1. Strophe (nach Röll15):

Man sicht louber touber

vor dem walde balde risen, grisen sicht man berg und tal.

val überal

staet nun menger hande sumercleyder.

5

Vöglin singen, clingen

ist zerstoeret, hoeret winde schwinde wagen durch den walt.

kalt, ungestalt

sind nun berg und ouwe, anger leyder

Winter langk, din betwangk machet krangk.

10

sunder dangk sumerliche schoene.

Daz ir varwe garwe

muos verblichen, wichen losen rosen müessent iarlang me

be- cleit mit sne

bistu, ane mas in ouwen hoene.

Übersetzung: Man sieht vor dem Wald rasch dürres Laub herabfallen, Berg und Tal sieht man grau werden. Alle Sommerkleider stehen nun fahl da. Das Singen, Klingen der Vöglein ist ruiniert. Hört die geschwinden Winde durch den Wald rauschen. Kalt, hässlich sind nun leider Berg, Aue und Anger. Langer Winter, dein Bedrängen macht unfreiwillig die Sommerschönheit krank, so dass ihre Farbe ganz und gar ausbleichen muss, die fröhlichen Rosen müssen in dieser Jahreszeit verschwinden. Mit Schnee bist du bekleidet, maßlos böse in den Auen.

In den beiden Folgestrophen wirbt der Sänger intensiv um eine schöne Frau. In der letzten Zeile der 3. Strophe wird das Lied dann ausdrücklich als ,Reihen', als Tanzlied, bezeichnet: frow, von dir sing ich disen reyen.

Den Anspruch, den die metrische Form des Liedes an die Kunstfertigkeit der Autoren stellte, kann man sich am besten anhand des metrischen Schemas klar machen. Im folgenden Schema werden Takte gezählt, die sich jeweils aus einer Hebung und einer Senkung zusammensetzen (x). Endet eine Verszeile mit Hebung, so sprechen wir von männlicher, endet sie mit Senkung, von weiblicher Kadenz. Männliche Kadenzen bleiben unbezeichnet, weibliche werden

14 Vgl. Gisela Kornrumpf: Vom Hof zur Singschule. Zur Geschichte eines MinneliedTons. Zuerst 1979, Wiederabdruck in: Kornrumpf 2008 (Anm. 1), S. 245-256.

15 Röll 1976 (Anm. 13), S. 79. 
mit einem Akzentzeichen markiert (klein-l ist im Reimschema wegen der möglichen Verwechslung mit der Zahl 1 durch L ersetzt); hinzugefügt sind Zeilenzähler (im Reimschema):

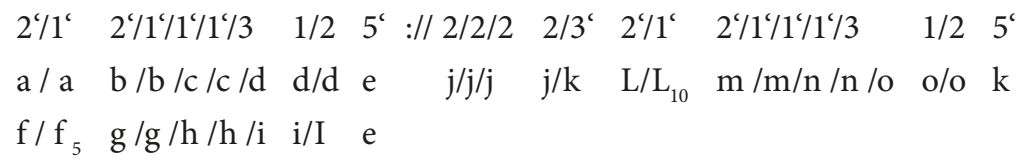

Fasst man die durch Binnenreime aufgegliederten Verszeilen zusammen, so zeigt sich folgende Versstruktur:

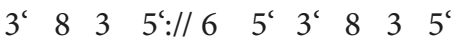

Die einzelnen Verszeilen sind somit drei-, sechs-, fünf- oder achthebig angesichts der Überfülle an Schmuckreimen, die den Versrahmen zergliedern, ja auflösen, bleiben die Zeilenlängen aber ein lediglich übergeordnetes, beim Vortrag kaum wahrnehmbares Merkmal. Metrisch handelt es sich um eine Kanzone mit 3. Stollen, d. h. am Ende des Abgesangs wird das Schema eines Stollens wiederholt. Allerdings wird diese Struktur in der Melodie nicht realisiert. ${ }^{16}$ Der hohe Anspruch an das Kunstvermögen des Dichters ergibt sich daraus, dass für die insgesamt 14 Verszeilen mit zusammen 68 Takten nicht weniger als 15 unterschiedliche Reimklänge gefunden werden mussten - und das bei einem dreistrophigen Lied eben dreimal.

Seiner metrischen Struktur nach steht diesem Text in der Kolmarer Handschrift am nächsten das ebenfalls in die Anfangsgruppe aufgenommene Lied mit der Überschrift Dys ist herr nythartz ffras ('Neidh/1). Das siebenstrophige Lied findet sich auch in der Sterzinger Miszellaneenhandschrift (hier ohne Überschrift), im Liederbuch der Clara Hätzlerin (unter der Überschrift Neidtharcz gefräß), sowie in der damit nahe verwandten späten Berliner Liederhandschrift des Martin Ebenreutter, ferner im Druck des ,Neithart Fuchs ${ }^{c}$ (unter der Überschrift hienach volget des Neitharcz gfreß)..$^{17}$ Ausschließlich in

16 Abdruck der Melodie in: Spruchsang. Die Melodien der Sangspruchdichter des 12. bis 15. Jahrhunderts. Hg. von Horst Brunner und Karl-Günther Hartmann. Kassel, Basel u. a. 2010 (Monumenta monodica medii aevi 6), S. 307-311.

17 Vgl. Horst Brunner: Neidhart bei den Meistersingern. Zuerst 1985, Wiederabdruck in: Horst Brunner: Literarisches Leben. Studien zur deutschen Literatur. Berlin 2018 (Philologische Studien und Quellen 246), S. 262-275. Neuausgabe des Liedes: Neidhart-Lieder. Texte und Melodien sämtlicher Handschriften und Drucke. 3 Bde. Hg. von Ulrich Müller, Ingrid Bennewitz und Franz Viktor Spechtler. Berlin, 
der Kolmarer Handschrift begegnet in der letzten Zeile der letzten Strophe Neidharts Name: [...] und wil dann singen Nythartz gút gefresse (Bl. 70va). Das Lied beginnt mit einem Frühlings-Natureingang, in dem der Reigentanz, der Reihen, genannt wird: wer nu den meyen / wolle heyen / der sol reyen / mit den frauwen, die sint frolich gerne (Str. I,21-24); im weiteren Verlauf entpuppt der Text sich jedoch als Schlemmerlied in der Nachfolge von Steinmars bekanntem Herbstlied..$^{18}$ Sowohl den echten Neidhartliedern als auch den Neidhart lediglich zugeschriebenen Liedern steht der Text in jeder Hinsicht fern, Neidhartmotive fehlen völlig. Die vorwiegend aus auftaktlosen Versen zusammengesetzte Strophenform ist weit aufwendiger als die der sonstigen Neidhartlieder: ${ }^{19}$

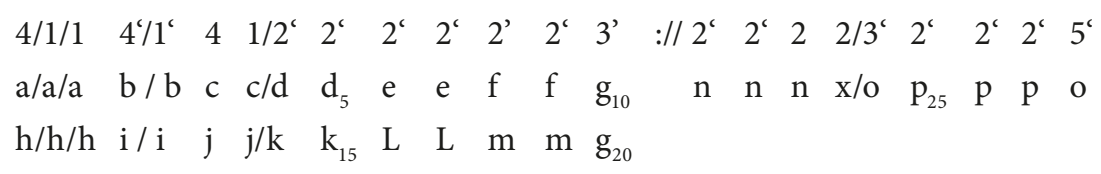

Der Ton umfasst 28, großenteils nur zweihebige Verse, lediglich die Stollenanfänge und der Abgesangsschluss werden durch längere Verse markiert. Der Gesamtumfang beträgt 84 Takte, 62 davon im Aufgesang, nur 22 im leichtgewichtig-tänzerischen Abgesang; es gibt 16 unterschiedliche Reimklänge, zu Beginn beider Stollen begegnet ein Dreireim.

Damit zu den in den Überschriften, Reihen' genannten Liedern. In der bereits erwähnten, vom jungen Hans Sachs 1517/18 geschriebenen Handschrift Berlin Mgq 414 ist der Parat Peters von Sachs, der ja im Text selbst als Reihen benannt wird, unter der Bezeichnung Paratreihen überliefert. Parat und Reihen wurden offensichtlich als zusammengehörige, gewissermaßen miteinander verknotete Bezeichnungen angesehen. Gemeint sind damit unzweifelhaft besonders kunstvolle Tanzlieder: parat verweist auf die anspruchsvolle Strophenform, den Ton, reyen auf den Tanzliedcharakter. In den echten Neidhartliedern ist ,Reihen' die Bezeichnung für den sommerlichen Reigentanz im Freien, die entsprechenden Aktivitäten im Winter in der Stube werden als ,Tanz' bezeichnet. In der Liedkunst der Meistersinger werden - wie wir noch sehen - die Bezeichnungen

New York 2007 (Salzburger Neidhart-Edition), Bd. 2, S. 288-301. Abdruck der Melodie: Brunner/Hartmann 2010 (Anm. 16), S. 287-289.

18 Vgl. Eckhard Grunewald: Die Zech- und Schlemmerlieder des deutschen Spätmittelalters. Diss. Köln 1976, S. 78-85.

19 Vgl. Horst Brunner: Die Töne der Neidhartlieder. In: Neidhart und die Neidhartlieder. Ein Handbuch. Hg. von Margarethe Springeth und Franz Viktor Spechtler. Berlin, Boston 2018, S. 143-167. 
,Tanz' und ,Reihen' jedoch synonym, ohne Bedeutungsunterschied, verwendet. Freilich darf man bei den Reihen und bei den Tänzen hier keineswegs an tatsächliche Tanzmusik denken, vielmehr handelt es sich um Texte, in denen der Tanz apostrophiert wird.

Als Beispiel für einen Reihen zitiere ich zunächst die 1. Strophe des dreistrophigen, außer in der Kolmarer Handschrift noch in weiteren neun Handschriften ${ }^{20}$ verbreiteten Goldenen Reihen $s^{21}\left({ }^{1} \mathrm{Hardr} / 2 / 1\right)$ des Harders (zitiert nach der Kolmarer Handschrift, Bl. 36ra-36vb; Emendationen durch Recte markiert); in der Wiltener Hs. (Cgm 5198) wird er übrigens als parat bezeichnet:

I

Man horet aber richen schal

von quinten quarten one zal, octaf und prymus ${ }^{22}$ discantieren uberal.

Galander clymmet in accutis vff eynmal, so felt die lerch in gradibus irn sußen fal, $u ß$ scharpfen dönen fydelt, harpfet nachtigal, daz sie zusammen dönen, discantieren.

Sus stet die gancze musica $z u$ wald vuff yren koren da; 'uß fogels kel herclingt schon ut re mi fa sol la.

Sag mey, sol ich mich freuwen diner ${ }^{23}$ kunst? sprich ja!

durch lust ferbt ${ }^{24}$ sich die erde grün, der hymmel bla,

uff ruhen esten helt sich manges fogels cla, von dem geschrey berg unde tal signieren.

Doch hat der mey der nachtigal geholfen mit yrem meinsterlichen sußen solpfen bymollis falseten ${ }^{25}$ seytenspil.

Die halten sich gar sunder dyssonierren; ut floris canticis quadrantes zieren, hort man zu walde manig tryppel, sußperdunen vil.

$20 \mathrm{Zu}$ den im RSM nachgewiesenen neun Hss. kommt noch Leipzig, UB, Ms 342, Bl. 1v Nachtrag.

21 Vgl. zur musikalischen Gestalt des Goldenen Reihens den Beitrag Lorenz Welkers in diesem Band (S. 71-101).

22 Hs.: prym.

23 Hs.: diner fehlt.

24 Hs.: frawt.

25 Hs.: falen. 
Übersetzung: Wieder hört man vielfaches Klingen von zahllosen Quinten und Quarten, Oktave und Primton erklingen überall. Die Haubenlerche erklimmt sogleich die Höhe, ebenso fällt auf süße Weise die Lerche schrittweise nach unten. In eindringlichen Tönen fiedelt und harft die Nachtigall, sodass sie alle zusammenklingen. So ertönt die ganze Fülle der Musik im Wald in ihren Chören. Aus Vogelkehlen erklingt ut re mi fa sol la. Sprich, Mai, soll ich mich dieser Kunst erfreuen? Sag ja! Freudig färbt die Erde sich grün, der Himmel blau. Auf rauhen Ästen halten sich die Krallen vieler Vöglein. Von ihrem Geschrei widerhallen Berg und Tal. Der Mai hat der Nachtigall zu ihrem meisterlichen süßen Musizieren verholfen. Bmollis und Falsett ertönen ohne Dissonanzen. Manchen Gesang hört man im Wald mit Melismen dreistimmig und mit Bordun.

In den beiden Folgestrophen wird weiterhin in hoch elaborierter Kunstsprache die Geliebte des Sängers gepriesen, es handelt sich somit um ein Frauenpreislied. Das metrische Schema lautet folgendermaßen:

$$
\begin{array}{lllllllllllll}
4 & 4 & 6 & 6 & 6 & 6 & 5^{\varsigma}: / / & 5^{c} & 5^{c} & 4 & 5^{c} & 5 & 7 \\
\mathrm{a} & \mathrm{a} & \mathrm{a} & \mathrm{a} & \mathrm{a}_{5} & \mathrm{a} & \mathrm{b} & \mathrm{d}_{15} & \mathrm{~d} & \mathrm{e} & \mathrm{f} & \mathrm{f} & \mathrm{e}_{20} \\
\mathrm{c} & \mathrm{c} & \mathrm{c}_{10} & \mathrm{c} & \mathrm{c} & \mathrm{c} & \mathrm{b} & & & & & &
\end{array}
$$

Wir haben hier eine 20-zeilige, aus nicht weniger als 105 Takten bestehende, also sehr umfangreiche Strophe vor uns. Auf- und Abgesang sind von auffallend unterschiedlicher Länge, der Aufgesang umfasst 74, der Abgesang nur 31 Takte. Verwendet werden lediglich vier Versarten: 4, 5', 6, 7 und fünf unterschiedliche Reimklänge; Binnenreime fehlen. Der Kunstanspruch ergibt sich aus der gehäuften Zahl von Tiradenreimen $(a, c)$ in den Stollen: hier hatte der Dichter nicht weniger als zweimal sechs gleich reimende Wörter zu finden, und das bei einem dreistrophigen Lied jeweils dreimal. ${ }^{26}$

Vergleichbar hohen Anspruch an das Reimvermögen der Autoren zeigen auch andere als Reihen bezeichnete Lieder. Ebenfalls mit einem FrühlingsNatureingang beginnt der Reihen des in die erste Hälfte des 14. Jahrhunderts zu datierenden Mülich von Prag ( ${ }^{1}$ Mülich/1/1). ${ }^{27}$ Es folgt dann wie bei Harder ein Frauenpreis. Die Strophenform ist strukturell mit der des jüngeren HarderTones verwandt, dieser könnte vom Ton Mülichs abgeleitet sein. Der Ton Mülichs umfasst 22 Zeilen mit 82 Takten, ist also etwas kürzer als der Harders.

26 Abdruck der Melodie bei Brunner/Hartmann 2010 (Anm. 16), S. 127-130.

27 Abdruck der Melodie ebd. S. 280f. 
Auf- und Abgesang sind hier von ähnlicher Länge, sie umfassen 44 bzw. 38 Takte; Versarten sind 3‘, 4, 5, 5‘. Anspruchsvoll ist der Ton, wie der Harders, durch je fünfmal wiederholte Tiradenreime ( $a, c, f)$ in den beiden Stollen und am Ende des Abgesangs:

$$
\begin{array}{llllllllllllllll}
3^{c} & 3^{c} & 3^{c} & 3^{c} & 5^{c} & 5: / / & 4 & 4 & 4 & 4 & 3^{c} & 3^{c} & 3^{c} & 3^{c} & 5^{c} & 5 \\
\text { a } & \text { a } & \text { a } & a & a_{5} & \text { b } & \text { d } & \text { e } & d_{15} & \text { e } & f & f & f & f_{20} & f & \text { b } \\
c & c & c & c_{10} & c & b & & & & & & & & & &
\end{array}
$$

Drei ausdrücklich als Reihen bezeichnete Lieder stammen von dem in das späte 14. Jahrhundert gehörenden Albrecht Lesch. In der Eingangsgruppe der Kolmarer Handschrift findet sich sein Goldener Reihen ( $\left.{ }^{1} \mathrm{Lesch} / 2 / 1\right)$, anderswo enthält der Codex einen Gekrönten Reihen ( ${ }^{1}$ Lesch/1/1), ${ }^{28}$ ein in Kolmar Konrad von Würzburg zugeschriebenes Goldenes Reihel findet sich anderwärts (Dresden M 13), glaubhafter, aber nicht unumstritten, als Kurzer Reihen Leschs $\left({ }^{1}\right.$ Lesch/10/1); aufgrund seines umfangreichen und kunstvollen Strophenbaus, seines Themas und der nur einmaligen Verwendung des Tones gehört in die Gruppe der artifiziellen Lieder auch Leschs Tagweise ( ${ }^{1}$ Lesch/4/1). Der Goldene Reihen enthält ein Marienlob; Gekrönter Reihen, Kurzer Reihen und Tagweise sind Weihnachtslieder, in letzterer verbunden mit Tageliedmotiven. Lesch kann geradezu als Spezialist für Weihnachtslieder gelten. Der Kurze Reihen findet sich (verbunden mit zwei Liedtexten) in insgesamt fünf Handschriften, die Tagweise in drei, für den Gekrönten und den Goldenen Reihen ist Kolmar codex unicus. Johannes Rettelbach hält es für möglich, dass Lesch, sollte seine Lokalisierung nach München zutreffen, als zumindest ,Teilzeit-Berufsdichter für den Herzogshof tätig war, etwa im Zusammenhang mit Weihnachtsfeierlichkeiten. ${ }^{29}$

Zusammenfassend lassen die vier Lieder bzw. Töne sich folgendermaßen beschreiben: Goldener und Kurzer Reihen sind dreistrophig, Gekrönter Reihen und Tagweise fünfstrophig. Die Strophenformen umfassen 16, 22, 33 und 38 Zeilen mit nicht weniger als 72, 85, 95 und 127 Takten. Die Zahl der

28 Zur Verwandtschaft des Schemas des Gekrönten Reihens mit dem älteren Überzarten Ton Ps.-Frauenlobs vgl. Rettelbach 1993 (Anm. 1), S. 33f.

29 Vgl. Johannes Rettelbach: Sangspruchdichtung zwischen Frauenlob und Heinrich von Mügeln - eine Skizze. In: Studien zu Frauenlob und Heinrich von Mügeln. Festschrift Karl Stackmann. Hg. von Jens Haustein und Ralf-Henning Steinmetz. Freiburg/Ue. 2002 (Scrinium Friburgense 15), S. 145-174, hier S. 147. 
unterschiedlichen Versarten ist begrenzt auf zwei, drei, in der Tagweise sieben. Die Anzahl der Reimklänge beträgt 5, 7, 13, 15. Formal auffallend ist der nichtstollige Kurze Reihen: auf einen achtzeiligen ersten folgt ein siebenzeiliger zweiter Teil, dann ein Refrain, der in der Überlieferung, auch in Kolmar, allerdings zum Teil weggefallen ist. Tanzmotivik fehlt in allen vier Liedern, die Bezeichnung Reihen ist hier offensichtlich allein durch die anspruchsvollen Formen bedingt. ${ }^{30}$

Als Beispiel für die Reimkünste in den Reihen Leschs gebe ich das Reimschema des (melodielos überlieferten) Gekrönten Reihens. Die mit Sternchen versehenen Reime sind Kornreime, die in allen fünf Strophen des Weihnachtsliedes wiederkehren. An Versarten finden sich in den beiden Aufgesangsstollen ausschließlich - vergleichbar dem Gefräß Ps.-Neidharts - Zweiheber, in den Versen 15-27 des Abgesangs Vierheber, am Ende des Abgesangs in dem um eine Verszeile verkürzten 3. Stollen ab Vers 28 dann wieder Zweiheber:

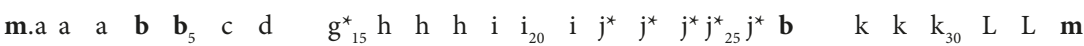

$$
\begin{aligned}
& \text { e e } e_{10} f \text { f c d }
\end{aligned}
$$

Der letzte Vers des Abgesangs (m) in ${ }^{1}$ Lesch/1/1 (Bl. 842ra-843ra) reimt auf den Anreim des 1. Aufgesangsverses: $\underline{Z u-k u n f t ~ d e r ~ w o r t ~[. . .] \mid ~ g a b ~ m e y n s c h e n ~}$ heyl an dem cristmorgen frů (Str. I); in den Stollen finden sich Dreireime und Paarreime, verbunden sind die beiden Stollen durch die Reime c und d. Der Abgesang beginnt mit einem Kornreim (g), weitere aufeinander reimende Kornreime finden sich in der Tiradenreimsequenz von Vers 22 bis $26\left(j^{\star}\right)$; der b-Reim im Abgesang bezieht sich auf einen Reim im 1. Stollen. Das Ganze geht dann durch fünf Strophen hindurch so weiter. Mehr an Reimkunst kann man kaum erwarten!

In der Anfangsgruppe der Kolmarer Handschrift finden sich zwei als Reihen bezeichnete Lieder, deren metrische Form vor dem Hintergrund dessen, was ich bisher ausgeführt habe, überrascht. Es handelt sich um Ps.-Frauenlobs Gekrönten Reihen ( $\left.{ }^{1} \mathrm{Frau} / 16 / 1\right)$ und um Ps.-Konrads von Würzburg Reihen ( ${ }^{1}$ KonrW/11/1). Deren Strophenformen sind auffallend schlicht und, verglichen mit den bisher genannten Reihen, auch kurz. Ps.-Frauenlobs Reihen setzt ein

30 Zum Vergleich: Die, richtigen' Spruchtöne Leschs umfassen 16, 17, 18, 22 Verszeilen mit 51, 55, 59, 66 und 68 Takten, sind also kürzer als die Töne der Einzellieder, vgl. Horst Brunner: Formgeschichte der Sangspruchdichtung des 12. bis 15. Jahrhunderts. Wiesbaden 2013 (Imagines medii aevi 34), S. 179. 
mit einem Frühlingseingang, in dem der Reihen genannt wird (Text nach der Kolmarer Hs., Bl. 41ra-vb):

Sint frolich, fraw, mit zuchten gein dem meyen,

Die lieb wil sich in rechter liebe zweyen

Und wil nach freude ringen.

Jr lant uch nit verdriesen pfaffen, leyen,

Jr merckt und brüfet eynen guten reyen:

Wann den wil ich uch singen! [...]

Der allgemeine Frauenpreis verengt sich dann nach der 1. Strophe auf Maria. Der Ton des Liedes umfasst nur 13 Zeilen mit 53 Takten, das Reimschema ist ohne auffallende Besonderheiten ( $a$ a b, $a a_{5} b / / c d_{c} d_{10}$ e e d). Noch weniger scheint Ps.-Konrads Reihen in diese Reihe zu passen. Es handelt sich ebenfalls um ein Marienlied, der Frühlingseingang fehlt. Der Ton umfasst 14 Zeilen mit 48 Takten, die Reimstellung ist ebenfalls unauffällig ( $a \mathrm{a} \mathrm{a} \mathrm{b}, \mathrm{c}_{5} \mathrm{c} \mathrm{c} \mathrm{b} / / \mathrm{d} \mathrm{e} \mathrm{e}_{10} \mathrm{~d} \mathrm{~d}$ $\mathrm{d}$ e). Der Grund, weshalb beide Lieder in die vorgezogene Gruppe geraten sind, kann - abgesehen vom Liedeingang des Ps.-Frauenlob - nur auf ihrer Vielstrophigkeit beruhen: Ps.-Frauenlob hat 7 Strophen, Ps.-Konrad 9. In diesem Zusammenhang ist auch das nicht in der Anfangsgruppe vertretene anonyme Lied ,Dreizehn Reihen in der Torenweise $\left({ }^{1} \operatorname{Regb} / 11 / 1\right)$ zu erwähnen..$^{31}$ Der Ton, der wiederum nur bei diesem einzelnen Lied vorkommt, wird in der Überschrift Regenbogen zu Unrecht zugeschrieben, er gilt in der Forschung als „unechter“ Ton, dessen wirklicher Autor unbekannt ist. Die Strophenform ist ebenfalls kurz und einfach, sie besteht aus 14 Zeilen, durchweg männlichen Vierhebern, mit zusammen 56 Takten; im Reimschema fallen mehrere reimlose Zeilen (Waisen) auf ( $\mathrm{x}$ a b a $\mathrm{a}_{5}, \mathrm{x} \mathrm{c} \mathrm{b} \mathrm{c} \mathrm{c}_{10} / / \mathrm{x} \mathrm{d} \mathrm{x}$ d). Der Text kündigt eingangs ewig summer sang an, es folgen dreizehn gezählte Reigentänze der Heilsgeschichte von Luzifers Fall über Adam und Eva und dem Sündenfall bis zu Christi Passion und dem Jüngsten Gericht. Das Lied, dessen inhaltlicher Ablauf dem der gleich zu besprechenden Tänze entspricht, umfasst nicht weniger als 23 Strophen.

Ein einziges in einem singulären Ton abgefasstes Lied wird in der Kolmarer Handschrift als Tanz bezeichnet. ${ }^{32}$ Es handelt sich um den in der Überschrift

31 Vgl. zu diesem Reihen in der Torenweise auch den Beitrag Lorenz Welkers in diesem Band (S. 71-101).

32 Unter der Überschrift clein propheten tancz steht in $\mathrm{k}$ ein anonymes dreistrophiges Marienlob in Frauenlobs Süßem Ton ( $\left.{ }^{1} \mathrm{Frau} / 27 / 2\right)$, ohne Überschrift findet sich ein anonymer, ebenfalls dreistrophiger Prophetenreihen in Regenbogens Langem Ton ( $\left.{ }^{1} \operatorname{Regb} / 4 / 564 a\right)$. 
dem alten Spruchdichter Marner aus der Mitte des 13. Jahrhunderts zu Unrecht zugeschriebenen Prophetentanz, einen dreistrophigen Marienpreis, in dem mehrere Propheten aus dem Alten Testament aufgezählt werden ( ${ }^{1}$ Marn/11/1). Die Bezeichnung Tanz überrascht, denn es gibt weder einen Frühlingseingang noch Tanzmotivik. Eine Begründung für die Benennung des Liedes als Tanz liefert einzig die Form des Tones. Er ist mit 36 Zeilen und 127 Takten außerordentlich lang, verwendet werden nur vier Versarten, durch eine Vielzahl von Tiradenreimen erweist er sich jedoch als äußerst anspruchsvoll:

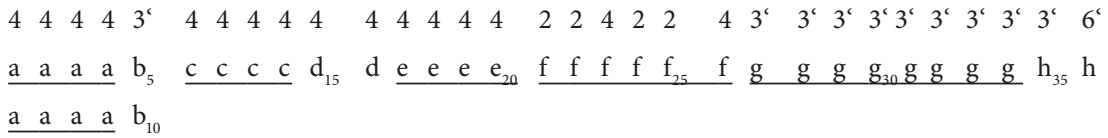

Die a- und die g-Reime erscheinen je achtmal, die f-Reime sechsmal, die cund e-Reime je viermal - und all das wiederum drei Strophen hindurch. Metrische Vielfalt begegnet allein im Abgesang mit dem Wechsel der Verslängen $4,2,3^{\text {' }}$ und 6 .

Wir haben keinerlei Anhaltspunkt, wann dieser Prophetentanz entstanden sein könnte. Es gibt jedoch einen weiteren Prophetentanz ( $\left.{ }^{1} \mathrm{Ket} / 2 / 1\right)$, der diesem Titel in vollem Umfang gerecht wird. Er findet sich nicht in Kolmar, sondern in der um 1425/30 in Nürnberg entstandenen älteren Meistersingerhandschrift München Cgm 351. Autor des Liedes ist der zwischen 1392 und 1430 in Nürnberg bezeugte Fritz Kettner, der als der älteste Meistersinger der Reichsstadt gilt. ${ }^{33}$ Kettners Prophetentanz, abgefasst nach Meistersingerart in einem übernommenen Ton, nämlich dem Goldenen Ton Zwingers, setzt mit der Tanzmotivik ein: ${ }^{34}$
$\mathrm{Nu}$ hort ein wunecleichen tanz,
der ist so wirdig und so glanz,
vird und zweinzig altheren daran springen.
Es ist der erst Adam genant,
der wart ins paradeiß gesant,
es wert nit lang, er must mit sorgen ringen.
Eua und Adam hat uns den tanz geprawen;
ein schlang pfeif uns den reien vor,
pis Adam kam al auf ein spor,
da er fünf tausent iar must ligen in rauen [...].

33 Von ihm stammt übrigens auch ein metrisch hochkomplizierter Paratreihen (vgl. das metrische Schema in RSM Bd. 2.1, S. 106).

34 Zitiert nach Cramer (Anm. 1), Bd. 2, S. 119. 
Die Folgestrophen schildern den Reihen - das Wort findet sich in den Folgestrophen zwölfmal, einmal auch die Bezeichnung Tanz - der vierundzwanzig Alten, die von Adam aus dem Paradies heraus in die Finsternis geführt wurden, dann erscheint Christus und führt den Reihen zurück ins Paradies und in den Himmel. Etwas überraschend ist die Kunstlosigkeit des übernommenen Tons. Er umfasst lediglich zehn Verse aus männlichen Vier- und weiblichen Fünfhebern, zusammen sind es 44 Takte - das Reimschema ist so simpel wie möglich ( $\mathrm{a}$ a b , c c $\mathrm{b}_{5} / / \mathrm{d}$ e e $\mathrm{d}_{10}$ ), am Ende steht vermutlich (die Melodie ist nicht erhalten) ein 3. Stollen. Der Kunstanspruch ergibt sich hier - ähnlich wie bei den oben besprochenen Reihen Ps.-Frauenlobs und Ps.-Konrads - aus dem Umfang: Das Lied, das Kettner am Ende signiert hat, besteht aus immerhin neun Strophen. Es wäre möglich, dass der anonyme Autor des Ps.-Marnerschen Prophetentanzes von Kettners Lied angeregt wurde. Denkbar wäre freilich auch, dass dem Marienlied von Ps.-Marner ein nicht erhaltener, richtiger Prophetentanz, vergleichbar demjenigen Kettners, vorausging und dass das erhaltene Lied lediglich eine Folgedichtung im gleichen Ton ist. Über das Verhältnis zu Kettners Lied ist damit freilich noch nichts ausgesagt.

Ich versuche ein kurzes Fazit. Neben ihrem ,Alltagsgeschäft', dem Abfassen von Spruchstrophen in relativ einfachen oder auch metrisch komplizierten Spruchtönen, erwiesen mehrere herausragende Spruchautoren im Zeitraum von Walther von der Vogelweide bis Frauenlob ihr Kunstvermögen zusätzlich in der aufwendigen Form des großen Leichs. Diese Form war allerdings seit der zweiten Hälfte des 14. Jahrhunderts nicht mehr produktiv, sie kam außer Gebrauch. Freilich verschwand sie nicht spurlos, der Kunstanspruch der Autoren lebte vielmehr in artifiziellen Formen der strophischen Lieddichtung weiter. Zum einen handelte es sich dabei, wie wir gesehen haben, um vielstrophige Lieder, bezeichnet als Leich, Hort, Reihen und Tanz, zum anderen waren es Lieder - wiederum bezeichnet als Parat, Reihen/Paratreihen, Tanz -, die in ihrer metrischen und sprachlichen Gestalt das Kunstvermögen der Autoren herausforderten und geeignet waren, die Bewunderung des Publikums zu erregen. Wie man sieht, sind die Typenbezeichnungen nicht streng definiert, ihre Bedeutungen überschneiden sich, doch heben sie jeweils hervor, dass es sich bei den betreffenden Liedern um etwas ,Besonderes', etwas besonders Artifizielles, handelt.

Im Spruchsang finden sich derart anspruchsvolle Formen bis zum Ende der Kunstübung in der zweiten Hälfte des 15. Jahrhunderts. Zu erwähnen ist in diesem Zusammenhang der in der Mitte des 15. Jahrhunderts wirkende Jörg Schiller, von dem neben regelrechten Spruchtönen auch zwei Einzellieder ('Schil/3/1 und 4/1) überliefert sind: ein fünfstrophiges reimreiches Marienlied, 
bezeichnet als ,Parat' (18 Verszeilen, 60 Takte, 13 Reimklänge), und eine 11strophige nichtstollige Zeitklage, bezeichnet als ,Reihen' (22 Zeilen, 84 Takte, 7 Reimklänge, der a-Reim erscheint zehnmal). Abschließend zu nennen ist schließlich auch noch Michel Beheim, der letzte professionelle Spruchsänger überhaupt. Beheims von seinen übrigen, verhältnismäßig wenig anspruchsvollen Spruchtönen deutlich zu unterscheidende artifizielle Töne - die Gekrönte Weise, die Sleht guldin Weise und die Hohe guldin Weise - übertrafen hinsichtlich ihrer Reimkunst alles, was es bis dahin gegeben hatte. ${ }^{35}$ Eindeutig unter die Reihen, obwohl nicht eigens als solche bezeichnet, gehören - neben drei weiteren Texten in diesem Ton - zwei 11- und 3-strophige Frühlingslieder in der Gekrönten Weise ( ${ }^{1}$ Beh/283 und 284). Beide Lieder beginnen mit einem umfangreichen Natureingang, im ersten Lied (Str. I,15) begegnet auch das Wort $r e i$, das hier auf den Reihen der Vögel bezogen ist. Im weiteren Verlauf erweisen sich beide Texte dann als geistliche Lieder (die Freude über den Mai wird mit dem Erscheinen Christi in eins gesetzt). Der Ton stellt sich durch seine überbordende Zahl von Tiradenreimen eindeutig in die Tradition anderer Reihen-Töne. Er umfasst 23 Zeilen und 89 Takte, kommt aber mit nur zwei unterschiedlichen Reimen aus:

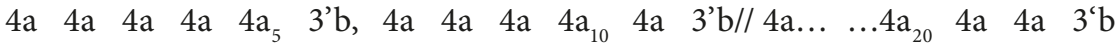

Der a-Reim findet sich zwanzigmal, immer gebunden an einen männlichen Vierheber, die Verse der Form 3'b markieren jeweils das Ende der drei Strophenteile. Für das 11-strophige Lied ${ }^{1}$ Beh/283 hatte Beheim somit nicht weniger als elfmal zwanzig aufeinander reimende Wörter zu finden. Insgesamt benutzte er den Ton für fünf Lieder mit durchweg geistlicher Thematik. Es gehörte offenbar zu seinem Kunstanspruch, selbst bei schwierigsten Tönen der Mitund Nachwelt beweisen zu können, dass er in der Lage war, auf einen Trumpf immer noch einen weiteren setzen zu können.

35 Vgl. Brunner 2013 (Anm. 30), S. 200, 208-210. 

Lorenz Welker

\title{
Reyen in der Kolmarer Liederhandschrift Gattungscharakteristika und Kontext in musikhistorischer Perspektive
}

Für Horst Brunner

\begin{abstract}
The Colmar Liederhandschrift titles several songs with the term "Reihen" (a round dance), which means that these songs were either dealing with the topic of a row of dancers or were considered dance music. On researching Reihen as a genre, the article analyses the texts and melodies of five Reihen in the second quire of the manuscript, comparing them with other extant traditions. It explains the history and usage of the term "Reihen" and shows, in English and French sources, the influence of a specific German tradition of this genre.
\end{abstract}

\section{I. Überlieferung von Reihen (Reyen) in der Kolmarer Liederhandschrift $^{1}$}

In der Kolmarer Liederhandschrift (München, Bayerische Staatsbibliothek, Cgm 4997) sind insgesamt acht Strophenfolgen überliefert, die in der Überschrift den gattungsdefinierenden Begriff Rey bzw. Reye tragen und damit auf jenen Liedtypus verweisen, der, wie zahlreiche Quellen belegen, nicht nur gesungen, sondern zu dem auch getanzt wurde. Nach Michael Baldzuhn handelt es sich um folgende Lieder: „Frauenlob: Gekrönter Reihen (1.3), Harder: Goldener Reihen (2.2), Albrecht Lesch: Goldener Reihen (3.1), Albrecht Lesch: Gekrönter Reihen (3.6), Mülich von Prag: Reihen (5.1), Konrad von Würzburg: Reihen (6.1), Konrad von Würzburg: Goldener Reihen (6.2), Regenbogen: Torenweise

1 Im Folgenden übernehme ich für die mittelalterliche Gattungsbezeichnung rei/reien (vgl. im Cgm 4997 rey/reyen) die in der neueren germanistischen Mediävistik übliche Graphie, wie sie etwa auch im RSM aufscheint (Repertorium der Sangsprüche und Meisterlieder des 12. bis 18. Jahrhunderts. 16 Bde. Hg. von Horst Brunner und Burghart Wachinger. Tübingen 1986-2009), und schreibe im fortlaufenden Text einheitlich ,Reihen'. 
(12.3).“2 Davon finden sich allein sechs in der jetzigen zweiten Lage der Handschrift, und sie sind in dichter Folge nacheinander aufgezeichnet, sodass man mit guten Gründen von einem Reihen-Corpus sprechen kann, das der Kompilator des Codex bewusst und gezielt angelegt hat. Das Reihen-Corpus steht neben einem Corpus von Leichs und umschließt auch den Barantton Peters von Sachsen bzw. des Mönchs von Salzburg. Die zweite Lage setzt sich wie folgt zusammen: ${ }^{3}$

Bl. 32r: [Seitenüberschrift mittig:] harders leich, sonst leer 32v: $\quad$ Leer

33ra-34rb: Jn dez harders korwyse [:] d(er) guldyn schilli(n)g [.] jst ein leych Melodie: 33r, $8+1$ Systeme, Deutsche Choralnotation (DChN)

34r: [Seitenüberschrift mittig:] dez hard(er)s leich

34rb-34va: Ein ave in dyse $(m)$ ton

34va-34vb: Anderdrui(n) dyse(m) ton

35rv: $\quad$ Leer

36ra-36vb: Des harders guldy(n) rey

Melodie: 36r, 7 + 7 1/2 Systeme, DChN

37ra-37vb: Diß ist Leschen guldy/rer Reye

Melodie: 36r-36va, $6+8+1$ Systeme, DChN

2 Michael Baldzuhn: Vom Sangspruch zum Meisterlied. Untersuchungen zu einem literarischen Traditionszusammenhang auf der Grundlage der Kolmarer Liederhandschrift. Tübingen 2002 (MTU 120), S. 446, Anm. 6.

3 Vgl. zum Aufbau mit Lagenschema Heinrich Husmann: Aufbau und Entstehung des cgm 4997 (Kolmarer Liederhandschrift). In: Deutsche Vierteljahrsschrift für Literaturwissenschaft und Geistesgeschichte 34 (1960), S. 189-243, sowie Frieder Schanze: Meisterliche Liedkunst zwischen Heinrich von Mügeln und Hans Sachs. Zwei Bände. Band I: Untersuchungen. München, Zürich 1983 (MTU 82), S. 3586; zum Bestand Karin Schneider: Die deutschen Handschriften der Bayerischen Staatsbibliothek München: Die mittelalterlichen Handschriften aus Cgm 4001-5247. Wiesbaden 1996, S. 423-444. Abkürzungen erscheinen hier in runden, Ergänzungen in eckigen Klammern. 
38ra-38va: Dyß ist ein Barant ton h(er) peter von Saßen Melodie: 38r, $8+6$ Systeme, DChN

38va-39ra: $\quad$ Als her peter von Sahsen $\mid$ dem münch vo[n] saltzburg $\mid d y \beta$ vorgeschr(iben) par schic/ket da schicket er yme $\mid$ dy $\beta$ nachgende Latynysch $\mid$ par her wyder vmb in $\mid$ dem selbe(n) tone

39r: [Seitenüberschrift mittig:] Pet(er) vo(n) sahsen Bara(n)t ton 39ra-39rb: $\quad$ Ein ander par Jn dyse[m] | ton vonn meye(n) ein pryßl[ied (?)] 39v: Leer

40ra-40vb: Mulichs vo(n) prage Rey Melodie: 40r-40va, $7+9+1$ Systeme, DChN

41ra-41vb: Her frauwe(n)lobs gecro(n)|ter Rey Melodie: $41 \mathrm{r}, 8+4$ Systeme

42ra-43ra: Cunrades von Wurtzburg rey Melodiezeilen: 42r, $8+1$ Systeme, mit Textunterlegung aber ohne Noten

43r: [Seitenüberschrift mittig:] Meinst(er) Cunrat guld(in) rey

43ra-43va: $\quad$ Meinster cunrads guldin $\mid$ reyel Melodie: 43r, $4+9$ Systeme, DChN

43va-59vb: $\quad$ Dyß ist frauwe(n)lobs tauge(n)|hort oder sin sloss hort Vnd | solt da vorn nach sim leich sten Melodie: 43vb, 7 Systeme und weitere auf den folgenden Bll.

Der Ort der Eintragungen innerhalb der physischen Struktur der zweiten Lage ergibt sich aus folgendem Lagenschema (die Bezeichnungen der Einträge folgen dem Katalogeintrag von Karin Schneider): 


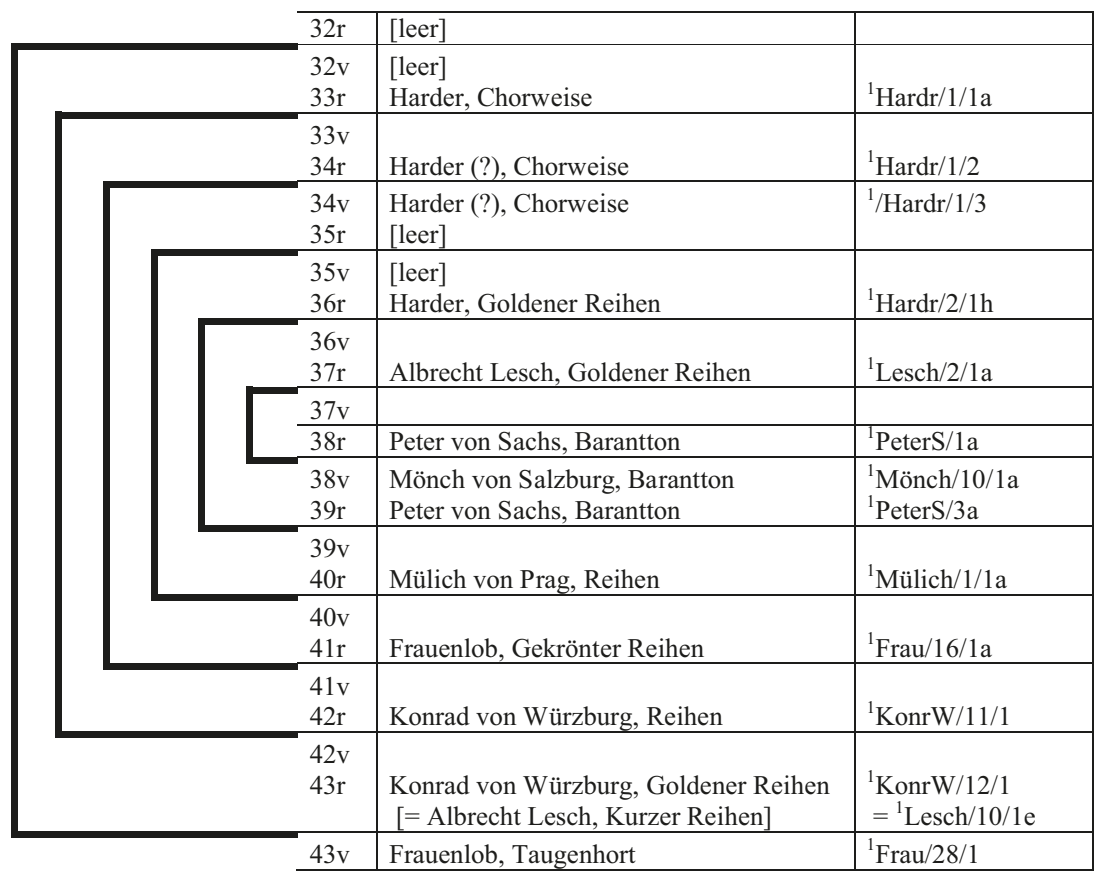

Abb. 1: Schema der 2. Lage

Zwei der von Baldzuhn angeführten Strophenfolgen finden sich nicht in der zweiten Lage: die hier Regenbogen zugeschriebene Torenweise (Bl. 297va300rb, mit Melodie, Überschrift: Hie fahent an die dryzehen Reyen in der torn wise) und Albrecht Leschs Gekrönter Reihen (Bl. 842ra-843rb, mit Notenlinien, aber ohne Melodie; Überschrift: Leschen gecronter Rey). Warum Leschs Gekrönter Reihen, der auf dem ersten Recto der 63. und jetzt letzten Lage der Handschrift zu finden ist, nicht in die Auswahl des Corpus übernommen wurde, muss offen bleiben.

Die Torenweise (oder besser: Tor[e]nweise) ${ }^{4}$ hingegen bietet zwar den Hinweis auf den Reihen schon in der Überschrift und schildert mithilfe der

4 Vgl. hierzu Johannes Rettelbach: Variation - Derivation - Imitation. Untersuchungen zu den Tönen der Sangspruchdichter und Meistersinger. Tübingen 1993 (Frühe Neuzeit 14), hier insbesondere S. 57 zur Herleitung von „Tor-“ oder „Dorn-“. 
Reihen-Metapher Momente der biblischen Heilsgeschichte, stellt aber nicht zwangsläufig ein weiteres Exemplar der Gattung Reihen dar, weder in der Strophenfolge noch in der Melodiegestalt. Die bereits in der Überschrift angesprochenen dreizehn Reihen sind zudem nicht regelmäßig auf die 23 Strophen verteilt, vielmehr ergibt sich folgende Zuordnung: Schon die erste Strophe nennt die ersten beiden Reihen, in der zweiten werden der dritte und vierte Reihen angesprochen, auf die dritte Strophe fällt der fünfte Reihen und auf die vierte Strophe der sechste Reihen. Die Strophen fünf bis acht bieten keine Hinweise auf einen Reihen, erst in Strophe neun folgt der siebte Reihen. Strophen zehn bis siebzehn enthalten erneut keine Hinweise auf den Tanz, erst in den Strophen 18 bis 21 folgen der achte, neunte, zehnte und elfte Reihen. Die beiden letzten Reihen, zwölf und dreizehn, fallen auf Strophe 22, die letzte Strophe bietet einen Rückblick und eine Zusammenfassung. ${ }^{5}$

Die Erwähnung der Reihen-Metapher fällt im Text des Lieds zusammen mit biblischen Bewegungsabläufen, in denen der ,Reihen'von jeweils anderen Protagonisten ,geführt' wird. Schon zu Beginn der ersten Strophe wird ausgeführt, wie Gott einen Reihen in die Zeit führt: Ich singen ewig summer sang $\mid$ wy gott vss siner almechtikeit $\mid$ furt einen reien in die zit (Vers I,1-3), das Bild des Anführers eines Reihens wird gegen Ende der Strophe noch zweimal aufgenommen: daz was der erste reye | den furt von hymmel lucifer | den andern reyen in daz paradiss | von ebra vnser war schopfer (Vers I,11-14). Damit wird nicht nur der Tanzcharakter des Reihen deutlich, sondern auch, wie in der Praxis des Tanzes ein Anführer die Bewegung vorgibt. Die Erschaffung Adams und Evas und der Sündenfall mit der Vertreibung aus dem Paradies sind Gegenstände des dritten und vierten Reihens. Im fünften Reihen wird das Volk Israel durchs Rote Meer geführt. Der sechste Reihen schildert die Menschwerdung Gottes im Bild eines Ritts ins Erdental

5 Der Text der Torenweise ist jetzt greifbar in: Max Lütolf, Mechthild Sobiela-Caanitz, Cristina Hospenthal und Max Schiendorfer (Hgg.): Das deutsche Kirchenlied. Abt. II: Geistliche Gesänge des deutschen Mittelalters. Melodien und Texte handschriftlicher Überlieferung bis um 1530. Bd. 3: Gesänge I-M (Nr. 331-536). Kassel u. a. 2009, S. 56-60 (Nr. 366); Anmerkungen und kritischer Bericht in: Laurenz Lütteken, Mechthild Sobiela-Caanitz, Cristina Hospenthal, Bernhard Hangartner und Max Schiendorfer (Hgg.): Das deutsche Kirchenlied. Abt. II: Geistliche Gesänge des deutschen Mittelalters. Melodien und Texte handschriftlicher Überlieferung bis um 1530 (begründet von Max Lütolf †). Bd. 7: Kritischer Bericht zu Gesänge I-Z und Nachträge (Nr. 331-813), Kritischer Bericht zu Zyklische Sammlungen (Band 5). Kassel u. a. 2018, S. 25. 
und modifiziert damit die Reihen-Metapher: Daz was der sechste reye $\mid$ got mangen engel mit ym nam | dürch vns so reyt er zü tal |vnder einer meyde brüste er quam (Vers IV,11-14). Das Passionsgeschehen, das mit dem Weg zur Martersäule einsetzt, wird im siebten Reihen dargestellt: $N v$ faht der sübent reye an | wie man ihesum marien bar |zü einer süle fürte hin. Auch hier wird ein Reihen angeführt, nur eben nicht mehr von einem biblischen Protagonisten, sondern von einem Marterknecht, während Jesus geführt wird, also auch in der grammatikalischen Konstruktion zum leidenden Individuum wird. Mit der Höllenfahrt und der anschließenden Auferstehung übernimmt Christus wieder die Führung im achten Reihen: sich hüb der achtend rey $\mid$ do got vss helle fürt ein michel her (Vers XVIII,1-2). Und am vierzigsten Tag wird zwar kein Reihen angeführt, doch Gott fährt zum Himmel auf: Sich hüb an dem vierczigsten dag | der neunde reye daz ist war | do got gein hymmelriche für (Vers XIX,1-3). Der Schluss des Lieds bietet ab dem zehnten Reihen apokalyptische Bilder und Szenen: sich hebet noch der zehend rey $\mid$ zu josephat ein breytes wal $\mid$ so kumment engel vnd blasent horn (Vers XX,1-3) und sich hebt ein engestlicher dantz| zü josepffat ist mir wol künt | so fürt den eylfften reyen hin (Vers XXI,1-3). Hier wird die ReihenMetapher mit Anführer und Gefolge umgedeutet in Aufzug und Tanz der Engel, wobei der Hinweis auf die Horn blasenden Engel für die spätmittelalterliche Instrumententerminologie insofern spannend ist, als die Tuba der Vulgata nicht wie später bei Luther als ,Posaune' und auch nicht als ,Trompete‘, sondern als ,Horn` übersetzt wird. Das Horn könnte hier ebenso für einen generischen Ausdruck für ein Blechblasinstrument stehen wie auch für eine sprachliche Umsetzung einer bis in die Frühe Neuzeit reichenden Bildtradition, die die apokalyptischen Engel mit einem langen, gebogenen Blechblasinstrument darstellt. Ein solches Instrument kommt in der zeitgenössischen Musikpraxis nicht vor. Und die Bildtraditionen zur Apokalypse bieten in der Regel auch keine Darstellungen von geraden Langtrompeten (sog. businen) in den Händen der Engel, wie sie auf zahllosen höfischen und militärischen Szenen der Zeit und anderen Engelsrepräsentationen (etwa zur Krönung Mariens) dargestellt werden. Die moderne Zugposaune, die ja erst in den letzten Jahrzehnten des 15. Jahrhunderts erfunden wurde, findet sich in diesem Bildzusammenhang selbstverständlich auch nicht. Die Übersetzung des Terminus tuba der Vulgata als horn kehrt wieder in deutschen Bibelübersetzungen vor Luther, etwa in der von Anton Koberger 1483 in Nürnberg gedruckten (Biblia, deutsch. Nürnberg: Anton Koberger, 17.II.1483, $2^{\circ}$ [GW 04303]). 
Trotz der aufschlussreichen Hinweise zu Tanzpraxis und Musik, die sich aus der Beschreibung der dreizehn biblischen Reihen ableiten lassen ([an-]geführter Tanz, Musikinstrumente), bleibt es fraglich, ob die 23 hier unter Regenbogens Namen überlieferten Strophen gleichfalls einen Reihen konstituieren. Weder die textliche noch die musikalische Form geben hierzu eindeutige Aufschlüsse; da zudem jegliche Rhythmisierung fehlt, ist die Identifikation des biblischen Lieds als Tanzlied rein hypothetisch. ${ }^{6}$

Die folgenden Bemerkungen beziehen sich auf die musikalische Gestalt der fünf in der zweiten Lage aufgezeichneten und notierten Reihen. Harders Goldener Reihen ist musikhistorisch allein schon wegen der zahlreichen musikalischen Fachtermini bemerkenswert, die das Vogelkonzert der ersten Strophe illustrieren (quinten, quarten, octaf, prym, quint, discantieren, ut re mi fa sol la etc. in der Fassung der Kolmarer Liederhandschrift), die den Autor als poeta doctus ausweisen und die wohl auch dazu führten, dass die Fassung der Wiltener Meisterliederhandschrift (München, Bayerische Staatsbibliothek, Cgm 5198, Bl. 145r-146r) die Überschrift Musica trägt. ${ }^{7}$ Die Melodie zu Harders Goldenem Reihen ist in vier Handschriften in zwei deutlich unterschiedenen Fassungen aufgezeichnet: Eine Version ist in den Handschriften Erfurt, Universitätsbibliothek, Cod. Ampl. Q 56 (um 1400 bzw. erste Hälfte 15. Jh.) und Augsburg, Staats- und Stadtbibliothek, $2^{\circ}$ Cod. 197 (15. Jh.) überliefert, die andere liegt in der Kolmarer Liederhandschrift und in der im 17./18. Jahrhundert in Nürnberg entstandenen Handschrift Weimar, Herzogin Anna Amalia Bibliothek, Fol. 421, vor. ${ }^{8}$ Die Datierung der Quellen lässt mutmaßen, ob es sich bei den Fassungen in Erfurt und Augsburg um eine frühere Fassung der Weise handelt. Immerhin ist der e-Modus allen Fassungen gemein. Demgegenüber bietet Frauenlobs Gekrönter Reihen vier nahe verwandte Melodieversionen, von denen allerdings die in Nürnberg, Landeskirchliches Archiv, Fen. 4o V 182 (um 1590/1595), Berlin, Staatsbibliothek Preußischer Kulturbesitz, Mgf 24 (Anfang 17. Jh.) und

6 Vgl. dagegen Christoph Petzsch: Frühlingsreien als Vortragsform und seine Bedeutung im Bîspel. In: Deutsche Vierteljahrsschrift für Literaturwissenschaft und Geistesgeschichte 45 (1971), S. 35-79.

7 Vgl. Schanze 1983 (Anm. 3), S. 267, Anm. 32, und Baldzuhn 2009 (Anm. 2), S. 219: iij lied hat der harder ge/macht. haist musica (Bl. 145r).

8 Vgl. zur Handschrift die Ausführungen in: Horst Brunner: Die alten Meister. Studien zur Überlieferung und Rezeption der mittelhochdeutschen Sangspruchdichter. München 1975 (MTU 54), S. 84-94 und öfter. Die Weimarer Handschrift ist z. Z. über den Katalog der Herzogin Anna Amalia Bibliothek nicht zu finden. 
Weimar, Herzogin Anna Amalia Bibliothek, Fol. 421, eingetragenen von denen in der Kolmarer Liederhandschrift abhängig sind. Die Textfassung der Kolmarer Handschrift bietet im Text des zweiten Stollens einen Hinweis auf die Gattung:

Ir lant uch nit verdriessen, pfaffen, leyen, ir merckt vnd brüfet eynen guten reyen, wann den wil ich uch singen. (I, V. 4-6)

War die Melodieversion der Kolmarer Handschrift noch durch eine außerordentlich schlichte Melodieführung mit zahlreichen Tonrepetitionen gekennzeichnet, so weist die Weimarer Fassung ein hohes Maß an Zwei- und Dreitongruppen sowie an ausgeprägten Melismen im engeren Sinn auf, die dem älteren Tanzliedcharakter zuwiderlaufen. ${ }^{9}$ Auch der Text enthält in den Folgeversionen keine Anspielungen auf den Reihen mehr.

Lediglich im Goldenen Reihen Albrecht Leschs finden sich Andeutungen einer rhythmisierten Vortragsanweisung, und auch dort nur im Abgesang. Die Melodie bietet damit in Aufzeichnung und mutmaßlicher Aufführung eine Parallele zu jenen partiell rhythmisierten Liedern, wie wir sie bei Hugo von Montfort (im Frau-Welt-Lied Fro welt, ir sint gar hüpsch und schön) und Oswald von Wolkenstein finden (etwa in Kl. 20, Es seusst dort her). ${ }^{10}$

Vergleichbar mit der Aufzeichung des Frau-Welt-Lieds in der Handschrift Heidelberg, Universitätsbibliothek, Cpg 329, Bl. 35r, war sich der Notator

9 Vgl. zur Melodiebildung im vorliegenden Bestand allgemein Brunner 1975 (Anm. 8), S. 224-295, darin zur Melismatik S. 224: „Die Melismatik ist eines der Hauptmerkmale der Melodiestile in den hier berücksichtigten Handschriften“ und S. 225: „Im 15. Jahrhundert ist die Zahl der Melismen extrem niedrig, im 16./17. Jahrhundert nimmt sie wieder zu."

10 Vgl. dazu meine Beiträge: Lorenz Welker: Some aspects of the notation and performance of German song around 1400. In: Early Music 18 (1990), S. 235-246, und ders.: Melodisch-rhythmische Differenzierungen im Vortrag von Spruch und Minnelied. In: Sangspruchdichtung zwischen Reinmar von Zweter, Oswald von Wolkenstein und Michel Beheim. Hg. von Horst Brunner und Freimut Löser. Wiesbaden 2017 (Jahrbuch der Oswald von Wolkenstein-Gesellschaft 21), S. 401-414. 


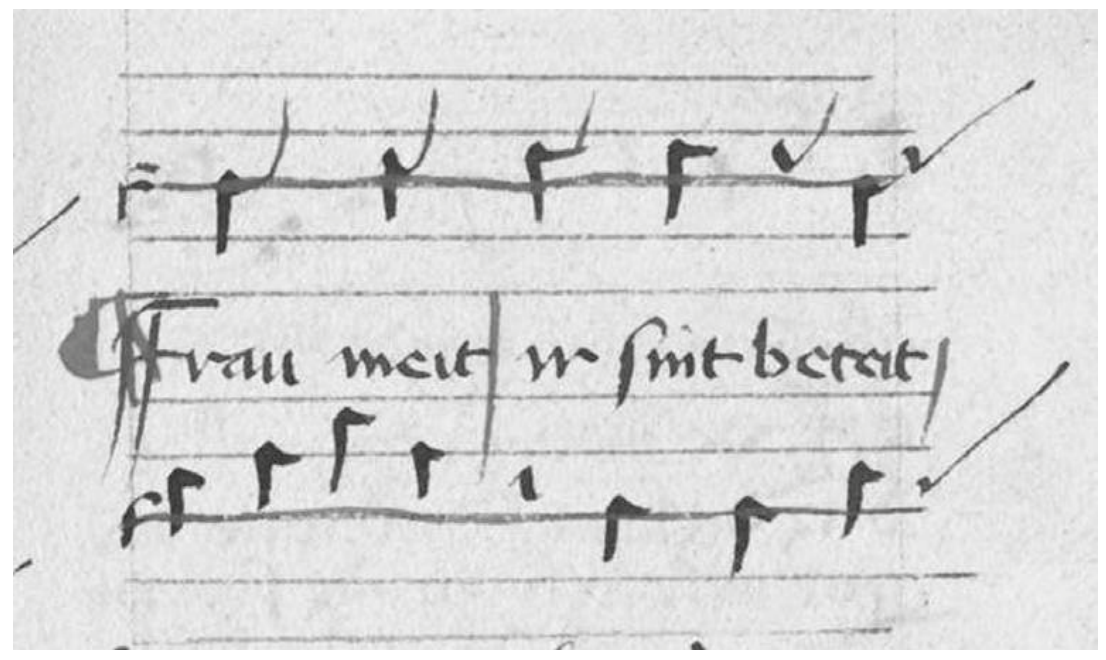

Abb. 2: München, Bayerische Staatsbibliothek, Cgm 4997, Bl. 37rb: Albrecht Lesch, Goldener Reihen; Beginn des Abgesangs

offensichtlich auch hier über die Bedeutung der Kaudierung im Unklaren, übernimmt deshalb diesen Aspekt der Notation der mutmaßlichen Vorlage zunächst inkonsequent für jedes Notenzeichen (drei Virgen, ein Punctum), um dann wieder darauf zu verzichten und zur gewohnten Melodieaufzeichnung mit (überwiegend) Virgen und (wenig) Puncta zurückzukehren. Analog zur Interpretation von Hugos Frau-Welt-Lied lässt sich auch für Leschs Goldenen Reihen eine editorische Lösung finden, die eine konsequent alternierende Rhythmisierung des zweiten Teils vorsieht. Wie die Übertragung in Abb. 3 zeigt, wird ab Vers 15 die Melodie zu Vers 3 bzw. 7 wieder aufgenommen, nur diesmal in rhythmisierter Gestalt. 

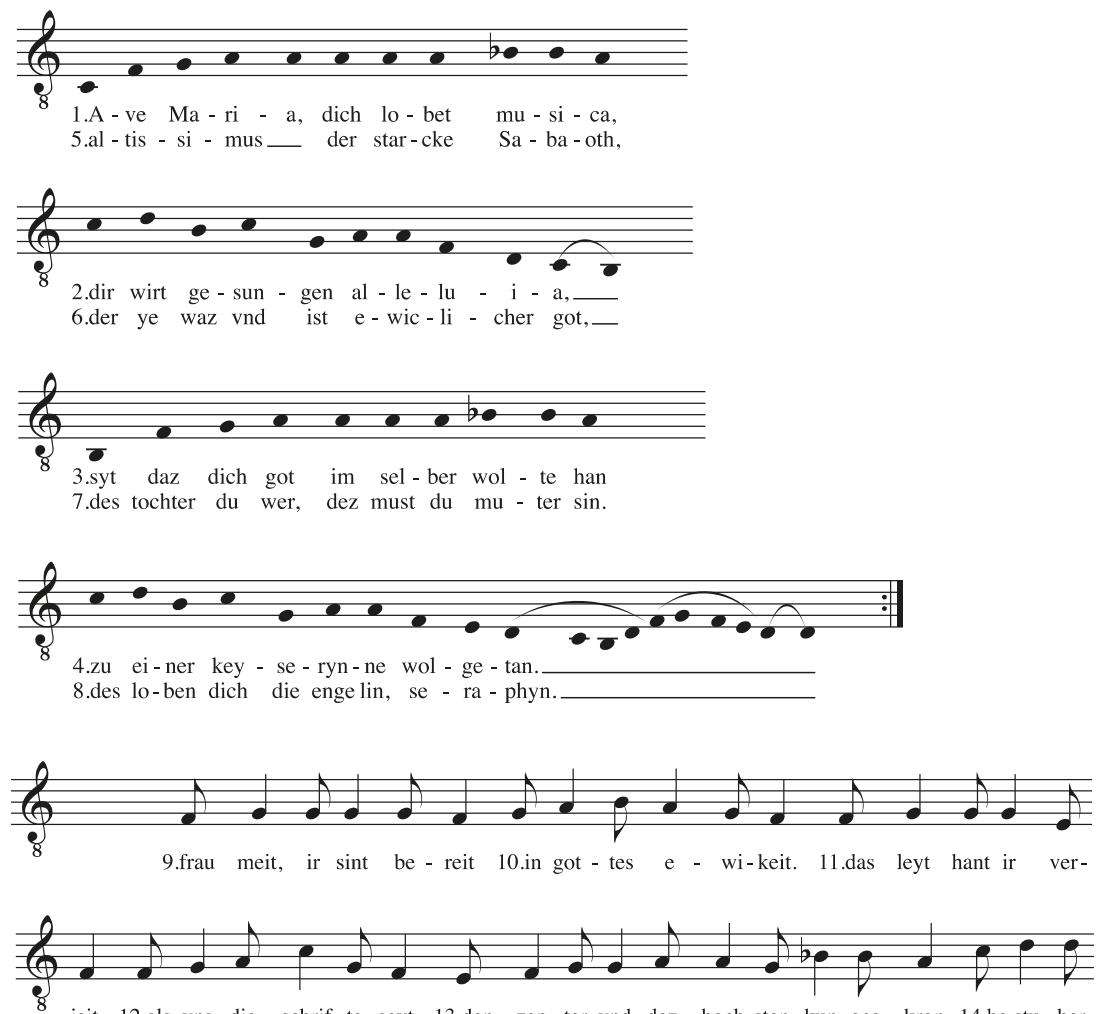

jeit, 12.als vns die schrif-te seyt. 13.den zep-ter vnd dez hoch-sten kun-ges kron 14.ha stu her-
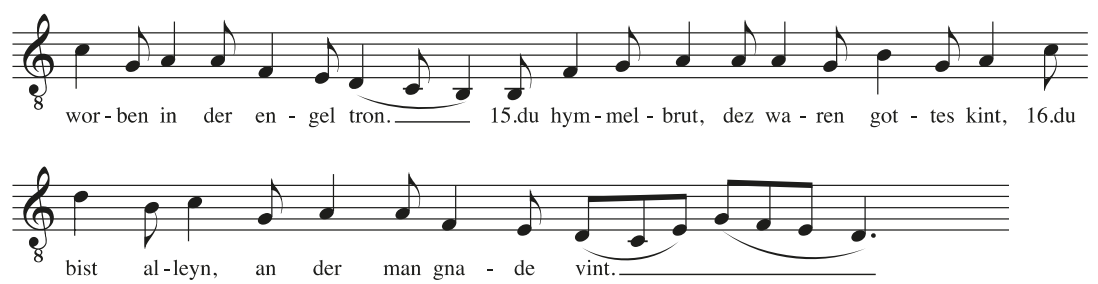

Abb. 3: Albrecht Lesch, Goldener Reihen, Edition mit rhythmisiertem Abgesang (Übertragung von LW) 


\section{Reihen: Definition und Gattungskontext}

Swie kleine mich diu minne twanc, ze dienest ich der frowen sanc

einen reien minneclîch, mit süezen worten donerîch. den sanc ich gegen der sumerzît, sô perg und tal gezieret lit und daz der walt hat grüene dach. nu sült ir horen, wie der sprach. ${ }^{11}$

So heißt es im Frauendienst Ulrichs von Liechtenstein; ein gesungener Reihen, donerîch, wird hier erwähnt. Und unmittelbar nach dieser Einleitung lässt Ulrich unter der Überschrift: Ditz ist ein reye fünf Strophen eines Sommerlieds (Lied XXIX) folgen, dessen erste Strophe lautet:

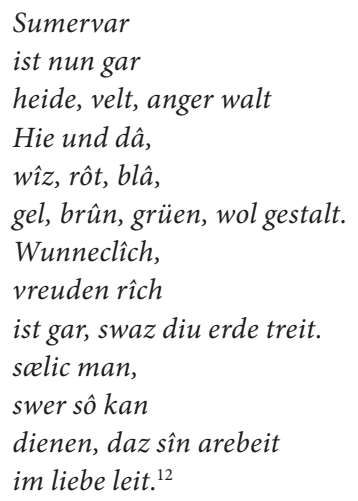

Obwohl zu diesem reye keine Melodie überliefert ist, bietet doch bereits die textliche Gestalt (2a 2a 4b // 2c 2c 4b // 2d 2d 4e 2f 2f 4e 2e) Charakteristika, die dieses Lied einerseits formal in die Nähe der Reihen bei Neidhart von Reuental stellen (etwa mit der Übernahme der „Reihenstroph“"; siehe dazu unten), andererseits zumal im Blick auf die Verslänge und den Strophenumfang - von denen der Kolmarer Handschrift beträchtlich unterscheiden.

11 Ulrich's von Liechtenstein Frauendienst, Zweiter Theil. Hg. von Reinhold Bechstein. Leipzig 1888 (Deutsche Dichtungen des Mittelalters 6), S. 152-153, Strophe 1380. Vgl. dazu auch die Neuausgabe unter der Herausgeberschaft von Franz Viktor Spechtler: Ulrich von Liechtenstein, Frauendienst. Göppingen 1987 (GAG 485).

12 Ebd., S. 153. 
Das Beispiel Ulrichs von Liechtenstein belegt überdies schon früh den musikalischen Aspekt der Gattung. Trotz der Vielzahl der Belege für ein so wichtiges textlich-musikalisches Phänomen enthielt sich die ältere Musikforschung weitgehend einer lexikalischen Gattungsbestimmung und in jedem Fall einer näheren Auseinandersetzung damit. In älteren deutschsprachigen Musiklexika wie dem „Riemann Musik Lexikon ${ }^{\text {“13 }}$ und der ersten Auflage der Enzyklopädie „Die Musik in Geschichte und Gegenwart“ (MGG) ${ }^{14}$ suchen wir den Begriff vergeblich, ${ }^{15}$ erst in der Neuauflage der MGG (MGG2) wird immerhin explizit auf den Überblicksartikel ,Tanz' verwiesen. ${ }^{16}$ Dort lesen wir etwa unter der Rubrik ,Profaner Tanz' des Mittelalters, dass der „höfische Tanz, der zumeist in geschlossenen Räumen stattfand, [...] im Unterschied zu den Tänzen der unteren Schichten in maßvollen, schleifenden, am Boden haftenden Schritten ausgeführt [wurde], in Reigenform oder in Paaren." Dazu erfahren wir überdies, „dass es gelegentlich zu einer Mischung von höfischem und bäuerischem Tanz kommen konnte“, das „beweisen die Dichtungen Neidharts von Reuenthal, Ulrichs von Lichtenstein u. a." Einige Spalten später, unter der Rubrik

13 Riemann Musik Lexikon. Zwölfte, völlig neubearbeitete Auflage in drei Bänden. Hg. von Willibald Gurlitt. Sachteil. Mainz 1967.

14 Die Musik in Geschichte und Gegenwart. Allgemeine Enzyklopädie der Musik. 17 Bände. Hg. von Friedrich Blume. Kassel 1949-1986.

15 Die Lexika bieten an den entsprechenden Orten Leerstellen: das Riemann Musik Lexikon zwischen den Lemmata ,Reichenau', ,Reihe‘ und ,Reim“ “(S. 788-790), die MGG zwischen ,Reifner, Vinzenz' und ,Reimann, Heinrich` (Bd. 11, Kassel 1963, Sp. 168-169). Innerhalb des von Heinrich Besseler verfassten Artikels ,Tanz` findet sich im Riemann Musik Lexikon (S. 935-940) immerhin der Hinweis: „In der Stauferzeit verband man gern den Gruppen-T. (mhd. reien; altfrz. carole) mit einem vorangehenden ruhigen Einzelpaar-T. (mhd. t.; altfrz. danse); dies wurde bald zum Prinzip“; leider fehlen dazu Belege. Die MGG bietet innerhalb des von Fritz Feldmann und Hans Hickmann erstellten Artikels ,Tanz' (Bd. 13, Kassel 1966, S. 89-110) lediglich die Anmerkung: „Vom höfischen Tanz des MA. ist zwar allenthalben das Gegensatzpaar Reigen- (= Schreit-) und Springtanz (ma.-lat. chorea-ballatio, ital. carola-danza) sowie die mus. Struktur der frz. (exklusiv ritterlichen) Ballade, ital. Ballata, und der Estampie bekannt; ob und wie sie getanzt wurden, bleibt unklar" (Sp. 95).

16 Die Musik in Geschichte und Gegenwart. Allgemeine Enzyklopädie der Musik. Zweite, neubearbeitete Ausgabe. Hg. von Ludwig Finscher, begründet von Friedrich Blume (MGG2). Sachteil, Band 8. Kassel, Stuttgart 1998, Sp. 141. Janet AdsheadLansdale et al.: ,Tanz. In: MGG2 (Anm. 16), Sachteil, Band 9. Stuttgart 1998, Sp. $228-$ 408; auch benutzt nach der Online-Ausgabe (abgerufen zuletzt am 28.07.2019). 
,Europäische Volkstanzformen und ihre Verbreitung ${ }^{17}$ wird über ,Ketten-, Kreis- und Reigentänze informiert: „Tänze, an denen viele Personen durch Anfassen der Hände miteinander verbunden oder ohne Fassung neben- bzw. hintereinander einen offenen oder geschlossenen Kreis, einen Halbkreis, eine lange Kette oder Reihe bilden, scheinen der Urbestand des europäischen Volkstanzes gewesen zu sein." Schließlich wird im Blick auf die "Geschichte des Volkstanzes“ ${ }^{\text {“18 }}$ ausgeführt, dass „,das ganze Mittelalter hindurch bis ins 16. Jahrhundert [...] zum Volkstanz in der Regel gesungen [wurde]. Die Tanzlieder hatten oft derbe, aber auch sozialkritische und spöttische Texte, weshalb nach den Bauernkriegen (1524-1526) das Singen dieser Lieder und damit zugleich das Tanzen mit zahlreichen Verboten unterdrückt wurde. ${ }^{\text {"19 }}$

So spärlich die Informationen der Musiklexika, so ausführlich und mit einer Fülle von Belegen versehen äußert sich das von Jacob und Wilhelm Grimm herausgegebene ,Deutsche Wörterbuch' ${ }^{20}$ wo im 1893 erschienenen und von Moritz Heyne besorgten achten Band unter dem Stichwort ,reihen, reigen' folgende Begriffsbestimmung zu finden ist: ${ }^{21}$

zuerst begegnet uns der reie in der höfischen poesie des mittelalters und bezeichnet zunächst eine bestimmte volksthümliche art des tanzes, die zur sommerzeit im freien von den bauern gepflegt wurde: die tanzenden bildeten entweder eine kette oder standen paarweise hintereinander und folgten den bewegungen eines oder mehrerer vortänzer, der den leitstab als zeichen seiner würde führte; die rhythmische bewegung schlosz sich der weise eines tanzliedes an, das zu den tönen einer geige oder mehrerer instrumente von dem vorsänger angestimmt und von den tanzenden aufgenommen wurde. der vortänzer war zugleich meist auch vorsänger (Neidhart 40, 21), auch vorsängerinnen werden erwähnt MSH. 2, 78 a der reie, den die bauern springen, steht im gegensatze zu dem tanze, den hovetenzen, welche die ritterliche gesellschaft übte. der höfische tanz wird getreten, der reie gesprungen.

17 Sibylle Dahms: ,Profaner Tanz', als Unterkapitel C. (Gesellschaftstanz) I. (Mittelalter) 3. (Historischer Überblick) b. (Profaner Tanz). In: MGG2 (Anm. 16), Bd. 9, Sp. 267.

18 Marianne Bröcker: ,Europäische Volkstanzformen', Unterkapitel E. (Volkstanz) V. (Europäische Volkstanzformen und ihre Verbreitung) 1. (Ketten-, Kreis- und Reigentänze). In: MGG2 (Anm. 16), Bd. 9, Sp. 370.

19 Ebd., Unterkapitel E. (Volkstanz) VI. (Geschichte des Volkstanzes) 1. (Musik und Tanz), Sp. 373-374, hier Sp. 373.

20 Deutsches Wörterbuch, 16 Bände in 32 Teilbänden. Hg. von Jacob und Wilhelm Grimm. Leipzig 1854-1961 (im Folgenden DWb).

21 DWb, Bd. 8. Hg. von Moritz Heyne, Leipzig 1893, Sp. 644. Benutzt wurde die OnlineVersion der Berlin-Brandenburgischen Akademie der Wissenschaften und der Akademie der Wissenschaften zu Göttingen (zuletzt abgerufen am 27.07.2019). 
- eine Differenzierung, die freilich sogleich und unter Heranziehung weiterer Belege wieder relativiert werden muss:

doch dieses verhältnis verwischt sich, und auch der reie wird getreten: also vlôs mîn vrouwe ir vingerrîde. / dô si den krumben reien ûf dem anger trat, dô wart ez ir ab ir hant, seht ân ir danc genomen. Neidhart 60, 2.

Wie die neue MGG2 vermerkt auch Grimms Wörterbuch das Ende des gesungenen Tanzes in der frühen Neuzeit, hat aber eine andere Erklärung parat:

die einheit von gesang und tanz im reien blieb bis zum überhandnehmen der ausländischen tänze im 17. jh. bewahrt: chorus der rey, die dantzen oder zusehen, conventus canentium et saltantium, singendantz Alberus $k 4^{b}$; bezeichnend ist folgende stelle: es musz aber fürnemlich darbey (beim tanze) seyn eine feine instrumental-music, denn ich schwerlich glaube, das es sich wol dantzen lässet, wenn man nur darzu singet. Schmid schauplatz d. dantzenden (1671) 22.

Dass das Grimmsche Wörterbuch gegen Ende des 19. Jahrhunderts in einer Atmosphäre nationalen Hochgefühls auch eine nationale Erklärung findet, verwundert nicht. Dass die alte MGG das religiös begründete Verbot des Tanzes erst im 16. Jahrhundert als wirksam ansieht, erstaunt eher, denn bekanntermaßen galt schon in den Jahrhunderten davor: Chorea est circulus cuius centrum est diabolus; ${ }^{22}$ und während des ganzen Mittelalters hatten schließlich geistliche Autoren nicht nur den Tanz selbst, sondern auch die daran Beteiligten, die Tänzer genauso wie die Spielleute, buchstäblich verteufelt und ihnen die Möglichkeit abgesprochen, dereinst ins Paradies einzugehen..$^{23}$ Auf die bereits im

22 Mitunter wurde die Sentenz bereits Augustin zugewiesen, plausibler erscheint jedoch die Zuschreibung an Jakob von Vitry (gest. 1240), siehe hierzu Julia Zimmermann: Teufelsreigen - Engelstänze. Kontinuität und Wandel in mittelalterlichen Tanzdarstellungen. Frankfurt/Main u. a. 2007 (Mikrokosmos. Beiträge zur Literaturwissenschaft und Bedeutungsforschung 76). Vgl. dagegen allerdings jetzt Philip Knäble: Eine tanzende Kirche. Initiation, Ritual und Liturgie im spätmittelalterlichen Frankreich. Köln, Weimar, Wien 2016, sowie neuerdings Therese BruggisserLanker: Tanz in der christlichen Kirche des Mittelalters. Kultische Reigentänze, ihre Symbolik und ästhetische Resonanz. In: Religion - Musik - Macht. Musikalische Dimensionen einer ästhetischen Theologie. Hg. von Wolfgang W. Müller und Franc Wagner. Basel 2021 (TeNOR - Text und Normativität, Bd. 8), S. 321-373.

23 Vgl. hierzu etwa die Auslassungen des um 1200 wirkenden Pariser Klerikers Petrus Cantor in seiner Schrift Contra hystriones, meretrices, mimos, ioculatores, alleatores, magos, tyrocinatores. In: Petri Cantoris Parisiensis Verbum Adbreviatum. Textus conflatus. Hg. von Monique Boutry. Turnhout 2004, S. 313-320. Siehe hierzu weiterhin Wolfgang Hartung: Die Spielleute. Wiesbaden 1982. 
Mittelalter getroffene Feststellung, dass der Reihen ein ,deutsches' Phänomen sei, werde ich später zurückkommen.

Abgesehen von den zahlreichen und vielfältigen Belegen informiert der Artikel des Grimmschen Wörterbuchs auch über die Wortformen: So sei die im Mittelhochdeutschen gewöhnliche Form reie, die im älteren Neuhochdeutschen durch reien verdrängt worden sei, während der verkürzte Nominativ rei auch noch später anzutreffen sei, sowie vereinzelt die Formen rê und rae. Schon im Mittelhochdeutschen erscheint reige neben reie, auch hier mit der Verkürzung reig. Besonders durch Luther seien die Formen mit , g üblich geworden, die in der Bibelübersetzung ausschließlich Verwendung fanden.

Schließlich verweist das Grimmsche Wörterbuch auf die handlungsübergreifende Bedeutung des Begriffs:

der begriff reie, ursprünglich eine einheit rhythmischer körperbewegung, dichtung und musik bezeichnend, spaltet sich im verlaufe der sprachentwickelung gemäsz den angegebenen elementen dreifach: reie kann also den eigentlichen tanz (s. oben), das tanzlied, und die von instrumenten gespielte tanzweise bezeichnen; mit dem gesungenen tanzliede ist der neueren zeit auch die entsprechende bedeutung von reihen entschwunden. im mhd. bezeichnet reie, worte und melodie umfassend, ein tanzlied und gilt als bestimmte liedgattung. bei den meistersingern begegnet reie neben tanz und leich als technische bezeichnung (meisterl. der Kolmarer handschr. s. 370, ebenda s. 201 hern Frouwenlobes gekroenter reie, geistlichen inhalts).

Worin die Eigenart der Verwendung des Gattungsterminus Reihen als ,technische Bezeichnung liegt, lässt der Autor des Beitrags freilich offen. Immerhin wird in diesen Ausführungen die Möglichkeit einer Bedeutungsverschiebung angedeutet.

Das Wörterbuch führt weiter aus: „Adelung bemerkt, dasz auch reihen noch in der bedeutung lied im volke hin und wieder vorkomme." Spätestens im 18. Jahrhundert habe der Begriff also eine Bedeutungseinengung erfahren, allerdings vermutet der Autor des Beitrags dies bereits vereinzelt für Neidhart: „der dichter nennt oder erwähnt sich am schlusz des liedes: her Nithart disen reien sanc. Neidhart L, $25^{\prime}$.

Neidhart von Reuental konnte wie kaum ein anderer Autor so ausgiebig als Zeuge für die Verwendung und Gestalt des Reihen herangezogen werden nicht zuletzt nennt er sich ja auch selbst, wie eben gezeigt, als Sänger des Reihen, eine Funktion, die auch in den Titel der Neidhart-Ausgabe von Siegfried 
Beyschlag und Horst Brunner aus dem Jahr 1989 eingegangen ist. ${ }^{24}$ In der Tat ist der Reihen im Text zahlreicher Lieder Neidharts präsent: ${ }^{25}$

Muoter, lât ez ân melde!

Jâ wil ich komen ze velde

Und wil den reien springen;

Jâ ist ez lanc, daz diu kint niht niuwes hôrte singen. [HW 4, 6-10; Sommerlied 2]

Ich bin holt dem meien:

Dar inne sach ich den reien. [HW 6, 13-14; Sommerlied 5]

In dem tal

Hebt sich aber der vogel schal:

Wan si grüezent alle nû den meien.

Den wolgemuoten leien

Den wil ich helfen reien. [HW 6, 19-23; Sommerlied 6]

Merze vor den reien spranc:

Bî dem sult ir mich vinden. [HW 7, 17-18; Sommerlied 7]

An den beiden kiese wir den meien

Ir mägde, ir sult iuch zweien

Gein dirre liehten sumerzît in hôhem muote reien. [HW 15, 25-28; Sommerlied 14]

Aber nicht nur die Sommerlieder Neidharts kennen den Reihen, auch in die Winterlieder hat er Eingang gefunden, wenngleich eher als Reminiszenz denn weit öfter als vom Reihen ist nun vom $\tan z$ die Rede:

Rüele enwolte enwiderstrît

An dem reien springen:

Daz was Lanzen nît. [HW 36, 4-6; Winterlied 1]

Mehr noch als durch die Nennung des Begriffs in den Liedern ist der Name Neidharts mit dem Reihen durch die Beischriften der Berliner NeidhartHandschrift c (Berliner Staatsbibliothek, Mgf 779, entstanden um 1460 wohl in Nürnberg) verbunden. ${ }^{26}$ Neben zahlreichen anderen, meist recht anschaulichen

24 Siegfried Beyschlag und Horst Brunner (Hgg.): Herr Neidhart diesen Reihen sang: die Texte und Melodien der Neidhartlieder mit Übersetzungen und Kommentaren. Göppingen 1989 (GAG 468).

25 Im Folgenden zitiere ich nach der Ausgabe Die Lieder Neidharts. Hg. von Edmund Wießner, fortgeführt von Hanns Fischer. Vierte Auflage, rev. von Paul Sappler, mit einem Melodienanhang von Helmut Lomnitzer. Tübingen 1984 (Altdeutsche Textbibliothek 44).

26 Vgl. hierzu in jüngerer Zeit vor allem Anna Kathrin Bleuler: Zwischen Konservierung, Restaurierung und Aktualisierung. Zur Frage nach dem Verwendungszweck der Berliner Neidhart-Handschrift c. In: ZfdPh 127 (2008), S. 393-413. 
Beischriften wie der augstein oder der pal hat der Schreiber zu 23 Liedern explizit die Gattungsbezeichnung ray eingetragen. Die Tabelle zeigt diese Einträge mit Nummer in der Handschrift, Incipit, Beischrift, Aufzeichungsort in der Handschrift und gibt in der letzten Spalte einen Hinweis, ob vom Reihen auch im Text des jeweiligen Lieds die Rede ist (unter, Text').

Tabelle: Beischriften ray in mgf 779 (Neidhart-Hs. c; die Ziffern in Klammern zu den Liedern Nr. 22-40 verweisen auf die ergänzende Bleistiftzählung in der Handschrift)

\begin{tabular}{|c|c|c|c|c|}
\hline Nr. in c & Incipit & Beischrift & Blatt & Text \\
\hline 22. (21.) & Ich sahe die Heide & Ein ray & $153 \mathrm{v}$ & + \\
\hline 24. (23.) & Ich han ein feyoll gesehen & Ein ray & $155 \mathrm{v}$ & + \\
\hline 25. (24.) & Der waldt aber & Ain ray & $156 \mathrm{r}$ & + \\
\hline 26. (25.) & Der wintter hat ein ende & $\begin{array}{l}\text { Der spiegel vnd ist ein } \\
\text { Raye }\end{array}$ & $157 \mathrm{r}$ & + \\
\hline 31. (30.) & Winter wie verwachsen & Ein Ray & $162 \mathrm{r}$ & \\
\hline 40. (39.) & Der summer ist kummen & Ein Ray & $171 \mathrm{r}$ & + \\
\hline 46. & $\begin{array}{l}\text { Diese wandelung mange } \\
\text { freude }\end{array}$ & Ein Ray & $179 v$ & \\
\hline 47. & $\begin{array}{l}\text { Do der walt erst lauben } \\
\text { began }\end{array}$ & Aber ein Ray & $180 \mathrm{r}$ & + \\
\hline 48. & Der sumer der ist hie & Ein Raye & $181 \mathrm{r}$ & + \\
\hline 49. & Alle die den sumer wóllen & Aber ein Ray & $181 \mathrm{v}$ & \\
\hline 50. & Ich sahe den waldt & Aber ein Ray & $182 \mathrm{v}$ & \\
\hline 52. & $\begin{array}{l}\text { Ein alte vor den rayen } \\
\text { trat }\end{array}$ & Ein Raye & $184 \mathrm{r}$ & + \\
\hline 55. & Der may der ist reich & Ein ray & $185 \mathrm{v}$ & + \\
\hline 56. & Hayde anger vnd waldt & Ein ray & $186 \mathrm{r}$ & \\
\hline 57. & $\begin{array}{l}\text { Do man die summer } \\
\text { wunne }\end{array}$ & Aber ein Ray & $186 \mathrm{r}$ & + \\
\hline 59. & Nun ist zergangen & Ein Ray & $187 \mathrm{v}$ & + \\
\hline 67. & Frewet euch jung vnd alt & Ein Ray & $193 \mathrm{r}$ & \\
\hline
\end{tabular}




\begin{tabular}{|l|l|l|l|l|}
\hline Nr. in c & Incipit & Beischrift & Blatt & Text \\
\hline 68. & In dem tal & Aber ein Ray & $193 \mathrm{v}$ & + \\
\hline 69. & Wo sind $n$ u die alten & Aber ein Ray & $194 \mathrm{r}$ & + \\
\hline 71. & Der waldt mit laub stat & Ein Ray & $195 \mathrm{r}$ & + \\
\hline 73. & Ich gieng lugen & Ein Raye & $196 \mathrm{v}$ & \\
\hline 74. & Nun ist der waldt & Ein ray & $197 \mathrm{r}$ & \\
\hline 75. & Die zeit ist hie & Ein Ray & $197 \mathrm{v}$ & \\
\hline
\end{tabular}

Letzteres ist immerhin in 14 Liedern, also der Mehrzahl der Lieder mit der Beischrift ein ray der Fall; in den übrigen ist häufig vom Springen und Tanzen die Rede. Dies gibt Anlass zur Vermutung, dass der Schreiber mit den Beischriften nicht notwendigerweise eine aufführungsrelevante Gattungsklassifikation vornahm, sondern lediglich auf Elemente des Liedtexts reagierte. In ähnlicher Weise hat etwa zur gleichen Zeit in Salzburg der Schreiber der Mondsee-Wiener Liederhandschrift Lieder des Mönchs von Salzburg mit scheinbar aufführungsrelevanten Beischriften versehen (das Taghorn, das Nachthorn, die trumpet, und ist auch gut zu blasen), die bis in die jüngste Zeit als Indizien für eine Aufführung mit Blasinstrumenten missverstanden wurden. ${ }^{27}$

Die Handschrift c ist mit der Überlieferung von 45 Melodien zu 131 hier aufgezeichneten Liedern die wichtigste Quelle für die Weisen zu Neidharts Liedern, trotz der Einschränkungen, die mit den Melodieaufzeichnungen der Handschrift verbunden sind: Keiner der Notentexte in deutscher Choralnotation trägt einen Schlüssel und alle Melodien sind ohne Text den

27 Es sind dies die Lieder W 1, W 2 und W 5 der Ausgabe: Christoph März: Die weltlichen Lieder des Mönchs von Salzburg. Texte und Melodien. Tübingen 1999 (MTU 114) mit den Kommentaren dazu auf S. 367-374 und S. 382-385. Vgl. hierzu weiterhin Lorenz Welker: Weltliche Musik an den Höfen der Erzbischöfe Eberhard II. (1200-1246) und Pilgrim II. (1365-1396). In: Salzburger Musikgeschichte. Vom Mittelalter bis ins 21. Jahrhundert. Hg. von Jürg Stenzl, Ernst Hintermaier und Gerhard Walterskirchen. Salzburg 2005, S. 71-87, insbesondere S. 80-84 zum taghorn. Vgl. hierzu auch Dagmar Hirschberg: dy trumpet (MR 15). Ein Tagelied-Experiment des Mönchs von Salzburg. In: Lied im deutschen Mittelalter: Überlieferung, Typen, Gebrauch. Überlieferung, Typen, Gebrauch. Chiemsee-Colloquium 1991. Hg. von Cyril Edwards, Ernst Hellgardt und Norbert H. Ott, Berlin 1996, S. 203-216. 
Textaufzeichnungen vorangestellt. Leider ist für die mit der Beischrift ray versehenen Lieder nur eine einzige Melodie erhalten, nämlich zum ersten Lied in dieser Gruppe Ich sahe die heide (Bl. 153v), und diese Melodie bereitet der Textunterlegung noch größere Schwierigkeiten als die der anderen NeidhartMelodien. Denn hier übertrifft die Zahl der Einzelnoten und Ligaturen die der $\mathrm{zu}$ unterlegenden Silben bei weitem, was zahlreiche und weitreichende Interpretationen erforderlich macht. Bei den anderen Liedern korrespondieren Silben- und Notenzahl weitaus besser.

Die folgende Abbildung bietet eine Kollationierung der verschiedenen in den Editionen vorgeschlagenen Lösungen: A bietet die Lösungen von Beyschlag/Brunner und Lomnitzer mit der Textfassung nach Handschrift R; B und $C$ verweisen auf die beiden Versionen der Salzburger Neidhart-Edition, wobei sich die erste Salzburger Version eng an A anschließt. ${ }^{28}$ Mit D und E folgen die älteren Interpretationen von Schmieder und Rohloff ${ }^{29}$ und schließlich unter $\mathrm{F}$ eine weitere Version, die ich selbst als Alternative vorschlagen möchte und die sich ihrerseits eng an die zweite Salzburger Version anschließt. Wesentliches Unterscheidungsmerkmal der Versionen ist die Entscheidung, ob die Ligaturen der Handschrift, nämlich die beiden Clives zu Beginn der ersten und die beiden Clives am Ende der zweiten Melodiezeile erhalten bleiben sollen oder getrennt werden können. Darüber hinaus war in jedem einzelnen Fall zu entscheiden, welche Einzelnoten der Melodieaufzeichnung sinnvollerweise zu Melismen zusammengefasst werden können.

28 Beyschlag/Brunner 1989 (Anm. 24); Helmut Lomnitzer in Die Lieder Neidharts (Anm. 25). Salzburger Neidhart-Edition: Neidhart-Lieder. Texte und Melodien sämtlicher Handschriften und Drucke. 3 Bde. Hg. von Ulrich Müller, Ingrid Bennewitz und Franz Viktor Spechtler. Berlin 2007.

29 Wolfgang Schmieder: Neidhart von Reuenthal, Lieder, mit Reproduktion der Handschriften. Revision des Textes von Edmund Wiessner. Wien 1930 (Denkmäler der Tonkunst in Österreich 71); Ernst Rohloff: Neidharts Sangweisen. 2 Bde. Berlin 1962. 


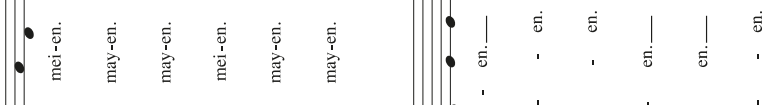

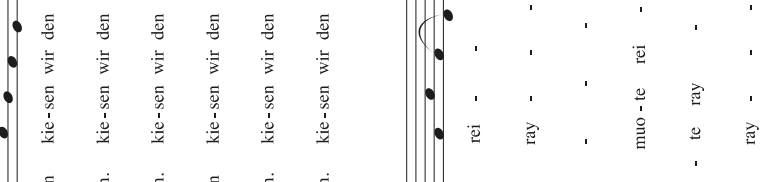

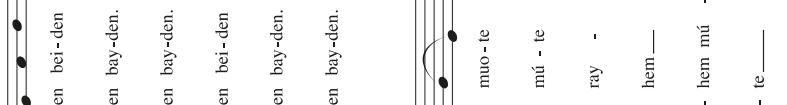

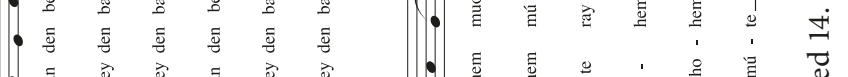

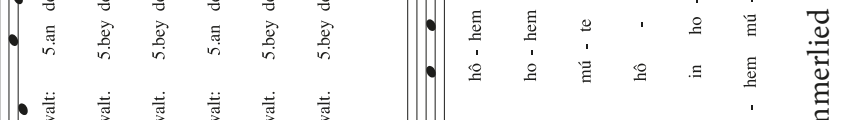

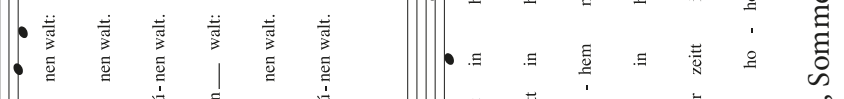

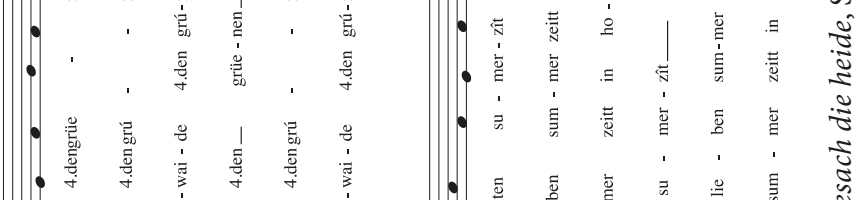

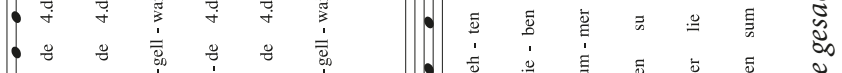

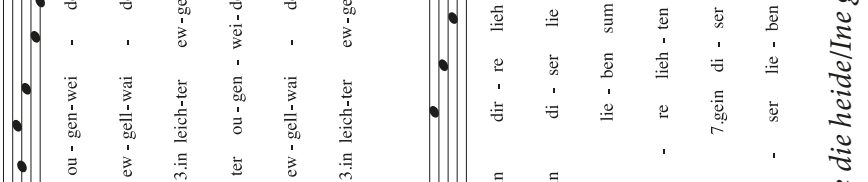

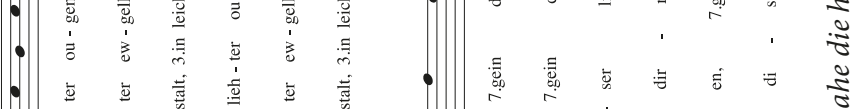

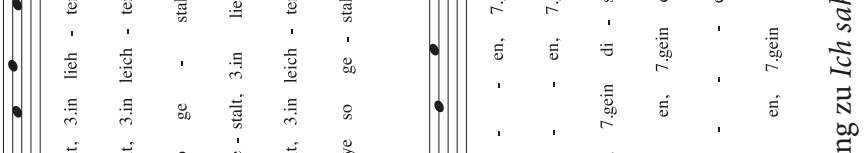

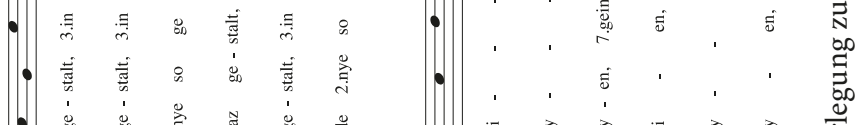

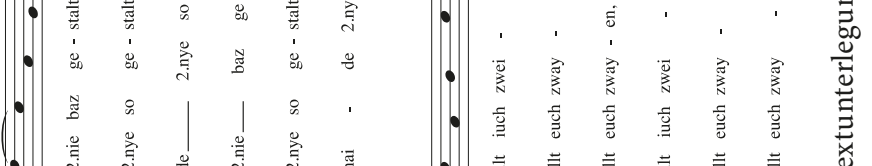

(ด)

- -

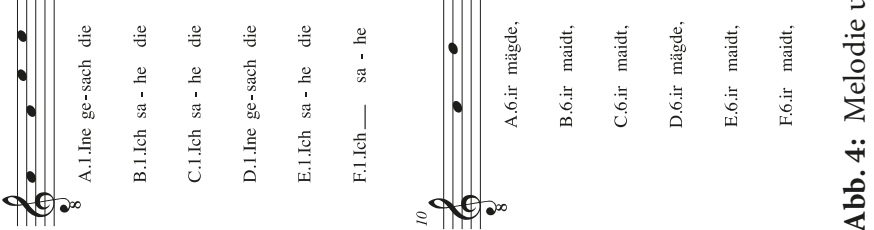

290

$\ddot{\dot{q}}$ 
Ich möchte auf eine detaillierte Diskussion der einzelnen Textunterlegungsstrategien verzichten, will jedoch auf den Konsens in der Unterlegung des fünften Verses hinweisen und die weitgehenden Übereinstimmungen zu Beginn des sechsten Verses. Weiterhin bieten fast alle Fassungen ein recht ausgedehntes Melisma am Ende der Strophe und weitere Melismen über grünen (Vers 4) und zweien (Vers 6). Im übrigen bietet der Liedtext im Gegensatz zu den anderen als Reihen klassifizierten Sommerliedern der Handschrift auch keinen einleitenden Paarreim, der eine formale Organisation im Rahmen einer sog. „Reihenstrophe“ konstituiert hätte („einleitende Reimpaarbasis“ nach Schweikle). ${ }^{30}$

Alle Reihen der Kolmarer Liederhandschrift weisen demgegenüber in der Tat einen Paarreim zu Beginn der Strophen auf, ebenso wie das oben wiedergegebene Lied Ulrichs von Liechtenstein. Ob damit ein wesentlicher Beitrag zur Gattungskonstitution- und differenzierung geleistet ist, muss allerdings fraglich bleiben, denn die „einleitende Reimpaarbasis" findet sich auch in Strophen, die weder dem Reihen-Corpus zugehören noch in anderer Weise als Reihen gekennzeichnet sind (vgl. dazu aus dem Bestand der Handschrift z.B. die Strophen zur Nachtweise Konrads von Würzburg ['KonrW/10/1], zu Albrecht Leschs Feuerweise [ ${ }^{1}$ Lesch/5/5] und zu Regenbogens Briefweise $\left[{ }^{1}\right.$ Regb/500]). Die Regenbogen zugeschriebene Torenweise bietet keinen einleitenden Paarreim (s.o.).

Die Melismatik der Liedmelodie zu Neidharts Sommerlied 14 lässt auch ohne eine definitive Entscheidung über die Platzierung der Silben Zweifel am Tanzcharakter des Lieds aufkommen und relativiert die gattungsklassifikatorische wie aufführungspraktische Bedeutung der Beischriften in Handschrift c. Tanzcharakter wird üblicherweise jenen Melodien zugesprochen, die entweder schon rhythmisch eindeutig überliefert sind oder deren Rhythmus leicht erschlossen werden kann und deren Texte sich problemlos syllabisch zuordnen lassen - abgesehen von weiteren Liedern Neidharts denke ich an einige Lieder Oswalds und an die Gegenüberstellung von Spruchlied- und Tanzliedcharakter im Frau WeltLied Hugos von Montfort. ${ }^{31}$ All dies ist für die vorliegende Melodie nicht der Fall.

30 Günther Müller: Zu Neidharts reien-strophik. In: Beiträge zur Geschichte der deutschen Sprache und Literatur 48 (1924), S. 492-494; Günther Schweikle: Neidhart. Stuttgart 1990, S. 103; Anna Kathrin Bleuler: Neidhart: Zur Typologie der Lieder. In: Margarete Springeth, Franz-Viktor Spechtler: Neidhart und die Neidhart-Lieder. Ein Handbuch. Berlin 2018, S. 117-130. Dazu auch Horst Brunner: Die Töne der Neidhartlieder. In: Ebd., S. 143-167, mit dem Kommentar: „die Unterscheidung zwischen Periodenstrophe und Reienstrophe bei Schweikle 1990, S. 102 f., scheint mir unnötig kompliziert und nicht wirklich weiterführend“ (S. 145).

31 Vgl. dazu meinen bereits erwähnten Beitrag zu,Melodisch-rhythmischen Differenzierungen' (Welker 2017 [Anm. 10]). 
Allerdings möchte ich nicht so weit gehen wie kürzlich Anna Kathrin Bleuler, die für die Aufzeichnungen in c generell annimmt, sie stellten keine brauchbare Grundlage für einen Gesangsvortrag dar. ${ }^{32}$ Denn eindeutig ist die Textzuordnung schon deshalb nicht, weil damit zu rechnen ist, dass ein Großteil der mündlich vermittelten zeitgenössischen Konventionen der Textunterlegung nicht mehr greifbar und deshalb nicht mehr nachvollziehbar ist.

Immerhin und über die Bedeutung als Zeugin für die Lieder Neidharts hinaus ist die Berliner Handschrift ein hochinteressantes Dokument für die spezifisch bürgerliche Musikpflege in Nürnberg um die Mitte und zu Beginn der zweiten Hälfte des 15. Jahrhunderts. Sie kann in diesem Zusammenhang in einer Reihe mit dem ,Lochamer Liederbuch' (Berlin, Staatsbibliothek Preußischer Kulturbesitz, Ms. mus. 40.613), dem ,Schedelschen Liederbuch ' (München, Bayerische Staatsbibliothek, Cgm 810) und der wohl in Nürnberg entstandenen Vorlage des ,Buxheimer Orgelbuchs' (München, Bayerische Staatsbibliothek, Mus. ms. 3725) gesehen werden. Es bleibt ein Desiderat, die vielfältigen und vielschichtigen Aspekte des Nürnberger Musiklebens in den Jahrzehnten unmittelbar vor der Reformation im Überblick und Kontext zu erschließen, die ja in jedem Fall auch die Rolle der Nürnberger Meistersinger einbeziehen müssen. Damit könnten auch die Parallelen wie die Abweichungen zum Entstehungskontext der Kolmarer Handschrift deutlich werden.

Mit der kritischen Bewertung der Reihen-Aufzeichnungen in Handschrift c in gattungstypischer und melodischer Hinsicht ist die Frage wieder offen, wie denn nun die musikalische Gestalt eines mittelalterlichen Reihen beschaffen gewesen sei. Um dieser Frage weiter nachgehen zu können, möchte ich das Augenmerk wieder zurück auf den Begriff und seine Gestalt, diesmal aber auf die Wortformen außerhalb des deutschen bzw. zumindest des hochdeutschen Sprachraums werfen. ${ }^{33}$

32 Bleuler 2008 (Anm. 26), S. 396-402.

33 Schon das Grimmsche Wörterbuch hat auch vereinzelt mittelniederdeutsche und mittelniederländische Belege aufgenommen, ergiebiger ist aber Karl Schiller und August Lübben: Mittelniederdeutsches Wörterbuch. 6 Bde. Bremen 1875-1881, hier der Artikel ,rei, reie, reige, rege. In: Bd. III, S. 449: de sunde is arch vnde menniger leyer, vnde mennich pipet to erem reye heißt es in Josef (Josep) Von den sieben Todsünden. (S. Emd. Mscr.) Im Auszuge hg. von Babucke. Norden 1875, v. 4449 (dazu die Neuausgabe von Eva Schütz: Joseps Sündenspiegel. Eine niederdeutsche Lehrdichtung des 15. Jahrhunderts. Kommentierte Textausgabe (Niederdeutsche Studien 19). Köln/Wien 1973); disse reie was wat lang, dat blive bestan umme der korte willen steht in der Magdeburger Chronik geschrieben: Die Magdeburger Schöppen-Chronik. Hg. von Karl Janicke. Leipzig 1869 = Die Chroniken der deutschen Städte VII, S. 205, Z. 8-9. 


\section{Reihen außerhalb des deutschen Sprachraums}

Auch auf der anderen Seite des Ärmelkanals war die Kenntnis vom Reihen angekommen. In Geoffrey Chaucers House of Fame, entstanden etwa 1370-80, ist im dritten Kapitel zu lesen: ${ }^{34}$

Ther saugh I than Atiteris, And of Athenes daun Pseustis, And Marcia that loste her skyn,

1230 Bothe in face, body, and chyn, For that she wolde envien, loo, To pipen bet then Apolloo. Ther saugh I famous, olde and yonge, Pipers of the Duche tonge,

1235 To lerne love-daunces, sprynges,

Reyes, and these straunge thynges. (V. 1227-1236)

Das mittelenglische Pendant zum deutschen Reihen - hier im Plural reyes erscheint im Zusammenhang von weiteren Tänzen, love-daunces - vielleicht weniger Liebestänze als Abkömmlinge der hovetänze, die schon bei Neidhart erwähnt wurden - und sprynges - sicher Springtänze, was den Reihen hier eher auf die Seite der Schreittänze stellt. ${ }^{35}$ Ausgeführt wird die Tanzmusik im House of Fame von pipers of the Duche tonge, wobei duche hier niederländisch wie deutsch heißen kann; und die pipers sind eben Spieler lauter Blasinstrumente wie Schalmei oder Sackpfeife. Und all dies zusammen wird als straunge thynges bezeichnet - fremdartig, seltsam oder auch nur bemerkenswert.

Etwa gleichzeitig mit Geoffrey Chaucers House of Fame entstand wohl in Nordfrankreich das anonyme Lehrgedicht der Échecs amoureux, in dem von einer idealtypischen höfischen Unterhaltung nach Tisch die Rede ist: ${ }^{36}$

34 The Riverside Chaucer, Third Edition. Hg. von Larry D. Benson. Oxford 1988, S. 347373, hier S. 362-363.

35 Die Anmerkung 1236, S. 363 im Riverside Chaucer (Anm. 34), erläutert: „Reyes: a round dance".

36 Vgl. die Teilausgabe in Christine Kraft: Die Liebesgartenallegorie der „Échecs amoureux“. Frankfurt am Main u. a. 1977 (Europäische Hochschulschriften, Reihe XIII 48). Die Ausgabe folgt der Fassung in der Handschrift Venezia, Biblioteca Marciana, ms. fr. App. XXIII [267]. Siehe weiterhin Hermann Abert: Die Musikästhetik der Échecs amoureux. In: Sammelbände der Internationalen Musikgesellschaft 6 (1904/ 05), S. 346-355. 
La oyt on res d'Alemaigne

De mainte guyse moult estraigne,

Danses, estanpies, chansons

En pluseurs divers plaisans sons

Et moult d'aultres notes nouvelles. (V. 633-637)

Es folgt im Text der Échecs noch einer jener für die Zeit typischen Instrumentenkataloge, der im Rahmen einer Überbietungsrhetorik alle nur denkbaren Instrumente auftreten lässt, Streich-, Zupf- und Blasinstrumente, am Schluss der Aufzählung aber einschränkt:

Et quant il vouloient danser

Et faire grans esbatemens,

On sonnoit les haus instrumens,

Qui miex as danseours plaisoient

Pour la grant noise, qu'il faisoient. (V. 650-654)

Für die Tanzmusik sind also die haus instrumens, die lauten Blasinstrumente, doch am geeignetsten.

Aus den reyes bei Chaucer, die von pipers of the Duche tonge gespielt werden, sind in den Échecs amoureux res d'Alemaigne geworden; res - im Kontext von danses und estanpies ohne Zweifel ebenfalls nichts anderes als jene reien, die jetzt noch deutlicher als typisch deutsch (d'Alemaigne) angesehen werden wobei auch hier das Land Alemaigne weit aufgefasst werden sollte. Auch in den Échecs ist dies moult estraigne, analog den straunge thinges bei Chaucer.

$\mathrm{Zu}$ Beginn des 15. Jahrhunderts war der Reihen in England wohl wieder in Vergessenheit geraten. Denn sogar bei einem Schüler Geoffrey Chaucers, dem Benediktiner John Lydgate, der ganze Abschnitte der Échecs amoureux für sein Lehrgedicht Reson and Sensuallyte, das im ersten Jahrzehnt des 15. Jahrhunderts (vor 1412) entstand, weitgehend wörtlich übersetzt hat, lautet die betreffende Passage jetzt: ${ }^{37}$

For ther wer rotys of Almanye

And eke of Arragon and spayne,

Songes, stampes, and eke daunces,

Dyners plente of plesaunces,

And many vkouth notys newe. (V. 5571-5575)

Offensichtlich hatte bereits der englische Bearbeiter Schwierigkeiten mit der Interpretation des res d'Alemaigne, und die reyes aus dem House of Fame waren

37 Vgl. Ernst Sieper: Lydgate's Reson and Sensuallyte. Vol. I: The Manuscript, Text (with Side-Notes by Dr. Furnivall), Glossary. London 1901 (Extra Series 84). 
ihm auch nicht mehr präsent: Aus res (d'Alemaigne) macht Lydgate rotys (of Almanye) ${ }^{38}$ - Rotten (Plural zur Rotte oder Rotta, einer vor allem im Hochmittelalter in ganz Europa weitverbreiteten Form des Psalteriums), und den Hinweis de mainte guyse moult estraigne modifiziert er zu and eke of Arragon and spayne. Dagegen erscheinen die nottez nouvelles korrekt als notys newe. ${ }^{39}$

Es fehlt noch ein letzter Beleg für die Rezeption des Reihen außerhalb des deutschen Sprachraums, und dieser Beleg ist zweifellos der spannendste, denn er stammt nicht nur von dem wichtigsten französischen Dichterkomponisten des 14. Jahrhunderts, Guillaume de Machaut, sondern er verweist mit seiner Erwähnung des Reihen wieder auf ein Musikstück.

Guillaume de Machaut hat in seinen letzten Lebensjahren unter dem Titel Le livre dou voir dit einen fiktiven Briefwechsel mit einer sehr viel jüngeren Péronne verfasst, den er zum Teil mit zahlreichen älteren und neuen Liedern garniert hat, der zum Teil aber auch auf anderweitig überlieferte Dichtungen verweist. ${ }^{40}$ Für unsere Fragestellung sind zwei Briefe des Livre dou voir dit relevant, Brief IV und Brief X. In beiden geht es um einen Text, Le grant desir, den Péronne an Machaut gesandt hat, mit der Bitte um Vertonung. Le grant desir ist zugleich der Beginn des Refrains einer in Text und Musik erhaltenen Ballade Machauts (B 33) mit dem Incipit Nes que on porroit les estoiles nombrer: ${ }^{41}$

38 In der Fassung der Handschrift Dresden, Sächsische Landesbibliothek, Ms. Oc 66, ist die Schreibung ros d'Allemaigne zu finden, welche die Fehldeutung und Transformation von res zu rotys pausibler macht. Siehe hierzu den Beitrag von Abert 1904/05 (Anm. 36), der die Dresdener Handschrift heranzieht.

39 Rotys of Almanye ergibt im Gegensatz zu res d'Alemaigne keinen Sinn, denn die Rotta war ja, anders als der Reihen, kein Spezifikum der deutschen Länder. Wohl deshalb hat Lydgate die „Fundorte“ der rotys um die Länderbezeichnungen Aragon und Spanien erweitert, damit der weiten Verbreitung der Rotta Rechnung getragen und den Widerspruch aufgelöst.

40 Guillaume de Machaut, Le livre du voire dit. Édition critique et traduction par Paul Imbs. Introduction, coordination et révision: Jacqueline Cerquiglini-Toulet, Index des noms propres et glossaire: Noël Musso. Paris 1999 (Le livre de Poche. Lettres gothiques 4557).

41 Ebd., S. 128 und S. 186-188. Die Nummerierung der Ballade folgt der in den Ausgaben von Friedrich Ludwig und Leo Schrade; siehe dazu die Überblicksdarstellung in Lawrence Earp: Guillaume de Machaut. A Guide to Research. New York/London 1995, zu dieser Ballade S. 349-350, mit Hinweisen zu Quellen und Editionen. 


\section{Lettre IVr:}

J'ay fait le chant sur Le grant desir que j'ai de vous veoir ainsi que vous le m'aviez commandé. Et l'ai fait ainsi comme un rés d'Alemaigne. Et vraiement il me semble moult estranges et moult nouviaus, si le vous envoierai le plus tost que je porrai.

Ich habe den Gesang über Le grant desir que jai de vous veoir so gemacht, wie Ihr es mir aufgetragen habt, und habe ihn so gemacht wie einen rés d'Alemaigne. Und in der Tat scheint er mir sehr seltsam und sehr neuartig, und ich sende ihn Euch sobald wie möglich.

\section{Lettre Xc:}

Je vous envoie mon livre de Morpheus, que on appelle La Fontaine Amoureuse, aveuc Le grant desir que j'ai de vous veoir, ou j'ai fait un chant a vostre commandement; et est a la guise d'un rés d'Alemaigne; et, par Dieu, long temps ha que je ne fis si bonne chose a mon gré, et sont les tenures aussi doulces comme papins dessalés: si vous suppli que vous le daigniés oyr et savoir la chose ainsi comme elle est faite, sans mettre ne oster, et se vuelt dire de bien longue mesure; et qui la porroit mettre sur les orgues, sur cornemuses ou autres instrumens, c'est sa droite nature.

Ich schicke Euch mein Buch von Morpheus, das man den Liebesbrunnen nennt, mit Le grant desir que j'ai de vous veoir, wofür ich einen Gesang nach Eurem Auftrag gemacht habe. Und er ist in der Art eines rés d'Alemaigne; und bei Gott, lange Zeit habe ich meiner Meinung nach keine so gute Sache mehr geschaffen. Und es sind die Tenores so süß wie salzloses Mus, und ich ersuche Euch dies anzuhören und kennen zu lernen so wie es gemacht ist, ohne etwas wegzulassen oder hinzuzufügen. Und es ist genau von richtiger Länge, und man kann es auf der Orgel spielen, auf Sackpfeifen oder anderen Instrumenten, das ist seine rechte Natur.

Über diese zwei Texte ist in der Machautforschung seit langem viel nachgedacht worden, denn sie gehören ja zu den ganz seltenen Zeugnissen, in denen der Komponist ein wenig von seinem Schaffensprozess preisgibt. Leider bleiben die Texte auch nach der Übersetzung in vielerlei Hinsicht dunkel, so ist die ästhetische Kategorie „süß wie salzloses Mus“ kaum mehr nachzuvollziehen. Dagegen sollte vor dem Hintergrund der zuvor vorgestellten Texte, Chaucer's House of Fame, der Échecs amoureux und ihrer Übersetzung bei Lydgate deutlich geworden sein, dass auch der rés d'Alemaigne bei Machaut nichts anderes als der deutsche Reihen ist, und eben nichts mit einer eher unbestimmten ,Sache - abgeleitet von lateinisch res zu tun hat, wie dies von musikwissenschaftlichen Autoren bis in die jüngste Vergangenheit immer 
wieder postuliert und spekuliert wurde, ${ }^{42}$ obwohl bereits vor Jahren der australische Musikhistoriker Patrick Little auf den Bezug zum Reihen hingewiesen hat. ${ }^{43}$

Unklar bleibt allerdings auch, wo denn in Machauts dreistimmig überliefertem Balladensatz die Spuren des Reihen zu finden sind - und es handelt sich ja offenbar auch gar nicht um einen echten Reihen, den Machaut hier zitiert hätte, sondern um eine Machautsche Eigenkomposition in der Art, a la guise, eines deutschen Reihen. Immerhin wird aus Machauts Formulierung auch deutlich, dass für das Publikum des 14. Jahrhunderts der Reihen auch noch in der Imitation stilistisch prägnant und erkennbar war, und zudem bei aller Fremdartigkeit, moult estranges, oder gerade deswegen, ästhetische Qualitäten aufwies.

42 Siehe etwa Marie Luise Göllner: Un Res d'Alemaigne. In: Festschrift für Horst Leuchtmann zum 65. Geburtstag. Hg. von Stephan Hörner und Bernhold Schmid. Tutzing 1993, S. 147-160, und Jennifer Bain: Balades 32 and 33 and the ,res dalemangne'. In: Machauts Music: New Interpretations. Hg. von Elizabeth Eva Leach. Woodbridge 2003 (Studies in Medieval and Renaissance Music 1), S. 205-220.

43 Patrick Little: Three Ballads in Machaut's Livre du Voir-Dit. In: Studies in Music [Australia] 14 (1980), S. 45-60; Littles Argumente wurden von Daniel LeechWilkinson aufgenommen in: Le Voir Dit and La Messe de Notre Dame: Aspects of Genre and Style in Late Works of Machaut. In: Plainsong and Medieval Music 2 (1993), S. 43-73, hier S. 50-53. 

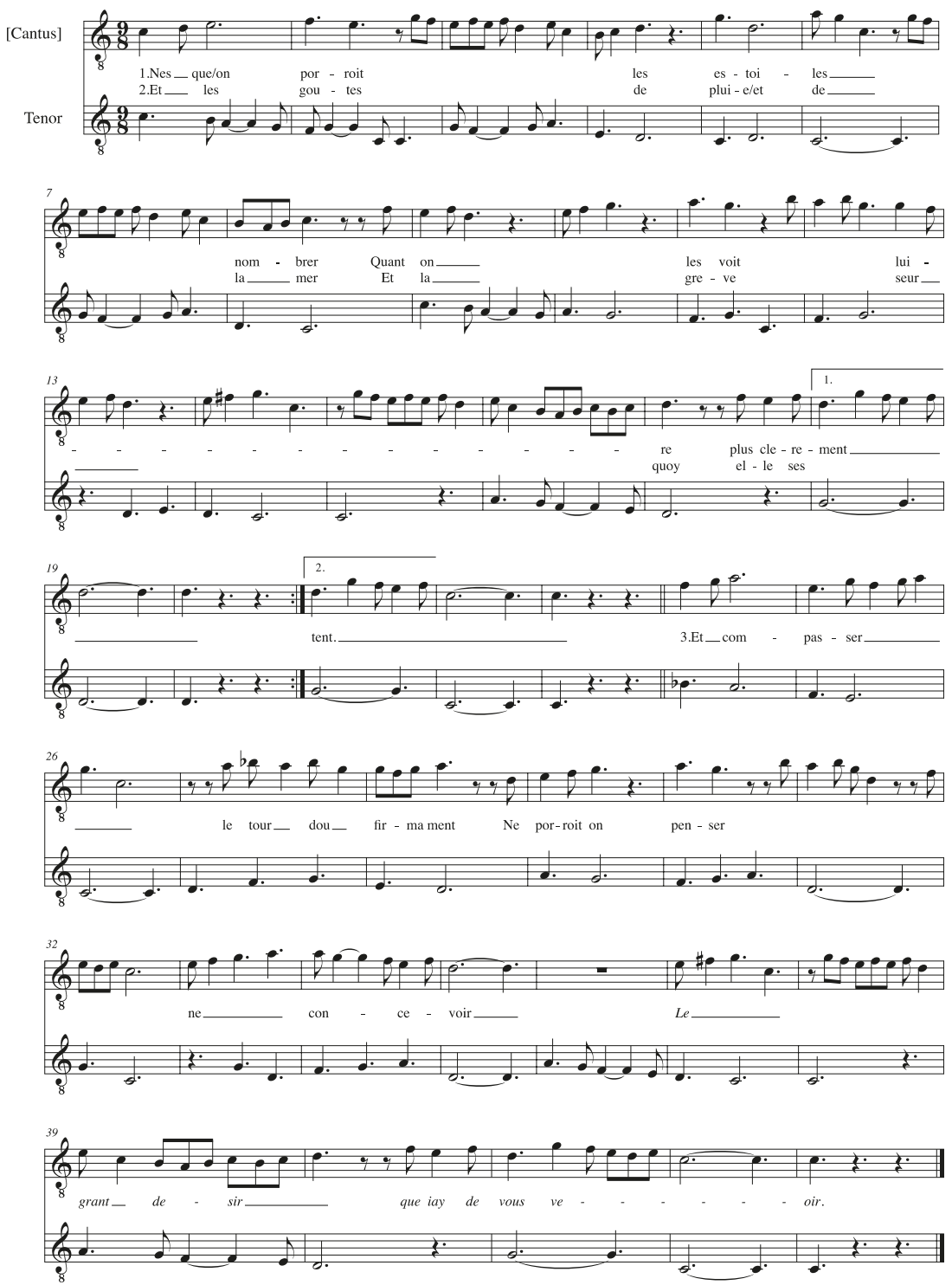

Abb. 5: Guillaume de Machaut, Nesque on porroit (B 33), zweistimmiger Gerüstsatz (Cantus und Tenor) nach Handschrift A und Ardis Butterfield ${ }^{44}$

44 Ardis Butterfield: The Art of Repetition: Machaut's Ballade 33, Nes qu'on porroi. In: Early Music 31 (2003), S. 347-360. 
Bislang fokussierten einschlägige Untersuchungen vor allem auf die Oberstimme, den textierten Cantus des dreistimmigen Balladensatzes - ausgehend von der traditionellen, insbesondere auf Hugo Riemann zurückgehenden Auffassung, dass es sich beim Machautschen Liedsatz um einen „instrumentenbegleiteten Oberstimmensatz" handle. ${ }^{45}$ Nur musste dabei offen bleiben, wo denn gerade hier das in den beiden Briefen angesprochene Neu- und Fremdartige zu finden sei, denn der Cantus von Nesque on porroit ist zum einen außergewöhnlich formelhaft und bietet auch im Vergleich mit weiteren Balladen eben nichts Neues, nimmt vielmehr jene Formeln und Formulierungen wieder auf, die auch anderswo Anwendung gefunden hatten; das zeigt eine Gegenüberstellung der Cantus-Incipits der drei Balladen Nesque on porroit, Ploures dames und Donnes signeurs - die Formelhaftigkeit der Cantusmelodik Machauts und die melodischen Entsprechungen dieser drei Balladen sind im übrigen schon mehrfach zur Sprache gekommen, zuletzt in der neuen Monographie zu Machaut von Elizabeth Eva Leach. ${ }^{46}$

Ein in meinen Augen weitaus besser geeigneter Kandidat für Machauts Experimente mit neuartigen, fremden, ja ,ausländischen' Formulierungen ist der Tenor des dreistimmigen Satzes. Dies wird umso plausibler, als in letzter Zeit nachgewiesen werden konnte, dass Machaut auch in anderen Balladen im Tenor präexistentes musikalisches Material untergebracht hat. ${ }^{47}$ Hier fällt zunächst die eigentümlich synkopierte Rhythmik auf; mehr noch - und auch für Machauts Tenorformulierungen ungewöhnlich - ist der recht große Ambitus von einer Oktave im Lydischen, der mehrfach in stufenweise absteigenden Bewegungen durchmessen wird. Auffallend ist weiterhin der wiederholte Gebrauch von Tonrepetitionen bei Schlussbildungen, ein Phänomen, das sich in dieser Art und Häufigkeit sonst bei Machaut nicht findet. All diese Aspekte der Melodiebildung des Tenors werden noch deutlicher in einer Fassung des Melodieverlaufs, die der rhythmischen Differenzierungen entkleidet ist: lydischer Modus, großer Ambitus, stufenweise absteigende Tonfolgen und Tonrepetitionen.

45 Hugo Riemann: Das Kunstlied im 14.-15. Jahrhundert. In: Sammelbände der internationalen Musikgesellschaft 7 (1905-1906), S. 529-550.

46 Elizabeth Eva Leach: Guillaume de Machaut. Secretary, Poet, Musician. Ithaca, London 2011, S. 123, S. 126 und S. 273, mit Verweisen auf die Arbeiten von Leech- Wilkinson 1993 (Anm. 43) und Ardis Butterfield (Anm. 44).

47 Vgl. Lorenz Welker: Guillaume de Machaut, das romantische Lied und die Jungfrau Maria. In: Annäherungen. Festschrift für Jürg Stenzl zum 65. Geburtstag. Hg. von Ulrich Mosch, Matthias Schmidt und Silvia Wälli. Saarbrücken 2008, S. 70-87. 


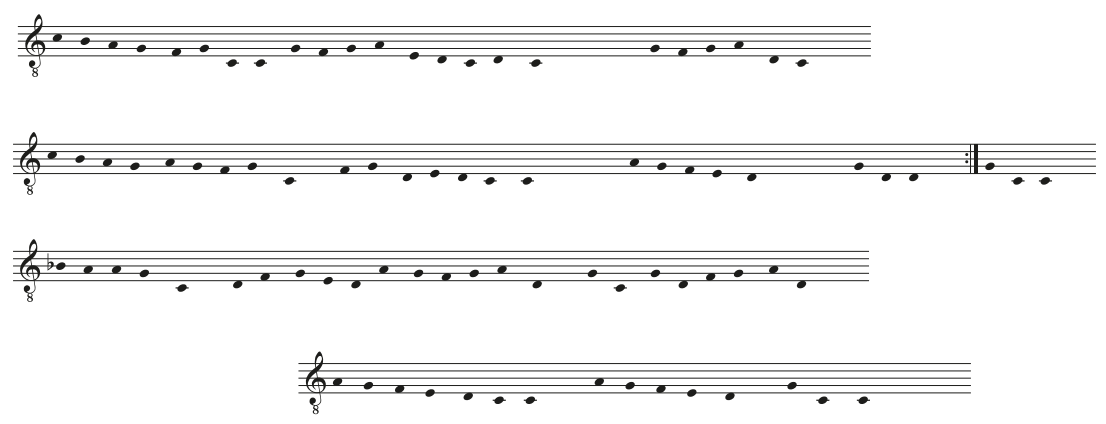

Abb. 6: Tenor von Guillaume de Machaut, Nesque on porroit (B 33), ohne Mensuration

Es kann gut sein, dass sich hinter diesen Aspekten jene prägnante Charakteristik verbirgt, die für Machaut und seine Zeitgenossen des 14. Jahrhunderts die stilistische Eigenart des deutschen Reihen, des rés d'Alemaigne in all ihrer Fremdartigkeit ausmachte.

Die hier vorgelegten Beispiele zur Überlieferung und zur europäischen Rezeption des Reihen im späten Mittelalter belegen, dass es offensichtlich für die Zeitgenossen, die Musiker, Sänger, Tänzer und Zuhörer, eine gut erkennbare Gattungscharakteristik gegeben hat, die sich uns nach wie vor in weiten Teilen entzieht. Auch wenn die Melodik des Reihen bei Machaut eindrückliche Besonderheiten aufweist, die ihn unterscheidbar von anderen Liedern in seinem Schaffen macht und darin ein Reflex der Melodik des „deutschen“ Reihen im Westen erkennbar werden könnte, fällt es doch schwer, ebendiese Charakteristika im Reihen-Corpus der Kolmarer Liederhandschrift wiederzufinden. Und für dreizehn der vierzehn als Reihen bezeichneten Lieder in der Berliner Neidhart-Handschrift liegen keine Melodieaufzeichnungen vor, die den an Machauts res d'Alemaigne erhobenen melodischen Befund hätten bestätigen können. Ob das Vorhandensein einer „Reihenstrophe“ auch schon die Gattung in textlich-musikalischer Gestalt und in ihrer Funktion als Tanzlied konstitutiert, bleibt, wie oben gezeigt, fraglich, zumal ja gerade das einzige notierte und als ray gekennzeichnete Lied in der Berliner Neidhart-Sammlung davon abweicht. So sehe ich als Hintergrund für die Entscheidung des Kompilators der Kolmarer Liederhandschrift, sechs Lieder als Reihen in einem kleinen Corpus in der zweiten Lage der Handschrift zusammenzustellen, nur noch zwei Möglichkeiten: (1) Die Lieder wurden ihm bereits in den Vorlagen mit der Kennzeichung als Reihen in ihrer Zusammengehörigkeit deutlich gemacht, oder 
(2) er konnte aufgrund seiner musikalisch-textlichen Erfahrung und aufgrund eines uns nunmehr verborgenen Wissens über weitere Gattungscharakteristika eigenständig Klassifikation, Ordnung und Zusammenstellung vornehmen. Doch auch ohne endgültige Entscheidung über die Kriterien der Gattungsklassifikation bleibt die Kolmarer Liederhandschrift für die Geschichte und den Stellenwert des Reihen als einer wichtigen Liedgattung im späten Mittelalter, die auch jenseits der Grenzen des deutschen Sprachbereichs in ihrer Besonderheit Beachtung fand, ein unschätzbarer Zeuge. 

Stefan Rosmer

\title{
Die Töne der Kolmarer Liederhandschrift Versuch zu den melodischen Formen, Strophenstrukturen und der Schichtung des Bestands
}

\begin{abstract}
The article probes into the music notated in the Colmar Liederhandschrift. After an overview of research on medieval German music, a detailed examination of the melodic forms ("Töne") in the manuscript shows that these are not as homogeneous as has been assumed until now. In a close examination of two melodies, two types or models of musical design are explicated. Nearly all of the melodies in the manuscript can be distinguished classified under these two types, which point to chronological layers within the collection. One group contains only works of later authors (after ca. 1350 A. D.) plus one older example (Konrad von Würzburg: Aspiston); the second group contains all the melodies for older authors plus one late example (Albrecht Lesch: Hofweise).
\end{abstract}

Die Töne der Kolmarer Liederhandschrift spielen in der jüngeren Forschung zur Musik der mittelalterlichen deutschsprachigen Lyrik bisher kaum eine Rolle. Im Rahmen der Gattungsgeschichte von Sangspruch, meisterlichem Lied und institutionalisiertem Meistergesang wurden sie dagegen mehrfach untersucht, aber immer unter diachronem Blickwinkel und selten als Gesamtheit. Der vorliegende Aufsatz skizziert zuerst die jüngere Forschung, die sich mit der Musik von mittelalterlichen deutschsprachigen (Lied-)Texten befasst hat, um sich in diesem Forschungsfeld zu situieren. Er versucht einen Beitrag zu der Frage zu leisten, welche Erkenntnispotentiale die Beschäftigung mit der Musik für die Literaturwissenschaft eröffnen kann. Im zweiten Teil wird die Forschung zur Musik der Kolmarer Liederhandschrift - im Weiteren steht k als Sigle für den Cgm 4997 - umrissen und die Fragestellung entwickelt. Der dritte Teil expliziert einerseits in Form von Analysen zweier Töne das analytische Vorgehen, das den Zusammenhang von Musik und Strophenform in den Mittelpunkt rückt; andererseits wird ein Typisierungsvorschlag für die Töne von $\mathrm{k}$ vorgelegt. Er soll zeigen, dass die aufgezeichnete Musik der Kolmarer Liederhandschrift möglicherweise ein Potential zur zeitlichen Sortierung der unechten Töne eröffnen kann. 


\section{Mittelalterliche deutschsprachige Liedkunst und ihre Musik: Zum Forschungsstand}

Die Erforschung der Musik, die zur deutschsprachigen Lyrik des Mittelalters überliefert ist, ${ }^{1}$ hat in den letzten rund zwanzig Jahren merklichen Aufschwung genommen. Die Klage, dass die literaturwissenschaftliche Forschung die Musik ignoriere - öfter zitiert wurde das Diktum, Philologen tendierten dazu, nach der Devise „Augen zu, wenn Noten kommen“2 zu arbeiten -, lässt sich nur noch mit Einschränkungen anstimmen. Vollständig traf sie schon länger nicht mehr zu, denn es lässt sich leicht eine Reihe älterer und neuerer Aufsätze und Monographien finden, die sich ganz oder in Teilen mit der überlieferten Musik zur mittelalterlichen deutschsprachigen Liedkunst befassen. ${ }^{3}$ Auch in Editionen

1 Einen instruktiven Überblick, der sich auch an Nicht-Spezialisten richtet, bietet Marc Lewon: Wie klang Minnesang? Eine Skizze zum Klangbild an den Höfen der staufischen Epoche. In: Dichtung und Musik der Stauferzeit. Wissenschaftliches Symposium, 12. bis 14. November 2010. Hg. von Volker Gallé. Worms 2011 (Schriftenreihe der Nibelungengesellschaft Worms 7), S. 69-123.

2 Helmut Lomnitzer: Liebhard Eghenvelders Liederbuch. Neues zum lyrischen Teil der sog. Schratschen Handschrift. In: Zeitschrift für deutsche Philologie 90 (1971), S. 190-216, hier S. 214. Die Verteilung auf die Disziplinen beklagte schon Heinrich Rietsch: Rez. zu Die Sangesweisen der Colmarer Handschrift und der Liederhandschrift Donaueschingen. Hg. von Paul Runge. Leipzig 1896. In: Zeitschrift für deutsches Altertum 42 (1898), S. 167-177, hier S. 167.

3 Einen Forschungsbericht zur Musik des Minnesangs, der Problembereiche und Desiderata benennt, bietet Florian Kragl: Walther, Neidhart und die Musik. Samt einem Anhang: Zur Erforschung der Musik des Minnesangs bis 1300. In: Der achthundertjährige Pelzrock. Walther von der Vogelweide - Wolfger von Erla - Zeiselmauer. Hg. von Helmut Birkhan. Wien 2005 (Österreichische Akademie der Wissenschaften. Philos.-Hist. Klasse. Sitzungsberichte 721), S. 273-346. Kragl hat weitere Literaturhinweise und Überlegungen in vier weiteren Studien vorgelegt: Florian Kragl: Walther, Neidhart und die Musik. Möglichkeiten der musikalischen Analyse. In: Der mittelalterliche und der neuzeitliche Walther. Beiträge zu Motivik, Poetik, Überlieferungsgeschichte und Rezeption. Hg. von Thomas Bein. Frankfurt am Main 2007 (Walther-Studien 5), S. 165-212; Florian Kragl: Bürk Mangolt singt Hugo von Montfort. Ein musikalischer Versuch zur ,Aufführung mittelalterlicher Lyrik. In: Daphnis. Zeitschrift für Mittlere Deutsche Literatur und Kultur der Frühen Neuzeit 38 (2009), S. 371-398; Florian Kragl: wort und wîse. Formen des sangbaren Verses in der deutschen Literatur des Mittelalters. In: Literaturwissenschaftliches Jahrbuch N. F. 52 (2011), S. 31-80; Florian Kragl: Musik. In: Germania Litteraria Mediaevalis Francigena. Handbuch der deutschen und niederländischen mittelalterlichen literarischen Sprache, Formen, Motive, Stoffe und Werke französischer 
finden sich wesentliche Beiträge zur musikalischen Seite der mittelalterlichfrühneuzeitlichen Lyrik. ${ }^{4}$ Richtig ist gleichwohl nach wie vor, dass eine

Herkunft (1100-1300). Hg. von Geert H. M. Classens, Fritz Peter Knapp und René Pérennec. Bd. 3: Lyrische Werke. Hg. von Volker Mertens und Anton Touber. Berlin, Boston 2012, S. 347-388. Zur Forschungsgeschichte von musikwissenschaftlicher Seite: Henry Hope: Constructing Minnesang Musically. Phil. Diss. Univ. Oxford 2014, online unter: https://ora.ox.ac.uk/objects/uuid:1fe51d00-5f31-4a6f-84209533a3a07ed6 (09.09.2020). Hope ergänzt die Forschungsbibliographie Kragls unter anderem um die englischsprachige Forschung.

Auf Forschungsliteratur, die bei Kragl und Hope verzeichnet ist, wird im Weiteren nur hingewiesen, wenn sie für die eigene Argumentation direkt herangezogen wird. Hopes und Kragls Arbeiten bieten umfangreiche Nachweise, für das Verständnis der Forschungsgeschichte ist daneben der Einbezug der Liedkunst des späten 14. und des 15. Jahrhunderts einerseits, der Gattungen Leich und Sangspruch andererseits instruktiv. Deswegen wäre z. B. zu ergänzen: Ursula Aarburg: Begirlich in dem herzen min. Ein Vorschlag zur Interpretation der Weise. In: Jahrbuch für Liturgik und Hymnologie 6 (1961), S. 112-115; Ursula Aarburg: Melodiesprache im G-Modus. In: Helmuth Osthoff zu seinem siebzigsten Geburtstag. Hg. von Ursula Aarburg und Peter Cahn. Tutzing 1969 (Frankfurter musikhistorische Studien), S. 33-49; Karl Bertau: Einige Gedanken zur poetisch-musikalischen Struktur und zu einer historischen Folgeerscheinung der Krypto-Polyphonie im ,Minneleich ' des Heinrich Frauenlob (ca. 1260-1318). In: Jahrbuch der Oswald von Wolkenstein-Gesellschaft 1 (1980/81), S. 139-159; Christoph Petzsch: Das mittelalterliche Lied: res non confecta. In: Zeitschrift für deutsche Philologie Sonderheft 90 (1971), S. 1-17; Walter Salmen: Zur Melodik des späthöfisch-bürgerlichen Minnesangs. In: RheinischWestfälische Zeitschrift für Volkskunde 1 (1954), S. 103-112.

4 So z. B. Die weltlichen Lieder des Mönchs von Salzburg. Texte und Melodien. Hg. von Christoph März. Tübingen 1999 (MTU 114); März teilt in der Einleitung zahlreiche Hinweise, Überlegungen und Beobachtungen (so zu Notationsarten in verschiedenen Handschriften) mit, die über das edierte Korpus hinaus aufschlussreich sind. Karl Bertaus kritische Rekonstruktion der Melodien zu den Leichs Frauenlobs im Rahmen der GA hat keine breite musikphilologische oder melodieanalytische Forschungsdiskussion angestoßen, obwohl es sich um eine beeindruckende Arbeit mit Potenzial für Kontroversen handelt: Frauenlob (Heinrich von Meissen): Leichs, Sangsprüche, Lieder. Hg. von Karl Stackmann und Karl Bertau. 2 Teile. Göttingen 1981 (Abhandlungen der Akademie der Wissenschaften in Göttingen. Philol.-hist. Klasse. Dritte Folge 119f.), Teil 1, S. 211-233. Die Melodiefassungen nach den einzelnen Handschriften sind jetzt ediert in: Geistliche Gesänge des deutschen Mittelalters. Melodien und Texte handschriftlicher Überlieferung bis um 1530. Hg. von Max Lütolf und Laurenz Lütteken, Kassel u. a. 2003-2018 (Das deutsche Kirchenlied. Kritische Gesamtausgabe der Melodien. Abt. II). Vgl. zur Musik von Frauenlobs Leichdichtungen weiter: Johannes Kandler: „Gedoene ân wort das ist ein tôter galm“. Studien zur Wechselwirkung von Wort 
Auseinandersetzung mit der Musik als unbedeutend für genuin literaturwissenschaftliche Erkenntnisinteressen angesehen wird. Daher werden bisweilen weder die überlieferte Musik selbst noch einzelne Forschungsbeiträge mit ihrer spezifischen Fragestellung in aktuelle Diskussionen einbezogen. ${ }^{5}$

Aufgrund dieser Randständigkeit fügt sich die Forschung nicht zu einem etablierten Teilgebiet zusammen. Einerseits wurden ältere Arbeiten mitunter kaum rezipiert, wodurch schon gelöste Probleme erneut thematisiert oder Fragen, die sich nach langer Diskussion als falsch gestellt erwiesen hatten, wieder aufgegriffen wurden. Andererseits gerieten tradierenswerte Erkenntnisse bisweilen in Vergessenheit, weil sie in Arbeiten standen, die auf überholten Vorannahmen beruhten ${ }^{6}$ oder sich mit einer verfehlten Fragestellung befassten, wie

und Ton in einstimmigen Gesängen des hohen und späten Mittelalters. Wiesbaden 2005 (Elementa musicae 5); Christoph März: Frauenlobs Marienleich. Untersuchungen zur spätmittelalterlichen Monodie. Erlangen 1987 (Erlanger Studien 69); Christoph März: Zum musikalischen Stil in Frauenlobs Kreuzleich. In: Cambridger FrauenlobKolloquium. Hg. von Werner Schröder. Berlin 1988 (Wolfram-Studien 10), S. 125-134; Barbara Newman: Frauenlob's Song of songs. A medieval German poet and his masterpiece. University Park, Pennsylvania 2006; Michael Shields: Zum melodischen Aufbau des Marienleichs. In: Cambridger Frauenlob-Kolloquium. Hg. von Werner Schröder. Berlin 1988 (Wolfram-Studien 10), S. 117-124.

5 Kragl 2009 (Anm. 3), S. 371-374; Kragl 2011 (Anm. 3), S. 39, hat darauf hingewiesen, dass die um die Kategorien Aufführung, Performanz, Performativität und Vokalität zentrierte Forschungsdiskussion mit der konkreten, sprachlichen und musikalischen Klanggestalt nur wenig anzufangen wusste. Zur Stimme als abstrakter Kategorie vgl. zuletzt Almut Suerbaum: Zwischen Stimme und Schrift. Rhythmische Strukturen im Repertoire der Jenaer Liederhandschrift am Beispiel von Frauenlobs ,Zartem Ton'. In: Stimme und Performanz in der mittelalterlichen Literatur. Hg. von Monika Unzeitig, Angela Schrott und Nine Miedema. Berlin, Boston 2017 (Historische Dialogforschung 3), S. 395-415, hier S. 408-411. Ob die neue Forschungsrichtung der Klang-Studien sich der überlieferten Musik zuwendet, ist noch offen, vgl. Markus Stock: Triôs, triên, trisô. Klangspiele bei Wernher von Teufen und Gottfried von Neifen. In: Beiträge zur Geschichte der deutschen Sprache und Literatur 138 (2016), S. 365-389. Dass die Modellierung einer konkreten Aufführungssituation Potenziale für das Textverständnis eröffnet, zeigt am Beispiel des Sangspruchrätsels Martin Schubert: Sangspruchaufführung. Das Rätsel der Repetition. In: Sangspruchdichtung zwischen Reinmar von Zweter, Oswald von Wolkenstein und Michel Beheim. Beiträge der internationalen und interdisziplinären Tagung vom 30. September bis 3. Oktober 2015 in Brixen. Hg. von Horst Brunner und Freimut Löser. Wiesbaden 2017 (Jahrbuch der Oswald von Wolkenstein-Gesellschaft 21), S. 21-29.

6 Die Terminologie für Strophenformen von Friedrich Gennrich: Grundriß einer Formenlehre des mittelalterlichen Liedes als Grundlage einer musikalischen 
der nach der rhythmischen Transkription, die die Forschung bis in die sechziger Jahre dominierte. ${ }^{7}$ Nach der Verabschiedung dieser Debatte entstanden nach wie vor weiterführende Arbeiten, aber durch den Wegfall des vermeintlich zentralen Problems öffnete sich die Forschung für andere Fragen und Perspektiven; sie mag daher im Überblick und im Vergleich mit den Vorgängern eher diskontinuierlich und unübersichtlich wirken. ${ }^{8}$ Zur Randständigkeit der

Formenlehre des Liedes. Halle 1932, ist z. B. unbrauchbar, weil sie zu stark von seinen Hypothesen über die Genese der Formen abhängt; siehe Erdmute PickerodtUthleb: Die Jenaer Liederhandschrift. Metrische und musikalische Untersuchungen. Göppingen 1975 (GAG 99), S. 176, 181-182, 191, 195-197. Wenn man um seine Mängel und Probleme weiß, kann man den „Grundriß“ aber wegen seines großen Überblicks über deutsche, romanische und lateinische Lieder immer noch mit Gewinn lesen. Zur mit den Namen Aarburg, Gennrich und Jammers verbundenen Forschungsgeschichte vgl. Hope 2014 (Anm. 3), S. 163-215.

7 Das Rhythmusproblem und mit ihm Übertragungen, die moderne, Tondauern festlegende Notenzeichen verwenden, waren für die Germanistik obsolet seit Burkhard Kippenberg: Der Rhythmus im Minnesang. Eine Kritik der literatur- und musikhistorischen Forschung mit einer Übersicht über die musikalischen Quellen. München 1962 (MTU 3); vgl. auch Wulf Arlt: Konrad von Würzburg und die Musik. In: Das ritterliche Basel. Zum 700. Todestag Konrads von Würzburg. Stadt- und Münstermuseum Im Kleinen Klingental, Basel 20. Mai-23. August 1987/Bayerisches Staatsarchiv, Würzburg, 9. September-11. Oktober 1987 [Ausstellungskatalog]. Basel 1987, S. 73-80, hier S. 75; Lewon 2011 (Anm. 1), S. 79-87. Die erneute Inangriffnahme des Rhythmusproblems bildete den Ausgangspunkt von mehreren Arbeiten Robert Lugs, vgl. Robert Lug: Drei Quadratnotationen in der Jenaer Liederhandschrift. In: Die Musikforschung 53 (2000), S. 4-40, weitere Arbeiten Lugs sind in Kragl 2005, 2007, 2012 (Anm. 3) und Hope 2014 (Anm. 3) verzeichnet. Oliver Huck hat Lugs Annahme einer in der Notation angedeuteten Feinrhythmik der Melismen für die Jenaer Liederhandschrift widerlegt (Oliver Huck: Die Notation der mehrfach überlieferten Melodien in der ,Jenaer Liederhandschrift'. In: Die ,Jenaer Liederhandschrift. Codex - Geschichte - Umfeld. Hg. von. Jens Haustein und Franz Körndle, Berlin 2010, S. 99-120). Andreas Haug hat zudem festgehalten, dass Lugs Annahme eines in der Notation der Melismen ausgedrückten Feinrhythmus für das von ihm erneut ins Zentrum gestellte Rhythmusproblem, wie es die ältere Forschung umtrieb, nichts ergeben, weil sie sich nur auf die Längenverhältnisse innerhalb von Melismen beziehen (Andreas Haug: Musikalische Lyrik im Mittelalter. In: Musikalische Lyrik. Teil 1: Von der Antike bis zum 18. Jahrhundert. Hg. von Hermann Danuser. Laaber 2004 [Handbuch der musikalischen Gattungen 8,1], S. 59-129, hier S. 60).

8 Kragl 2005 (Anm. 3), S. 311-312; Kragl 2007 (Anm. 3), S. 166f. und Hope 2014 (Anm. 3), S. 223 sehen einen Rückgang der Forschung nach einer Hochzeit um die Mitte des 20. Jahrhunderts, verzeichnen aber gleichwohl mehrere Arbeiten aus der Zeit 
musikbezogenen Forschung in der Älteren deutschen Literaturwissenschaft trug sicher die Konzentration auf den Minnesang bei, zu dem - sofern man von der Neidhart-Tradition absieht ${ }^{9}$ - wenig Musiknotation überliefert ist. ,Minnesang' war zwar in der Musikgeschichte als Oberbegriff für die mittelalterlichfrühneuzeitliche Lyrik insgesamt lange gebräuchlich, dennoch fand die breiter überlieferte Musik der Sangspruchtradition und der Liebeslieder des 14. bis 16. Jahrhunderts weniger Aufmerksamkeit. Mit Blick auf die geringe musikalische Überlieferung zum Minnesang - im Sinn von höfischer Liebeslyrik zwischen ca. 1180 und 1350 - ließ sich dann die Musik leicht als Nebensache abtun. $^{10}$

Ein anderes Problem der älteren Forschung war die Zugänglichkeit der Quellen. Dies hat sich durch günstigere Faksimile-Ausgaben ${ }^{11}$ und durch die

nach 1970. Zu ergänzen sind die Beiträge: Arlt 1987 (Anm. 7), Kandler 2005 (Anm. 4) und Martin Schubert: Die Form von Reinmars Leich. In: Amsterdamer Beiträge zur älteren Germanistik 41 (1995), S. 85-141. Von den bei Kragl oder Hope bereits erwähnten Arbeiten sind grundlegend: Karl Bertau: Sangverslyrik. Über Gestalt und Geschichtlichkeit mittelhochdeutscher Lyrik am Beispiel des Leichs. Göttingen 1964 (Palaestra 240); Pickerodt-Uthleb 1975 (Anm. 6); Johannes Rettelbach: Variation Derivation - Imitation. Untersuchungen zu den Tönen der Sangspruchdichter und Meistersinger. Tübingen 1993 (Frühe Neuzeit 14). Bertau ist grundlegend für das Verständnis des deutschsprachigen Sangverses, Pickerodt-Uthleb ist die umfassendste Darstellung der Strophenformen der Jenaer Liederhandschrift unter Berücksichtigung der Melodie; Rettelbach untersucht in erster Linie die sprachmetrische Seite von Strophenformen, aber allein sein terminologischer Vorschlag zur Benennung von Strophenformen, S. 12f., trägt wesentlich zur Klarheit und Verständigung bei. Die drei Arbeiten sind zusammen mit der neueren von Horst Brunner: Formgeschichte der Sangspruchdichtung des 12. bis 15. Jahrhunderts. Wiesbaden 2013 (Imagines Medii Aevi 34) die wichtigsten Arbeiten zum Verständnis von Strophik und Melodik in der mhd. Lyrik, weil sie einen umfassenden Bestand an Melodien und Texten untersuchen.

9 Die Melodieüberlieferung ist jetzt hervorragend dargestellt in Marc Lewon: Die Melodieüberlieferung zu Neidhart. In: Neidhart und die Neidhart-Lieder. Ein Handbuch. Hg. von Margarethe Springeth und Franz-Viktor Spechtler. Berlin, Boston 2018, S. $169-240$.

10 Siehe die von Kragl 2005 (Anm. 3), S. 315-317 u. 341 sowie Kragl 2007 (Anm. 3), S. 166-171, zurückgewiesenen Positionen.

11 Die Jenaer Liederhandschrift. In Abbildungen hg. von Helmut Tervooren und Ulrich Müller. Göppingen 1972 (Litterae 10); Die Kolmarer Liederhandschrift der Bayerischen Staatsbibliothek München (cgm 4997). Hg. von Ulrich Müller, Franz Viktor Spechtler und Horst Brunner. Göppingen 1976 (Litterae 35). Zumindest für 
Digitalisierung in den letzten zwanzig Jahren geändert. Viele Handschriften stehen inzwischen als Digitalisate zur Verfügung. Die Musiküberlieferung zu Neidhart ist durch die Salzburger Neidhart-Edition vollständig zugänglich. ${ }^{12}$ Im Bereich des Liederbuch-Lieds hat sich die Forschung erheblich intensiviert. ${ }^{13}$ Am besten stellt sich die Erschließungs-, Editions- und Interpretationslage im Bereich der Sangspruch- und Meisterliedtradition dar. Sie ist durch das RSM, ${ }^{14}$

die Jenaer Liederhandschrift lag aber schon lange ein sehr guter diplomatischer Abdruck vor (Jenaer Liederhandschrift. Bd. I: Getreuer Abdruck des Textes. Hg. von Georg Holz. Leipzig 1901), auch das erste Faksimile Die Jenaer Liederhandschrift. Hg. von K[arl] K[onrad] Müller. Jena 1896 war zumindest in großen Bibliotheken verfügbar.

12 Neidhart-Lieder. Texte und Melodien sämtlicher Handschriften und Drucke. Hg. von Ulrich Müller, Ingrid Bennewitz u. a. 3 Bde. Berlin 2007. Die Übertragungsversuche der älteren Neidhart-Editionen sind hier im Kommentarband ebenfalls dokumentiert; zur Musiküberlieferung siehe oben Anm. 9.

13 Neueditionen des Rostocker Liederbuchs und des Liederbuchs der Clara Hätzlerin stehen vor dem Abschluss, jüngst erschienen ist Valerie Lukassen: Die einstimmigen Lieder Oswalds von Wolkenstein. Edition der Melodien und Kommentar. Wiesbaden 2019 (Imagines Medii Aevi 46). Das polyphone deutschsprachige Lied ist in der Musikwissenschaft inzwischen intensiv aufgearbeitet worden, vgl. zuletzt Nicole Schwindt: Maximilians Lieder. Weltliche Musik in deutschen Landen um 1500. Kassel, Stuttgart 2018 (mit weiterer Literatur). Für diesen Bereich ist aus der Germanistik auf die medienkulturgeschichtlichen Studien Franz-Josef Holznagels zu verweisen, die die Musiküberlieferung mit im Blick haben, vgl. zuletzt: Franz-Josef Holznagel: Songs and Identities: Handwritten Secular Songbooks in German-Speaking Areas of the Fifteenth and Sixteenth Centuries. In: Identity, Intertextuality, and Performance in Early Modern Song Culture. Hg. von Dieuwke van der Poel, Louis Peter Grijp und Wim van Anrooij. Leiden, Boston 2016 (Intersections 43), S. 118-149; ders.: ,wil gi horen enen sanck?' Zum Konzept einer Medienkulturgeschichte der Lyrik in den handschriftlichen, weltlichen Liederbüchern des 15. und 16. Jahrhunderts. In: Überlieferungsgeschichte transdisziplinär. Neue Perspektiven auf ein germanistisches Forschungsparadigma. Hg. von Dorothea Klein, Horst Brunner und Freimut Löser. Wiesbaden 2016 (Wissensliteratur im Mittelalter 53), S. 307-336. Zum Liederbuch-Lied vgl. weiter (ohne Bezug auf die Musik, mit Überblick zur vorangehenden Forschung): Johannes Janota: Ich und sie, du und ich. Vom Minnelied zum Liebeslied. Berlin, New York 2009 (Wolfgang Stammler Gastprofessur für Germanische Philologie. Vorträge 18).

14 Repertorium der Sangsprüche und Meisterlieder des 12. bis 18. Jahrhunderts. Hg. von Horst Brunner und Burghart Wachinger. 16 Bde. Tübingen 1986-2009, im Weiteren zitiert als RSM mit Angabe der RSM-Nummer. 
Monographien, ${ }^{15}$ die Gesamtedition der Spruchsang-Melodien ${ }^{16}$ und ein Handbuch ${ }^{17}$ aufgearbeitet.

Zuletzt zeigt sich ein wieder intensiviertes Interesse an der musikalischen Seite der deutschsprachigen, mittelalterlich-frühneuzeitlichen Lyrik in interdisziplinär angelegten Sammelbänden, ${ }^{18}$ neuen Dissertationen ${ }^{19}$ und Aufsätzen. ${ }^{20}$ Weiterführend an den jüngsten Beiträgen ist, dass Gattungen und

15 Horst Brunner: Die alten Meister. Studien zur Überlieferung und Rezeption der mittelhochdeutschen Sangspruchdichter im Spätmittelalter und in der frühen Neuzeit. München 1975 (MTU 54); Frieder Schanze: Meisterliche Liedkunst zwischen Heinrich von Mügeln und Hans Sachs. 2 Bde. München 1983/84 (MTU 82f.); Rettelbach 1993 (Anm. 8).

16 Spruchsang. Die Melodien der Sangspruchdichter des 12. bis 15. Jahrhunderts. Hg. von Horst Brunner und Karl-Günther Hartmann. Kassel u. a. 2010 (Monumenta monodica medii aevi 6), im Weiteren zitiert als SpS.

17 Sangspruch/Spruchsang. Ein Handbuch. Hg. von Dorothea Klein, Horst Brunner und Jens Haustein. Berlin, Boston 2019.

18 Deutsche Liebeslyrik im 15. und 16. Jahrhundert. 18. Mediävistisches Kolloquium des Zentrums für Mittelalterstudien der Otto-Friedrich-Universität Bamberg. Hg. von Gert Hübner. Amsterdam, New York 2005 (Chloe. Beihefte zum Daphnis 37); Gattungen und Formen des europäischen Liedes vom 14. bis zum 16. Jahrhundert. Internationale Tagung vom 9. bis 12. Dezember 2001 in Münster. Hg. von Michael Zywietz, Volker Honemann u. a. Münster u. a. 2005 (Studien und Texte zum Mittelalter und zur frühen Neuzeit 8); „Ieglicher sang sein eigen ticht“. Germanistische und musikwissenschaftliche Beiträge zum deutschen Lied im Mittelalter. Hg. von Christoph März (†), Lorenz Welker, Nicola Zotz. Wiesbaden 2011 (Elementa musicae 4), S. 57-73; Das mittelalterliche Tanzlied (1100-1300). Lieder zum Tanz - Tanz im Lied. Hg. von Dorothea Klein. Würzburg 2012 (Würzburger Beiträge zur deutschen Philologie 37); „Teutsche Liedlein“ des 16. Jahrhunderts. Hg. von Achim Aurnhammer und Susanne Rode-Breymann. Wiesbaden 2018 (Wolfenbütteler Abhandlungen zur Renaissanceforschung 35).

19 Hope 2014 (Anm. 3), Marc Lewon: Transformational Practices in Fifteenth-Century German Music. Phil. Diss. University of Oxford 2017, S. 229-237, online unter: https:// ora.ox.ac.uk/objects/uuid:2a11c52f-52e5-4702-bab6-574d86f1f8bc (09.10.2020); David Murray: Poetry in Motion. Languages and Lyrics in the European Middle Ages. Turnhout 2019. Dass die drei Dissertationen aus dem englischsprachigen Raum stammen, kann nur wenig überraschen: Der Schwerpunkt der musikwissenschaftlichen Mittelalterforschung liegt seit mehreren Jahrzehnten im englischen Sprachraum, innerhalb dieses regen Forschungsfelds findet auch die Musik zur deutschsprachigen mittelalterlichen Lyrik Interesse.

20 So etwa vier Beiträge in einem der neueren Bände des Oswald-Jahrbuchs: Henry Hope: Zur Performanz von Frauenlobs Spruchmelodien: Der Versuch eines 
Autorkorpora nicht isoliert, sondern in ihren wechselseitigen Bezügen in den Blick genommen werden, und dass literaturwissenschaftliche und musikwissenschaftliche Forschung wechselseitig rezipiert werden. Der Zusammenführung von literatur- und musikwissenschaftlichen Fragen und Blickwinkeln wird zugearbeitet, indem der Formbegriff ins Zentrum gestellt wird ${ }^{21}$ oder durch Arbeiten, die das Verhältnis von Text und Musik in den Blick nehmen. ${ }^{22}$

Neuansatzes. In: Brunner/Löser 2017 (Anm. 5), S. 261-278; Franz Körndle und Freimut Löser: Gesänge vom Gesang. Meister der Jenaer Liederhandschrift über singer und sanc. Ebd., S. 213-230; Valerie Lukassen: Melodien des Spruchsangs: Musikalische Varianz als Charakteristikum. Eine Studie am Beispiel ausgewählter Lieder Oswalds von Wolkenstein. Ebd., S. 379-388; Lorenz Welker: Melodisch-rhythmische Differenzierungen im Vortrag von Spruch und Minnelied. In: Ebd., S. 401-414.

21 Kragl 2011 (Anm. 3), S. 45-55.

22 Mit verschiedenen methodischen Prämissen gehen dieser Frage nach: Hope 2017 (Anm. 20); Kandler 2005 (Anm. 4), der Musik zu lateinischen und deutschen Texten untersucht; Kragl 2009 (Anm. 3) und vor allem die instruktiven Arbeiten von Michael Shields: ,Ich mâle ûf des sanges simz / mit tichte als ich beste kann'. Zu den Melodie- und Textentsprechungen in Spruchdichtungen des 13. Jahrhunderts. In: Texttyp und Textproduktion in der deutschen Literatur des Mittelalters. Hg. von Elizabeth Andersen, Manfred Eikelmann und Anne Simon. Berlin, New York 2005, S. 249-266; Michael Shields: Spruchdichtung und Sirventes. In: Mertens/Touber 2012 (Anm. 3), S. 275-306; der zweite Beitrag von Shields legt zudem nahe, den Bereich romanisch-deutscher Einflussbeziehungen erneut zum Gegenstand von Forschungsbemühungen zu machen. Lukassen 2017 (Anm. 20) sieht Bedeutungspotential der Musik im Bereich von Gattungsstilen, vgl. zu diesem Ansatz auch März 1988 (Anm. 4), S. 126f. u. 133f.

Deutschsprachige musikwissenschaftliche Arbeiten zum Komplex Text und Musik nahmen ihren Ausgangspunkt beim lateinischen Lied, weswegen sie in der Germanistik zu wenig rezipiert wurden. Vgl. Wulf Arlt: Musik und Text. In: Die Musikforschung 37 (1984), S. 272-280, hier S. 276-280; ders.: Nova Cantica. Grundsätzliches und Spezielles zur Interpretation musikalischer Texte des Mittelalters. In: Basler Jahrbuch für historische Musikpraxis 10 (1986), S. 13-62; ders.: Das eine Lied und die vielen Lieder. Zur historischen Stellung der neuen Liedkunst des frühen 12. Jahrhunderts. In: Festschrift Rudolf Bockholdt zum 60. Geburtstag. Hg. von Norbert Dubowy und Sören Meyer-Eller. Pfaffenhofen 1990, S. 113-127; Gunnilla Björkvall und Andreas Haug: Altes Lied - Neues Lied. Thesen zur Transformation des lateinischen Liedes um 1100. In: Poesía latina medieval (Siglos V-XV). Actas del IV Congreso de „Internationales Mittellateinerkomitee“, Santiago de Compostela, 12-15 de septiembre de 2002. Hg. von Manuel C. Díaz y Díaz und José M. Díaz de Bustamante. Florenz 2005, S. 539-550; Haug 2004 (Anm. 7); vgl. weiter Leo Treitler: With Voice and Pen. Coming to Know Medieval Song and How it was Made. Oxford 2003. Einwände hat jüngst Lorenz Welker erhoben: Welker 2017 (Anm. 20) und 
Dieses intensivierte und über Fachgrenzen hinweg informierte Forschungsinteresse an der Musik der mittelalterlichen Liedkunst macht es wahrscheinlicher als zuvor, dass sich die Forschungstradition verstetigt, etabliert und einen gesicherten Wissensstand erarbeitet. ${ }^{23}$

Trotz dieser günstigen Lage muss man feststellen, dass die Musik der Kolmarer Liederhandschrift vom jüngsten Aufschwung noch nicht profitiert hat. Hier setzt sich eine zwiespältige Einschätzung von $\mathrm{k}$ fort, wie sie auch bei Lorenz Welker noch anklingt: $\mathrm{k}$ sei „nach der Jenaer Liederhandschrift, trotz ihrer späten Entstehung, die wichtigste Quelle für die Melodieüberlieferung zur deutschen Dichtung des Mittelalters". ${ }^{24}$ Wichtigkeit wurde und wird k einerseits zugesprochen, andererseits wird ihr Zweitrangigkeit aufgrund später Entstehung attestiert. Dass die Musik von k ein gewisses Schattendasein führte, hat aber dazu geführt, dass es eine zwar schmale, aber kontinuierliche Forschungstradition gibt, die ältere Arbeiten reflektiert und kritisch fortführt. Nach Ansätzen der älteren Forschung ${ }^{25}$ schufen Eva Schumann und

Lorenz Welker: „Ain anefangk“ oder: Vom Ende des Individuallieds. In: Beredte Musik. Konversationen zum 80. Geburtstag von Wulf Arlt. Hg. von Martin Kirnbauer. Basel 2019 (Schola Cantorum Basiliensis Scripta 8), S. 467-481. Welkers Einwände setzen auf verschiedenen Ebenen an, er kritisiert ein aus zugrundeliegenden älteren Arbeiten mitgeschlepptes, veraltetes Geschichtsbild, analysiert bei Oswald Überlieferungsbefunde und teilt knappe analytische Beobachtungen zu Melodien mit. Eine ausführliche Diskussion müsste die drei Punkte separat behandeln und die analytische Auseinandersetzung im Detail führen, bevor Welkers Einwände als entkräftet oder zutreffend eingeschätzt werden können.

23 Hilfreich wäre meines Erachtens eine einführende Darstellung in das Forschungsfeld ,Musik der deutschsprachigen Liedkunst ca. 1180 bis 1550'. Sie sollte jüngere Forschung kritisch sichten und aufeinander beziehen, den Gegenstand ausreichend breit kontextualisieren - also die romanische und lateinische Liedkunst nicht unzulässig ausblenden und differenziert auf den Bereich mittelalterlicher Musiktheorie und -lehre eingehen, ohne nur Basiswissen zu wiederholen -, dabei gleichzeitig auf den deutschsprachigen Bereich fokussiert und so angelegt sein, dass nach einführenden Kapiteln die übrigen einzeln in der akademischen germanistischen Lehre einsetzbar sind. Die Einführung müsste auch von Studierenden ohne Vorkenntnisse der mittelalterlichen Musikgeschichte - aber nicht ohne musikalische Vorkenntnisse - gelesen werden können.

24 Lorenz Welker: Kolmarer Liederhandschrift. In: Die Musik in Geschichte und Gegenwart. Allgemeine Enzyklopädie der Musik. 2. Aufl. Hg. von Ludwig Finscher. Sachteil Bd. 5. Kassel, Stuttgart 1996, Sp. 454.

25 Friedrich Eberth: Die Liedweisen der Kolmarer Handschrift und ihre Einordnung und Stellung in der Entwicklungsgeschichte der deutschen Liedweise im 
Horst Brunner in den siebziger Jahren wesentliche Grundlagen. Schumann verglich die Melodien von $\mathrm{k}$ mit der jüngeren Melodieüberlieferung, ${ }^{26}$ Brunner bettete die detaillierte vergleichende Analyse von älteren und jüngeren Melodien in die Geschichte von Sangspruchdichtung und Meistergesang ein. ${ }^{27}$ Die neueren Arbeiten Brunners ${ }^{28}$ und Rettelbachs ${ }^{29}$ zu den strophischen Formen haben die Entwicklung und die Geschichtlichkeit von Strophenformen und Melodien eindrücklich vor Augen gestellt. Hinzugekommen sind für k außerdem die überlieferungsgeschichtlichen Erkenntnisse Frieder Schanzes ${ }^{30}$, Gisela Kornrumpfs ${ }^{31}$ und Bernhard Schnells. ${ }^{32}$

14.-16. Jahrhundert. Detmold 1933; Rudolf Zitzmann: Die Melodien der Kolmarer Liederhandschrift. Würzburg 1944 (Literarhistorisch-musikwissenschaftliche Abhandlungen 9); Werner Bittinger: Studien zur musikalischen Textkritik. Würzburg 1953 (Literarhistorisch-musikwissenschaftliche Abhandlungen 11).

26 Eva Schumann: Stilwandel und Gestaltveränderung im Meistergesang. Göttingen 1972 (Göttinger musikwissenschaftliche Arbeiten 3).

27 Brunner 1975 (Anm. 15).

28 Brunner 2013 (Anm. 8).

29 Rettelbach 1993 (Anm. 8); Johannes Rettelbach: Die Bauformen der Töne in der Jenaer und in der, Kolmarer Liederhandschrift' im Vergleich. In: Die ,Jenaer Liederhandschrift'. Codex - Geschichte - Umfeld. Hg. von Jens Haustein und Franz Körndle, Berlin 2010, S. 81-98; Johannes Rettelbach: Minnelied und Sangspruch. Formale Differenzen und Interferenzen bei der Tonkonstitution im 13. Jahrhundert. In: Sangspruchdichtung: Gattungskonstitution und Gattungsinterferenzen im europäischen Kontext. Internationales Symposium Würzburg, 15.-18. Februar 2006. Hg. von Dorothea Klein zusammen mit Trude Ehlert und Elisabeth Schmid. Tübingen 2007, S. 153-168.

30 Schanze 1983/84 (Anm. 15), Bd. I, S. 35-86, Bd. II, S. 58-83. Schanze konnte für k aufbauen auf: Die kleineren Dichtungen Heinrichs von Mügeln. Hg. von Karl Stackmann. Erste Abteilung: Die Spruchsammlung des Göttinger Cod. Philos. 21. Teilbd. 1: Einleitung, Text der Bücher I-IV. Berlin 1959 (Deutsche Texte des Mittelalters 50). Bd. I, S. LXV-XCV, und Heinrich Husmann: Aufbau und Entstehung des cgm 4997. In: Deutsche Vierteljahrsschrift 34 (1960), S. 189-243, und setzte sich kritisch mit den Thesen Christoph Petzschs: Die Kolmarer Liederhandschrift. München 1978, auseinander. Zu verweisen ist auch auf zahlreiche Einzelstudien von Christoph Petzsch; sie sind bei Schanze und Rettelbach 1993 (Anm. 8) verzeichnet.

31 Gisela Kornrumpf: Die Kolmarer Liederhandschrift. Bemerkungen zu Plan, Provenienz und Funktion. In: dies.: Vom Codex Manesse zur Kolmarer Liederhandschrift. Aspekte der Überlieferung, Formtraditionen, Texte. Bd. I: Untersuchungen. Tübingen 2008 (MTU 133), S. 257-274 [zuerst 1990].

32 Bernhard Schnell: Medizin und Lieddichtung. Zur medizinischen Sammelhandschrift Salzburg M III 3 und zur Kolmarer Liederhandschrift. In: Archiv für das Studium der neueren Sprachen und Literaturen 230 (1993), S. 261-278. 
Die folgenden Überlegungen wollen zur jüngeren Diskussion um die Musik der mittelalterlichen Lyrik insgesamt beitragen, indem die Melodien von $\mathrm{k}$ wieder in das Forschungsgespräch eingebracht werden. Allerdings schließen sie in erster Linie an die Forschung zu $\mathrm{k}$ an. Daraus ergibt sich eine Fragestellung - und mit ihr eine analytische Vorgehensweise -, die sich nicht direkt mit den jüngsten Arbeiten zu Formbegriff, Gattungsstilen und dem Verhältnis von Text und Musik auseinandersetzen kann. Meine Ausführungen mögen daher wiederum etwas isoliert anmuten, sie können aber vielleicht zur Ausdifferenzierung des analytischen Umgangs mit ,mittelalterlicher Einstimmigkeit ${ }^{33}$ und so zu deren Verständnis insgesamt beitragen.

\section{Fragestellung, untersuchte Töne, Bemerkungen zur Methodik}

Aufgrund des langen Traditionszusammenhangs zwischen Sangspruchdichtung und Meistergesang lag und liegt es nahe, zuerst nach Entwicklungen $\mathrm{zu}$ fragen sowie ältere und jüngere Melodien zu vergleichen. Rettelbach hat in Fortführung der Arbeit Brunners die Töne von $\mathrm{k}$ und J verglichen und die formgeschichtlichen Positionen der Handschriften sowie die Hauptcharakteristika der Töne in $\mathrm{k}$ herausgearbeitet. ${ }^{34}$ Aus dem Interesse an der historischen Einordnung der Töne bei Brunner, Rettelbach und Schumann resultiert konsequenterweise, dass die Gemeinsamkeiten betont werden, die die Töne von $\mathrm{k}$ untereinander aufweisen und durch die sich ein für $\mathrm{k}$ charakteristischer musikalischer Stil bzw. eine für k typische Präferenz von Strophenformen zur Darstellung bringen lässt. In dieser Gesamtheit unterscheiden sich die Töne von $\mathrm{k}$ von den Töne-Gesamtheiten jüngerer und älterer Handschriften. Daraus ergibt sich, dass die Töne von $\mathrm{k}$ im historischen Vergleich als eine homogene Größe erscheinen.

Man kann die Töne in $\mathrm{k}$ aber auch in den Blick nehmen, ohne sie primär in historische Entwicklungslinien zu stellen. Die Handschrift selbst präsentiert sich in der Rubrik zum Register als eine Sammlung der Lieder der meinster ${ }^{35}$, nicht nur einiger oder ausgewählter Meister. Man darf den bestimmten Artikel

33 Zur Problematik der Kategorie Einstimmigkeit siehe Lewon 2011 (Anm. 1), S. 75.

34 Rettelbach 2010 (Anm. 29).

35 Hec est Tabula super carmina magistralia. Diß ist die tafel uber der meinster getiht gesanges, fol. 3r. Das Genitivattribut der meinster übersetzt das Adjektivattribut magistralia, die Fügung, Gedichte des Gesangs' (,Gesangsgedichte') steht für carmina. Da getiht in einigen Rubriken in k auf die sprachliche Seite verweist (fol. 184r, 
der deutschen Rubrik vielleicht als Hinweis verstehen, dass es um eine möglichst vollständige Sammlung der Texte und der Musik ging, die für die beiden Schreiber in die Meister-Tradition gehörten. Auch der Umfang zeigt, dass es ihnen um annähernde Vollständigkeit gegangen sein muss. Differenziert hat Schreiber A, der die Arbeit leitende Redaktor, die Lieder der Meisterkunst primär nach formalen Kriterien, wenn er die Lagen so umordnete, dass im Anfangsteil Leichs und andere besonders artifizielle Formen zusammengestellt wurden. Die zeitliche Schichtung der von den Schreibern gesammelten Lieder kann ihnen zwar nicht ganz unbewusst gewesen sein, denn sie wissen, dass in alten Tönen jüngere Texte stehen können, ${ }^{36}$ aber es gibt in der Handschrift keine Indizien für ein Bewusstsein, dass sich auch die Töne selbst in alte und neue gruppieren lassen. ${ }^{37}$ Diese Perspektive kann man sich probeweise zu eigen machen und die in $\mathrm{k}$ aufgezeichnete Musik als die der Meistertradition um 1450 und als eine Einheit betrachten.

Daneben ist aber auch offensichtlich, dass im Zuge des Sammelns auch Lieder und Liedtypen aufgenommen wurden, die nach heutigem Kenntnisstand nicht in die Sangspruchtradition gehören, sondern vermutlich aus anderen sozialen und literarischen Zusammenhängen stammen, wie der Neidhart zugeschriebene Fraß, die Lieder aus dem Mönch-Korpus, von Peter von Sachsen und Peter von Arberg. Die Arbeiten Schanzes, Kornrumpfs und Schnells haben zudem gezeigt, dass die beiden Schreiber aus vielfältigen Quellen geschöpft haben müssen und die Sammlung nach und nach anwuchs. Präsentiert sich die Handschrift also als Sammlung der Meister-Gedichte einerseits, so legen die nicht-meisterlichen Anlagerungen andererseits nahe, dass die Sammlung nicht so homogen ist, wie sie sich selbst darstellt. Aus der Konzentration auf die Töne von $\mathrm{k}$ in der Gestalt, in der sie in der Handschrift versammelt sind, einerseits und aus der Erwartung, dass sich die Sammlung vielgestaltiger erweisen könnte, als sie den Anschein erweckt,

490r) und bspw. mit dem Wort auch die Texte einem Autor zugewiesen werden, nicht nur der Ton (fol. 489r, 719r), dürfte die deutsche Formulierung betonen, dass es sich um carmina handelt, die aus Text und Musik bestehen. Vgl. zu den Rubriken Christoph Petzsch: Die Rubriken der Kolmarer Liederhandschrift. Mit besonderer Berücksichtigung von fol. 492r. In: Zeitschrift für deutsche Philologie 93 (1974), S. 88-116; zu gedicht in der Rubrik zum (Jungen) Meißner auf fol. 797r vgl. Shields 2012 (Anm. 22), S. 294-295.

36 So z. B. in der Rubrik zum Goldenen Ton Marners, fol. 490r.

37 Auf fol. 545v werden einmal Melodien als schwer oder leicht zu singen qualifiziert, die beiden Melodien zum Goldenen Ton des Kanzlers sind herlich hoch und swer bzw. senfter und sußer zu singen. Damit wird aber nichts über ihr Alter gesagt. 
andererseits, resultiert die Frage: Wie vielfältig bzw. wie einheitlich ist die Gestaltung der Töne - als Einheit von Musik-, Vers- und Reimstrukturen - innerhalb von k? Das Hauptaugenmerk liegt dabei auf der Musik. Dabei richtet sich das Interesse - hier folge ich dem Sammlungsimpetus der Redaktoren nicht - auf Töne, die nach bisherigem Kenntnisstand Teil der Sangspruchtradition sind.

Gegenstand der Untersuchung waren also nicht alle Töne in k. Ausgeschlossen blieben zum einen Töne von Autoren, die wahrscheinlich in andere Liedtraditionen zu stellen sind. Zum anderen wurden die artifiziellen Lieder oder Prunkformen, die in den Lagen 1-6 zusammengestellt wurden, nicht berücksichtigt..$^{38}$ Bei diesen besonderen Liedern, die der Redaktor als solche ansah und zusammenstellte, ist es möglich, dass sie auch formal und melodisch eine herausgehobene Gestaltung aufweisen. Sie sind daher separat zu untersuchen und wären in einem zweiten Schritt mit den Ergebnissen der übrigen Töne zu vergleichen. Durch die Nicht-Berücksichtigung der Prunkformen sind die meisten Leichs ausgesondert, so dass nur stollige Strophen untersucht wurden, was die Vergleichbarkeit erhöht. Da die Leichs der Lagen 1-6 nicht berücksichtigt wurden, wurde auch der in Lage 21 aufgezeichnete, in k Regenbogen zugeschriebene Kreuzleich ausgeschlossen. ${ }^{39}$ Eingeschlossen wurde dagegen der Frauenlob zugeschriebene Überzarte Ton, der noch in Lage 1 aufgezeichnet wurde, bevor das Frauenlob-Korpus durch den Anschluss der anderen Prunkformen an den Marienleich zerteilt wurde. ${ }^{40}$ Weiter ausgenommen bleiben Töne ohne oder mit nur unvollständiger Musikaufzeichnung. Untersucht wurden also die Töne ab Frauenlobs Langem Ton (Bl. 94r) ${ }^{41}$ bis zum Ende der Handschrift mit Ausnahme des Kreuzleichs (Bl. 291r-297v), dem Mönch (Bl. 644r-662r), Peter von Arberg (824r-830r) und der Töne ohne vollständige Musiknotation. ${ }^{42}$ Die Töne wurden in der Reihenfolge der Handschrift untersucht, wobei sie aber der schnelleren Lesbarkeit wegen zumeist nach SpS durchgesungen und -gehört

38 Siehe zu diesen artifiziellen Liedern den Beitrag von Horst Brunner in diesem Band.

39 Letzte Konsequenz wird freilich nicht erreicht, denn in der restlichen Handschrift stehen einige Stücke, die zumindest ihrem Tonnamen nach (Reihen, Prophetentanz) den Prunkformen der Lagen 1-6 an die Seite zu stellen wären.

40 Siehe Husmann 1960 (Anm. 30), S. 194f.; Brunner 1975 (Anm. 15), S. 157; Schanze 1983/84 (Anm. 15), Bd. 1, S. 42.

41 Die letzte Prunkform ist Zwingers Roter Ton, den k als hort qualifiziert, fol. 79r-83r, Lage 5 und 6. Der erste Ton danach ist Muskatbluts Alter Ton, fol. 84r, bei dem die Musik aber unvollständig eingetragen ist.

42 Ebenfalls auszuschließen waren der Neidhart zugeschriebene Fraß und der Barantton Peters von Sachsen (sowie sein lateinisches Gegenstück des Mönchs). Sie stehen 
wurden. ${ }^{43}$ Das Digitalisat von $\mathrm{k}$ wurde aber vergleichend und kontrollierend herangezogen, es war beim Singen, Hören und Analysieren stets mit im Blick.

Ein musikalischer Stil ist von verschiedenen Parametern abhängig, wie dem Gesamtambitus einer Melodie und dem Ambitus der einzelnen Melodiezeilen, dem Ausmaß von Melismatik und ihrer Verteilung in Strophe und Vers, der Kontur der Melodiezeilen, der Bevorzugung von Aufwärts- oder Abwärtsbewegung oder von engen oder weiten Intervallen, der Häufigkeit von Tonrepetition und dem Umgang mit der Modalität. ${ }^{44}$ Erst im charakteristischen Zusammenwirken mehrerer Eigenschaften entsteht ein wahrnehmbarer Melodiestil. Eine Zeile, in der z. B. fast nur ein Ton wiederholt wird, kann im Kontext einer sonst bewegten Melodik einen effektvollen Kontrast setzen, in einer Strophe, die auch sonst öfter Töne wiederholt, kann sie dagegen konturlos bleiben. Dabei muss natürlich nicht jeder mögliche Parameter eine Rolle spielen. Will man charakteristische Eigenschaften darstellen, muss man erkennen, was gestaltprägend ist und was auf welche Weise in Bezug zu einander gesetzt wird. Natürlich handelt es sich um einen hermeneutischen Prozess, der - wie jeder andere Verstehensprozess - nicht vollständig vom verstehenden Subjekt ablösbar ist. Er ist gleichwohl mitsamt seinen Voraussetzungen kommunizierbar, damit diskutier- und gegebenenfalls auch falsifizierbar. Allerdings ist dazu die genaue und ausführliche sprachliche Beschreibung der Melodiefaktur - für

aber bereits in den Lagen 1-6. Ausgenommen bleiben auch die Nachträge des 16. Jahrhunderts: Wickrams Freudenton, fol. 753r-v, und Hans Lusch im Langen Ton Meienscheins, fol. 822r-v.

43 Nicht in SpS (Anm. 16) ediert, aber hier berücksichtigt sind Liebe, Sanfter Ton, fol. 792 (= Konrad Nachtigall, Sanfter Ton), ediert in Schumann 1972 (Anm. 26), Notenteil, S. 11, und Frauenlob, Verhohlener Ton, fol. 155r (= Kettners Osterweise). Vgl. Brunner 1975 (Anm. 15), S. $79 f$.

44 Auf den Bereich der Modi (in der allgemeinen Musiklehre im deutschen Sprachraum ist oft von den Kirchentonarten die Rede) kann hier nicht eingegangen werden, weil er historisch verzweigt ist und mittelalterliche Praxis und Theorie einzubeziehen wären. Für die Musik in k genügt als Orientierung zumeist das Erkennen des HauptBezugstons (oder der Hauptbezugstöne, denn Modus-Bereiche/Klangfelder können wechseln), seiner Lage und des Ambitus, um ein analytisches Vorverständnis zu ermöglichen. Knappe Darstellungen der Modi finden sich viele, z. B. in Brunner 2013 (Anm. 8); sie genügen, um sich in mittelalterliche modale Musik einzusingen und einzuhören; ausführliche Darstellungen: Christopher Schmidt: Harmonia Modorum. Eine gregorianische Melodielehre. Winterthur 2004; Bernhard Meier: Alte Tonarten dargestellt an der Instrumentalmusik des 16. und 17. Jahrhunderts. 3. Aufl. Kassel 2000 . 
Kritik und Falsifikation auch deren Nachvollzug - nötig; das erfordert bisweilen einige Geduld.

Ein Verständnisprozess braucht einen Ansatzpunkt, von dem aus er sich mit dem Gegenstand befasst. Im Prinzip könnte jeder musikalische Parameter der Ausgangspunkt sein. ${ }^{45}$ Hier wird als Ansatzpunkt die Einheit der Strophe gewählt. Die Strophe war den Schreibern von k - wie allen Schreiberinnen und Schreibern, die eine Strophenmelodie für mehrere Texte nur einmal aufzeichnen - als Einheit bewusst. Die Schreiber von k wussten zudem darum, dass die von ihnen aufgezeichneten Strophen grundsätzlich ,stollig' (A A B) gebaut sind. Das zeigen die einmalige Notation der Stollenmelodie mit Unterlegung beider Stollentexte sowie die gelegentlich anzutreffenden Benennungen ander stoll, dritt stoll und steyg (für den Abgesang). Die Leitfrage nach der Einheitlichkeit und Vielfältigkeit der Töne in $\mathrm{k}$ lässt sich also dahingehend spezifizieren, dass gefragt wird, wie die Musik zur Etablierung und Strukturierung der Einheit Strophe beiträgt und wie vielfältig dieser melodische Strophenbau in den untersuchten Tönen ist. ${ }^{46}$

\section{Zwei Beispielanalysen}

Achtet man beim mehrfachen Lesen, Singen, Hören und Analysieren der Musik von k gezielt auf ihre Funktion für die Formstruktur bzw. den Gesamtaufbau der Strophe, dann treten deutlich zwei verschiedene Arten der Gestaltung hervor, die das Verhältnis der Strophenteile - Stollen und Abgesang, aber auch darunter liegende Abschnitte - zueinander bestimmen. Es lassen sich so zwei Typen modellieren, denen die Mehrzahl der untersuchten Töne zugeordnet werden kann. Die Töne der ersten Gruppe zeichnen sich im Verhältnis der Bestandteile der Strophe zueinander dadurch aus, dass sie aus Gliedern von gleicher oder annähernd gleicher Länge bestehen. Die Töne der zweiten Gruppe dagegen bevorzugen einen stärker variativen, ,asymmetrischen' Aufbau. Beides ist mit eigenen melodischen Eigenschaften verbunden und umgesetzt. Als Beispiel für Töne des ersten Typs dient Regenbogens Leidton.

45 Hope 2017 (Anm. 20) setzt beispielsweise mit der Ermittlung musikalischer Motive und ihres Zusammenhangs an und baut darauf seine Überlegungen zu Struktur und möglichem musikalischem Sinn auf. Lukassen 2017 (Anm. 20) setzt für Oswalds Lieder bei Notation und Rhythmus sowie Melismatik an.

46 Angesichts dieser Konzentration auf den Strophenbau habe ich auf die Schemata des Katalogs der Töne von Johannes Rettelbach, RSM (Anm. 29) Bd. 2 dankbar zurückgegriffen. 


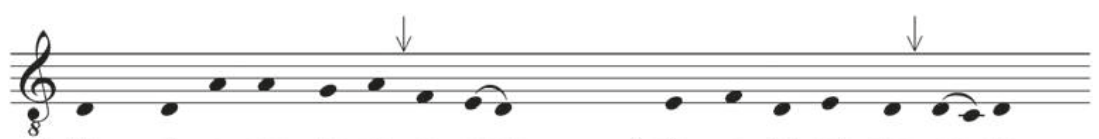

1. Ma - ri - a mu - ter rey-ne meyt

2. ein e-del got-tes am-me

9. Du namst? A-dam vs hel-le glut

10. fürt in in ta - ges glin-ster

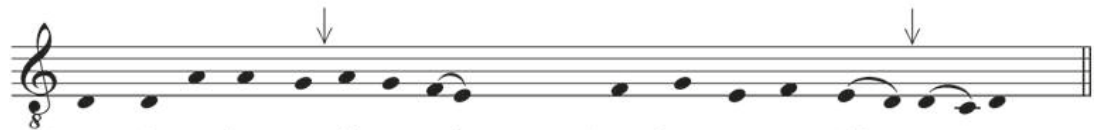

3. pro-phe-ten hant von dir ge-seit

4. ge - born von e- delm stam-me

11. du nert No-e vß wa-ges flut

12. hulff A-bra-ham $\mathrm{vB}$ _ vin - ster

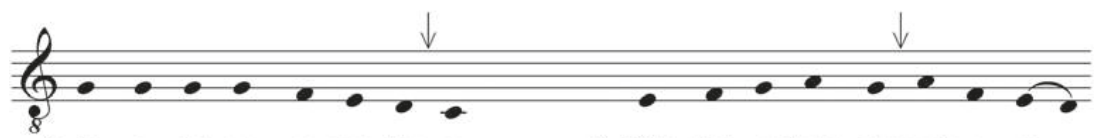

5. du e-del ro - se von Jes-se

6. Dich hat er-lucht das wort a - ve -

13. dry en-gel wor-den im ge-sant

14. Din ma-ge-tum tut vns be- kant_

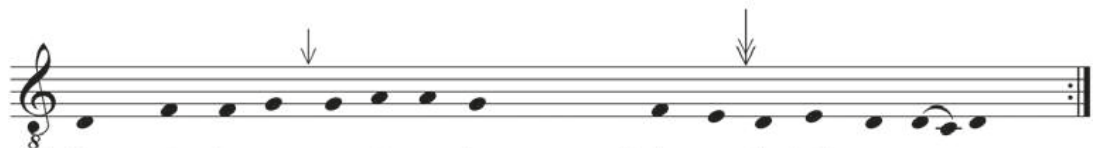

7. Du trüg den ers - ten stür-me fan

8. da wart die hell $\mathrm{zu}$ - sto-ret

15. Den busch der vor Mo-y-ses bran

16. da nie blat wart ver-se - ret

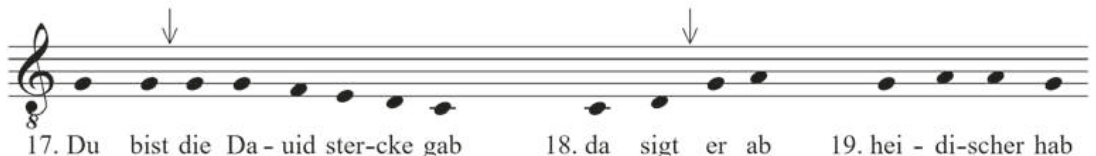

17. Du bist die $\mathrm{Da}$ - uid ster-cke gab 18. da sigt er ab 19. hei - di-scher hab

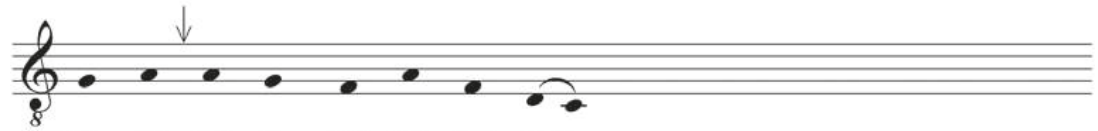

20. da er mit si - ner slin-gen stab_

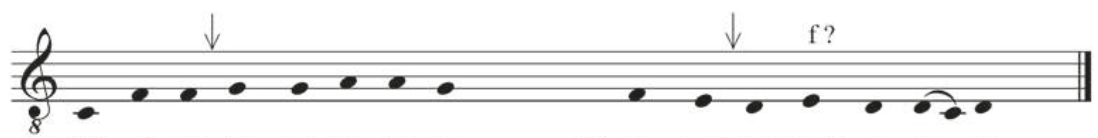

21. falt ei-nen rie - sen Go-ly-an 22. da wart der glaub ge-me-ret.

Notenbeispiel 1: In Regenbogen leyt don oder bluwend wys, $\mathrm{k} \mathrm{Bl} .442 \mathrm{r}$ 


\section{Anmerkungen zur Wiedergabe:}

Ein Pfeil über dem Notensystem zeigt Systemumbruch in der Hs. an, der Pfeil mit doppelter Spitze Spaltenwechsel. Eigennamen sind gegen die Hs. alle großgeschrieben.

- Vers 8: zustoret korrigiert aus zubrochen; -brochen rot durchgestrichen, -storet darüber im ersten Zwischenraum des Notensystems eingetragen.

- Vers 9: Die Lesart namst ist der Parallelüberlieferung RSM ${ }^{1}$ Regb/8/1c entnommen ( ${ }^{1}$ Regb/8/1c war mir nicht zugänglich). In k stand zuerst furt, das rot durchgestrichen wurde, darüber ist ein im Digitalisat kaum leserliches Wort nachgetragen. Vielleicht ist hulff zu lesen, allerdings wird hulff auch drei Verse später verwendet und der Grund für die Streichung von furt könnte sein, dass das Wort auch in Vers 10 fürt verwendet ist. Vorstellbar wäre auch hast, dann müsste man aber eines korrekten Satzes halber konjizieren zu Du hast Adam aus helle glut gfürt in tages glinster.

- Vers 15: das Wort vor steht bereits unter dem achten Notensystem, in dem ein Ton weniger als Silben steht, im vorigen siebten steht ein Ton zu viel. Alternativ könnte man daher Moyses zweisilbig mit Diphthong oy lesen, Hebungsprall zwischen busch und der ansetzen und ein überzähliges $g$ aus dem siebten Notensystem ausfallen lassen:

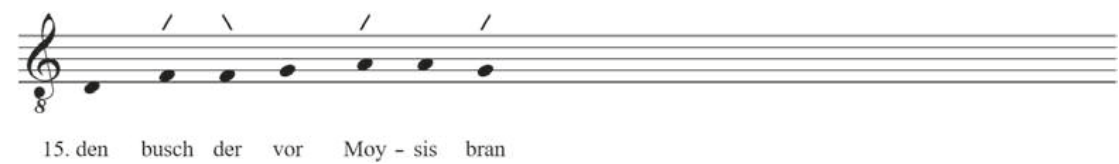

- Vers 16: da nie steht bereits im folgenden Notensystem der zweiten Spalte, der Raum in der zweiten Textzeile unter da wart ist freigeblieben. Eine sinnvolle alternative Melodielesart nur mit den Tönen, die in Vers 8 über die hell zustoret stehen ist aber nicht möglich.

- Vers 21: vor Golyan ein rot und schwarz durchgestrichenes her, darüber keine Note. Vielleicht ist Golyam zu lesen? Eine Reimbindung mit den Versen $7 /$ 15 dürfte nicht intendiert sein; Vers 21 ist in den übrigen Strophen des Lieds Waise, auch der RSM-Tönekatalog (RSM 2,1 [Anm. 14], S. 222) setzt Waise an.

$\mathrm{Zu}$ Beginn werden die beiden Hauptbezugstöne des Modus $d$ und $a$ markiert, die melodische Linie orientiert sich deutlich am Rahmen des Dorischen. Die initiale ansteigende Quinte erweist sich bereits im Zusammenhang mit dem unmittelbar folgenden gemächlicheren Abstieg in Sekunden und Terzen als ein großer Intervallschritt; sie bleibt auch im weiteren Verlauf das größte 
Intervall. ${ }^{47}$ Der zweite Vers greift die Abstiegsbewegung auf und bekräftigt die Finalis $d$. Vers 1 und 2 sind als zwei in sich klar abgeschlossene Verse zu erkennen, die gleichwohl aufeinander bezogen sind, weil der zweite den ersten weiterführt. Vers 3 beginnt mit einer wörtlichen Wiederholung von Vers 1, er endet aber melodisch offen auf $e$, so dass Vers 4 enger angebunden wird. Der Schlusseffekt auf $d$ wird dadurch gestärkt, mit Vers 4 ist eine erste melodische Entwicklung zu Ende, die sich in zwei Verspaare gliedert.

Mit Vers 5 beginnt eine neue Entwicklung. Nach dem stabilen Gerüst des D-Modus wird nun kontrastierend mit dem repetierten $g$ in den Gegenklangbereich gewechselt. ${ }^{48}$ Vers 6 bleibt zunächst mit dem Anfangston $e$ in diesem Bereich, die melodische Linie steigt dann aber bis zum $a$ an, von dem der Rückweg zu $d$ zügig eingeschlagen wird. Vers 7 bekräftigt wieder den Klangbereich des D-Modus, tönt aber mit $g$ als Versschluss den Gegenklangbereich noch einmal kurz an, bevor Vers 8 endgültig den D-Modus bekräftigt.

Ein Stollen des Leidtons gliedert sich damit melodisch in zwei Teile oder Abschnitte, die ihrerseits aus Zeilenpaaren bestehen. Die Abschnitte, Zeilenpaare und Zeilen haben zudem alle die gleiche Länge. Alle Verse 1-16 sind sprachmetrisch gleich lang, wenn man Vers 2, 4, 10 und 12 sowie 8 und 16 mit klingender Kadenz (ámmè, stámmè) singt; für die klingende Kadenz spricht die im Grunde gleichstufige Tonfolge $d$ - $d$, die nur um ein $c$ erweitert ist, das als ,Zierton' oder ,Nebennote' aufzufassen ist. Die Verse weisen dann alle vier Sangverstakte ${ }^{49}$ auf. Beim Vortrag werden die Sangverstakte hörbar; ein Sänger

47 Der Quinte, die mit auftaktigen Tonwiederholungen erweitert ist (sprachmetrisch ist der zweite der wiederholten Töne betont: $d$ - $^{\prime} d-a$-á), kann ein Gestus des Anrufens oder Ausrufens eignen, insbesondere im Kontext der sonst engschrittigen Melodik des Tons. Zumindest der erste Text des Tones in k (fol. 442r-443r; RSM ${ }^{1}$ Regb/8/1) geht mit dem Anruf-Gestus sinnvoll um. Er verbindet die Viertongruppe öfter mit Namen, Personenbezeichnungen - wie in Vers 3 propheten, Verkünder des Wortes Gottes - oder Formen des Pronomens der 2. Ps. Sg., die Maria anreden. Ich gebe alle Textstellen der fünf Strophen, gefettet sind die Wörter, die gut zum Anruf- bzw. Ausruf-Charakter der Musik passen: I: Maria, propheten, du namst Adam, du nert Noe; II: Mary ezech[ielis], Ysayas, Du bist daz licht, propheten; III: Maria, her Josephs rut, Du bist dazfel, got sich zu mensch; IV: Von diner wirde, ee dich nie, her daniel, von diner wird; V: Ein bürgerynn von Nazareth (= Maria), du bist, din barmung, din wirde.

48 Der Klangbereich im ersten Modus ist die Terzenkette über $d: d, f, a,\left(c^{\prime}\right)$, Töne, die strukturell für die Stabilität des Modus wichtig sind und die oft an melodisch wichtigen Stellen stehen. Der Gegenklangbereich ist die Terzenkette über $e: e, g, h / b$.

49 Den Begriff prägte Bertau 1964 (Anm. 8) in Auseinandersetzung mit dem Taktbegriff Andreas Heuslers. Wenn bisweilen doch verkürzend von, Takt' die Rede ist, kann das 
konnte den Versgang nur dezenter oder markanter realisieren, ihn aber wahrscheinlich nicht außer Kraft setzen. ${ }^{50}$ In der Melodie begegnen auch keine überlangen Melismen, die eine Dehnung oder Erweiterung eines Verses verlangen würden. Mit dem Vers werden die Zeitspannen, die die Sangverstakte ausfüllen, erfahrbar; sie werden in der Wahrnehmung - nicht mit der Stoppuhr gemessen - als gleich lang empfunden. So füllen auch die Verse und Abschnitte jeweils ihre eigenen Zeitspannen aus, die beim Aufgesang des Leidtons alle gleich lang sind.

Der Abgesang kontrastiert zu Beginn wenig, sondern knüpft melodisch an den Beginn des zweiten Stollenteils an, Vers 17 wiederholt die Musik der Verse 5/ 13. Die Musik der beiden anschließenden kurzen Verse 18 und 19 hat mit der der Verse 6/14 den Ziel- und Hochton $a$ gemeinsam. Der Anstieg über ein größeres Intervall, hier die Quarte, und die Wiederholung von $a$ erinnern an den melodischen Gestus des Strophenbeginns. Der folgende Vers 20 wiederholt am Beginn die Musik von Vers 19 und weist damit zugleich Bezüge zu den Versen 3/11 des ersten Stollenteils auf, indem $a$ repetiert und nochmals von unten erreicht wird. Vers 20 endet modal schwach auf $c$, was als Reminiszenz an die Verse 5/13 des zweiten Stollenteils hörbar ist. Der Abgesang zieht also den modalen und melodischen Kontrast zwischen den beiden Stollenteilen in einen Formteil zusammen,

zu Verwechslungen mit dem modernen, vom Sprach- und Versakzent unabhängigen musikalischen Akzentstufentakt führen. Das Verhältnis von musikalischem Takt und sprachgebundenem Sangverstakt ist - soweit ich sehe - weder historisch noch systematisch geklärt, vgl. aber die Ausführungen in März 1999 (Anm. 4) und März 1987 (Anm. 4) sowie Manfred Günter Scholz: Die Kadenz - eine metrische quantité négligeable? In: „Texte zum Sprechen bringen“. Philologie und Interpretation. Festschrift Paul Sappler. Hg. von Christiane Ackermann und Ulrich Barton. Tübingen 2009, S. 1-17, weiter die Überlegungen zu einem Referenzrhythmus in Lewon 2017 (Anm. 19), S. 26-30, 204-210 sowie Marc Lewon: Vom Tanz im Lied zum Tanzlied? Zur Frage nach dem musikalischen Rhythmus in den Liedern Neidharts. In: Das mittelalterliche Tanzlied (1100-1300). Lieder zum Tanz - Tanz im Lied. Hg. von Dorothea Klein. Würzburg 2012 (Würzburger Beiträge zur deutschen Philologie 37), S. 137-179. Eine metrische Beschreibung, die Hebungen zählt, wie in Brunner 2013 (Anm. 8) und im RSM-Tönekatalog, hat daneben natürlich gleichfalls ihren Zweck und ihre Berechtigung.

50 Es scheint mir fraglich, ob man sich auch einen Sänger vorstellen könnte, der Verse aus Unverständnis wie Prosa vorgetragen hätte. Dass Verse wie Prosa gelesen werden, könnte sich jüngeren Rezeptionsgewohnheiten und medialen Bedingungen verdanken. Liedtexte behalten auch heute noch viele Menschen nur oder besser im Gedächtnis, wenn sie mit einer - wenn auch ungenauen - Erinnerung an tonale und rhythmische Strukturen verbunden sind. 
bevor er zur Stollenschlussmelodie zurückkehrt. Melodisch genau wiederholt werden jeweils ganze Zeilen; ${ }^{51}$ Rückgriffe treten daneben in Gestalt von klanglichen oder melodisch-gestischen Reminiszenzen auf. Einzelne Melodieabschnitte oder Motive werden dagegen nicht wörtlich aufgegriffen und weiterentwickelt.

Während die Melodik des Abgesangs an den Aufgesang anschließt, bilden die Reime einen Kontrast: Von den Versen 5-6/13-14 her würde man mit einem Reimpaar in den ersten beiden Abgesangsversen rechnen, aber mit dem kurzen Vers 18 tritt der Reimklang spürbar früher ein, als vom bisherigen Verlauf der Verse zu erwarten war. Der Reimklang wird dann zudem insgesamt viermal wiederholt, auch dies ist klanglich neu. Der Reim sorgt so für eine gewisse Auflockerung. Der Abgesang als fünfter Formteil - da man den Aufgesang treffend mit dem Schema A B A B darstellen sollte - weicht auch vom strikten Gleichmaß der A- und B-Teile ab, weil er mit Vers 20 eine Zeile mehr aufweist, die nicht zum Paar ergänzt ist; dafür weist er Bezüge zu allen übrigen Strophenteilen auf.

Charakteristisch für Regenbogens Leidton und für den Typ von melodischem Strophenbau, für den er als Beispiel dient, ist die weitgehende Symmetrie der Formteile. Die Abschnitte der Strophe sind klar als solche erkennbar und sie sind bei allen Tönen dieses Typs annährend gleich groß, auch wenn das Gleichmaß etwas stärker aufgelockert sein kann. Klare Abschnitts- bzw. Blockbildung findet sich auch innerhalb der Stollen und des Abgesangs. Auch die Länge der Einzelverse variiert bei diesen Tönen wenig. Die Musik bildet zudem oft Zeilenpaare aus, die auf der Finalis enden, solche Zeilenpaare können zu umfangreicheren Gruppen kombiniert werden. Für den Zusammenhalt der Strophe sorgt zum einen die Wiederholung ganzer Zeilen. Zum anderen lässt sich der Einsatz von melodischen Mitteln und melodischer Variation als insgesamt eher sparsam bezeichnen. Im Ergebnis - oder als Auslöser - der melodischen Einheitlichkeit werden keine scharfen melodischen Kontraste innerhalb der Strophe gesetzt. Die meisten Lieder verzichten z. B. auf Lagenwechsel oder eine ausgeprägte modale Differenzierung der Strophenteile.

Symmetrie, sparsame Melodik und Einheitlichkeit sind für den melodischen Strophenbau der Töne des zweiten Typs, der sich in k ausmachen lässt, nicht prägend. Positiv formuliert ist die Melodik kontrastreicher und der Aufbau setzt auf die Variation der Länge verschiedener Bestandteile der Strophe. Als Beispiel dient Frauenlobs Leidton.

51 Das stimmt zur Tendenz der Verfestigung der Zeile in k, die Rettelbach 2010 (Anm. 29) herausgearbeitet hat, und setzt diese Töne von $k$ ab von der Variationskunst, die Brunner 1975 (Anm. 15) für die Töne der Jenaer Liederhandschrift dargestellt hat. 


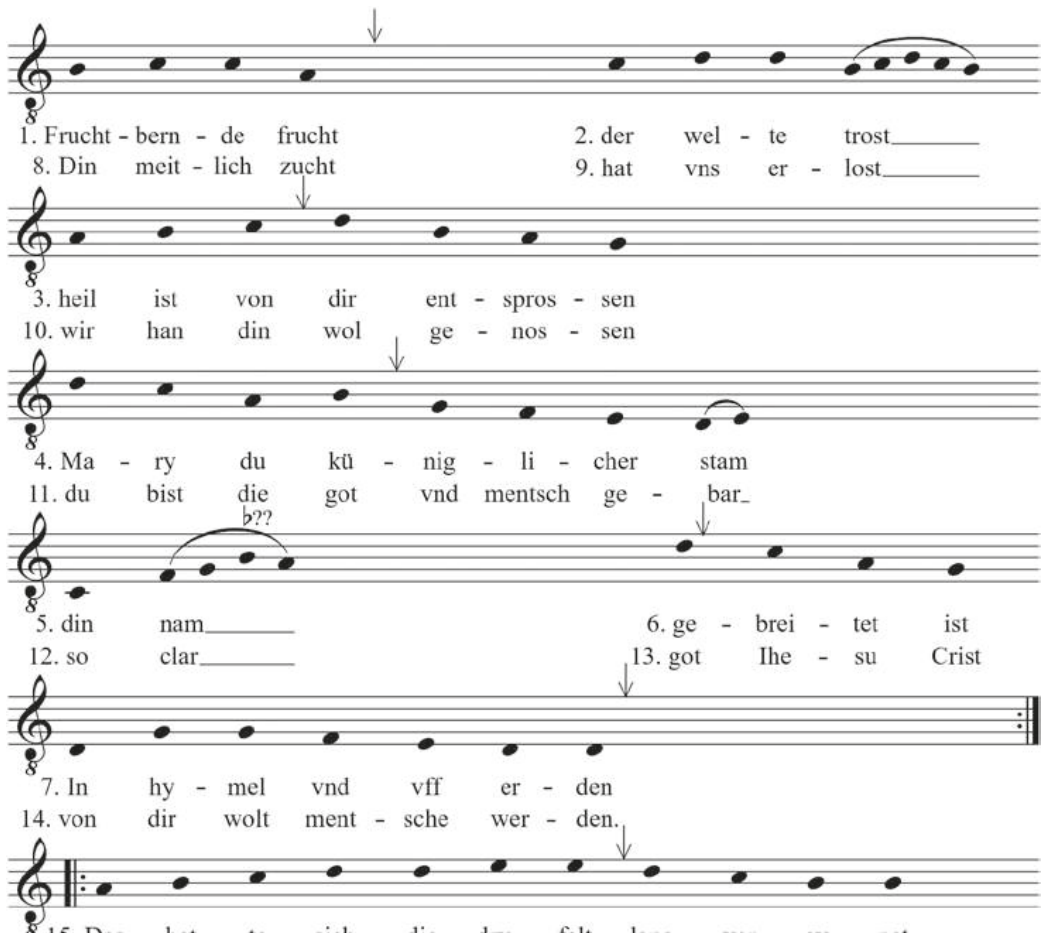

815. Des het - te sich die dry - falt lang ver - ey - net 17. da sloss sich der $\downarrow$ ge - walt $\bigotimes_{\text {tig }}$ got ver - clei - net

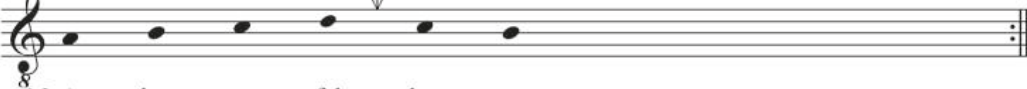

16. A - dam ge - fal - len was

18. yn din meit $\Psi$ li - ches fas

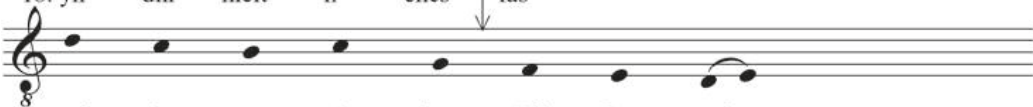

19. vmb daz er A - dams fall be - zalt
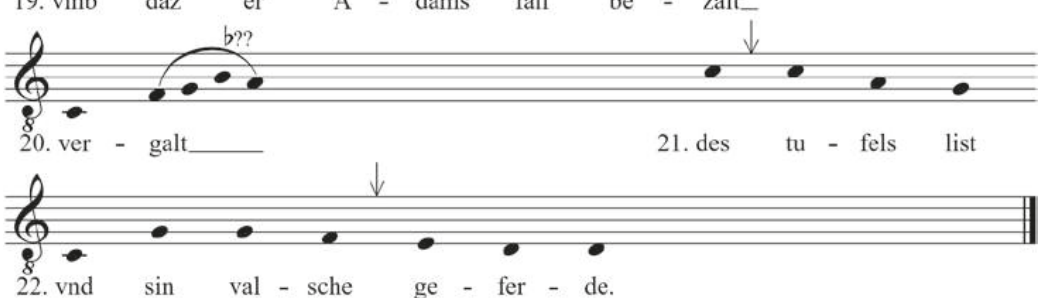

Notenbeispiel 2: In Frawenlobs leyt ton, k Bl. 188r. 


\section{Anmerkungen zur Wiedergabe:}

Zur Einrichtung der Transkription siehe oben Bsp. 1. Die Melodiewiederholung V. 17-18 ist in der Hs. ausnotiert, hier wird sie als Wiederholung mit zweifacher Textunterlegung wiedergegeben. Die Systemumbrüche der ausnotieren Wiederholung sind in der zweiten Textzeile markiert.

Im Vergleich mit Regenbogens Leidton fällt zunächst die stark variierende Verslänge in den Stollen auf. Die Strophe beginnt mit zwei kurzen Versen. Den zweiten Vers kann man als melodische Steigerung des ersten hören: Vers 1 setzt relativ hoch, im oberen Bereich des Gesamtambitus ein. Die melodische Geste besteht aus stufenweisem Anstieg und fallender kleiner Terz. Vers 1 schließt auf $a$, Vers 2 setzt auf dem oberen Ton $c$ der eben gehörten kleinen Terz an und wiederholt nun eine Stufe höher die melodische Geste: Der Anstieg ist nun ein Ganztonschritt, es folgt wiederum eine fallende kleine Terz. Vers 2 gibt der Schlusssilbe ein auffälliges - im Kontext der Strophe und von k großes Melisma. Trotz dieses Zusammenhangs sind die Verse 1 und 2 zwei selbstständige melodische Phrasen, die für sich stehen. Der weitere melodische Verlauf ist am Ende von Vers 2 noch ganz offen. Der längere Vers 3 steht ebenfalls eher für sich, er bietet eigenes melodisches Material, nimmt aber den Terzfall $d$ - $h$ auf. Die Selbstständigkeit der ersten drei Verse wird dadurch verstärkt, dass sie ihren Reimpartner erst bei der Stollenwiederholung finden.

Vers 4 bringt wiederum Neues. Die vorigen Verse begannen mit steigender Bewegung, Vers 4 beginnt fallend. Im Grunde führt der ganze Vers schrittweise abwärts, die Abwärtsbewegung wird nur einmal durch Terzfall und Sekundschritt nach oben gestaut (die drei stauenden' Töne $c$, $a$ und $h$ kann man noch aus Vers $1 \mathrm{im}$ Ohr haben). Erkennbar ist in den Versen 1-4 ein Gestaltungsprinzip, nach dem die Länge der melodischen Phrasen nach und nach zunimmt. ${ }^{52}$ Modal ist die Strophe bis Vers 4 offen. In Vers 1 und 2 könnte man einen auf $h$ transponierten E-Modus hören. Vers 3 schließt dann aber auf $g$. Ist das der Bezugston, und der Schlusston $h$ in Vers 2 war Teil des Klangbereichs über $g$ ? Vers 4 bestätigt die Vermutung nicht, sondern schließt auf $e$. Für sich

52 Ob Vers 3 mit klingender oder weiblich-voller Kadenz enden soll, lässt sich nicht festlegen und bleibt an die Realisierung im Sang gebunden. Erkennt man aber das Gestaltungsprinzip ,Phrasen werden länger' an, dann könnte die Realisierung mit (nur) drei Sangverstakten die bessere sein: Verse 1 und 2 haben zwei Sangverstakte, Vers 3 hätte drei, Vers 4 hat sicher vier. Im Vortrag kann man sich zwischen diesen drei Versen - anders als bei Regenbogens Leidton - durchaus längere Pausen vorstellen, zumindest bei der ersten Strophe. 
genommen sind die Phrasen alle stimmig, aber wie sie sich klanglich aufeinander beziehen, bleibt noch im Vagen.

Mit Vers 5, der eine neue, kurze markante Phrase bringt, ${ }^{53}$ beginnt eine neue Entwicklung. Das Prinzip ,die Verse werden länger' wird wiederholt, es erklingen in Vers 5-7 zwei kürzere, melodisch selbstständige Phrasen, gefolgt von einer längeren. Im melodischen Material gibt es kaum Anknüpfungen an die ersten vier Verse, immerhin tritt im Abstieg von Vers 6 wieder $c$ - $a$ auf und Vers 6 und 7 weisen wie Vers 4 fallende Kontur auf. Blickt man auf Melodie und Versstruktur, ergibt sich auch hier eine Zweiteilung der Stollen, aber im Vergleich mit den Zeilenpaaren von Regenbogens Leidton sind die Bestandteile der Abschnitte viel selbstständiger. Der Reim verbindet die Verse 4 und 5 und stellt so einen Zusammenhang über die Zweiteilung des Stollens hinweg her.

Modal bleibt man in Vers 5 zunächst weiter im Vagen, er schließt aber wie der erste Vers auf $a$. Vers 6 endet wie Vers 3 auf $g$. Vers 7 bringt dann einen recht eindeutigen und stabilen Schluss auf $d$. Soll man also die Verse 1-4 alle auf $d$ bezogen hören? Das scheint durchaus möglich: Im Nachhinein und vor allem im Mitvollzug bei der folgenden Wiederholung der Stollenmelodie kann man die Verse 4/ 11 als sicher auf $d$ bezogen verstehen. Denn ließe man dort die Töne $a$ und $h$ die Plätze tauschen, ergäbe sich eine absteigende Tonfolge von $d \mathrm{zu} d$, an die nur ein $e$ angehängt wird. In dem Fall würde man sicher stark dazu tendieren diesen Zeilenschluss mit $e$ als auf den Bezugston $d$ bezogen zu hören und ihn dementsprechend als einen schwachen Schluss zu empfinden. Der Anschluss an die Verse 5/12 wäre dann auch enger, womit die beiden Blöcke des Stollens stärker verbunden wären.

Die überlieferte Melodie meidet jedoch eine solche frühe Eindeutigkeit. Die Verse 1-3/8-10 muss man eher als einen Weg zum oder als ein schrittweises Finden des Modus verstehen. Die ganze Strophe auf den Hauptbezugston, den Klanganker $d$ bezogen zu hören (und die Verse des Stollens als zusammengehörigen Strophenteil wahrzunehmen), wird frühestens mit der Stollenwiederholung möglich gewesen sein; vielleicht klärten sich die modal-tonalen Bezüge für einige Hörer auch erst mit den Wiederholungen des Tons zu den Texten der folgenden Strophen. ${ }^{54}$

53 SpS (Anm. 16), S. 95f., schlagen vor, im Melisma der Verse 5, 12 und 20 ein $b$ zu singen. Angesichts der Rolle, die $h$ zuvor zukam, erscheint eine Ausführung mit $h$ nicht undenkbar, auch wenn sie zuerst ungewohnt klingen und sängerisch schwierig sein mag. Unabhängig von $h$ oder $b$ sticht die Phrase heraus und markiert Neueinsatz.

54 Das kann auch vom einzelnen Hörer abhängen, der vielleicht beim ersten Hören des Liedes stärker auf den Text achtete und der Musik wenig Aufmerksamkeit schenkte, so dass er den melodischen Prozess erst bewusst wahrnahm, wenn er den Text verstanden hatte. Natürlich ist die umgekehrte Rezeptionshaltung genauso plausibel. In jedem Fall ist mehrfaches Hören nötig, vgl. dazu Schubert 2017 (Anm. 5). 
Der folgende wiederholte Formteil ${ }^{55}$ greift zu Beginn mit dem Anstieg von $a$ zu $d^{\prime}$ auf den Anfang von Vers 3 zurück. Allerdings wird er zum $e^{\prime}$ weitergeführt und im ganzen Abschnitt der Verse 15-18 bewegt sich die Musik erstmals nur in Sekundschritten auf- und abwärts. Die unterschiedliche Länge der beiden Verse arbeitet aber dem Eindruck eines Zeilenpaars entgegen. Durch den Kreuzreim sind die Verse 15-18 als in sich abgeschlossener Block von vier Versen markiert. Der Block ließe sich einerseits mit einem modalen Zwischenzentrum auf $a$ hören, was in Melodien im D-Modus nicht ungewöhnlich wäre. Die Zeilenschlüsse auf $h$ halten aber die fragile Modalität des Stollenanfangs präsent. Der Schluss von Vers 16 auf $h$ kann als Rückführung zu $a$ in Vers 17 gehört werden. In Vers 18 muss das Ende auf $h$ als Reminiszenz an Vers 2 und den ersten Strophenteil verstanden werden, denn der folgende Vers 19 greift auf Vers 4 zurück, womit die Rückbewegung zu $d$ und die verkürzte Stollenwiederholung eingeleitet werden.

Im zweiten Stollen konnte man den Vers 11 als Hinweis darauf hören, dass $d$ als Bezugston anvisiert wird. Die leicht variierte Wiederholung der Verse 4/11 in Vers 19 schwächt aber diesen Bezug zu $d$ etwas, indem der Ton $a$ weggelassen wird. Dafür setzt sich Vers 19 deutlicher vom vorangehenden Klangfeld um $a$ ab. Mit dem kurzen Vers 20 und seinem Melisma beginnt dann wieder ein aus den Stollen bekannter Abschnitt, der endgültig zu $d$ führt.

Auch Frauenlobs Leidton erweist sich unterhalb der Ebenen von Stollen und Abgesang gegliedert, es gibt aber keine so klare Abschnittsbildung wie in Regenbogens Leidton. Die Abschnitte korrespondieren nicht so deutlich, sondern stehen stärker für sich. Neben dem Reim entsteht der Zusammenhalt der Strophe durch die fortschreitend-variierende Wiederaufnahme melodischer Phrasen und einen planvollen, aber nicht leicht oder beim ersten Hören erkennbaren Umgang mit der Modalität.

Wie Frauenlobs Leidton können auch die anderen Töne des Typs, für den er als Beispiel dient, unterhalb der Ebenen von Stollen und Abgesang gegliedert sein. Die Abschnitte sind aber unabhängiger als bei Tönen des ersten Typs, der durch Regenbogens Leidton repräsentiert wurde, und sie sind weniger deutlich als Struktur oder Bauteile aufeinander bezogen. Auch die Länge der Formteile unterscheidet sich deutlich. Selbstständigkeit und variierende Länge herrschen auch auf der Ebene des einzelnen Verses. Die Kontraste wirken in diesen Tönen auch deswegen ausgeprägter, weil - zumindest in einem Teil dieser Töne ${ }^{56}-$ das

55 In $\mathrm{k}$ ist die Wiederholung hier ausnotiert.

56 Es ist verführerisch, aber vorschnell, bei Tönen des Typs B, deren Melodik reduziert oder blass wirkt, zu vermuten, dass die Melodien aufgrund von 
verwendete melodische Material vielfältiger ist. Auf der anderen Seite wird der Zusammenhalt der Strophenmelodie durch - variierend fortschreitende - melodische Wiederaufnahmen und/oder durch die modale Disposition sichergestellt. Beides erfordert ein aufmerksames, auch klanglich erinnerndes Hören, das die Zusammenhänge nachvollziehen kann, die sich nach und nach entfalten.

\section{Ergebnisse}

Die beiden Beispielanalysen zeigen zunächst, dass eine genaue Analyse der Musik das Verständnis von Strophik und Form in der Sangspruch- und Meisterliedtradition weiter vertiefen und differenzieren kann. Sie zeigen eine beträchtliche Spannbreite von melodischen Gestaltungsmöglichkeiten für das auf, was man als stollige Strophenform benennt und was den Schreibern als Formprinzip bewusst gewesen sein muss. Auch die Töne von $k$ allein lohnen die intensive Beschäftigung, viele Melodien brauchen den Vergleich mit Melodien aus der Jenaer Liederhandschrift nicht zu scheuen.

Die beiden Beispiele, Regenbogens Leidton und Frauenlobs Leidton, stehen darüber hinaus für zwei Typen oder Modelle der musikalischen Gestaltung eines Tons, denen sich der Großteil der untersuchten Töne zuordnen lässt. In der Liste im Anhang (S. 131-133) sind alle untersuchten Töne einem der beiden Typen zugeordnet, für den ersten Typus habe ich noch Untergruppierungen vorgenommen. Diese Typisierung wird - sowohl was die Anzahl der Typen als auch die Zuordnung der Töne angeht - zu diskutieren sein, was auch für die vorgelegten Analysen gilt. Die vorgenommene versuchsweise Zuordnung zu Typen des melodischen Strophenbaus eröffnet aber einen neuen Zugang zur Frage nach der zeitlichen Schichtung der Töne in $k .{ }^{57}$ Die Arbeit an den Tönen von $\mathrm{k}$ ging von der Sammlung der Töne als einer Einheit aus. Sie klammerte Fragen nach der Entwicklung gezielt aus. In der Typisierung zeigt sich aber nun

Überlieferungsprozessen ihre - vielleicht nur scheinbar defizitäre - Gestalt erhalten haben. Dazu wären zuerst die von der Forschung erarbeiteten Veränderungsprozesse zu rekapitulieren, die sich mit Hilfe der neun vor und nach 1350 überlieferten Melodien rekonstruieren lassen. Dann wäre sorgsam abzuwägen, wo man die melodische Gestalt mit diesen Prozessen erklären kann und wo nicht. Ob man damit das „tragende Glatteis“ verlässt (März 1999 [Anm. 4], S. 7), müsste sich erst noch zeigen.

57 Die zeitliche Schichtung der Texte arbeitet mithilfe des Barvergleichs Michael Baldzuhn heraus: Michael Baldzuhn: Vom Sangspruch zum Meisterlied. Untersuchungen zu einem literarischen Traditionszusammenhang auf der Grundlage der Kolmarer Liederhandschrift. Tübingen 2002 (MTU 120). 
eine Korrelation mit dem Alter der Töne: Dem ersten Typ konnte nur ein alter Ton (Konrads Aspis) zugeordnet werden. Ansonsten stehen unter A. unechte Töne und Töne von Autoren, die nach der Mitte des 14. Jahrhunderts produktiv waren. Unter B. finden sich dagegen alle anderen altüberlieferten Töne, unechte Töne sowie nur ein sicher junger Ton von Albrecht Lesch. Das ist bei insgesamt 73 ausgewerteten Tönen ein ungewöhnlich eindeutiges Ergebnis. Es könnte darauf hinweisen, dass es sich um einen älteren und einen jüngeren Typ des melodischen Strophenbaus handelt. Die Fälle Konrads Aspiston und Leschs Hofweise mahnen jedoch zur Zurückhaltung, denn bei der Annahme, dass es sich um zwei historisch zu unterscheidende Typen handelt, wären für diese beiden Fälle Sondererklärungen nötig. ${ }^{58}$ Dennoch kann man die Annahme eines älteren und eines jüngeren Typs zumindest als begründete Arbeitshypothese formulieren.

Vor allem für die unechten Töne böte eine solche Arbeitshypothese zumindest eine Möglichkeit, ihr relatives Alter grob einzuschätzen und die vom melodischen Strophenbau her gewonnene Einschätzung mit den bisherigen Resultaten der Formgeschichte und der überlieferungsgeschichtlichen Studien zu vergleichen. Fragt man - vorsichtig spekulierend - weiter, ab wann der vermutlich jüngere Typ als gängig anzusehen wäre, dann könnte man zumindest darauf hinweisen, dass sich Töne Heinrichs von Mügeln in beiden Gruppen finden. Er könnte also beide Typen gekannt und produktiv umgesetzt haben oder an der Entwicklung des jüngeren Typs mitgewirkt haben.

Für die unechten Töne, die dem Typ B. zugeordnet wurden, wäre eine weitere Differenzierung nach Untertypen hilfreich, sofern dies melodieanalytisch objektivierbar und kommunizierbar ist. ${ }^{59}$ Einen solchen möglichen Untertyp könnte man vielleicht in Frauenlobs Überzartem Ton $(B 1.28 v-29 v)^{60}$ und dem Geschwinden Ton Rumslands bzw. Wolframs (Bl. 776, später Frauenlob zugeschrieben) ${ }^{61}$ erkennen, die untereinander stärkere Ähnlichkeiten im melodischen Strophenbau

58 Im Fall von Konrads Aspis könnte man die Schuld dem Überlieferungsprozess in die Schuhe schieben, der die Melodie stark verändert und modernisiert hätte. Im Fall Lesch ist eine ad-hoc-Erklärung schwieriger zu extemporieren.

59 Vielleicht bieten die in einigen Tönen eingetragenen Kaudierungen - deren Interpretation als Mensuralismen oder Referenzrhythmus im Rahmen des Codex aber noch offen ist - einen Ansatzpunkt dafür. Ich habe in der Liste im Anhang daher Töne, in deren Notation Kauden begegnen, markiert. Dass ich keine Kauda übersehen habe, kann ich leider nicht garantieren; ferner wären die Töne in den Lagen 1-6 mit zu berücksichtigen.

60 SpS (Anm. 16), S. 104-114.

61 SpS (Anm. 16), S. 81-84, zur späteren Zuschreibung an Frauenlob vgl. Brunner (Anm. 15), S. 107-109. 
aufweisen. Da Rettelbach die Datierung eines Texts im Überzarten Ton auf 1322 gelang, ${ }^{62}$ könnte man vielleicht auch den Geschwinden Ton ins zweite Jahrzehnt des 14. Jahrhunderts setzen und den beiden Tönen weitere ähnliche an die Seite stellen. Dabei müssten stets Argumente mit einbezogen und geprüft werden, die sich aus der Überlieferung und der Textfaktur ergeben und die für bzw. gegen eine Ansetzung z. B. in das zweite Viertel des 14. Jahrhunderts sprechen können.

\section{Abschließende Bemerkungen}

Diese Überlegungen zur zeitlichen Schichtung sind vor allem als Arbeitshypothesen zu verstehen. Die Analyse der Musik liefert für die Bildung dieser Hypothesen nur Indizien. Indes ist man bei der Frage nach der zeitlichen Schichtung des in den frühen Meisterliederhandschriften überlieferten Guts und der Geschichte der Sangspruchdichtung zwischen der Jenaer und der Kolmarer Liederhandschrift ohnehin in weiten Teilen auf Indizien angewiesen, so dass die sorgfältige und geduldige Analyse der Musik als ein Lieferant von weiteren Indizien nicht unwillkommen sein kann, um das Netz von Indizien etwas engmaschiger zu knüpfen. Die Beschäftigung mit der Musik kann also auch für so bodenständige Fragen wie die nach dem Alter eines Tons durchaus lohnenswert sein.

Gerne zugegeben sei, dass dazu vielleicht ein größeres, differenzierteres melodieanalytisches Instrumentarium als das hier vorgestellte nötig sein könnte. Deswegen sollen die vorgelegten Analysen und die Typisierung in erster Linie als Impuls zur Auseinandersetzung über das Forschungsfeld der Musik der mittelalterlichen deutschsprachigen Liedkunst und zu dessen Weiterentwicklung verstanden werden. Wenn es gelingt, den analytischen Umgang mit der überlieferten Musik zu verfeinern und sie immer besser zu verstehen, wäre das für alle beteiligten Disziplinen und Forscher_innen ein Gewinn.

62 Rettelbach 1993 (Anm. 8), S. 27. 


\section{ANHANG: Zuordnung der untersuchten Töne von $k$ zu Typen des melodischen Strophenbaus}

Autorzuschreibung und Tonnamen wie in k, in Klammern andere Zuschreibungen und Tonnamen,

* = Melodien, in denen stellenweise kaudierte Noten (Mensuralismen? Referenzrhythmus?) auftreten,

${ }^{a}=$ altüberlieferte bzw. als echt geltende Töne,

$\mathrm{aM}=$ auch Melodie vor 1350 überliefert.

A. Strophen mit Strophenteilen von nahezu gleichem Umfang (vgl. oben S. 119-123)

\section{A.1 Starke, Symmetrie der Strophenteile}

- Frauenlob, Froschweise

- Frauenlob, Ritterweise

- Heinrich von Mügeln, Kurzer Ton

- Kanzler, Süßer Ton

- Konrad von Würzburg, Aspiston ${ }^{\mathrm{a}}$

- Konrad von Würzburg, Blauer Ton

- Konrad von Würzburg, Kurzer oder Werter Ton (Frauenlob, Hagenblühweise)

- Konrad von Würzburg, Morgenweise

- Konrad von Würzburg, Nachtweise/Friedrich von Sonnenburg, Süßer Ton

- Liebe von Gingen, Jahrweise (Radweise)

- Meffrid, Gedicht(weise)

- Regenbogen, Goldener Ton

- Regenbogen, Leidton oder Blühende Weise

- Tannhäuser, Hauptton oder Goldener Ton

- Ungelehrter, Ton (Schwarzer Ton)

\section{A.2 ,Symmetrie` durch Einschübe oder einzelne Verse abweichender Länge} aufgelockert

- Ehrenbote, Schallweise (Frauenlob, Kupferton)

- Frauenlob, Gekrönter Ton

- Frauenlob, Verhohlener Ton (Fritz Kettner, Osterweise)

- Lesch, Sangweise

- Lesch, Zirkelweise

- Liebe, Sanfter Ton (Konrad Nachtigall)

- Magister sc. scriptor huius libri, Unerkannter Ton (Nestler von Speyer)* 
- Mülich von Prag, Langer Ton

- Regenbogen, Tagweise

- Regenbogen, Torenweise

- Suchensinn, Ton

A.3 ,Symmetrische Strophenteile', Strophen zudem besonders umfangreich durch Reihung vieler melodischer Blöcke

- Lesch, Tagweise*

- Heinrich von Mügeln, Traumton

- Marner, Prophetentanz

Zuordnung zu A. fraglich:

- Regenbogen, Grundweise

- Tugendhafter Schreiber, Grußweise (Winsbecke) ${ }^{\mathrm{a}}$

- Harder, Hofweise

B. Strophen mit selbstständigen Formteilen variierender Länge, oft auch variierende Verslängen (vgl. oben S. 123-128)

- Anker, Ton/Frauenlob, Grundweise

- Boppe, Hofton ${ }^{\mathrm{aM}}$

- Ehrenbote, Spiegelweise (-ton)

- Frauenlob, Vergessener Ton ${ }^{\mathrm{a}}$

- Frauenlob, Ankelweise

- Frauenlob, Goldener Ton ${ }^{\mathrm{a}}$

- Frauenlob, Grüner Ton ${ }^{\mathrm{a}}$

- Frauenlob, Hundweise (Kelin, Ton III) ${ }^{\mathrm{am}}$

- Frauenlob, Langer Ton ${ }^{\mathrm{a}}$

- Frauenlob, Leidton

- Frauenlob, Neuer Ton ${ }^{\mathrm{a}}$

- Frauenlob, Spiegelweise (Konrad von Würzburg, Ton XVIII) ${ }^{\mathrm{a}}$

- Frauenlob, Süßer Ton

- Frauenlob, Tannton

- Frauenlob, Überzarter Ton*

- Frauenlob, Würgendrüssel ${ }^{\mathrm{aM}}$

- Frauenlob, Zarter Ton ${ }^{\mathrm{am}}$

- Frauenlob, Zugweise

- Heinrich von Mügeln, Grüner Ton

- Heinrich von Mügeln, Langer Ton 
- Heinrich von Ofterdingen, Gekaufter oder Fürstenton (Wartburgkrieg Ton I $)^{\mathrm{aM}}$

- Junger Meißner, Gedicht (Ton I) ${ }^{\mathrm{a}}$

- Junger Stolle (Junger Spervogel), Gedicht (Ton I) ${ }^{\mathrm{a}}$

- Kanzler, Hohe Goldene Weise (Mel. a) und Goldener Ton (Mel. b) ${ }^{\mathrm{a}}$

- Kanzler, Langer Ton*

- Klingsor, Schwarzer Ton (Wartburgkrieg, Ton II) ${ }^{\mathrm{aM}}$

- Konrad von Würzburg, Hofton ${ }^{\mathrm{am}}$

- Lesch, Hofweise

- Marner, Goldener Ton ${ }^{\mathrm{a}}$

- Marner, Kurzer oder Hofton ${ }^{\mathrm{aM}}$

- Marner, Langer Ton ${ }^{\mathrm{a}}$

- Regenbogen, Briefweise ${ }^{\mathrm{a}}$

- Regenbogen, Grauer Ton ${ }^{a}$

- Regenbogen, Langer Ton ${ }^{\mathrm{a}}$

- Reinmar von Brennenberg, (Ton IV) ${ }^{\mathrm{aM}}$

- Reinmar von Zweter, Frau-Ehren-Ton ${ }^{\mathrm{a}}$

- Rumsland/Wolfram, Geschwinder Ton (Frauenlob, Geschwinder Ton)*

- Stolle, Alment ${ }^{\mathrm{am}}$

- Walther, Goldene Weise (Wolfram, Vergoldete Weise)

- Walther, Hof oder Wendelweise (Ton III) ${ }^{\mathrm{a}}$

- Wolfram, Goldener Ton 



\title{
Michael Baldzuhn
}

\section{nachsenger und Fremdtext-Verwertung Barauffüllung und Wiederverwendung alter Sangspruchstrophen im neuen Meisterlied}

\begin{abstract}
The article deals with those songs in the Colmar Liederhandschrift that include older stanzas from the Sangspruch tradition. While previous research considered such combinations as the results of 'compiling' or 'filling up' to reach the odd number of stanzas customary with the Meistersänger, the contribution attempts to analyse these songs on the background of the production process, within a phase of transitional stanzacombinations. Based on the content of the different stanzas, it proposes four basic types of combination that may indicate the intentions of the "Nachsänger".
\end{abstract}

Die Kolmarer Liederhandschrift ist Hauptzeuge für eine Überlieferungskonstellation, in der alte Sangspruchstrophen und neue Meisterlieder auf eine Weise verklammert erscheinen, die sich die Forschung bis in jüngste Zeit hinein nach einem eingespielten Muster erklärt. Wo echte Spruchstrophen eines noch mhd. Tonerfinders von unechten begleitet und zum neuen, mehrstrophigen Meisterlied zusammengeführt erscheinen, rechnet man regelmäßig mit nachträglicher Zudichtung. Mit den Worten Brunners im Handbuch „Sangspruch/Spruchsang“ von 2019: „Alte Sangspruchstrophen, die man weiter überlieferte, wurden regelmäßig durch Zudichtungen in Bare mit ungerader Strophenzahl eingebunden

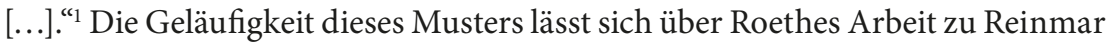
von Zweter, de Boors „Texte und Zeugnisse“, Schanzes Dissertation zur „Meisterlichen Liedkunst" und Hausteins Habilitationsschrift zum Marner hinweg bis zu einzelnen Artikeln im „Repertorium der Sangsprüche und Meisterlieder“ und Rettelbachs Beitrag im besagten Handbuch „Sangspruch/Spruchsang“ zur Rezeption der Sangspruchdichtung im Meistergesang verfolgen. ${ }^{2}$

1 Horst Brunner: Einzelstrophe - Mehrstrophigkeit - Barbildung - Anordnung in den Quellen. In: Sangspruch/Spruchsang. Ein Handbuch. Hg. von Dorothea Klein, Jens Haustein und Horst Brunner. Berlin, Boston 2019, S. 317-328, hier S. 325 (unter Verweis auf einen Beitrag Brunners bereits von 1983).

2 „Die Corruption in Wort und Sinn, die die erste, also wol auch die zweite und dritte Strophe in F erlitten haben, macht eine Entscheidung über die Echtheit dieser 
Das Erklärungsmuster wird zwar oft, aber keineswegs unbefangen als Variable zur Erklärung für entsprechende Überlieferungskonstellationen in Anschlag gebracht. Bereits Roethe ${ }^{3}$ wusste um seine Koppelung an die Echtheitsfrage.

Strophen aus formellen und stilistischen Gründen unmöglich: sie sind angeschlossen, um die meistersingerische Dreizahl zu gewinnen, und mögen echt sein.“: Die Gedichte Reinmars von Zweter. Herausgegeben von Gustav Roethe. Leipzig 1887, S. 153 (zu ${ }^{1}$ ReiZw/1/512a). - Mittelalter. Texte und Zeugnisse. Hg. von Helmut de Boor. Bd. 1. München 1965 (Die deutsche Literatur vom Mittelalter bis zum 20. Jahrhundert. Texte und Zeugnisse 1), dort etwa S. 552f. - „Die ersten beiden Strophen halte ich für jüngere Zudichtungen [...]": Frieder Schanze: Meisterliche Liedkunst zwischen Heinrich von Mügeln und Hans Sachs. München, Zürich 1982-83 (MTU 83-84), Bd. 1, S. 83 (zu ${ }^{1}$ Regb/1/532a). - „Will man auf der Unechtheit der Strophe bestehen, dann wird man doch zugeben müssen, daß sie äußerst geschickt, ja kunstvoll im Blick auf das übrige Strophengefüge konzipiert ist und keineswegs eine Verlegenheitslösung, etwa um die Erweiterung zum Fünferbar zu erreichen, darstellt.“: Jens Haustein: Marner-Studien. Tübingen 1995 (MTU 109), S. 56. - „Die von BARTSCH und STRAUCH aufgrund der Überschrift behauptete Echtheit der Strophe ist unbewiesen und eher unwahrscheinlich; die Strophe dient der Vervollständigung zum Fünferbar [...]": so im Artikel zu ${ }^{1}$ Marn/1/500a im RSM: Repertorium der Sangsprüche und Meisterlieder des 12. bis 18. Jahrhunderts. Hg. von Horst Brunner und Burghart Wachinger. Tübingen 1986-2009, Bd. 4, S. 265. - „Zu diesem Zweck wurden mehrere Strophen desselben Tons meist nach inhaltlichen Kriterien zu Baren zusammengestellt, oder es wurden einzelne alte Strophen durch neu hinzugedichtete ergänzt. [...] Das Zusammenstellen und Zudichten ist eine Kunst, in der man die hohe Verehrung der Alten zeigen konnte, zugleich in der Zudichtung den eigenen Kunstverstand.“: Johannes Rettelbach: Die Rezeption der Sangspruchdichtung im Meistergesang. In: Sangspruch/Spruchsang. Ein Handbuch. Hg. von Dorothea Klein, Jens Haustein und Horst Brunner. Berlin, Boston 2019, S. 501-508, hier S. 504.

3 Siehe oben Anm. 2. Das Erklärungsmuster hatte Roethe bereits ein Vierteljahrhundert zuvor sehr wahrscheinlich Bartschs Ausgabe von k geliefert: Meisterlieder der Kolmarer Handschrift. Hg. von Karl Bartsch. Stuttgart 1862 (StLV 68), S. 154: „Nicht unwahrscheinlich ist es, wenn man diesen zug der spätern meisterdichtung festhält, daß viele einzelne sprüche älterer meister, namentlich Frauenlobs, durch hinzudichtung von zwei andern zu einem liede vervollständigt wurden." Zwanzig Jahre vor Bartsch ist dies Ettmüllers Frauenlob-Ausgabe noch unbekannt: Heinrichs von Meissen des Frauenlobes Leiche, Sprüche, Streitgedichte und Lieder. Erläutert und herausgegeben von Ludwig Ettmüller. Quedlinburg, Leipzig 1843 (Bibliothek der gesammten deutschen National-Literatur von der ältesten bis auf die neuere Zeit 16). Man wird also Karl Bartsch als Inaugurator ansprechen müssen. Er bringt es freilich nur en passant ins Spiel. 
Denn sobald für das, was unecht erscheint, Echtheit erwogen wird, verschiebt sich die Frage. Dann mag das nun durchweg vom Tonerfinder stammende Material einfach thematisch passend zusammengestellt worden sein, und man benötigt keinen anonymen nachsenger mehr, sondern kann erwägen, ob die Zusammenstellung bereits konzeptionell auf den Verfasser zurückgeht oder nur mit einem sachkundigen späteren Strophenarrangeur zu rechnen ist. Das sieht auch Rettelbach ${ }^{4}$, der einerseits Zusammenstellen - wobei beim Zusammenstellen der Zudichter verschwindet - und Zudichten unterscheidet. Andererseits sieht er aber in beidem, eben auch im Zusammenstellen - hier lässt er nun den Tonautor $=$ Textautor als denkbaren Initiator außen vor - einen zentralen Ausdruck der Verehrung der Tradition der alten meister durch ihre meisterlichen Nachfolger. Damit ist zugleich eine erste Antwort auf die Frage nach der Funktion entsprechender Strophenkonglomerate gegeben - unabhängig von Fragen der Echtheit oder Unechtheit, unabhängig auch von Fragen ästhetischer Qualität. Was diese wiederum anbelangt, sind Differenzierungen unreflektiert-abschätziger Erwartungen schon länger in Umlauf - wie etwa bei Haustein $^{5}$ zu sehen, der einerseits den von ihm in den Blick genommenen Fall, auch wenn er eine Zudichtung darstelle, dennoch als „äußerst geschickt, ja kunstvoll" reklamiert, ihn also nicht per se, nur weil unecht, als minderwertig abtut. Andererseits rechnet er gleichwohl noch mit mechanischen Auffüllungen, mit „Verlegenheitslösung[en]“, um den Umfang des mehrstrophigen Liedes auch bei nur unvollständig vorliegenden Altstrophen zu erreichen.

Methodologisch kaum reflektiert wird hingegen, dass das Überlieferungsphänomen des Strophenkonglomerats ,echt+unecht' im Meisterlied - oder im folgenden neutraler: Strophen des Tonerfinders plus Strophen eines Fremdtonverwenders im Meisterlied - wesentlich an den Vorgang der Durchsetzung des mehrstrophigen Meisterliedes gegenüber der älteren, prinzipiell selbstständigen Einzelstrophe gebunden ist. Dass es in den Handschriften um oder kurz nach 1500 kaum mehr anzutreffen ist, liegt wohl daran, dass diese Material aus der entsprechenden Phase der Gattungsgeschichte kaum mehr versammeln. ${ }^{6}$ Auf der anderen Seite ist die Vorstellung von der Auffüllung durch Zusammenstellung oder Zudichtung wesentlich gekoppelt an die Art und Weise, wie man sich die Durchsetzung des mehrstrophigen Meisterliedes im 14. Jahrhundert vorstellt. Sofern eher produktionsästhetisch und gesetzhaft, lässt sich ein

4 Rettelbach 2019 (Anm. 2), S. 504.

5 Haustein 1995 (Anm. 2), S. 56.

6 Zusammenfassend dazu Rettelbach 2019 (Anm. 2), S. 504. 
Hintergrundgebot zur Auffüllung, auf welchem Wege auch immer, prinzipiell eher zeitlich festlegen, gibt es, der Tendenz nach, ein vorher und ein nachher. Denkt man hingegen eher an ein Gefüge aus Beziehungen zwischen verschiedenen Realisationsformen von Strophen - Produktion, mündliche Überlieferung (Vortrag), schriftliche Überlieferung (Handschrift) - und damit für die Durchsetzung des mehrstrophigen Meisterliedes an einen Prozess, dann verschwinden feste Bezugspunkte und werden die Dinge, um es vage zu formulieren, kompliziert. Dies werden sie insbesondere dann, wenn man für die Herausbildung des neuen Bars mit einer eigenen Übergangsphase obligater Mehrstrophigkeit rechnet, in der Strophen im neuen, mehrstrophigen Kontext noch nicht für eine weitere Verwendung gewissermaßen verbraucht waren, mit einer Phase unfester Mehrstrophigkeit also.?

Das Phänomen ist also in der Forschung bisher allenfalls en passant reflektiert worden. Das ist erstaunlich, stellt doch das Einmontieren fremder Strophen in ein neues, eigenes Liedgebilde einen bemerkenswerten Vorgang dar, der prinzipiell Beachtung verdient. Er verdient sie schon deshalb, weil wirklich eindeutige Beispiele für nachweislich konzeptionell integrierte fremde ,Stimmen'/ Strophen in ein neues, eigenes Lied eines zweiten Textdichters, der nicht mit dem Tonerfinder identisch ist, in der mittelalterlichen deutschen Lyrik eher selten anzutreffen sind. Bedenkt man hingegen die sehr viel zahlreicher anzutreffenden uneindeutigen Beispiele - etwa alle Minnelieder oder auch Lieder in der Neidhart-Tradition, in denen die Forschung, meist aus editionsphilologischem Interesse, um einen echten Textbestand aus der Überlieferung zu gewinnen, echte von unechten Strophen absetzt -, dann heben diese ins Bewusstsein, wie rasch die Ausrichtung des Hauptaugenmerks auf dem Text des Tonerfinders

7 Vgl. Michael Baldzuhn: Vom Sangspruch zum Meisterlied. Untersuchungen zu einem literarischen Traditionszusammenhang auf der Grundlage der Kolmarer Liederhandschrift. München 2002 (MTU 120), S. 55-68, für eine dahingehende Modellierung des Barbildungsprozesses. Erst aus seiner nicht hinreichend durchgreifenden Modellierung resultiert das Problem, vor das sich Wachinger angesichts der Echtheitsuntersuchungen von Helmuth Thomas gestellt sieht: „Auf welcher Stufe er sich die sekundären Barbildungen vorgestellt hat, wird mir nicht ganz deutlich." Burghart Wachinger: Von der Jenaer zur Weimarer Liederhandschrift. Zur Corpusüberlieferung von Frauenlobs Spruchdichtung. In: Philologie als Kulturwissenschaft. Studien zur Literatur und Geschichte des Mittelalters. Festschrift für Karl Stackmann zum 65. Geburtstag. Hg. von Ludger Grenzmann, Hubert Herkommer und Dieter Wuttke. Göttingen 1987, S. 193-207, hier S. 205. 
naheliegende Folgefragen beiseite schiebt, darunter vor allem die, wie man sich eigentlich die Entstehung und die Existenzweise des Strophenkonglomerats - im Vortrag vor kundigstem Publikum, das Strophenzitate erkennt? - zu denken hat. Nicht zuletzt sieht man sich auch auf die Ausarbeitung eines den mittelalterlichen Verhältnissen angemessenen Zitatbegriffs verwiesen: Sollten die nachsenger im Gefolge der mhd. Sangspruchdichter die ersten deutschsprachigen Liederdichter gewesen sein, die ganze Strophen zitieren - vor kundigstem Publikum, um vom Renommée des Tonerfinders zu zehren? Oder verhält es sich umgekehrt und sie segelten nicht nur mit dem fremden Ton, sondern auch mit dem eigenen Text, der als neuer gar nicht wahrgenommen werden sollte, unter falscher Flagge? Traten sie dann also, wie im 16. Jahrhundert ja nicht wenige Meistersinger, nur als Reproduzent, als Sänger auf und gar nicht als Produzent, als Autor?

Doch schon auf einfachere Fragen gibt es bisher keine Antworten: Sind denn überhaupt nur die alten meister von diesen Ergänzungen betroffen, oder dazu Tonerfinder, die unter den meisterlichen Lieddichtern und später den Meistersängern weniger berühmt waren? So wenig die Praxis des Zusammenstellens und Zudichtens bisher um ihrer selbst willen bedacht wurde, so wenig ist das einschlägige Material bisher um seiner selbst willen erhoben worden. Damit liegen einstweilen noch alle Chancen brach, die Schlüssigkeit des Erklärungsmusters aus dem Vorkommen und der Verteilung der belegten Typen zu überprüfen oder es zu modifizieren. Liegt es doch auf der Hand, dass eine Zudichtung von einer einzigen neuen Strophe zu vier alten des Tonerfinders anders in der Entstehung zu erklären und in der Funktion einzuschätzen sein wird als eine Zudichtung umgekehrt von vier neuen zu einer einzigen alten.

Diese ersten Beobachtungen und Überlegungen sollen als Begründung hinreichen, das einschlägige Material nachstehend einmal um seiner selbst willen systematisch zusammenzustellen und durchzusehen.

\section{Eine erste Bestandserhebung}

Grundlage der nachfolgenden Bestandserhebung sind jene Artikel im älteren Teil des RSM, in denen mehrstrophige Gebilde angesetzt werden, die nicht durchgängig dem Tonerfinder als Textautor zugewiesen werden. Dass damit nicht alles Einschlägige erfasst ist, steht außer Frage: So mag unter den zahllosen anonymen Regenbogen-Texten noch der eine oder andere des Tonerfinders kursieren, nur eben von der Forschung bislang unerkannt. Andererseits ist vieles vom Textdichter Stolle im RSM als, echt' nur mit Fragezeichen versehen und mag nun wiederum gerade nicht von ihm stammen. Zweifelsfälle, soweit eben 
die Bearbeiter des Repertoriums Nicht-Übereinstimmung von Textautor und Tonautor innerhalb eines Liedes als Möglichkeit erwogen und auch markiert haben, sind nachstehend stets aufgenommen.

Eine entsprechende Durchsicht der Bde. 3-5 des RSM ergibt folgenden Bestand: ${ }^{8}$

- Alblin: vier Lieder (recte nur zwei Lieder, die zwei Dubletten haben), zwei ,echte' Strophen (recte nur eine, die eine Dublette hat) in Frauenlobs Froschweise

${ }^{1}$ Frau/14/1a (Karlsruhe St. Georgen 74³): Str. 1

${ }^{1} \mathrm{Frau} / 14 / 1 \mathrm{~b}\left(\mathrm{k} 109^{3}, 122^{3}\right.$, y $\left.1^{3}\right):$ Str. 3

$(=1 \mathrm{~b})$

$(=1 \mathrm{a})$

- Boppe: acht Lieder, neun ,echte' Strophen (recte, wegen Dubletten, sieben) in seinem Hofton

${ }^{1}$ Bop/1/500a ( $\left.{ }^{*} k 592^{5}\right)$ : Str. 2 (= 520a)

${ }^{1}$ Bop/1/504a $\left({ }^{*} \mathrm{k} 596^{5}\right):$ Str. 5 (= 541a)

${ }^{1}$ Bop/1/507a (k 5993): Str. 1f.

${ }^{1}$ Bop $/ 1 / 510 \mathrm{a}\left({ }^{*} \mathrm{k} 602^{3}\right)$ : Str. 3

${ }^{1}$ Bop/1/517a $(\mathrm{k} \mathrm{6093):} \mathrm{Str.} 2$

${ }^{1}$ Bop $/ 1 / 520 \mathrm{a}\left({ }^{\star} \mathrm{k} 612^{5}\right)$ : Str. 1 (= 500a)

${ }^{1}$ Bop/1/531a $\left({ }^{*} \mathrm{k} 623^{3}\right)$ : Str. 3

${ }^{1}$ Bop/1/541a (k 633 $)$ : Str. 3 (= 504a)

- Frauenlob: 26 Lieder, 72 ,echte' Strophen (recte, wegen Dubletten, 60) in acht Tönen

- sieben Lieder, vierzehn (recte dreizehn), echte' Strophen in seinem Langen Ton

\author{
${ }^{1} \mathrm{Frau} / 2 / 113$ (f $\left.31^{10}\right)$ : Str. 1f. $+7-10$ \\ ${ }^{1} \mathrm{Frau} / 2 / 519 \mathrm{a}\left({ }^{\star} \mathrm{k} 66^{3}\right)$ : Str. 1 \\ ${ }^{1}$ Frau/2/541a (k 943): Str. $1+3$
}

\author{
${ }^{1} \mathrm{Frau} / 2 / 505 \mathrm{a}\left({ }^{*} \mathrm{k} 52^{3}\right)$ : Str. 1f. \\ ${ }^{1}$ Frau/2/522a $\left({ }^{*} \mathrm{k} 69^{3}\right)$ : Str. 1 \\ ${ }^{1}$ Frau/2/552a (k 106 3 ): Str. 2 (= 562a) \\ ${ }^{1} \mathrm{Frau} / 2 / 562 \mathrm{a}$ (Karlsruhe $\left.408^{5}\right)$ : Str. 5 (= \\ $552 \mathrm{a})$
}

8 In der Angabe zur Überlieferung werden für Meisterliederhandschriften die üblichen Siglen benutzt. Sternchen an der Überlieferungsangabe markieren Begleitung durch jüngere Zusatzstrophen, die andernorts noch in anderen Strophenumgebungen belegt sind, und eine hochgestellte Ziffer gibt die Strophenanzahl des Bars an. 
- sechs Lieder, fünfzehn (recte neun), echte' Strophen in seinem Grünen Ton ${ }^{1}$ Frau/4/100a (f $\left.36^{3}\right):$ Str. $1+3(3=502 \mathrm{ab}, 7) \quad{ }^{1}$ Frau/4/101a (f 373): Str. 2 f.

${ }^{1} \mathrm{Frau} / 4 / 502 \mathrm{a}\left(\mathrm{k} \mathrm{216}{ }^{7}\right)$ : Str. 4-7 (= 502b; $\quad{ }^{1}$ Frau/4/502b (x 327): Str. 4-7 (= 502a;

$4=519 \mathrm{a}, 1 ; 7=100 \mathrm{a}, 3)$ $4=519 \mathrm{a}, 1 ; 7=100 \mathrm{a}, 3)$

${ }^{1}$ Frau/4/511a $\left({ }^{*} \mathrm{k} 225^{3}\right):$ Str. 3 ${ }^{1} \mathrm{Frau} / 4 / 519 \mathrm{a}\left({ }^{*} \mathrm{~m} 18^{3}\right):$ Str. $1+3(1=502 \mathrm{ab}, 4)$

- ein Lied, eine ,echte`Strophe in seinem Zarten Ton ${ }^{1} \mathrm{Frau} / 5 / 512 \mathrm{a}\left({ }^{\star} \mathrm{k} 202^{3}\right)$ : Str. 1

- zwei Lieder, drei ,echte' Strophen in seinem Würgendrüssel ${ }^{1} \mathrm{Frau} / 6 / 104 \mathrm{~d}\left(\mathrm{w} 122^{3}\right):$ Str. 1f. ${ }^{1} \mathrm{Frau} / 6 / 502 \mathrm{a}(\mathrm{k} \mathrm{87})$ : Str. 2

- vier Lieder, zehn (recte vier) ,echte' Strophen in seinem Vergessenen Ton ${ }^{1} \mathrm{Frau} / 7 / 101 \mathrm{a}\left({ }^{*} \mathrm{f} 50^{5}\right):$ Str. $3-5(=101 \mathrm{bc}) \quad{ }^{1} \mathrm{Frau} / 7 / 101 \mathrm{~b}\left({ }^{*} \mathrm{k} 158^{5}\right):$ Str. $3-5(=101 \mathrm{ac})$ ${ }^{1}$ Frau/7/101c $\left({ }^{*} \mathrm{~d} 8^{7}\right)$ : Str. $2-4(=101 \mathrm{ab}) \quad{ }^{1}$ Frau/7/502a $\left(\mathrm{k} \mathrm{154}{ }^{3}\right)$ : Str. 1

- vier Lieder, neun ,echte 'Strophen in seinem Neuen Ton ${ }^{1} \mathrm{Frau} / 8 / 101$ (f $\left.3^{4}\right)$ : Str. 3f. ${ }^{1}$ Frau/8/506a $\left({ }^{*} \mathrm{k} 176^{3}\right)$ : Str. 1f. ${ }^{1} \mathrm{Frau} / 8 / 512 \mathrm{a}(\mathrm{d} \mathrm{10})$ : Str. $4-7$ ${ }^{1}$ Frau/8/515a (p 193): Str. 3

- ein Lied, neun ,echte' Strophen in seinem Goldenen Ton ${ }^{1}$ Frau/9/100 (f $\left.1^{11}\right)$ : Str. $1-8+11$

- ein Lied, zwölf ,echte` Strophen in seinem Kurzen Ton ${ }^{1} \mathrm{Frau} / 10 / 500 \mathrm{a}$ (Wien $3344^{19}$ ): Str. 3-6, 8, 10, 12-14, 17-19

- Gast: ein Lied, eine ,echte Strophe in seinem Ton ${ }^{1}$ Wolfr/2/1a $\left(\mathrm{k} 805^{3}\right)$ : Str. 1

- Hardegger: drei Lieder, drei ,echte' Strophen in Stolles Alment ${ }^{1}$ Stol/500a $\left(\mathrm{k} 761^{3}\right)$ : Str. 3 ${ }^{1}$ Stol/507a $\left({ }^{*} \mathrm{k} 768^{3}\right)$ : Str. 2

${ }^{1}$ Stol/511a $(\mathrm{k} \mathrm{772}$ ): Str. 1 
- Heinrich von Mügeln: zwei Lieder, vier ,echte` (recte, wegen Dubletten, drei) Strophen in seinem Langen Ton

${ }^{1}$ HeiMü/56-70p (k 651,7/6544): Str. 1+3f. $(1=516 a) \quad{ }^{1}$ HeiMü/516a (w 603): Str. $3(=56-70$ p, $)$

- Kelin: ein Lied, eine ,echte' Strophe in seinem Ton III

${ }^{1} \mathrm{Kel} / 3 / 501 \mathrm{a}\left(\mathrm{k} 146^{2}\right)$ : Str. 1

- Konrad von Würzburg: elf Lieder (recte, wegen Dubletten, zehn), achtzehn (recte, wegen Dubletten, vierzehn), echte' Strophen in drei Tönen

- ein Lied, zwei ,echte' Strophen in seinem Aspiston ${ }^{1}$ KonrW/5/503a ( $\left.{ }^{*} \mathrm{k} 536 / 537^{7}\right)$ : Str. 3f.

- zwei Lieder, drei ,echte` Strophen in seiner Morgenweise ${ }^{1}$ KonrW/6/503a (k 5443): Str. 1

${ }^{1}$ KonrW/6/515a (k 556 $)$ : Str. 1f.

- acht (recte sieben) Lieder, dreizehn (recte neun), echte' Strophen in seinem Hofton

${ }^{1}$ KonrW/7/500a (*k 5643): Str. 2 (= 500c,3)

${ }^{1}$ KonrW/7/500c $\left({ }^{\star}\right.$ w $\left.94^{3}\right):$ Str. $3(=500 \mathrm{a}, 2)$

${ }^{1}$ KonrW/7/502a $\left({ }^{*} \mathrm{k} 566^{3}\right)$ : Str. 2 (= 504a,5)

${ }^{1}$ KonrW/7/503a (k 5677): Str. 2-4

${ }^{1}$ KonrW/7/504a (k 568 $)$ : Str. 2-5 (2f.= 504f;

${ }^{1}$ KonrW/7/504f (w 963): Str. 2f. (= 504a,2f.) $5=502 \mathrm{a})$

${ }^{1}$ KonrW/7/510ab $\left(\mathrm{k} 574^{3}\right.$, w $\left.91^{3}\right)$ : Str. 3

- Marner: 22 Lieder (recte, wegen Dubletten, 21), 36 (recte 25) ,echte` Strophen in drei Tönen

- ein Lied, vier ,echte` Strophen in seinem Goldenen Ton ${ }^{1}$ Marn/1/500a (k 5205): Str. 1-3+5

- zehn Lieder (recte neun), siebzehn (recte elf), echte' Strophen in seinem Kurzen Ton

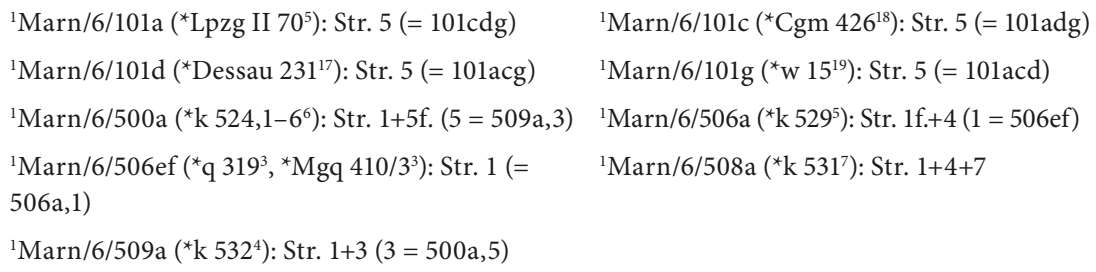


- elf Lieder, fünfzehn (recte zehn), echte'Strophen in seinem Langen Ton

${ }^{1}$ Marn/7/101a (H 350-363 $\left.{ }^{17}\right):$ Str. 1

${ }^{1} \operatorname{Marn} / 7 / 102 \mathrm{f}\left({ }^{*} \mathrm{k} 480^{3}\right):$ Str. 3 (= 102ag)

${ }^{1}$ Marn/7/500a (k 470 ): Str. 1

${ }^{1}$ Marn $/ 7 / 502 \mathrm{a}\left({ }^{*} \mathrm{k} 472 / 474^{5}\right)$ : Str. 1f. $(1=502 \mathrm{de}, 1$;

$2=502 \mathrm{~d}, 4)$

${ }^{1}$ Marn/7/502d ( $\left.{ }^{*} \mathrm{y} 8^{5}\right):$ Str. $1+4(1=502 \mathrm{ae}, 1 ;$ $4=502 \mathrm{a}, 2)$

${ }^{1} \operatorname{Marn} / 7 / 503 a\left(k 473^{5}\right)$ : Str. 1f.
${ }^{1}$ Marn/7/102a $\left({ }^{*} \mathrm{R} 388-394^{7}\right)$ : Str. 7 (= $102 \mathrm{fg})$

${ }^{1}$ Marn/7/102g $\left({ }^{*} \mathrm{k} 503^{3}\right):$ Str. 3 (= 102af)

${ }^{1} \operatorname{Marn} / 7 / 501 \mathrm{a}(\mathrm{k} \mathrm{471}$ ): Str. $1+3$

${ }^{1} \operatorname{Marn} / 7 / 502 \mathrm{e}\left({ }^{*} \mathrm{k} 495^{3}\right):$ Str. 1 (= 502ad,1)

${ }^{1} \operatorname{Marn} / 7 / 512 \mathrm{a}(\mathrm{k} \mathrm{483})$ : Str. 1

- Regenbogen: vier Lieder, vier (recte, wegen Dubletten, zwei) ,echte' Strophen in zwei Tönen

- zwei Lieder, zwei (recte eine), ,echte' Strophe in seiner Briefweise ${ }^{1} \operatorname{Regb} / 1 / 532 \mathrm{a}\left(\mathrm{k} 286^{3}\right)$ : Str. 3 (= 532b)

${ }^{1}$ Regb/1/532b (Straßburg 19953): Str. 3 $(=532 \mathrm{a})$

- zwei Lieder, zwei (recte eine), echte'Strophe in seinem Grauen Ton ${ }^{1} \operatorname{Regb} / 2 / 30 \mathrm{a}\left(\mathrm{k} 340^{3}\right)$ : Str. 1 (= 50a)

${ }^{1} \operatorname{Regb} / 2 / 50 \mathrm{a}\left(\mathrm{m} 68^{3}\right):$ Str. 1 (= 30a)

- Reinmar von Brennenberg: neun Lieder (recte, wegen Dubletten, acht), vierzehn (recte, wegen Dubletten, neun), echte' Strophen in seinem Hofton

${ }^{1} \operatorname{ReiBr} / 506 a\left({ }^{*} \mathrm{k} 735^{3}\right)$ : Str. 1f. $(1=517 \mathrm{a}, 1,524 \mathrm{a}, 526 \mathrm{a}, 534 \mathrm{ab})$

${ }^{1} \operatorname{ReiBr} / 507 \mathrm{a}\left({ }^{\star} \mathrm{k} 736^{5}\right)$ : Str. $2 \mathrm{f}$.

${ }^{1} \operatorname{ReiBr} / 510 \mathrm{a}\left(\mathrm{k} 739^{7}\right)$ : Str. 3f.+7

${ }^{1} \operatorname{ReiBr} / 517 \mathrm{a}\left({ }^{*} \mathrm{Mgq} 719^{3}\right)$ : Str. $1+3(1=506 \mathrm{a}, 1,524 \mathrm{a}, 526 \mathrm{a}, 534 \mathrm{ab})$

${ }^{1} \operatorname{ReiBr} / 520 \mathrm{a}\left({ }^{*} \mathrm{Mgq} 719^{4}\right)$ : Str. 2

${ }^{1} \operatorname{ReiBr} / 524 \mathrm{a}\left({ }^{*}\right.$ Wien $\left.3344^{9}\right)$ : Str. 1 (= 506a, 1, 517a,1, 526a, 534ab)

${ }^{1} \operatorname{ReiBr} / 526 \mathrm{a}\left({ }^{*} \mathrm{Cgm} \mathrm{811}\right)$ : Str. 1 (= 506a,1, 517a,1, 524a, 534ab)

${ }^{1} \operatorname{ReiBr} / 534 \mathrm{ab}\left({ }^{\star}\right.$ Druck $37 \mathrm{a}^{3}$, ${ }^{\star}$ Druck 28b/II $\left.{ }^{3}\right):$ Str. 1 (= 506a, $\left.1,517 \mathrm{a}, 1,524 \mathrm{a}, 526 \mathrm{a}\right)$

- Reinmar von Zweter: ein Lied, eine ,echte Strophe in seinem Frau-Ehren-Ton ${ }^{1}$ ReiZw/1/508a (k 728 $)$ : Str. 2 
- Stolle: drei Lieder, drei ,echte` Strophen in seiner Alment

${ }^{1}$ Stol/500a $\left(\mathrm{k} 761^{3}\right):$ Str. 2

${ }^{1}$ Stol/511a $\left(\mathrm{k} 772^{3}\right):$ Str. 2

${ }^{1}$ Stol $/ 528 \mathrm{a}\left({ }^{*} \mathrm{w} 107^{5}\right):$ Str. 5

- Tannhäuser: zwei Lieder, fünf, echte`Strophen in zwei Tönen

- ein Lied, zwei ,echte`Strophen in seinem Hofton ${ }^{1}$ Tanh/1/500a (q $\left.280^{7}\right)$ : Str. 1f.

- ein Lied, drei ,echte' Strophen in seinem ,Ludeleich ${ }^{1} \operatorname{Tanh} / 4 / 1 \mathrm{c}\left(\mathrm{k} 20^{11}\right)$ : Str. 1f.+3

- Walther von der Vogelweide: drei Lieder, vier ,echte` (recte, wegen Dubletten, drei) Strophen in seiner Gespaltenen Weise

${ }^{1}$ Walt/8/500a $\left(\mathrm{k} 807^{3}\right)$ : Str. 1

${ }^{1}$ Walt $/ 8 / 501 \mathrm{a}(\mathrm{k} \mathrm{8083})$ : Str. $2 \mathrm{f}$.

${ }^{1}$ Walt $/ 8 / 502$ a $(\mathrm{k} \mathrm{809})$ : Str. 1

\section{Eine erste Durchsicht}

Diese erste Erhebung bringt 100 Strophengruppen (,Lieder') ans Licht (ohne Dubletten 95) mit 177 (ohne Dubletten und ohne Mehrfach-Ergänzung 138) Altstrophen. An ihrer Bezeugung sind nahezu alle Meisterliederhandschriften beteiligt. Dies sind sie indes in unterschiedlichem Umfang. Die meisten bieten nur einen oder zwei Belege (d, l, m, p, q, x, y). Immerhin sechs haben w und f. Mit größtem Abstand die Hauptmasse entstammt jedoch k (60).

Welche Tonautoren sind betroffen? Keineswegs nur der alten Meister zwölf, sondern fünfzehn, und darunter fallen Namen wie Alblin, Hardegger, Kelin, Tannhäuser, die eher überraschen. Hingegen erscheinen mit mehreren Tönen fast nur die alten Meister: Frauenlob, Konrad von Würzburg, der Marner, Regenbogen, aber auch der Tannhäuser. Frauenlob geht allen voran, und dies auch in der Zahl der Lieder. Er erscheint hier zweistellig vor allen anderen (26), gefolgt mit Abstand erst vom Marner (22, recte 21) und Konrad von Würzburg (11, recte 10). Nahe an der Zweistelligkeit sind immerhin Reinmar von Brennenberg (9, recte 8) und Boppe (8), mit Abstand gefolgt von Regenbogen (4), dem Hardegger (3), Stolle (3) und Walther von der Vogelweide (3), dann von Alblin (4, recte 2), Heinrich von Mügeln (2) und dem Tannhäuser (2) und schließlich Gast, Kelin und Reinmar von Zweter mit je einem Lied. 
Auf ihren Umfang hin betrachtet zeigen die Konglomerat-Lieder manchmal ein Strophenpaar, Dreierbare indes in 57 Fällen, manchmal Vierergruppen, Fünferbare in sechzehn Fällen, manchmal eine Sechsergruppe, zehnmal ein Siebenerbar und vereinzelt Neuner-, Zehner- und noch größere Gruppen. Die Dreier-, Fünfer- und Siebener-Bare dominieren erwartbar deutlich.

Der Umfang der Wiederverwendung beträgt meistenteils nur eine Altstrophe (60 Belege), aber auch zwei (22), gelegentlich drei (8) oder noch mehr Strophen. Ferner bieten fast 50\% der Lieder anonyme Begleitstrophen, die nicht an das vorliegende Bar gebunden bleiben, sondern auch in anderen Liedern noch einmal erscheinen. Umgekehrt erscheinen von 177 alten Strophen 38 mehrfach - zumeist zweimal - verarbeitet.

Auf die Position des Altmaterials im neuen Lied hin betrachtet lässt sich keine Regel erkennen. Es dominiert die Verwendung einer einzigen Strophe gleich an erster Stelle (24 Belege). Hinzu kommen 24 Belege für die Besetzung noch weiterer Positionen über den Eingang hinaus im Lied durch Altstrophen. Eine einzige Strophe an zweiter Stelle ist elfmal belegt; hinzu kommen sieben weitere Belege, in denen über die zweite Strophe hinaus weitere vom Tonerfinder stammen. Einsatz an dritter Stelle findet sich siebzehnmal; sechsmal folgen zudem weitere Altstrophen. Daneben findet sich Einsatz auch an vierter, fünfter, siebter und zwölfter Stelle des Liedverbunds.

Verschiedenes gibt bereits bei solchem oberflächlichen Auszählen grundsätzlich zu denken. Das ist der Fall etwa beim Anteil an Paaren oder Vierergruppen, in denen eine Ergänzung zum Bar als Erklärung nicht hinreichen kann, da gar kein Barumfang erreicht wird. Das ist der Fall ferner beim Blick auf einen Bestand von drei Altstrophen im neuen Lied in mehreren Belegen, da dort eine Ergänzung auf ein regelgerechtes Bar von ungerader Strophenzahl gar nicht erforderlich wäre. Das ist weiterhin der Fall beim Blick auf fast $50 \%$ der ergänzten Strophen, die noch in weiteren Liedern begegnen außer demjenigen mit einer oder mehreren Strophen bereits des Tonerfinders, die also nicht ausschließlich für Ergänzung zu einem einzigen Bar verfasst sein können, da sie ja noch andernorts eingesetzt wurden. Und wieso wurden eigentlich alte Strophen auch mehrfach verarbeitet? Waren das etwa besonders attraktive Sprüche, die das Interesse gleich verschiedener Zudichter auf sich gezogen haben? Solche Bedenken und Fragen erfordern eine genauere Durchsicht des Bestands. 


\section{Eine zweite Durchsicht}

Die nachstehende Durchsicht überprüft die Belege forciert im Hinblick auf die Frage, ob die Ergänzung der Altstrophen um der Barform willen erfolgt sein kann. Ich beginne mit Alblin, da sich hier in extremo zeigt, mit welchen Verkürzungen eine unreflektierte Annahme schlichter Barergänzung arbeitet.

In Alblin wird ein Autor des 14. oder der ersten Hälfte des 15. Jahrhunderts gesehen - gestützt auf die Überschrift Alblin ơnn sinne über einem dreistrophigen Lied in einer Karlsruher Handschrift ( $\left.{ }^{1} \mathrm{Frau} / 14 / 1 \mathrm{a}\right)$, dessen Eingangsstrophe in einem in drei Meisterliederhandschriften ( $\mathrm{k} 109,122$, y 1) bezeugten anderen Lied die Schlussstrophe bildet: „Eine ältere Einzelstr. (Anf. 14. Jh.?) scheint also im 15. Jh. zweimal nach Meistersingerart zum Dreierbar ergänzt worden zu sein. Welcher Altersschicht der Name A. zuzuordnen ist, bleibt unsicher. ${ }^{\text {"9 }}$ Der benutzte Ton, die Froschweise, ist in den Meisterliederhandschriften Frauenlob untergeschoben, gehört ihm aber nicht, wenngleich er noch aus dem 14. Jahrhundert stammen muss, da in ihm noch eine selbstständige Einzelstrophe verfasst wurde. Er könnte mithin von Alblin stammen - zumal spätere Kataloge von Meistern (K. Nachtigall, H. Folz, V. Voigt) einen Elbel/Elb kennen. ${ }^{10}$ Doch muss der Name dann weithin verloren gegangen sein, oder er wurde gezielt getilgt: vielleicht, weil mit ihm als Tonerfinder nicht hinreichend zu prunken war. Der Ton geht jedenfalls später dann, erstmals seit 1440 (Meisterliederhs. d), an den berühmteren Meister. Die Einzelstrophe könnte prinzipiell ebenfalls von einem Tonerfinder Alblin sein - oder aber bereits von einem Fremdtonverwender Alblin, wobei der Ton zum Zeitpunkt ihrer Abfassung namenlos, unter anderem Namen oder bereits unter Frauenlobs Namen gelaufen sein kann. Diese ohnedies schon vielen Möglichkeiten vermehren sich noch einmal beträchtlich, wenn man den Blick auf den zweistrophigen Nachspann in der Karlsruher Handschrift beziehungsweise den zweistrophigen Vorspann in k, 1 und y richtet. Die Strophenpaare können prinzipiell (1.) gemeinsam von Alblin wie der Ton und die Einzelstrophe stammen. Alblin hätte dann im Umfeld der Herausbildung des neuen mehrstrophigen Liedes zu Zeiten unfester Mehrstrophigkeit gedichtet; das Wiederverwenden eigener Strophen wäre nicht Barergänzung von etwas nach rezenten Vorstellungen Defizitärem, sondern geläufige Praxis. ${ }^{11}$ Sie können (2.) gemeinsam von Alblin stammen, zwar nicht wie der

9 Burghart Wachinger: Alblin. In: ${ }^{2}$ VL 1 (1978), Sp. 155-156, hier Sp. 155.

10 Vgl. ebd.

11 Vgl. zu dieser Phase im Übergang von der Einzelstrophe zum Meisterlied Baldzuhn 2002 (Anm. 7), S. 59, 456, 498 sowie Michael Baldzuhn: Der ,Hort von Kidron` in 
Ton, aber wie die Einzelstrophe: Alblin wäre dann Fremdtonverwender - ob unter Bezug auf Frauenlob bereits, steht infrage - in Zeiten unfester Mehrstrophigkeit. Sie können (3.) gemeinsam von Alblin stammen, nicht jedoch muss der Ton oder die Einzelstrophe von ihm sein: Alblin wäre dann Fremdtonverwender - ob unter Bezug auf Frauenlob bereits, steht nach wie vor infrage - wie Fremdtextverwender - wobei die Anschauung, dass der Text als einer Frauenlobs gegolten hätte, an den dann Alblin sich angeschlossen hätte, genau wie der Tonbezug infrage steht. Und sie können beide (4.) von einem einzigen anonymen nachsenger stammen, von einem Fremdton- wie Fremdtextverwender, der sich zweimal einer älteren Strophe bedient hätte, wobei Alblin (4.a) entweder gleichzeitig Tonerfinder wie Verfasser der Einzelstrophe oder (4.b) zwar nicht Tonerfinder, aber Verfasser der Einzelstrophe, mithin selbst bereits, wie der Anonymus, Fremdtonverwender gewesen sein mag. (Hier lasse ich, um die Dinge nicht noch komplizierter zu machen, einmal außer acht, wann und in welcher Weise dann noch eine ,Fehlzuweisung' an den berühmteren Meister Frauenlob ins Spiel kommen könnte.) Und last not least müssen die jeweils zwei ,Zusatz'-Strophen gar nicht gemeinsam betrachtet werden: Für das eine Strophenpaar mag eine andere der Möglichkeiten Nr. 1-4 in Anschlag zu bringen sein als für das andere.

Anders als die Entfaltung der Vielzahl von Möglichkeiten soll das Fazit kurz sein. Die vier Liedüberlieferungen aus dem Alblin-Umfeld lassen sich sowenig umstandslos als Beleg für die Weiterverarbeitung fremder, älterer Texte im neuen Lied heranziehen wie als Beleg für eine nachträgliche Auffüllung von Defizitärem durch Zusatzstrophen zum mehrstrophigen Bar. Sowenig aber nun von Alblin her Barergänzung zu belegen ist, sowenig von Gast, Kelin und Reinmar von Zweter her, die jeweils mit einer Liedeinheit vertreten sind und daher als nächstes betrachtet werden sollen.

Gast, der im 13. Jahrhundert dichtete, vielleicht in der Jahrhundertmitte, gilt als Verfasser des bereits altbezeugten Spruchs k 805,1 (s. ${ }^{1} \mathrm{Gast} / 1 \mathrm{abc}$ ) sowie als Erfinder des benutzten Tons, der freilich in k unter Wolframs von Eschenbach Namen läuft. Gast ist zudem als Autor der zwei Zusatzstrophen k 805,2f. in Betracht zu ziehen. Dann wäre Fremdtextverwendung hinfällig. Aber auch das

Regenbogens Grauem Ton. Strophengruppenreihen als Prunkform zwischen Einzelspruch/Spruchreihe und Meisterlied/Liedzyklus. In: Sangspruchdichtung um 1300. Akten der Tagung in Basel vom 7. bis 9. November 2013. Hg. von Dorothea Klein und Gert Hübner. Hildesheim 2015 (Spolia Berolinensia 33), S. 331-361. 
in k angehängte Strophenpaar war „ursprünglich wohl selbständig[]“.12 Dann gälte dasselbe. Das Bar ist also allenfalls Ergebnis späterer gezielter Zusammenstellung.

Der Ton III Kelins, Spruchdichter der Mitte oder der zweiten Hälfte des 13. Jahrhunderts, ist erst seit $\mathrm{k}$ für Frauenlob bezeugt, eine Zudichtung von k 146,2 im Hinblick auf den berühmteren Tonerfinder (und angenommenen Textdichter von $\mathrm{k}$ 146,1) ist damit unwahrscheinlich. Ohnedies wird die Barform mit einem irregulären Paar von Strophen nicht erreicht. Ferner folgt mit k 147 in der Handschrift ein weiteres irreguläres Paar. Der Schreiber hatte hier Schwierigkeiten mit der Barbildung (Hie in dysem tone volgen dru lieder $<$ oder $>$ vier die nit geparet sin Man mag sie teylen wohin etc. sowie Ander ij lied abenturr, liest man bei $\mathrm{k}$ 147), arbeitete also in einer nicht widerspruchsfreien, daher wohl älteren, jedenfalls nicht ,meisterlich' eingerichteten Vorlagensituation.

Die Mittelstrophe Reinmars von Zweter ${ }^{13}$ in k 728 über die Unbeständigkeit des Glücks ist thematisch passend gerahmt. Roethe zog für Str. 1 wie 3 ebenfalls noch Verfasserschaft Reinmars in Betracht, womit Zudichtung hinfällig wäre, betrachtet sie jedenfalls als Einzelstrophen; de Boor hat entsprechend Str. 1 gar als Einzelstrophe ohne k-Umgebung ediert. ${ }^{14}$ Wenn Roethes Vermutung also zuträfe, müsste für keine der Strophen erwogen werden, dass sie auf ein meisterliches Bar hin konzipiert worden wäre.

Mit je zwei Liedbelegen sind Heinrich von Mügeln und der Tannhäuser erfasst. Die zweite Strophe der Vierergruppe k 651,7/654 in Mügelns Langem Ton ist ganz sicher nicht im Hinblick auf ein - weil damit ja ,irreguläres - Viererbar hinzugedichtet worden, sondern verdankt ihre Stellung

12 Vgl. Gisela Kornrumpf: Gast. In: ${ }^{2}$ VL 2 (1980), Sp. 1102-1104, hier Sp. 1103: „In k wird Str. 1 durch ein ursprünglich wohl selbständiges Strophenpaar eines gernden zu einem Dreierbar (k 805) ergänzt. Für die von BARTSCH [1862, wie Anm. 3], S. 157) erwogene Echtheit von k 805 II-III könnte sprechen, daß das Gold-Blei-Motiv dieser Strophen dem Ton vermutlich seinen bei den Meistersängern üblichen Namen ,Goldener Ton' gegeben hat und III auf G. selbst anzuspielen scheint.“

13 Zu den zwei Sprüchen fraglicher Verfasserschaft Reinmars im Dreierbar f 53 ( ${ }^{1} \mathrm{ReiZw} /$ 1/512a: „Str. 1: Reinmar von Zweter; Str. 2-3: Reinmar von Zweter? [s. Lit.]“) vgl. das oben Anm. 2 zitierte Urteil Roethes („mögen echt sein“). Das entsprechende Bar wäre so oder so allenfalls aus sekundärer schriftlicher Zusammenstellung entstanden. Die bei Roethe 1887 (Anm. 2), S. 133 mit der Bemerkung „Mindestens die 4 religiösen Sprüche 283-286, die in meistersingerischer Art Str. 217 zu einem fünfstrophigen Bar ergänzen, sind unecht " erfassten Sprüche ${ }^{1}$ ReiZw/1/242-245 aus Teil H des Heidelberger Cpg 350 sind im RSM zu Recht als Einzelsprüche erfasst.

14 Vgl. Roethe 1887 (Anm. 2), S. 133, 155, 157 sowie de Boor 1965 (Anm. 2), S. 717. 
zunächst Unsicherheiten des k-Schreibers bei der Auflösung einer längeren Fabelspruchreihe - ähnlich der Fünfzehnerreihe von Fabelsprüchen im Buch IV der Göttinger Mügeln-Handschrift, die in späterer Überlieferung oft in Dreiergruppen aufgeteilt begegnet (vgl. ${ }^{1} \mathrm{HeiM} \ddot{\mathrm{M}} / 56-70$ ). So beendete $\mathrm{k} 651,7$ zunächst ein Siebenerbar, das der Schreiber aber dann in zwei Dreierbare aufgeteilt hat, wobei er die Schlussstrophe dem alten Dreierbar k 654 zuschlug, das wiederum selbst erst nachträglich von $\mathrm{k} 655$ - einem unechten, mit einem Fabelspruch beginnenden Fünferbar - durch Rubrik abgetrennt erscheint. Für die Auswertung für Fremdtextverwendung im Hinblick auf das meisterliche Lied fällt der - im übrigen aus sich heraus verständliche, selbstständige $^{15}$ - Spruch damit aus. Im Dreierbar w 60 gehen zwei unechte Sprüche, die nur „locker aufeinander bezogen[]“, aber je aus sich selbst heraus verständlich sind, dem vom Tonerfinder stammenden dritten voraus: Auf diesen dezidiert und ausschließlich hin verfasst erscheinen sie nicht. ${ }^{16}$ Für die Genese dieses Bars liegt eine auf wechselnde schriftliche Unterteilungen von Strophenreihen (siehe oben) rekurrierende Erklärung näher: Sie belegen lediglich Fremdtonverwendung unter Anlehnung an Mügelnsche Fabelsprüche - aber nicht im Blick auf die Barform.

Anders liegen die Verhältnisse beim Tannhäuser. In der Elfergruppe von $\mathrm{k}$ 20 erscheint eine alte Dreiergruppe des Tonerfinders, eine ironische Klage über die unerfüllbaren Forderungen seiner Minnedame, gezielt aufgenommen und „in aller Breite“, so im RSM-Artikel zu 'Tanh/4/1, weitergeführt. Barergänzung freilich steht dort nicht im Hintergrund, liegt doch ein Dreier bereits vor und ist ein Elfer, der in $\mathrm{k}$ als lideleich überschrieben ist und in den besonderen Vorspann der Handschrift mit Pracht- und Prunkformen eingegliedert erscheint, ${ }^{17}$ sicher keine übliche Zielform. Ebenso ist für das neue siebenstrophige Lied in q 280 die gezielte Aufnahme von Altmaterial, nun zwei Einzelstrophen, und ihr konzeptionell durchdachter Ausbau zur größeren Einheit zu erkennen. Dies geschah freilich nicht, weil die Altstrophen oder das Paar unvollständig wären. Sondern der neue Verfasser hat sich die Vorgabe der Rolle des umherziehenden Heimatlosen (Vorgabe der Altstrophe 1: der, arme Gast') zu eigen gemacht und wollte in dieser mit deutlicherer Verve auftreten (Vorgabe Altstrophe 2: Katalog

15 Davon (und von Unechtheit) geht implizit auch Karl Stackmann aus: Philologische Untersuchungen zur Ausgabe der kleineren Dichtungen Heinrichs von Mügeln. Göttingen 2004 (Abhandlungen der Akademie der Wissenschaften zu Göttingen. Phil.-Hist. Kl. 3. Folge, 265), S. 47-48.

16 Vgl. ebd., S. 53-54 (das Zitat S. 53).

17 Vgl. dazu jetzt den Beitrag Horst Brunners im vorliegenden Band (S. 53-69). 
von Orts- und Flussnamen - weitergeführt in q 280,3-7 in der Nennung weiterer geografischer Gegebenheiten; dabei nehmen die Schlussverse 132f. die GastRolle wieder auf: die perg vnd wasser lis ich far, / wolt mich der wirt behaussen [Siebert V. 132f.]). Das neue Gebilde ist allerdings, sofern Sieberts Hinweis auf ein Ereignis des Jahres 1505 zutrifft, das V. 92 zugrunde liegt (der kolenperck, der print so starck / zwickaw yn meichsner lande [Siebert V. 92f.]), vor dem Hintergrund des längst durchgesetzten mehrstrophigen Liedes entstanden. ${ }^{18}$

Der Hardegger, Stolle und Walther von der Vogelweide sind mit je drei Belegen vertreten. Das Dreierbar k 761 belegt Benutzung von Stolles Alment durch den bereits zwischen 1225 und 1250 dichtenden Hardegger ${ }^{19}$ - also kaum mit Blick bereits auf ein Bar. Die zweite Strophe ist zumindest im Aufgesang altbezeugt und stammt hier noch vom Tonerfinder. Die Eingangsstrophe, ein Gebet an Gott und Maria, kann gut Einzelstrophe sein: Bartsch erwog gar Echtheit. ${ }^{20}$ Wenn überhaupt je die Barform dezidiert im Blick stand, denn die Vorlagentradition, auf der k hier aufruht, reicht sehr weit zurück, ${ }^{21}$ dann ist am ehesten von Gruppierung lediglich in schriftlicher Aufzeichnung auszugehen. Auch für k 768,2 ist von Verfasserschaft bereits des Hardegger auszugehen; für Str. 3 erwog Bartsch noch den Tonerfinder als Verfasser, ${ }^{22}$ Str. 1 ist, wie die beiden folgenden, alte Einzelstrophe. ${ }^{23}$ Das Fazit ist mithin das gleiche wie für k 761 . Auch die Eingangsstrophe des Dreierbars k 772 stammt vom Hardegger, Str. 2, eine polemisierende Antwort auf Str. 1, vielleicht von Stolle; Str. 3 polemisiert wie Str. 2 gegen den Hardegger, gehört mithin engstens zum Paar, obgleich sie, so Wachinger, „kaum vor dem 14. Jahrhundert“ entstanden ist. Dem mag man folgen; kaum aber seiner weiteren Annahme, sie sei „vermutlich“ „vornehmlich zu dem Zweck gedichtet [...], das polemische Strophenpaar zu einem Dreier-

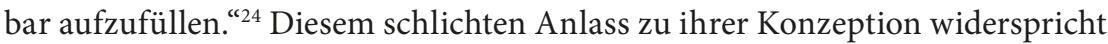
ihre keineswegs schlichte, sondern sehr präzise Abstimmung auf ihren Kontext: Sie „scheint von den drei Strophen den theologischen Hintergrund“ des

18 Vgl. Johannes Siebert: Der Dichter Tannhäuser. Leben - Gedichte - Sage. Halle/Saale 1934, S. 230 mit Anmerkung zu V. 92-93.

19 Gisela Kornrumpf: Der Hardegger. In: ${ }^{2}$ VL 3 (1981), Sp. 465-466.

20 Bartsch 1862 (Anm. 3), S. 164.

21 Vgl. Baldzuhn 2002 (Anm. 7), S. 387-388.

22 Vgl. Bartsch 1862 (Anm. 3), S. 717.

23 Vgl. Baldzuhn 2002 (Anm. 7), S. 390.

24 Vgl. zum ganzen Strophenkomplex Burghart Wachinger: Sängerkrieg. Untersuchungen zur Spruchdichtung des 13. Jahrhunderts. München 1973 (MTU 42), S. 132-138 (die Zitate S. 135). 
ganzen Streits „am genauesten zu kennen“, und sie „formuliert am präzisesten und abgewogensten“, wie Wachinger selbst feststellt, wodurch sie, „obwohl sie sich als Fortsetzung der Antwort auf Hardeggers Strophe gibt, doch beinahe wie die scholastische Synthese zwischen den beiden widersprüchlichen Meinungen" wirkt. ${ }^{25}$ Angesichts des Befundes, dass k 772 nun ein drittes Mal in eine spezielle Stolle/Hardegger-Textkombination führen könnte und dass hinter $\mathrm{k}$ hier zumindest partiell eine sehr alte Vorlagentradition steht, erscheint die Annahme einer bereits sehr viel älteren Zusammenführung der Strophen ohne Blick bereits auf das meisterliche Bar von weniger Vorannahmen belastet und plausibler.

Die Stolle-Lieder k 761 und k 772 wurden schon oben behandelt. ${ }^{26}$ Das Fünferbar w 107 enthält (1.) eine Parallele zu der alten Einzelstrophe k 768,3 (siehe oben), (2.) eine Parallele zu der altbezeugten Einzelstrophe eines Anonymus $\left({ }^{1}\right.$ Stol/37a), die Bartsch, wie auch alle anderen des Bars, noch für echt hielt, ${ }^{27}$ (3.) eine sehr wahrscheinlich ehedem selbstständige Strophe mit Parallele in $\mathrm{k} 770,3,{ }^{28}$ (4.) eine nur hier bezeugte Strophe, die aus sich heraus verständlich ist, mithin als Einzelstrophe gelesen werden $\mathrm{kann}^{29}$ und die von Bartsch, wie gesagt, noch für echt gehalten wurde, sowie (5.) den vielleicht von Stolle verfassten, jedenfalls altbezeugten (in J) und in k 776 (Beischrift Bl. 714r: Diß liet stet alleyn oder mangelt noch eins) als Einzelstrophe notierten Spruch ${ }^{1}$ Stol/34a. Damit liegt eine - im übrigen thematisch nicht unpassend angelegte - Einzelstrophenzusammenstellung vor, die in dieser Form nicht zwingend erst für Handschriften, die schon nach dem Barprinzip ordnen, reklamiert werden muss.

Eine solche Zusammenstellung lässt sich auch im Hintergrund der drei Dreierbare k 807-809 annehmen, in denen Altstrophen Walthers von der Vogelweide beziehungsweise des Schulmeisters von Esslingen erscheinen. ${ }^{30}$ Dazu passt sowohl die Zurückhaltung, die „Walther-Abstinenz der Meistersinger“,

25 Ebd., S. 137-138.

26 Sie sind hier erneut unter Stolle verzeichnet, weil, sofern man Stolle als Tonerfinder und Textdichter ansetzt, teils der Hardegger Fremdton- und Fremdtextverwender wäre, teils ein Anonymus. Unter dem Hardegger demgegenüber wurden sie verzeichnet im Blick auf den Textdichter Hardegger, der aus der Perspektive der anonymen Zweitverwender seiner Texte auch als Tonerfinder gelaufen sein mag.

27 Vgl. Bartsch 1862 (Anm. 3), S. 717.

28 Vgl. zum gesamten Bar k 770 Baldzuhn 2002 (Anm. 7), S. 391-392.

29 Vgl. den Text bei Bartsch 1862 (Anm. 3), S. 620-621, dort V. 46-60.

30 Baldzuhn 2002 (Anm. 7), S. 403, Anm. 348. 
die Haustein in der Überschau über die Walther-Rezeption seitens der Meistersinger für diese reklamiert, ${ }^{31}$ als auch, dass Haustein die Leistung von k eher im redaktionellen Bereich und als „Ordnungsbemühen “32 erfasst. Freilich zeigt Haustein für alle drei Lieder auch auf, „mit welchem literarischen Geschick die alten Strophen auf die jüngeren hin umgeformt sind“:

„Die Veränderungen an den alten Strophen sind allesamt auf die Fortführung des Themas in den jüngeren bezogen; sie sind nicht etwa Zeugnis mangelnden literarischen Verständnisses oder gar nur überlieferungsgeschichtlicher Entstellung, sondern bewußter, literarisch produktiver Ausdruck des Bemühens, sich die Texte der alten Meister in variierender Aufnahme und unter thematischer Ausgestaltung anzueignen. ${ }^{\left({ }^{33}\right.}$

Auf welcher Überlieferungs- und Rezeptionsstufe die Zudichtungen der Texte indes und die Anpassungen der Altstrophen an sie zu verorten sind, das lässt Haustein offen. Mechanische Barergänzung jedenfalls sind die Zusätze nicht. Dass sie gezielt mit dem Renommée des Tonerfinders arbeiten würden, ist nicht ersichtlich und erscheint vor dem oben angesprochenen allgemeinen Rezeptionshintergrund auch unwahrscheinlich.

Die vier ermittelten Lieder Regenbogens mit Strophen des Tonerfinders verarbeiten nicht auch vier, sondern nur zwei Altstrophen (k 286,3 = Straßburg 1995,3; k 340,1 = m 68,1): einmal in der Briefweise, einmal im Grauen Ton. Das thematisch zur Ständelehre von Str. 3 passende Paar vor k 286,3 - im Straßburger Zeugen umgestellt, denn $\mathrm{k} 286,2$ ist dort Eingangsstrophe - hielt Bartsch für ,echt', Schanze spricht von Zudichtungen. Str. 2 kann jedenfalls noch alte Einzelstrophe sein. So oder so sind die zwei Strophen nicht umstandslos als anonyme und schlicht auf einfache Barergänzung hin konzipiert zu reklamieren - schon weil dafür Regenbogens Verfasserschaft sicher ausgeschlossen werden müsste. ${ }^{34}$

31 Jens Haustein: Walther in k. In: Lied im deutschen Mittelalter. Überlieferung, Typen, Gebrauch. Chiemsee-Kolloquium 1991. Hg. von Cyril Edwards, Ernst Hellgardt und Norbert H. Ott. Tübingen 1996, S. 217-226, hier S. 219. Vgl. a. a. O. weiter: „Es bestand also unter den Meistersingern offenbar kein besonderes Interesse an alten Walther-Strophen oder daran, in seinen Tönen zu dichten, oder gar eigene Töne dem alten Meister zuzuschreiben." Und a. a. O.: „Aber auch für eine inhaltliche Auseinandersetzung, für ein Fortdichten einer alten Strophe zu einem Lied, boten sich kaum Anknüpfungspunkte.“

32 Haustein 1996 (Anm. 31), S. 221.

33 Ebd., S. 226.

34 Vgl. Bartsch 1862 (Anm. 3), S. 176, Schanze 1982-83 (Anm. 2), Bd. 1, S. 83 sowie zum ganzen Komplex ausführlicher Baldzuhn 2002 (Anm. 7), S. 271-272. 
Genauso verhält es sich in k 340: Das Bar enthält eine alte Einzelstrophe und ein thematisch passendes Ergänzungspaar, hier ist jedoch nun jede, nicht nur die erste beziehungsweise die zweite der beiden Strophen auch aus sich heraus verständlich. Bartsch hielt auch die zwei nicht altüberlieferten Strophen für echt, Schanze hält sie für Zudichtung. ${ }^{35}$ Es gilt also wiederum: Auch diese sind nicht einfach als anonyme und schlicht auf einfache Barergänzung hin konzipiert zu reklamieren. Dagegen ist $m 68$ Schanze zufolge Einzelstrophenkompilation, mithin allenfalls sekundäre Zusammenstellung, nicht Zudichtung. ${ }^{36}$

Vor der Durchsicht der noch verbleibenden vier größeren Bestände - Boppe, Frauenlob, Konrad und Marner - sei ein Blick auf den befremdlichen Befund bei Reinmar von Brennenberg geworfen: befremdlich deshalb, weil einerseits recht viele Lieder mit Altverwertung anzutreffen zu sein scheinen, andererseits er unter den Meistersingern des späteren 15. und dann 16. Jahrhunderts doch eine Sonderrolle einnimmt, die ihn von den alten Meistern unterscheidet: Sein Hofton wurde vorwiegend für Minnethematik verwendet, daher im Gemerk, wie sich etwa bei Hans Sachs in Nürnberg sehen lässt, als nicht schulgemäß gemieden und den eigentlichen Meistertönen nicht gleich geachtet; seine Sonderstellung kommt überdies in einer außergewöhnlich breiten Drucküberlieferung zum Ausdruck. ${ }^{37}$ Das Thema Minne/Liebe prägt auch alle hier erfassten ,neuen' Lieder. Ihre Überlieferung bestätigt die Sonderrolle ebenso: Nur mit $\mathrm{k}$ erscheint dreimal eine - cum grano salis - ,Meisterliederhandschrift; daneben aber führt sie zweimal ins Königsteiner Liederbuch des Mgq 719, je einmal in Liebhard Eghenvelders Liederbuch, letzteres doch sehr am Rande der Sammlungen meisterlicher Lieddichtung stehend, und in das Liederbuch des Jacob Kebitz im Cgm 811, schließlich in zwei Drucke. Solche relative Distanz zu dezidiert meisterlichen/meistersingerischen Traditionen kommt denn auch in den Altstrophen verwertenden Liedern zum Ausdruck. So genügt das Liebeslied ${ }^{1} \mathrm{ReiBr} / 520$ a des Mgq 719 mit seiner zweiten Strophe Reinmars in seiner Vierstrophigkeit der Barform nicht und entfällt als Beleg für meisterliche Ergänzung um des Bars willen. Ferner kann auch das Siebenerbar k 739, das ein konzeptionell geschlossenes Streitgespräch zwischen Schönheit und Liebe bietet, mit seiner Ergänzung der neuen Strophen nicht auf das Bar als solches

35 Vgl. Baldzuhn 2002 (Anm. 7), S. 282; Schanze 1982-83 (Anm. 2), Bd. 1, S. 85; Bartsch 1862 (Anm. 3), S. 400-402 (Text) und S. 177 (zu Nr. 80).

36 Vgl. Schanze a. a. O.

37 Vgl. Schanze 1982-83 (Anm. 2), Bd. 1, S. 26, 33-34, 120, 343-344, 357-358. 
gezielt haben, da ihm eine Dreiergruppe des Tonerfinders als „in sich geschlossene Einheit ${ }^{\text {" }}{ }^{8}$ bereits zugrunde liegt. Immerhin ist am neuen Lied aber sehr schön zu erkennen, wie die Zusätze konzeptionell gezielt die Vorgaben des Tonerfinders in Thema und Durchführung ein- und weiter ausbauen: Dem Wiedergebrauchs-Typus nach ist $\mathrm{k} 739$ somit $\mathrm{k} 20$ und q 280 mit TannhäuserStrophen (siehe oben), bezeichnenderweise ebenfalls eher vom Rande der meisterlichen Gattungstradition, an die Seite zu stellen. Demgegenüber führt das Fünferbar k 736 auf einen ,Pool' von alten Einzelstrophen: Die zweite und dritte Strophe stammen wohl noch vom Tonerfinder und sind altbezeugt, die Eingangsstrophe ist zwar nicht altbezeugt, aber in weiteren Liedern als fungibel einsetzbare, selbstständige Einzelstrophe belegt, und bei Str. 4 und 5 handelt es sich um „minneliedhafte Einzelstrophen“" ${ }^{\text {“9 }}$. Der Text von k 736 zeigt das Material lockerer verbunden als andere Zeugen, die kohärentere Zusammenhänge in Richtung einer geschlossenen Ballade herstellen. ${ }^{40}$ Der k-Text steht damit der Praxis des Tonautors zumindest typologisch relativ näher, denn „Reinmar von Brennenberg unterscheidet sich von anderen Minnesängern dadurch, daß er in seinem großen Ton ,Minnelieder' dichtete, die jeweils nur aus einer Strophe bestehen ${ }^{\text {“41 }}$. Eine nähere Bestimmung der Zeitstufe indes, auf der die in $\mathrm{k}$ bezeugte Zusammenstellung anzusiedeln ist, setzt sehr viel weiter ausgreifende Untersuchungen zur Brennenberg-Rezeption voraus: Nicht nur ist auch das Dreierbar k 735 einzubeziehen, das ebenso aus drei alten Einzelstrophen zusammengesetzt ist - separate Zudichtung der dritten Strophe, um auf den Barumfang zu kommen, ist jedenfalls auszuschließen,$-{ }^{42}$ sondern vor allem begleitend zu klären, auf welcher Rezeptionsstufe man sich eigentlich die zahlreichen Teilverwertungen von Reinmar-Vorgaben vorzustellen hat, die vielfach nur aus einzelnen Versen bestehen, nicht aber aus ganzen Strophen. An diese Frage führt bereits k 735 mit der ersten Strophe, und weiterhin sind dann alle restlichen oben verzeichneten Lieder von ihr tangiert: ${ }^{1} \operatorname{ReiBr} / 517 \mathrm{a}, 524 \mathrm{a}, 526 \mathrm{a}$ und 534ab. Das kann mit der gebotenen Sorgfalt hier nicht entfernt geleistet

38 Ingeborg Glier: Artes amandi. Untersuchungen zu Geschichte, Überlieferung und Typologie der deutschen Minnereden. München 1971 (MTU 34), S. 111.

39 Das Königsteiner Liederbuch. Ms. Germ. qu. 719 Berlin. Hg. von Paul Sappler. München 1970 (MTU 29), S. 311. Vgl. zum ganzen Bar Baldzuhn 2002 (Anm. 7), S. 384f.

40 Vgl. Sappler 1970 (Anm. 39), S. 311.

41 So ebd., S. 227.

42 Vgl. zu diesem Lied detaillierter und differenzierter Baldzuhn 2002 (Anm. 7), S. 380383. 
werden. Festgehalten sei aber für das spezielle Untersuchungsziel des vorliegenden Beitrags,

- dass Sappler für die anonyme Str. 2 in ${ }^{1} \operatorname{ReiBr} / 517$ a (Str. 1 und 3 stammen vom Tonerfinder) zwar jüngere Entstehung ansetzt, aber gleichwohl ursprüngliche Selbstständigkeit; ${ }^{43}$

- dass man für das neunstrophige Liebeslied aus Teilen anderer Lieder Reinmars in Eghenvelders Liederbuch ( $\left.{ }^{1} \mathrm{ReiBr} / 524 \mathrm{a}\right)$ kaum eine Zudichtung von acht Strophen wesentlich im Blick auf das Bar annehmen wird - dies auch deshalb nicht, weil es sich dem im engeren Sinne meisterlichen Gattungszusammenhang und seinen Formerwartungen durch seinen variablen Strophenumfang entzieht, der zwischen vier und sieben Versen wechselt;

- dass das dreistrophige Lied ${ }^{1} \operatorname{ReiBr} / 526 a$ aus dem Kebitz-Liederbuch mit Reinmars alter Eingangsstrophe zumindest in Str. 2 über eine weitere alte, andernorts in anderer Umgebung bezeugte Einzelstrophe verfügt, die damit nicht primär als Barergänzung konzipiert worden sein kann - was, eben im Rahmen solcher Mitüberlieferung, für die dritte Strophe dann ebenfalls eher auszuschließen ist. ${ }^{44}$

\section{Eine erste Zwischenbilanz}

Die detaillierte Durchsicht zunächst der kleineren Bestände ergibt einen eindeutigen Befund: Von den 33 (recte 30) Liedern und den 42 (recte 32) Strophen führen nur drei Liedeinheiten der Überlieferung, k 20, q 280 und k 739, auch auf zweifellos alte Vorgaben aufnehmende, konzeptionell neue Lieder - wobei ich ,Lied' hier nun im engeren Sinne auffasse. Selbst dort spielt das Erreichen des Bars aber in zwei Fällen gar keine Rolle: k 20 stellt eine Elferreihe her, und k 739 hat bereits eine Dreierreihe als Ausgang. Ferner sind in q 280 zwar zwei Altstrophen aufgenommen und um fünf auf sieben Strophen erweitert, doch geschah das vielleicht erst 1505 oder wenig später und damit in deutlicher zeitlicher Distanz zu den anonymen nachsengern der meisterlichen Liedkunst, zeitlich allenfalls in Nähe zum institutionalisierten Meistergesang. Unabhängig davon kommt Distanz zur Tradition der Fremdtonverwendung innerhalb der meisterlichen Liedkunst über alle drei Lieder hinweg durch anonyme nachsenger in den betroffenen Autoren und Tönen - beim Tannhäuser mit dem ,Ludeleich ${ }^{c}$

43 Vgl. Sappler 1970 (Anm. 39), S. 302.

44 Sapplers Kommentar formuliert in diese Richtung jedenfalls keine Beobachtungen: vgl. ebd., S. 304-307. 
und seinem Hofton sowie bei Reinmar von Brennenberg mit seinem Hofton - zum Ausdruck. Diese Ergänzungen sind kaum dezidiert für die Praxis der nachsenger und einen besonderen Abschnitt der Gattungsgeschichte - die Phase des Übergangs zum mehrstrophigen Meisterlied - zu reklamieren. Sie stellen eher eine für strophische Dichtung des Spätmittelalters generell vorhandene Möglichkeit des produktiven Umgangs mit vorgegebenem Material dar.

Für die übrigen Liedeinheiten sind Zudichtungen vereinzelt, v. a. bei irregulärem Barumfang, dezidiert auszuschließen. Oft sind sie das zwar nicht mit Sicherheit, oft ist aber ebenso statt Zudichtung auch die schlichte nachträgliche Zusammenstellung älteren, ehedem ganz selbstständigen oder doch fungiblen, sprich andernorts auch in anderen Strophenumgebungen belegten Strophenmaterials zu erwägen. Das ist dann aber keine nachsenger- und Vortrags-, sondern Sammlerpraxis schriftlicher Überlieferung, wobei das Ergebnis eigentlich immer inhaltlich-thematisch sinnvolle Liedgebilde sind. Eine größere Wahrscheinlichkeit als Zudichtungen haben solche Zusammenstellungen insbesondere dort, wo das Altmaterial des Tondichters in Verbindung mit andernorts noch einmal in anderen Liedkontexten belegten, mithin fungiblen, nicht allein auf ein einziges Bar hin konzipierten Strophen erscheinen. Diese in der Übersicht oben mit Sternchen gekennzeichneten Konstellationen waren bis hierher noch nicht allzu häufig, beziehungsweise vor allem beim ,untypischen' Reinmar von Brennenberg anzutreffen. Sie häufen sich aber signifikant in den Korpora Boppes, Frauenlobs, Konrads, des Marner (s. u.).

Besonders hervorgehoben sei bis hierher schon, dass sekundäre Funktionalisierung von Altstrophen der Tonerfinder, die von nachsengern noch einmal verwendet worden wären, nicht zuletzt zum Zwecke der Barauffüllung, nicht nur nicht in jener Breite und Selbstverständlichkeit sichtbar geworden ist, die der Breite und Selbstverständlichkeit entspräche, mit der die Forschung auf dieses Erklärungsmuster für die Entstehung, inhomogener' Bare zurückgreift. Sie ist eigentlich nirgends wirklich deutlich sichtbar geworden. Die Zahl der alten meister, deren Texte diesem Verfahren unterzogen worden wären, hat sich von fünfzehn auf die nachstehend noch durchzusehenden vier reduziert.

Vor diesem Hintergrund sei die Durchsicht der noch ausstehenden 66 Liedeinheiten Boppes, Frauenlobs, Konrads und des Marner etwas abgekürzt, indem nämlich ein Perspektivwechsel vollzogen und die Nachweispflicht gewissermaßen umgekehrt wird. Nachstehend werden die nunmehr als per se unwahrscheinlicher gewordenen Zudichtungen nicht mehr zunächst dezidiert ausgeschlossen, sondern es wird - angesichts des begrenzten Raumes in aller Kürze - vor allem auf die Möglichkeit anderer Erklärungen verwiesen. Nur wo sie nicht sofort zuhanden sind und auch nichts Vergleichbares anzuführen ist, 
das Zudichtung relativiert, wird noch einmal genauer nach dieser einen Möglichkeit gefragt.

\section{Boppe, Frauenlob, Konrad, Marner: vier einschlägigere Korpora?}

\subsection{Boppe}

Die zweite Strophe im Fünferbar k 592 in Boppes Hofton wurde auch im Fünferbar k 612 noch einmal verarbeitet - sie ist also nicht fest in ein neues Lied im engeren Sinne eingebunden, deren Strophen damit verbraucht wären und nicht mehr eingesetzt werden könnten. Das gilt ebenso für die Zusatzstrophen, die nicht allein auf dieses Bar hin gedichtet wurden, da sie auch andernorts begegnen. Es handelt sich durchweg sehr wahrscheinlich um alte Einzelstrophen. ${ }^{45}$ Mit denselben Argumenten lässt sich für k 623 verfahren: Die Zusatzstrophen sind alte, auch andernorts eingesetzte, fungible Einzelstrophen. ${ }^{46}$ Im Dreierbar k 602 mit jeweils einem Tierbeispiel von Einhorn (Str. 1), Löwe (Str. 2) und Leopard (Str. 3) ist Str. 3 alte Einzelstrophe vom Tonerfinder, Str. 1 ebenfalls alte, fungibel bezeugte Einzelstrophe (in k 606,7); die Mittelstrophe ist nur hier bezeugt, doch spricht von ihrem Text her nichts gegen die bereits vom Kontext her nahegelegte alte Selbstständigkeit. ${ }^{47}$ Auch wenn sie sich thematisch gut in die Reihe der Tierbeispiele einfügt, muss sie deshalb keine Zudichtung sein.

Der bisher unedierte Text (für Str. 1 vgl. Baldzuhn [wie Anm. 7], S. 356, für Str. 3 in der Boppe-Ausgabe von Alex ${ }^{48}$ Nr. I,7) nachstehend abgedruckt unter Auflösung von Abbreviaturen, Absetzung von Gegenstollen und Abgesang und der - ergänzend gezählten - Verse sowie Vereinheitlichung der Groß- und Kleinschreibung und der Grapheme $<\mathrm{y}>$ und $<\mathrm{ii}>$ nach Lautwert $\mathrm{zu}<\mathrm{i}>$ sowie gelegentlich von $<\mathrm{v}>$ nach Lautwert $\mathrm{zu}<\mathrm{u}>$. Ferner sind überflüssige Tremata beseitigt (mehrfach $<\ddot{\mathrm{u}}>$, dazu vereinzelt $<$ öu $>$ und $<$ aü>) und ist die Interpunktion ergänzt.

Des lewen art ist harte wonderlich getan: er tiliget mit dem sweiffe nach im sine ban, daz er sine spor dem jager mache tougen. wanne er siht dot geborn die sinen welffelin,

45 Vgl. detaillierter zum ganzen Bar Baldzuhn 2002 (Anm. 7), S. 344-347.

46 Vgl. ebd., S. 367.

47 Vgl. ebd., S. 356 (ohne Besprechung der Mittelstrophe).

48 Heidrun Alex: Der Spruchdichter Boppe. Edition - Übersetzung - Kommentar. Tübingen 1998 (Hermaea N. F. 82). 
er machet lebendig sie mit dem schreie sin;

er slaffet auch mit uff standen augen.

got durch uns sam ein lewe starck

die gotheit sin bi der vil reinen megde

mit ir nature so gar verbarg,

10

daz sie gespürte nie des tüfels iagde.

uns toden kinden er erwarp

ein immer (Hs. vmmer) leben an dem crütze here,

do sine menscheit schriende erstarb:

des dancken wir ime hut und immer mere.

15

gein uns auch immer uffen stant die augen siner güte,

daz uns hie lat in keiner not

der milte got,

lan wir die sönde, und dut uns fri dort vor der hellen glüte. (k 602,2: Bl. 562vab)

Ebenso kann wiederum für das Fünferbar k 612 argumentiert werden: Str. 1 ist alter Einzelspruch vom Tonerfinder (siehe oben k 592,2), Str. 3 und 4 sind ebenfalls entweder Einzelsprüche oder, so als Paar konzipiert, doch ohne Rücksicht auf die Barform angelegt; sie werden jedenfalls noch an anderer Stelle, fungibel also, eingesetzt (in k 598,1f.); Str. 2, nur hier bezeugt, kann „sehr gut für sich bestehen “49. Für die bisher nirgends besprochene und bisher unedierte Str. 5 gilt dasselbe.

Ach süsser zarter minniclicher Jhesus Crist, wie mich herbarmet, daz du so gepinet bist vor mich vil gar an lib und auch an hertzen. wan du wol vor bekantest diner martel last,

5 da von was dir die grimme sorge nit ein gast, die schanckte dir unmeßeclichen scmertzen

durch achtung und der juden haz, ir spot und all ir falschen hertzen rete. wer mochte gar betrachten daz,

10 wie vochtiklich du vor die martel bete. dar nach fing dich der juden schar, als sie wiste Judas, der ungetrüwe. din antlitz war verspüwen gar; von dorne scharpf wart dir ein crone nüwe;

15 gegeisselt wurdu und gespannen an daz crütze, herre, da litte du den grimmen dot.

mit dirre not

vergiltu unser missetat durch diner mutter ere.

(k 612,5: Bl. 571vab)

49 Baldzuhn 2002 (Anm. 7), S. 362 (vgl. dort auch zum ganzen Bar sowie den Textabdruck des Bittspruchs der Str. 2 S. 363). 
Demgegenüber ist für das Dreierbar k 609 mit zweiter Strophe des Tonerfinders ${ }^{50}$ und nur hier bezeugter Eingangs- (RSM zu ${ }^{1}$ Bop/517a,1: „Schilderung der himmlischen Herrlichkeit" - für den Text s. u.) und Schlussstrophe (RSM zu ${ }^{1}$ Bop/517a,3: „Anrufung Gottes“ - für den Text s. u.) als zu Boppes Rede von der wunderbaren Menschwerdung Gottes passender Rahmung zunächst eine längere alte Strophenreihe im Hintergrund zu erwägen, die dem k-Schreiber noch ohne Bargliederung vorlag und innerhalb derer der ganze fragliche Themenkomplex von insgesamt acht Strophen umspielt wurde. Das Bar ist nämlich vom vorangehenden $\mathrm{k} 608$ (das freilich mit Aber fünff [Bl. 568va] bereits korrekt angekündigt wird) erst nachträglich durch erst marginal hinzu gesetztes aber iij (Bl. 569rb) abgetrennt worden, zudem ist dort nachträglich eine größere Lombarde eingetragen. Die Annahme einer älteren längeren Strophenreihe wird über die erst ergänzte Barteilung und den thematischen Zusammenhang aller Strophen hinaus durch die erneute Verarbeitung einer alten Einzelstrophe (freilich nicht mehr des Tonerfinders) auch in $\mathrm{k} 608$ gestützt. ${ }^{51}$

Ach susser got wie lange sol ich din enbern, an dem ich finde, waz min hertze mag begern, so ich dich sehen werd in dinem riche.

da wirt min lip und auch min sel herluchtet gar. min minnen wirt nach dinem willen glich gefar, suß richz ich mit dir iemer sicherlichen.

siech tag, drackeit und alles leit, alter und dot, nit muß ußerhalp bliben. dumpheit, not und auch arebeit,

$10 \quad$ kan din antlitz vol wonnen gar vertriben.

Maria schinet sunder bar

in keiserlicher er bi dinem trone.

dar nach der claren engel schar,

die lobent mit den heiligen dich vil schone.

15 die uber suße geselleschaft enmag kein sin begriffen.

ir sang und all ir wünnen spil

daz ist so vil.

zuch uns dar, minniclicher got. las uns dir nit entsliffen. (k 609,1: Bl. 569rb-va)

50 Vgl. zu ihrer Selbstständigkeit die Diskussion in Auseinandersetzung mit der älteren Forschung bei Baldzuhn 2002 (Anm. 7), S. 361-362.

51 Der RSM-Artikel notiert zum Inhalt von k 608,1: „Ermahnung an die Seele, Gott zu lieben und ihm zu folgen“, von k 608,3-5: „Jüngstes Gericht und ewige Vergeltung“. Die zweite Strophe bietet eine „Anrufung Gottes“. Zu ihrer Selbstständigkeit siehe Baldzuhn 2002 (Anm. 7), S. 361. 
$\mathrm{Nu}$ il, hochgelopter vatter, sun (Hs. Sunn), heiliger geist, almechtig got, wan du gewalteclichen weist gericht besitzen wilt ob uns vil armen.

so gip dinem sünder dinen gnedeclichen drost.

5 gedencke, daz du in so tüer hast herlost, und laß dich, herre, sine sünd herbarmen.

gedencke an din demu'tikeit. gedencke an dine manigfaltig güte. laz im die sünde werden leit, so daz din crafft in vorbaß me behüte von engestlicher wunder not und vor des leiden tüfelz angesichte. daz bitt ich dich durch dinen dot. gedenck, daz du gemacht uns hast von nichte, und sende dinen fronen geist durch diner mutter ere. auch bitten wir den selben got, daz sin gebot ob uns vil armen an dem tag er gnedeclichen kere.

(k 609,3: Bl. 569vb)

In ähnlicher Weise führen auf einen, Pool' von inhaltlich-thematisch - nun qua gemeinsamer Ausrichtung auf Marienpreis, dabei aber durch Verwendung der Strophenanapher Ave Maria teils noch einmal enger - verwandten Strophen die Bare k 596 und k 633: Ersteres bietet in Str. 5 einen Marienpreis des Tonerfinders und vier weitere Preisstrophen, von denen Str. 1f. und 4 nur hier erscheinen, indes Str. 3 in eine neunstrophige Mariengruß- und Preisreihe bereits des Faszikels $\mathrm{H}$ im Cpg 350, also vor die Mitte des 14. Jahrhunderts zurückführt, wo sie die vierte bildet. Sechs der dort alle die Ave Maria-Strophenanapher aufweisenden neun Strophen, darunter auch die vierte, erscheinen dann noch einmal im Siebenerbar k 634, dort ergänzt um eine weitere mit Ave Maria-Eingang. Diesen hat im übrigen auch k 596,4, so dass diese Strophe ebenfalls in einen alten, von $\mathrm{H}$ in extenso, aber nicht vollständig bezeugten ,Pool' einzubeziehen sein mag. Die - hier nicht zu leistende - weitere Erörterung eines solchen Materialkomplexes hat schließlich - mindestens - noch das in $\mathrm{k}$ unmittelbar vor k 634 stehende Dreierbar k 633 zu berücksichtigen: ebenfalls eine Reihe von Marienpreisstrophen, in der k 596,5 nun die dritte Strophe bildet, während Str. 1 und 2 nur hier bezeugt sind. ${ }^{52}$

$52 \mathrm{Zu}$ allen drei Baren (k 596, k 633, k 634) vgl. Baldzuhn 2002 (Anm. 7), S. 350 und S. 369. 
Als einziger Kandidat, für den man weder sogleich auf weitere anonyme alte und unfeste Einzelstrophen in der unmittelbaren Umgebung noch auf alte Strophenreihen der Überlieferung noch auf alte Strophen-Pools hinweisen kann, für den mithin Zudichtung zu erwägen ist, verbleibt k 599 mit einem alten Strophenpaar Boppes, das freilich alt auch getrennt bezeugt ist, und einer anonymen Schlussstrophe:

Allz gut, daz all dies welt nu hat und ie gewan, obe daz nu hett und kond geleisten ein einiger man, der wer gar unmassen sere riche.

und hett er alles lant gar untz ein (Hs. an) einges lant, und daz das alles samment stonde in sinre hant, wer moht dem edelen fürsten denne glichen.

dannoch gewonn er nimmer genug, er hette dann daz einige lant getrungen. daz ist ein michel ungefug:

10 gitekeit hat manichen man betwongen. nieman sich nu benugen lat: wie wol er hat, so hette er gern mere. des lidet manich man große not umb czitlich gut und auch umb weltlich ere.

15 wir hettent alsamt gerne vil und mogens nit behalten. got nimt und wider wanne er wil: er seczt ein zil. ez stat alles in siner hant und auch in sime gewalte.

Der Text tadelt Geiz und mahnt, sich mit dem Gegebenen zu bescheiden, da letztlich doch alles in Gottes Hand stünde. Er fügt sich sehr gut zur vorangehenden Rede Boppes vom vollkommenen Menschen, dessen vorzüglichsten körperlichen und besonders geistigen Fähigkeiten ihm auf der Welt ohne Geld letztlich nichts einbringen (Str. 1: I,30), beziehungsweise zu seiner Rede vom omnipotenten Menschen, der auf Erden alles erreichen kann und doch ohne Gottes Huld nichts erreicht hat (Str. 2: I,1). Er ist freilich auch aus sich heraus verständlich und bedarf keines Vorspanns. Ein separater Bezug auf die meister-Autorität des Tonautors Boppe und dessen Textautorschaft in Str. 1f. ist nicht zu erkennen. Zudichtung ist also vorderhand nicht zwingend anzunehmen. Einer (hier nicht zu leistenden) Überprüfung bedarf dies freilich noch im Hinblick auf die Veränderungen, denen die alten Boppe-Texte 
unterworfen wurden, da sie auf den Zusatz einer dritten Strophe abgestimmt worden sein könnten. ${ }^{53}$

\subsection{Konrad von Würzburg}

Im Unterschied zu den späten Liedeinheiten Boppes liefern diejenigen Konrads von Würzburg einige signifikantere Belege für eine Ausrichtung der jüngeren Strophen auf die Vorgaben des Tonerfinders. Festzuhalten ist freilich zunächst, dass die Liedeinheiten ganz überwiegend dem Cgm 4997 entstammen, der unvergleichlich weiter in die ältere Überlieferung zurückgreift als alle anderen Meisterliederhandschriften. Weiterhin hat für die Konrad-Überlieferung von k Günter Mayer festgehalten, dass „keine großen Umarbeitungen feststellbar sind “. ${ }^{54}$ Das stützt noch einmal, nun im Blick auf k 536/537 mit dem Altstrophenpaar von Str. 3f. im Aspiston, die an anderer Stelle schon einmal angesichts dieser Siebenerreihe (aus zwei Strophenpaaren und einer Dreiergruppe bestehend) sowie der folgenden vier Einzelstrophen des Tonerfinders Konrads in $\mathrm{k} 538$ vorgetragene Vermutung, dass dieser ganzen Reihe eine ältere Vorlage zugrundeliegt, die einzelne Strophen und Strophenpaare des Tonerfinders mit denen von Fremdtonverwendern zusammenführte, der aber Barzusammenhänge noch nicht wichtig waren. ${ }^{55}$

Ein kleinerer Ausschnitt aus einer solchen Reihe ist im Dreierbar k 556 in der Morgenweise zu fassen: Str. 1f. ist von Konrad, Str. 3, die sich Bartsch gar noch von einem Zeitgenossen Konrads verfasst dachte, ${ }^{56}$ gesellt sich als selbstständige Einzelstrophe sinnvoll dazu, ohne dass Auffüllung um der Barform willen ersichtlich würde. Demgegenüber könnte im zweiten oben erfassten Lied in der Morgenweise, in k 544, sehr gut der - dann nach bisherigem Stand der

53 Für die zweite Strophe (Boppe I,1) ist von den ersten Hinweisen bei Alex 1998 (Anm. 48), S. 15-16 auszugehen. Die neue Strophenumgebung der Boppe-Sprüche wird bei Alex leider weder hier noch für die anderen Bare weitergehend einbezogen. Ihre Ausgabe begnügt sich mit kurzen Paraphrasen der Zusatzstrophen und der Abbildung der entsprechenden Blätter aus der jüngeren Handschriftenüberlieferung.

54 Günter Mayer: Probleme der Sangspruchüberlieferung. Beobachtungen zur Rezeption Konrads von Würzburg im Mittelalter. München 1974, S. 114. Das ist im Einzelfall freilich zu differenzieren. Ausgegangen kann in einem ersten Schritt von den Anmerkungen Bartschs in seinen Abdrucken aus k (vgl. etwa S. 685-686 zu seiner Nr. 110).

55 Vgl. Baldzuhn 2002 (Anm. 7), S. 233-235.

56 Vgl. Bartsch 1862 (Anm. 3), S. 165-166 und seinen Rekonstruktionsversuch S. 685686. 
Durchsicht durchaus als selten zu bezeichnende - Fall einer gezielten Ergänzung vorliegen: An den selbstständigen objektiven Frauenpreis des Tonerfinders, in $\mathrm{C}$ von ganz anders ausgerichteten Sprüchen gerahmt, schließen zwei Strophen an, in denen nunmehr ein subjektiv von der minne betroffenes Ich spricht und auf diese Weise die Aussagen der Eingangsstrophe gewissermaßen in ihrer Gültigkeit am eigenen Leib belegt. Dabei greift die erste Zusatzstrophe Reime der ersten Strophe gezielt auf (I,6 und 12 : beslozzen: verdrozzen; II,6 und 12: geslozzen: geschozzen), und im Eingang der dritten Strophe (III,1-4) werden signifikant die eben nicht nur einseitigen, sondern wechselseitigen Blicke von I,14-17 aufgenommen. Für die damit erreichte Dreistrophigkeit ist freilich zu bedenken, dass sie sich auch wesentlich der Umformung zum Liebeslied verdanken könnte - dann rückte diese Konrad-Aufnahme dem Typus nach an die Wiederaufnahmen von Tonerfinderstrophen in k 20, k 739 und q 280 heran. Hinweise auf eine Beseitigung von Defizienz und auf eine Instrumentalisierung Konrads als alter meister für das eigene Sprechen des nachsengers finden sich jedenfalls keine. Sollte ihm die Barform überhaupt von Bedeutung gewesen sein, dann wahrscheinlich nur als bereits verbreitete, selbstverständliche Konvention: Subjektiviertes Sprechen von der Minne in Sangspruchtönen ist breiter nämlich besonders in der Nachfolge Frauenlobs im 14. Jahrhundert zu belegen..$^{57}$

Die Verhältnisse im Hofton seien nachstehend von w 96,1 aus entfaltet. ${ }^{58}$ Die Strophe ist zwar aus sich heraus verständlich und erscheint abgeschlossen, hängt aber doch mit ihrem Schluss, der Zusicherung Jesu an Gottvater, sich auch um den Preis seines Blutes willen opfern zu wollen, etwas in der Luft: Man erwartet eine Fortsetzung des begonnenen Themas, in welche Richtung sie auch

57 Bartsch freilich dachte sich beide Strophen noch von einem Zeitgenossen Konrads verfasst. Vgl. Bartsch 1862 (Anm. 3), S. 165-166 und seinen Rekonstruktionsversuch S. 683-684. Zur Subjektivierung der Minne im Sangspruch vgl. Michael Baldzuhn: Minne in den Sangspruchtönen Regenbogens. Eine Überschau in typologischer Absicht. In: Sangspruchdichtung. Gattungskonstitution und Gattungsinterferenzen im europäischen Kontext. Internationales Symposium Würzburg, 15.-18. Februar 2006. Hg. von Dorothea Klein, Trude Ehlert und Elisabeth Schmid. Tübingen 2007, S. 187-242, hier S. 212-219.

58 Vgl. zum folgenden auch Baldzuhn 2002 (Anm. 7), S. 240-246 zu k 564, 566-568 und 574 einschließlich der Entsprechungen in w 91 (wie k 574) und w 94 (wie k 564, jedoch mit vertauschten Strophen). Dort ist lediglich die Eingangsstrophe von w 96 (Str. 2f. nämlich dort wie k 568,2f.) unerörtert geblieben. Ihren Text bietet Bartsch 1862 (Anm. 3), S. 691. 
ginge. Str. 2 in w 96 kann man als eine solche verstehen, ohne dass es freilich genau nach dieser Folgestrophe verlangte. Mit dieser nur noch partiellen Offenheit stellt sich w 96,1 ebenso zu w 96,2f. = k 568,2f. wie zu k 568,4f., mithin zu allen Strophen des ganzen Komplexes, die der Forschung als noch von Konrad verfasst gelten, aber eben auch zu k 568,1. Auch diese Eingangsstrophe ist wie w 96,1 nur einmal in jüngerer Liedeinheit belegt und nicht, wie die Altstrophen, dazu in wechselnden Zusammenstellungen. Konrads Einzelstrophen waren hier wohl für nicht gänzlich eigenständigen Einsatz konzipiert, sondern auf eine Verwendung zwar in wechselnden, aber eben thematisch enger verwandten Kontexten hin gedacht. Genauso sind k 568,1 und w 96,1 angelegt. Das gilt ebenso für die zwei Ergänzungen von Marienpreis und Marienanrufung, die Konrads Marienpreis aus diesem Komplex (vgl. k 568,5) in k 566,1 und 3 neu rahmen: Sie können als ,gezielte Zudichtung [...] um der Auffüllung zum Bar willen nicht zureichend verstanden werden ${ }^{\text {“59 }}$, da sie andernorts (in Straßburg, UB, Cod. 1995) eben auch ohne sie kursieren. Je spezifischer freilich der besprochene Gegenstand wird, desto engere Grenzen sind dem wechselnden Einsatz gesetzt, desto eher ist mit gezielten Zudichtungen zu Altstrophen eines meisters zu rechnen, desto eher gewinnt das Bar auch eine innere Einheit und textuelle Kohärenz, desto weniger freilich erscheint mechanische Zudichtung um der Barform willen wahrscheinlich. Auf solchen Wiedergebrauch führen zum einen die Dreierbare k 564 beziehungsweise mit vertauschten Strophen w 94, die recht präzise Konrads Lobspruch auf die Selbstdisziplinierung der Frau, die ihr Verlangen nach unkiusche durch kiusche zu beherrschen weiß, umrahmen beziehungsweise in ihn münden. Bartsch dachte sich beide ergänzten Strophen noch in Konrads näherem Umkreis entstanden, ${ }^{60}$ jedoch weisen zumindest für die erste Strophe mehrere Indizien eher in die Mitte des 14. Jahrhunderts, in eine Konrad-Verehrung im Umkreis Michaels de Leone und Lupold Hornburgs ${ }^{61}$ Auf ihn führen zum weiteren die strophenidentischen Dreierbare k 574 und w 91, die Konrads Preis des Gesangs vor der Instrumentalmusik zweistrophig präludieren: noch „das werk eines gleichzeitigen dichters" vielleicht, wie Bartsch meinte, ${ }^{62}$ auf jeden Fall aber in einem Kontext entstanden, der noch von einem höfisch-adeligen Publikum der Gattung, von küngen, fürsten, herren

59 Baldzuhn 2002 (Anm. 7), S. 242.

60 Vgl. Bartsch 1862 (Anm. 3), S. 165.

61 Vgl. Baldzuhn 2002 (Anm. 7), S. 241.

62 Vgl. Bartsch 1862 (Anm. 3), S. 165. 
und frîen ausgeht. ${ }^{63}$ Eine meisterlich-späthöfische Phase der Konrad-Rezeption im fortgeschrittenen 14. Jahrhundert könnte zukünftig einmal von einer ersten Phase in seinem zeitlich näheren Umfeld zu unterscheiden sein. Leider ist so viel Sicherheit nicht zu gewinnen, dass man noch die mehreren Verarbeitungsstufen Konrads, auf die schließlich das Siebenerbar k 567 führt, diesen Phasen eindeutig zuordnen könnte: Drei Altstrophen Konrads erscheinen zwar je selbstständig, aber doch, darin $\mathrm{k} 564$ und $\mathrm{k} 574$ vergleichbar, thematisch mit der Ausrichtung auf die verlorne[] zyt - so die Liedrubrik in $\mathrm{k} \mathrm{Bl.} 532 \mathrm{va}$ - bereits so spezifisch, dass man sie sich nicht ohne passende Ergänzungen vorstellen möchte - die nun Konrad ja auch selbst schon mit den in k 567,2-4 verarbeiteten Strophen bereit hält. ${ }^{64}$ Hinzu kommt mit k 567,1 ein jüngerer Eingang zu dieser Gruppe, die damit eine mindestens zwei- und maximal vierstrophige Gruppe gebildet hätte, der zumindest auf die Folgestrophe k 567,2 u. a. in den Reimen präzise abgestimmt ist. Ferner sind der ganzen Gruppe noch drei jüngere Strophen angehängt, die Bartsch zufolge von einem anderen Verfasser als dem des neuen Eingangs stammen ${ }^{65}$ und die das Vergänglichkeitsthema zu Sündenbekenntnis und Sündermahnung ausweiten. Barauffüllung um der Form willen spielte bei alledem sicher keine Rolle, und die Erklärung des Vorliegenden mit lediglich sinnvoller Zusammenstellung eines sammelnden Redaktors vereinfacht ganz sicher: dies wenigstens kann man festhalten und ferner, dass spezifische Referenzen auf Konrad als Verfasser der weiterverarbeiteten Strophen im Liedtext selbst nirgends zu erkennen sind.

\subsection{Marner}

Der Fall der vier Sprüche des Marner im Goldenen Ton in k 520 mit der anonymen zweiten Zusatzstrophe wird bei Haustein differenziert diskutiert; sein Fazit lautet im Hinblick auf die Ergänzung u. a.: „keineswegs eine

63 Vgl. ebd., Nr. 120, Str. 1, V. 2 für küngen fürsten herren frîen und Str. 2, V. 1 vor hôhen fürsten.

64 Auch dem Rubrikator ist diese engere Ausrichtung nicht entgangen. Er hat sich angesichts ihrer - das ist nicht selten in $\mathrm{k}$, doch nicht auch völlig selbstverständlich - zum Eintrag einer den besonderen Inhalt des ganzen Liedes benennenden, damit individuellen Überschrift entschlossen: Vij lied in dysem ton von der verlornen zyt (Bl. $532 \mathrm{va})$.

65 Vgl. Bartsch 1862 (Anm. 3), S. 165-166 zu Nr. 116 seiner Ausgabe: Str. 1 sei „das werk eines gleichzeitigen dichters“, Str. 5-7 hingegen seien „spätern ursprungs“. 
Verlegenheitslösung, etwa um die Erweiterung zum Fünferbar zu erreichen“. ${ }^{66}$ Für eine schlichte Verlegenheitslösung nimmt Str. 4 in der Tat zu deutlich Gedanken und gar Wortlaut aus Str. 1 und 5 auf - Haustein schließt für sie gar eine „Variation“ ${ }^{6_{77}}$ nicht aus, die im Vortrag die eine oder andere Strophe ersetzen könne. Denkt man nicht gleich auf das ganze Bar hin, sondern erfasst die Verhältnisse zunächst kleinteiliger, ist festzuhalten: Wenn Str. 4 von einem nachsenger stammt, hat hier ein Fremdtonverwender bei der Ausarbeitung Bestehendes des Tonerfinders im Blick gehabt, daran angeschlossen und sich damit potentiell Möglichkeiten für eine Vortragsreihe mit seiner eigenen Strophe in Kombination mit weiteren alten, vielleicht nur einer, vielleicht mehreren, eröffnet.

Keine ,Verlegenheitslösung (Haustein): Das ist ebenso für den Strophenkomplex im Kurzen Ton festzuhalten, in den k 529 führt. Denn altes Gut ist hier einerseits „auf grandiose Weise zu einer kleinen ,Künstlerbiographie“ “ zusammengeführt, ,,in der die Themen ,Kunst und Gesellschaft', ,Armut des Sängers und ,Sterblichkeit' auf vielfache Weise untereinander verbunden sind und sich gegenseitig erläutern“ ${ }^{68}$ Andererseits wird man für Str. 5 nicht übersehen, dass sie auch für sich bestehen kann und noch in andere Liedkontexte einging. Und für Str. 3 ist zwar diese Fungibilität nicht belegt, doch erscheint auch ihr Text multipler einsetzbar als ausschließlich in ihrem durch $\mathrm{k}$ bezeugten Kontext. ${ }^{69}$ Beide Lieder, $\mathrm{k} 520$ wie k 529, führen wohl noch in jene Phase der Herausbildung des mehrstrophigen Meisterliedes im 14. Jahrhundert, in der unfeste Mehrstrophigkeit dominierte und in der dann - unter allenfalls beiläufiger Rücksicht auf die Barform - mit zuhandenen Sprüchen des Tonerfinders wie mit neuen eigenen hantiert wurde. Dorthin führt wohl auch das Siebenerbar k $531 \mathrm{mit}$ drei Einzelsprüchen des Marner an erster, vierter und siebter Stelle und mit einer „sehr wahrscheinlich “70 alten Einzelstrophe an fünfter Stelle: Dezidiert

66 Vgl. Haustein 1995 (Anm. 2), S. 55-58 (das Zitat S. 56). Dem Kommentar zur ganzen nach k edierten Strophengruppe in: Der Marner. Lieder und Sangsprüche aus dem 13. Jahrhundert und ihr Weiterleben im Meistergesang. Herausgegeben, eingeleitet, erläutert und übersetzt von Eva Willms. Berlin, New York 2008, S. 342-345, ist zu ihrer Genese nichts Weiterführendes zu entnehmen.

67 Haustein 1995 (Anm. 2), S. 57.

68 Haustein 1995 (Anm. 2), S. 198. Dem Kommentar zur ganzen nach k edierten Strophengruppe in Willms 2008 (Anm. 66), S. 345-348, ist zu ihrer Genese nichts Weiterführendes zu entnehmen.

69 Vgl. für Str. 5 Baldzuhn 2002 (Anm. 7), S. 341-342 und für die dort nicht näher erörterte Str. 3 den Text bei Bartsch 1862 (Anm. 3) unter Nr. 104.

70 Baldzuhn 2002 (Anm. 7), S. 342. 
gegen die Qualifizierung der Gruppe als „Konglomerat“ - so im RSM-Artikel zu ${ }^{1} \mathrm{Marn} / 6 / 508 \mathrm{a}$ - mündet Hausteins Erörterung des Strophenkomplexes in der Feststellung, man werde sich „kaum eine geschicktere Auswahl und Verbindung alter mit jüngeren Strophen vorstellen können ". ${ }^{71}$ Angesichts der Unsicherheiten des k-Schreibers bei der Unterteilung der Siebenerreihe - zweimal hat er durch größere Lombarden noch andere Strophengruppierungen angesetzt - ist jedoch zunächst zu erwägen, ob nicht eine Strophenreihe älterer Überlieferung des 14. Jahrhunderts noch ohne Barkennzeichnung vorlag, ${ }^{72}$ die passendes Material teils des Tonerfinders, teils von Fremdtonverwendern dann keineswegs sinnlos zusammenstellte: Hausteins Schluss auf ein „,Marnerlied" des 15. Jahrhunderts" ${ }^{\text {“73 }}$ ist jedenfalls verfrüht. Davon unabhängig ist für Str. 2f. und 5f. die Annahme von Zudichtungen, um auf eine Siebenerreihe zu kommen, zu einfach. ${ }^{74}$ Einfache Zudichtungen auf das Bar sind auch für $\mathrm{k}$ 524 und k 532 auszuschließen: u. a. schon deshalb, weil einmal eine Sechserreihe, einmal eine Viererreihe erreicht wird. Im Detail stellen sich die Verhältnisse für die drei Altstrophen und drei jüngeren in $\mathrm{k} 524$ und die zwei alten (eine davon auch in $\mathrm{k}$ 524) und eine jüngere in $\mathrm{k} 532$ überaus komplex dar. ${ }^{75}$ Im Blick auf die hier verfolgte, einfache Frage nach Barergänzungen sei hervorgehoben, dass die Genese von k 524 auch über eine Vierergruppe geführt haben könnte, ${ }^{76}$ was Barzusammenhänge wiederum relativierte, und dass von den jüngeren Zusatzstrophen $\mathrm{k}$ 524,2-4 und 532,2+4 für die letzten zwei ebenso wie für mindestens die zweite in k 524 alte Selbstständigkeit angenommen werden kann: Auch dies führte wiederum eher ins 14. Jahrhundert zurück (für k 532,2 auch die Aufnahme von Versen Wachsmuts von Mühlhausen) als auf eine Zusammenstellung im 15. Jahrhundert. ${ }^{77}$ Angesichts des im RSM unter

71 Vgl. Haustein 1995 (Anm. 2), S. 108-110 (das Zitat S. 110).

72 Dahingehend bereits Baldzuhn 2002 (Anm. 7), S. 342-343.

73 Haustein 1995 (Anm. 2), S. 110.

74 Haustein 1995 (Anm. 2), S. 110. Der Kommentar zur ganzen nach k edierten Strophengruppe in Willms 2008 (Anm. 66), S. 302-306 ist zu ihrer Genese nichts Weiterführendes zu entnehmen.

75 Vgl. Haustein 1995 (Anm. 2), S. 68-72 und Baldzuhn 2002 (Anm. 7), S. 338-339 und S. 343 sowie Willms 2008 (Anm. 66), S. 296-300 (mit Edition jeweils nach k).

76 Vgl. Haustein 1995 (Anm. 2), S. 70 mit Anm. 44.

77 Dahingehend indes ebd., S. 72, im Blick auf die Gruppierung des Altmaterials von k 532 - wofür er freilich nur sehr allgemeine religionsgeschichtliche Argumente beibringen kann. Zum Mühlhausen-Bezug s. Gisela Kornrumpf: Eine Melodie zu Marners Ton XIV in Clm 5539. ZfdA 107 (1978), S. 218-230, hier S. 224, Anm. 15. 
${ }^{1}$ Marn/6/acdg erfassten Komplexes schließlich, der in die bis zu neunzehnstrophige ,Sibyllen-Weissagung führt, wird man kaum annehmen, dass der eine in fünf von sieben Zeugen aufgenommene Marner-Spruch der fünften Strophe Ausgangspunkt und Anlass zur Konzeption der ganzen vielstrophigen Reihe gewesen ist: Er wurde vielmehr, und dies nach Ausweis des ältesten Textzeugen, der Leipziger Handschrift, spätestens um 1400, „erst sekundär [...] verbunden“ und dabei „aktualisierend geändert" (RSM zu ${ }^{1}$ Marn/6/a). ${ }^{78}$

Von den elf Liedeinheiten in Marners Langem Ton, der bereits im 13. und mehrfach im 14. Jahrhundert von anderen Autoren verwendet wurde,$^{79}$ führen k 480,3 und k 503,3 in Faszikel R des Cpg 350, damit ins zweite Viertel des 14. Jahrhunderts zurück und an eine alte Siebenerreihe heran, deren Rubriken vor jeder Strophe die Barkennzeichnung zwar noch nicht geläufig war, die aber vor dem Hintergrund ausgeweiteten Fremdtongebrauchs durch nachsenger und der damit nicht mehr selbstverständlichen Gleichsetzung von Tonautor und Textautor angebracht wurden. ${ }^{80}$ Die anonymen Str. 1f. von k 480 und Str. 1f. von k 503 sind ebenfalls alt bezeugt, führen damit ebenfalls in diese Phase der Fremdtonverwendung: Sie dominant von produktionsästhetischer Warte aus ohne entschiedenen Einbezug der Eigengesetzlichkeiten der handschriftlichen Überlieferung zu betrachten und lediglich als Zusätze zu begreifen, um ein Lied zu erhalten, blendet zahlreiche andere Möglichkeiten ihres Herantretens an den und ihres Zusammenspiels mit dem alten Marner-Spruch aus. ${ }^{81}$

Willms 2008 (Anm. 66), S. 296-300 und S. 348-350, gibt den Text beider Lieder nach k. Ihr Kommentar zu k 532 S. 350 bleibt ganz in der Echtheitsdiskussion befangen.

78 Vgl. Ingeborg Neske: Die spätmittelalterliche deutsche Sibyllenweissagung. Untersuchung und Edition. Göppingen 1985 (GAG 438), sowie Haustein 1995 (Anm. 2), S. 179-182 und Willms 2008 (Anm. 66), S. 171-174 (mit Textabdrucken der Altstrophe jeweils nach allen Handschriften) und S. 314-317 (Text der Strophenfolge der Leipziger Handschrift).

79 Knappe Übersicht bei Schanze 1982-83 (Anm. 2), Bd. 1, S. 72.

80 Vgl. zu den Rubriken Baldzuhn 2002 (Anm. 7), S. 83-85 und Haustein 1995 (Anm. 2), S. 87, der - von anderen Überlegungen angestoßen - S. 87 ganz zu Recht fragt: „Vielleicht sollten die Strophen [sc. in R, M. B.] gar kein siebenstrophiges Lied bilden (wie allgemein angenommen wird, vgl. RSM 4, S. 294) [. . .].?". Vgl. ferner zu den späteren Liedern in k (wobei k 479 einzubeziehen ist) Baldzuhn 2002 (Anm. 7), S. 321-322, 322 und 332.

81 Vgl. die in Rücksicht auf die gesamte Überlieferung geführte und sehr differenzierte, sehr viele Möglichkeiten eröffnende Diskussion bei Haustein 1995 (Anm. 2), S. 80-89. Die Texte nach R, k 480 und k 503 jetzt auch bei Willms 2008 (Anm. 66), S. 289-294, 332-333, 338-340. Auf eine Diskussion von Fragen nach der Genese dieser Einheiten ist dort leider verzichtet. 
Ebenfalls im zweiten Jahrhundertviertel aufgezeichnet führt die (fragmentarische) siebzehnstrophige Reihe in Teil $\mathrm{H}$ des Cpg 350 demgegenüber auf eine denkbar signifikante Wiederaufnahme eines Marner-Spruchs: Die Altstrophe, nunmehr die erste Strophe der Reihe, diente allen folgenden bereits mit ihrem Verseingang als Modell, an das sie zum einen durchgängig anknüpfen (V. 1,1: Da minne menshin müt besaz) ${ }^{82}$; zudem wendet sich in Str. 14 das textinterne Ich mit einer Frage an Petrus (V. 2: Petre, waz det sie dir?), der in seiner Antwort das Ich als Marner anspricht (V. 6: Marner, ich wil dir sagin daz): „ein seltsame[s] Versteckspiel, das zumindest im Umkreis der Dichter durchschaut worden sein dürfte" und dem Weiteres aus dem Frauenlob/Regenbogen- und Konrad von Würzburg-Umkreis an die Seite zu stellen ist. ${ }^{83}$ Auf weitere Spuren eines produktiven Umgangs des 14. Jahrhunderts mit Marner-Sprüchen im Langen Ton führt die Liedgruppe k 470-474, eine kleine "Marner-Sammlung“, in der „ein Rest einer älteren Quellenschicht greifbar" ${ }^{\text {“84 }}$ wird. Ich hebe für diesen ganzen Komplex nur jene sicheren Befunde hervor, die ausschließen, dass primär auf das Bar hin gedichtet wurde:

- In k 470,2-5 liegen deutlich aufeinander abgestimmte Zusätze zu Str. 1 vor, die aber nicht in einem einzigen Durchgang ergänzt wurden, so dass nicht einfach von Auffüllung zum Fünferbar auszugehen ist. ${ }^{85}$

- In k 471 ist Str. 2 präzise Zudichtung zu Str. 1, die das dort gestellte Rätsel auflöst, womit zunächst ein Paar, kein Bar erreicht würde. Nicht ganz so sicher ist für die Mittelstrophe, dass sie auch bereits Str. 3 berücksichtigt hätte. ${ }^{86}$

- In 472/474,3-5 stellen die Zusätze, in die die Parallelen zu k 495 und y 8 noch einzubeziehen sind, ${ }^{87}$ nicht einfach eine an ein altes Strophenbar angehängte

82 Vgl. den Text nach H bei Willms 2008 (Anm. 66), S. 306-313.

83 Vgl. Burghart Wachinger: Rez. zu Mittelhochdeutsche Spruchdichtung, früher Meistersang. Der Codex Palatinus Germanicus 350 der Universitätsbibliothek Heidelberg [. . .]. Wiesbaden 1974 [. . .]. In: AfdA 87 (1976), S. 186-198, hier S. 197-198 (das Zitat S. 197).

84 Schanze 1982-83 (Anm. 2), Bd. 1, S. 72. Vgl. für die Texte aller Liedeinheiten nach k Willms 2008 (Anm. 66), S. 317-329.

85 Vgl. Baldzuhn 2002 (Anm. 7), S. 316 und Haustein 1995 (Anm. 2), S. 91-93, hier besonders S. 93.

86 Vgl. Baldzuhn 2002 (Anm. 7), S. 316-317 und Haustein 1995 (Anm. 2), S. 214-215, hier besonders S. 215.

87 Vgl. für die Texte von k 495 und y 8 Willms 2008 (Anm. 66), S. 350-353 bzw. S. 336338 . 
Strophentrias dar. Denn zumindest für Str. 3 und 4 ist der Parallelüberlieferung zufolge zudem wechselnder Einsatz in anderen Zusammenhängen belegt; gebunden wird die Gruppe zur Trias erst durch die Schlussstrophe des Bars. In die unfeste Mehrstrophigkeit des 14. Jahrhunderts führen auch die Bezugnahmen der Str. 3f. noch auf andere Marner-Sprüche. ${ }^{88}$

- Für die Ergänzungen des eröffnenden Altstrophenpaares k 473,1f. zum Fünferbar setzt Haustein unter Bezug auf ältere Forschungsbeiträge für Str. 4 einen anderen, jüngeren Verfasser an als für Str. 3 und $5{ }^{89}$

Ebenfalls noch in eine alte Quellenschicht führt schließlich das Dreierbar k 483 mit alter Tonerfinder-Eingangsstrophe. Die zuletzt von Willms wieder eröffnete Echtheitsdiskussion um die Zusatzstrophen erbringt zumindest dies: ${ }^{90} \mathrm{Sie}$ mögen unecht und nicht bereits im 13. Jahrhundert entstanden sein, ins 14 . gehören sie auf jeden Fall und damit potentiell in das nähere Umfeld der unfesten Mehrstrophigkeit. Damit ist Zudichtung zur Barauffüllung nicht die einzige Option, sondern auch alte Selbstständigkeit zu erwägen (ihr Text schließt das nicht aus) - auch wenn sie in diesem Fall durch eine wechselnde Separatüberlieferung von Str. 2f. nicht direkt belegt ist.

\subsection{Frauenlob}

Unter den Tönen Frauenlobs finden sich, jedenfalls prima vista, gleich drei, in denen Strophen des meisters nur jeweils ein einziges Mal von nachsengern sekundär verwertet wurden: sein Kurzer, sein Goldener und sein Zarter Ton. Ersterer wurde von den Meistersingern nicht rezipiert und ist überhaupt nur schmal überliefert. Die Überlieferung der sieben vielleicht nicht von Frauenlob stammenden Strophen im Kurzen Ton in Eghenvelders Liederbuch ${ }^{91}$ steht

88 Vgl. Baldzuhn 2002 (Anm. 7), S. 317-319 und Haustein 1995 (Anm. 2), S. 225-226.

89 Vgl. Haustein 1995 (Anm. 2), S. 102-103, zudem Baldzuhn 2002 (Anm. 7), S. 319321.

90 Vgl. Haustein 1995 (Anm. 2), S. 231-233, Baldzuhn 2002 (Anm. 7), S. 326-327 und Willms 2008 (Anm. 66), S. 334-336 (mit Text nach k; vgl. zur Echtheitsdiskussion den Kommentar S. 335-336).

91 Vgl. zur Echtheitsfrage zuletzt das GA-S: Sangsprüche in Tönen Frauenlobs. Supplement zur Göttinger Frauenlob-Ausgabe. Unter Mitarbeit von Thomas Riebe und Christoph Fasbender herausgegeben von Jens Haustein und Karl Stackmann. Göttingen 2000 (Abhandlungen der Akademie der Wissenschaften in Göttingen. Phil.-Hist. Kl. 3. Folge 232), S. 325-326 (dort S. 325-328 auch der Text der Zusatzstrophen) sowie 
räumlich, zeitlich und dem Sammlungstyp nach den Meisterliederhandschriften eher fern, und das Ergebnis der Zusammenführung, ein neunzehnstrophiges Gebilde, dem meisterlichen Bar ohnehin. Zudem wird es als Barat beiß angekündigt, mithin - im weitesten Sinne - als „Sonderform ${ }^{\text {“92 }}$ deklariert. Die gedanklich eher locker verbundene Reihe kann nach alledem auch sehr gut auf eine alte, vielleicht noch einmal sekundär überarbeitete ${ }^{93}$ Zusammenstellung einer Strophenreihe nach dem benutzten Ton - bereits im Kontext extensiver Fremdtonverwendung und noch in einiger Nähe zu Frauenlob, aber ohne Rücksicht auf das gefestigte Meisterlied - zurückgehen. Eine solche alte Reihe ist ebenso für die Elfergruppe von Sprüchen im Goldenen Ton in der Weimarer Liederhandschrift anzunehmen, deren Sprüche gedanklich erneut nur locker zusammenhängen.

Aus anderen Gründen ist eine echte und unechte Strophen gemischt präsentierende Reihe einer älteren Handschriftenvorstufe im Hintergrund des Dreierbars k 202 im Zarten Ton und im Dreierbar w 122 im Würgendrüssel zu erwägen: Hier wie dort müsste eine Erklärung der jeweils vorliegenden TextMelange primär aus gezielter meister-Funktionalisierung und/oder Rücksicht auf die Barform dezidiert ausschließen können, dass lediglich im Abschreibevorgang verschiedene Bauteile der Kanzonenstrophe übersprungen wurden und für die vorliegende Textverwirrung gesorgt haben. ${ }^{94}$ Für das zweite Lied

S. 61: „[...] wird man den Kreis der vermutlich echten Strophen um die aus der GA ausgeschlossenen Strophen im Kurzen Ton [...] erweitern müssen“.

92 Vgl. zum ,Parat' jetzt auch den Beitrag von Horst Brunner im vorliegenden Band (S. 53-69) sowie zuvor Horst Brunner: Die alten Meister. Studien zur Überlieferung und Rezeption der mittelhochdeutschen Sangspruchdichter. München 1975 (MTU 54), S. 160, Anm. 306.

93 Vgl. im GA-S S. 326 zur Textqualität der echten Sprüche: „Die Fassung des Eghenvelderschen Liederbuches steht regelmäßig ziemlich weit von dem aus älterer Überlieferung rekonstruierten kritischen Text ab.“

94 Vgl. für k 202 die Auseinandersetzung mit Karl Stackmann: Wiederverwerteter Frauenlob. Nichts Ungewöhnliches - und was man daraus lernen kann. In: WolframStudien 15 (1998), S. 104-113, und den alternativen Vorschlag zur Genese des Bars bei Baldzuhn 2002 (Anm. 7), S. 193-194. Bei w 122 liegt der Fall noch komplizierter, zum einen, da die Schlussstrophe unvollständig geblieben ist, zum zweiten, da die Versatzstücke, aus der die Mittelstrophe gebaut ist (vgl. den Textabdruck in der GA S. 957), nicht den Bauteilen der Kanzonenstrophe entsprechen. Der Fall bedarf genauerer Prüfung - aber eben, und darauf kommt es hier an, in Rücksicht dezidiert auch auf die Möglichkeit einer im schriftlichen Überlieferungsprozess zunächst irrtümlich eingetretenen Textveränderung. 
im Würgendrüssel, die drei Strophen von k 87, bleibt immerhin festzuhalten, dass Bartsch die Echtheit der zwei rahmenden Strophen, damit ihr hohes Alter in Betracht zog, aber an Barergänzung nicht dachte, und dass Thomas die Echtheit zwar ausschloss, aber ebenfalls nirgends von Barergänzung spricht. ${ }^{95}$ Mechanisch ergänzt ist jedenfalls nichts, der Befund ist der so häufige: Die zwei anonymen Sprüche ergänzen die Altstrophe sehr gut, können aber auch für sich bestehen, so dass man zur Annahme ausschließlich gezielter Hinzudichtung zur Vorgabe nicht gezwungen ist - zumal eine Gestaltungsebene, auf der die Tatsache des wiederverwertenden Bezugs auf den Text des Ton-meisters reflektiert würde, nicht ersichtlich ist. ${ }^{96}$

Von den vier Liedern im Neuen Ton genügt $\mathrm{f} 3$ nicht der Barform. Die erste der zwei vorangestellten anonymen Strophen klingt ,ausgesprochen frauenlobisch “ ${ }^{97}$ Beide sind je für sich verständlich. Es ist mithin eine alte Vorlagentradition hinter $\mathrm{f}$ mit lockerer Zusammenstellung von Sprüchen des Tonerfinders und von Fremdtonverwendern zu erwägen. Für die anonymen ersten zwei Strophen des Dreierbars p 19 mit Schlussstrophe Frauenlobs geht Wunderle von späterer Hinzufügung aus, „um den im Meistergesang geforderten Prinzipien der Mehrstrophigkeit und der ungeraden Strophenzahl zu genügen “ ${ }^{98}$ Andere Möglichkeiten werden nicht erwogen. Sie sind in diesem Fall auch nicht einfach zur Hand, da die Str. 1f. keine wechselnde Parallelüberlieferung haben, ihre Klage über gebrochene Worte der Fürsten und deren Schelte sich gut zur Schlussstrophe Frauenlobs mit ihrer Ermahnung der Edlen zur Wahrhaftigkeit fügt und eine Gegenprobe auf zumindest hypothetische alte Selbstständigkeit angesichts des streckenweise schwer verständlichen Textes nicht leicht durchzuführen ist. Das Dreierbar k 176 und das Siebenerbar d 10 schließlich im Neuen Ton nehme ich aus der Betrachtung mit dem Hinweis aus, dass im RSM zwar Frauenlobs Verfasserschaft einiger Strophen nicht ausgeschlossen wird,

95 Vgl. Bartsch 1862 (Anm. 3), S. 171 zu Nr. 21 seiner Ausgabe und Helmut Thomas: Untersuchungen zur Überlieferung der Spruchdichtung Frauenlobs. Leipzig 1939 (Palaestra 217), S. 131.

96 Die beiden Rahmenstrophen sind in der GA-S nicht berücksichtigt, weil sie nur einfach überliefert sind, vgl. GA-S S. 41 zu den Prinzipien, nach denen spät überlieferte Texte für die Ausgabe berücksichtigt wurden.

97 Wachinger 1987 (Anm. 7), S. 200.

98 Vgl. den Kommentar S. 374-377 (das Zitat S. 375) zum Text Nr. 19A und 19B in Elisabeth Wunderle: Die Sammlung von Meisterliedern in der Heidelberger Handschrift cpg 680. Edition und Kommentar. Göppingen 1993 (GAG 584). 
das später erschienene Supplement zur Göttinger Frauenlob-Ausgabe indes sie weder für k 176,1f. noch für d 10,4-7 erwägt. ${ }^{99}$

Im Vergessenen Ton bewahrt k 158 mit Str. 4 und 5 „zwei gezielte Zudichtungen $\mathrm{zu}$ einer alten Vortragsfolge des Tonerfinders, die [...] noch vor der Mitte des 14. Jahrhunderts angefügt wurden. ${ }^{\text {"100 }}$ Die Datierung ist aus der Zusammensetzung des Siebenerbars d 8 zu erschließen: Auf die alte Dreierreihe des Tonerfinders k 158,1-3 folgt dort nur Str. 4 ohne Str. 5, ferner ist ihr vorangestellt und folgt ihr je eine Strophe, die andernorts noch in anderen Strophenumgebungen erscheinen (sowie schließlich nur die in d belegte Strophe d 8,7). Die Zudichtung k 158,4f., zur Barauffüllung ohnedies unnötig, da schon drei Strophen vorlagen, entstand demnach sehr wahrscheinlich noch zu Zeiten unfester Mehrstrophigkeit. Dorthin führen auch die Erweiterungen der drei Strophen Frauenlobs in $\mathrm{f} 50$ zum Fünferbar und in d 8 zum Siebenerbar; zudem wurde mit zweien der verschiedenen Zusatzstrophen im Dreierbar k 161 noch einmal ohne Frauenlob-Begleitung gearbeitet. ${ }^{101}$ Von den Zusatzstrophen können die erste und zweite in $\mathrm{f} 50$ auch für sich bestehen. Die Reihe in $\mathrm{d} 8$ scheint hingegen wie die in k 158 - nun aber unter Verwendung eben auch noch anonymer Einzelsprüche - konzeptionell gezielt hergestellt worden zu sein, da sich Str. 6 und 7 ohne den Vorlauf von Str. 1-5 nicht verstehen lassen. Für das Dreierbar k 154 im Vergessenen Ton schließlich hält der RSM-Artikel zu ${ }^{1} \mathrm{Frau} / 7 / 502 \mathrm{a}$ fest: „Str. 2-3 schließen formal wie inhaltlich an Str. 1 an und zählen, anaphorisch reihend, Unmöglichkeiten auf“. Sie bleiben dennoch auch als Einzelstrophe in sich verständlich, ${ }^{102}$ und sie müssen ihre Priamelstruktur auch nicht aus dem Vorbild des eröffnenden Frauenlob-Spruchs bezogen haben: Es ist damit

99 Vgl. GA-S XI,201 und XI,206.

100 Vgl. die Argumentation bei Baldzuhn 2002 (Anm. 7), S. 182-183 (das Zitat S. 183) sowie die Vorbemerkung zu GA-S X,204: „ein Dreierbar Frauenlobs (GA X,1-3) durch Zusatzstrophen erweitert".

101 Die Strophe f 50,1 erscheint nämlich auch als d 8,1 und ferner in k 161,1; die Strophe f 50,2 ist dagegen nur einfach bezeugt. Die Strophe d 8,1 erscheint auch als f 50,1, die Strophe d 8,5 auch in $\mathrm{k}$ 158,4, ferner d 8,6 auch in k 161,3; die Strophe d 8,7 ist dagegen nur einfach bezeugt. Die Strophe k 161,1 entspricht f 50,1 und d 8,1, die Strophe k 161,3 entspricht d 8,6; die Strophe k 161,2 ist dagegen nur einfach bezeugt. Das GA-S bietet unter X,204 eine Überlieferungssynopse und den Abdruck aller unechten Strophen.

102 Vgl. den Text bei Bartsch 1862 (Anm. 3), unter Nr. 39. Bartsch erwog für beide Sprüche Echtheit (S. 173); vgl. dagegen Thomas 1939 (Anm. 95), S. 132, der im übrigen zwar bemerkt, sie „schlössen“ an Frauenlobs Spruch an, indes Barauffüllung nicht ins Spiel bringt. 
nicht allein und ausschließlich von Zudichtung auszugehen; die Dreiergruppe kann sich ebenso einer aufmerksamen Zusammenstellung verdanken.

Die Überlieferungen von $\mathrm{f} 36 \mathrm{f}$. im Grünen Ton können für die hier verfolgte Frage kaum belastet werden, da in der GA für f 36,2 Echtheit erwogen wird (vgl. GA VII, ${ }^{\star 5}$ ) und sie für $\mathrm{f} 37,1$ gar angesetzt ist (vgl. GA VII,8). Sollte es sich hier wie dort dennoch um Zusatzstrophen von Fremdtonverwendern handeln, gehörten sie auf jeden Fall noch ins engere Frauenlob-Umfeld, in dem in der Manier des Meisters gedichtet wurde. Zweifellos selbstständig ist GA VII,8. Die Zusammenstellungen in $\mathrm{f} 36 \mathrm{f}$. können mithin gut lediglich auf alten Vorlagen beruhen, die ihr Material thematisch passend gruppierten. Die Siebenerbare k 216 und $\mathrm{x} 32$ sind gemeinsam zu sehen, da x 32 lediglich zwei Strophen wohl nur versehentlich umstellt. ${ }^{103}$ Die vier alten Einzelstrophen, eine von fraglicher Echtheit (vgl. GA VII, ${ }^{\star} 7$ ), wurden vielleicht schon von Frauenlob in diese Reihe gebracht; sollte lediglich spätere Zusammenstellung vorliegen, erfolgte sie jedenfalls nicht willkürlich. Am ehesten aber wirken im vorliegenden Bestand wohl ältere Zusammenstellungen nach - die so oder so nicht primär auf das Bar ausgerichtet waren, da ja drei (oder vier?) Strophen schon vorgegeben waren. In Str. 1-3 liegt hingegen eine geschlossene Reihe vor, die entweder an die ältere Gruppe herangedichtet worden sein kann (aber dann nicht, um die Barform $\mathrm{zu}$ erreichen) oder selbst einmal selbstständig war. Im Dreierbar k 225 sind die zwei Ergänzungsstrophen selbstständig und wohl alte Einzelstrophen; die Reihe führt statt auf ausgemachte Zudichtung eher auf eine thematisch passende Zusammenstellung, die freilich mit ihrer mehrfachen Anlehnung an den typischen Minnereden-Eingang einen gewissen erzählerischen Zusammenhang herstellt. ${ }^{104}$ Und auch im Dreierbar $\mathrm{m} 18$ ist die Ergänzungsstrophe in der Mitte eine per se selbstständige und wohl alt. ${ }^{105}$ Ihr Einsatz noch einmal in k 223,1 erweist ihren prinzipiell fungiblen Einsatz und ihren voraussetzungslosen Eingang; sie ist dort freilich auch bereits umgebaut - ihre Aussagen werden ins Gegenteil verkehrt - im Hinblick auf die dort dann ihr folgenden zwei Strophen. In der älteren Fassung von m 18 stellt sie keine ausgemachte Zudichtung

103 Vgl. zum folgenden Baldzuhn 2002 (Anm. 7), S. $199 f$.

104 Vgl. zum folgenden Baldzuhn 2002 (Anm. 7), S. 204-205 und im GA-S S. 177 zu VII,216 (dort u. a. „gewisser erzählerischer Zusammenhang").

105 Vgl. zu m 18,1 = k 223,2 Baldzuhn 2002 (Anm. 7), S. 204, für den Text aller drei Strophen nach m GA VII,2- $\gamma$, GA-S VII,204 A2, GA VII,2- $\alpha$, für den Text von k 223 GA-S VII,204 B. 
dar; die erreichte Reihe verdankt sich eher der (älteren?) Zusammenstellung von zueinander passendem Gut.

Im Langen Ton zielt die Reihe von $\mathrm{f} 31$ sicherlich nicht auf ein Zehnerbar, sondern geht auf eine Überlieferungsreihe in einer älteren Vorlage der Weimarer Liederhandschrift zurück, die trotz ihrer "Tendenz zur Bargliederung" diese Bare noch nicht „äußerlich markiert“ hat. ${ }^{106}$ Die Fünfergruppe des Karlsruher Cod. 408 bietet eine mehr oder minder weitgreifende Umarbeitung von Altmaterial - Kiepe rechnet auch die Str. 1-4 ins 14. Jahrhundert - in die Reimpaarform und gehört damit nicht in den engeren meisterlichen Zusammenhang. ${ }^{107}$ In k 106 sind die Zusätze „sicher nicht jüngere Zudichtungen, sondern wohl ebenfalls ältere Einzelstrophen“, so Schanze, ${ }^{108}$ die hier mit der Klage um Frauenlobs Tod (Str. 1) und der Erinnerung des Adels an die Vergänglichkeit des Irdischen (Str. 3) das memento mori der Mittelstrophe GA V, ${ }^{\star} 66$ sinnvoll ergänzen. Man möchte sich die Zusammenführung dieser Reihe vielleicht sogar auch zu einem Vortrag, dann am ehesten in größerer Nähe zum späten Frauenlob vorstellen. Für Str. 3 des Dreierbars k 52 steht die Einzelstrophe außer Zweifel; sie wurde auch an anderer Stelle, im Viererbar k 93 als Str. 2, in gänzlich ausgetauschter Umgebung verwertet und ist mithin nicht einfach Zudichtung zu k 52,1 und/oder 2. ${ }^{109}$ Str. 3 des Dreierbars k 66 „stammt von einem zeitlich noch im Frauenlob-Umkreis dichtenden Fremdtonverwender. Nach Ausweis ihrer separaten Überlieferung in $\mathrm{f}$ wurde sie noch als Einzelstrophe konzipiert“ "110 Auch die zweite Strophe, wenngleich „wegen der Konventionalität des Themas (Ermahnung des Sünders) schwer zu beurteilen, wirkt [...] im Inhalt gegenüber den anderen Strophen relativ selbständig". ${ }^{111}$ Das Dreierbar bietet drei ursprünglich selbstständige Gebetsstrophen, die die

106 Vgl. Wachinger 1987 (Anm. 7), S. 199 zu GA V,90-92 (= f 30,5 und f 31,1-2), dort auch die Zitate.

107 Vgl. Hansjürgen Kiepe: Sangspruch und Reimpaarform. Zu 5 Strophen im Codex Karlsruhe 408. In: ZfdA 105 (1976), S. 53-66.

108 Schanze 1982-83 (Anm. 2), Bd. 1, S. 82. Vgl. für den Text Bartsch 1862 (Anm. 3), Nr. 29 sowie Franziska Wenzel: Meisterschaft im Prozess. Der Lange Ton Frauenlobs - Texte und Studien. Berlin 2012 (Deutsche Literatur. Studien und Quellen 10), S. 544-545.

109 Vgl. Baldzuhn 2002 (Anm. 7), S. 151-152 sowie für den Text nach k Wenzel 2012 (Anm. 108), S. 438-439.

110 Vgl. Baldzuhn 2002 (Anm. 7), S. 66 (unter Verweis auf Thomas und Schanze).

111 Schanze 1982-83 (Anm. 2), Bd. 1, S. 80. Der Text des gesamten Bars nach k bei Wenzel 2012 (Anm. 108), S. 465-467. 
gemeinsame Sprechsituation - angesichts des Todes - und ihre Sprechhaltung eint. ${ }^{112}$ Wie für k 106 kann man sich auch hier die Zusammenführung der Reihe zum Vortrag sehr gut, und dies vielleicht auch in größerer Nähe zu Frauenlob, vorstellen. Im Dreierbar k 94 schließlich mit Str. 1 und 3 von Frauenlob ist die Mittelstrophe „eine thematisch verwandte, aber inhaltlich selbständige Einzelstrophe über schatz und tugend. "113

\section{Zusammenfassung: Barauffüllung, Typen der Wiederverwendung}

Die Kolmarer Liederhandschrift ist Hauptzeuge für die obenstehend systematisch in den Blick genommene Überlieferungskonstellation der Kombination einer oder mehrerer alter Strophen des Tonerfinders mit anonymen Strophen von Fremdtonverwendern im Rahmen des meisterlichen Liedes. Das ist nicht lediglich ihrem besonderen Umfang geschuldet, sondern bestätigt, was man von $\mathrm{k}$ ohnedies weiß: Diese Handschrift greift wie keine andere in bedeutend ältere Überlieferung aus. Denn es gibt - siehe unten - keinerlei Anlass, die Zusammenstellung dieser Bare in einer breiten und lebendigen Praxis des Jonglierens mit Strophen alter Meister noch im 15. Jahrhundert oder gar im unmittelbaren Umfeld von $\mathrm{k}$ zu verorten.

Die zunächst oberflächliche Auszählung des Materials lässt kein eigenes System in den Zusammenstellungen erkennen, etwa derart, dass Altstrophen gerne am Anfang stünden oder gerne von jüngeren umrahmt würden oder atypisch häufig in Baren bestimmten Umfangs erschienen. Es hat diese Praxis nämlich in einer derartigen, partiell konventionalisierten Form gar nicht gegeben. Auffüllungen von Altstrophen lediglich ,um des Bars willen', ,um auf die Barform zu kommen' - das hat sich nirgends wirklich nachweisen lassen. Eine solche Beschreibung des Vorfindlichen ist mithin sehr irreführend. Auf sie sollte zukünftig verzichtet werden. Wenn sich gezielte ,Zudichtungen' überhaupt ausmachen lassen, dann finden diese vor dem Hintergrund, dann finden sie im Rahmen der etablierten Konvention statt, dass Lieder mehrstrophig zu sein haben, und nicht in dominierender Rücksicht auf diese Konvention.

Gezielte Wiederverwendung einer oder mehrerer Strophen des Tonerfinders im neuen, durch anonyme ,Zudichtung` erweiterten und dann festen Lied

112 Vgl. zu Str. 1f. Baldzuhn 2002 (Anm. 7), S. 158 und zu Str. 3 Schanze 1982-83, Bd. 1, S. 80. Der Text des gesamten Bars nach k bei Wenzel 2012 (Anm. 108), S. 471-472.

113 Schanze 1982-83 (Anm. 2), Bd. 1, S. 81. Vgl. zum Bar auch Baldzuhn 2002 (Anm. 7), S. 161-162 sowie die Ausgabe nach k bei Wenzel 2012 (Anm. 108), S. 114-116. 
ist selten - jedenfalls beträchtlich seltener anzutreffen als es die Geläufigkeit erwarten lässt, mit der in der Forschung mit dieser Vorstellung operiert wird. Idealiter lassen sich vier Grundtypen der Identifizierbarkeit von Wiederverwendungen unterscheiden, die immerhin auf zwei eindeutig erkennbare (Typ 1 und 2), sehr wahrscheinlich auch auf drei (Typ 3) historische Formen einer primär konzeptionellen, produktionsseitig intendierten Wiederverwendung und Einbindung von Altstrophen führen:

Typ 1: Das Ergebnis ist ein festes, ein in sich kohärentes, als solches neu durchkonzipiertes Lied. Seine Ergänzungsstrophen werden nirgends anders noch einmal wiederverwendet, sie funktionieren eigentlich nur im vorliegenden Zusammenhang. Die Zusatzstrophen haben sich von einem sehr speziellen Merkmal des Ausgangstextes anregen lassen, nehmen es auf, bauen es aus, spinnen es fort. Musterfälle sind k 20, q 280 (jeweils Tannhäuser), k 739 (Reinmar von Brennenberg) und die siebzehnstrophige Minnelehre mit Strophenanapher im Cpg 350 (Marner).

Typ 2: Die Zusatzstrophen stellen quasi eine Antwort dar auf eine inhaltlichthematisch spezifische Vorgabe, sei es zustimmend oder ablehnend - etwa indem sie ein Rätsel lösen oder eine Streitfrage, ein Problem aufnehmen und zur zunächst eingenommenen Position sich dann verhalten. Ohne den Vorlauf sind die Zusatzstrophen nicht verständlich, denn sie sind dezidiert auf das Ausgangsangebot hin konzipiert und ergeben nur mit ihm gemeinsam Sinn. Die Strophen werden wohl auch alle gemeinsam vorgetragen worden sein. Musterfälle sind k 772 (Stolle/Hardegger), k 471 (Marner), d 8 (Frauenlob). Weiterhin sind die Bezüge sehr eng in k 544, k 564, k 574, k 567 (jeweils Konrad von Würzburg). Jedoch erfüllen dort die Strophen nicht durchgängig das Kriterium ,Unverständlichkeit ohne alten Vorlauf‘. Hingegen wird kein breiterer ,Pool von weiteren Strophen ersichtlich, die potentiell ersatzweise eintreten könnten, und es sind die Zusatzstrophen nicht auch andernorts nachweisbar, also nicht auch unfest eingesetzt worden: Dann wären diese Konrad-Lieder nämlich eher zu Typ 3 (siehe unten) zu setzen. Hier sind die Grenzen fließend. Das könnte speziell bei Konrad seinen Grund teils auch in einer eigenen Phase seiner bereits sehr frühen Rezeption schon im 13. Jahrhundert haben.

Typ 3: Das Altmaterial führt auf ein vergleichsweise spezielles Themenfeld, zu dem man eigentlich noch weitere Strophen erwartet, da eine einzelne Strophe zum Thema erratisch allein stünde - es sei denn, ihr Verfasser durfte ein hochinformiertes Publikum erwarten, das sich den entsprechenden Rahmendiskurs auch ohne konkrete Textstütze, ohne weitere Strophe aufzufüllen vermochte. Wenn zu solch einer Altstrophe, die bereits selbst auch auf Ergänzung angelegt sein kann, Strophen hinzutreten - zunächst: von wem auch immer 
verfasst, Tonerfinder oder Fremdtonverwender -, dann nehmen sie auf diese enge Themenvorgabe zwar entschieden Rücksicht, da sonst leicht Brüche entstünden. Aber ihr Verfasser ist von der Vorgabe her doch nicht gezwungen, derart explizit anzuknüpfen, dass sein Zusatz ohne exakt diese eine Altstrophe unverständlich würde. Es können die Zudichtung auch andere Strophen begleiten als diese Altstrophe, respektive aus umgekehrter Perspektive: Es kann zu der Altstrophe auch anderes Material treten, solange es nur die engere Themenvorgabe berücksichtigt. In diesen Fällen wurde bei der Durchsicht des Materials von einem ,Pool' von Strophen gesprochen. Regelmäßig führen die Strophenbestände solcher ,Themenpools' in die unfeste Mehrstrophigkeit, in das noch unfeste Meisterlied. Wer sich einen solchen ,Pool' auffüllt und sich aus ihm bedient, dem stehen noch weitere Möglichkeiten der Wiederverwendung der Strophen offen: Er kann daraus auch andere Liedeinheiten bilden. Hierher gehören am ehesten k 736 (Reinmar von Brennenberg), k 596, k 633 (jeweils Boppe), w 96 und k 568 (jeweils Konrad). ${ }^{114}$

Typ 4: Den weitaus größten Anteil am untersuchten Material nehmen Liedeinheiten ein, die mehr oder minder zueinander passendes, ja eigentlich fast immer sehr gut sich ergänzendes Strophenmaterial vereinen - ohne dass jedoch ein einzelnes Textspezifikum, eine explizite Textposition oder ein allzu spezielles Thema des Altmaterials aufgenommen worden wären. Fast immer ist wie für die Altstrophe auch für die Begleitstrophen ursprüngliche Selbstständigkeit nachzuweisen - vor allem, wenn die Überlieferung sie noch in anderen Liedkontexten zeigt - oder (wenn Parallelüberlieferung fehlt) zu erwägen (weil vom Text her nicht auszuschließen). Und fast immer lassen sich für die Entstehung solcher ,Lieder ${ }^{\text {a }}$ andere Faktoren als nur ,Zudichtung ins Spiel bringen. Sehr häufig ist hier insbesondere die ältere Überlieferungsreihe einzubringen: Strophenzusammenstellungen aus überwiegend nicht erhaltenen Handschriften vermutlich kleineren Umfangs, die in der Überlieferungslücke der Gattung zwischen J und dem Einsatz der Meisterliederhandschriften eine bedeutendere Rolle für die schriftliche Bewahrung der Gattung gespielt haben müssen, als das heute am Erhaltenen noch zu erkennen ist. Diese kleineren Sammlungen dürften jenen nicht mehr erhaltenen Vorstufen der Meisterliederhandschriften eng verwandt sein, auf die an anderer Stelle speziell für $\mathrm{k}$ mit anderen Begründungen schon einmal aufmerksam gemacht

114 Vgl. zur Bildung eines solchen ,Pools` entlang einer Erzählung von Erlösungsratschluss, Leben Jesu und Passionsgeschichte Baldzuhn 2015 (Anm. 11) zum ,Hort von Kidron' in Regenbogens Grauem Ton. 
wurde. ${ }^{115}$ Sie wurden vor dem Hintergrund bereits extensiver Fremdtonverwendung angelegt und haben Strophen und Strophengruppen wie die ,Jenaer Liederhandschrift' nach Tönen zu Reihen zusammengestellt, vom Tonerfinder abweichende Textautorschaft aber nicht markiert, und sie kannten noch keine systematische Barkennzeichnung, waren aber sehr wohl, wie die ,Jenaer Liederhandschrift', bemüht, thematisch zusammen passendes Material zueinander zu stellen. Solche Reihen sind im übrigen ja durchaus auch für Strophengruppen nachzuweisen, die allein echtes Gut, d. h. Strophen vom Tonerfinder, bewahren. Diese Reihen konnten prinzipiell mechanisch, schlicht durch die Einfügung von Liedüberschriften - vereinzelt ist das in der späteren Überlieferung des meisterlichen Liedes ja noch zu erkennen - zu einer damit dann rein schriftlich hergestellten Reihe von Liedern umgeformt werden. Und diese Liederreihen konnten, über weitere, freilich heute wohl kaum mehr sauber rekonstruierbare Zwischenstufen, dann in einzelne Lieder aufgelöst werden. ${ }^{116}$ Dass solche Überlieferungs-Lieder noch einmal in den Vortrag überführt wurden, dürfte im Einzelfall schwer nachzuweisen sein. In dieser Hinsicht kann eigentlich nur noch von der allgemeinen Situation der Gattung her, mit ihrer mehr oder minder noch vorhandenen Attraktivität und ,Lebendigkeit' unter Fremdtonverwendern auch mehr als nur zwei, drei Dezennien nach Frauenlob und unmittelbar vor dem breiteren Einsatz der nicht unwesentlich schriftlichen Sammlungsbewegung, wie sie in den Meisterliederhandschriften des 15. Jahrhunderts zum Ausdruck kommt, argumentiert werden. Ich halte solche Vorträge für eher unwahrscheinlich. Der Anteil des 15. Jahrhunderts jedenfalls an der Zusammenstellung dieser Überlieferungs-Lieder wird eher überschätzt, der des 14. Jahrhunderts in der Forschung wohl noch sehr unterschätzt.

Was bleibt schließlich im Hinblick auf den zwar geringen, aber einigermaßen sicher zu bestimmenden Bestand an Zudichtungen festzuhalten, auf Verfahren

115 Vgl. Baldzuhn 2002 (Anm. 7), S. 451-454, S. 476-481 und S. 481-486.

116 Vgl. zum Ansatz solcher Reihen im Vorfeld speziell der Weimarer Liederhandschrift Wachinger 1987 (Anm. 7), S. 196 (F aufbauend auf einer ,thematisch wohlgeordnete[n] Hauptsammlung“, die aus anderen Quellen ergänzt worden ist), S. 199 (Bareinteilung durch Überschriften „relativ mechanisch“), S. 205 (Die Vorstufe von F hatte „noch keine ganz feste Bargliederung“ und „brachte auch Einzelstrophen und Strophenpaare in lockeren zyklischen Strophenverbänden unter“), S. 205-206 („Die Prinzipien der Barergänzung und der freien Zusammenstellung von thematisch verwandten Strophen zu lockeren Gruppen haben gewiß eine Zeitlang miteinander konkurriert"). Für ein prinzipiell vergleichbares, aber spätes Beispiel aus der HarderÜberlieferung vgl. Baldzuhn 2002 (Anm. 7), S. 221-226 sowie grundsätzlich S. 62. 
des Anschlusses an den Tonerfinder, auf zeitliche Schichtungen im Rahmen der spezielleren Gattungsgeschichte? Typ 1 stellt eine gattungsübergreifende Möglichkeit der Wiederverwendung dar und ist für die spezielle Gattungsgeschichte kaum zu belasten. Mehrere Beispiele können immerhin sensibilisieren für die Bedeutsamkeit textintern bereits im Altmaterial entworfener Auftrittsrollen des Sänger für eine ausbauende Wiederverwertung (k 20: Klage des Ich über die Minnedame; q 280: Klage des heimatlosen/vielgereisten Ich; $\mathrm{k}$ 544: liebendes Ich), die eine Wiederverwertung umstandslos weitergehend durchinszenieren konnte. Der Körper des Sängers stellte wohl grundsätzlich ein wichtiges Trägermedium für Wiederaufnahmen mit deutlicherem Bezug zum alten Texterfinder dar. (Auch die Vorgaben zum Streitgespräch in k 739 ließen sich vom Sänger im Vortrag wohl recht umstandslos als weitergehende Inszenierung auffüllen.)

Vor diesem Hintergrund muss dann auffallen, dass unter den Beispielen für Typ 2 der Wiederaufnahme die Fortführung der alten Textvorgabe durch Strophenanaphern in der siebzehnstrophigen Minnelehre des Cpg 350 vom Eintreten des Text-Ich in die Marner-Rolle begleitet wird und dass dieses deutlichste Beispiel auch das einzige ist, für das sich eine separate Funktionalisierung des alten Textdichters für das eigene Sprechen im neuen Lied beobachten lässt. In allen anderen Beispielen für eng an die Textvorgabe anschließender Lieder lässt sich das nicht beobachten, oder umgekehrt: muss man, wollte man sie ansetzen, mit der Annahme operieren, das - dann ausgesprochen kundige - Publikum hätte um die Tatsache der partiell fremden Textverfasserschaft der neuen Strophengruppe gewusst. Solches Kontextwissen wird mit je größerer zeitlicher Distanz zur alten Textverfasserschaft desto unwahrscheinlicher. So deutliche Anschlüsse wie gelegentlich bei Stolle/Hardegger und Konrad wird man am ehesten in die unmittelbare Umgebung der Tonerfinder zu setzen haben. Sollten die entsprechenden Lieder aber erst ins fortgeschrittene 14. Jahrhundert gehören, sinkt die Wahrscheinlichkeit eines dezidiert die alte Textautorschaft funktionalisierenden Spiels erheblich, reduziert sich der meister-Bezug auf die Tonverwendung. Weiterer Aufschluss ließe sich in diesem Punkt in Zukunft vielleicht über eine Untersuchung speziell alter Sprüche von Fremdtonverwendern gewinnen, die bis zur Mitte des 14. Jahrhunderts bezeugt sind. Daraus wäre vielleicht ein weiterer Datierungsanhalt zu gewinnen. Indes wird er leider im Umfeld Frauenlobs kaum zu nutzen sein, da sich engere, potentiell textorientierte Frauenlob-Nachfolge und der aktuelle, massive Trend zur Fremdtonverwendung hier bereits überlagern.

Die textuell engeren Anknüpfungen des Typs 2 besagen unter dieser Einschränkung daher kaum etwas für die Praxis speziell der nachsenger des 
14. Jahrhunderts, da mit ihnen - vorerst jedenfalls - bereits im 13. Jahrhundert gerechnet werden muss. Da andererseits das Spiel mit alter Textautorschaft speziell im Umfeld des neuen Liedes so oder so nur unter exzeptionellkundigen Rezeptionsvoraussetzungen möglich ist, müssten genauere Untersuchung potentieller Fälle diese immer noch einmal separat wahrscheinlich machen. Daraus ist speziell für die nachsenger dann - vorerst jedenfalls - dieser Umkehrschluss zu ziehen: Ein solches Spiel ist wohl nur dann für möglich erachtet worden, wenn man es seinem Publikum in deutlicher Form markiert hat. Das aber kann eben durch die Übernahme der Rolle des Tonerfinders und Textverfassers im Text selbst geschehen. (Von rahmenden Ansagen im Vorfeld eines Liedvortrags, die in diese Richtung gingen, wissen wir nichts.) Im Umfeld der im 14. Jahrhundert inszenierten Auseinandersetzungen zwischen Frauenlob und Regenbogen, aber auch anderwärts im 14. Jahrhundert, sind solche Rollenübernahmen ja ohnedies mehrfach belegt. ${ }^{117}$ Diese Spielarten des ausdrücklichen Anschlusses des eigenen Sprechens an den meister gewinnen vor dem Hintergrund einer sehr zu relativierenden Altstrophen-Textkennerschaft des Publikums der nachsenger noch einmal an Bedeutung - ebenso wie das Hauptinstrument des meister-Bezugs, die Wahl des entsprechenden Tons.

$\mathrm{Zu}$ einer Differenzierung geben vielleicht aber die Belege des dritten Typs Anlass, der am sichersten auf das von nachsengern bestellte Terrain führt, da die Strophen-,Pools' qua Ausrichtung auf die unfeste Mehrstrophigkeit ihnen schon zeitlich nahestehen. Sofern solche, Pools' auch mit einzelnen Altstrophen oder Altstrophengruppen des meisters bestückt waren - was im übrigen für ihre mediale Form des Zuhandenseins ganz entschieden auf Schriftlichkeit verweist $^{118}$-, könnten einzelne, in je besonderer Hinsicht als charakteristisch für den Tonerfinder wahrgenommene Konvolute sich nicht nur mit dem Namen des Ton-, sondern auch des Textdichters verbunden haben: als FrauenlobStrophen identifizierbar gewesen sein, wenn sie in anspruchsvollster Form von höchsten geistlichen Dingen sprachen, als Boppe-Strophen, soweit sie nur

117 Vgl. Wachinger 1973 (Anm. 24), S. 280-298 und die Hinweise auf weiteres Einschlägiges im Cpg 350 (Ps.-Konrads von Würzburg 40strophiges ,Ave Maria', Walther von der Vogelweide) bei Wachinger 1976 (Anm. 83), S. 197. Von Relevanz sind zudem die ,Sterbelieder, die Tonerfindern auf dem Sterbebett in den Mund gelegt werden. Vgl. die Hinweise bei Christoph Fasbender: ,Frauenlobs Sterbegebet' in Johanns von Neumarkt Privatgebetssammlung. In: Studien zu Frauenlob und Heinrich von Mügeln. Festschrift für Karl Stackmann. Hg. von Jens Haustein und Ralf-Henning Steinmetz. Freiburg/Schweiz 2002 (Scrinium Friburgense 15), S. 125-144, hier besonders S. 140-144.

118 Vgl. auch einen dahingehenden Hinweis bei Wachinger 1976 (Anm. 83), S. 194-195. 
mit Tierbeispielen hantierten, als Konrad-Strophen, sofern sie Maria in nicht allzu exaltierter, mit Frauenlobs Sprüchen zu verwechselnder Form priesen, vielleicht sogar auch als Regenbogen-Strophen, sofern sie in extenso biblische Stoffe versifizierten. ${ }^{119}$ Wenn unfeste ,Konglomerat'-Lieder auf einer solchen Grundlage entstanden sein sollten, dann ließe sich mit für das neue Lied funktionalisierten Bezügen auf die alte Textautorschaft durchaus rechnen, freilich ohne dass man sie dann noch an genau eine einzelne alte Vorgabestrophe binden müsste. Denn greift ein nachsenger solchermaßen eine Altstrophe auf und knüpft an sie - oder präziser formuliert: an das Diskurs-Charakteristikum des entsprechenden Strophenpools - an, dann nivellierte er damit zugleich die Unterscheidung von Fremdtextverwender und Tonerfinder. Denn er spräche dann ja auch wie ein Frauenlob, wie ein Boppe, wie Konrad. Singen tut er, qua Tonwahl, ja ohnehin schon wie der meister. Diese Möglichkeit hebt einerseits, hinsichtlich moderner Beschreibungen eines solchen Konglomerats nach seinem Strophenbestand, ins Bewusstsein, wie historisch unangemessen respektive wie voraussetzungsreich und modern es sein kann, zwischen ,echt' und ,unecht' zu unterscheiden. ${ }^{120}$ Andererseits deutet sich - eingedenk der oben ja bereits hervorgehobenen Bedeutsamkeit von Texten, die ein Sprechen in der Rolle des meisters zeigen, erneut - an, wie viel wichtiger als detaillierte textuelle Wiederaufnahmen es für den Anschluss der nachsenger des 14. Jahrhunderts an die meister gewesen sein könnte, mit ihrem Liedvortrag den Eindruck eines Wieder-Auftritts eines alten meisters zu erwecken.

119 Vgl. Baldzuhn 2015 (Anm. 11).

120 In der Vortragsfassung ist seinerzeit das Material zu Frauenlob nur oberflächlich besprochen worden. Es konnte erst im Rahmen einer Vortragsreihe zum FrauenlobJubiläum 2018/2019 in Mainz detaillierter vorgestellt werden. Ich habe daher den Mainzer Kolleginnen Uta Störmer-Caysa und Claudia Lauer ebenso für ihre Anregungen zu danken wie den Teilnehmern des diesem Sammelband vorangegangenen Kolloquiums zur Kolmarer Liederhandschrift. 
Sophie Knapp und Holger Runow

\title{
Kopieren - Kompilieren - Kreieren Aspekte der Überlieferung und Textualität am Beispiel des Frauenlobcorpus der Kolmarer Liederhandschrift
}

\begin{abstract}
Within the large corpus of "Frauenlobtöne" (songs to melodies of Frauenlob), the Colmar Liederhandschrift contains at least 32 songs and one Leich that stem back to Frauenlob in the early 14 th century. The article takes song duplicates within the Frauenlob corpus as a starting point and analyses the integration of older stanzas and songs. It is demonstrated that creative productivity is involved in the handling of older stanzas, e. g. through new contexts or by selective editing. It is reinforced that the manifold ways of transmission and recombination can not be fitted under a single hypothesis, but that all cases have to be dealt with separately.
\end{abstract}

Der Kolmarer Liederhandschrift $\mathrm{k}^{1}$ kommt in jeder Hinsicht eine Sonderstellung in der meisterlichen Liedüberlieferung zu. Im Hinblick auf ihr Format und ihren enormen Umfang, ihren Anspruch auf Vollständigkeit in der Dokumentation der spätmittelalterlichen Liedproduktion sowie der damit verbundenen redaktionellen Leistung gibt es nichts Vergleichbares. Besonderes Gewicht liegt auf der Sammlung von Liedern in Tönen der Alten Meister. Dabei nimmt Frauenlob eine Sonderposition ein: Abgesehen von seinem Zeitgenossen Regenbogen, dessen Berühmtheit in der Altüberlieferung freilich nicht in gleicher Weise nachzuvollziehen ist, wird keinem anderen Dichter und seinen anonymen Nachdichtern mehr Raum zugedacht. ${ }^{2}$ In der die Kolmarer

1 München, Bayerische Staatsbibliothek, Cgm 4997; in älteren Arbeiten auch unter der Sigle t.

2 Zu Frauenlob und seiner Nachwirkung vgl. zuletzt Jens Haustein: Kap. VII.11: Frauenlob (Heinrich von Meißen). In: Sangspruch/Spruchsang. Ein Handbuch. Hg. von Dorothea Klein, Jens Haustein und Horst Brunner in Verbindung mit Holger Runow. Berlin, Boston 2019, S. 423-430, sowie das Handbuch Frauenlob. Hg. von Claudia Lauer und Uta Störmer-Caysa unter Mitarbeit von Sara Lahr. Heidelberg 2018. 
Sammlung eröffnenden Sektion ${ }^{3}$ mit den Prunk- und Großformen (Leich, ,Reihen', ,Parat' ${ }^{4}{ }^{4}$ nimmt Frauenlobs ,Marienleich ' die prominente Spitzenstellung ein, gefolgt von zwei Baren im Frauenlob zugeschriebenen und besonders artifiziellen Überzarten Ton. In diesem Abschnitt steht als wichtiges Zeugnis der Wertschätzung des alten Meisters auch der ihm ebenfalls zugeschriebene ,Taugenhort', der mit seinen über 900 Versen die monumentalste unter den Großdichtungen in $\mathrm{k}$ ist. ${ }^{5}$

Vor allem aber bietet $\mathrm{k}$ unter Frauenlobs Namen, d. h. unter seiner Tonautorschaft, mit 200 Baren in sieben ,echten'sowie $14 \mathrm{ihm}$ zugeschriebenen Tönen das umfangreichste Liedcorpus der Handschrift. Mit dieser außergewöhnlichen Breite stellt das Frauenlobcorpus in k ein einzigartiges literarhistorisches Untersuchungsfeld dar, an dem sich innerhalb eines in sich geschlossenen Überlieferungszusammenhangs Überlegungen zu den spezifischen Traditions-, Rezeptions-, aber auch Produktionsbedingungen der Meisterlieder anstellen lassen. Ansatzpunkt für die folgenden Untersuchungen ist die Beobachtung, dass es, wie in der gesamten Handschrift, auch innerhalb dieses Corpus zu verschiedenen Formen von Mehrfachüberlieferungen kommt. Dabei sind grob zwei Kategorien zu unterscheiden: Einerseits gibt es die ,einfache' Doppelung, also den Fall, dass ein Lied zweimal innerhalb des Corpus aufgezeichnet ist; andererseits ist die Mehrfachüberlieferung einzelner Strophen oder Strophenteile zu beobachten, die in verschiedenen Barzusammenhängen erscheinen und dadurch neu kontextualisiert oder bisweilen auch durch erkennbare Umarbeitungen kontextspezifisch angepasst werden. Dieser zweite Typus ist für literaturwissenschaftliche Erkenntnisinteressen ergiebiger, weil er nicht nur ein

3 Zur planvollen Anlage der Handschrift vgl. bes. Frieder Schanze: Meisterliche Liedkunst zwischen Heinrich von Mügeln und Hans Sachs. Bd. 1: Untersuchungen. München 1983 (MTU 82), S. 35-47; vgl. auch die ausführliche Übersicht in ders.: Meisterliche Liedkunst zwischen Heinrich von Mügeln und Hans Sachs. Bd. 2: Verzeichnisse. München 1984 (MTU 83), S. 58-83.

4 Vgl. dazu den Beitrag von Horst Brunner in diesem Band.

5 Frauenlobs ,Kreuzleich'steht in k innerhalb des Regenbogencorpus und zeigt auch auf dieser Ebene die vielfältige Verbindung der beiden Dichter, die sich in den bereits altbezeugten Fehden in Frauenlobs Langem Ton oder dem ihnen später angedichteten ,Krieg von Würzburg' in Regenbogens Briefweise (RSM ${ }^{1}$ Regb/1/512; k fol. 254r-258v) zeigt; vgl. grundlegend hierzu Burghart Wachinger: Sängerkrieg. Untersuchungen zur Spruchdichtung des 13. Jahrhunderts. München 1973 (MTU 42), S. $188-298$. 


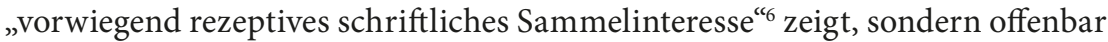
Formen des produktiven Umgangs mit bereits vorhandenen Strophen und Liedern dokumentiert. Das eröffnet den Raum für Fragen nach den poetischen Verfahrensweisen und dem poetologischen Selbstverständnis der Meistersinger, und zwar weitestgehend jenseits von Fragen nach Autorschaft und Originalität, die sich in dieser gerade vom Prinzip der Anonymität geprägten Dichtung kaum je werden beantworten lassen. Darauf ist weiter unten zurückzukommen. Doch auch der vermeintlich weniger ergiebige Fall von Lieddubletten, die doch keinerlei produktive Aneignung zu zeigen scheinen, wirft interessante Fragen auf, denn wie kann es überhaupt dazu kommen, dass ein und dasselbe Lied zweimal abgeschrieben wurde? Stehen unterschiedliche Vorlagen im Hintergrund oder jeweils dieselbe? Handelt es sich dann um bloße Versehen, und was sagt das ggf. über die redaktionelle Koordinationsleistung der beiden Schreiber A und B aus? Sind auch hier weitere Beobachtungen zu Gestalt und Umgang mit den (nicht erhaltenen) Vorlagenhandschriften möglich? Dazu mag es sich lohnen, genauer auch auf die sonst leicht vernachlässigten kleinen Unterschiede innerhalb der Abschriften zu blicken.

Idealerweise müssten diese Beobachtungsebenen auf die gesamte Gattung des Meistergesangs ausgeweitet werden. Einem solchen Anspruch können wir hier freilich nicht nachkommen. Größere Studien sind auf breiterer Basis bereits einigen der hier aufgeworfenen Fragen erfolgreich nachgegangen, in jüngerer Zeit insbesondere die Erschließungsarbeiten von Frieder Schanze ${ }^{7}$ zur Entstehungsgeschichte und den Redaktionsprinzipien von k, Michael Baldzuhns Untersuchungen zur historischen Schichtung der Überlieferung zwischen Sangspruch und Meisterlied ${ }^{8}$ sowie Franziska Wenzels Studien zu textuellen Formationen am Beispiel von Frauenlobs Langem Ton. ${ }^{9}$ Das Frauenlobcorpus in $\mathrm{k}$ ist uns in seinem besonderen Zuschnitt - breit, aber doch noch überschaubar - Anlass, auf dieser Grundlage etwas genauer auf einige Einzelfälle zu schauen und die Fragestellungen weiterzuentwickeln. Erleichternd hinzu kommt, dass im Fall von Frauenlob, auch über die vollständige Erschließung

6 Michael Baldzuhn: Vom Sangspruch zum Meisterlied. Untersuchungen zu einem literarischen Traditionszusammenhang auf der Grundlage der Kolmarer Liederhandschrift. Tübingen 2002 (MTU 120), S. 3.

7 Schanze 1983 und 1984 (Anm. 3).

8 Baldzuhn 2002 (Anm. 6).

9 Franziska Wenzel: Meisterschaft im Prozess. Der Lange Ton Frauenlobs - Texte und Studien. Mit einem Beitrag zu vormoderner Textualität und Autorschaft. Berlin 2012 (Deutsche Literatur. Studien und Quellen 10). 
der Überlieferung durch das, Repertorium der Sangsprüche und Meisterlieder $(\mathrm{RSM})^{10}$ hinaus, das Material besonders gut aufbereitet und zugänglich ist, insbesondere durch die Edition vieler Texte im ,Frauenlob-Supplement ${ }^{\prime}(G A-S)^{11}$ zur Göttinger Ausgabe (GA) ${ }^{12}$ sowie auch durch die Edition und die Konkordanzen zum Langen Ton bei Wenzel. ${ }^{13}$ Dass die Einzelfallanalysen Allgemeingültigkeit beanspruchen dürften, ist nicht zu erwarten. Aber vielleicht können sie dabei helfen, andere Perspektiven einzunehmen und neue Fragen zu entwickeln, die man dann wiederum auch an weitere Texte und Corpora herantragen kann. In diesem Sinne wäre zu hoffen, dass einzelne Beobachtungen zumindest eine gewisse Exemplarität für sich beanspruchen können.

\section{Dubletten: Textkritik und Textgenese}

Die Kolmarer Handschrift lässt in ihrer Anlage klar ein planvolles Vorgehen unter der redaktionellen Federführung des Schreibers A erkennen. Dass dieser als scriptor huius libri (fol. 482r sowie Register, fol. 9r) wahrscheinlich mit Nestler von Speyer, dem Erfinder des Unerkannten Tons, zu identifizieren ist, ${ }^{14}$ spielt dabei vielleicht weniger eine Rolle als die Entdeckung Gisela Kornrumpfs, ${ }^{15}$ dass das nämliche Duo aus Schreiber A, dem „Redaktor, der

10 Repertorium der Sangsprüche und Meisterlieder des 12. bis 18. Jahrhunderts (RSM). 16 Bde. Hg. von Horst Brunner und Burghart Wachinger. Tübingen 1986-2009.

11 Sangsprüche in Tönen Frauenlobs. Supplement zur Göttinger Frauenlob-Ausgabe. Unter Mitarbeit von Thomas Riebe und Christoph Fasbender hg. von Jens Haustein und Karl Stackmann. 2 Bde. Göttingen 2000 (Abhandlungen der Akademie der Wissenschaften in Göttingen, Phil.-Hist. Klasse, Dritte Folge 232).

12 Frauenlob (Heinrich von Meissen). Leichs, Sangsprüche, Lieder. Auf Grund der Vorarbeiten von Helmuth Thomas hg. von Karl Stackmann und Karl Bertau. 2 Bde. Göttingen 1981 (Abhandlungen der Akademie der Wissenschaften in Göttingen, Phil.-Hist. Klasse, Dritte Folge 119/120).

13 Eine große Erleichterung und ein erheblicher Gewinn gegenüber dem älteren Schwarz-Weiß-Faksimile (Die Kolmarer Liederhandschrift der Bayerischen Staatsbibliothek München [cgm 4997]. In Abbildung hg. von Ulrich Müller, Franz Viktor Spechtler und Horst Brunner. 2 Bde. Göppingen 1976 [Litterae 35.1-2]) ist die vollständige Digitalisierung der Kolmarer Handschrift durch die Bayerische Staatsbibliothek (URL: http://daten.digitale-sammlungen.de/ db/0010/bsb00105055/ images).

14 Vgl. dazu Schanze 1983 (Anm. 3), S. 52-55 sowie Baldzuhn 2002 (Anm. 6), S. 28, jeweils mit Verweisen auf die ältere Forschung.

15 Gisela Kornrumpf: Die Kolmarer Liederhandschrift. Bemerkungen zur Provenienz. In: Ja muz ich sunder riuwe sin. Fs. für Karl Stackmann. Hg. von Wolfgang 
die Arbeit leitet ${ }^{\text {"16 }}$, und seinem Gehilfen B in vergleichbarer Konstellation auch eine medizinische Sammelhandschrift (Salzburg, Universitätsbibliothek, M III 3) angefertigt hat. Das lässt vermuten, dass die beiden ein eingespieltes Team waren, und schließlich erfordert ein so großes Projekt wie k in erheblichem Maß Planung, Routine und Koordination, d. h. einen hohen Grad an Professionalisierung.

Vor diesem Hintergrund scheint es umso erstaunlicher, wenn es immer wieder vorkommt, dass ein ganzes Lied - zumal mit so wenig textueller Varianz, dass kaum von unterschiedlichen Fassungen zu sprechen ist - gleich zweimal abgeschrieben wurde. Schanze hat anhand einer genauen Untersuchung des verwendeten Papiers und der Lagenanordnung den Entstehungsprozess der Handschrift nachgezeichnet. Dabei konnte er zeigen, wie die Anlage des Codex bei seinem Anwachsen noch angepasst wurde, wohl auch, weil im Lauf der Arbeit mehr Vorlagenmaterial zur Verfügung stand, als man zunächst vermutete. ${ }^{17}$ Unter diesen Umständen scheint es plausibel, aus dem (vermehrten) Auftreten von Dubletten auf das Einpflegen von neuem Quellenmaterial zu schließen: Eine neu hinzugekommene Vorlagenhandschrift kann neben neuen Liedern auch bereits Bekanntes und schon einmal Abgeschriebenes enthalten haben. Gerade bei sich abwechselnden Schreibern, die sich bei einem solchen Mammutprojekt nicht über jedes einzelne Lied verständigen können, kann ein solches ,Versehen', wenn man einen derartigen Nebeneffekt des Vollständigkeitsanspruchs denn überhaupt so nennen möchte, leicht passieren. Nun ist aber die Lage nicht immer so eindeutig. Es gibt nämlich auch den Fall von Dubletten ein und desselben Schreibers, und zwar auch innerhalb noch überschaubaren Abstands in der Handschrift, so dass man dem Schreiber entweder unterstellen müsste, dass ihm die Doppelung aufgefallen sein sollte, oder aber man hätte ihm zu attestieren, dass er seine Vorlagen eher mechanisch und ohne besondere Achtsamkeit für die Texte abschrieb. Zudem kann im Einzelfall ein genauer Textvergleich der Dubletten durchaus wahrscheinlich machen, dass es sich tatsächlich um Abschriften aus ein und derselben Vorlage handelt. Beides zusammen - identischer Schreiber, identische Vorlage - ist bei zumindest einer

Dinkelacker, Ludger Grenzmann und Werner Höver. Göttingen 1990, S. 155-169; vgl. Bernhard Schnell: Medizin und Lieddichtung. Zur medizinischen Sammelhandschrift Salzburg M III 3 und zur Kolmarer Liederhandschrift. In: Archiv für das Studium der neueren Sprachen und Literaturen 230 (1993), S. 261-278.

16 Schanze 1983 (Anm. 3), S. 39.

17 Ebd., S. 42-47. 
Dublette, die noch etwas ausführlicher zu besprechen sein wird, der Fall. Insofern lohnt es sich, diesen Typus genauer anzuschauen.

Im Frauenlobcorpus von k gibt es insgesamt sechs Fälle von Dubletten. Nur einmal kann man dem Redaktor-Schreiber A gleichsam dabei über die Schulter schauen, wie er sein Versehen bemerkt und korrigiert: Auf fol. 186r hat er zwei Strophen, die erste mit Melodie, unter der Rubrik In frauwenlob spiegelwyse eingetragen (RSM $\left.{ }^{1} \mathrm{Frau} / 26 / 1 \mathrm{~b}\right)$. Dann ist ihm offenbar aufgefallen, dass das (insgesamt fünfstrophige) Lied bereits abgeschrieben worden war, woraufhin er beide Strophen mit schwarzer, die Überschrift mit roter Tinte ausgestrichen hat; ebenfalls mit roter Tinte hat er den doppelten Hinweis stet vor bzw. Stet vorhin angebracht, unter Verweis auf die zeitgenössische Blattzählung mit der arabischen Nummer 72 (nach heutiger Zählung: fol. 163r). Dort findet man das vollständige Lied ${ }^{18}$ nach dem in $k$ häufig anzutreffenden Verfahren aufgezeichnet: Schreiber A hat die Melodiestrophe eingetragen, Schreiber B die übrigen Strophen. ${ }^{19}$ Die Streichung macht sichtbar, was ohnehin offensichtlich zu sein scheint, dass es sich nämlich bei der Doppelung um ein Versehen handelt. Warum nicht mehr solcher Versehen aufgefallen sind und korrigiert wurden, muss ungeklärt bleiben.

Auch beim ,Gehilfen', Schreiber B, kann man zumindest einmal in einem besonders interessanten Fall von Doppelaufzeichnung eines Liedes den redaktionellen Prozess erahnen. Eine fünfstrophige Johannesvision mit Verweis auf den Rat der Trinität sowie deren Verhältnis zu Maria ${ }^{20}$ (RSM ${ }^{1} \mathrm{Frau} / 8 / 501$; Edition: GA-S XI,210) hat er doppelt eingetragen ( $\mathrm{k} 171$, fol. 176v-177v, und $\mathrm{k} 178$, fol. 183rv), diese Doppelung aber sehr wohl bemerkt. Die beiden Aufzeichnungen weisen deutliche Varianzen auf, die z. T. umfangreichere Formulierungen über ganze Verse und sogar Umstellungen von Versen innerhalb der Strophe umfassen. Es ist von zwei Textfassungen, mithin von verschiedenen Vorlagenhandschriften auszugehen, so dass vieles dafürspricht, dass hier tatsächlich Schanzes Vermutung zutrifft, dass also neues Quellenmaterial hinzukam, das

18 RSM ${ }^{1} \mathrm{Frau} / 26 / 1 \mathrm{a}$; das Lied ist zudem noch zwei weitere Male in anderen Meisterliederhandschriften überliefert, was hier aber außen vor bleiben mag.

19 Vgl. Schanze 1983 (Anm. 3), S. 39.

20 Es handelt sich geradezu um eine Beischlafvision der Trinität mit Maria, vgl. GA-S XI,210, V. 73-78: dri fürsten her hant bi der meid geslaffen. / Der vatter liess sie lieplich grüssen, / der son begund sie minniclich umbsliessen, / der vatter sleich den zweien vor / und tet ir hertz durchsüssen, / der heilig geist begund die meit umbzaffen (wohl „Gelegenheitsbildung“ zu mhd. zâfen sw.V. ,pflegen, schmücken', vgl. GA-S II, S. 623). 
die Dublette verursachte. ${ }^{21}$ Zweierlei macht diesen Fall besonders bemerkenswert. Erstens hat der Schreiber B die Dublette nicht nur bemerkt, sondern dies auch explizit vermerkt. Mehr noch, er hat die beiden Versionen miteinander verglichen und bewertet. Der zweiten gibt er eindeutig den Vorzug, denn hier heißt es in der Rubrik (fol. 183r): Ander fünff ym nuwen ton alten meß beßerer wan die fordergen fünff. ${ }^{22}$ Das kann sich nur auf die erste Niederschrift beziehen; warum er dennoch das Lied doppelt stehen ließ und nicht die offenbar verworfene Fassung k 171 ausstrich, wie es Schreiber A auf fol. 186r getan hat, bleibt unklar. Zweitens, und das lässt letztere Frage umso mehr aufkommen, hat er nach der zweiten, von ihm favorisierten Abschrift unter der Rubrik Eyn ander steig (fol. 183v) noch eine Variante des Abgesangs nachgetragen. Obwohl diese im Wortlaut gar nicht so gravierend abweicht, bessert sie doch eine syntaktische Ungereimtheit in k 178, Str. 3, V. 11f. Dort heißt es von Maria mit Bezug auf das apokalyptische Weib (Apc 12,1): Dry fürsten her hant reine meyt / ye mit der sonnen gantz becleit [...]. Der Satz ist so nicht recht stimmig. Dies korrigiert der alternative Abgesang, der sehr nahe an jenem von $\mathrm{k} 171$ ist: ${ }^{23}$ Dry fürsten hant die reine meyt / fry mit der sonnen glantz becleit. Man darf also davon ausgehen, dass (1.) die fehlerhafte Lesart aus $\mathrm{k} 178$ bereits in der Vorlage gestanden hat und dass (2.) Schreiber B sich an seine Aufzeichnung von k 171 erinnert und diese dann vergleichend zur Korrektur herangezogen hat.

Weitere vier Fälle von Dubletten, drei im Langen Ton und einer im Zarten Ton, seien hier genannt und nur knapp auf ihr Erkenntnispotenzial hin perspektiviert. Sie sind bereits grob nach Typen sortiert. Dabei nennen wir die betreffende RSM-Sigle, beziehen uns aber hier wie im Folgenden primär auf die Liednummern in der Zählung nach Karl Bartsch, ${ }^{24}$ weil die Dubletten so

21 Schanze 1983 (Anm. 3), S. 44.

22 Die etwas jüngere Donaueschinger Liederhandschrift u (Karlsruhe, Badische Landesbibliothek, Cod. Donaueschingen 120, um 1480/90) bietet das Lied nahezu identisch mit k 178; insbesondere ist auch die Rubrik mit dem Hinweis Besser wann die vorderen kopiert worden, was in diesem Fall ein recht eindeutiges Indiz dafür ist, dass die Abschrift direkt auf k zurückgeht. Zur Diskussion der Verwandtschaft zwischen k und u vgl. Burghart Wachinger: Kolmarer Liederhandschrift. In: ${ }^{2}$ VL 5 (1985), Sp. 27-39, hier Sp. 34f.

23 Es gibt gleichwohl geringfügige Abweichungen (vgl. den Apparat GA-S II, S. 622).

24 Meisterlieder der Kolmarer Liederhandschrift. Hg. von Karl Bartsch. Stuttgart 1862. Auf Bartschs Zählung verweisen auch die RSM-Einträge. Statt der Großbuchstaben, die Bartsch auf die Meisterliederhandschriften verteilt hat, stehen hier die üblich 
besser zu differenzieren sind als nur anhand des RSM, wo die Liedeinheiten unter einer Katalognummer zusammengefasst sind (und dann nach Buchstaben weiter unterschieden werden). In Klammern folgt der Hinweis auf den Schreiber des jeweiligen Stücks. Da es sich in allen Fällen um Texte in ,echten Frauenlobtönen handelt, sind diese im ,Frauenlob-Supplement ' (GA-S) ediert, auf das ebenfalls verwiesen wird.

1.) Dreierbar RSM ${ }^{1} \mathrm{Frau} / 2 / 502$ (Langer Ton): $\mathrm{k} 49$ (Schreiber A) $=\mathrm{k} 68$ (Schreiber B); GA-S V,222. - Inhalt: Mariengebet, in dem die Gottesmutter an das Martyrium Christi erinnert und um Beistand gegen die Anfechtungen des Teufels angerufen wird. Die beiden Abschriften „differieren nur unwesentlich " ${ }^{25}$, insbesondere ist durchgehend das Reimgerüst genau bewahrt. Abgesehen von geringfügigen Wortumstellungen und iterierenden Varianten v. a. im Kleinwortschatz, weichen die Abschriften nur an wenigen Stellen etwas gravierender voneinander ab, dies aber auch nur im Rahmen jeweils eines Verses (z. B. Str. 2, V. 12; Str. 3, V. 11) bzw. Verspaares (Str. 2, V. 13-14) und ohne Beeinträchtigung der Aussage sowie unter Einhaltung der metrischen Erfordernisse. Eigenständige Fassungen (im Sinne eines

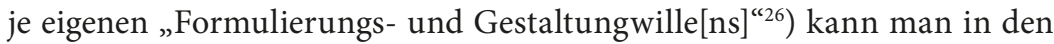
beiden Abschriften kaum erkennen. Ob die vorhandenen Unterschiede auf separate Vorlagen zurückzuführen sind, ist nicht zu entscheiden. Gerade bei zwei verschiedenen Schreibern könnten die Textabweichungen auch aus unterschiedlichen Memorierleistungen beim Abschreiben ganzer Verse und Sätze resultieren.

2.) Dreierbar RSM ${ }^{1}$ Frau/2/520 (Langer Ton): $k 67$ (Schreiber $\left.A+B\right)=k 74$ (Schreiber B); GA-S V,227. - Inhalt: Preis Mariens als Himmelskönigin, die von allen Engelschören und Aposteln gelobt wird, und ihre Präexistenz als spygel der drivaltikeyt (Str. 3, V. 13). Die Varianz zwischen den beiden Abschriften ist ausgesprochen gering ${ }^{27}$ und bewegt sich ganz auf der Ebene des semantisch nicht relevanten Austauschs einzelner Wörter; auch die

gewordenen Minuskeln, die Siglen richten sich zudem nach der aktuellen Aufstellung bei Dorothea Klein: Kap. III.3: Die Überlieferung der Sangspruchdichtung. In: Klein u. a. 2019 (Anm. 2), S. 65-90, hier S. 71 (so dass beispielsweise Bartschs „L 14“ nun als „, 14 “ erscheint usf.).

25 GA-S I, S. 106.

26 Joachim Bumke: Die vier Fassungen der ,Nibelungenklage. Untersuchungen zur Überlieferungsgeschichte und Textkritik der höfischen Epik im 13. Jahrhundert. Berlin, New York 1996 (Quellen und Forschungen zur Literatur- und Kulturgeschichte 8), S. 32.

27 GA-S I, S. 115: „ohne größere Differenzen“; vgl. den Apparat in GA-S II, S. 412. 
Metrik ist nie von der Varianz berührt. Bemerkenswert ist der Schreiberwechsel innerhalb von k 67. Er erfolgt mitten in der ersten Strophe (nach V. 17) zum Wechsel der Spalte auf fol. 104va/b und zeigt damit anscheinend, dass die Arbeitsteilung zwischen den beiden Schreibern keinem an Texteinheiten orientierten Prinzip folgt, sondern dass eine rationale Arbeitsökonomie vorherrscht. ${ }^{28}$

3.) Dreierbar RSM ${ }^{1}$ Frau $/ 5 / 518$ (Zarter Ton): $\mathrm{k} 208$ (Schreiber B) $=\mathrm{k} 212$ (Schreiber A); GA-S VIII,206A. - Inhalt: Lob der Armut in geistlichheilsgeschichtlicher Perspektive. Bei geringfügigen Abweichungen der Abschriften voneinander und trotz einiger kleinerer Missverständnisse ${ }^{29}$ hier wie dort bieten die k-Dubletten einen insgesamt sehr konsistenten Text, der keine unterschiedlichen Fassungen erkennen lässt. Auch hier scheint es möglich, dass beide Abschriften derselben Vorlage folgen. Der Bar ist zudem noch in der etwas jüngeren Donaueschinger Liederhandschrift $^{30}$ überliefert (u 39), hier mit deutlicheren Abweichungen gegenüber dem in $\mathrm{k}$ doppelt bewahrten Text. Eine eigenständige Fassung mit einer ganz anderen dritten Strophe repräsentiert die ältere Münchner Meisterliederhandschrift (m 44). ${ }^{31}$

4.) Fünferbar RSM ${ }^{1} \mathrm{Frau} / 2 / 517$ (Langer Ton): $\mathrm{k} 64$ (Schreiber $\left.\mathrm{A}\right)=\mathrm{k} 75$ (Schreiber B); GA-S V,233. - Herausforderung zum Wettsingen (,Fürwurf') mit anschließendem Rätsel. Der Bar ist zudem ebenfalls in der Donaueschinger Handschrift überliefert (u 14). „Die Differenzen zwischen den drei Überlieferungsträgern sind unerheblich. ${ }^{“ 32}$ Was die Typen von Varianz angeht, gilt für die k-Dubletten dasselbe, was zu den

28 Üblicherweise fällt der Schreiberwechsel mit dem Ende einer Liedeinheit zusammen; Wechsel innerhalb eines Liedes am Strophenende (z. B. fol. 188rv, wo das Strophenende mit dem Seitenende zusammenfällt) bzw. Wechsel innerhalb einer Strophe wie hier ist sehr selten; vgl. etwa noch fol. 320v-321r.

29 Vgl. GA-S I, S. 193: „Die Strophen sind mit recht geringem sprachlichen Geschick verfertigt. [...] Die meisten Unklarheiten dürften auf sprachlichem Unvermögen beruhen."

30 Karlsruhe, Badische Landesbibliothek, Cod. Donaueschingen 120 (vgl. Anm. 22).

31 München, Bayerische Staatsbibliothek, Cgm 351, um 1420/25; vgl. dazu auch Baldzuhn 2002 (Anm. 6), S. 195f.

32 GA-S I, S. 128. - Die ebd. geäußerte Vermutung, der Text sei zusammengesetzt aus einem dreistrophigen Fürwurf und einem zweistrophigen Rätsel, ist, trotz älterer Motivanklänge, nicht zwingend (und für unsere Fragestellung zunächst unerheblich); Str. 4 stellt mit der erneuten Sängeraufforderung immerhin einen kohärenten Anschluss her. 
vorherigen Fällen gesagt wurde (Kleinwortschatz, Wortstellung etc.). Jedoch fällt auf, dass die Abweichungen von k 75 gegenüber k 64 fast durchweg eine Parallele in u 14 finden. Damit ist die oben geäußerte Hypothese, die Varianz könne auf unterschiedlichem Abschreibeverhalten auf der Grundlage derselben Vorlage beruhen, ggf. zu modifizieren. Zwei Optionen sind denkbar: Entweder ist hier doch von zwei unterschiedlichen Vorlagen für k 68 einerseits sowie für $\mathrm{k} 75$ und u 14 andererseits auszugehen oder aber der Befund ist so zu deuten, dass beide Versionen auf dieselbe Vorlage zurückgehen, wobei der Kolmarer Schreiber B (k 75) und der Donaueschinger Schreiber (u 14) recht sklavisch derselben Vorlage folgen, während der Kolmarer Schreiber A sich eher Freiheiten in der einzelnen Formulierung erlaubt. ${ }^{33}$

Die bislang angesprochenen Dubletten lassen mehrheitlich keine ganz eindeutigen Rückschlüsse auf ihre Vorlage(n) zu, sie können aber auch nicht die Vermutung bestärken, dass jeweils neues Vorlagenmaterial hinzugekommen wäre, welches die Dubletten veranlasst hätte (außer bei k 171/178). Im Gegenteil lässt die Form der Varianz es als durchaus möglich erscheinen, dass ein Bar jeweils von den beiden Schreibern aus derselben Vorlage abgeschrieben wurde. Das irritiert umso mehr, als auch kein konzeptioneller Grund für das doppelte Abschreiben von Baren ersichtlich wäre; vielmehr zeigt die erwähnte Streichung auf fol. 186r, dass solche Doppelungen gerade nicht vorgesehen waren. Das stellt die (kaum zu beantwortende) Frage nicht nur nach der Beschaffenheit der Vorlagen, sondern nach dem konkreten Umgang mit ihnen, nach der Sortierung und Organisation, sowie nach der anscheinend nicht immer gelingenden Koordination zwischen den beiden Schreibern. Der beobachtete Schreiberwechsel auf fol. 104v mitten im Text könnte immerhin tatsächlich so $\mathrm{zu}$ deuten sein, dass es mehr um Arbeitsökonomie als um einen stets achtsamen Blick auf den einzelnen Text ging. ${ }^{34}$

33 Letztere Option wäre weiter zu untersuchen. Wenn dieser Befund - Dublettenüberlieferung in $\mathrm{k}$, die nicht vom selben Schreiber stammen, gestützt durch ,externe Parallelüberlieferung - sich durch mehrere ähnlich gelagerte Fälle bestätigen ließe, dann wäre das unterschiedliche Abschreibeverhalten der Schreiber A und B eine überlieferungsgeschichtlich bedeutsame Beobachtung, die für textgenetische Beobachtungen sowie auch als textkritisches Argument und damit für editorische Entscheidungen fruchtbar zu machen wäre.

34 Weiter zu untersuchen wäre ggf., ob Bardubletten innerhalb des syntagmatischen Gefüges eines Tons (vgl. Wenzel 2012 [Anm. 9]) ein eigenes semantisches Potential 
Insbesondere der zuletzt betrachtete Fall $(\mathrm{k} 64=\mathrm{k} 75)$ hat zudem gezeigt, dass für Fragen nach der Überlieferungsgeschichte bzw. der Textgenese, sofern vorhanden, unbedingt auch die weitere Parallelüberlieferung mit einbezogen werden muss. Eine weitere Dublette ist hier anzuschließen, die zudem deshalb interessant ist, weil dabei das ggf. unterschiedliche Abschreibeverhalten und die damit verbundene Frage nach der redaktionellen Koordination der beiden Schreiber untereinander keine Rolle spielen.

\section{Textgenese und Textkritik: Chancen und Grenzen}

Es geht um einen Dreierbar im Grünen Ton, RSM ${ }^{1}$ Frau/4/503 (GA-S VII,213A), der in $\mathrm{k}$ doppelt aufgezeichnet ist: $\mathrm{k} 217=\mathrm{k} 227$. Inhaltlich handelt es sich um eine rühmende Anrufung Marias mit Lob der Trinität sowie Aufforderung an die Gottesmutter zur Fürbitte für die Menschheit. Dabei wird Maria u. a. bezeichnet als $d u$ hymmelport, $d u$ form der trinitate (Str. 1, V. 6) und mit einer Reihe weiterer Apostrophierungen gepriesen: Sie ist die Rose, der Schrein Salomos, die Krone über allen Chören. Beide Aufzeichnungen stammen von Schreiber B und bieten einen nahezu vollständig identischen Text, fast immer sogar bis in die Schreibweisen der einzelnen Wörter hinein. Selbst die Rubriken sind (nach Auflösung der wenigen Abkürzungen) gleich: Aber iij von unser lieben frauwen ym grunen ton. Die ganz wenigen geringfügigen Abweichungen sind leicht als niedrigschwellige Abschreibefehler zu werten. ${ }^{35}$

Die hohe Konsistenz der beiden Abschriften ist geeignet, den Eindruck zu bestätigen, der sich zuvor (s. o. bei k 75) eingestellt hat, dass nämlich der Schreiber B seinen Vorlagen sehr genau folgt und sich (dem Anschein nach anders als Schreiber A) geradezu sklavisch an sie hält. Das scheint auch hier so zu sein und lässt dann mit einiger Sicherheit darauf schließen, dass es sich bei der Bardublette k 217/227 um zwei Abschriften ein und derselben Vorlagenhandschrift handelt. Wenn es dazu noch eines deutlicheren Beweises bedürfte, so fände man ihn in der ersten Strophe. In V. 16f. heißt es identisch in beiden

entfalten können - dass sie also nicht (immer) bloßes Versehen sein müssen, sondern ihnen vielleicht auch eine bestimmte kompositorische Intention eignet.

35 Sie beschränken sich auf die dritte Strophe, wo sie aber etwas gehäufter auftreten: V. 5 ényer [!] vogel visch ( $\mathrm{k} 227)$ vs. (richtig) tyer vogel visch ( $\mathrm{k} 217)$ - V. 9 woll dencken (k 217) vs. (richtig) volldencken $(\mathrm{k} 227)$. - V. 10. wie got es selb hat vollenbracht $(\mathrm{k} 217)$ vs. (gleichwertig) wie es got selber hat volbracht (k 227). - V. 12 ist in $\mathrm{k} 227$ ein Wort ausgefallen (dank). - V. 16 ist in $\mathrm{k} 217$ wolt nachträglich zu (richtigem) welt (so auch k 227) korrigiert. 
Niederschriften: er [Gott] sach dich [Maria] an mit flisse, / ee daz er ye kein ding entsarff. Die Wortform entsarff ist sonst nirgends nachweisbar und auch hier nicht auf befriedigende Weise zu deuten. Das $\mathrm{RSM}^{36}$ liest stattdessen entwarff, was auch die Edition im ,Frauenlob-Supplement' übernimmt. Das scheint inhaltlich mehr als plausibel. Formal ist der Vorschlag gleichwohl nicht ganz unproblematisch, denn die Konjektur stellt identischen Reim zum nächsten Vers her (warff), was doch - nicht nur nach den Regeln der Meistersinger - eher verpönt ist. ${ }^{37}$ Nun ist aber die ungewöhnliche Form dem Schreiber B offenbar gar nicht als Fehler aufgestoßen. Das wirft Fragen auf: Hat er seine Vorlage ganz einfach ohne nachzudenken kopiert? Das würde besagtes entsarff nur umso mehr für die Vorlagenhandschrift sichern (denn der nicht denkende, ,mechanische' Schreiber ist ja gewissermaßen der textkritische Idealfall). Oder hat er im Gegenteil zweimal seine Vorlage, in der das eher zu erwartende entwarff gestanden hat, bewusst geändert zu etwas, was (zumindest heute) niemand mehr versteht?

Die Stelle bleibt insofern eine gewisse Crux für die Textkritik. Mit einiger Bestimmtheit wird man aber sagen können, dass Bardubletten wie diese ein Phänomen der spezifisch schriftlichen Reproduktion sind. Das implizieren auch die weiteren, oben vorgestellten Fälle, wo auch bei wechselnden Schreibern insgesamt erstaunlich wenig Varianz herrscht. Viel weiter wird man von hier aus kaum kommen. Dass die Doppelungen, gerade innerhalb überschaubarer Distanzen von nur wenigen Blättern, nicht aufgefallen sein sollten, ist zumal bei identischem Schreiber noch sonderbarer, als es bei zweien ist, denen man doch unterstellen würde, dass sie sich in irgendeiner Weise koordinieren mussten. Es ist eine seltsam paradoxe Beobachtung, dass derartige Unachtsamkeiten in nennenswerter Anzahl auftreten, während doch zugleich die planvolle Anlage des monumentalen Codex ins Auge fällt. Vielleicht ist das

36 RSM (Anm. 10), Bd. 5, S. 392.

37 So könnte ggf. die in den Schulkünsten und Tabulaturen mehrfach begegnende Warnung vor equivoca - noch in einem ganz vorterminologischen Sinne (also nicht schon als Gleichklang bei Bedeutungsverschiedenheit) - verstanden werden. Vgl. etwa RSM ${ }^{1}$ Regb/4/510a (k 360), Edition Bartsch 1862 (Anm. 24), Nr. 82, V. 20: (Wer die Sangeskunst beherrschen will,) er hüet sich vor eqwivocâ. - Zum terminologischen Gebrauch von equivoca im Meistergesang vgl. Brian Taylor: Das Meisterlied als poetologische Urkunde. In: Sangspruchdichtung. Gattungskonstitution und Gattungsinterferenz im europäischen Kontext. Internationales Symposium Würzburg, 15.-18. Februar 2006. Hg. von Dorothea Klein, Trude Ehlert und Elisabeth Schmid. Tübingen 2007, S. 353-370. 
tatsächlich nur erklärbar, wenn, wie oben bereits vermutet, im Rahmen eines solchen Großprojekts der Vollständigkeitsanspruch und die Makroplanung die Aufmerksamkeit für den Einzeltext zurücktreten lassen.

Die Beobachtungen zu diesem Dubletten-Fall lassen sich noch erweitern. Direkt im Anschluss an die zweite Abschrift (k 227) folgt mit k 228 ein Dreierbar (RSM $\left.{ }^{1} \mathrm{Frau} / 4 / 514\right)$, in dem die zweite Strophe der Dublette wiederkehrt, so dass diese zweite Strophe nun zum dritten Mal innerhalb von nur sieben Blättern überliefert ist, in k 228 allerdings mit einiger Varianz gegenüber der Dublettenfassung (s. Textbeispiel 1 im Anhang [S. 215]: Synopse k 227 - k 228; die wörtlichen Übereinstimmungen sind in k 228, Str. 2 durch Fettdruck hervorgehoben).$^{38}$ Thema dieses zweiten Bars ist ebenfalls ein Marienpreis, eingeleitet mit einem neuen Bild: Die Gottesmutter ist umfangen von einem verschlossenen Ring aus Sternen..$^{39}$ Ihr neigt sich eine Rose zu; zum Rosengarten - es klingt das Motiv vom hortus conclusus an - gewährt sie ihren vriunden Zutritt, ihre Feinde bekommen die Dornen zu spüren. An das Bild von der Rose schließt dann recht kohärent die bekannte Strophe an, deren erster Vers lautet: Ros aller engel frauwe. Die dritte Strophe lobt abschließend den Schöpfer und Maria für die Menschwerdung Gottes. Es fällt auf, dass k 228, Str. 2 deutliche Varianz gegenüber der Dublettenfassung k 217/227 zeigt, ohne dass indes der Sinn in nennenswerter Weise verändert wäre..$^{40}$ Die Strophe fügt sich in den Liedzusammenhang, ohne dass größere konzeptionelle Umarbeitungen nötig waren.

Mit zwar erheblicher Varianz ist die besagte zweite Strophe zudem noch in der Trierer Meisterliederhandschrift erhalten, hier als letzte innerhalb eines Fünferbars ( $\mathrm{t}$ 30). ${ }^{41}$ Das lässt kaum einen Zweifel daran, dass es sich um eine

38 Es dürfte kein Zweifel daran bestehen, dass auch hier der weiterhin tätige Schreiber B seine Vorlage treu abgeschrieben hat. Die Bare, die sich dieselbe Strophe jeweils ,einverleibt' haben, gehen nicht auf sein Konto. Und doch könnte es einer planvollen Zusammenstellung entsprechen, dass die Bare mit der gemeinsamen Strophe hier direkt aufeinander folgen.

39 Man kann darin vielleicht Anklänge an die kosmologische Dimension des vorausgehenden Liedes erkennen.

40 Vgl. die Edition GA-S VII,213B, die hiervon einen guten Eindruck vermittelt, indem dort die Übereinstimmungen zwischen der A-Fassung (k 217/227) und der B-Fassung (k 228) durch Fettdruck hervorgehoben sind.

41 Trier, Stadtbibliothek, Ms. 1032/1943, um 1490/1500. - Zum Text vgl. RSM ${ }^{1}$ Frau/ 4/532; Abdruck der Strophe in GA-S II, S. 475; Inhalt des Bars: Geburt Marias und Weihnachtsgeschichte, Verkündigung, Geburt Jesu, Verkündigung an die Hirten, Anbetung durch die Heiligen drei Könige; abschließendes Marienlob. 
ältere Marienpreis-Einzelstrophe handelt, ${ }^{42}$ die später in verschiedene Liedzusammenhänge eingegangen ist. Über die Richtung solcher Wanderungsbewegungen sind freilich nur selten sichere Aussagen möglich. In unserem speziellen Fall gibt es indes einen Anhaltspunkt: In k 228, Str. 2 ergeben die V. 11f. (ave, du gottz tochter zart, / her Salomon voll aller gnaden synne) keinen hinlänglichen Sinn. So kommentiert auch das ,Frauenlob-Supplement': „Aus einer Vorlage entstellt übernommen, die den A-Text bot. In dieser Form sinnlos. ${ }^{{ }^{4} 3}$ Was ist passiert? In der Dublette k 217/227 ist der Reim küniginne : schrîne am Ende der Stollen (V. 6/12) auffällig. Der Text bewahrt ansonsten - wie sehr oft in $\mathrm{k}$ - die überkommenen mittelhochdeutschen Quantitäten und reimt diese untereinander rein. $\mathrm{k} 228$ hat mit küniginne : sinne also den reinen Reim hergestellt. Dieser kann aber, wenn der Text korrumpiert ist, nicht ursprünglich sein. Ein reiner Reim ließe sich indes auch in der Strophe in k 217/227 noch erkennen, wenn man statt küniginne von der Form künigîn mit der langen Nebensilbe ausgeht. Das würde rein reimen auf Salomones wol gezierter schrîn (nämlich, wie man es eigentlich auch erwarten würde, ohne das epithetische -e). Die Verse 6 und 12 stünden dann nicht in weiblicher, sondern in männlicher Kadenz. Damit aber repräsentiert die zweite Strophe in k 217/ 227 eine ältere Textstufe, denn diese Form 1 des Grünen Tons ${ }^{44}$ weist auf eine Entstehung im früheren 14. Jahrhundert; spätestens ab der Jahrhundertmitte herrscht die Form 2 mit weiblicher Kadenz vor. ${ }^{45}$ Die weiteren Liedzusammenhänge (k 228 und t 30) sind in diesem Punkt Ergebnis jüngerer formgeleiteter Umarbeitung. ${ }^{46}$

42 Vgl. Baldzuhn 2002 (Anm. 6), S. 201.

43 GA-S II, S. 477.

44 Vgl. RSM, Bd. 2.1, S. 56.

45 Vgl. Johannes Rettelbach: Variation - Derivation - Imitation. Untersuchungen zu den Tönen der Sangspruchdichter und Meistersinger. Tübingen 1993 (Frühe Neuzeit 14), S. 107. - Auf den Übergang verweist auch der Reim in k 217/227, Str. 3, V. 6/12 kame: gezame, der eigentlich männlich ist, hier aber, künstlich ' zweisilbig erscheint. Bilden demnach die Strophen 2 und 3 ein älteres Paar?

46 Vgl. V. 6 in t 30, wo sich dieser Trend weiter fortsetzt. Das Bemühen, die Reimklänge zu erhalten, ist erkennbar (aber nicht immer erfolgreich), ansonsten verselbständigt sich der Text, dessen Grundtenor inhaltlich weitgehend erhalten bleibt, wobei allerdings die Einzelmotive des Marienlobs deutlich verblassen. 


\section{Kreatives Kompilieren: Poetik der Wiederverwertung}

Damit ist man bei grundlegend anderen Fragen angekommen, nämlich jenen nach der Produktionsweise der anonymen Meisterlieddichter. Es gehört zur Spezifik dieser Gattung, dass in ihr älteres Textmaterial aufgenommen und weiterverarbeitet, d. h. neu kontextualisiert, kompiliert und transformiert wird. Dabei können im Übergang der Sangspruchdichtung zum Meistergesang ältere Einzelstrophen mit neuem Textmaterial zur Bar-Norm angefüllt werden $^{47}$ oder bereits bestehende Bare bzw. Teile davon zu neuen Liedeinheiten kombiniert und umkonfiguriert werden. ${ }^{48}$ Gerade mehrfach überlieferte Strophen oder Strophenteile innerhalb einer Handschrift erlauben einen Einblick in derartige Prozesse. ${ }^{49}$ Auch hierfür bietet das Frauenlobcorpus in $\mathrm{k}$ reiches Material, das Baldzuhn differenziert aufgearbeitet hat. ${ }^{50}$ Für die vorliegenden Fälle wäre zu unterscheiden zwischen der Mehrfachüberlieferung vollständiger Strophen einerseits und von Strophenteilen andererseits, wobei diese entweder vom Tonerfinder stammen bzw. altbezeugt sein können (eindeutige Kriterien zur Unterscheidung sind für die fraglichen Strophen nicht auszumachen; eine solche Differenzierung war womöglich für die Meistersinger nicht von Belang) $)^{51}$ oder aber jünger überliefert

47 Das steht im Fokus bei Baldzuhn 2002 (Anm. 6), der den Möglichkeiten der historischen Schichtung in der Meisterliedüberlieferung nachgeht.

48 Vgl. den Versuch der Visualisierung solcher,Wanderungsbewegungen' bei Holger Runow: Mouvance - Cluster - Edition. Zum Problem der Darstellbarkeit liedübergreifender Überlieferungsformationen in Regenbogens Langem Ton. In: Sangspruchdichtung zwischen Reinmar von Zweter, Oswald von Wolkenstein und Michel Beheim. Hg. von Horst Brunner und Freimut Löser unter redaktioneller Mitarbeit von Janina Franzke. Wiesbaden 2017 (Jahrbuch der Oswald von WolkensteinGesellschaft 21), S. 295-308.

49 Auf das Potential einer differenzierten - auch inhaltlichen - Analyse solcher Mehrfachüberlieferungen verweist Baldzuhn mit Nachdruck, vgl. Michael Baldzuhn: Kap. VIII.2: Der Sangspruch im 14. und 15. Jahrhundert. In: Klein u. a. 2019 (Anm. 2), S. 485-500, hier S. 495f.

50 Baldzuhn 2002 (Anm. 6), S. 142-217.

51 Mehrfach überlieferte vollständige altbezeugte Strophen sind: RSM ${ }^{1}$ Frau/2/514a, $3=$ 537a,1 (=67a); 2/519a,3 = 540a,1 (= 72a); 2/524a,1 = 552a,2 (= 69a; möglicherweise echt, vgl. Helmut Thomas: Untersuchungen zur Überlieferung der Spruchdichtung Frauenlobs. Leipzig 1939, S. 71-73; nach GA entsprechend V,66*, ebenso Baldzuhn 2002 [Anm. 6], S. 158). Mehrfach überlieferte Strophenfragmente sind: RSM ${ }^{1} \mathrm{Frau} /$ 5/512a,1 V. 8-14 = 520a,2, V. 1-7 (= RSM ${ }^{1}$ Frau/10/107a; echt nach Thomas, S. 99; 
sind. ${ }^{52}$ Diese Strophen(-teile) können nun in Baren zusammentreten mit (1.) Strophen(-teilen) des Tonerfinders, ${ }^{53}$ mit (2.) Strophen(-teilen) aus einer älteren Überlieferungsschicht ${ }^{54}$ oder (3.) mit jüngeren Strophen(-teilen). ${ }^{55}$

Versucht man bezüglich des Inhalts eine gewisse Typisierung vorzunehmen, wird schnell deutlich, dass die meisten dieser mehrfach überlieferten Strophen sich durch recht stereotype meistersingerische Thematik und topische Redeweise auszeichnen. Sie sind damit - das lässt sich auch am vorangegangenen Beispielfall k 217/227, k 228 beobachten - innerhalb eines bestimmten thematischen Kontextes leicht (re-)kombinierbar, so etwa im Marien- und Gottespreis (Trinitätsthematik, Eucharistie). Die Strophen fügen sich insofern in verschiedene Bare ein, ohne deren Aussage wesentlich zu verändern. Dabei stehen sie - wie sich ebenfalls beispielsweise an k 217/227, k 228 zeigt - meist nicht unverbunden neben den übrigen Strophen des Bares, sondern erscheinen häufig durch ein Netz von Wort- und Motivresponsionen in das Liedgefüge integriert, was seinerseits wiederum durch die topische Bildsprache dieser Themen begünstigt wird.

Daneben begegnen aber auch Fälle mehrfachüberlieferter Strophen mit deutlich spezifischeren Themen, die zudem in thematisch sehr unterschiedliche Bare eingebunden sind. Diese Strophen erscheinen durch ihre jeweilige

s. a. Karl Stackmann: Probleme der Frauenlob-Überlieferung. In: PBB 98 [1976], S. 203-230, hier S. 216).

52 Mehrfach überlieferte jünger bezeugte vollständige Strophen sind: RSM ${ }^{1} \mathrm{Frau} / 2 /$ 501a, $1=2 / 501 c, 3 ; 2 / 501 \mathrm{a}, 2=2 / 501 \mathrm{c}, 2 ; 2 / 505 \mathrm{a}, 3=2 / 540 \mathrm{a}, 2 ; 2 / 540 \mathrm{a}, 4=2 / 554 \mathrm{a}, 2 ; 4 /$ 503a, $2=2 / 514 a, 2 ; 7 / 513 a, 5=7 / 515 a, 2 ; 9 / 501 a, 3=9 / 519 a, 4 ; 9 / 504 a, 2=9 / 509 a, 3 ; 9 /$ $504 \mathrm{a}, 3=9 / 506 \mathrm{a}, 2$. Mehrfach überlieferte jünger bezeugte Strophenfragmente sind: RSM ${ }^{1} \mathrm{Frau} / 5 / 512 \mathrm{a}, 1, \mathrm{~V} .8-21=5 / 520 \mathrm{a}, 2$, V. $1-7$ und $15-21 ; 5 / 514 a, 1$, V. $3-17=5 /$ 514b,3, V. 3-17; 5/514a,2, V. 1-8 = 5/14b,1, V. 1-8; 5/514a,3, V. 15-21 = 5/514b,1, V. 15-21.

53 Vollständige Strophen des Tonerfinders in Baren mit mehrfach überlieferten Strophen sind RSM ${ }^{1}$ Frau/2/522a,1 ( $\left.{ }^{1} \mathrm{Frau} / 2 / 24\right) ; 2 / 519 \mathrm{a}, 1$ ( $\left.{ }^{1} \mathrm{Frau} / 2 / 54\right)$; Strophenteile Frauenlobs sind enthalten in RSM ${ }^{1} \mathrm{Frau} / 5 / 512 \mathrm{a}, \mathrm{V} .1-7$ ( $\left.{ }^{1} \mathrm{Frau} / 5 / 10\right)$.

54 Vollständige altbezeugte Strophen in Baren mit mehrfach überlieferten Strophen (-teilen) sind RSM ${ }^{1}$ Frau/2/540a,3; 2/524,2-3.

55 Vollständige jünger bezeugte Strophen in Baren mit mehrfach überlieferten Strophen(-teilen) sind RSM ${ }^{1}$ Frau/2/501a,3; 2/501c,1; 2/505a; 2/514a,1-2; 2/519a,2; 2 / 524a, 1 und $3 ; 2 / 537 a, 2-3 ; 2 / 554 a, 1$ und $3 ; 4 / 503 a, 1$ und $3 ; 4 / 514 a, 1$ und $3 ; 5 / 512 a, 2-3$; 5/514b,2; 5/520a,1 und 3-5; 7/513a,1-4; 7/515a,1 und 3; 9/501a,1-2; 9/504a,1; 9/506a,1 und 3; 9/509a,1-2; 9/519a,1-3 und 5. Jüngere Strophenteile sind: RSM ${ }^{1} \mathrm{Frau} / 5 / 514 a$, Str. 1, V. 1-2. und 18-21, Str. 2, V. 9-21, Str. 3, V. 1-7; 5/514b, Str. 1, V. 9-14, Str. 3, V. 1-2 und 18-21; 5/520a, Str. 2, V. 8-14. 
Kontextualisierung inhaltlich umakzentuiert und dokumentieren damit deutlicher eine bewusste produktive Rezeption. ${ }^{56}$

Ein Beispiel dafür bieten im Langen Ton RSM ${ }^{1} \mathrm{Frau} / 2 / 524 \mathrm{a}$ und 2/552a: $\mathrm{k} 71$ und $\mathrm{k} 106$ (k 71, Str. 1 = k 106, Str. 2). ${ }^{57} \mathrm{k} 71$ besteht aus drei altbezeugten Strophen ${ }^{58}$ in $k 106$ tritt die erste Strophe von k 71 mit zwei jüngeren zu einem Bar zusammen. Diese Wanderstrophe handelt von der Vergänglichkeit aller irdischen Gewalt und Macht (beispielsweise der Päpste, Könige, Fürsten), welche nur der tugend tat zu überleben vermöge (V. 16). In k 71 ist sie Eröffnungsstrophe und Ausgangspunkt einer in der Folgestrophe geäußerten subjektiven Klage über den Tod der Verwandten, über die Unabwendbarkeit des eigenen Todes und über die quälende Ungewissheit, was danach kommen mag. Dieser sich ankündigenden desperatio des Sprecher-Ichs setzt die dritte Strophe hier einen Wechsel der Sprechhaltung entgegen und ermahnt stark didaktisch zur maze in liebe und leid (Str. 3, V. 11f.). ${ }^{59}$ Die drei Strophen stehen schon in der älteren Überlieferung zusammen, wenn auch nicht als Bar und in anderer Reihenfolge (dort Str. 3, 1, 2). Die Vorstellung von einer Zusammengehörigkeit dieser Strophen könnte insofern vorlagen- bzw. überlieferungsbedingt sein; ihre ,Umstellung' bei der Barwerdung in k dokumentiert aber einen deutlichen redaktionellen Eingriff zugunsten einer klareren Argumentationslogik..$^{60}$

56 Die Grenzen zur zuvor genannten Kategorie ,topischer' Strophen sind dabei im thematisch nicht unendlich variationsreichen Meistergesang fließend und auch davon abhängig, wie un-/erwartbar die Einbindung erfolgt.

57 Edition: k 71: GA V, ${ }^{\star} 65,{ }^{\star}{ }^{6} 66,{ }^{\star} 67$; Wenzel 2012 (Anm. 9), S. 475-477 (k 78-80); k 106 ebd., S. 544-546 (k 191-k 193); im Folgenden zitiert nach Wenzel.

58 Sie sind vor 1350 in Cpg 350 überliefert (RSM ${ }^{1}$ Frau/2/68a, 2/69a, 2/70a); nach Baldzuhn ist für alle drei Strophen noch die Autorschaft des Tonerfinders zu erwägen, vgl. Baldzuhn 2002 (Anm. 6), S. 158; in der Göttinger Ausgabe (GA) sind sie aufgrund ihrer nicht gesicherten Echtheit mit Asterisk versehen (s. Anm. 57).

59 Zum inhaltlichen Zusammenhang dieses Bars vgl. auch Wenzel 2012 (Anm. 9), S. $256 f$.

60 Interessant ist in dieser Hinsicht auch die Überlieferung dieser drei Strophen in der Handschrift F (Weimar, Herzogin Anna Amalia Bibliothek, Cod. Q 564): Hier stehen RSM ${ }^{1}$ Frau/2/69a (k 71, Str. 1) und RSM ${ }^{1}$ Frau/2/70a (k 71, Str. 2) als Strophenpaar zusammen (RSM $\left.{ }^{1} \mathrm{Frau} / 2 / 104 \mathrm{a}\right)$; RSM ${ }^{1} \mathrm{Frau} / 2 / 68 \mathrm{a}$ (in k 71, Str. 3) geht diesen dort unmittelbar voraus als letzte Strophe einer Vierergruppe mit nur hier überlieferten Strophen (RSM ${ }^{1}$ Frau/2/103a); darüber hinaus ist RSM ${ }^{1}$ Frau/2/69a (k71, Str. 1) noch in der Donaueschinger Handschrift (s. Anm. 22) überliefert, wo sie eher unvermittelt einen Fünferbar über den Verfall von Welt und Werten abschließt (Karlsruhe 408, 144r-145r; RSM ${ }^{1}$ Frau/2/562a). 
In $\mathrm{k} 106$ steht die Eingangsstrophe von $\mathrm{k} 71$ an zweiter Stelle. ${ }^{61}$ Voraus geht ihr hier ein sonst nicht überlieferter Nachruf auf Frauenlob. Es wird bedauert, dass sein (Langer) Ton nun verwaist sei, in welchem er Maria und Jesus gepriesen habe und mit richer kunste / grub also wunderwehe wort (V. 10f.). Dem folgt dann mit unserer mehrfach überlieferten Strophe eine Klage über die Vergänglichkeit aller irdischen Gewalt (am Beispiel der Päpste und Könige), der die Beständigkeit des tugendhaften Handelns (tugend tat) entgegengesetzt wird. Die Figuren der irdischen Würdenträger greift die dritte Strophe wieder auf und thematisiert nun auch die Vergänglichkeit ihres Reichtums. Eine subtile Heische wird hörbar, wenn es dann heißt, dieser Reichtum ermögliche es ihnen, leichter ihren Adel zu beweisen, als es den Armen möglich sei (V. 13-19). Die mehrfach überlieferte (hier zweite) Strophe wird durch diesen Kontext also ganz anders profiliert als in $\mathrm{k} 71{ }^{62}$ Besonders reflektiert wirkt die Einbindung dieser altbezeugten Strophe hier dadurch, dass sich der Verfasser der ersten Strophe als Nachfolger Frauenlobs geriert, indem er dessen Tod thematisiert und in seinem - ja angeblich verwaisten - Ton dichtet. Die nachfolgende ,Wiederverwendung' der altbezeugten Strophe erscheint damit zugleich als Huldigung des verblichenen Vorbilds wie auch als Partizipation an dessen Schaffen. Die altbezeugte Strophe erfährt dabei aber durch ihr neues Umfeld eine deutliche Umakzentuierung. Ihre Frage danach, was (von den Mächtigen) letztlich bleibe, wird durch die erste Strophe poetologisch umgedeutet, indem diese die Dichtkunst Frauenlobs trotz seines Todes im Gedenken ruhmvoll bewahrt und mit der Übernahme seiner Strophe im Folgenden performativ umsetzt. Sang wird damit einerseits als unsterblich ausgestellt, andererseits wird die Vergänglichkeit alles Irdischen und der Wert der tugend tat in der abschließenden Strophe unterschwellig in Argumente für die Entlohnung und damit in eine Heische überführt. Deutlich spiegelt dieser Bar mithin das Verhältnis der Meistersinger zur Tradition und zu ihren Vorbildern sowie die sich daraus ergebende meistersingerische Rezeptionspraxis, die sich in diesem Fall als produktiv und reflektiert zeigt.

Selten nur lässt sich im Rahmen der Mehrfachüberlieferung von Strophen in $\mathrm{k}$ beobachten, dass sie in einen Bar deutlich besser als in den anderen, passen'. Ein solcher Fall scheint aber vorzuliegen bei RSM ${ }^{1} \mathrm{Frau} / 2 / 514 \mathrm{a}$ und 2/537a, also k 61

61 Vgl. zu k 106 auch Wenzel 2012 (Anm. 9), S. $275 f$.

62 Baldzuhn bewertet diesen vollständigen Kontextwechsel als Indiz dafür, dass es sich um eine ursprüngliche Einzelstrophe handelt, vgl. Baldzuhn 2002 (Anm. 6), S. 168. 
und $\mathrm{k} 84$ im Langen Ton ( $\mathrm{k} 61$, Str. 3 = k 84, Str. 1) ${ }^{63}$ Die Wanderstrophe ist hier erneut eine altbezeugte, die jenseits von $\mathrm{k}$ viermal als Einzelstrophe und einmal in einem anderen Bar überliefert ist. ${ }^{64}$ Sie bietet einen mit Adam beginnenden Katalog der Minnesklaven und erzählt, wie diese von den Frauen betrogen wurden. Die Strophe schließt mit der Feststellung des Sänger-Ichs: daz macht der reynen wybes stam. / Was schat es dann, ob mich ein wip auch hitzet unde froret? (k 61, Str. 3, V. 18f.). ${ }^{65}$ Damit fügt sich diese Strophe gut in den Barzusammenhang k 61 mit seinem Thema verwerflichen weiblichen Minneverhaltens: Die erste Strophe dieses Bares beklagt, dass die Frauen ihre Minne heutzutage nicht mehr dem Edlen schenkten, sondern demjenigen, der Geld habe. Daran anschließend warnt die zweite Strophe den jungen Mann vor falscher Minne und schlechten Frauen, die keine triuwe kennen, sondern auf Geld fixiert seien. Die mehrfach überlieferte Strophe, der Katalog der Minnesklaven, illustriert diese Warnung abschließend anhand der topischen Exempelfiguren betrogener Männer. Dass sich das Sänger-Ich in der Schlusspointe selbst als bereitwillig leidender Minner offenbart, eröffnet verschiedene Deutungsmöglichkeiten, ${ }^{66}$

63 Edition: k 61: GA-S V,204/214; Wenzel 2012 (Anm. 9), S. 453-455 (k 41-43); k 84: ebd., S. 506-508 (k 129-131); im Folgenden zitiert nach Wenzel.

64 Zur Einzelüberlieferung s. RSM ${ }^{1} \mathrm{Frau} / 2 / 67 \mathrm{a}-\mathrm{d}$, zur weiteren Überlieferung als Bar s. RSM ${ }^{1} \mathrm{Frau} / 2 / 557 \mathrm{a}$; daneben ist das Initium einmal in einer Überschrift als Tonangabe verwendet ( $\left.\mathrm{RSM}^{1} \mathrm{Frau} / 2 / 67 \mathrm{~h}\right)$.

65 In der älteren Überlieferung: sit daz fugte der minnen stam, / waz schat denn, ab ein reinez wip mich brennet unde fröret? (GA-S V,204, V. 18f.).

66 Wenzel 2012 (Anm. 9), S. 248, argumentiert, dass der Rat des Spruchdichters aus der Position der Inversion richtigen Verhaltens erfolge: „Das schlagende Beispiel für die falsche Minne ist mit dem Topos vom bösen wip [Str. 2] und dem gehörnten Mann (Topos der Minnesklaven) anschaulich gemacht [Str. 3]. Dadurch wird die Forderung einer auf der Differenz zwischen der reine [n] zarte[n] frauw [...] [Str. 3, V. 6] und dem bose[n] wyp [Str. 3, V. 7] basierenden klugen Entscheidung (ich ler dich einen [...] clugen $\sin$ [Str. 3, V. 1]) legitimiert." - Wenn es aber heißt, die Tatsache, dass die Männer zu Minnetoren werden, geschehe durch der reynen wybes stam, ließe sich auch argumentieren, dass das die Anempfehlung einer reine[n], zarte[n] frauwen an den jungen Mann aus Str. 2 geradezu unterläuft. Besonders auffallend ist, dass dieser vorletzte Vers von der älteren und der Parallelüberlieferung in $\mathrm{k}$ abweicht, denn dort heißt es: sit sie betwang der mynne stam (k 84,1, V. 18f.). Zudem ist die daran anschließende Pointe der Strophe (Was schat ez dann, ob mich ein wip auch hitzet unde froret, V. 19) eine revocatio, also eine Redefigur, die nicht selten im Minnesang begegnet: Als dergestalt selbst betroffenes Ich verliert der Sprecher seine Kredibilität, was die vorangehende Unterweisung einerseits 
lässt die Strophe aber dennoch thematisch und argumentativ klar in den Barzusammenhang eingebunden erscheinen. ${ }^{67}$

Ganz anders in k 84: Hier eröffnet die Minnesklaven-Strophe - mit kleinen Abweichungen ${ }^{68}$ - einen Dreierbar, der im Folgenden den Verrat Jesu durch Judas thematisiert. Dieser Verrat wird verrätselt über das Bildfeld der Krämerei metaphorisiert, was den Aspekt des Verkaufs besonders hervorhebt. Die letzte Strophe betont, dass der Verrat nur möglich gewesen sei, weil Jesus es so wollte, um Adams Fall zu sühnen, und schließt mit einer gebethaften Anrufung Gottes. Die Zusammenstellung dieses Bars irritiert, selbst wenn sich Verbindungslinien zwischen den Strophen konstruieren lassen: Es ließe sich etwa argumentieren, dass das tertium von Judasverrat und Minnesklaven im Betrogenwerden durch einen vertrauten und geliebten Menschen liegt. Zudem eröffnet die Erwähnung alttestamentlicher Minnesklaven, besonders indem sie mit Adam beginnt, den Horizont der Heilsgeschichte: Die Perspektive der (erb-)sündigen Menschheit bis hin zu Christi Opfertod, mit welchem dieser Adams Fall sühnt (wie die Strophe dezidiert hervorhebt), würde dem Bar gewissermaßen einen typologischen Rahmen verschaffen, der den zunächst fehlenden Zusammenhang stiftet. ${ }^{69}$ Gerade in Hinblick darauf, wie eng die Strophen 2 und 3 dieses Bares aufeinander bezogen sind, scheint aber die erste (altbezeugte) Strophe deutlich sekundär hinzugefügt, sei es um den jüngeren Zweierbar zu adeln oder um ihn zum Dreierbar zu ergänzen. Erstaunlich bleibt dabei, dass „der redaktionelle Ehrgeiz [...] nicht so weit [ging], den

partiell zur Disposition stellt, andererseits aber spielerisch performativ die Macht der Minne vorführt.

67 Wenzel 2012 (Anm. 9), S. 248f., zeigt hier zudem, wie der Bar in eine gewisse Redaktion eines Gesamtzusammenhangs des Tones in k eingepasst sein könnte, denn die klagende Rede der ersten Strophe von k 61 schließe an den klagenden Gestus der letzten Strophe des vorangehenden Bares an. Die nach k 61 folgende Reihe von Fabeln, die „im Sinne einer ,Belegfabel“ jeweils einen Lehrsatz bestätigen“, nehme damit die Rhetorik der Schlussstrophe von k 61 auf (zum Begriff der ,Belegfabel` in der Sangspruchdichtung vgl. Klaus Grubmüller: Meister Esopus. Untersuchungen zu Geschichte und Funktion der Fabel im Mittelalter. Zürich, München 1977 [MTU 56], S. 425). Das wäre zwar je nach Interpretation der Schlusspointe etwas zu relativieren (s. Anm. 66), die Fabeln korrespondieren in ihrer Funktionalisierung als ,Belegfabeln' aber mit der vordergründigen Funktionalisierung der Minnetoren als Exempel.

68 Dabei stimmt sie mit der älteren Überlieferung überein, s. Anm. 65.

69 Vgl. dazu auch Wenzel 2012 (Anm. 9), S. $265 f$. 
Abgesang der ersten Strophe auf die Thematik der beiden folgenden Strophen hin umzuformen" ${ }^{70}$

Neben diesen verschiedenen Formen vollständiger mehrfach überlieferter Strophen erscheinen für Fragen hinsichtlich der meistersingerischen Produktionspraxis zudem Fälle interessant, in denen nur Teile von Strophen in mehreren Baren überliefert sind. Als erstes Beispiel sei k 207 herausgegriffen (RSM ${ }^{1} \mathrm{Frau} / 5 / 514 \mathrm{~b}$; GA-S VIII,202), ein Dreierbar im Zarten Ton, der ein Gotteslob mit Bitte um Gnade unter Berufung auf das Leiden Gottes als Mensch bietet. Gestützt wird diese Liedfassung durch eine recht konsistente Parallelüberlieferung in der älteren Basler Meisterliederhandschrift ${ }^{71}$ (b 34). Besonders interessant ist der Schluss, in dem Gott an die jemerliche stymme im Angesicht des Kreuzestodes gemahnt wird (V. 15), ${ }^{72}$ woran sich die Bitte anschließt, die Seele Frauenlobs in den Himmel aufzunehmen. Man beachte den semantischen Konnex von Stimme und dem Sängermeister Frauenlob, was auch diesem Lied eine poetologische Dimension verleiht.

Wenige Blätter vor dem Lied steht der Bar k 204 (RSM ${ }^{1} \mathrm{Frau} / 5 / 514 \mathrm{a}$ ), in dem nach Auskunft des ,Frauenlob-Supplements ${ }^{{ }^{773}}$ die erste Strophe von k 207 als zweite erscheint, dabei aber stark verändert wurde (s. Textbeispiel $2 \mathrm{im}$ Anhang: Synopse k 207 - k 204). Das klingt zunächst nach dem geläufigen Typus einer wandernden Einzelstrophe. Tatsächlich ist die Sache jedoch viel komplizierter, wie schon die Beschreibung im RSM sowie v. a. bei Baldzuhn ${ }^{74}$ zeigt. Die mehr oder weniger wörtliche wie motivliche Übereinstimmung der

70 GA-S I, S. 66.

71 Basel, Universitätsbibliothek, Cod. O IV 28, um 1430. - Die Varianz zwischen k und b bleibt auch hier überschaubar und weist wiederum auf den schriftgebundenen Tradierungsprozess. Beide Handschriften gehen erkennbar auf eine gemeinsame Vorstufe zurück, ohne dass aber zwingend dieselbe Handschrift mechanisch abgeschrieben worden sein muss. b hat dabei an manchen Stellen den sinnvolleren Text, $\mathrm{k}$ entspricht aber besser den formalen Anforderungen an den Ton, ist also eher um Aufführbarkeit bemüht; dazu passt, dass k die Melodien überliefert, b aber nicht. Auffällig ist allerdings, dass ausgerechnet die ältere Handschrift b Schwierigkeiten mit einigen älteren mittelhochdeutschen Verbformen hatte (vgl. den Kommentar GA-S II, S. 494f.). Das verweist ggf. auf ein höheres Alter der gemeinsamen Vorstufe oder aber auf einen ,moderneren' Sprachgebrauch des b-Schreibers, während die $\mathrm{k}$-Schreiber doch mehr Routine im Umgang mit älteren mhd. Texten hatten?

72 Das korrespondiert mit Str. 1, V. 11: ,hely' gar jemerlich du rieff (vgl. ,Eli, Eli, lama asabtani?” - „Mein Gott, mein Gott, warum hast du mich verlassen“, Mt 27,46).

73 GA-S I, S. 184.

74 Baldzuhn 2002 (Anm. 6), S. 194f. 
Strophe k 207, Str. 1, und k 204, Str. 2, der Dank für Gottes Taufgaben an die Menschen (Ring und Kleid), betrifft nämlich nur die Verse 1-9. ${ }^{75}$ In k 207, Str. 1 folgt im zweiten Stollen der Verweis auf den Lanzenstoß des Longinus und im Abgesang das Leiden Marias, die in einen kleinen Dialog mit Gott tritt (mit Verweis auf Johannes als Tröster). Beide Motive hat k 204 in der dritten Strophe. Dort findet sich der Abgesang aus k 207, Str. 1 fast wörtlich wieder, das Longinus-Motiv ist im ersten Stollen verarbeitet (k 204, Str. 3, V. 4: ein blinder heyde). Der zweite Stollen bindet beides zusammen: Marias Leid über den Lanzenstoß in Christi Seite und eine erweiterte Einleitung ihrer wörtlichen Rede an Gott. Statt der einen Strophe in k 207 bietet k 204 mithin zwei Strophen über dasselbe Thema. - Zudem bildet die Schlussstrophe von k 207 den Eingang zu k 204; geändert ist allerdings der Wortlaut der beiden Eingangsverse, und vor allem ist im Abgesang die Fürbitte für Frauenlob getilgt, die in k 207 die Schlusspointe bildet. (Die Textsynopse im Anhang [S. 216] versucht durch entsprechende Markierungen die beschriebenen Verschiebungen und Verschränkungen augenfällig zu machen.)

Kann man angesichts dieser Vermengung von Textelementen über Stollenund Strophengrenzen hinweg eine Entwicklungsrichtung zwischen den beiden Liedfassungen bestimmen? Baldzuhn hält es für naheliegend, in k 207 / b 34 eine sekundäre Bearbeitung von k $204 \mathrm{zu}$ sehen. ${ }^{76}$ Aus den beiden Strophen k 204, Str. 2-3 wäre also die eine Strophe k 207, Str. 1 kompiliert worden. Als Argument mag man sich dabei auch auf das Frauenlob-Motiv in k 207 stützen. Gut denkbar ist schließlich, dass die allgemeinere Gebetsversion k 204 im Kontext zunftmäßiger Verehrung des alten Meisters in k 207 entsprechend angepasst und konkretisiert wurde. - Genauso wenig ist aber auch die andere Richtung, eine Entkonkretisierung zum weniger kontextabhängigen Gebetslied, auszuschließen. Der Fall lässt einen einigermaßen ratlos zurück, weil er Fragen nach der Liedproduktion der Meistersinger aufwirft, die offenbar nicht nur auf Strophenebene kompilieren, sondern auch darüber hinaus mit inhaltlichen und formalen Versatzstücken arbeiten - Fragen, die jedenfalls keineswegs mehr mit den Mitteln der Textkritik zu beantworten sind, sondern welche die

75 Damit liegt zugleich ein Textausschnitt vor, der über die Stollengrenze hinausreicht, die Neukonfigurierung der Textversatzstücke kann insofern auch nicht einfach mit dem Phänomen des häufiger vorkommenden sog. ,Stollentauschs` erklärt werden.

76 Baldzuhn 2002 (Anm. 6), S. 194f.; dafür mag im Kontext seiner Untersuchungen sprechen, dass k 207, Str. 2 vielleicht eher als neu hinzugedichtete Strophe aufzufassen ist? 
spezifische Textualität des Meistergesangs und die poetischen Verfahrensweisen der anonymen Dichter betreffen.

Gerade solchen Fragen soll im Folgenden an einem weiteren Beispiel mehrfach überlieferter Strophenteile im Zarten Ton nachgegangen werden, nämlich in RSM ${ }^{1} \mathrm{Frau} / 5 / 512 \mathrm{a}$ und 5/520a: k 202 und k 210 (k 202, Str. 1, V. 15-21 = k 210, Str. 2, V. 15-21; GA-S VIII,215B/C). Der Fall ist ähnlich gelagert wie der vorherige, es handelt sich um zwei Bare, die stollenweise Übereinstimmungen aufweisen, dabei aber zudem - im Gegensatz zum vorherigen Beispiel - altbezeugtes, also ,ursprüngliches' Frauenlob-Material produktiv rezipieren. Karl Stackmann hat diesen Fall bereits diskutiert ${ }^{77}$ und geht dabei besonders auf die vorliegende meistersingerische Frauenlob-Rezeption ein. Hier soll vor dem Hintergrund der Mehrfachüberlieferung in k das Verhältnis der beiden jüngeren Bare zueinander noch einmal aufgegriffen werden. Die folgende Textsynopse stellt das Verhältnis der alten Frauenlobstrophen (links, zitiert nach GA, der Göttinger Frauenlobausgabe) zu k 202, Str. 1, dar. Letztere ist zitiert nach dem Frauenlob-Supplement (GA-S), wobei auch die Auszeichnungen der Edition weitgehend übernommen sind: Fettdruck markiert Übereinstimmungen mit den älteren Texten ${ }^{78}$, eckige Klammern indizieren, dass die Übereinstimmung nur auf einer Lesart zu diesen beruht. ${ }^{79}$

77 Karl Stackmann: Wiederverwerteter Frauenlob. Nichts Ungewöhnliches - und was man daraus lernen kann. In: Neue Wege der Mittelalter-Philologie. Landshuter Kolloquium 1996. Hg. von Joachim Heinzle, L. Peter Johnson und Gisela VollmannProfe. Berlin 1998 (Wolfram-Studien 15), S. 104-113.

78 Auf die Unterscheidung von Fettdruck und Unterstreichung, welche GA-S im Hinblick auf die zwei älteren Strophen vornimmt, kann hier im Rahmen der Synopse verzichtet werden.

79 Vgl. GA-S II, S. 217. 
GA VIII,16

(RSM $\left.{ }^{1} \mathrm{Frau} / 5 / 10 \mathrm{a}\right)$

Wip, selden hort, der wunnen spil,

wip, vröuden zil,

ein spiegel zarter süze, ich sprechen wil.

wip, wurzel aller werdicheit,

5 wip, aller güte ein fiol, der nie craft vermeit, 5

wip, tugende vil

durch dich got hat gegeben.

Wip, wereclicher ere ein dach,

wip, triuwe ein bach,

10 wip, senfticlicher höhe ein prisgemach,

wip, mannes lip geselleschaft,

wip, aller sune ein sigeriche magenkraft,

wip, milte ein vach,

nach dem die werden streben.

15 Wip, minniclicher wunne ein trutlich garte, wip, aller edele ein überliuchtic warte,

wip, din lop kein scharte

hat nie verwunt, des wol dich, wip!

wip, leitvertrip,

20 hochgerter lip.

trac, wip, wiplich din leben.

\section{GA XIII,42}

(RSM ${ }^{1}$ Frau/10/107a,1)

Wip, sit du loser blicke bist, als dich von art ist angeborn,

Ich wil dich leren einen list,

daz wandel wirt an dir verkorn:

5 Wis diner blicke nicht zu bald.

wan da du spürest zucht der jugent

oder ritterliches herzen tugent,

da wis mit blicken wol gestalt.

\section{GA-S VIII,215B1}

(k 202,1, fol. 204v; vgl. RSM ${ }^{1}$ Frau/5/512a,1)

Wip, selden hort, wip, wonnen spil, wip, freüden [vil],

wip, spiegel liecht, ir suss ${ }^{80}$ ich sprechen wil: wip, wortzel aller [selikeit],

ein gerte von Jesse, die nie kein sachs verschneit, wip, wirden [zil]

hat got dorch dich getragen.
Wip, hastu boser ${ }^{81}$ blicke gir, sint sie an dir

10 geborn von muter art, so volge mir: biss diner blicke nit zu balt, biss daz du sehest mannes tugent wolgestalt. so nit verbir, du la din blicke jagen.

15 Wip, la din güte von dir nit entrinnen. hab ere liep! wiltu dich recht besinnen, die ere soltu minnen, so wirt dir lobeliche wat, die dir wol stat,

20 schand ende hat. den priss la dir behagen.

80 GA-S setzt gegen die Handschrift sus; der Rest des Verses dort kursiv (statt fett).

81 GA-S normalisiert zu böser, was jedoch die Nähe von loser (GA XIII,42, V. 1) - boser (k 202,1, V. 8) überdeckt. 
In der ersten Strophe von k 202 finden sich also Versatzstücke einer, echten und einer altbezeugten Frauenlob-Strophe: ${ }^{22}$ Der erste Stollen der k-Strophe entspricht bis auf einen Vers dem ersten Stollen von GA VIII,16, einer anaphorischen Frauenpreis-Strophe Frauenlobs. ${ }^{83}$ Der zweite Stollen der Kolmarer Strophe k 202, Str. 1 weist punktuelle Übereinstimmungen mit GA XIII,42 auf, einer Frauenlehre in Frauenlobs Kurzem Ton. ${ }^{84}$ Das heißt, wo Frauenlobs Frauenpreisstrophe GA VIII,16 den anaphorischen Lobpreis konsequent über die gesamte Strophe fortsetzt, überführt k 202, Str. 1 ihn im zweiten Stollen in eine Frauenlehre. Die Kolmarer Strophe schließt letztlich mit einem ,neuen' Abgesang, der die Themen des Aufgesangs aufgreift und synchronisiert, indem er die Notwendigkeit vorbildlichen Verhaltens hervorhebt und für das Befolgen der vorgängig erteilten Lehre das metaphorische Kleid der Ehre in Aussicht stellt, welches Ruhm und Preis verspreche..$^{85}$

Deutliche Parallelen zu dieser ersten Strophe von k 202 weist die etwas später in k notierte zweite Strophe von k 210 auf. Das verdeutlicht die folgende Synopse (zit. nach GA-S), in der für k 210,2 wiederum Fettdruck die Übereinstimmungen der beiden Strophen untereinander hervorhebt; ${ }^{86}$ zusätzlich markiert Unterstreichung Übereinstimmungen zwischen k 210,2 und GA XIII,42.

82 Darauf verweist schon Thomas 1939 (Anm. 51), S. 132f., der GA VIII,16 und GA XIII,42 als echt einstuft, ebenso Stackmann 1976 (Anm. 51), S. 215f.; das RSM klassifiziert GA XIII,42 allerdings mit dem Vermerk ,echt nach Thomas“ als RSM ${ }^{1}$ Frau/ 10/107.

83 Vgl. Stackmann 1998 (Anm. 77), S. 108.

84 Vgl. ebd., S. 109; dass von der Strophe im Kurzen Ton der Text, nicht aber die Melodie übernommen wird, belegt besonders deutlich, dass von den Meistersingern vorwiegend die komplexen, langen Töne rezipiert werden (gerade der Kurze Ton Frauenlobs, konstatiert Baldzuhn, werde in der Rezeption „als zu schlicht gemieden“, vgl. Baldzuhn 2019 [Anm. 49], S. 497; vgl. dazu auch Haustein 2019 [Anm. 2], S. 425). Das Beispiel zeigt aber, dass die Texte dennoch bekannt sind und geschätzt werden.

85 Stackmann stellt sehr differenziert die umfassende Kenntnis der Frauenlobschen Lyrik heraus, die sich in der Verfasstheit der Strophe bis ins Detail spiegele: „Der Verfasser hat [...] den Versuch gemacht, einige Hauptpunkte von Frauenlobs Minnelehre zu sammeln und in einer einzigen Strophe zusammenzufassen. Die Ausführung seines Plans ist ihm nicht besonders gut geglückt, vor der Originalität und Eleganz der Sprache Frauenlobs kann er nicht bestehen." Stackmann 1998 (Anm. 77), S. 109.

86 Der Text von k 202,1 erscheint hier ohne weitere Auszeichnungen, wie sie GA-S vornimmt (s. o.). 
GA-S VIII,215B1

(k 202,1, fol. 204v; vgl. RSM ${ }^{1} \mathrm{Frau} / 5 / 512 \mathrm{a}, 1$ )

Wip, saelden hort, wip, wonnen spil,

wip, freüden vil,

wip, spiegel liecht, ir suss ich sprechen wil:

wip, wortzel aller selikeit,

5

ein gerte von Jesse, die nie kein sachs ver-

schneit,

wip, wirden zil

hat got dorch dich getragen.

Wip, hastu böser blicke gir,

sint sie an dir

10 geborn von muter art, so volge mir:

biss diner blicke nit zu balt,

biss daz du sehest mannes tugent wolgestalt.

so nit verbir,

du la din blicke jagẹn.

15 Wip, la din güte von dir nit entrinnen,

hab ere liep! wiltu dich recht besinnen,

die ere soltu minnen.

so wirt dir lobeliche wat,

die dir wol stat,

20 schand ende hat.

den priss la dir behagen.
GA-S VIII,215C2

(k 210,2, fol. 209r; vgl. RSM $\left.{ }^{1} \mathrm{Frau} / 5 / 520 \mathrm{a}, 2\right)$

Wip, bistu sneller blicke gir,

sint die an dir

geborn von muter art, so volge mir.

bißdiner blicke nit $z u$ balt,

5 bißdu er[schauwest] mannes tugend wol-

gestalt.

da nit verbir

und la din blick hin jagẹn.

Vil vast dort uff der minne spor

gang im sin vor,

10 biss daz du offen vindst der truwe tor.

so sich dar in, wieß dir behag,

merck, ob er icht valsches in sinem herczen trag. da hüt dich vor.

wip, merck, waz ich dir sage!

15 Wip, laß dir dine güte nit entrinnen, unrechter fure soltu nit beginnen,

die ere soltu minnen, so wirt dir lobeliche wat,

die wol anstat,

20 schand ende hat.

den rat la dir behagen.

k 210, Str. 2 setzt allerdings direkt mit dem didaktischen zweiten Stollen von k 202, Str. 1 ein. Diesem folgt nun ein ,neuer zweiter Stollen, dessen erster Vers gewissermaßen apo koinu anschließt, indem er das Bildfeld der Jagd (hinjagen, V. 7) vom Ende des ersten Stollens mit der Metapher von der minne spor am Anfang des zweiten Stollens aufnimmt (V. 8). Und auch thematisch bleibt der zweite Stollen dem ersten verpflichtet, indem er die Anweisung zum richtigen Verhalten in der Minne ergänzt (V. 8-14), bevor die Strophe in den gleichen Abgesang wie k 202, Str. 1 mündet, nämlich für vorbildliches Verhalten das belohnende Ehrenkleid in Aussicht stellt (V. 15-21).

Baldzuhn vermutet für die,Verstellung' der Stollen zwischen k 202, Str. 1 und k 210, Str. 2 aufgrund der „vielen Stollenvertauschungen im Zarten Ton“ eine vorgängige Überlieferungsstufe, die den Text von k 202 direkt im Anschluss an GA VIII,16 geboten habe. Ein nachlässiger Schreiber könnte die beiden Texte dann durch Augensprung zwischen den Strophenteilen kontaminiert haben. ${ }^{87}$

87 Vgl. Baldzuhn 2002 (Anm. 6), S. 197f. 
Stackmann dagegen erwägt für die Abweichungen zwischen den beiden Strophen produktionsästhetische Gründe und vermutet, dass der Autor von k 210 Anstoß an der Kombination von Frauenpreis und Frauenlehre aus k 202 genommen habe ${ }^{88}$ Baldzuhn und Stackmann nehmen für beide Varianten der in k mehrfach überlieferten Strophe eine ursprüngliche Selbstständigkeit und erst spätere Einbindung in Bare an. ${ }^{89}$ Was diese Einbindung angeht, fällt Stackmanns Urteil über die in k 202 hinzutretenden Strophen vernichtend aus, für k 210 kritisiert er das Fehlen eines Gesamtkonzeptes und hält den Bar daher für ein Konvolut ursprünglicher Einzelstrophen. ${ }^{90}$

Hier lohnt sich aber vielleicht doch noch einmal ein näherer Blick darauf, wie die betreffende Strophe in $\mathrm{k}$ in die beiden verschiedenen Barzusammenhänge eingebunden ist, bzw. darauf, ob und inwiefern das mit den an ihr zu beobachtenden Abweichungen korreliert. In k 202 wird die Strophe durch zwei weitere Frauenpreisstrophen ergänzt. Thematisch und rhetorisch greifen diese damit den ursprünglich Frauenlobschen ersten Stollen der Einleitungsstrophe auf. Mit der durchgehenden wîp-Anapher referieren die, neuen' Strophen zudem auf die ursprüngliche Gestalt der in der ersten Strophe des Bars aufgegriffenen Frauenlobstrophe GA VIII, $16 .{ }^{91}$ Etwas überraschend erscheint in Hinblick auf

88 Stackmann 1998 (Anm. 77), S. 111f. (allerdings ist die Verbindung von Frauenpreis und -lehre im Sangspruch durchaus verbreitet, vgl. Dorothea Klein: Kap. IV.1: Gattungsinterferenzen und literarische Kontexte: Minnesang. In: Klein u. a. 2019 [Anm. 2], S. 119-133, hier S. 129); dass k 210, Str. 2 eine Bearbeitung von k 201, Str. 1 darstellt, äußert Stackmann unter Vorbehalt, hält es aber aufgrund einer Reihe überzeugender Beobachtungen für sehr wahrscheinlich, vgl. ebd., S. 110f.

89 Vgl. Baldzuhn 2002 (Anm. 6), S. 197; Stackmann 1998 (Anm. 77), S. 109f., 112.

90 Vgl. Stackmann 1998 (Anm. 77), S. 109-112.

$91 \mathrm{k} 202$, Str. 2: Wyp, aller tugend volles vass, / wip nit vergass, / wip tunt den senden dicke sorgen lass. / wip sint din usserwelte frucht, / got der beschuff ym selb ein wip zu einer genucht. / wip, süss und bass / wann blumen, rosen rot. / Wip, aller wunn ein paradiess, / wip, selden riss, / wip trut, wip zart, wip fürent eren priss. / wip mannes leit wol wenden kan. / wip fürent unde leitend mit der eren fan. / wip man tunt griss, / die mynne daz gebot. / Wip gent den mannen freuden hochgemüte, / wip, reines wip, daz macht ein gütlich güte, / wip, diner mynnen glüte. / wip sint ein wunnenbernder ast. / wip fürt den gast, / wip wendet sende not.

Str. 3: Wyp, übergulter eren schrin! / wip, frisch und vin! / wip, robin rot! wip, brehend sonnen schin! / wip, zockersüsser balsam smack! / wip, aller freud sint wip ein spilnder osterdag. / wip sende pin / an mannen werden wil. / Wip, aller blut ein bernder stan! / wip, milter fan! / wip furt getrüwen schilt uff eren ban. / wip, aller ding ein ewig hort! / wip haltet wirdiclichen schon der eren port, / wip, milt und zan, / wip sint der freuden spyl. / Wip, küsche blum, du adeliches bilde, / durchlüchtig gantz, wip, fyol off gefilde! / 
diese Integration in einen reinen Frauenpreis nun wiederum die didaktische Ausrichtung des zweiten Stollens und Abgesangs der ersten Strophe, zumal diese stilistisch das anaphorische Reihungsprinzip des restlichen Bares aufbrechen. All das spricht durchaus dafür, dass die erste Strophe eine ehemalige Einzelstrophe ist, die bedingt durch ihren ersten Stollen und ungeachtet ihrer didaktischen Komponente eine sekundäre (und eher eintönige) Aufschwellung zum Dreierbar erfahren hat - und zwar nach dem Vorbild der im Zarten Ton schon beim Tonerfinder begegnenden anaphorischen wîp-Preisstrophen. ${ }^{92}$

Etwas anders liegt der Fall aber bei k 210. Hier ist die mehrfach überlieferte Strophe als zweite in einen Fünferbar eingebunden, der durchgehend eine stark didaktische Ausrichtung aufweist. ${ }^{93}$ Angelegt ist diese belehrende Grundhaltung bereits in den ersten Versen des Bares, wo es in unterweisender $d u$-Apostrophe heißt: wipliches wip, ich rate dir, / du folge mir (Str. 1, V. 1f.), gefolgt von einer minnetheoretischen Warnung: Die Frau solle des herzen gier vor valscher lust bewahren (Str. 1, V. 3) und nicht den Weg zur Schande einschlagen, damit sich ihr werde $[\mathrm{r}]$ wibes nam nicht warer schuld schämen müsse (Str. 1, V. 4f.). Der zweite Stollen der ersten Strophe stellt die Belohnung für vorbildliches Verhalten in Aussicht, nämlich das ,Ehrenkleid', das - wie der Abgesang expliziert - nicht nur innerweltliches Ansehen verspreche, sondern auch die Krone aus frauw eren rise (Str. 1, V. 16) und unaussprechlichen Ruhm im Jenseits. ${ }^{94}$

wip reb in dem gewilde / sint, wip ein ross on allen dorn, / wip uss erkorn, / wip hoch geborn! / wip sint der eren ein zil.

92 Neben der hier zugrundeliegenden Strophe RSM ${ }^{1} \mathrm{Frau} / 5 / 10$ a auch RSM ${ }^{1} \mathrm{Frau} / 5 /$ 12-14 und damit beide Frauenpreisstrophen im Zarten Ton. In $\mathrm{k}$ ist zudem ein weiterer nach diesem Muster gebildeter Frauenpreis-Dreierbar unikal überliefert (RSM ${ }^{1} \mathrm{Frau} / 5 / 521$ ), was ebenfalls darauf verweist, dass diese anaphorischen wîpPreisstrophen Frauenlobs im Zarten Ton die meistersingerische Rezeption geprägt haben. Auf ein Bewusstsein für thematische Eigenheiten altüberlieferter Töne verweist Baldzuhn 2019 (Anm. 49), S. 497; vgl. dazu auch Schanze 1984 (Anm. 3), S. 59-76.

93 Schon Thomas 1939 (Anm. 51), S. 134, meint, dass die Strophen dieses Bars „ursprünglich nicht zusammengehören“; diesem Urteil schließt sich Stackmann 1998 (Anm. 77), S. 112, an, verweist aber auf die sie durchziehenden FrauenlobAnleihen unterschiedlicher Intensität. Baldzuhn 2002 (Anm. 6), S. 197, urteilt, dass für die Strophen aufgrund ihrer thematischen Ausrichtung auf wîp und minne zumindest „eine lockere Zusammenstellung für den Vortrag im Bereich des Möglichen lieg[e]".

94 GA-S VIII,215C1: Wipliches wip, ich rate dir, / du folge mir, / uff valschen lust stell nit dins herczen gier, / daz sich din werder wibes nam / von warer schuld an keiner stat 
Die Strophe weist damit deutliche Parallelen zur zweiten Strophe, der mehrfach überlieferten, auf. Gerade dadurch, dass diese zweite Strophe den Frauenpreis-Stollen ihrer ,Schwesterstrophe' k 202, Str. 1 nicht hat, lassen die ersten beiden Strophen des Bares k 210 die gleiche argumentative Linie erkennen: Sie beginnen mit einer kritisch-warnenden Frauenlehre und stellen daraufhin den Lohn für richtiges Verhalten in Aussicht, der in beiden Fällen als veredelndes Gewand der êre metaphorisiert wird (Str. 1, V. 10f.; Str. 2, V. 17f.). Durch die Tilgung des anaphorischen wîp-Lobpreises setzen beide Strophen prominent mit einem autoritativ-belehrenden Sprechgestus ein - besonders deutlich in der $d u$-Apostrophe (Str.1, V. 1f.; Str. 2, V. 1f.) -, dem sie durchgehend verpflichtet bleiben. Durch die Verschiebung des Stollens spiegelt die zweite Strophe auch das handlungsanweisende so volge mir (Str. 1, V. 2) ihrer Vorgängerstrophe am Strophenbeginn (Str. 2, V. 3), wodurch die Strophen noch enger aufeinander bezogen erscheinen. Eine weitere Klammer bildet das rat-Motiv, das am Anfang der ersten Strophe (Str. 1, V. 1, ich rate dir) und am Ende der zweiten Strophe (Str. 2, V. 21, den rat la dir behagen) steht. Die Parallelüberlieferung von k 202 lautet hier übrigens bezeichnenderweise: den priss la dir behagen (Str. 1, V. 21), eine Variante, die die unterschiedlich ausgeformte Thematik der beiden Strophen geradezu programmatisch abbildet.

Was die Gesamtkonzeption des Bares k 210 angeht, scheint die zweite Strophe der warnenden Belehrung der ersten, sich vor falschem Minneverhalten und lust zu bewahren, noch eine konkretere Verhaltensanweisung nachzuschieben. Sie greift das Thema falschen weiblichen Minneverhaltens aus der ersten wieder auf und warnt vor snellen blicken (Str. 2, V. 1): Die Frau solle hinsichtlich ihrer blicke nit zu balt sein (Str. 2, V. 4), sie nicht zu provokativ oder vorschnell aussenden. Das leitet im Folgenden zu einer Aufforderung über, erst die triuwe des Mannes zu prüfen, bevor sie ihm ihre Blicke schenke (Str. 2, V. 5-7). Der Abgesang schließt an das Thema der Selbstkontrolle und Tugendhaftigkeit der Frau aus der ersten Strophe wieder an, wenn diese ermahnt wird, [nit] unrehter fure zu beginnen (Str. 2, V. 16).

Der darin angelegte Gedanke richtiger und falscher zwischengeschlechtlicher Beziehungen leitet bruchlos zum Thema der dritten Strophe über,

icht dürffe scham. / den gang verbir, / der dir geschaden mag. / So wird din hohes lop vil breit, / dir wirt bereit, / daz dir frau Ere geben wil ein cleit, / daz si vor aller welt an hat. / wo gwan ufferden frauwe ie (Hs. nie, fol. 208vb) so riche wat? / es si geseit: / got diner wirde pflag. / In himmelriche dort, im paradise, / bistu bekronet mit fraw Eren rise. / wo wart ie man so wise, / der kunde dine wirdikeit / on underscheit / han (Hs. het, fol. 209ra) ußgeleit? / dem lucht ein selig tag. 
die - ebenfalls in didaktischem Gestus - Typen richtiger und falscher minne diskutiert und in einer Feier des Beischlafs endet. ${ }^{95}$ Dies wiederum könnte den Anlass zum Anschluss der folgenden, vierten Strophe gegeben haben, ${ }^{96}$ die in anaphorischer Reihung die (richtige) minne preist. ${ }^{97}$ Die letzte, fünfte Strophe schließt dann - gewissermaßen symmetrisch zur Frauenlehre am Beginn des Bares - den Rahmen mit einer Aufforderung an den Mann, lobesane Frauen zu preisen und sich ihnen mit Anstand zu nähern, wobei die Strophe Frauenpreis und Didaxe synthetisiert. ${ }^{98}$

95 GA-S VIII,215C3: Wer steter minne gerne pfligt, / wie hoch daz wigt, / wo minnen mit der stetikeit †begigt. / wo stete minne gerne vert, / die wurckent nit, wann daz (Hs. do, fol. 209ra) ein reine hercze gert. / wa wandel sigt, / da rat ich nieman hin. / Die wandelminn ist also swach, / prist ungemach. / wer hie mit lip behuset undr ir dach / mit als gantzer unstetigkeit, / dem wer der tot weger, dann er das leben treit. / mit we, mit ach / verzert er mut und sin. / Wann aber liebe mit der minne ringet / und sich ein sloss zuschen den zweien dringet, / waz dann lust dar zu bringet (Hs. dringet, fol. 209rb), / daz kumpt von wissen armen blanck. / der minne zwang / dez lustes schranck, / dang hab er, heils begin!

96 GA-S VIII,215C4: Die minn ist aller selden blut, / die minn ist gut, / die minn, die hat den lip in irer hut, / die minn, die wurcket mit der scham, / die minn ist mangem spiegel aller selden stam, / die minne tut, / was lust volbringen wil. / Die minne mit der milte fert, / die minn hin zerrt (Hs. zert, fol. 209rb; gegen die Ausgabe wäre eine Beibehaltung von zert im Sinne von, sie zehrt aus' mit Blick auf den Reim erwägenswert), / die minne sich vor ungemüte wert, / die minn ist besser dann der tag, / die minn ist süsser dann der edel balsamsmag, / die minn, die rert / den lust uß herczen zil. / Die minne sich †von (Hs. vor, fol. 209rb) ungemüte lestet†. / sich hin, sich her, wie sich die minne vestet, / in richem herczen restet: / so slecht sich in der minne strick / mang lieplich blick / nimpt da den sick, / wann es sich scheiden wil.

97 Mit dieser anaphorischen Struktur zeigt sie - trotz des Umbaus in eine neue Liedeinheit, die gerade den anaphorischen Frauenlob-Stollen ausspart - dennoch Assoziationen an ein poetisches Verfahren, das einerseits der Zarte Ton befördert und das andererseits Teil der konkreten hier verarbeiteten Vorlage bzw. Vorlagentradition war.

98 GA-S VIII,215C5: Wer wol naturlichs (Hs. naturlich, fol. 209va) prüfen kan / uff frauwen stan / und in büt er, wann sie sint lobesan, / und frauwen ding zum besten wigt / und ir mit frucht in ganzer wirdikeite pfligt: / got sicht es an, / wer frawen bi gestat. / Wip sint naturlichen geborn, / daz in ist zorn. / wann sie hat frucht, so hat sie got erkorn. / wip sint ob aller engel schar, / got nimpt der tugenthaften zallen zitten war / und git im (Hs. get in, fol. 209va) vor, / der wip in eren hat. / La dinen mut von frauwen nit vergahen, / †war wibe† zucht mit tugend tu in nahen. / du must von in (Hs. im, fol. 209va) enpfahen / den dinen lebendigen lip. / ein reines wip / an allen kip / vor got in eren gat. 
Entgegen Stackmanns Einschätzung, so hoffen wir gezeigt zu haben, gibt der Bar durchaus eine das Ganze durchziehende sinnvolle Gedankenführung zu erkennen - und zwar unabhängig von der Frage, ob der Text aus ursprünglichen Einzelstrophen besteht; entscheidend ist die kompositorische Anpassung. Der Bar zeichnet sich strukturell durch eine gewisse Symmetrie aus, die einen Spannungsbogen von Frauenlehre über Minnedidaxe und Minnepreis zu Männerlehre entwirft. Die erste Strophe wirkt dabei beinahe prologartig, indem sie diese Themen präludiert, zugleich zeichnen sich in ihrer didaktischen Ausrichtung deutliche Parallelen zu unserer mehrfach überlieferten Strophe $2 \mathrm{ab}$. Insofern könnte man die Tatsache, dass in dieser zweiten Strophe gerade der Frauenpreis-Stollen getilgt ist und ausgerechnet durch eine Vertiefung der Didaxe ersetzt wird, als Vorgang eines spezifischen Zuschneidens der Strophe auf die Eingliederung in diesen Bar werten. ${ }^{99}$

Dieser Fall lässt sich freilich nicht verallgemeinern. Dennoch kann man daraus unseres Erachtens einige Schlüsse ziehen: erstens, dass sich darin, wie die Strophe hier in den Barzusammenhang eingefügt ist, eine spezifische Art produktiv gestaltender Redaktion, nämlich ihre punktuelle Anpassung an ihr Umfeld beobachten lässt; zweitens - und wichtiger -, dass sich die einzelnen Fälle mehrfacher Überlieferung gleicher Bare, Strophen oder Strophenteile nicht pauschal erklären, sondern nur je für sich untersuchen lassen. Genau darauf wollten wir hindeuten: Um einer spezifischen Poetik der anonymen meistersingerischen Liedproduktion weiter nachzuspüren, wären - ganz der Eigenlogik der Gattung entsprechend - jenseits von Fragen nach Originalität und damit verbundenen Qualitätsurteilen für jeden Einzelfall die besondere Machart, der je erkennbare Gestaltungswille und die sich daraus ergebenden Sinnpotentiale zu betrachten. So haben unsere Analysen weniger spektakuläre Antworten gefunden, als vielmehr versucht, auf unterschiedlichen Beobachtungsebenen

99 Gerade angesichts der Verhältnisse in k merkt schon Rettelbach an: „Das Zusammenstellen und Zudichten ist eine Kunst, in der man die hohe Verehrung der Alten zeigen konnte, zugleich in der Zudichtung den eigenen Kunstverstand“; s. Johannes Rettelbach: Kap. VIII.3: Die Rezeption der Sangspruchdichtung im Meistergesang. In: Klein u. a. 2019 (Anm. 2), S. 501-508, hier S. 504. Stackmann 1998 (Anm. 77), S. 113, beurteilt allerdings gerade die vorliegenden Bare deutlich abwertend als Ausdruck dessen, wie sich das Verhältnis zur Tradition in der meisterlichen Dichtung verändere: „die Alten fordern nicht mehr zu produktiver Erneuerung und Überbietung heraus. Es bleibt bei der Wiederverwertung ihrer Hinterlassenschaft.“ Damit legt er einen normativen Maßstab an, dessen Gleichsetzung von Innovation und Qualität gerade nicht (mehr) im Zentrum unserer Beobachtungen stand. 
neue Fragen zu generieren, um die verschiedenen Dimensionen der Textproduktion und -tradition noch weiter auszuleuchten. Wir meinen, dies weiterzuführen könnte sich lohnen, um noch besser zu verstehen, wie Meistergesang funktioniert, über dessen Produktionsmechanismen, Aufführungs- und Verschriftlichungspragmatik trotz guter Erschließung des Materials immer noch erstaunlich wenig bekannt ist. 


\section{Anhang: Textbeispiel 1}

k 227, fol. 219v (=k 217, fol. 214v)

1 Maria, küniginnen,

wirf dinen bernden hymmel samen

uff uns sünder vil armen,

Maria, dorch den sußen namen,

5 daz du bist aller sünder trost,

du hymmelport, du form der trinitate!

Got ein selb drytt mit synnen

in dines hertzen closen quam,

flacht sich drivaltichlichen

10 zu einem gantzem blünden stam. er lost uns uß der helle rost, der gottes son, nach sines vatter ratte.

Mary, dez wer du forme,

an der er nam sich mentscheit an

15 nach sines sones norme.

er sach dich an mit flisse, ee daz er ye kein ding tentsarff,

dar nach den ancker in dich warff,

den gottes son mit einer tuben wisse.

2 Ros aller engel frauwe,

du gottes muter unde magt, din lop nieman durch gründet noch auch volsinget noch vol sagt.

5 in dir die mynn enzündet wart, du hochgeborne ware küneginne,

Hilff mir, daz ich beschauwe in hymmelrich die freude din, der engel sammenunge,

10 die Cherubin und Seraphin, du edel gottes tochter zart, her Salomones wol gezierter schrine.

Du edels kunges künne, du lüchtest vor die sonnen clar,

15 ros aller engel wünne, du cron ob allen choren! sich flacht in dir ein drivalt ryss, gar wol geschickt in alle wiss: daz riss ist got und wolt die hell zerstoren.

3 Wie got mit richem wunder die creatur getempert hat, der engel sammneunge, die er beschuff mit wiser tat,

5 tyer $^{1}$, vogel, visch, für, lufft und erd, walt, waßers crafft uß sim gebot nie kame.

Menschlicher form besunder $z u$ hohen selden wart erdacht, daz nieman kann volldencken,

10 wie es got selber hat volbracht mit sinem lust nach hohem wird, des hab er dank ${ }^{2}$, daz ym daz ye gezame.

Mary, des wer dü spiegel in siner claren gotheit gantz,

15 da er dich one triegel ym selber welt gar taugen. nu bit für uns, Maria maget, sit dir din trut kint nit versaget, wann er gewert dich, daz ist one laugen.

\section{k 228, fol. 220 r}

1 Es ist ein ring umbfangen in witen kreiß einer Juncfrauw schon. der ring der ist verslossen mit mangem sternen lobesan.

5 Maria, muter, reine meyt, zu dinr gnad neigt sich ein rosen zwye, Wer wil die rosen langen, der sol in yren garten gan; wem sie ir nit engünne,

10 ich rat ym, daz er la $\beta$ da von. ir rosen bletter die sint breit, den yren fründen sint sie alle fry. Woltens ir vind abbrechen, der wart, daz yn die scharpfen dorn

15 nit in die hende stechen. wem sie ir gan zu lesen, der ist vor sünden wol behut. und geb mir alle küng ir gut, dar umb word ir der rosen nit ein fesen.

2 Ros aller engel frauwe,

du cristus muter reine meit, din lop wirt nymmer mere dorch grabet, -gründet noch volseit.

5 in dir die lieb enzüindet wart in warem liecht, hymlische künegynne, $\mathrm{Nu}$ hilf, daz ich an schauwe in hymmelrich die freude din, der engel sammenunge,

10 in Jerarchi, in Seraphin. ave, du gottz tochter zart, her Salomon voll aller gnaden synne. Du edels künges künne, dü lïchtes vor den sonnen clar,

15 meit aller hymmel wünne, din kron lücht dorch nü $\mathrm{n}\rangle$ koren. In sich sloss sich drivaltig ryss, des hymmels und der erden bryss: das ryß ist got und gund die hell zerstoren.

3 Wol in der hymmel gleste und der syben planeten lauff, Maria, Cristus done, ich man dich an dins kindes tauff,

5 der in dem Jordan wart genant, got vatter, son und auch heiliger geiste.

Der glaube der ist feste, ave, do dich der engel fant. $d u$ bist daz edel fure,

10 do sich der fenix inn verbrant, $d u$ bist des olbaums riss herkant, daz Noe bracht ein tub uns zu volleiste. Adam der hat gebrochen, dar umb der reinen meyde son

15 wart in sin hertz gestochen mit einem scharpfen spere. er leit vor uns den bittern tot. Maria kußt daz blut so rot, daz von ym ran nach sines vatters gere.

\footnotetext{
${ }^{1}$ Hs.: eyer; korrigiert nach k 217.

${ }^{2}$ Fehlt; ergänzt nach k 217.
} 


\section{Textbeispiel 2}

k 207, fol. $207 \mathrm{r}$ (= b 32)

Ich danck dir, lieber herre myn,

der gaben din.

uns wart von dinen gnaden her ein fingerlin,

es wart uns in dem tauff gegeben,

5 des dancken wir dir, lieber her, die wil wir leben,

gar luter fin

vor aller sünden flut.

Du geb uns in dem tauff ein cleit

dein arebeit,

10 da man dich an dem crütze, lieber herre, sneyt,

, hely' gar jemerlich du rieff.

Longinus stach dir eine große wunde tieff. $u \beta$ der menscheit

ran wasser unde blut.

15: Maria weint und wand ir wissen hende.

sie sprach: ,nu bin ich wurden yar elende.

[pin] ach got, wer sol mir wende

myn clag und swere pin?

fraw, mutter myn,

20. und daz sol sin

Johannes der vil yut

.

$2 \mathrm{Her}$, aller welte schopfer gut,

es kam din blut

uns hie zu troist in also richer flut,

daz her $u \beta$ dinen wunden ran,

5 da man dir an dem crütz daz leben an gewan.

hilff wol gemut,

die edeln dry person,

Hilff, daz wir by dir wonen dort.

den selben hort

10 den teyl uns mit auch all durch din ewig wort, die du sprecht, e dan umm dich sleich

da mit der ruten ob din rücken mangen streich, den selben mort

lit du am crütze fron.

15 Der dinen martel laß uns, her, geniessen. her Moyses der liess sich nit verdryessen, du ließ $\beta$ ym wasser fliessen

uß einem steine hin. verlih uns sin

20 und recht gewin,

für uns ynß hymmels tron!

3 Ach, hochgelopter starker got,

küng Sabaoth.

ich danck dir diner dieffen wunden rot und auch des crantz, der dir durch stach

5 din gotlich heupt gewan ein blutig farwe bach. in dodes not

satz man dir uff die cron.

Ich man dich, herre, an den sweiß,

din blut so heyss,

10 da man dir an dem crütz den lip uff reiß, und man dich an daz crutze zwang.

jch man dich an den jemerlichen bittern trang,

din munt sich fleiß,

wie er ez drincke schon.

15 Ich man dich an die jemerliche stymme, die du rufft an dem crütz uß todes grymme. her, nu laß zu dir clymme

ein meister ane mel:

behüt vor quel

20 Frauwenlobz sel,

für sie in hymmels tron.

Amen

\section{k 204, fol. 205v}

1 Genad, her vatter, wares brot durch dinen dot

und durch dyn großen dieffen wunden rot und durch den crancze, der dir durch stach

5 din heubet und auch durch die blutes farwe bach, die da von not

uß diner siten fioss.

Ich man dich, herr got, an den sweiß von blute heiss

10 und an daz sper, dar an din leben reiß,

do din lip mit dem tode rang.

jch man dich an den yemerlichen gallen trang.

gall essich weiß.

der jamer der was gro $\beta$.

15 Ich man dich an die yemerliche stymme, do du rüfft an dem crütz mit todes grymme.

min gebett zu dir clymme.

dorch diner heiligen martel er.

Maria her,

20 mich hie gewer

dorch gnad, die zu dir floss.

2 Ich danck dir, herr und schopfer myn, der gnaden din.

mir wart von diner yut eyn fingerlin,

duz wart mir in dem tauff gegeben;

5 duz dunck ich dir, vil lieber herr, die wil ich leben Ein sele vin

was luter unde reyn.

Du geb mir in dem tauff ein cleit

waz schon bereit

10 al mit der martel, die du vor uns leit,

do du dich an das crütze bot

und gingest williclichen für uns in den dot

uff mynen eit,

des dancken wir dir clein.

15 Din großen wunden gunden sere giessen, der bittern martel wolt dich nit verdriessen. al von den juden spiessen daz blut al uff die erde ran. sie warent gran

20 dem selben man. sünder, daz soltu weyn.

3 Maria die trug jamers see und leit ir flee.

mir tut myns lieben kindes wunden we, die ym ein blinder heyde stach.

5 vor grossem leyd Marien nach ir hertze brach, da sie nüste

von yres kindes dot.

"Mary uss großen noten sprach

do sie an sach.

10 uss yres kindes sitten fioss ein bach,

-dar zu uß sines hertzen grunt.

Maria jemerlichen sprach: ,owe der stunt,

:hat ungemach

"der sich da zu mir bot!"

15: Sie kust daz blut und wand ir wißen hende

,vil liebes kint, wem lestu mich ellende,

und wer $\{.$. ) furbas wenden

min leyt und auch myn swere pyn?'

-fraw mutter myn,

20 und daz sol sin

Johannes t $n+$ din rat. 
Nils Hansen

\title{
„gräulich verderbt“ und „übel zugerichtet“? Überlieferungstreue und Bearbeitungstendenzen der Kolmarer Liederhandschrift am Beispiel von Liedern in Tönen Konrads von Würzburg
}

\begin{abstract}
The article scrutinizes the delivery of songs and stanzas by Konrad von Würzburg in the Colmar Liederhandschrift in order to describe the attitude of its scribes towards their exemplars. Comparing parallel versions within the manuscripts on one side and older manuscripts (Cpg 350, Cpg 848) on the other, it is argued that the body of text shows traces of different forms of processing. A majority of the alterations is concerned with establishing the upbeat or adapting the meter in a typical Meistersinger manner. It is concluded that, within the wide range of processing techniques, the Colmar Liederhandschrift also sports rather faithful reproductions of older versions.
\end{abstract}

I.

Die um 1460 entstandene Kolmarer Liederhandschrift (k) ist besonders als Quelle für den frühen Meistergesang ab der Mitte des 14. Jahrhunderts von Bedeutung, ${ }^{1}$ sie enthält daneben aber auch in nicht geringem Umfang älteres Material, für das durch Parallelüberlieferung eine Entstehung vor oder um die Mitte des 14. Jahrhunderts gesichert ist. Nach den Untersuchungen Michael Baldzuhns gilt dies für 504 der insgesamt 4596 in k überlieferten Strophen. ${ }^{2}$ Sowohl die absolute Zahl als auch der Anteil dieser altbezeugten Strophen an der Gesamtzahl der in den jeweiligen Toncorpora überlieferten Strophen ist dabei recht unterschiedlich, wie die folgende, auf Baldzuhns Arbeit basierende Darstellung zeigt: ${ }^{3}$

1 Vgl. Burghart Wachinger: Kolmarer Liederhandschrift. In: Die deutsche Literatur des Mittelalters. Verfasserlexikon $\left(={ }^{2}\right.$ VL). 2. Aufl., hg. von Kurt Ruh u.a. (ab Bd. 9 hg. von Burghart Wachinger). 11 Bde. Berlin/New York 1977-2006, hier Bd. 5 (1985), Sp. $27 f$.

2 Vgl. Michael Baldzuhn: Vom Sangspruch zum Meisterlied. Untersuchungen zu einem literarischen Traditionszusammenhang auf der Grundlage der Kolmarer Liederhandschrift. Tübingen 2002 (MTU 120), S. 48.

3 Vgl. ebd., S. 38-47. 
Corpus (Töne)

Tugendhafter Schreiber (Grußweise) [Winsbecke]

Wartburgkrieg (Schwarzer Ton, Fürstenton)

Frauenlob (Langer Ton, Hundweise, Zarter Ton, Grüner

Ton, Leichs)

Konrad von Würzburg (Aspiston, Morgenweise, Hofton)

Marner (Langer Ton, Goldener Ton, Kurzer Ton)

Boppe (Hofton)

Reinmar von Zweter (Frau-Ehren-Ton)

Regenbogen (Briefweise, Langer Ton)

Junger Meißner (Ton I)

Reinmar von Brennenberg (Hofton)

Stolle (Alment)

Walther von der Vogelweide (König-Friedrichs-Ton)

Tannhäuser (Ton IX)

Junger Stolle (Ton)

Wolfram von Eschenbach (Goldener Ton)

Ehrenbote (Spiegelweise)

\section{altüberliefert}

123 von 124 (99\%)

112 von $336(33 \%)$

77 von $409 \quad(19 \%)$

70 von $176 \quad(40 \%)$

39 von $265 \quad(15 \%)$

19 von $190 \quad(10 \%)$

15 von $33 \quad(46 \%)$

15 von $743 \quad(2 \%)$

9 von 78

7 von 56

7 von 80

4 von 9

3 von 11

2 von 16

1 von 12

1 von 18

Ein Großteil der Strophen mit Altüberlieferung konzentriert sich auf die Toncorpora Frauenlobs, Konrads von Würzburg, des Marners sowie auf das Winsbecke-Corpus und die beiden,Wartburgkrieg'Töne, die zusammen über $80 \%$ des Materials enthalten. Prozentual hohe Anteile weisen neben dem Winsbecke-Corpus und den ,Wartburgkrieg'Tönen auch die Toncorpora Walthers von der Vogelweide und Reinmars von Zweter auf. ${ }^{4}$

Die in den Meistersingerhandschriften vorgenommenen systematischen Änderungen der metrischen Strukturen der alten Töne sind insbesondere durch

4 Ein hoher prozentualer Anteil von altüberlieferten Strophen dürfte vor allem als Hinweis darauf zu sehen sein, dass diese Töne im frühen Meistergesang nur selten produktiv verwendet wurden (vgl. zu Walther auch Jens Haustein: Walther in k. In: Lied im deutschen Mittelalter. Überlieferung, Typen, Gebrauch. Chiemsee-Colloquium 1991. Hg. von Edward Cyril u. a. Tübingen 1996, S. 217-226, hier S. 219). 
Arbeiten von Horst Brunner und Johannes Rettelbach gut erforscht. ${ }^{5}$ Diese betreffen vor allem die Auftaktverhältnisse (nur noch einsilbiger Auftakt), die Versfüllung (streng alternierender Rhythmus) sowie Zeilenlänge und Reimschemata (Aufteilung langer Zeilen, ggf. mit Zäsurreimen; Tendenz zur Angleichung bzw. Vereinfachung der Strophenform). Auch wenn die Kolmarer Liederhandschrift die Einheitlichkeit der anderen Meistersingerhandschriften ${ }^{6}$ hier nicht ganz erreicht, ${ }^{7}$ gelten diese Erkenntnisse im Großen und Ganzen auch für diese Handschrift.

Das in k überlieferte Material ist im Hinblick auf die Nähe zur Altüberlieferung bisher keiner umfassenden Analyse unterzogen worden, die vorliegenden Einschätzungen zu Einzelcorpora ergeben jedoch ein eher diverses Bild: ${ }^{8}$

Karl Simrock, der 1858 die Kolmarer Liederhandschrift als einer der ersten nach ihrem Wiederauftauchen für seine Ausgabe des ,Wartburgkrieges' heranzog, nannte das Ausmaß der „Verderbnis“ bei dem aus der Altüberlieferung bekannten Material „ungeheuer“, 9 an Neuem fänden sich nur „Sudeleien“, „fast werthlose Um- und Zudichtungen von der Hand späterer sogenannter Meister, die beßer Stümper hießen“. ${ }^{0}$ „[Ü]bel zugerichtet" und „gräulich verderbt" nennt auch eine Dissertation aus den 1890er Jahren die in k überlieferten Texte in den beiden ,Wartburgkrieg'Tönen, die „willkürlich verändert“ und „mit Interpolationen meistersingerischer Herkunft belastet" seien; ${ }^{11}$ und noch bei

5 Vgl. Horst Brunner: Die alten Meister. Studien zu Überlieferung und Rezeption der mittelhochdeutschen Sangspruchdichter im Spätmittelalter und in der frühen Neuzeit. München 1975 (MTU 54), insbes. S. 195-223; Johannes Rettelbach: Variation - Derivation - Imitation. Untersuchungen zu den Tönen der Sangspruchdichter und Meistersinger. Tübingen 1993 (Frühe Neuzeit 14), S. 82-145.

6 Zur Sonderstellung von k unter den Meistersingerhandschriften des 15. Jahrhunderts vgl. Wachinger 1985 (Anm. 1), Sp. 36f.; vgl. auch Haustein 1996 (Anm. 4), S. 218 mit Anm. 5.

7 Vgl. Brunner 1975 (Anm. 5), S. 224; vgl. auch Baldzuhn 2002 (Anm. 2), S. 26.

8 Vgl. zum Folgenden auch die sich in einigen Punkten überschneidende knappe Darstellung bei Baldzuhn 2002 (Anm. 2), S. 26f., der auch Strophen ohne Altüberlieferung diskutiert.

9 Vgl. Der Wartburgkrieg. Hg., geordnet, übersetzt und erläutert von Karl Simrock. Stuttgart 1858, S. 239.

10 Vgl. ebd.; Simrock hatte sein Manuskript bereits abgeschlossen, als ihm die Überlieferung von k zugänglich wurde (vgl. ebd., S. 238). Ein gänzlich neutraler Blick wird ihm daher wohl nicht mehr möglich gewesen sein.

11 Vgl. Emil Oldenburg: Zum Wartburgkriege. Diss. Rostock 1892, Zitate S. 16 und S. 25. 
Burghart Wachinger klingt eine gewisse Skepsis gegenüber der Spätüberlieferung an, wenn er dem, Wartburgkrieg'-Herausgeber Tom Albert Rompelman ${ }^{12}$ vorwirft, $\mathrm{k}$ für die Anfertigung seines Textes zu oft gefolgt zu sein, da sie auch „an gut lesbaren Stellen“ wegen „Plattheit und Formelhaftigkeit des Ausdrucks und Banalität des Inhalts" verdächtig sei. ${ }^{13}$

Auch für die im Frau-Ehren-Ton Reinmars von Zweter in k überlieferten Strophen bilanziert Gustav Roethe, dass wegen ihrer weitgehenden Umarbeitung „für den Text [seiner Ausgabe, NH] [...] wenig zu ernten" sei. ${ }^{14}$ Heidrun Alex nennt in der Einleitung ihrer Ausgabe des Sangspruchdichters Boppe die Überlieferung in k ein zwar „interessantes gattungstypisches Produktions- und Rezeptionsphänomen", wegen der weitreichenden Umformungen, die von rein formalen bis hin zu tiefgreifenden inhaltlichen Änderungen reichten, sei die Überlieferung in k allerdings „textkritisch nicht von Belang“ ${ }^{15}$ Abwägend äußert sich Helmuth Thomas, der in seinen Untersuchungen zur Überlieferung der Spruchdichtung Frauenlobs feststellt, dass die Überlieferungsqualität in k von Spruch zu Spruch unterschiedlich und jedes Mal neu zu bewerten sei. ${ }^{16}$ Positive Einschätzungen des Überlieferungsbefundes finden sich für altüberliefertes Material dagegen deutlich seltener, etwa beim Winsbecke-Corpus. ${ }^{17}$

Deutlich hebt sich aber die Aussage Günter Mayers in seiner 1974 erschienenen Dissertation über die ,Probleme der Sangspruchüberlieferung' ab, der für die „echten “18 Strophen Konrads von Würzburg feststellt, dass es - mit einer einzigen Ausnahme, die er aber als Autorvariante verstanden wissen will keinerlei nennenswerte Umarbeitungen im Vergleich zur Altüberlieferung

12 Der Wartburgkrieg. Kritisch hg. von T[om] A[lbert] Rompelman. Amsterdam, Paris 1939.

13 Vgl. Burghart Wachinger: Sängerkrieg. Untersuchungen zur Spruchdichtung des 13. Jahrhunderts. München 1973 (MTU 42), S. 37.

14 Vgl. Die Gedichte Reinmars von Zweter. Hg. von Gustav Roethe. Leipzig 1887, S. 156.

15 Vgl. Heidrun Alex: Der Spruchdichter Boppe. Edition - Übersetzung - Kommentar. Tübingen 1998 (Hermaea. Neue Folge 82), S. 15.

16 Vgl. Helmuth Thomas: Untersuchungen zur Überlieferung der Spruchdichtung Frauenlobs. Leipzig 1939, S. 128f.; vgl. auch Baldzuhn 2002 (Anm. 2), S. 27.

17 Vgl. Baldzuhn 2002 (Anm. 2), S. 27.

18 Als echt gelten für Mayer hier wohl wie für Schröder alle in k überlieferten Sprüche mit Altüberlieferung mit Ausnahme des vierzigstrophigen Ave Maria im Hofton $\left({ }^{1}\right.$ KonrW/6/100). Vgl. Kleinere Dichtungen Konrads von Würzburg. Hg. von Edward Schröder. Bd. 3: Die Klage der Kunst. Leiche Lieder und Sprüche. Mit einem Nachwort von Ludwig Wolff. 4. Aufl. Dublin, Zürich 1970, S. IX. 
gebe. ${ }^{19}$ Überraschend ist Mayers Feststellung, weil Edward Schröder in seiner Ausgabe von Konrads Sprüchen betont, dass k einer „meistersingerischen redaction" verpflichtet sei und wie die anderen Handschriften des 15. Jahrhunderts „höchst selbständig und willkürlich“ mit ihrem Material umgegangen sei. $^{20}$

Es hat sich heute allgemein Jens Hausteins an den Walther-Strophen in $\mathrm{k}$ gewonnene Erkenntnis durchgesetzt, dass die häufig weitgehenden Umarbeitungen in Meistersingerhandschriften „nicht etwa Zeugnis mangelnden literarischen Verständnisses oder gar nur überlieferungsgeschichtlicher Entstellung“ sind, als die sie vor allem die ältere Forschung abgewertet hat, „sondern bewußter, literarisch produktiver Ausdruck des Bemühens, sich die Texte der alten Meister in variierender Aufnahme und unter thematischer Ausgestaltung anzueignen. ${ }^{21}$ Diese meistersingerliche Rezeption wird seither auch verstärkt editorisch gewürdigt. ${ }^{22}$ Es bleibt aber auffällig, dass die Bearbeitungsintensität in k offensichtlich sehr unterschiedlich stark ausgeprägt sein kann, was insbesondere im Fall mutmaßlich alter, aber nicht altbezeugter Strophen von Interesse ist, wenn Rückschlüsse auf deren ursprüngliche Form gezogen werden sollen. ${ }^{23} \mathrm{Da}$ die oben zitierten unterschiedlichen Einschätzungen zu Einzelcorpora zudem in der Regel nicht oder mit nur wenigen Belegen versehen werden ${ }^{24}$ und der Benutzer aufgefordert ist, ihre Plausibilität anhand von Variantenapparaten selbst zu überprüfen, scheint es mir angebracht, die Frage

19 Vgl. Günter Mayer: Probleme der Sangspruchüberlieferung. Beobachtungen zur Rezeption Konrads von Würzburg im Spätmittelalter. Diss. München 1974, S. 112114.

20 Vgl. Schröder 1970 (Anm. 18), S. X.

21 Haustein 1996 (Anm. 4), S. 226; vgl. auch Alex 1998 (Anm. 15), S. $16 f$.

22 Vgl. etwa die neueren Ausgaben zum Marner (Eva Willms: Der Marner. Lieder und Sangsprüche aus dem 13. Jahrhundert und ihr Weiterleben im Meistersang. Hg., eingeleitet, erläutert und übersetzt von Eva Willms. Berlin, New York 2008), zu Stolle (Volker Zapf: Stolle und die Alment. Einführung - Edition - Kommentar. Göttingen 2010 [Nova Medievalia 7]) oder zum Wartburgkrieg (Jan Hallmann: Studien zum mittelhochdeutschen Wartburgkrieg. Literaturgeschichtliche Stellung - Überlieferung - Rezeptionsgeschichte. Mit einer Edition der Wartburgkrieg-Texte. Berlin, Boston 2015).

23 Die Frage ist besonders für die chronologische Schichtung des Materials von Interesse. Vgl. hierzu auch Frieder Schanze: Meisterliche Liedkunst zwischen Heinrich von Mügeln und Hans Sachs. 2 Bde. München 1983-1984 (MTU 82/83), hier Bd. 1, S. $76 f$.

24 Für das Corpus Boppes vgl. dagegen recht detailliert Alex 1998 (Anm. 15), S. $15 f$. 
nach Überlieferungstreue und Bearbeitungstendenzen in der folgenden kleinen Detailstudie noch einmal aufzuwerfen. Ich möchte mich dabei auf das Corpus Konrads von Würzburg konzentrieren, das mir hierfür aus mehreren Gründen geeignet erscheint: erstens wegen der in der Forschung konstatierten ungewöhnlichen Nähe zur Altüberlieferung, die es zu hinterfragen gilt; zweitens aufgrund der speziellen Zusammensetzung des altüberlieferten Materials, das sowohl aus als authentisch geltenden Sprüchen des 13. Jahrhunderts als auch aus späteren, aber noch vor 1350 überlieferten Pseudo-Konrad-Strophen des 14. Jahrhunderts besteht, ${ }^{25}$ und drittens aufgrund des hohen Anteils an Dubletten, der zunächst einmal als Hinweis auf verschiedene Vorlagen interpretiert werden kann. ${ }^{26}$ Neben der Frage, wie altüberliefertes Material in k präsentiert wird, lassen sich hier auch möglicherweise einige Hinweise darauf finden, welche Art von Vorlagen die Redaktoren der Handschrift verarbeiteten und wie sie mit diesen umgingen.

\section{II.}

Die 70 in k überlieferten altbezeugten Strophen in Tönen Konrads verteilen sich auf die folgenden Überlieferungseinheiten: ${ }^{27}$

25 Gemeint ist das vierzigstrophige Ave Maria im Hofton in Cpg 350 ( $\left.{ }^{1} \mathrm{KonrW} / 6 / 100 \mathrm{a}\right)$. Appelhans datiert diesen Text auf die Zeit um 1300 (vgl. Peter Appelhans: Untersuchungen zur spätmittelalterlichen Mariendichtung. Die rhythmischen mittelhochdeutschen Mariengrüße. Diss. Hamburg 1970, S. 30); sein terminus ante quem ist dabei allerdings die Entstehung des Cpg 350, die er mit „spätestens am Beginn des 14. Jahrhunderts“ angibt (ebd.). Diese Datierung gilt nach neueren Untersuchungen allerdings nur für den ältesten Faszikel (fol. 1-43); das Ave Maria steht im zweiten Faszikel (fol. 43a-64), der auf das zweite Viertel des 14. Jahrhunderts datiert wird (vgl. Matthias Miller und Karin Zimmermann: Die Codices Palatini germanici in der Universitätsbibliothek Heidelberg [Cod. Pal. germ. 304-495]. Wiesbaden 2007 [Kataloge der Universitätsbibliothek Heidelberg VIII], S. 187). Appelhans' sonstige Argumente, die Abweichungen im Tonschema (vgl. Kap. IV) und die Überlieferung lassen - mit einer gewissen Unschärfe - konkreter eine Entstehung in den ersten Jahrzehnten des 14. Jahrhunderts vermuten.

26 Von den 70 altüberlieferten Strophen in Tönen Konrads von Würzburg sind 12 doppelt in k überliefert (vgl. die Übersicht in Kap. II), dies entspricht einem überdurchschnittlichen Dubletten-Anteil von 17\% (gegen 5\% im Gesamtbestand, vgl. Baldzuhn 2002 [Anm. 2], S. 479, Anm. 52).

27 Angaben nach RSM 4, S. 188-215 unter Benutzung von Baldzuhn 2002 (Anm. 2), S. $41 f$. 


\begin{tabular}{|c|c|c|c|}
\hline $\begin{array}{l}\text { RSM-Nr. } \\
\text { Bartsch Verz. } \\
\text { fol. in k }\end{array}$ & Altüberlieferung & Str. & Beschreibung \\
\hline $\begin{array}{l}{ }^{1} \text { KonrW/5/503a } \\
\text { K } 536 / 537 \\
\text { fol. } 508 \mathrm{r}-509 \mathrm{r}\end{array}$ & C, $388 \mathrm{r}$ & 2 & $\begin{array}{l}7 \text { Strophen in k; Str. } 3 \text { und } 4 \text { als Ein- } \\
\text { zelstrophen }{ }^{1} \text { KonrW/5/5a und } 6 \text { a in C } \\
\text { altüberliefert }\end{array}$ \\
\hline $\begin{array}{l}{ }^{1} \text { KonrW/5/504a } \\
\text { K } 538 \\
\text { fol. } 509 \mathrm{rv}\end{array}$ & C, $388 \mathrm{r}$ & 4 & $\begin{array}{l}4 \text { Strophen in k [5. fehlt]; Str. 1-4 als Ein- } \\
\text { zelstrophen }{ }^{1} \text { KonrW/5/2a [1], 1a [2], 3a [3] } \\
\text { und } 4 \mathrm{a}[4] \text { in C altüberliefert }\end{array}$ \\
\hline $\begin{array}{l}{ }^{1} \text { KonrW/6/100b } \\
\text { K } 554 \\
\text { fol. } 519 \mathrm{r}-524 \mathrm{v}\end{array}$ & Cpg 350, 48r-54v & 40 & $\begin{array}{l}40 \text { Strophen in k; alle in gleicher Rei- } \\
\text { henfolge }{ }^{28} \text { in }{ }^{1} \text { KonrW/6/100a in Cpg } \\
350 \text { altüberliefert [11 Dubletten in k in } \\
{ }^{1} \text { KonrW/6/100c-e (s. dort)] }\end{array}$ \\
\hline $\begin{array}{l}{ }^{1} \text { KonrW/6/100c } \\
\text { K } 542 \\
\text { fol. } 512 \mathrm{rv}\end{array}$ & Cpg 350, 48r-54v & 3 & $\begin{array}{l}3 \text { Strophen in k; als Str. } 18,17 \text { und } 12 \text { in } \\
{ }^{1} \text { KonrW/6/100a in Cpg } 350 \text { altüberliefert } \\
\text { [Dubletten in k: }{ }^{1} \text { KonrW/6/100b Str. 18, } \\
17 \text { und 12] }\end{array}$ \\
\hline $\begin{array}{l}{ }^{1} \text { KonrW/6/100d } \\
\text { K } 543 \\
\text { fol. } 512 \mathrm{v}-513 \mathrm{v}\end{array}$ & Cpg $350,48 \mathrm{r}-54 \mathrm{v}$ & 6 & $\begin{array}{l}7 \text { Strophen in k; die sechs Str. } 1,3,4,5 \text {, } \\
6,7 \text { als Str. } 11,8,22,27,32 / 35^{29} \text { und } 38 \text { in } \\
{ }^{1} \text { KonrW/6/100a in Cpg } 350 \text { altüberliefert } \\
\text { [Dubletten in k: }{ }^{1} \text { KonrW/6/100b Str. } 11,8 \text {, } \\
22,27,32 / 35,38 \text { ] }\end{array}$ \\
\hline $\begin{array}{l}{ }^{1} \mathrm{KonrW} / 6 / 100 \mathrm{e} \\
\text { nicht bei Bartsch } \\
\text { fol. } 513 \mathrm{v}-514 \mathrm{r}\end{array}$ & Cpg $350,48 \mathrm{r}-54 \mathrm{v}$ & 2 & $\begin{array}{l}3 \text { Strophen in k; Str. } 1 \text { und } 2 \text { als Str. } 39 \\
\text { und } 40 \text { in }{ }^{1} \text { KonrW/6/100a in Cpg } 350 \\
\text { altüberliefert [Dubletten in k: }{ }^{1} \text { KonrW/6/ } \\
\text { 100b Str. } 39 \text { und 40] }\end{array}$ \\
\hline $\begin{array}{l}{ }^{1} \text { KonrW/6/503a } \\
\text { K } 544 \\
\text { fol. } 514 \mathrm{rv}\end{array}$ & C, 389r & 1 & $\begin{array}{l}3 \text { Strophen in k; Str. } 1 \text { als Einzelstrophe } \\
{ }^{1} \text { KonrW/6/6a in C altüberliefert }\end{array}$ \\
\hline $\begin{array}{l}{ }^{1} \text { KonrW/6/515a } \\
\text { K } 556 \\
\text { fol. } 525 \mathrm{rv}\end{array}$ & C, 389r & 2 & $\begin{array}{l}3 \text { Strophen in k; Str. } 1 \text { und } 2 \text { als Ein- } \\
\text { zelstrophen }{ }^{1} \text { KonrW/6/5a und } 7 \text { a in C } \\
\text { altüberliefert }\end{array}$ \\
\hline
\end{tabular}

28 Appelhans' missverständliche Anmerkung, dass k die Reihenfolge der Strophen ändere (vgl. Appelhans 1970 [Anm. 25], S. 31), trifft nicht zu. Sein Beispiel („Strophen $18,17,12$ “, vgl. ebd.) zeigt, dass er offensichtlich das Dreierbar ${ }^{1} \mathrm{KonrW} / 6 / 100 \mathrm{c}$ vor Augen hat, nicht die kompletten 40 Strophen in ${ }^{1} \mathrm{KonrW} / 6 / 100 \mathrm{~b}$.

29 V. 1-2 der sechsten Strophe sind in Str. 32 altbezeugt, V. 3-19 in Str. 35, vgl. auch RSM 4, S. 196. 


\begin{tabular}{|c|c|c|c|}
\hline $\begin{array}{l}\text { RSM-Nr. } \\
\text { Bartsch Verz. } \\
\text { fol. in k }\end{array}$ & Altüberlieferung & Str. & Beschreibung \\
\hline $\begin{array}{l}{ }^{1} \text { KonrW/7/500a } \\
\text { K } 564 \\
\text { fol. 531rv }\end{array}$ & $\mathrm{C}, 389 \mathrm{v}-390 \mathrm{r}$ & 1 & $\begin{array}{l}3 \text { Strophen in k; Str. } 2 \text { als Einzelstrophe } \\
{ }^{1} \text { KonrW/7/7a in C altüberliefert }\end{array}$ \\
\hline $\begin{array}{l}{ }^{1} \text { KonrW/7/502a } \\
\text { K } 566 \\
\text { fol. 532rv }\end{array}$ & $\begin{array}{l}\text { C, 389v } \\
\text { J, 102r } \\
\text { Basel N I 6 50, 1v } \\
\text { Basel B XI 8, 162rv } \\
\text { Clm 27329, 75r }\end{array}$ & 1 & $\begin{array}{l}3 \text { Strophen in k; Str. } 2 \text { als Einzelstro- } \\
\text { phe }{ }^{1} \text { KonrW/7/4a-e in fünf Hss. und } \\
\text { Fragmenten altüberliefert [Dublette in } \\
\text { k: }{ }^{1} \text { KonrW/7/504a Str. 5] }\end{array}$ \\
\hline $\begin{array}{l}{ }^{1} \text { KonrW/7/503a } \\
\text { K } 567 \\
\text { fol. } 532 \mathrm{v}-533 \mathrm{v}\end{array}$ & $\begin{array}{l}\mathrm{C}, 390 \mathrm{v} \\
J, 102 \mathrm{v}\end{array}$ & 3 & $\begin{array}{l}7 \text { Strophen in k; Str. } 2 \text { und } 4 \text { in }{ }^{1} \text { KonrW/ } \\
7 / 18-19 a-b \text { als Str. } 2 \text { und } 1 \text { in C und J } \\
\text { altüberliefert; Str. } 3 \text { als Einzelstrophe } \\
{ }^{1} \text { KonrW/7/24a in J altüberliefert }\end{array}$ \\
\hline $\begin{array}{l}{ }^{1} \text { KonrW/7/504a } \\
\text { K } 568 \\
\text { fol. } 533 \mathrm{v}-534 \mathrm{v}\end{array}$ & $\begin{array}{l}\text { C, 389rv }[2,3,4,5] \\
\text { J, 102rv }[2,5,3] \\
\text { Basel N I 6 50, 1v } \\
{[2,3,5]} \\
\text { Basel B XI 8, 161v- } \\
\text { 162rv }[2,5] \\
\text { Clm 27329, 75r [5,2] }\end{array}$ & 4 & $\begin{array}{l}5 \text { Strophen in k; Str. } 2-5 \text { altüberliefert: } \\
\text { Str. } 2 \text { als }{ }^{1} \text { KonrW/7/1a-e in } 5 \text { Hss. und } \\
\text { Fragmenten, } \\
\text { Str. } 3 \text { als }{ }^{1} \text { KonrW/7/2a-c in } 3 \text { Hss. und } \\
\text { Fragmenten, } \\
\text { Str. } 4 \text { als }{ }^{1} \text { KonrW/7/3a in C, } \\
\text { Str. } 5 \text { als }{ }^{1} \text { KonrW/7/4a-e in } 5 \text { Hss. und } \\
\text { Fragmenten [Dublette in k: }{ }^{1} \text { KonrW/7/ } \\
\text { 502a Str. 2] }\end{array}$ \\
\hline $\begin{array}{l}{ }^{1} \text { KonrW/7/510a } \\
\text { K } 574 \\
\text { fol. 538v-539r }\end{array}$ & $\mathrm{C}, 390 \mathrm{v}-391 \mathrm{r}$ & 1 & $\begin{array}{l}3 \text { Strophen in k; Str. } 3 \text { als Einzelstrophe } \\
{ }^{1} \text { KonrW/7/21a in C altüberliefert }\end{array}$ \\
\hline
\end{tabular}

Den größten Anteil an den altbezeugten Strophen hat der erstmals im zweiten Faszikel des Cpg 350 überlieferte vierzigstrophige Mariengruß ${ }^{1}$ KonrW/6/ 100b, wobei dessen Strophen 8, 11, 12, 17, 18, 22, 27, 32/35, 38, 39 und 40 zusätzlich noch in den Dreierbaren ${ }^{1}$ KonrW/6/100c und ${ }^{1}$ KonrW/6/100e bzw. dem Siebenerbar ${ }^{1}$ KonrW/6/100d doppelt in k überliefert sind. Bei den restlichen Strophen (darunter eine weitere Dublette) handelt es sich um alte Sangsprüche Konrads, die alle in $\mathrm{C}$ und teilweise noch in weiteren Handschriften altüberliefert sind.

Für die in C überlieferte Strophe ${ }^{1}$ KonrW/5/2a, die sich als erste von vier Strophen in ${ }^{1}$ KonrW/5/504a in $\mathrm{k}$ findet, hat Mayer durch Gegenüberstellung zu belegen versucht, dass sich hier die Bearbeitung in engen Grenzen halte. Nach Mayer habe dieses Paradigma ebenfalls „für alle anderen in $\mathrm{k}$ tradierten echten 
Konrad-Strophen mit Ausnahme von Spruch 32,301“ Gültigkeit. ${ }^{30}$ Ich gebe das Beispiel zur Veranschaulichung noch einmal im synoptischen Abdruck, wobei in k abweichende Wörter bzw. Passagen halbfett unterlegt werden, fehlende Silben oder einzelne Konsonanten mit \{\} gekennzeichnet werden und Umstellungen unterstrichen dargestellt werden: ${ }^{31}$

${ }^{1} \mathrm{KonrW} / 5 / 2 \mathrm{a}, \mathrm{C}$ fol. 388r

Aspis ein wurn geheissen ist

der zů der erden streket

ein ore und in das ander steket

sines zagels ort

5 durh das er kein wispel wort

verneme so man in vahen wil

owe daz nu der selbe list

niht mangen herren deket

der boser rede sin ore empleket

10 hie beide unde dort

da von er den schaden bekort

daz er verlúret eren vil

schalc in sinem munde wunde

bernde sprúche treit

15 da mit er sin schande leit

nu ritter unde knehte

die durh sin lasterlich gebrehte

werdent vil gemeit

swaz ein zúhtic man geseit

20 daz hant si fúr ein gŏggel spil
${ }^{1}$ KonrW/5/504a, Str. 1, k fol. 509r

Asspis ein slang geheissen ist

der uff die erden strecket

ein or \{\} und in daz ander stecket

dez sinen wadels ort

5 also daz er kein wyspel wort

an hör so man in vahen wil.

owe daz nit der falsche list

etliche herren decket

do falsche red \{\} ir oren \{\}blecket

10 beyde hie und auch dort

da huft sich vil der schanden hort

da mit verlurt er eren vil

ein schalk in synem munde \{\}\{\}

lose spruche treit

15 da mit er hie jn jamer leit

gut rytter und $\{$ auch knechte

die durch daz lasterlich gebrechte

dick werden so gemeit

was in ein zuchtig man $\boldsymbol{n u}\{\}$ seit

20 daz hant sie fur ein gauggel spil

Der Aspis-Ton ist in seiner ursprünglichen Form in den Versen 4-6, 1012, 13, 15 und 18-20 geregelt auftaktlos, ${ }^{32}$ ein größerer Teil der Abweichungen in $\mathrm{k}$ ließe sich mit dem Bestreben eines Bearbeiters erklären, Lesung mit Auftakt und Alternation ohne größere Tonbeugungen zu ermöglichen, etwa

30 Vgl. Mayer 1974 (Anm. 19), S. 112.

31 Der Abdruck der Strophen erfolgt hier wie im Folgenden, sofern nicht ausdrücklich anders angegeben, nach den Handschriften, wobei Abbreviaturen (ggf. nach metrischen Erfordernissen) aufgelöst, Groß- und Kleinschreibung angepasst (nur Initialen und Eigennamen groß), ein $\mathrm{u} / \mathrm{v}$-Ausgleich durchgeführt und der Text nach Versen umgebrochen dargestellt wird. Die dargestellte Strophenform folgt dabei dem Tonschema des RSM.

32 Vgl. das Tonschema (Form 1), RSM 2.1, S. 109. Schon für die Altüberlieferung in C gilt dies aber nur mit Einschränkungen (vgl. hier V. 6, 10, 12 und 20). 
zusätzliches $\operatorname{dez}$ (V. 4), also (V. 5), ein (V. 13), dick (V. 18) und in (V. 19), die Apokope in V. 3, aber wohl auch die deutlich abweichenden Verse 11 und 15. In den Versen 6, 12 und 20 hat auch die Strophe in C bereits Auftakt, in V. 6 und 12 ist er in $\mathrm{k}$ aber anders hergestellt. Präsumtivvarianten dürften slang für wurn (V. 1), uff die für zu der (V. 2) und wohl auch wadel für zagel (V. 4) sein. ${ }^{33}$ Größere Abweichungen finden sich noch in den Versen 10 und 13: In Vers 13 fehlt der Schlagreim wunde, die Strophe ist an dieser Stelle in k defekt. Vers 10 ist nur mit mehreren Tonbeugungen alternierend mit Auftakt lesbar.

Wenn man auch angesichts dieses Beispiels Mayers These, dass in $\mathrm{k}$ bei den echten Strophen Konrads „keine großen Umarbeitungen“ feststellbar seien, wohl etwas relativieren muss, so kann man doch dem zweiten Teil der These, dass „niemals die von Konrad intendierte Aussage verändert wurde“, an dieser Stelle zustimmen. ${ }^{34}$ Die Strophe kann allerdings nicht paradigmatisch für die ganze ,echte' Konrad-Überlieferung in k stehen. Neben der von Mayer diskutierten Stelle 32,3015 ( ${ }^{1}{ }^{1}$ KonrW/7/510a Str. 3, alt ${ }^{1}$ KonrW/7/21a in C) finden sich sowohl Stellen, die auf einen freieren Umgang mit dem altüberlieferten Material hindeuten, als auch andere, in denen $\mathrm{k}$ der Altüberlieferung noch näher steht. Als illustratives Beispiel möchte ich das Bar ${ }^{1}$ KonrW/7/504a diskutieren, das mir zudem auch allgemein für die Frage, wie k mit seinen Quellen umgeht, interessant zu sein scheint.

\section{III.}

Das Bar liegt in k gewissermaßen in zwei Redaktionen vor. Es wurde zunächst als Dreierbar (im Folgenden als Redaktion ${ }^{\mathrm{A}}$ bezeichnet) unter der Überschrift Ander dru in dysem ton eingetragen. Später wurde dies korrigiert und auf einem

33 Gegen Mayers Erklärung, das als obszön empfundene zagel sei in k durch wadel ersetzt worden (vgl. Mayer 1974 [Anm. 19], S. 113), ist einzuwenden, dass auch wadel in frnhd. Zeit in der Bedeutung ,Penis' belegt ist, vgl. Mittelhochdeutsches Handwörterbuch von Matthias Lexer. Zugleich als Supplement und alphabetischer Index zum Mittelhochdeutschen Wörterbuch von Benecke - Müller - Zarncke. 3 Bde. Leipzig 1872-1878, hier Bd. 3, Sp. 627f.

34 Vgl. Mayer 1974 (Anm. 19), S. 114.

35 Vgl. hierzu auch die Diskussion der Strophe bei Burghart Wachinger: Die Bedeutung der Meistersingerhandschriften des 15. Jahrhunderts für die Edition der Spruchdichtung des 13. Jahrhunderts. In: Probleme altgermanistischer Editionen. Kolloquium Marbach am Neckar 26. und 27. April 1966. Referate und Diskussionsbeiträge. Hg. von Hugo Kuhn, Karl Stackmann und Dieter Wuttke. Wiesbaden 1968, S. 114-122, hier S. $115 f$. 
eingefügten Halbblatt vermerkt, dass es sich um ein Fünferbar handle, von dem das bereits in der Handschrift stehende Dreierbar der Mittelteil sei (im Folgenden Redaktion $\left.{ }^{\mathrm{B}}\right){ }^{36}$ Die Strophen ${ }^{\mathrm{B}} 1$ und ${ }^{\mathrm{B}} 5$ wurden auf diesem Halbblatt nachgetragen. Wann genau die Änderung erfolgte, lässt sich nur ungefähr sagen: Offenbar nach Anfertigung beider alter Paginierungen, die das Halbblatt nicht erfassen, aber vor Anfertigung des Registers, das das Incipit der nachgetragenen Strophe ${ }^{\mathrm{B}} 1$ bietet. ${ }^{37}$ Mit Ausnahme der ersten Strophe $\left({ }^{\mathrm{B}} 1\right)$ handelt es sich bei den fünf Strophen um meist mehrfach altüberlieferte geistliche Sangsprüche Konrads. In allen Handschriften, die sie überliefern, stehen die Sprüche eng beieinander. ${ }^{38}$

Beim folgenden Vergleich der vier Strophen ${ }^{\mathrm{B}} 2{ }^{\mathrm{B}} 5$ mit ihren altüberlieferten Entsprechungen werden aus Gründen der Übersichtlichkeit jeweils nur die Wörter bzw. Passagen halbfett dargestellt, die nicht mindestens in einer Handschrift altüberliefert sind, in denen $\mathrm{k}$ also einen im Vergleich zur gesamten Altüberlieferung abweichenden Text bietet; fehlende Silben oder einzelne Konsonanten werden mit \{\} gekennzeichnet, Umstellungen werden unterstrichen dargestellt. Die teilweise umfangreiche Altüberlieferung ist nach der digitalen Edition des Projekts ,Lyrik des Deutschen Mittelalters' zu vergleichen, die eine synoptische Darstellung ermöglicht: ${ }^{39}$

Str. ${ }^{\mathrm{B}} 2\left(={ }^{\mathrm{A}} 1\right)$, k fol. 533v-535r, Altüberlieferung: ${ }^{1} \mathrm{KonrW} / 7 / 1 \mathrm{a}-\mathrm{e}$ (Schröder 32,1ff.)

Got herre was du wunders an dir selber hast geschicket wie gar din fron almechtikeit mit creften ist verzwicket und die sich hat gericket tieff in die ewikeite din

got herre in ein drylichen gancz in einen got geflochten

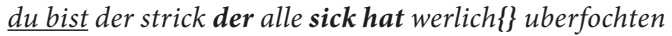
\{\} gedenck \{\} ym nit enmochten gebrechen in die hende sin

36 Vgl. k, fol. 533v-534v; vgl. auch Nine Miedema: Konrad von Würzburg als Sangspruchdichter. Studien und Texte zum Wandel des Autorbildes eines der zwölf alten Meister. Teil I: Studien. Teil II: Texte, Anhänge. Habil. masch. Münster 2002 [in Auszügen zur Verfügung gestellt von der Verfasserin, N.H.], hier Teil 1, S. 110f.

37 Vgl. k, fol. 9v.

38 Vgl. hierzu die Diskussion bei Baldzuhn 2002 (Anm. 2), S. 244f. mit Literaturangaben.

39 Vgl. Manuel Braun und Stephanie Seidl (Hgg.): k KonrW/HofT 19-23 [mit Altüberlieferung]. In: Lyrik des deutschen Mittelalters, online (ldm-digital.de). Hg. von Manuel Braun, Sonja Glauch und Florian Kragl. Veröffentlicht seit 01.01.2019/Fassung vom 20.02.2019. 
got herr on end \{\} on underscheit in siner werden maiestat und der sich under mischet hat in $d r y\{\}$ person \{\} gar faste

got vatter son heiliger geist jn dryer bilde laste zu dir barg sich ein dryfalt rich zu einem ganczen ast \{\} der uns mit sinem glaste bracht endelosen berden schin

Erwartbare Abweichungen im Vergleich zur Altüberlieferung finden sich in Strophe ${ }^{\mathrm{B}} 2\left(={ }^{\mathrm{A}} 1\right)$ in Vers $3,7,9,10$ und 14, wo Konrads Hofton geregelt Auftaktlosigkeit fordert. ${ }^{40}$ Durch Füllwörter (und V. 3/10, uns V. 14) bzw. Umstellung (V. 7) oder Umdichtung (V. 9) herrscht in k hier überall Auftakt.

Nicht nur formal erklärbare inhaltliche Abweichungen finden sich neben V. 9 auch in den Versen 5 und 12, sodass in k beide Stollen, der Steg und der 3. Stollen im Abgesang jeweils mit got herre bzw. got vater beginnen. Mit $d u$ bist der strick der alle sick [...] in Vers 6 gibt es in k neue Ansätze zu Binnenreimen, ${ }^{41}$ wie sie auch in der nicht altüberlieferten Strophe ${ }^{\mathrm{B}} 1$ vorkommen (vgl. dort V. 5/ 6). Der im Vergleich zur Altüberlieferung recht stark abweichende Vers 13 ist in k entstellt, was auch den Reim betrifft. Ebenfalls abweichend ist der Schluss der Strophe in k im Präteritum gehalten.

Str. ${ }^{\mathrm{B}} 3$ (= ${ }^{\mathrm{A}}$ 2), k fol. 535r, Altüberlieferung: ${ }^{1}$ KonrW/7/2a-c (Schröder 32,16ff.)

Got herr ein schopfer den ich hoh ob allen dingen bryse $d u$ bist ein bruner jungeling und ein alt herre gryse der sich zu einer spyse gib uns vil armen tegelich

fleisch unde blüt sin vetterliches wort ist dorch uns worden die beydesampt die niesen wir nach \{\} cristenlichem orden recht als die juden morden begunden an dem crucze dich der ie was got und ymmer ist on anfang end und ane schrancz so daz sin gotheit blybet gancz gar one ser da zuschen

da mitte wir die armen siechen selen wyder \{\}fryschen so stet daz osterliche\{\} lamp dort uff dem fronen tischen daz da zu brote mischen sin heilikeit begynnet sich

40 Vgl. RSM 2.1, S. 110.

41 Bartschs Konjektur sige verdunkelt dies. Vgl. Meisterlieder der Kolmarer Handschrift. Hg. von Karl Bartsch. Stuttgart 1862, S. 476. 
Die in der Altüberlieferung stets mit Almehtic schepfer (u. ä.) beginnende Str. ${ }^{B} 3$ $\left(={ }^{\mathrm{A}} 2\right)$ findet sich in $\mathrm{k}$ als Got herr ein schopfer; die sonstigen Unterschiede zur Altüberlieferung in den beiden Stollen scheinen eher formal-metrisch zu erklären zu sein. ${ }^{42}$ Stärker abweichend ist dagegen der Beginn des Stegs, wo sich der in der Altüberlieferung anzitierte Empfang der Hostie (vgl. etwa C fol. 369v: din lichame der wirt enpfangen sunder pin und ane schranz) durch eine allgemeine Beschreibung Gottes ersetzt findet. Ebenfalls markant sind die Abweichungen im dritten Stollen, wo die wandelunge Christi fehlt und das osterliche lamp nur auf dem Altar steht, statt dort geschlachtet zu werden. Es liegt nahe, hier an eine inhaltliche Änderung zur Entschärfung der recht drastisch formulierten Pascha-Typologie zu denken. ${ }^{43}$

Str. ${ }^{\mathrm{B}} 4$ (= ${ }^{\mathrm{A}}$ 3), k fol. 535r, Altüberlieferung: ${ }^{1} \mathrm{KonrW} / 7 / 3 \mathrm{a}$ (Schröder 32,31ff.)

Got wil am junsten sinen tot herzeugen den vil armen

ee daz sie in der helle müssen ewiclich erwarmen

daz lass dich fraw erbarmen

du milte muter usserkorn

5

wann got sin rosenfarwes blüt an dem gericht \{\} enblösset

daz sol mit diner brüste milche werden ab geflosset

und ee wann uns verstosset

von ym sin \{\} grymmiclicher zorn

eya wie mag uns ymmer leyt von dynem lieben kind geschehen

10

wann $d u$ in last din brüst\{\} an sehen

und er dich sin\{\} funff wunden

die er so hart herarnet hat daz sie in swanger funden

sin rein urkunde daz hat dort uns ewiclich enbonden

hilff daz $z$ ullen stunden

15

an uns sin tot nit werd verlorn

Eher unspezifisch scheinen die Unterschiede zwischen der Altüberlieferung und dem Text in $\mathrm{k}$ in der Strophe ${ }^{\mathrm{B}} 4\left(={ }^{\mathrm{A}} 3\right) \mathrm{zu}$ sein. Trotz eines insgesamt recht hohen Grades an Abweichung sind nur marginale inhaltliche Unterschiede festzustellen, etwa V. 11 sin funff wunden (gegen sine wunden in C). Eine

42 V. 3 erscheint bereits in der Altüberlieferung mit diesem Auftakt, in V. 7 ist durch eine kleinere Umdichtung Auftakt hergestellt. Metrisch erklärbar sind wohl auch die sonstigen Änderungen in V. 1 und 6.

43 Zum Hintergrund der Strophe vgl. Peter Nowak: Studien zu Gehalten und Formen mittelhochdeutscher Gebetslyrik des 13. Jahrhunderts. Diss. Bonn 1974, S. 2366 . und Braun/Seidl 2019 (Anm. 39), Kommentar zu C KonrW 95. 
Ausnahme ist Vers 12 (die er so hart herarnet hat daz sie in swanger funden), der in $\mathrm{k}$ offensichtlich entstellt und unverständlich ist. ${ }^{44}$

Als Zwischenresümee lässt sich festhalten, dass die Strophen ${ }^{\mathrm{B}} 2$ bis ${ }^{\mathrm{B}} 4$, also

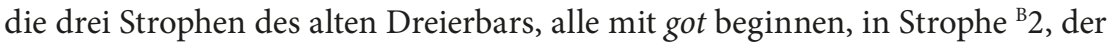
ersten Strophe des alten Dreierbars, sogar zusätzlich beide Stollen, der Steg und der 3. Stollen. Die drei Strophen sind damit formal besonders stark verbunden. ${ }^{45}$

Str. ${ }^{\mathrm{B}}$ 5, k fol. 534v, Altüberlieferung ${ }^{1}$ KonrW/7/2a-e (Schröder 32,46ff.)

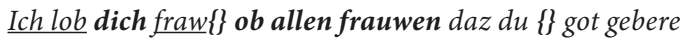
dez tochter und dez muter du in ganczer kuscheit were sodaz dir nichte swere was aller burden heubet last

5 den tort die hymmel nit begreiff no hye daz erde gerüste der wolte din gefangen sin mit fryer mütgeluste so wol der engen bruste dar jnn sich barg der hohe gast dez selben her almechtikeit ist allen \{\}\{\} riesen uber gro $\beta$ dar yn din hercze sich versloss mentschlichen hie besunder und dort zu hymmel sammenthaft sin gotheit ie dar under sin wort by dir zu fleische wart von sines geistz zunder ey frauwe durch $d y \beta$ wunder dir hohes lobes nie gebrast

In Strophe ${ }^{\mathrm{B}} 5$ finden sich mit Ausnahme des ersten Verses kaum nennenswerte Abweichungen zur Altüberlieferung. Am auffälligsten ist noch kiuschheit für in der Altüberlieferung stehendes kiusche in Vers 2; das offenbar gegen Ende des

44 Die von Braun/Seidl 2019 (Anm. 39) z. St. vorgeschlagene Lesung „,bedeckt mit etw. (hier den Wunden)“ scheint mir hier nicht möglich. Bei den zum Vergleich herangezogenen Belegen aus dem BMZ (= Mittelhochdeutsches Wörterbuch. Mit Benutzung des Nachlasses von Georg Friedrich Benecke ausgearbeitet von Wilhelm Müller und Friedrich Zarncke. 3 Bde. Leipzig 1854-1866) in Bezug auf anger und heide handelt es sich doch wohl vielmehr um Übertragungen der eigentlichen Bedeutung, schwanger auf unbelebte Objekte. Der hier vorliegende Fall ist anders gelagert.

45 Vgl. auch Michael Baldzuhn: Wege ins Meisterlied. Thesen zum Prozess der Barbildung und Beobachtung am k-Bestand unikaler Strophen in unfesten Liedern. In: Zeitschrift für deutsche Philologie 119 (2000), Sonderheft, S. 252-277, hier S. 271, der dieses besonders für die beiden Strophen ${ }^{B} 2$ und ${ }^{B} 3$ feststellt. Vgl. auch Baldzuhn 2002 (Anm. 2), S. 244f. und Braun/Seidl 2019 (Anm. 39), Kommentar zu k KonrW/HofT 19-23. 
15. Jahrhunderts außer Gebrauch geratene kiusche dürfte zur Zeit der Anfertigung der Kolmarer Liederhandschrift bereits veraltet gewesen sein. ${ }^{46}$ Ansonsten beschränken sich die Abweichungen hier vor allem auf die Verse 3, 9, 10 und 14, in denen ursprünglich Auftaktlosigkeit geherrscht hat: Es wird Auftakt und alternierender Rhythmus hergestellt.

Angesichts der verhältnismäßig starken und durchgehenden Umarbeitungen der Strophen ${ }^{\mathrm{B}} 2{ }^{\mathrm{B}} 4$, also der Strophen des ursprünglichen Dreierbars, scheint es mir plausibel, in diesen eine eigene Bearbeitung zu sehen, zu der Strophe ${ }^{\mathrm{B}} 5$, ebenso wie ${ }^{\mathrm{B}} 1$, ursprünglich nicht gehörte. ${ }^{\mathrm{B}} 5$ weist bis auf die geistliche Thematik keine Zeichen näherer Zugehörigkeit zu den anderen drei Strophen ${ }^{\mathrm{B}} 2{ }^{\mathrm{B}} 4$ auf und steht der Altüberlieferung zudem so eindeutig näher, dass sie aus einer anderen Vorlage stammen dürfte. Vielleicht liegt der Schlüssel zu der Frage, wie diese Strophe zu den anderen gekommen sein könnte, im Überlieferungsbefund der alten Strophen ${ }^{1}$ KonrW/7/1-4, die in der erhaltenen Altüberlieferung stets eng zusammenstehen. Denkbar wäre, dass dem Redaktor nach Eintragung des ursprünglichen Dreierbars (Redaktion ${ }^{\mathrm{A}}$ ) eine der erhaltenen Altüberlieferung nahestehende Vorlage zugänglich wurde, die ${ }^{1}$ KonrW/7/1-4 (in dieser Reihenfolge) zusammen überlieferte, weshalb diese Strophen als alter Verbund wahrgenommen wurden. Die der Redaktion ${ }^{A}$ hiervon noch fehlende Strophe ${ }^{1}$ KonrW/7/4 könnte dann ergänzt worden sein, wobei man voraussetzen müsste, dass die mutmaßlich abweichende Gestalt der Strophen ${ }^{1}$ KonrW/7/1-3 nicht als Grund gesehen wurde, diese noch einmal in k einzutragen. Zur Barauffüllung wäre dann schließlich noch die wahrscheinlich jüngere Strophe ${ }^{\mathrm{B}} 1$ hinzugekommen, deren Herkunft unklar bleibt.

Für ein höheres Alter der Vorlage, aus der die Strophe ${ }^{\mathrm{B}} 5$ stammt, kann ein Vergleich mit einer Dublette in ${ }^{1}$ KonrW/7/502a (Str. 2) sprechen, die ebenfalls nur marginal von der Altüberlieferung abweicht:

Dublette von Str. ${ }^{\mathrm{B}} 5$ in ${ }^{1} \mathrm{KonrW} / 7 / 502$ a Str. 2, k 532rv

Ich lob dich fraw \{\} aller frauwen daz du den got gebere des tochter unde muter $d u$ in rechter kusche were dar umb ist dir nit swere

fraw aller börden heubet last

5 den dort der hymmel nie begreiff noch hie daz erdgerüste der wolte din gefangen sin mit fryer mut geluste

46 Vgl. Frühneuhochdeutsches Wörterbuch (= FWB). Hg. von Robert R. Anderson, Ulrich Goebel und Oskar Reichmann. Bd. 1ff. Berlin/New York 1989ff., hier Bd. 8, Sp. 846 s. v. keusche, spätester Beleg vom Ende des 15. Jahrhunderts. 
so wol der engelbruste

dar in sich barg der hohe gast

dez frone hoch almechtikeit ist allen \{\}\{\} riesen uber gro $\beta$

10

der in din hercze sich besloß

mentschlichen hie besunder

zu hymmel ist er sammenthaff sin gotheit ob und under

sin wort by dir zu mentsche wart von sines geistes zunder

sich fraw $\{$ al durch daz wunder

15

dir hohes lobes nie gebrast

Ähnlich wie in Str. ${ }^{B} 5$ aus ${ }^{1}$ KonrW/7/504a steht in der ebenfalls von Schreiber A eingetragenen und in der Handschrift nur zwei Blätter entfernt stehenden Dublette in V. 1 aller frauwen gegen vreude bzw. tugende der Altüberlieferung, auch der Versbeginn stimmt gegen die Altüberlieferung überein. In V. 9 fehlt beiden das in der Altüberlieferung stets stehende starken, in V. 15 bieten beide gegen die gesamte Altüberlieferung die Wortstellung dir/nie statt nie/dir.

An einigen Stellen ist die Dublette näher an der Altüberlieferung als Str. ${ }^{\mathrm{B}} 5$, so in V. 1 aller statt ob allen, in V. 2 kusche statt kuscheit, in V. 5 der und erdgerüste statt die und erdegerüste sowie in V. 10 besloz statt versloss. An anderen Stellen ist sie dagegen weiter entfernt, so in V. 7 engelbruste statt engen bruste und in V. 13 mentsche statt fleische. Abweichungen im Vergleich zur Altüberlieferung finden sich auch hier vor allem dort, wo Auftakt und alternierender Rhythmus hergestellt werden, auffällig ist hierbei aber besonders, dass dies in beiden Strophen auf unterschiedliche Weise geschieht, gut sichtbar etwa in V. 14, wo Strophe ${ }^{\mathrm{B}} 5$ ey frauwe durch $d y \beta$ wunder formuliert, die Dublette dagegen sich fraw al durch daz wunder. Die Altüberlieferung hat hier stets auftaktlos Vrouwe durch das (bzw. dis) wunder. Der Befund legt den Schluss nahe, dass beide Strophen unabhängig voneinander aus eng verwandten Vorlagen entstanden sind, die noch die ursprünglichen auftaktlosen Verse enthielten. Angesichts der geringen Abweichungen zwischen beiden Strophen kann man von Vorlagen ausgehen, in denen Vers 1 schon geändert war: Dass es im ersten Vers schon früh Varianz gab, zeigt das Beispiel aus der um 1300 entstandenen Baseler Liederhandschrift (Basel, Cod. B XI 8, 162rv), wo es frowe aller tugende heißt. Auch die beiden gemeinsamen Abweichungen in den Versen 9 und 15 dürften auf diese Vorlagen zurückgehen, die ansonsten der erhaltenen Altüberlieferung sehr nahegestanden haben dürften. Unterschiede wie kusche/ kuscheit, engelbruste/engen bruste und mentsche/fleische können als Ad-hocÄnderungen oder als Missverständnisse (engelbruste) verstanden werden. 
Ob beide Strophen vom selben Bearbeiter (Schreiber A?) mit einigem zeitlichen Abstand unterschiedlich mit Auftakten versehen wurden oder ob weitere Zwischenstufen anzunehmen sind, ist nicht sicher zu entscheiden. Doch spricht angesichts des bekannten Sachverhalts, dass alte auftaktlose Verse in $\mathrm{k}$ fast durchgängig mit Auftakt und alternierendem Rhythmus erscheinen, wohl nichts gegen die Annahme, dass beide Strophen erst bei bzw. unmittelbar vor ihrer Eintragung in $\mathrm{k}$ bearbeitet wurden. - Akzeptiert man diese Prämisse, kann an dieser Stelle ein Eindruck von der Vorlagentreue bzw. den Bearbeitungsfreiheiten von k gewonnen werden. Beide Strophen sind dann offensichtlich gleichwertige Umsetzungen des Regelwerks, das die Bearbeiter bei der formalen Anpassung alter Strophen anwendeten.

\section{IV.}

Dass Dubletten im Corpus Konrads von Würzburg verschiedene Bearbeitungsstufen repräsentieren können, zeigt auch ein Vergleich der Strophen des vierzigstrophigen Ave Maria ${ }^{1} \mathrm{KonrW} / 6 / 100 \mathrm{~b}$ mit den Entsprechungen in den Baren ${ }^{1}$ KonrW/6/100c-e. Für die älteste Überlieferung in Cpg 350 ( ${ }^{1} \mathrm{KonrW} / 6$ / 100a) gilt, dass in den Versen 3 und 9 Waisen statt eines Reimes stehen und der Steg (V. 13) sechshebig ist. ${ }^{47}$ In k steht in der vierzigstrophigen Fassung 100b an diesen Stellen dagegen fast ${ }^{48}$ durchgängig ein Reim, der Steg ist (in der Regel) siebenhebig. ${ }^{49}$ Diese Verse weichen entsprechend häufig von der Altüberlieferung ab.

Auch im Dreierbar ${ }^{1}$ KonrW/6/100c steht in allen drei Strophen der Reim: Str. 1 meit/geseit, Str. 2 kint/blint, Str. 3 barn/scharn. Zwei dieser Reime stimmen dabei mit den Entsprechungen in 100b überein: Str. 18 magt/gesagt (meit/geseit) und Str. 17 kint/blint; in Str. $12 \mathrm{seh} / \mathrm{smeh}$ ist der Reim abweichend hergestellt. Für die Übereinstimmung meit/geseit bzw. magt/gesagt zeigt ein direkter Vergleich der Verse mit der Altüberlieferung aber, dass beide das Reimwort in V. 9 beibehalten und in V. 3 im Reim vielleicht nur zufällig zusammenstimmen (hier Abweichungen von ${ }^{1}$ KonrW/6/100c Str. 1 in ${ }^{1}$ KonrW/6/100b Str. 18 markiert):

47 Vgl. Rettelbach 1993 (Anm. 5), S. 98.

48 Nicht in Str. 1 (vgl. RSM 4, S. 194 und Rettelbach 1993 [Anm. 5], S. 99); aber z. B. auch nicht in Str. 27, wo sich die Waisen jagt/tag der Altüberlieferung erhalten haben, was wohl gegen Rettelbachs These von dem erst nach Eintragung von Str. 1 bemerkten und daher erst ab Str. 2 korrigierten Defekt (vgl. ebd.) spricht.

Vgl. Rettelbach 1993 (Anm. 5), S. 98. 
${ }^{1}$ KonrW/6/100c Str. 1, k fol. 512r

Ave maria kusche maget stete

wie gern ich frage tete

du keyserliche meit

wohin din kint bekeme

5 al nach dez todes reme

sich daz wil ich dir sagen sunder laugen

er geleyte da sin frunt den schacher wyse

hin zu dem paradyse

daz sy dir nu geseit

$10 \quad$ du myn vil trut geselle

dar nach fur er zur helle

dar uß herlost er sin erwelten taugen

er lost in lewen creft uß helle her Adam

und Iheremyam vnd Johans Baptisten

15 den wolt er auch gefristen

beyd frauwen unde man

die lost er an der stunde

dieff $u ß$ der hell ab grunde

und gab da liecht vil mangen blinden augen

Entsprechung ${ }^{1}$ KonrW/6/100b Str. 18, k fol. 521rv

Ave maria zarte maget stete

wie gern ich frage tete

du mynnicliche magt

wahin din kint bekeme

$5\{\{$ nach sines todes reme

\{\} daz soltest du mir sagen sunder laugen

o frunt sich er beleyt den schacher wyse

hin zu dem paradyse

daz sye dir \{\} gesagt

$10 d u$ myn vil trut geselle

dar nach hin zu der helle

da wolt er keren zu den herwelten taugen

die lost er wol in lewen wyse alz ein kempfe kam $^{50}$

Adam Jeremyam und \{\}\{\} Baptiste

$15\{\{$ wolt er furbas da \{\}frysten

auch frauwen unde man

50 Verschreibung? Vielleicht zu lesen: kan. (vgl. aber Adam in ${ }^{1}$ KonrW/6/100c Str. 1). 
die sin begeret hatten

den kam er da zu statten

erluchtet da vil manch begernde augen

Altüberlieferung ${ }^{1}$ KonrW/6/100a Str. 18, Cpg 350, 50v-51r

Ave Maria zarte magt stete

gerne ich frage dete

frauwe widir dich

war din kint bequeme

5

nach des dodis reme

daz sal ich dir sagin sundir laugin

er beleite frunt den shecher wise

zů deme paradyse

daz si dir gesagit

$10 \quad$ min vil drut geselle

dar nach er zưr hellin

wolte kerin die er weltin daugin

loste er in lewin wise alsam ein kemphe dan

Adam Jeremiam unde Baptistin

$15 \quad$ wolde er fürbaz fristin

reine frauwin man

den quam er mit vattin

also ein helt zů statin

er bot lieht vil manigin blindin augin

In der Gestaltung des Auftakts stimmen die beiden Versionen in $\mathrm{k}$ in den Versen 2, 4, 8 und 10 dagegen auffallend überein. Ab dem Ende des zweiten Stollens, im Steg und im gesamten Abgesang weichen sie dann aber wieder deutlich voneinander ab; in 100b Str. 18 sind die letzten drei Verse im Vergleich zur Str. 1 im Dreierbar 100c umgedichtet, die hier näher an der altüberlieferten Form ist. Der Steg ist in 100c Str. 1 wie in der Altüberlieferung nur sechshebig. ${ }^{51}$

Auch wenn also eine Verwandtschaft der Strophen (oder nur der ersten 10 Verse?) bestehen dürfte, liegt hier offensichtlich der Fall zweier verschiedener Bearbeitungen vor, die unterschiedliche Änderungen vornehmen. Die in diesem Beispiel festgestellte Verwandtschaft der Strophen in 100b und 100c sowie

51 Der von Rettelbach als sechshebig angeführte Steg in 100c, Str. 3 (vgl. Rettelbach 1993 [Anm. 5], S. 99), ist dagegen siebenhebig zu lesen (l. crucze). Bei seiner Angabe handelt es sich möglicherweise um eine Verwechslung von Str. 1 und 3. 
die größere Nähe der Bearbeitung des Dreierbars 100c zur Altüberlieferung lässt sich für die beiden anderen Strophen indes nicht durchgehend bestätigen. ${ }^{52}$

Ein ähnliches Bild ergibt sich beim Vergleich der sechs altüberlieferten Strophen des Siebenerbars ${ }^{1}$ KonrW/6/100d (Str. 1; 3-7) mit ihren Entsprechungen im vierzigstrophigen Ave Maria 100b. In Str. 1 (Dublette $=100 \mathrm{~b}$ Str. 11) haben beide Bearbeitungen in identischer Formulierung den Reim geschach/ungemach (gegen die Waisen was/ungemach der Altüberlieferung) und zeigen auch in den Versen 13 und 15 eine deutliche Verwandtschaft. ${ }^{53}$ Die Strophe des Siebenerbars geht zudem auffallend häufig mit der Altüberlieferung zusammen, in den Versen 4, 7, 9, 10, 12 und 14 formuliert sie sogar weitgehend identisch und bietet - in dieser Häufung ungewöhnlich für k - deren auftaktlose Verse; in den Versen 2, 3, 5, 8, 11, 16 und 18 herrscht dagegen Auftakt (hier in ${ }^{1}$ KonrW/6/100d Str. 1 Abweichungen von der Altüberlieferung markiert):

${ }^{1}$ KonrW/6/100d Str. 1, k fol. 512v

Ave Maria iemerlichen smertzen

daz dir an dyme hertzen

vil reine mag $\{$ t geschach

do die iuden gingen

5

und den vil zarten fingen

der gewaltig waz dez hymmelz und der erde\{\}

52 Dies gilt besonders für die mittlere Strophe: Der 100c Str. 2 und ihrer Entsprechung 100b Str. 17 gemeinsame Reim kint/blint in V. 3/9 ist in V. 3 in beiden Versionen unterschiedlich hergestellt (da dir nu starp din kint [Str. 2] gegen alz du verlör din kint [Str. 17]). Der Steg ist in 100c Str. 2 siebenhebig, ein mit der Altüberlieferung identischer auftaktloser Vers findet sich in V. 9 (gar an milte blint). Gelegentlich entfernt sich 100c Str. 2 weiter von der Altüberlieferung als 100b Str. 17, vgl. etwa in V. 16/17: nye mande zü der stünt / mir da vil armen eine [Str. 2]; ich waz vil ser verwunt / daz leyt was myn alleyne [Str. 17]; Altüberlieferung: mir ich was verwunt / wan gar ie alleine. $-100 \mathrm{c}$ Str. 3 und ihre Entsprechung 100b Str. 12 stellen unterschiedliche Reime V. 3/9 her (vgl. oben), Verwandtschaft zeigt sich hier aber in den übereinstimmenden Versen 1-2 (V. 1 wie Altüberlieferung) und dem fast identisch abweichenden V. 6; vgl. auch V. 11: beide truriclichem (drüreclichem) müte gegen druregim müte der Altüberlieferung sowie V. 12: beide bitter [n] galle gegen surin galle der Altüberlieferung. Auftaktlos in 100c Str. 3 nur V. 15 (fehlende Silbe!). Die Abweichungen der verschiedenen Bearbeitungen von der Altüberlieferung sind ansonsten unspezifisch.

53 In V. 13 haben beide gedultig lamp statt einfaches lamp der Altüberlieferung; in V. 15 beide gegen die Altüberlieferung hertz. 
waz und da by aller creatüre

dï milte mag\{\}t gehüre

sendez ungemach

10 hüp sich da gar swinde

da du zü dyme kinde

blicktest an gedülteclich geberde

er sweig alz\{\} ein gedultig lamp mit willen $\sin \{\}$ dot vertrůg

sich daz mi̊sten ye din\{\} aügen schaüwen

15 und din hertz verhäuwen

disen gross ungefüg

sehe dü magt \{\} milte

daz dich vil sere befilte

doch droste dich daz konne din so werde

Altüberlieferung ${ }^{1}$ KonrW/6/100a Str. 11, Cpg 350 fol. 49v

Ave Maria iemerlichis smerzin

der an dime herzin

reine magit was

da die iůdin giengin

$5 \quad$ und den zartin fiengin

der gewaltig hiemils und der erdin

was und da bi aller creatire

zarte magit gehure

sendiz ungemach

10

hủb sich da vil swinde

da dì dime kinde

blictis an geduldecliche geberde

Er sweig alsame ein lamp er sinin dot verdrüg

sich daz müstin ie dine augin shauwin

15 ane swert verhauwin

disin ungefüg

sehe dư früht sa milte

des dich gar befilte

da hielt dich daz kunne du werde

Die entsprechende Strophe 11 in 100b weist dagegen in allen Versen konsequent Auftakt auf, in der Regel jedoch in abweichender Versgestaltung (hier Abweichungen von ihrer Entsprechung 100d, Str. 1 markiert):

\section{Entsprechung ${ }^{1}$ KonrW/6/100b, Str. 11, k fol. 520rv}

Ave Mary\{\} ich man dich dines smerczen

der dir an dinem herczen 
vil reine meit geschach

alz da die juden gingen

der waz gewaltig \{\} hymmels und der erde

er was auch herre aller creature

vil reyne magt gehure

groß sendez ungemach

10

hub sich alda geswinde

[V. 11 fehlt]

erblicktest da gar jemerlich geberde

er sweig alz ein gedultig lamp \{\}\{\}\{\} er sinen tot vertrug

owe dez musten ie din augen schauwen

15

on swert din hercz verhauwen

den goßen [!] ungefug

sehe du frucht so milde

daz dich gar ser \{\} bevilde

daz dich daz din geslechte hielt unwerde

Aufgrund der Übereinstimmungen in V. 3, 13 und 15 wird man von einer gemeinsamen Vorlage beider Strophen ausgehen dürfen, die aber noch die alten auftaktlosen Verse enthielt. Etwaige Zwischenstufen sind auch hier natürlich nicht auszuschließen. Das Fehlen von V. 11 in 100b Str. 11 dürfte auf ein Versehen beim Eintragen der Strophe in k zurückzuführen sein. Die unterschiedlich konsequente Herstellung von Auftakten in 100d Str. 1 kann vielleicht als Flüchtigkeit des Redaktors interpretiert werden, wenn er die auftaktlosen Verse der Vorlage erst bei Eintragung in $\mathrm{k}$ mit einem Auftakt versah, ${ }^{54}$ oder sie spiegelt eine inkonsequente Vorlage, die nicht noch einmal redaktionell überarbeitet wurde.

Liegt in dieser Strophe, wie gezeigt, sowohl eine Verwandtschaft der Dubletten als auch eine größere Nähe der Fassung des Siebenerbars 100d zur Altüberlieferung vor, so gilt dies auch hier nicht für alle Strophen des Siebenerbars. Der Fall eines in beiden Versionen gleichlautenden Reims V. 3/9 ist in Str. 1 singulär; ${ }^{55}$ erkennbare Ähnlichkeiten gibt es zwar auch in anderen Strophen

54 Zum Eindruck einer gewissen Flüchtigkeit passt auch, dass in ${ }^{1}$ KonrW/6/100d Str. 1 in V. 7 offensichtlich auf alte Vorlage zurückgehendes waz stehen bleibt, obwohl es hier in V. 6 bereits steht.

55 Str. 3: schar (1. schal)/fal gegen qual/val in 100b Str. 8; Str. 4: kam/nam gegen worm/ storm in 100b Str. 22; Str. 5: mag/dag gegen Waisen jagt/tag (wie altüberliefert) in $100 \mathrm{~b}$ Str. 27; Str. 6: Waisen hat/verdroß (abweichend von der Altüberlieferung) gegen christenheit/bereit in 100b Str. 35; Str. 7: bereit/geleit gegen zyt/gelyt in 100b Str. 38. 
vereinzelt, die Abweichungen überwiegen insgesamt jedoch so deutlich, dass man nicht von einer nahen Verwandtschaft sprechen kann. ${ }^{56}$ Die Strophen des Siebenerbars sind nicht durchgehend näher an der Altüberlieferung, genauso häufig entfernen sie sich auch weiter von ihr als die Strophen aus 100b, etwa in 100d Str. 3 (Dublette $=100 \mathrm{~b}$ Str. 8), die besonders in den Versen 5, 6, 13 und 16-19 größere Abweichungen zeigt (hier in beiden Strophen die Abweichung von der Altüberlieferung markiert):

${ }^{1}$ KonrW/6/100d, Str. 3, k fol. 512v-513r

Ave Maria wol dir gantzer wonne

daz aller juden konne

dribent den yren schar

vor dir dü maget reine

$5 \quad$ küsche und wandels \{\}eine

wanne dü wer gewesen ir geslechte

dar umbe so worden sie so ser gekrencket

da sie sich hant gesencket

mit willen uff den fal

10 milte dü magt gewere

du worde yn gar zü swere

da sie ir leben staltn so unrehte

verstoret und vernihtet \{\} ir falsch \{\} sinagoga wart

und wart der \{\} zarte taüff an dir ernüwet

15\{\} wer dir nü wol getrüwet

deme ist unbespart

fraüwe din zarte mynne

wer dir hie wol mit synne

gedienen kan dar nach ein wiser fehte

Entsprechung in ${ }^{1}$ KonrW/6/100b, Str. 8, k fol. 520r

Ave Maria wol dir gantzer wunne

von dir als \{\} judisch kunne

kam ußer jamers qual

56 Ähnlichkeiten: Str. 3 (= 100b, Str. 8), V. 4 nahezu identisch; Str. 4 (= 100b Str. 22) V. 19 beide gegen die Altüberlieferung verkünden und welt statt diet (sonst abweichend); Str. 5 (= 100b Str. 27): V. 3 und V. 9 gleich Auftakt gebildet (hin/beid); Str. 6, V. 6 (= $100 \mathrm{~b}$ Str. 32, V. 6) stark übereinstimmend gegen die Altüberlieferung (100a hier wohl defekt: fehlende Hebung), V. 17/18 identisch; Str. 7 (= 100b Str. 38), V. 1 identisch (wie altüberliefert), V. 4 identisch Auftaktlesung durch zusätzliches mir ermöglicht. 
von dir du maget reyne also $d u$ yn alleine

her komen wer gar schon von irm geslechte

darnach da wurden sie vil gar gekrencket

alz sie sich da verschrencket

nu hetten uff den val

$10 d \boldsymbol{d}$ milte mag \{\} gewere

da wurd du in gar swere

alz da ir leben stalte sich unrechte

vil gar vernichtet da ir valsche synagoge wart

der cristenliche růff von dir ernuwet

15 ach fraw wer dir getruwet

der wirt dez wol gewert

daz man da heysset mynne

wer darnach in sym synne

wol werben kan jch rat \{\} er dar umb vechte

Altüberlieferung: ${ }^{1}$ KonrW/6/100a Str. 8, Cpg 350, fol. 49r

Ave Maria wol dir ganzir wunne

al der iudin kunne

gar gerichit wart

von dir magit reine

5

da di̊ ien alleine

were komin gar von ir geslehte

dar nach würdin sie vil gar gekrenkit

da sie sich geshrenkit

hettin uf den val

10 milte magit gewere

du wưrde ien gar swere

da ir lebin stalte sich unrehte

vernihtit gar ir falshe synagoge wart

der vil zarte dauf von dir ernuwit

15 ward wer dir gedruwit

der wird des gewert

daz man heizit minne

wer dar nach mit sinne

werbin kan ich rade er drumme fehte 
In Str. 6 (Dublette $=100 \mathrm{~b}$ Str. 32/35) werden schließlich Verse mehrerer Strophen verarbeitet. ${ }^{57}$ Eine einheitliche Tendenz lässt sich somit nicht ausmachen. Entweder stellen die Strophen des Siebenerbars keine einheitliche Bearbeitung dar, sondern sind zu verschiedenen Zeiten bearbeitet und erst später zusammengestellt worden, oder ein Bearbeiter hat seinen Freiraum in den einzelnen Strophen unterschiedlich genutzt. Dieser Eindruck verfestigt sich auch beim Vergleich der beiden altüberlieferten Strophen 1 und 2 des Dreierbars ${ }^{1}$ KonrW/ 6/100e mit ihren Entsprechungen in 100b. ${ }^{58}$

\section{V.}

Die besprochenen Beispiele vermitteln einen Eindruck davon, wie altbezeugtes Material in Tönen Konrads von Würzburg in k überliefert wird. Neben einer auffälligen Nähe zur Altüberlieferung in ${ }^{1}$ KonrW/7/504a Str. 5 und ihrer Dublette ${ }^{1}$ KonrW/7/502a Str. 2, wo sich die Änderungen weitestgehend auf die konsequente Einführung von Auftakten beschränken, findet sich auch stärkere Bearbeitung, etwa bei den Strophen ${ }^{1}$ KonrW/7/504a Str. 2-4, die für ihre Anlage als Dreierbar sowohl formal als auch inhaltlich angepasst werden. Eine größere Zahl von Dubletten ermöglicht im Fall der Strophengruppen ${ }^{1} \mathrm{KonrW} /$ 6/100a-e, die bis auf wenige Ausnahmen kaum nähere Verwandtschaft zeigen, einen genaueren Einblick in die Praxis der meistersingerlichen Überarbeitung alten Materials. Im Gegensatz zur einheitlichen Komposition ${ }^{1}$ KonrW/7/504a Str. 2-4 ist hier ein eher disparater Charakter festzustellen: Die Bearbeitungen erlauben sich an vielen Stellen offensichtlich unterschiedliche Freiheiten im Umgang mit der Altüberlieferung, sodass der Eindruck zu gewinnen ist, dass es sich um Zusammenstellungen verschiedener, nicht aus einer einheitlichen Bearbeitung entstandener Strophen handelt. Insgesamt ergibt sich so ein eher uneinheitliches Bild. Die von Mayer für die echten Strophen postulierte Überlieferungstreue ist in dieser Form jedenfalls nicht durchgehend zu belegen, wenngleich festzuhalten ist, dass sich tiefgreifende Umarbeitungen, wie sie in anderen Corpora durchaus vorkommen, ${ }^{59}$ hier nicht finden.

57 Vgl. Anm. 29.

58 Reim V. 3/9 in 100e Str. 1 uppikeit/leyt gegen uppikeit/meit in Entsprechung 100b Str. 39 ; in 100 e Str. 2 valt/gewalt gegen tag/clag in $100 \mathrm{~b}$ Str. 40. Identische Verse: 100e Str. 2 (=100b Str. 40), V. 10; gemeinsame Abweichungen von der Altüberlieferung: 100e Str. 1, V. 3: dick han mit uppikeit, vgl. 100b Str. 39, V. 3: han dick mit uppikeit (Altüberlieferung 100a Str. 39, V. 3: hant mit ůpekeit). Eine durchgehende Nähe einer der beiden Fassungen zur Altüberlieferung lässt sich nicht feststellen.

59 Vgl. etwa die Beispiele bei Alex 1998 (Anm. 15), S. $15 f$. 
Es ist im Einzelfall nicht mit Gewissheit zu entscheiden, welchen Anteil die Redaktion von $\mathrm{k}$ an der endgültigen Gestalt einer Strophe hatte und welche Bearbeitungen auf ältere Vorstufen zurückgehen. Bei ${ }^{1}$ KonrW/7/504a Str. 5 und ihrer Dublette ${ }^{1}$ KonrW/7/502a Str. 2 deutet in meinen Augen einiges auf alte Vorlagen, die erst bei Eintragung in $\mathrm{k}$ ihre angepasste Form erhalten haben. Im Fall von ${ }^{1}$ KonrW/6/100d Str. 1, die sechs auftaktlose Verse enthält, oder auch im Fall von ${ }^{1}$ KonrW/6/100d Str. 3, die in V. 3 durch die Verschreibung schar den im Vergleich zur Altüberlieferung neuen Reim V. 3/9 verwischt, deutet dagegen wenig auf eine abschließende redaktionelle Tätigkeit vor der Eintragung hin. Hier wurde offenbar recht flüchtig eine Vorlage übernommen. Es ist wohl neben einer Vielzahl von Quellen auch mit einer nicht immer einheitlichen redaktionellen Bearbeitung zu rechnen. Die diskutierten Beispiele zeigen aber, dass altes Material im Einzelfall auch unter den Bedingungen (früh-)meistersingerlicher Überlieferung in $\mathrm{k}$ relativ unverändert tradiert sein kann.

\section{Handschriften}

Basel N I 6, 50 Basler Rolle; Basel, Universitätsbibliothek, Cod. N I 6, 50; Pergament; Rolle; Ende 13. Jh./um 1300.

Lit.: Martin Steinmann: Das Basler Fragment einer Rolle mit mittelhochdeutscher Spruchdichtung. In: Zeitschrift für deutsches Altertum 117 (1988), S. 296-310 (mit Edition); e-codices. ch/de/description/ubb/N-I-0006-50/HAN (mit weiterer Lit.). Digitalisat: e-codices.ch/de/list/one/ubb/N-I-0006-50

Basel B XI 8 Baseler Liederhandschrift; Basel, Universitätsbibliothek, Cod. B XI 8; Pergament; 163 Blätter; um 1300.

Lit.: e-codices.ch/de/description/ubb/B-XI-0008/HAN (mit weiterer Lit.).

Digitalisat: e-codices.ch/de/list/one/ubb/B-XI-0008

C

Große Heidelberger Liederhandschrift; Heidelberg, Universitätsbibliothek, Cpg 848; Pergament; noch 426 Blätter; um 1300 (Grundstock)/1. Hälfte 14. Jh. (Nachträge).

Lit.: Pamela Kalning, Matthias Miller und Karin Zimmermann: Die Codices Palatini germanici in der Universitätsbibliothek Heidelberg (Cod. Pal. germ. 671-848). Wiesbaden 2016 (Kataloge der Universitätsbibliothek Heidelberg XII), S. 705-727; handschriftencensus.de/4957 (mit weiterer Lit.).

Digitalisat: digi.ub.uni-heidelberg.de/cpg848 
Clm 27329 München, Bayerische Staatsbibliothek, Clm 27329; Pergament; 128 Blätter; lat. Sammelhandschrift des 13./14. Jh.; Nachtrag von Versen Konrads von Würzburg auf fol. 75r (Anfang 14. Jh.). Lit.: Rolf Bergmann und Stefanie Stricker: Katalog der althochdeutschen und altsächsischen Glossenhandschriften. Berlin, New York 2005, Bd. 3, S. 1306f. (Nr. 694);

handschriftencensus.de/2236 (mit weiterer Lit.).

Benutzt nach dem Digitalisat der ldm-online, s. Braun/Seidl 2019 (wie Anm. 39) [Hs. M ${ }_{2}$. Jenaer Liederhandschrift; Jena, Universitäts- und Landesbibliothek, Ms. El. f. 101; Pergament; noch 133 Blätter; um 1330. Lit.: Burghart Wachinger: Artikel: Jenaer Liederhandschrift. In: ${ }^{2}$ VL 4 (1983), Sp. 512-516 + ${ }^{2}$ VL 11 (2004), Sp. 757; handschriftencensus.de/4998 (mit weiterer Lit.).

Digitalisat: archive.thulb.uni-jena.de/collections/receive/His Best_cbu_00008190

Cpg $350 \quad$ Heidelberg, Universitätsbibliothek, Cpg 350; Pergament; 69 Blätter in drei Faszikeln:

I: fol. 1-43; um 1300; südrheinfränkisch mit alem. Formen

II: fol. 43a-64; 2. Viertel 14. Jh.; rheinfränkisch/hessisch

III: fol. 65-68; 2. Viertel 14. Jh.; nordbairisch

Lit.: Miller/Zimmermann 2007 (wie Anm. 25); handschriftencensus.de/4924 (mit weiterer Lit.).

Digitalisat: digi.ub.uni-heidelberg.de/diglit/cpg350

$\mathrm{k}$

Kolmarer Liederhandschrift; München, Staatsbibliothek, Cgm 4997; Papier, 854 Blätter; um 1460

Lit.: Schanze 1983 (Anm. 23); Wachinger 1985 (Anm. 1); handschriftencensus.de/6355 (mit weiterer Lit.).

Digitalisat: mdz-nbn-resolving.de/urn:nbn:de:bvb:12bsb00105055-7 

Anabel Recker

\title{
Der Cgm 1019 im Kontext der rheinisch- schwäbischen Meisterliederhandschriften \\ Mit einer Analyse der Konkordanzen zur Kolmarer Liederhandschrift
}

\begin{abstract}
Both the Colmar Liederhandschrift and the Liederhandschrift Cgm 1019 belong to the collections of Rhinelandic-Swabian Meistergesang. In the article, the corresponding material in both manuscripts is scrutinized in order to find possible sources for the Colmar scribes and to follow the contacts between different centers of Meistersinger tradition. It is very probable that both manuscripts are based on corresponding exemplars. The Cgm 1019 seems to be rooted in a context that goes back to an active Meistersinger tradition.
\end{abstract}

Welche Verbindungen zwischen der Kolmarer Liederhandschrift $(\mathrm{k})$ und den anderen Meisterliederhandschriften des 15. Jahrhunderts bestehen, ließ sich lange Zeit kaum beurteilen, vor allem wegen der schieren Masse an Überlieferung. Obwohl die Kolmarer Liederhandschrift mit Abstand den prominentesten und umfangreichsten, daneben sicherlich auch den bedeutendsten Überlieferungszeugen für den frühen Meistergesang ${ }^{1}$ des 14. und 15. Jahrhunderts darstellt, verfügt die Forschungsgemeinschaft erst seit dem Abschluss des ,Repertoriums der Sangsprüche und Meisterlieder des 12. bis 18. Jahrhunderts

1 Für die im 14. und 15. Jahrhundert enstandene meisterliche Dichtung existieren verschiedene terminologische Vorschläge, die sich an Merkmalen wie Mehrstrophigkeit, Bekanntheit des Textautors sowie den unterstellten Produktions- und Rezeptionsbedingungen orientieren. Die in den Tönen alter Meister, aber mit Textautornamen überlieferte Dichtung nennt Frieder Schanze ,meisterliche Lieddichtung/ Liedkunst', vgl. Frieder Schanze: Meisterliche Liedkunst zwischen Heinrich von Mügeln und Hans Sachs. 2 Bde. München 1983/84 (MTU 82/83), hier Bd. 1, S. 7-11. Mit dem ,Handbuch Sangspruch/Spruchsang' spreche ich von frühem Meistergesang, der sich vornehmlich (aber nicht ausschließlich) durch Verfasseranonymität auszeichnet, gegenüber der späten Spruchdichtung, die bis ins 15. Jahrhundert begegnet und deren Textautoren namentlich greifbar werden. Vgl. Holger Runow: Sangspruchdichtung als Gattung (statt einer Einleitung). In: Sangspruch/ Spruchsang. Ein Handbuch. Hg. von Dorothea Klein et al. Berlin, Boston 2019, S. 1-19, hier S. If. 
(RSM) vor einem guten Jahrzehnt über ein geeignetes Arbeitsmittel, das es erlaubt, in dieser Fülle einzelnen Spuren nachzugehen, entferntere Korrespondenzen auszumachen und manche Strophen und Bare ${ }^{2}$ überhaupt erst aufzufinden. ${ }^{3}$ Auf der medial-materiellen Seite gewährt die erfolgte, vollständige Farbdigitalisierung einen verbesserten Zugang zur Handschrift, ${ }^{4}$ so dass die durch das Tagungskonzept zu dem vorliegenden Band initiierte Aufforderung, diese weiter zu erforschen, auf fruchtbaren Boden fallen dürfte.

Mehrere die Kolmarer Liederhandschrift betreffende Forschungsinteressen würden davon profitieren, die anderen Meisterliederhandschriften des 15. Jahrhunderts aus der rheinisch-schwäbischen Teilgruppe tiefer zu erschließen. Diese Teilgruppe besteht aus folgenden Codices: ${ }^{5}$

Basel O IV 28 (b, südwestl. Schwaben, um 1430)

Dresden M 13 (d, Schwaben, etwa 1440/45)

2 Ob es ,der Bar' oder ,das Bar' heißen müsse, bleibt umstritten. Für die historische Bezeichnung belegt die Überlieferung beide Genera. Im Folgenden gebrauche ich die sächliche Form. Vgl. Frieder Schanze: Bar. In: Reallexikon der deutschen Literaturwissenschaft. Neubearbeitung des Reallexikons der deutschen Literaturgeschichte. Gem. mit Harald Fricke et al. hg. von Klaus Weimar. Bd. 1. Berlin, New York 2007, S. 198f. Zur historischen Semantik des Barbegriffs gilt nach wie vor der Beitrag von Christoph Petzsch: Parat- (Barant-) Weise, Bar und Barform. Eine terminologische Studie. In: Archiv für Musikwissenschaft 28 (1971), S. 33-43, als grundlegend.

3 Repertorium der Sangsprüche und Meisterlieder des 12. bis 18. Jahrhunderts. Hg. von Horst Brunner und Burghart Wachinger, unter Mitarbeit von Eva Klesatschke u. a. 16 Bde. Tübingen 1986-2009.

4 Digitale Bibliothek der BSB München: http://daten.digitale-sammlungen.de/ $\sim \mathrm{db} / 0010 / \mathrm{bsb} 00105055 /$ images (online seit 21.01.2016, zuletzt eingesehen am 29. 09. 2020). Zuvor gedruckt: Die Kolmarer Liederhandschrift der Bayerischen Staatsbibliothek in München (cgm 4997). In Abbildung hg. von Ulrich Müller, Franz Viktor Spechtler und Horst Brunner. Göppingen 1972 (Litterae 35).

5 Die Einteilung in zwei Gruppen folgt Horst Brunner: Die alten Meister. Studien zu Überlieferung und Rezeption der mittelhochdeutschen Sangspruchdichter im Spätmittelalter und in der frühen Neuzeit. München 1975 (MTU 54), S. 138. Brunner zählt zusätzlich den Augsburger Cpg 680 zur ersten Gruppe, dessen Meisterliedersammlung im ersten Faszikel sich inzwischen aufgrund der Wasserzeichen auf 1533 datieren lässt. Vgl. Frieder Schanze: Meisterliederhandschriften. In: ${ }^{2} \mathrm{VL}$ 6 (1987), Sp. 347-356, hier Sp. 354; Pamela Kalning u. a.: Die Codices Palatini germanici in der Universitätsbibliothek Heidelberg (Cod. Pal. germ. 671-848). Wiesbaden 2016 (Kataloge der Universitätsbibliothek Heidelberg XII), S. 22-28, hier S. 22. 
München Cgm 1018 (x, Nordwürttemberg/Franken, bald nach 1450)

München Cgm 1019 (y, Franken, um 1450)

München Cgm 4997 (k, Rheinfranken, um 1460)

Heidelberg Cpg 392 (h, Augsburg, um 1500)

München Cgm 5198 (w, Tirol, um 1500)

Trier 1032/1943 (t, Moselfranken, um 1500)

Die zweite Untergruppe überliefert frühen Meistergesang aus Nürnberg:

München Cgm 351 (m, Nürnberg, etwa 1425/35)

Weimar Q 566 (Nürnberg, Hans Folz, 1475/80)

München Cgm 6353 (Nürnberg, Hans Folz, 1485/95)

Berlin Mgq 414 (q, Nürnberg, Hans Sachs, 1517/18) ${ }^{6}$

Drei Handschriften aus der rheinisch-schwäbischen Gruppe datieren später als die Kolmarer Liederhandschrift (h, w, t), ${ }^{7}$ vier wurden früher als $k$ (b, d) oder zeitnah zu $\mathrm{k}(\mathrm{x}, \mathrm{y})$ verfasst. Vergleichende Untersuchungen der in den Handschriften parallel überlieferten Bare sollten in beide Richtungen blicken: Auf der einen Seite kann die Wahrscheinlichkeit gemeinsamer Vorlagen von k mit anderen Meisterliederhandschriften geprüft werden, auf der anderen Seite können mögliche Rezeptionskonstellationen beleuchtet werden, in denen Bare aus der Kolmarer Handschrift weitertradiert wurden. Leider verharrt die Forschung zu den späteren vorreformatorischen Meisterliederhandschriften bisher auf einem deskriptiven Stand. ${ }^{8}$

6 Das erste Autograph von Hans Sachs stammt aus dem frühen 16. Jahrhundert, es zählt aber zum vorreformatorischen Meistergesang und erhält daher seinen Platz in dieser Gruppe.

7 In dieser Teilgruppe darf der Augsburger Cpg 392 (h) am ehesten als Produkt einer aktiven Gesangspraxis gelten. Vgl. RSM Bd. 1 (1994), S. 176. Zum späteren Augsburger Meistergesang s. Fritz Schnell: Zur Geschichte der Augsburger Meistersingerschule. Augsburg 1958 (Abhandlungen zur Geschichte der Stadt Augsburg 11); Horst Brunner et al.: Die Schulordnung und das Gemerkbuch der Augsburger Meistersinger. Tübingen 1991 (Studia Augustana 1).

8 Matthias Miller und Karin Zimmermann: Die Codices Palatini germanici in der Universitätsbibliothek Heidelberg (Cod. Pal. germ. 304-495), Wiesbaden 2007 (Kataloge der Universitätsbibliothek Heidelberg VIII), S. 293-303; Ignaz Vinzenz Zingerle: Bericht über die Wiltener Meistersänger-Handschrift. Wien 1861 (Sitzungsberichte der Österreichischen Akademie der Wissenschaften, Phil.-hist. Cl. 37); RSM Bd. 1 (1994), S. 213f.; Schanze 1983 (Anm. 1), S. 122-133; Schanze 1987 (Anm. 5), S. 349-351; Karin Schneider: Die deutschen Handschriften der Bayerischen Staatsbibliothek München. Die mittelalterlichen Handschriften aus Cgm 
Das Dreierbar ${ }^{1} \operatorname{Regb} / 2 / 39$, das in $\mathrm{k}$ auf Blatt 330rv, in der Wiltener Liederhandschrift (w, Bll. 64v-65r) und in der Handschrift Trier 1032/1943 (t, Bll. $158 \mathrm{v}-159 \mathrm{v}$ ) verzeichnet wurde, gibt ein Beispiel für die Überlieferung eines Bars in $\mathrm{k}$ und späteren Handschriften. ${ }^{9}$ Obwohl unbekannt ist, wo genau die Wiltener Liederhandschrift entstand, ${ }^{10}$ wird ihre Niederschrift anhand des Schreibsprachendialekts für um 1500 in Tirol angenommen. Ihre Überschriften benennen häufig den Ton und den Tonautor (regenpog in dem Graben don iij lied, Bl. 64v). Augenfällig ist das große Mügeln-Korpus der Wiltener Liederhandschrift, alle vier Töne Mügelns überliefern sonst nur k und q. ${ }^{11}$

Der mit der Sigle t bezeichnete Codex 1032/1943 der Stadtbibliothek Trier datiert auf die Mitte des 15. Jahrhunderts bis um $1500 .{ }^{12}$ In mediengeschichtlicher Perspektive könnte seine präzisere Erschließung interessant sein, weil er Handschrift und Inkunabel verbindet. ${ }^{13}$ Auf welchem Weg das genannte Bar in Regenbogens Grauem Ton von Rheinfranken nach Moselfranken und sogar bis nach Tirol gelangte, und ob eine oder mehrere gemeinsame Vorlagen für alle

4001-5247. Editio altera. Wiesbaden 1996 (Catalogus codicum manu scriptorum Bibliothecae Monacensis T. 5, Ps. 7), S. 530-536; Betty C. Bushey: Die deutschen und niederländischen Handschriften der Stadtbibliothek Trier bis 1600. Beschr. Verz. der Handschriften der Stadtbibliothek zu Trier. Bd. 1. Wiesbaden 1996, S. $158-167$.

9 Anabel Recker: Maßgebendsein. Texte und Studien zur Poetologie des frühen Meistergesangs. Wiesbaden 2021 (Imagines Medii Aevi 53), S. 99-101, mit Nachweisen der älteren Abdrucke durch von der Hagen (1838) und R. Schröder (1984).

10 Schneider 1996 (Anm. 8), S. 531, bemerkt: „[I]m Kloster Wilten hat sich die Handschrift nie befunden", sondern sie wurde Ende des 16. Jahrhunderts in der Wolkensteinschen Bibliothek auf Schloss Rodenegg aufbewahrt. S. auch Schanze 1987 (Anm. 5), Sp. 349ff.

11 Bll. 2v-7r, 29r-54r, 55r-64v, 102r-103r. Vgl. RSM Bd. 1 (1994); Schneider 1996 (Anm. 8).

12 Papier. 171 Bl. 20,7 x 13,7 cm. Mehrere Hände. Vermutet wird ein Bezug zum Kloster Eberhardshausen (Klausen bei Wittlich). Vgl. Bushey 1996 (Anm. 8), S. 158; Schanze 1987 (Anm. 5), Sp. 349; RSM Bd. 1 (1994), S. 25.

13 Die aus drei unterschiedlichen Teilen bestehende Meisterliedersammlung nimmt die Blätter 89-171 ein, der erste Faszikel bis Blatt 88 enthält eine Rezeptsammlung medizinischer Natur, insbesondere aus der Pferdeheilkunde. Nach Blatt 53 ist eine Inkunabel eingehängt, die ebenfalls ein Rossarzneibuch beinhaltet. 
drei Überlieferungszeugen bestanden haben, bleibt spekulativ. Vor allem aufgrund ihrer isolierten Entstehungsräume, die sie weit außerhalb meisterlicher Gesangszentren positionieren, wird den Handschriften ein konservierender Charakter zugeschrieben, der jedoch mangels genauerer Studien weder bestätigt noch widerlegt werden kann. ${ }^{14}$

Über die Kolmarer Liederhandschrift wissen wir überdurchschnittlich viel mehr als über die anderen Handschriften der rheinisch-schwäbischen Gruppe, ${ }^{15}$ wie etwa, dass ihre Schreiber glaubhaft in Speyer verortet werden können ${ }^{16}$ oder dass ihre strikte Ordnung nach Tonautorenkorpora, die keine andere Meisterliederhandschrift aufweist, unter anderem durch erst nach der Bindung

14 Schanze beurteilt w folgendermaßen: „Man hat aber nicht den Eindruck, als ob hinter w überhaupt wie bei den genannten Handschriften eine lebendige und produktive Meistergesangssituation mit eigenen Traditionen stünde. Jedenfalls ist davon für uns nichts erkennbar. Die Gegend, in der w geschrieben wurde, lag ja auch weit entfernt von den oberdeutschen Zentren des Meistergesangs. Zwar gab es, wie $\mathrm{w}$ am besten beweist, auch dort Interessenten für die Meisterkunst, ob diese aber auch selbst in nennenswertem Umfang an der schöpferischen Weiterführung der Tradition beteiligt waren, scheint zweifelhaft; sie haben sich offenbar eher rezeptiv verhalten." Schanze 1983 (Anm. 1), S. 108. Zu der Trierer Hs. liegen außer der Handschriftenbeschreibung keine Studien vor.

15 Vgl. Karl Bartsch: Meisterlieder der Kolmarer Handschrift. Stuttgart 1862 (Bibliothek des Litterarischen Vereins in Stuttgart 68), S. 1-89 (zur Hs.), S. 188-595 (Teilabdruck der Hs.); Paul Runge: Die Sangesweisen der Colmarer Handschrift und die Liederhandschrift Donaueschingen. Leipzig 1896. Nachdruck Hildesheim 1965; Ursula Aarburg: Verzeichnis der im Kolmarer Liedercodex erhaltenen Töne und Leiche. In: Festschrift Heinrich Besseler zum sechzigsten Geburtstag. Leipzig 1961, S. 127-136; Christoph Petzsch: Die Kolmarer Liederhandschrift. Entstehung und Geschichte. München 1978; Schanze 1983 (Anm. 1), S. 58-83 u. 209; Burghart Wachinger: Kolmarer Liederhandschrift. In: ${ }^{2}$ VL 5 (1985), Sp. 27-39; RSM Bd. 1 (1994), S. 206-209; Schneider 1996 (Anm. 8), S. 423-444; Michael Baldzuhn: Vom Sangspruch zum Meisterlied. Untersuchungen zu einem literarischen Traditionszusammenhang auf der Grundlage der Kolmarer Liederhandschrift. Tübingen 2002 (MTU 120); Gisela Kornrumpf: Kolmarer Liederhandschrift. In: Killy Literaturlexikon. 2., vollst. überarb. Aufl. hg. von Wilhelm Kühlmann u. a. Bd. 4. Berlin, New York 2009, S. 608-611.

16 Vgl. Gisela Kornrumpf: Die Kolmarer Liederhandschrift. In: dies.: Vom Codex Manesse zur Kolmarer Liederhandschrift. Aspekte der Überlieferung, Formtraditionen, Texte. Bd. 1: Untersuchungen. Tübingen 2008 (MTU 133) [Bd. 2 n.e.], S. 257-274. 
vorgenommene Umstrukturierungen erzielt wurde. ${ }^{17}$ Die Auseinandersetzung mit den anderen vorreformatorischen Meisterliedersammlungen fördert die Schließung weiterhin bestehender Forschungslücken für k. Dazu gehören Fragen nach den Verwandtschaftsverhältnissen der Handschriften untereinander, die Aufschluss darüber geben können, woher die Schreiber von k das Material für ihre Kollektion bezogen. Produktionsästhetisch gesehen werden auf diesem Weg nicht nur gemeinsame Vorlagen, sondern auch Kontaktpunkte zwischen einzelnen meistersingerischen Produktionszentren plausibilisiert.

Für Vorlagenuntersuchungen rückt die ältere Untergruppe der rheinischschwäbischen Handschriften ins Zentrum der Betrachtung, die in chronologischer Reihung zunächst die älteste bekannte Meisterliederhandschrift, Basel O IV 28 (b, 1430), beinhaltet. Der Codex aus der Universitätsbibliothek Basel wurde bislang nur unzureichend beschrieben. ${ }^{18}$ Hingegen wurde die Dresdner Meisterliederhandschrift d vor Kurzem erneut untersucht. Die Staats- und Universitätsbibliothek Dresden hat mit dem DFG-Projekt „Tiefenerschließung und Digitalisierung der deutschsprachigen mittelalterlichen Handschriften der Sächsischen Landesbibliothek “(2008-2016) dafür gesorgt,

17 Vgl. ebd., S. 258f.

18 Siehe für eine erneute Autopsie der Handschrift Recker (Anm. 9), S. 110-112. Digital eingesehen werden kann der Codex derzeit nicht. Karl Bartsch stellte ihn seiner Inhalte wegen knapp dar und in seiner Übersicht der wichtigsten Meisterliederhandschriften bespricht auch Frieder Schanze die Handschrift, insgesamt nehmen sich die verfügbaren kodikologischen und paläographischen Angaben aber unpräzise und lückenhaft aus. Vgl. Karl Bartsch: Beiträge zur Quellenkunde der altdeutschen Literatur. Straßburg 1886, S. 275-301; Vgl. Schanze 1983 (Anm. 1), S. 94-100; ders. 1987 (Anm. 5), S. 346f. Die ausführlichsten und brauchbarsten Ergebnisse stammen von Karl Stackmann: Die kleineren Dichtungen Heinrichs von Mügeln. Hg. von Karl Stackmann. 3 Bde. Berlin 1959 (DTM 50-52), S. XVII-XXIII. Das Wasserzeichen (zwei gekreuzte Schlüssel, ohne Umrandung, zweikonturiger Schaft, runder Griff, ohne Beizeichen, ohne Schlaufe) bestätigt Stackmanns Datierung auf die Zeit um 1430. Die Handschrift ist in schlechtem Zustand, das Wasserzeichen kann nicht abgepaust werden. In Frage kommen zahlreiche Wasserzeichen vornehmlich im schwäbisch-alemannischen Raum zwischen 1417 in Speyer und 1442 in Baden-Baden. Diese beiden Rahmendaten sind jedoch Ausreißer, der Großteil der Wasserzeichen datiert zwischen 1425 und 1430. Vgl. www.wasserzeichen-online.de (29. 09. 2020). Vgl. außerdem zu b Heinrich Wilhelm Wackernagel: Die altdeutschen Handschriften der Basler Universitätsbibliothek. Verzeichnis. Beschreibung. Auszüge. Basel o. J.; RSM Bd. 1 (1994), S. $75 f$. 
dass Dresden M 13 online zugänglich gemacht wurde. ${ }^{19}$ Anhand der Wasserzeichen datiert sie auf $1440 / 45,{ }^{20}$ örtlich konkretisiert sich die Herkunft der Handschrift nach der jüngsten Untersuchung auf Ulm. ${ }^{21}$ Die Lokalisierung von $\mathrm{d}$ in Ulm unterstreicht die Annahme, dass frühe Meisterliederhandschriften in städtischen Zentren entstehen und verknüpft sie mit einer greifbaren soziologischen Sphäre des performativen Vollzugs. Abgesehen von dem eigenständigen materialwissenschaftlichen Wert, der damit generiert wird, können sich theoretische Überlegungen zu Aufführungspraxis, Fiktionalitätsanspruch und soziologischer Einbettung der Dichtung damit auf ein philologisches Fundament stützen.

Im Folgenden wende ich mich den beiden verbleibenden älteren Meisterliedersammlungen zu, die etwa zu derselben Zeit wie die Kolmarer Liederhandschrift entstanden: dem Cgm 1018 und dem Cgm 1019. ${ }^{22}$ Anschließend verengt der Beitrag den Blick auf den Cgm 1019 sowie seine Konkordanzen zum Cgm 4997. Auf diese Weise sollen erste Rückschlüsse auf Beziehungen zwischen den beiden Handschriften gezogen werden. Begleitet wird die Analyse von Editionen aller auschließlich in $\mathrm{k}$ und y parallel tradierten Bare (s. Anhang).

19 Vgl. die Handschriftenbeschreibung von Werner Hoffmann auf Manuscripta Mediaevalia. www.manuscripta-mediaevalia.de/dokumente/html/obj31601114 (29. 09. 2020).

20 Schanze 1987 (Anm. 5), Sp. 347; RSM Bd. 1 (1994), S. 134. Werner Hoffmann (Anm. 19) nennt „insgesamt 5 verschiedene Zeichen (davon 2 Formenpaare), Ochsenkopf mit Augen, Nase, Maul, einkonturiger Stange und siebenblättriger Blume, alle Typ PICCOK XII 981 (belegt 1439-1443); ein Zeichen (Bl. 16-18) Variante zu Piccard-Online Nr. 81257 (Weinsberg 1443); ein Zeichen (Bl. 27 und 29) Variante zu Leipzig UB, Ms 7866, Spiegel vorne (Leipzig 1446 oder kurz nach 1446) und Piccard-Online Nr. 81255 (Aalen 1441)“.

21 Über die Bünau’sche Bibliothek (Graf Heinrich von Bünau, ${ }^{\star} 1697-\dagger 1762$, im Besitz der Bibliothek bis 1764) und den Berner Bibliothekar und Politiker Samuel Engel $\left({ }^{\star} 1702-\uparrow 1784\right.$, Besitz bis 1744$)$ lässt sich die Provenienz der Handschrift bis zu dem Ulmer Bürgermeister Raymund Krafft zu Delmensingen $\left({ }^{\star} 1663-\dagger 1729\right)$ zurückverfolgen. Vgl. ebd.

22 Die kodikologische Beschreibung wird verdeutlichen, warum sie gemeinsam betrachtet werden. 


\section{Der Cgm 1018 (x) und der Cgm 1019 (y)}

Die Quartbände Cgm 1018 (x) und Cgm 1019 (y), auf die Horst Brunner im Zusammenhang mit dem Meistergesang zuerst 1975 verwies, ${ }^{23}$ wurden räumlich und zeitlich in relativer Nähe zur Kolmarer Liederhandschrift angefertigt. Karin Schneider datiert die Cgm 1018-20 auf um oder kurz nach 1450 und verortet sie im Grenzraum von Nordwürttemberg und Franken. Der Cgm 1020 enthält keine Meisterliedersammlung, verfügt aber über dieselbe Größe, Entstehungszeit, Mundart und Provenienz wie der Cgm 1018 und der Cgm 1019. ${ }^{24}$ Spiegel, Vor- und Nachsatzblatt aller drei Handschriften sind aus dem gleichen Papier gefertigt, die Blätter 1-24 des Cgm 1018 und die Blätter 1-12 des Cgm

23 Brunner 1975 (Anm. 5), S. 138 mit Anm. 239. Brunner erhielt den Hinweis auf die Handschriften von Burghart Wachinger. Vgl. zu den beiden Hss. außerdem Johann Andreas Schmeller: Codicum Germanicorum partem priorem complectens. München 1866, S. 166; Karl Goedeke: Grundriß zur Geschichte der deutschen Dichtung. 2 Bde. 2. Aufl. Dresden 1884 und 1886, hier Bd. 1, S. 309; Deutsche Liederdichter des 13. Jahrhunderts. Hg. von Carl von Kraus. 2. Aufl. durchges. von Gisela Kornrumpf. 2 Bde. Tübingen 1978, hier Bd. 1, S. XXII; Die geistlichen Lieder des Mönchs von Salzburg. Hg. von Franz Viktor Spechtler. Berlin 1972 (Quellen und Forschungen zur Sprach- und Kulturgeschichte der germanischen Völker 175), S. 81; Günter Mayer: Probleme der Sangspruchüberlieferung. Beobachtungen zur Rezeption Konrads von Würzburg im Spätmittelalter. Diss. München 1974, S. 30f.; Frauenlob (Heinrich von Meissen). Leichs, Sangsprüche, Lieder (GA). Auf Grund der Vorarbeiten von Helmuth Thomas hg. von Karl Stackmann und Karl Bertau. 2 Teile, Göttingen 1981 (Abhandlungen der Akademie der Wissenschaften in Göttingen, Philol.-Hist. Klasse III,119.120), S. 20-30; Schanze 1984 (Anm. 1), S. 133-135 u. 208; ders. 1987 (Anm. 5), Sp. 348; Karin Schneider: Die deutschen Handschriften der Bayerischen Staatsbibliothek München. Die mittelalterlichen Handschriften aus Cgm 888-4000. Wiesbaden 1991 (Catalogus codicum manu scriptorum Bibliothecae Monacensis V,6), S. 54-62; RSM Bd. 1 (1994), S. 203f.; Jens Haustein: Marner-Studien. Tübingen 1995 (MTU 109), S. 275; Sangsprüche in Tönen Frauenlobs. Supplement zur Göttinger Frauenlob-Ausgabe (GA-S). Unter Mitarbeit von Thomas Riebe und Christoph Fasbender hg. von Jens Haustein und Karl Stackmann. 2 Teile. Göttingen 2000 (Abhandlungen der Akademie der Wissenschaften in Göttingen, Philol.-Hist. Klasse III,232), S. 24; Franziska Wenzel: Meisterschaft im Prozess. Der Lange Ton Frauenlobs - Texte und Studien. Mit einem Beitrag zu vormoderner Textualität und Autorschaft. Berlin 2012 (Deutsche Literatur. Studien und Quellen 10), S. 338. Siehe überdies die Einträge zu den Hss. im Handschriftencensus, http://www.handschriftencensus.de/9980, /9981 (29.09.2020).

Vgl. Schneider 1991 (Anm. 23), S. 54 u. $58 f$. 
1019 tragen dasselbe Wasserzeichen. ${ }^{25}$ Schneider räumt die Möglichkeit einer ursprünglichen Sammelhandschrift aus allen oder einigen Faszikeln der drei Handschriften ein, gleichfalls jedoch die einer späteren Kompilation der einzelnen Teile des Cgm 1019 erst im 16. Jahrhundert. ${ }^{26}$ Die Bände wirken schmucklos und erwecken den Anschein von Gebrauchshandschriften.

Der Cgm 1018 (48 Bll.) enthält 36 Bare, von denen 20 parallel überliefert und 16 Sondergut sind. Die in der Auflistung der RSM-Sigle folgenden Kleinbuchstaben (a, b, c...) nummerieren die parallel überlieferten Texte, wie das RSM sie beziffert.

Inhalt Cgm $1018(\mathrm{x})^{27}$

\begin{tabular}{lll}
\hline Nr. & RSM-Sigle & Bll. \\
\hline 1. & ${ }^{1}$ Ungl/1/6 & $1 \mathrm{r}-2 \mathrm{v}$ \\
2. & ${ }^{1}$ Ungl/1/7 & $2 \mathrm{v}-4 \mathrm{r}$ \\
3. & ${ }^{1}$ Regb/1/514c & $4 \mathrm{r}-5 \mathrm{r}$ \\
4. & ${ }^{1} \mathrm{Frau} / 23 / 12$ & $5 \mathrm{rv}$ \\
5. & ${ }^{1} \mathrm{Frau} / 6 / 507$ & $5 \mathrm{v}-9 \mathrm{v}$ \\
6. & ${ }^{1}$ Regb/4/521d & $9 \mathrm{v}-10 \mathrm{v}$ \\
7. & ${ }^{1} \mathrm{Marn} / 7 / 505 \mathrm{~b}$ & $11 \mathrm{r}-12 \mathrm{r}$ \\
8. & ${ }^{1} \mathrm{Frau} / 4 / 522$ & $12 \mathrm{r}-13 \mathrm{r}$ \\
9. & ${ }^{1} \operatorname{Regb} / 4 / 614 \mathrm{a}$ & $13 \mathrm{r}-14 \mathrm{v}$ \\
10. & ${ }^{1} \operatorname{Regb} / 4 / 615$ & $14 \mathrm{v}-17 \mathrm{v}$ \\
11. & ${ }^{1} \mathrm{Marn} / 7 / 518 \mathrm{c}$ & $17 \mathrm{v}-20 \mathrm{r}$ \\
12. & ${ }^{1} \mathrm{WaltV} / 24 / 6$ & $20 \mathrm{rv}$ \\
13. & ${ }^{1} \mathrm{Frau} / 26 / 5$ & $20 \mathrm{v}-21 \mathrm{r}$ \\
14. & ${ }^{1} \mathrm{Frau} / 26 / 4 \mathrm{~b}$ & $21 \mathrm{rv}$ \\
15. & ${ }^{1} \mathrm{Kanzl} / 2 / 500 \mathrm{c}$ & $22 \mathrm{rv}$ \\
16. & ${ }^{1} \operatorname{Regb} / 2 / 43 \mathrm{~b}$ & $23 \mathrm{rv}$ \\
17. & ${ }^{1} \operatorname{Regb} / 2 / 56$ & $24 \mathrm{rv}$ \\
18. & ${ }^{1} \mathrm{Marn} / 6 / 505 \mathrm{c}$ & $25 \mathrm{r}-26 \mathrm{v}$ \\
\hline
\end{tabular}

25 Ochsenkopf, Piccard Typ I, 315 u. 316, zwischen 1449 und 1457 u. a. in Basel, Frankfurt und Würzburg belegt. Ebd., S. 54, 58.

26 I: Bll. 1-12, II: Bll. 13-24, III: Bll. 25-30. Vgl. ebd., S. 58f.; GA, S. $20 f$.

27 Zur besseren Orientierung wurden die enthaltenen Texteinheiten durchnummeriert. Bei y sind die Faszikel durch römische Zahlen voneinander abgesetzt. 


\begin{tabular}{|c|c|c|}
\hline Nr. & RSM-Sigle & Bll. \\
\hline 19. & ${ }^{1} \operatorname{Regb} / 2 / 57$ & $26 v-27 v$ \\
\hline 20. & ${ }^{1} \operatorname{Regb} / 2 / 58$ & $27 \mathrm{v}-28 \mathrm{v}$ \\
\hline 21. & ${ }^{1} \operatorname{Regb} / 4 / 595 \mathrm{c}$ & $28 \mathrm{v}-30 \mathrm{r}$ \\
\hline 22. & ${ }^{1}$ Frau $/ 11 / 4$ & $30 r-31 r$ \\
\hline 23. & ${ }^{1} \mathrm{Pfalz} / 4$ & $31 r-32 r$ \\
\hline 24. & ${ }^{1}$ Frau $/ 4 / 523$ & $32 r-33 v$ \\
\hline 25. & ${ }^{1}$ Frau $/ 2 / 516 b$ & $33 v-34 v$ \\
\hline 26. & ${ }^{1} \mathrm{Frau} / 2 / 545 \mathrm{~b}$ & $34 v-35 v$ \\
\hline 27. & ${ }^{1}$ Frau $/ 4 / 518 \mathrm{c}$ & $36 r-37 r$ \\
\hline 28. & ${ }^{1} \operatorname{ReiBr} / 514 b$ & $37 \mathrm{rv}$ \\
\hline 29. & ${ }^{1}$ Frau/9/528a & $38 \mathrm{rv}$ \\
\hline 30. & ${ }^{1}$ Ungl/1/8 & $38 v-40 v$ \\
\hline 31. & ${ }^{1} \operatorname{Regb} / 4 / 550 \mathrm{~b}$ & $40 v-42 v$ \\
\hline 32. & ${ }^{1} \mathrm{Frau} / 4 / 502 \mathrm{~b}$ & $42 v-44 v$ \\
\hline 33. & ${ }^{1}$ Marn/7/553a & $45 r-46 r$ \\
\hline 34. & ${ }^{1}$ Marn/7/534b & $46 \mathrm{r}-47 \mathrm{v}$ \\
\hline 35. & ${ }^{1} \mathrm{Frau} / 23 / 2 \mathrm{~b}$ & $47 v-48 r$ \\
\hline 36. & ${ }^{1} \mathrm{Mönch} / 5 / 4^{28}$ & $48 \mathrm{v}$ \\
\hline
\end{tabular}

In der Kolmarer Liederhandschrift stehen 16 der 20 mehrfach überlieferten Bare des Cgm 1018, von denen 14 ausschließlich dort ein zweites Mal tradiert sind. ${ }^{29}$ Von den vier verbleibenden Mehrfachüberlieferungen, die nicht in $\mathrm{k}$ stehen, entfallen zwei auf $w,{ }^{30}$ die dritte auf das Hausbuch des Simprecht Kröll

28 Mitten in der 2. Str. endet die Handschrift, danach Blattverlust. Vgl. die Inhaltsübersicht bei Schneider 1991 (Anm. 23), S. 54-58 u. RSM Bd. 1 (1994), S. $203 f$.

29 Die beiden Ausnahmen bilden Nr. 31, eine Johannesvision im Langen Ton Regenbogens ( $\left.{ }^{1} \mathrm{Regb} / 4 / 550\right)$, die in $\mathrm{x}, \mathrm{k}$ und in $\mathrm{w}$ überliefert ist, und Nr. 32 ( $\left.{ }^{1} \mathrm{Frau} / 4 / 502\right)$, ein breiter überliefertes Siebenerbar in Frauenlobs Grünem Ton mit vier in C altbezeugten Strophen.

30 Nr. $16{ }^{1} \operatorname{Regb} / 2 / 43 b$ u. Nr. $18{ }^{1}$ Marn/6/505c, wobei sich Nr. 16 zusätzlich im Cgm 351 findet. Vgl. Karin Schneider: Die deutschen Handschriften der Bayerischen Staatsbibliothek München. Cgm 351-500. Wiesbaden 1973 (Catalogus codicum manu scriptorum Bibliothecae Monacensis V,3), S. 17-26, hier S. 21. 
aus dem frühen 16. Jahrhundert ${ }^{31}$ und die vierte auf das Autograph des Hans Sachs ${ }^{32}$. Die Kolmarer Liederhandschrift erweist sich somit als hauptsächlicher Bezugspunkt für Varianten der in $\mathrm{x}$ überlieferten meisterlichen Bare. Während $\mathrm{x}$ zusammenhängend von einer Hand geschrieben, bis auf wenige Blätter durchgehend rubriziert und mit regelmäßig ausgeführten Initialen zu den Liedanfängen ausgestattet wurde, besteht y aus drei Faszikeln, die von verschiedenen Schreibern in unterschiedlichen Schreibsprachen abgefasst wurden, wobei keiner von ihnen mit den Schreibern des Cgm 1018 oder des Cgm 1020 identisch ist. ${ }^{33}$ Alle drei Faszikel verblieben ohne Initialen in den dafür ausgesparten Lücken und lediglich Faszikel I weist rote Überschriften auf. Mit 30 Blättern und 21 Baren fällt der Band etwas übersichtlicher aus als x. Sein dritter Faszikel verzeichnet einen Text, der nicht der Gattung Meistergesang angehört. Das Reimpaargedicht im Duktus einer Zeitklage von Konrad Suchendank (Bll. 25r-28r) mahnt die adligen Zuhörer, dem Laster des Fluchens auszuweichen, das sich derzeit schlimmer denn je verbreite. Am Anfang der Basler Meisterliederhandschrift begegnet eine Parallelüberlieferung des Reimpaargedichts (Bll. $2 \mathrm{v}-5 \mathrm{v}$ ). Ein dritter Textzeuge steht im Codex Weimar Oct. $145 .{ }^{34}$ Ich gebe eine Umschrift der ersten drei Reimpaare aus den Meisterliedersammlungen $\mathrm{b}$ und $\mathrm{y}$.

31 Cpg 109. Der zweite Überlieferungsträger zu Nr. $9^{1}$ Regb/4/614a steht dort als Streuüberlieferung. Das Hausbuch enthält neben Briefen, Todesanzeigen und einigen anderen geistlichen Liedern den,Wolfdietrich'. S. Karin Zimmermann u. a.: Die Codices Palatini germanici in der Universitätsbibliothek Heidelberg (Cod. Pal. germ. 1-181). Wiesbaden 2003 (Kataloge der Universitätsbibliothek Heidelberg VI), S. 249-260.

32 Mgq 414 (q), Bll. ${ }^{1} \mathrm{Frau} / 4 / 522$.

33 Schneider bemerkt dazu: „Wegen der unterschiedlichen Schreiber und Schreibsprachen (die zwar den Grenzgebieten desselben Sprachraums angehören) wäre ein aus verschiedenen Einzelfaszikeln zusammengebundener Sammelband denkbar; die Abstände der Bünde stimmen in Cgm 1018-19, in Cgm 1020 sind sie, wohl infolge der Neubindung, leicht verschoben. Möglich wäre auch, daß die Faszikel erst im 16. Jh. [...] vereint wurden." Schneider 1991 (Anm. 23), S. 59.

34 Bll. 82v-88v. Vgl. Frieder Schanze: Suchendank, Konrad. In: ${ }^{2}$ LL 9 (1995), Sp. $477 f$. Baldzuhn verortet den Codex Weimar Oct. 145, der Minnereden, Didaktisches und Schwankerzählungen tradiert, um 1480 im ostschwäbischen Raum. Vgl. Michael Baldzuhn: Schulbücher im Trivium des Mittelalters und der Frühen Neuzeit. Die Verschriftlichung von Unterricht in der Text- und Überlieferungsgeschichte der ,Fabulae` Avians und der deutschen, Disticha Catonis‘. 2 Bde. Berlin, New York 2009 (Quellen und Forschungen zur Literatur- und Kulturgeschichte 44), S. 932. 
b $2 v-5 v$

Ich hon gehorrt von wisem ràt was übels in dier welt uff stàt das sol man dem adel sagen ich wil küngen und fursten clagen des aller grosten übel rüff sijt Gott den ersten menschen geschüf y $25 \mathrm{r}-28 \mathrm{r}$

Ich han gehart von wissen rat wie gras wbel in diser welt stat daz sol man den adel[en] klaen $n u$ wil von kungen und fursten sagen all heren und allen edelman nu dunns durch Got und fa es an

Alle drei Codices überliefern das Reimpaargedicht innerhalb einer Zeitspanne von 50 bis 60 Jahren (b um 1430, y um 1450, Weimar Oct. 145 um 1480). Wüsste man mit Sicherheit, dass der Codex Cgm 1019 nahe der Entstehungszeit der einzelnen Teile als Meisterliedersammlung zusammengefügt wurde, ließe sich eindeutiger schlussfolgern, dass Meisterliederhandschriften aus der aktiven Gesangspraxis Reimpaargedichte in ihrem anfänglichen Sammlungskonzept geduldet haben, bevor sie sich ganz auf Meistergesang spezialisierten. Sowohl die Baseler Meisterliederhandschrift als auch die fränkische Faszikelsammlung stehen der aktiven Gesangsproduktion und -pflege nahe, beide zeugen von sich institutionalisierenden Sangeskonventionen um 1430-1450. Suchendanks Reimpaargedicht kann zufällig überliefert worden sein, und doch wirkt es bemerkenswert, dass es in zwei Meisterliederhandschriften derselben Untergruppe innerhalb von zwanzig Jahren als jeweils einziger nicht-meisterlicher Text mitüberliefert wurde. An dieser Stelle scheint ein gemeinsamer überlieferungsgeschichtlicher Zwischenschritt im Sammelkonzept der Liederhandschriften auf, unter Umständen - das müsste ein genauerer Abgleich mit dem dritten Überlieferungszeugen beleuchten - sogar ein Hinweis auf gemeinsame Vorlagen. Mit der Basler Meisterliederhandschrift b teilt y darüber hinaus den ausgesprochen weltlichen inhaltlichen Schwerpunkt: Nur vier der insgesamt 21 Bare haben Geistliches zum Inhalt.

Inhalt Cgm 1019 (y)

\begin{tabular}{lll}
\hline Nr. & RSM-Sigle & Bll. \\
\hline I & & \\
1. & ${ }^{1} \mathrm{Frau} / 14 / 1 \mathrm{c}$ & $1 \mathrm{rv}$ \\
2. & ${ }^{1} \mathrm{Hardr} / 3 / 19$ & $1 \mathrm{v}-2 \mathrm{r}$ \\
3. & ${ }^{1} \mathrm{Hardr} / 3 / 20$ & $2 \mathrm{r}-3 \mathrm{r}$ \\
4. & ${ }^{1} \mathrm{Marn} / 7 / 55$ & $3 \mathrm{r}-4 \mathrm{r}$ \\
5. & ${ }^{1}$ WaltV/7/501 & $4 \mathrm{rv}$ \\
6. & ${ }^{1}$ KonrW/5/509 & $4 \mathrm{v}-5 \mathrm{v}$
\end{tabular}




\begin{tabular}{|c|c|c|}
\hline Nr. & RSM-Sigle & Bll. \\
\hline 7. & ${ }^{1} \operatorname{Hardr} / 3 / 21$ & $5 v-6 v$ \\
\hline 8. & ${ }^{1} \operatorname{Marn} / 7 / 502 \mathrm{~d}$ & $6 \mathrm{v}-8 \mathrm{r}$ \\
\hline 9. & ${ }^{1} \mathrm{Ehrb} / 2 / 2 \mathrm{~b}$ & $8 \mathrm{rv}$ \\
\hline 10. & ${ }^{1}$ Frau $/ 33 / 8$ & $9 \mathrm{r}-10 \mathrm{r}$ \\
\hline 11. & ${ }^{1}$ Suchs/22 & $10 \mathrm{r}-11 \mathrm{r}$ \\
\hline 12. & ${ }^{1} \operatorname{ReiBr} / 527 \mathrm{a}(=507 \mathrm{~b})$ & $11 \mathrm{r}-12 \mathrm{r}$ \\
\hline 13. & ${ }^{1}$ KonrW/6/509b & $12 \mathrm{rv}$ \\
\hline 14. & ${ }^{1} \operatorname{Regb} / 2 / 5 c^{35}$ & $12 \mathrm{v}$ \\
\hline \multicolumn{3}{|l|}{ II } \\
\hline 15. & ${ }^{1}$ Frau $/ 5 / 501 \mathrm{c}$ & $13 \mathrm{r}-15 \mathrm{v}$ \\
\hline 16. & ${ }^{1} \operatorname{Regb} / 4 / 616$ & $15 \mathrm{v}-17 \mathrm{r}$ \\
\hline 17. & ${ }^{1}$ Mönch $/ 5 / 3 \mathrm{~h}$ & $17 \mathrm{r}-19 \mathrm{r}$ \\
\hline 18. & ${ }^{1} \operatorname{Regb} / 4 / 518 \mathrm{~b}$ & $19 \mathrm{r}-21 \mathrm{v}$ \\
\hline 19. & ${ }^{1} \mathrm{Frau} / 7 / 500 \mathrm{~b}$ & $21 v-23 v$ \\
\hline 20. & ${ }^{1} \mathrm{Wartb} / 2 / 511 \mathrm{~b}$ & $23 v-24 v$ \\
\hline \multicolumn{3}{|l|}{ III } \\
\hline 21. & $\begin{array}{l}\text { Suchendank: Reim- } \\
\text { paargedicht }\end{array}$ & $25 r-28 r$ \\
\hline 22. & ${ }^{1} \operatorname{Regb} / 2 / 17-18 \mathrm{c}$ & $28 r-30 r$ \\
\hline
\end{tabular}

\section{Die Parallelüberlieferung von $\mathrm{y}$ und $\mathrm{k}$}

Das parallel in y und k überlieferte Strophenkonvolut wird nun näher betrachtet, um die Stellung des Cgm 1019 in der Gruppe der rheinisch-schwäbischen Meisterliederhandschriften und seine Beziehung zur Kolmarer Liederhandschrift besser einschätzen zu können. Die folgende Übersicht enthält die zwölf parallel überlieferten Bare. ${ }^{36}$

35 Ein Teil der ersten Strophe, danach Blattverlust.

36 Zwei weitere Bare von y verfügen andernorts über Parallelüberlieferungen: Nr. 4. ${ }^{1}$ Marn/7/554a, b) Dresden M 9, S. 479-499, c) Weimar Q 572, Bll. 200v203r, d) Weimar Fol 418, S. 195-197 und Nr. 6. ${ }^{1}$ KonrW/5/509b, a) Cgm 351 (m), Bll. 206v-207r. 
Konkordanz y und $\mathrm{k}$

\begin{tabular}{|c|c|c|c|c|}
\hline Nr. in $y$ & RSM-Sigle & Bll. in $\mathrm{k}$ & weitere Überlieferungen & Edition nach y \\
\hline 1. & ${ }^{1} \mathrm{Frau} / 14 / 1 \mathrm{c}$ & a) $\mathrm{k} 136 \mathrm{r}$ & $\begin{array}{l}\text { b) Donaueschingen } 120^{37} \text {, S. } 278 \text {, } \\
\text { d) }={ }^{1} \mathrm{Albl} / \mathrm{la}\end{array}$ & $\begin{array}{l}\text { Cramer Bd. 1, } \\
\text { S. } 37 \text { f. }\end{array}$ \\
\hline 8. & ${ }^{1} \operatorname{Marn} / 7 / 502 \mathrm{~d}$ & a) $\mathrm{k} 449 \mathrm{r}-450 \mathrm{r}$ & $\begin{array}{l}\text { b-c) Str. } 1 \text { u. } 2 \text { s. }{ }^{1} \text { Marn/7/14a, } \\
\text { 12a, e) k } 468 \text { rv }\end{array}$ & $\begin{array}{l}\text { Willms } 2008 \text {, } \\
\text { S. } 350-353\end{array}$ \\
\hline 9. & ${ }^{1} \mathrm{Ehrb} / 2 / 2 \mathrm{~b}$ & a) $\mathrm{k} 727 \mathrm{v}$ & - & s. Anhang \\
\hline 12. & ${ }^{1} \operatorname{ReiBr} / 507 \mathrm{~b}$ & a) $\mathrm{k} 674 \mathrm{r}-675 \mathrm{r}$ & c)-e) RSM 5 (1991), S. 208 & - \\
\hline 13. & ${ }^{1}$ KonrW/6/509b & a) $\mathrm{k} 516 \mathrm{v}-517 \mathrm{r}$ & - & s. Anhang \\
\hline 14. & ${ }^{1} \operatorname{Regb} / 2 / 5 c^{38}$ & a) $\mathrm{k} 312 \mathrm{r}-\mathrm{v}$ & b) $m 248 \mathrm{r}-249 \mathrm{v}$ & - \\
\hline 15. & ${ }^{1} \mathrm{Frau} / 5 / 501 \mathrm{c}$ & a) $\mathrm{k} 197 \mathrm{r}-198 \mathrm{v}$ & $\begin{array}{l}\text { b) Donaueschingen 120, S. 291- } \\
295\end{array}$ & GA-S VIII, 208 \\
\hline 17. & ${ }^{1}$ Mönch $/ 5 / 3 h^{39}$ & g) $k 648 \mathrm{r}-649 \mathrm{v}$ & $\begin{array}{l}\text { a)-f) und i)-1) RSM } 4 \text { (1988), } \\
\text { S. } 363\end{array}$ & $\begin{array}{l}\text { Spechtler 1972, } \\
\text { G } 37\end{array}$ \\
\hline 18. & ${ }^{1} \operatorname{Regb} / 4 / 518 b$ & a) $\mathrm{k} 354 \mathrm{v}-356 \mathrm{r}$ & d) h $46 r-47 r, c)$ w $71 r-72 r$ & - \\
\hline 19. & ${ }^{1}$ Frau $/ 7 / 500 \mathrm{~b}$ & a) $\mathrm{k} 166 \mathrm{r}$ & c) Cpg $680(\mathrm{p}) 1 \mathrm{v}-3$ & GA-S X, 205 \\
\hline 20. & ${ }^{1} \mathrm{Wartb} / 2 / 511 \mathrm{~b}$ & a) $\mathrm{k} 697 \mathrm{v}-698 \mathrm{r}$ & - & s. Anhang \\
\hline 22. & ${ }^{1} \operatorname{Regb} / 2 / 17-18 c$ & a) $\mathrm{k} 318 \mathrm{r}-319 \mathrm{r}$ & $\begin{array}{l}\text { vgl. für b), d) u. e) RSM } 5 \text { (1991), } \\
\text { S. } 68 \text { f. }\end{array}$ & - \\
\hline
\end{tabular}

Für die Analyse werden die parallel überlieferten Bare nach Merkmalen sortiert, die sie ihrer potentiellen Aussagekraft nach hierarchisieren, aufsteigend beginnend bei den schwächeren Merkmalen, so dass sie vier Gruppen bilden: zunächst Barkompilationen mit breiter Überlieferung ( $\left.{ }^{1} \mathrm{Marn} / 7 / 502 \mathrm{~d},{ }^{1} \mathrm{ReiBr} / 507 \mathrm{~b}\right)$ dann originär mehrstrophige Bare mit breiter Überlieferung ( ${ }^{1} \mathrm{Mönch} / 5 / 3 \mathrm{~h},{ }^{1} \mathrm{Regb} / 4$ / 518b, ${ }^{1}$ Regb/2/17-18c), Bare in Tönen Frauenlobs $\left({ }^{1} \mathrm{Frau} / 14 / 1 \mathrm{c},{ }^{1} \mathrm{Frau} / 5 / 501 \mathrm{c},{ }^{1} \mathrm{Frau} /\right.$

37 Bei der Donaueschinger Hs. handelt es sich höchstwahrscheinlich um eine Teilabschrift von k. Vgl. Gesine Freistadt: Zur Abhängigkeit der Liederhandschriften Kolmar und Donaueschingen. Göttingen 1966, S. 319. Vgl. auch Brunner 1975 (Anm. 5), S. 164.

38 Infolge von Blattverlust nur bruchstückhaft überliefert.

39 Kommentiert von Burghart Wachinger: Der Mönch von Salzburg. Zur Überlieferung geistlicher Lieder im späten Mittelalter. Tübingen 1989 (Hermaea 57), S. 43-46, und Stefan Rosmer: Der Mönch von Salzburg und das lateinische Lied. Die geistlichen Lieder in stolligen Strophen und das einstimmige gottesdienstliche Lied im späten Mittelalter. Wiesbaden 2019 (Imagines Medii Aevi 44), S. 262-265. 
7/500b) und schließlich die nur in k und y überlieferten Bare ( ${ }^{1} \mathrm{Ehrb} / 2 / 2 \mathrm{~b},{ }^{1} \mathrm{KonrW} /$ 6/509b, $\left.{ }^{1} \mathrm{Wartb} / 2 / 511 \mathrm{~b}\right)$.

\section{Kompilierte Bare mit breiter Überlieferung}

Um nachzuvollziehen, ob Einzelstrophen und Strophenverbünde als mehrstrophige Bare konzipiert oder erst nachträglich zusammengeführt wurden, lässt sich im RSM die Überlieferungsgeschichte von Strophen nachschlagen, die in dem Verdacht stehen, eventuell altbezeugt zu sein. Oft kann der Entstehungsweg mehrstrophiger Bare auf diesem Weg rekonstruiert werden. Unsicher gestaltet sich auch die Kongruenz von Text und Tonschema. Überdies existieren Töne verschiedener Tonautoren, deren Komponenten sich ähneln, wobei ihr tatsächliches Verhältnis zueinander unklar verbleibt. ${ }^{40}$ Tonversionen konnten abweichen, wenn der Tonverwender das Tonschema missverstand, der Schreiber es fehlerhaft aufzeichnete oder beabsichtigte Varianten erschaffen wurden, indem man die Töne weiterentwickelte. ${ }^{41}$ Zusätzlich kommt es vor, dass derselbe Ton anders bezeichnet oder unterschiedlichen Autoren zugesprochen wird. Die Briefweise beispielsweise wird in $\mathrm{k}$ dezidiert sowohl Frauenlob als auch Regenbogen zugewiesen und vom Redaktor entsprechend eingeführt: Dyß ist die pruff wyse die ist frauwenlobs vnd regenbogen gemein daz iglicher dar ynn tichtet (Bl. 244r). In allen anderen Meisterliederhandschriften des 15. Jahrhunderts gehört die Briefweise ausschließlich dem Regenbogen-Korpus an. ${ }^{42}$

Stellt sich ein breit überliefertes Bar als kompiliert heraus, verlangt eine tiefergreifende Analyse, die Forschungsergebnisse zu den verwendeten Tönen und deren Tonautoren zu berücksichtigen. Entsprechend gehe ich an dieser Stelle nur kurz auf Bare wie Nr. $8^{43}$ und Nr. $12^{44}$ ein, da eine ausführlichere

40 Vgl. Johannes Rettelbach: Variation - Derivation - Imitation. Untersuchungen zu den Tönen der Sangspruchdichter und Meistersinger. Tübingen 1993 (Frühe Neuzeit 14), S. 44.

41 Rettelbach unterscheidet drei Typen der Abwandlung von Tönen: a) Variation: die Weiterentwicklung eines bestehenden Tonschemas, b) Derivation: die direkte Ableitung eines bestehenden Tonschemas, c) Imitation: die „kreative Fortführung einzelner innovativer Elemente in später komponierten Tönen“. Ebd., S. 2.

42 b Bll. 41v-42v, 43v-45r, 47r-53r; x Bll. 4r-5r; h Bll. 67r-72r, 77v-79r; w Bll. 68r-71r, $73 \mathrm{r}-89 \mathrm{r}, 140 \mathrm{v}-142 \mathrm{r}$.

$43{ }^{1}$ Marn/7/502d, 5 Str., a) k 449r-450r, b-c) Str. 1 u. 2 s. ${ }^{1}$ Marn/7/14a, 12a, e) k 468rv. Ausgabe nach y bei Eva Willms: Der Marner. Lieder und Sangsprüche aus dem 13. Jahrhundert und ihr Weiterleben im Meistersang. Einführung, Übersetzung, Stellenkommentar. Berlin 2008, S. 350-353.

${ }^{1} \mathrm{ReiBr} / 507 \mathrm{~b}$. 
Untersuchung den Forschungskontext des Tons ausgreifend einbeziehen müsste. Am Beispiel von Nr. $8{ }^{1}$ Marn/7/502d hat Jens Haustein gezeigt, wie die Genese kompilierter Bare plausibilisiert und eine wahrscheinliche Fassungschronologie rekonstruiert werden kann. In seiner Studie zu den Spruchstrophen des Marners analysiert er die fünf verschieden alten Strophen hinsichtlich ihrer Zusammenstellung, Assoziativität und Rekontextualisierung im meisterlichen Bar. ${ }^{45}$ Zwischen den beiden altbezeugten Strophen sieht Haustein die erste Assoziation gegeben, sie stehen in der ersten Fassung von $\mathrm{k}$ (Bll. 449r-450r) sowie in y als Strophen 1 und 2 des Fünferbars. ${ }^{46}$ Die zweite Aufzeichnung in k (Bll. 468rv) spart die Strophe 2 aus, was den Überlieferungszusammenhang der altbezeugten Strophen aufbricht. Daraus folgert Haustein, dass die Überlieferung des Strophenkomplexes im Cgm 1019 „eine gewisse Mittelstellung einzunehmen [scheint]. Hier ist zwar XV,12 [Str. 2, A. R.] noch erhalten, mußte aber seine exponierte Stellung als zweite Strophe mit der neuen Strophe 4 vertauschen. ${ }^{477}$ Rekonstruktionen wie diese stützen Hypothesen zu den Überlieferungsverhältnissen zwischen den Meisterliederhandschriften ab. Für das Bar in Marners Langem Ton im Cgm 1019 kann also vermutet werden, dass die Vorlage einer Fassung entspricht, die sich textgenetisch zwischen den beiden Fassungen der zwei betrachteten Aufzeichnungsschichten der Kolmarer Liederhandschrift befindet. In Ergänzung zu den kodikologischen Befunden untermauern überlieferungsgeschichtliche Einzelanalysen, dass k und y relativ zeitgleich entstanden sein dürften.

\section{Originär mehrstrophige Bareinheiten mit breiter Überlieferung}

Ersichtlich als mehrstrophige Bare entworfene Texte, die in überdurchschnittlich vielen Textzeugen tradiert wurden, bieten wenig signifikante Merkmale, mit deren Hilfe sich Handschriften zueinander in Beziehung setzen lassen. Im Cgm 1019 betrifft dies zwei Bare in Tönen Regenbogens (Nr. 18 ${ }^{1}$ Regb/4/518b, Nr. $22{ }^{1}$ Regb/2/17-18c) und das Bar Nr. 17 im Langen Ton des Mönchs von Salzburg $\left({ }^{1}\right.$ Mönch $\left./ 5 / 3 h^{48}\right)$. Einige Töne des Mönchs erscheinen von der volkssprachlichen Liedtradition geprägt, verfügen aber zugleich über

45 Haustein 1995 (Anm. 23), S. 218-226.

46 Das Blatt 450 in k wurde nachträglich eingeschoben. Der Argumentationsgang wird dadurch nicht beeinträchtigt, da es vornehmlich um die Einheit der beiden altbezeugten Strophen geht. Siehe RSM Bd. 4 (1988), S. 296.

47 Haustein 1995 (Anm. 23), S. 226.

48 Ausgabe bei Spechtler 1972 (Anm. 23), Nr. G 37. 
Gemeinsamkeiten mit anderen Liedtypen, die auf die Tradition lateinischer Liturgie zurückgehen. ${ }^{49}$ Viele Lieder des Mönchs von Salzburg besitzen eine lateinische Entsprechung und haben auch melodisch-metrisch „einen eindeutigen Bezug zur lateinischen gottesdienstlichen Liedkunst" ${ }^{\text {"50, }}$, wie Stefan Rosmer nachweist. Das zwölfmal und fast immer mit allen Strophen überlieferte Bar über die Eucharistie entstammt wahrscheinlich einer anderen als der meisterlichen Gesangstradition.

Das in Regenbogens Langem Ton abgefasste Bar ${ }^{1}$ Regb/4/518b kann als erzählendes Bar beschrieben werden. Dank dem Projekt zum Langen Ton Regenbogens wird der Text in Kürze in allen Fassungen vorliegen. Folglich sind dann optimale Bedingungen gegeben, die parallelen Versionen zu vergleichen. ${ }^{51}$ Ein weiteres Bar in einem Ton Regenbogens folgt mit Nr. 22. Das sechsstrophige Mühlenrätsel ${ }^{1} \mathrm{Regb} / 2 / 17-18 \mathrm{c}^{52}$ in Regenbogens Grauem Ton begegnet in k, aber auch im Cgm 351 (m), im Cpg 392 (h) und im Codex Wien 2856. ${ }^{53}$ In der Wahl des Rätselstellers Regenbogen und des Befragten Frauenlob spiegelt sich die Sprechhaltung ihrer im frühen Meistergesang gepflegten fiktionalen Opposition, die der Tradition des Sängerkriegs entspringt. ${ }^{54}$ Aufschluss über die ungewöhnliche

49 Rosmer 2019 (Anm. 39), S. 262.

50 Ebd., S. 241.

51 Das von der Universität Duisburg-Essen getragene DFG-Projekt ,Edition der in Regenbogens ,Langem Ton' überlieferten Lieder' unter der Leitung von Martin Schubert wurde kürzlich abgeschlossen. Vgl. https:/www.uni-due.de/germanistik/mediae/aktuell.php (29. 09. 2020). Das Nachfolgeprojekt ,Edition der in Regenbogens ,Brief- und Grundweise und ,Grauem Ton' überlieferten Lieder` wird die Erschließung der als ,echt' geltenden, unter dem Namen ,Regenbogen ‘ überlieferten Töne komplettieren. Nils Hansen widmet sich in seiner Dissertation den Regenbogen zugeschriebenen Tönen; vgl. seinen Beitrag in diesem Band (S. 217-243).

52 HMS Bd. 3, S. 347-349 (nach k).

53 Ausgaben bei Bernhard Joseph Docen: Kritische Beschreibung einer Sammlung alter Meistergesänge in einer HS. des XV. Jahrhunderts. In: Beyträge zur Geschichte und Literatur 9 (1807), S. 1128-1187, hier: S. 1164-1166; HMS Bd. 3, S. 347f.; Das deutsche Kirchenlied. Von der ältesten Zeit bis zum Anfang des XVII. Jahrhunderts. Mit Berücksichtigung der deutschen kirchlichen Liederdichtung im weiteren Sinne und der lateinischen von Hilarius bis Georg Fabricius und Wolfgang Ammonius. Hg. von Philipp Wackernagel. 5 Bde. Leipzig 1864-1877. Nachdr. Hildesheim 1964, hier Bd. 2, Nr. 419 (alle nach m).

54 Vgl. Burghart Wachinger: Sängerkrieg. Untersuchungen zur Spruchdichtung des 13. Jahrhunderts. München 1973 (MTU 42), S. 283. Siehe dazu auch Eva KiepeWillms: Geistliches Mühlenlied. In: ${ }^{2}$ VL 2 (1980), Sp. 1169-1172. 
Strophenzahl von sechs gibt die vom RSM angesetzte Portmanteauzählung 1718, die deren Einheit aus zwei Teilen hervorhebt: Rätsel und Lösung, jeweils als Dreierbar konstruiert, gliedert $\mathrm{k}$ durch die Überschriften Aber iij die mül ein rat vor Strophe eins und Aber iij der vff rat der mi̊l vor Strophe vier, während die Rubriken sie zugleich als zusammengehörige Einheit auszeichnen. ${ }^{55}$ Über die lange Zeit ihrer anhaltenden Verwendung hinweg wurden für viele Töne thematische Gebrauchstraditionen geprägt. Sie für einen Ton zu kennen, kann zumindest eruieren helfen, ob auch der Textautor sie gekannt haben könnte und damit seine Dichtung stärker in der Traditionalität hat verankern wollen. Eine übermäßig große Abweichung von den Gepflogenheiten wiederum setzt einen Akzent, der den thematischen Schwerpunkt verschiebt oder sogar konterkariert. Unter den Themen des Grauen Tons überwiegt deutlich das Geistliche, so dass die Tontradition mit der durch die Rätselform gattungstypologisch aufgerufenen Sängerkriegsthematik in ein Spannungsfeld tritt. Darüber hinaus steht die Verbindung von Frömmigkeit und Gelehrsamkeit für eine spezifisch meisterliche Strategie, mit der meisterschafft errungen werden will. ${ }^{56}$

\section{Bare in Tönen Frauenlobs}

Das Supplement zur Göttinger Frauenlob-Ausgabe ediert Sangsprüche in Tönen Frauenlobs, sofern deren Überlieferung vor 1460 einsetzt, weshalb die beiden fränkischen Handschriften im Grenzbereich des Editionskorpus zu liegen kommen. ${ }^{57}$ Weiterhin beschränken sich die Editionen auf acht Töne Frauenlobs, die als echt gelten, das RSM verzeichnet insgesamt 33 Töne, von denen immerhin zehn zu den echten gezählt werden. ${ }^{58}$ Aus diesen Gründen ist etwa Nr. ${ }^{1}$ Frau/14/1

55 Vgl. RSM Bd. 5 (1991), S. 68f.

56 Vgl. Burghart Wachinger: Rätsel, Frage und Allegorie im Mittelalter. In: Werk - Typ Situation. Studien zu poetologischen Bedingungen in der älteren deutschen Literatur. Hg. von Ingeborg Glier u. a. Stuttgart 1969, S. 137-160; Tomas Tomasek: Das deutsche Rätsel im Mittelalter. Tübingen 1994 (Hermaea N. F. 69); Franziska Wenzel: Rätsel, ,Stubenkrieg` und ,Sonrat‘. Geltungskämpfe nach dem Klingsor-Wolfram-Streit in der Kolmarer Liederhandschrift? In: Geltung der Literatur. Formen ihrer Autorisierung und Legitimierung im Mittelalter. Hg. von Beate Kellner u. a. Berlin 2005, S. 91-110; Tobias Bulang: wie ich die gotes tougen der werlte gar betiute. Geltungspotentiale aenigmatischen Sprechens in der Sangspruchdichtung. Ebd., S. 43-62; Tobias Bulang und Holger Runow: Allegorie und Verrätselung in der mittelhochdeutschen Spruchdichtung. In: Verrätselung und Sinnerzeugung in Spätmittelalter und Früher Neuzeit. Hg. von Beatrice Trînca. Würzburg 2016, S. 27-45.

57 GA-S Bd. 1, S. 7.

58 Vgl. RSM Bd. 3 (1986), S. 320. 
des Cgm 1019 im Supplement nicht abgedruckt. ${ }^{59}$ Nicht nur aus arbeitsökonomischen Beweggründen grenzt die Edition sinnvoll ein, sie bemüht sich erfolgreich, die ausufernde Spätüberlieferung zugunsten einer Teiledition der Textmassen einzuhegen. Die Kollation der Varianten wird mit dem Ziel vorgenommen, „eine kritische Überprüfung der Echtheitsentscheidungen zu ermöglichen, die der

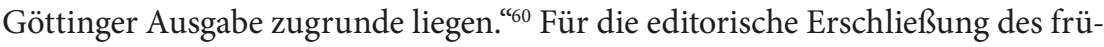
hen Meistergesangs leisten solche Editionsprinzipien einerseits eine begrüßenswerte Teiledition, andererseits schneidet die von ihnen angelegte Schablone quer durch das für den Meistergesang relevante Korpus. Denn zu den signifikanten Überlieferungsbedingungen frühen Meistergesangs gehört eine Substitution der personalen Tonautorinstanz durch ein fiktionales, traditionsbestimmtes Tonautorbild. Die Textautoren verbleiben bei einem großen Teil der Dichtung unbekannt. Auf eine Berücksichtigung aller Varianten zielende Editionen würden als Sangsprüche und Bare in Tönen Frauenlobs jegliche Strophen aufnehmen, die in einem Frauenlob zugeschriebenen Ton abgefasst wurden, unabhängig von seiner Echtheit. In solchen Fällen referierte die Ordnungsgröße entweder auf den fiktionalen Tonautor Frauenlob oder die technische Anerkennung der Formgleichheit von Baren, wie es das DFG-Projekt, Edition der in Regenbogens Langem Ton

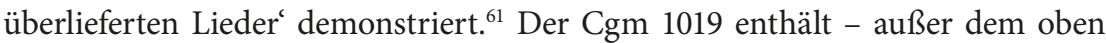
genannten ${ }^{1} \mathrm{Frau} / 14 / 1$ - mit ${ }^{1} \mathrm{Frau} / 5 / 501 \mathrm{c}$ (9) und ${ }^{1} \mathrm{Frau} / 7 / 500 \mathrm{~b}$ (7) zwei weitere Bare, die im Supplement der Göttinger Ausgabe ediert wurden. Die Herausgeber bewerten die Fassung des neunstrophigen Marienlobs ${ }^{1} \mathrm{Frau} / 5 / 501$ in y als minderwertig gegenüber der des Cgm 4997 und edieren den Text

nach der Kolmarer Hs. Der Cgm 1019 bietet eine Fassung, die teilweise in desolatem Zustand ist. Hier ist eine Umstellung von Form 1 auf Form 2 des Tonschemas vorgenommen. Einige Verse (z. B. 10. 73. 87. 115) sind freilich in der alten fünfhebigen Fassung erhalten geblieben. Eine sichere Beurteilung des metrischen Zustandes ist freilich wegen der unsorgfältigen Aufzeichnung nicht möglich. ${ }^{62}$

Haustein und Stackmann beobachten für die Schreiber von y Unsicherheiten im Umgang mit den Tonschemata besonders solcher Töne, die über mehr als

59 a) k 136r, b) Donaueschingen 120, S. 278, d) Str. 3 s. ${ }^{1}$ Albl/1a Str. 1. Ausgabe bei Runge 1965, Nr. 24 (nach b); Durward Saline Poynter: The Poetics of the Early Meistersänger as Reflected in the Kolmarer Handschrift (Cgm 4997). Diss. masch. Los Angeles 1965, S. 193-195; Die kleineren Liederdichter des 14. und 15. Jahrhunderts. 4 Bde. Hg. von Thomas Cramer. München 1977-1985, hier Bd. 1, S. 37f. (nach a und c).

60 GA-S Bd. 1, S. 7.

61 Siehe Anm. 51

62 GA-S Bd. 1, Nr. XIII, 208, S. 201-206, hier S. 201. 
eine Form verfügen. Zudem stellen sie mangelnde Sorgfalt bei der Aufzeichnung fest. Zwar begegnen im Cgm 1019 Bare, die wenig gewissenhaft notiert wurden, sowie Ungereimtheiten in den Tonschemata. Anhand der Editionsbeispiele im Anhang möchte ich aber zeigen, dass sich die Texte nicht darin erschöpfen, dass sie eine unsaubere, mangelhafte Version der Parallelüberlieferung in $\mathrm{k}$ darstellen - eine Auffassung, mit der letztlich ihre Marginalisierung innerhalb autorzentrierter Editionen gerechtfertigt wird.

Das siebenstrophiges Bar ${ }^{1} \mathrm{Frau} / 7 / 500$ im Vergessenen Ton erfährt eine andere Textherstellung im Supplement. ${ }^{63}$ Elisabeth Wunderle hat den Text nach dem Cpg 680 herausgegeben, lehnte ihn dabei aber sehr eng an die lediglich fünfstrophige Fassung von $\mathrm{k}$ an, weil sie diese für ursprünglicher hielt. ${ }^{64}$ Da Haustein und Stackmann sich an dieser Stelle nicht eindeutig auf $\mathrm{k}$ als ursprünglichste Version festlegen wollten, bieten sie das Bar, das vom Turmbau zu Babel handelt, in der Fassung von y dar, wenngleich „an einer Reihe von Stellen mit Hilfe der Parallelüberlieferung, an einzelnen Stellen auch durch Konjektur gebessert werden" musste. ${ }^{65}$ Als lectio difficilior betrachten sie im Zweifelsfall den Text der Kolmarer Liederhandschrift. Es sollte erwogen werden, ob zukünftige Editionen des frühen Meistergesangs nicht das Dokument der einzelnen Meisterliederhandschrift ernster nehmen und Texte in Tönen namhafter alter Meister losgelöst von deren rekonstruiertem Stil herstellen sollten.

\section{Nur in $k$ und $y$ überlieferte Bare}

Von den drei Baren Nr. $9^{1}$ Ehrb/2/2 (3 Str.), Nr. $13{ }^{1}$ KonrW/6/509 (3 Str.) und Nr. 20 ${ }^{1}$ Wartb/2/511 (3 Str.), die nur in der Kolmarer Liederhandschrift und im Cgm 1019 überliefert sind, gebe ich einen synoptischen Abdruck (vgl. Anhang). ${ }^{66}$ Blickt man der Reihe nach auf die Parallelüberlieferungen, stellt man zunächst fest, dass das Bar in Ehrenbotes Schallweise ('Ehrb/2/2) im Cgm 1019 als küpffer don ernpot (Bl. 8r) überschrieben wurde. Erst in der Überlieferung des 15. Jahrhunderts finden sich Bare in Tönen des Ehrenboten mit Autornennung. ${ }^{67}$ Der Spiegelton

63 Ebd., Nr. X, 205, S. 261-265.

64 Elisabeth Wunderle: Die Sammlung von Meisterliedern in der Heidelberger Handschrift cpg 680. Edition und Kommentar. Göppingen 1993 (GAG 584), S. 1-8 und 311-313.

65 GA-S 1, Nr. X, 205, S. 262.

66 Die Texte wurden behutsam normalisiert. Großgeschrieben sind Eigennamen, Nomina sacra und die Anfänge der Stollen und des Abgesangs, eine moderne Interpunktion wurde hinzugefügt. $\mathrm{u} / \mathrm{v} / \mathrm{w}$ sowie $\mathrm{i} / \mathrm{j}$ wurden nach Lautwert normalisiert. Eingriffe in den Text sind ausgewiesen und im Apparat erläutert.

67 Eine namenlose Strophe in der Spiegelweise steht bereits in der Niederrheinischen Liederhs. Vgl. Burghart Wachinger: Ehrenbote. In: ${ }^{2}$ VL 2 (1980), Sp. 387-389, hier 387. 
Ehrenbotes etwa ist verwandt mit Reinmars von Zweter Frau-Ehren-Ton, die Schallweise Ehrenbotes weicht nur marginal vom Ton II des Kanzlers ab. ${ }^{68}$ Im Fall des mehrheitlich spätüberlieferten Ehrenboten, über den wir so gut wie nichts wissen, müssen tonschematische Zuordnungsprobleme somit nicht überraschen. ${ }^{69}$ Umso erstaunlicher erscheint die metrische Sauberkeit des Ehrenbote-Bars im Cgm 1019, das sich nur unmerklich von der Version in der Kolmarer Liederhandschrift unterscheidet. Lediglich in der dritten Strophe (III,4) bleibt ein Reim ungebunden. Ausgenommen einige phonemische Abweichungen (z. B. y > ei) stehen sich die Versionen sehr nahe.

Der in Form 2 der Morgenweise verfasste Marienpreis ${ }^{1}$ KonrW/6/509 trägt die Züge einer im 14. und 15. Jahrhundert weit verbreiteten Form von Marienfrömmigkeit. Sie zeichnet sich durch die formelhafte Addition bestimmter Elemente aus, die seit dem 12. Jahrhundert üblich werden, wie Eva Rothenberger ausführt, unter anderem die Barmherzigkeit der Gottesmutter, ihre Gnadenvermittlung und ihre Beschreibung als Himmelskönigin. ${ }^{70}$ Maria erscheint als rosz in des himels taue (y II,2), das Ich des Textes appelliert an ihre Barmherzigkeit (y/k, II,7). Die Strophen hängen zwar thematisch, aber nicht erzähllogisch zusammen, denn die Verkündigung wird erst in der dritten Strophe erwähnt, nachdem in der ersten schon von Marias schmerzloser Niederkunft berichtet wurde. Auch wenn maßgeblich die Trinität verhandelt wird, die in $\mathrm{k}$ mit in die Rubrik aufgenommen wurde (Von der dryvaltikeit in $\sim$, Bl. 516v), gehört das Bar wohl nicht in die Reihe der Texte, die „zum litaneiartigen Ringen um

68 Horst Brunner: Formgeschichte der Sangspruchdichtung des 12. bis 15. Jahrhunderts. Wiesbaden 2013 (Imagines Medii Aevi 34), S. 84f.

69 Siehe die Schilderung der auftretenden Zuschreibungen bei Wachinger 1980 (Anm. 67).

70 Vgl. Eva Rothenberger: Die Gottesmutter Maria an exponierter Stelle im Meistergesang. Ein thematischer Querschnitt am Beispiel von Regenbogens ,Langem Ton'. In: Editionen deutscher Texte des Mittelalters - Aktuelle Projekte. Beiträge des Festkolloquiums zum 80. Geburtstag von Rudolf Bentzinger am 22. August 2016 Erfurt 2019 (Akademie gemeinnütziger Schriften zu Erfurt. Sonderschriften 50), S. 161-188, hier S. 168. Zum Marienlob in Sangspruchdichtung und Meistergesang s. außerdem Mary Juliana Schroeder: Mary-verse in Meistergesang. Washington 1943, Alwine Edelmann-Ginkel: Das Loblied auf Maria im Meistergesang. Versuch einer Typendifferenzierung auf der Basis spätmittelalterlicher Bedingtheiten und Wandlungsprozesse. Göppingen 1978 (GAG 248), Annette Gerok-Reiter: Maria als Reflexionsfigur zwischen Religion, Minnediskurs und Ästhetik. Semantische Traversalen im Werk Frauenlobs. In: Religiöses Wissen im vormodernen Europa. Schöpfung - Mutterschaft - Passion. Hg. von Steffen Patzold et al. Paderborn 2019, S. 321-351, Stefan Rosmer: Religiöse Unterweisung - Gebet - Gottes- und Marienpreis. In: Klein et al. 2019 (Anm. 1), S. 205-223. 
das theologische Paradoxon der ,Einheit in der Dreiheit “ "71 neigen. Die Dreifaltigkeit begleitet das Marienlob von Strophe zu Strophe, es entsteht dabei aber nicht der Eindruck, dass der Verfasser allzu sehr bemüht sei, sie verständlich zu erklären: Got der vater und Got der son und Got der heiligg geist / ist ein war Got und lassen sich zerdryen, / die hochgelobten fryen / sint ein gantz war volleist ( $\mathrm{k}$ II,13-16). Die Texte von k und y unterscheiden sich aufgrund von Tonschemabrechungen (y II,14) und nachlässiger Aufzeichnung auf Seiten von y. Ins Auge fällt das reduzierte Vorkommen von Jesus Christus in y gegenüber der Fassung von k. Dort wird er in jeder Strophe einmal genannt, während die Version y ihn nur in Str. 3 schlicht als dein kind (III,10) bezeichnet, wenn Maria adressiert wird, und statt Jesus wird in Strophe I Johannes um sein Geleit gebeten.

Der Ton II des Wartburgkriegs gilt als erster Ton, der einen dritten Stollen als Teil des Abgesangs aufweist. ${ }^{72}$ Brunner macht darauf aufmerksam, dass er „in jüngerer Überlieferung als Klingsors Schwarzer Ton bezeichnet und von den Meistersingern rezipiert wurde“ ${ }^{73}$ Chronologisch betrachtet stellt der Cgm 1019 einen Schnittpunkt dieser Tradierungsgewohnheiten dar, denn obgleich er nicht jünger, sondern wohl genauso alt ist wie der Cgm 4997, überschreibt er das Bar ${ }^{1}$ Wartb/2/511 mit In dem schwartzen don clingsar (Bl. 23v), während es in $\mathrm{k}$ im Kontext des Wartburgkriegs unter der Rubrik Ein anders von syben kinsten (Bl. 697vb) aufgezeichnet wurde. In y begegnet der Ton losgelöst von einer direkten Rezeption des Wartburgkriegs, vielleicht gänzlich ohne Kenntnis desselben. ${ }^{74}$ Die Textgestalt indes nimmt sich ähnlich aus wie in $\mathrm{k}$, zweimal weicht y vom Tonschema ab, einmal in Strophe III in den Versen 4-6:

y

Swolt ich machen worter clug, het ich die kunst retorica, das wer mein sanck gedeylt, die wolt ich

[hoffelichen ferben. $\mathrm{k}$

So wolt ich machen worten tig. kund ich die kunst rethorika, wer mir gefig gedichtes, wolt ich hofelichen werden.

71 Vgl. Rothenberger 2019 (Anm. 70), S. 162. Die Trinität in der Dichtung des 14. und 15. Jahrhunderts behandelt Peter Kern: Trinität, Maria, Inkarnation. Berlin 1971 (PhStQ 55), S. 94-108.

72 Vgl. Brunner 2013 (Anm. 68), S. 57.

73 Ebd.

74 Jan Hallmann zufolge „finden sich keine Hinweise, dass die meisterlichen Lieddichter und Meistersänger unmittelbar mit den Wartburgkrieg-Dichtungen vertraut waren oder auch nur rudimentäre inhaltliche Kenntnisse von ihnen besaßen.“ 
Der vom Tonschema vorgesehene Endreim der Verse vier und fünf kommt im Cgm 1019 nicht zustande. War der Reim tůg - gefüg bereits in der Vorlage enthalten, konnte womöglich der Schreiber von y damit nichts anfangen. Ein vergleichbarer Fall liegt am Beginn der dritten Strophe vor, wo die Kolmarer Liederhandschrift den septem artes die Alchemie mit an die Hand gibt, y hingegen diese Kunst nicht mit aufzählt (V. 1f.):

$\mathrm{y}$

Kont ich erginnen, merckt mich, an kupfer wolt ich goldesz werden also reich.

\section{$\mathrm{k}$} Kund ich mit alchemye mich, von kupfer wolt ich goldes werden also rich.

Judith Lange weist auf die bereits von Poynter bemerkte erhöhte Anzahl von Künsten hin, die in der Kolmarer Liederhandschrift im Zusammenhang mit den septem artes liberales genannt werden, wie alchemye und nicromancie. ${ }^{75}$ Innerhalb des fiktionalen Sängerwettstreits, wie ihn der Wartburgkrieg inszeniert, erfüllt die Aufzählung der sieben Künste die Funktion, die Gelehrsamkeit des Sängers zu unterstreichen. Die Vorstellung, weniger edle Rohstoffe in Gold zu verwandeln, geht auf alchemistische Praktiken zurück. ${ }^{76}$ Aus Kupfer Gold gewinnen zu wollen, wenn man in alchemistischen Fähigkeiten beschlagen wäre, ergibt demnach Sinn. In der Fassung y gerät der Zusammenhang

Jan Hallmann: Studien zum mittelhochdeutschen Wartburgkrieg. Literaturgeschichtliche Stellung - Überlieferung - Rezeptionsgeschichte. Mit einer Edition der Wartburgkrieg-Texte. Berlin, Boston 2015, S. 295. Anders Wachinger 1973 (Anm. 54), S. XI u. Brunner, Horst: Dichter ohne Werk. Zu einer überlieferungsbedingten Grenze mittelalterlicher Literaturgeschichte (Mit einem Textanhang: Die Dichterkataloge des Konrad Nachtigall, des Valentin Voigt und des Hans Folz). In: Überlieferungsgeschichtliche Editionen und Studien zur deutschen Literatur des Mittelalters. Kurt Ruh zum 75. Geburtstag. Hg. von Konrad Kunze et al. Tübingen 1989 (Würzburger Forschungen 31), S. 1-31, hier S. 8.

75 Vgl. Judith Lange: Wettstreit um die rehte kunst - Fürwurf und Straflied im Meistergesang des 15. Jahrhunderts. In: Editionen deutscher Texte des Mittelalters Aktuelle Projekte. Beiträge des Festkolloquiums zum 80. Geburtstag von Rudolf Bentzinger am 22. August 2016 Erfurt 2019 (Akademie gemeinnütziger Schriften zu Erfurt. Sonderschriften 50), S. 113-137, hier S. 118, Anm. 22; Poynter 1965 (Anm. 59), S. 40.

76 Seit dem 14. und zu Beginn des 15. Jahrhunderts sind volkssprachliche Traktate verbürgt, wie etwa die ,Alchymey teutczsch ' (1426), durch die alchemistisches Wissen ohne Lateinkenntnisse erworben werden konnte. Vgl. Joachim Telle: Alchemie. In: Lexikon des Mittelalters. Bd. 1. Hg. von Robert Auty u. a. München, Zürich 1980, Sp. 329-342, hier Sp. 333. 
zwischen Kupfer und Gold weniger nachvollziehbar, weil die Alchemie nicht erwähnt und der Gewinn von Kupfer und Gold davon abhängig gemacht wird, ob man den Mund recht weit aufsperren könne, was sich höchstens als Metapher für den in Münzen ausgezahlten Lohn eines Berufsmeisters deuten ließe.

Kurz darauf folgt in k der Reim tiog - gefig, der unterschiedliche Schwierigkeiten bereitet. Das einzig infrage kommende Wort, das hinter tůg gemäß der Form, Bedeutung und Satzstellung vermutet werden kann, ist touc von tugen. Angesichts der fehlenden adjektivischen Endung könnte es sich um ein postnominales Adjektiv handeln, mit einer Apokope des $-e$ (,so wollte ich angemessene Worte machen'). In diesem Fall wäre es aufgrund des Diphthongsturzes für einen Schreiber unter Umständen schwierig gewesen, die Wortbedeutung zu erfassen. Einerseits kann die Schreibung dialektal zu erklären sein, andererseits durch eine Angleichung an das Reimwort gefig. Womöglich war die Konstruktion nicht (mehr) besonders gängig, was erklären würde, warum in der Parallelüberlieferung das leichter verständliche cluog steht. Schlussendlich geben Spekulationen darüber aber nur bedingt Aufschluss, wie eine Vorlage ausgesehen haben mag, und sie tun dies nur hinsichtlich eines rein schriftlichen Tradierungsprozesses, der für frühen Meistergesang nicht angenommen werden sollte. ${ }^{77}$

Die zweite Tonschemabrechung liegt in Strophe I, Vers 7 vor. Wo er in k lautet: $\mathrm{Ob}$ ich mich sum an meister kunst an worten und an wysen, führt y an derselben Stelle: Ob ich mich seum an meinster gesang mit worten oder weysheit. Das Versende weysheit statt weysen reimt nun nicht mehr mit speysen. Interessanter noch wirkt eine andere Variante in dem Vers. Überall dort, wo k von meisterkunst oder meisterschafft spricht, ist in y von meinstergesang die Rede. Die Eingangsverse des Bars evozieren zudem unterschiedliche Bilder eines Aufführungskontexts (V. 1-3).

y

Got grusz euch all ir gesellen gut, uff meinstergesang so stet mir sin und auch [mein mut, das helfet mir geschicklich pflegen. $\mathrm{k}$

Nu grüsz ich alle senger güt, mit meynsterschafft darnach mir stet sin [unde mít, daz helffen mir geselliclichen pflegen.

Die Version von y bezieht Gott in den Gruß der gesellen ein, beide sind der Version von k unbekannt. Anstatt gesellen werden dort senger angesprochen, man möchte keinen meistergesang singen, sondern meisterschafft ermitteln. Der abweichende Vokabelgebrauch müsste allerdings großflächiger untersucht

77 Zum aktuellen Stand der Forschung vgl. Michael Baldzuhn: Der Sangspruch im 14. und 15. Jahrhundert. In: Klein et al. 2019 (Anm. 1), S. 485-500. 
werden, um daraus belastbare Schlüsse zu ziehen. Auf der sprachlichen Ebene des Textes spricht trotzdem einiges dafür, dass y in einem anderen Kontext entstand als k, das zeigen auch die kodikologischen Fakten und die einfache, heftartige Gestaltung. Um die Kollation der parallel überlieferten Strophen um eine weitere Perspektive von y als Meisterliederhandschrift des täglichen Gebrauchs zu erweitern, wird abschließend ihr Sondergut in den Blick genommen.

\section{Das Sondergut des Cgm 1019}

Sondergut y

\begin{tabular}{|c|c|c|c|c|c|c|}
\hline Nr. & RSM-Sigle & Bll. & Ton & Str. & Thema & Edition \\
\hline 2. & ${ }^{1} \mathrm{Hardr} / 3 / 19^{78}$ & $1 v-2 r$ & $\begin{array}{l}\text { Harder, } \\
\text { Sanfter Ton }\end{array}$ & 3 & Kunst, Meisterschaft & - \\
\hline 3. & ${ }^{1} \mathrm{Hardr} / 3 / 20$ & $2 r-3 r$ & $\begin{array}{l}\text { Harder, } \\
\text { Sanfter Ton }\end{array}$ & 3 & Straflied & s. Anhang \\
\hline 5. & ${ }^{1}$ WaltV/7/501 & $4 \mathrm{rv}$ & $\begin{array}{l}\text { Walther, Wendel- } \\
\text { weise }\end{array}$ & 3 & Memento mori & - \\
\hline 7. & ${ }^{1} \operatorname{Hardr} / 3 / 21$ & $5 v-6 v$ & $\begin{array}{l}\text { Harder, Sanfter } \\
\text { Ton }\end{array}$ & 5 & $\begin{array}{l}\text { Schwanklegende } \\
\text { von St. Loy }\end{array}$ & - \\
\hline 10. & ${ }^{1} \mathrm{Frau} / 33 / 8$ & $9 \mathrm{r}-10 \mathrm{r}$ & $\begin{array}{l}\text { Frauenlob, Zug- } \\
\text { weise }\end{array}$ & 5 & $\begin{array}{l}\text { Aristoteles und } \\
\text { Phyllis }\end{array}$ & - \\
\hline 11. & ${ }^{1}$ Suchs/22 & $10 \mathrm{r}-11 \mathrm{r}$ & Suchensinn & 5 & Frauenpreis & $\begin{array}{l}\text { Cramer Bd. 3, } \\
\text { S. } 337-339 .\end{array}$ \\
\hline 16. & ${ }^{1} \operatorname{Regb} / 4 / 616$ & $15 \mathrm{v}-17 \mathrm{r}$ & $\begin{array}{l}\text { Regenbogen, } \\
\text { Langer Ton }\end{array}$ & 3 & Rätselallegorie & $\begin{array}{l}\text { Rothenberger } \\
2019, \text { S. } 183- \\
186 .\end{array}$ \\
\hline
\end{tabular}

Wie erwähnt, zeigt das Sondergut ein ausnehmend weltliches Profil. Nach der Ei-Allegorie in Frauenlobs Froschweise folgen zu Beginn des ersten Faszikels zwei Dreierbare in Harders Sanftem Ton. Während das Memento mori in Walthers Wendelweise und der Frauenpreis Suchensinns eher topische Register bedienen, handelt es sich bei der Schwanklegende von St. Loy und der Geschichte von Aristoteles und Phyllis um erzählende Bare. ${ }^{79}$ Der überwiegende Teil des Sonderguts entfällt auf den ersten Faszikel der Handschrift, der sechs der sieben Unika trägt.

78 Edition bei Recker 2021 (Anm. 9), S. 53f.

79 Zum erzählenden Bar im frühen Meistergesang vgl. Gabriel Viehhauser: Treueproben in Sangspruchtönen. Zur Ausprägung des weltlichen Erzähllieds am Übergang der Gattung zur Mehrstrophigkeit. In: JOWG 21 (2016/17), S. 335-348. 
Ausgeprägte Spuren eines meisterlichen Diskurses darum, was Meisterschaft sei und wem sie gebühre, treten in den beiden Baren in Harders Sanftem Ton zutage. Die in ${ }^{1} \mathrm{Hardr} / 3 / 19$ aufgeworfene Reflexions- und Verhandlungsebene exponiert den Meisterbegriff, der diskursiv aufgeladen, jedoch nicht terminologisch stabilisiert wird. Das heißt, dass in der Inszenierung von Konkurrenzsituationen, beispielsweise mit Hilfe von Überbietungsrhetorik und Verrätselung, der größere Meister ermittelt werden kann, aber keine unumstößliche Definition dessen veranschlagt wird, was ein Meister sei. ${ }^{80}$ Stattdessen wird der Meisterbegriff immer wieder neu ausgehandelt. Der einen Gesangsgegner spöttisch abstrafende Bartyp ${ }^{81}$ des Straflieds ( ${ }^{1} \mathrm{Hardr} / 3 / 20$, s. Anhang) verstetigt „die Prinzipien des Agonalen und des Dialogischen“82, als die sich die wettkämpferischen Tendenzen der vorausgegangenen Spruchdichtung beschreiben lassen, zu einem literarischen Typus. Fürwurf und Straflied treten als dialogisches Paar in Erscheinung, das auf Textgenese hin angelegt ist. Zu jedem Zeitpunkt in der außerliterarischen Aufführungspraxis realisierbar, bestreiten sie gleichzeitig eine literarische Existenz in den Handschriften. Die Verstetigung solcher spezifisch meisterlicher Bartypen an sich ist als poetologisches Merkmal zu bezeichnen. Aus ihnen spricht ein Bewusstsein für literarische Formen, die fortwährend eingesetzt werden und deren Beherrschung perfektioniert wird.

\section{Fazit}

Die Codices Cgm 1018 und Cgm 1019 bestechen durch eine große Menge an parallelen Überlieferungen zum Cgm 4997 bei ähnlicher Datierung. Mit 16

80 Diese Form der Meisterschaft beschreiben Karl Stackmann: Der Spruchdichter Heinrich von Mügeln. Vorstudien zur Erkenntnis seiner Individualität. Heidelberg 1958 (Probleme der Dichtung 3), S. 69-173 u. Burghart Wachinger: Sangspruchdichtung und frühe Meisterliedkunst in der Literaturgeschichte. In: Ders.: Lieder und Liederbücher. Gesammelte Aufsätze zur mittelhochdeutschen Lyrik. Berlin 2011, S. 231-243, hier S. 243.

81 Die Forschungsgeschichte des frühen Meistergesangs brachte eine problematische Vermengung von historischen Selbstbezeichnungen und wissenschaftlicher Terminologie hervor, betreffend etwa Begriffe wie ,Singschule', ,Schulkunst' oder ,Lied ' Um eine konsistente wissenschaftliche Terminologie und Typologie für den frühen Meistergesang zu entwickeln und sich von der anhaltend verwendeten Eigenbezeichnung liet für ,Strophe' bei den Meistersingern abzugrenzen, spreche ich von ,Bartypen' und nicht von ,Liedtypen'.

82 Beate Kellner und Peter Strohschneider: Poetik des Krieges. Eine Skizze zum Wartburgkrieg-Komplex. In: Das fremde Schöne. Dimensionen des Ästhetischen in der Literatur des Mittelalters. Hg. von Manuel Braun und Christopher Young. Berlin, New York 2007 (Trends in Medieval Philology 12), S. 335-356, hier S. 355. 
parallel überlieferten Baren (von im Ganzen 36 Texteinheiten) stünde dem Cgm 1018 eine gründliche Konkordanzanalyse genauso zu Gebote wie dem betrachteten Cgm 1019. Von im Ganzen 21 Baren zeigen die zwölf83 Paralleltexte der kleinen fränkischen Handschrift einige Ähnlichkeiten, aber auch Unterschiede zur Kolmarer Handschrift.

Die kompilierten, breit bezeugten Bare der Sammelhandschrift können darauf hinweisen, dass ein Kontakt mit der Schicht der sich wandelnden, strophensammelnden meisterlichen Dichtung bestand. Bestätigen sie einerseits die Partizipation an diesem Prozess, erklärt sich diese Teilhabe andererseits allein aus der Datierung und Lokalisierung der Handschrift. Sich um 1450 eine Meisterliederhandschrift im südfränkischen Raum vorzustellen, in deren Baren keine Wanderungsbewegungen migrierender Strophen vorliegen, fällt schwer. Doch auch in den eher bewahrenden oder einem theoretischen Sammelinteresse geschuldeten Handschriften tauchen kompilierte Bare auf, zumal wenn sie gemessen an ihrer Überlieferung beliebt waren, weshalb Entstehungszeit und -ort für die Einschätzung des Cgm 1019 stärker ins Gewicht fallen als die Tradierung breit überlieferter, kompilierter Bare. Originär mehrstrophige Bare wie der Überlieferungszeuge von G 37 des Mönchs von Salzburg vermögen wenig auszusagen über charakteristische Gesichtspunkte einer Handschrift. Zumindest ansatzweise von meisterlichen Bezugspunkten zeugt das Mühlenrätsel in Regenbogens Grauem Ton.

Das Sondergut spricht dagegen deutlicher für eine Verbindung zu meistersingerlicher Kunstausübung. Darin findet sich mit ${ }^{1} \mathrm{Hardr} / 3 / 19$ und ${ }^{1} \mathrm{Hardr} / 3 /$ 20 Fürwurf und Straflied, die unmittelbar aufeinander folgen, eine Paarung, die in k ebenfalls auftaucht und dort sogar gelegentlich in einer gemeinsamen Rubrik: Disz sin furwurff und straff lied ( ${ }^{1} \mathrm{Regb} / 1 / 522, \mathrm{k}$ Bl. 263v). Ihre Überschriften verkörpern eine für die Erschließung des frühen Meistergesangs wichtige kodikologische Besonderheit der Kolmarer Liederhandschrift. Sie spiegeln Literarisierungsprozesse wider, in deren Verlauf Sprechhaltungen bestimmter Bare zu Bartypen verstetigt werden, wie etwa der Fürwurf oder das Straflied, deren schematische Bestandteile (Gruß der Anwesenden, Betonung der eigenen Fertigkeiten, Aufforderung zum Gesang an den Konkurrenten bzw. Spott über seinen schlechten Auftritt) es erlauben, sie wiederholt anzuwenden und unterschiedlich zu füllen. Während die meisten Handschriften zuvor lediglich den Tonnamen und den Tonautor nennen, nimmt $\mathrm{k}$ die typologischen Bezeichnungen regelmäßig in die Rubriken auf: ${ }^{84}$ Ein furwurff in dysem ton ( $\left.{ }^{1} \mathrm{Regb} / 1 / 549, \mathrm{k} 305 \mathrm{vb}\right)$, Ein ander straffliet $\left({ }^{1} \mathrm{KonnW} / 7 / 510 \mathrm{a}, \mathrm{k}\right.$

83 Effektiv elf Bare, da ${ }^{1}$ Regb/2/5c unvollständig und nicht Teil der Analyse ist.

84 Vgl. Petzsch 1978 (Anm. 15), S. 246-272. 
538va). Die Kolmarer Liederhandschrift setzt neue Maßstäbe in den Beischriften, die im Zusammenhang mit dem umfassenden Sammelanspruch und der Orientierungsfunktion für den Leser gesehen werden können. ${ }^{85}$ Ihre Funktion war wohl in kleineren Faszikeln und Gebrauchshandschriften wie y, die enger an die Praxis angeschlossen waren, für alle Teilhabenden unmittelbar verständlich, wodurch eine Bezeichnung von Baren als Fürwurf oder Straflied in der Niederschrift niemandem in den Sinn kam, obwohl das Verständnis für den Typus bereits ausgeprägt war. Dass sie im Cgm 1019 als zusammengehörige Bartypen wahrgenommen wurden, ergibt sich aus ihrer gemeinsamen Aufzeichnung in der korrekten zeitlichen Abfolge - zuerst der Fürwurf, dann die Antwort in Form eines Straflieds - sowie aus der Tatsache, dass sie in demselben Ton abgefasst wurden. Ihre Überlieferung im Cgm 1019 bestätigt letztlich, dass dieser Codex auf einer mit k vergleichbaren Entwicklungsstufe steht, wenn es um ein Bewusstsein für die poetologischen Formen der eigenen Dichtung geht.

Die Vergleiche von parallel in $\mathrm{k}$ und y überlieferten Bare erlauben den Schluss, dass für y Vorlagen mit Textfassungen zur Verfügung standen, die sich in der mittleren Entstehungsphase der Kolmarer Liederhandschrift positionieren lassen. Hausteins Analyse des Marnerbars ${ }^{1}$ Marn/7/502 liefert eine glaubhafte Erklärung für die Entwicklungsstufen der verschiedenen Fassungen, der zufolge y zwischen den Fassungen k1 (Bll. 449r-450r) und k2 (Bl. 468rv) steht. Als Ausgangspunkt für weitere Untersuchungen zum Cgm 1019 könnte die Frage nach den Veränderungen von Tonschemata dienen, denn obwohl einige Stellen der Handschrift deutlich von Unsicherheiten oder Unaufmerksamkeiten seitens der Schreiber zeugen, kann zu diesem Zeitpunkt nicht mit Sicherheit gesagt werden, welche Fehler vielleicht damit zusammenhängen, dass für einen Ton mehrere Schemata bestanden (oder im Entstehen begriffen waren), Töne verwechselt wurden oder das Prinzip des Wägens mit dem des Zählens von Silben vermengt wurde. ${ }^{86}$ Der Umstand, dass der Ton II des Wartburgkriegs in dieser Handschrift bereits wie in der jüngeren Überlieferung als Schwarzer Ton

85 Vgl. Baldzuhn 2002 (Anm. 15), S. 119-126. Zum sammelnden Kompendiencharakter von k vgl. Kornrumpf 2008 (Anm. 16), S. 257-274.

86 Silben im Vers wurden ab etwa der zweiten Hälfte des 14. Jahrhunderts nicht mehr streng nach metrischen Prinzipien gewägt, sondern gezählt. Vgl. Heinrich Husmann: Das Prinzip der Silbenzählung im Lied des zentralen Mittelalters. In: Die Musikforschung 6 (1953), S. 8-23; Brunner 1975 (Anm. 5), S. 217; Christoph März: Der silben zall, der chunsten grunt. Die gezählte Silbe in Sangspruch und Meistergesang. In: ZfdPh 119 (2000), Sonderheft, S. 73-84. 
Klingsors geführt wird, rückt sie gemeinsam mit dem in diesem Ton überlieferten Bar in einen Kontext meisterlicher Gesangspraxis, die den Wartburg-Krieg vielleicht nicht einmal mehr kannte.

Wie stark zudem die Editionspraxis von Baren in Tönen Frauenlobs durch die Frauenlob-Forschung determiniert ist, offenbart der Blick auf die editorische Handhabung der Textzeugen aus dem Cgm 1019 im Supplement zur Göttinger Ausgabe. Die Handschrift y präsentiert für das Bar ${ }^{1} \mathrm{Frau} / 5 / 501$ „eine Fassung, die teilweise in desolatem Zustand ${ }^{\text {“87 }}$ ist. Es soll nicht bestritten werden, dass Textherstellungsprozesse aus Meisterliederhandschriften eine schwierige Angelegenheit darstellen, in deren Verlauf sich EditorInnen mit unleserlichen, fehlerbehafteten und oft unverständlichen Textzeugen konfrontiert sehen, die es nahezu unmöglich machen, ohne Konjekturen auszukommen. Doch eine Aussage wie die obige setzt einen positiven Idealzustand voraus, der nicht erreicht wird. Zum Zweck einer ergebnisoffenen Erschließung von Handschriften wünscht man sich doch, dass ihre Textzeugen zukünftig nicht mehr als beklagenswert gelten müssen. Nicht nur, aber auch haben etablierte Editionspraktiken dazu beigetragen, dass kleinere Meisterliedersammlungen zwar zur notwendigen Kollation und für einzelne Textzeugen herangezogen, selten jedoch als wertvolle Forschungsobjekte an sich wahrgenommen werden.

Trotz der Vorsicht, die bei der Interpretation aller Einzelhinweise und Überlieferungsgegebenheiten geboten ist, geht man nicht zu weit, wenn man dem Cgm 1019 ein meisterliches Profil unterstellt. Die Datierung, die Verortung in Franken, die weltliche inhaltliche Ausrichtung, das spezifisch meistersingerliche Sondergut - all diese Merkmale machen ein Entstehungsumfeld, in dem meisterlicher Gesang produktiv ausgeübt wurde, plausibel. Die Tradierung bestimmter Varianten von Baren, die ebenfalls in der Kolmarer Liederhandschrift überliefert sind, spricht für anteilig gemeinsame Vorlagen. Mit der Baseler Liederhandschrift verbindet y, dass beide das gleiche Reimpaargedicht überliefern. Vor diesem Hintergrund kann festgehalten werden, dass der Cgm 1019 mit den frühesten Meisterliederhandschriften der rheinisch-schwäbischen Untergruppe bis hin zur Kolmarer Liederhandschrift eng verknüpft ist. Um die Ausübung von Meistergesang um die Mitte des 15. Jahrhunderts zu erforschen, dürfte dieser kleine Band auch zukünftig interessant sein.

87 GA-S 1, Nr. XIII, 208, S. 201-206, hier S. 201. 
${ }^{1}$ KonrW/6/509 (Morgenweise, Form 2)

y $12^{\text {rv }}$

Im morgen donn

I

$\mathrm{Ich}^{88}$ weisz drey furst, die sein gar geleiche

dem armen als dem reichen

nach der gerechtigkeit.

und die sind hoch geporen,

5 ich hann mirs auszerkornn.

Johannes, her, nun gib uns dein geleite.

Maria, magt, du uber gülter sternn,

pey dir so wusch $^{89}$ der kernn

in der dryfaltickeit,

10 dein lob ist hoch gemeszen,

sye sind pey dir geseszen,

die fursten rein sind also schon bereite.

Maria, müter hoch gepornn, hab uns in deiner hut.

des pit ich dich, vil edelle maget reine,

15 pit fur die welt gemeine

durch deines kindes plut,

den trugst du unter deinem herczen,

gepert in ane smerczen.

Got, fater, sun, pit für die cristenheite.

II

Maria, ${ }^{90}$ müter, hoch gelobte fraue,

rosz in des himels taue,

du pist genaden vol.

du edelle keiszerine,

$5 \quad$ nun gib uns rechte syne,

und hilff uns zu dir in dein zeszen ${ }^{91}$ schone.

Des pit ich dich durch dein barmherczickeite,

Maria, du werd bereite.

Jesus der kant dich wol,

88 Ich] Chy.

89 wusch] wiederkehr. Metathese von chs in y.

90 Maria] aria y.

91 Vgl. zese (Lexer III, Sp. 1091). 
${ }^{1}$ KonrW/6/509 (Morgenweise, Form 2)

k 516vb-517rb

Von der dryvaltikeit in

\section{I}

Ich weisz dry fursten sint meyr gelichen

dem armen alz dem richen

nach der gerechtikeit.

sie sint so hoch geboren,

5 ich han mirs uszherkoren.

Jesus, myn herr, nu gib uns din geleyte.

[517ra] Maria, meit, du ubergulter sterne,

by dir da wuhs der kerne

von der drivalt bereit,

10 din lob ist hoch gemessen,

sie sint by dir gesessen,

die fursten rein sind also schon bereyte.

Maria, muter hoch geborn, hab uns in diner hüt.

daz bit wir dich, du edel maget reyne,

15 bit fur die welt gemeyne

dorch dines kindes blut,

den du trüg je in hertzen,

geberd on allen smertzen.

bitt Got, den vatter fur die cristenheite.

II

Maria, maget, hoch gelobte frauwe,

ros in dem hymmel tauwe,

du bist genaden vol.

du edel keyserynne,

$5 \quad$ nu gib uns rechte synne,

hilf uns zu dir in dinen zeswen schone.

Des bitt ich dich durch din barmhertzikeite

Mary, du wer bereyt.

Jesus der kam dir wol, 
10 ee das du werd gepornn, er het dich auszerkornn, da was dir breit ein selden reiche krone.

[12v] Werd Got der vater, Got der heillig geist in ein person und laszen sich verdreyen,

15 die hoch gelopten freyen die sein ein gancz volleist. wer hacz in seinem herczen, der lebt an allen smerczen, hie auf der erd und in dem hochsten trone.

III

Got ${ }^{92}$ sant $z u$ Maria her in diszes quele denn engel Gabrihele, das sie solt sein bereit. er wolt sich pey ir jungen,

5 her wider umb zu pringen als menschlich heill an alles miszewenden.

Maria magt, du lichte himel rosze,

Got het dich in seinr kosze mit der dryfaltickeit.

10 dein kind het $z u$ dir luste, er sog an deiner prüste, alle disze welt stet, frau, in dinen henden.

Da ward enzünt der heillig geist in menschlicher art. ich man dich, Maria, das du in enpfingest

15 und menschlich mit im gingest.

Jesus, der was so zart, und da du in geperde und reine maget werde, des pistu dochter, müter, frau an ende.

${ }^{1}$ Wartb/2/511

y $23 \mathrm{v}-24 \mathrm{v}$

In dem schwarczen don clingsar

I

Got ${ }^{93}$ grusz euch all ir gesellen gut, uff meinstergesang so stet mir sin und auch mein mut, das helfet mir geselicklich pflegen.

92 Got] ot y.

93 Got] ot y. 
10 ee daz du word geboren,

hett er dich usserkoren

du was bereit, ein seldenriche krone.

Got der vatter und Got der son und Got der heiliggeist ist ein war Got und lassen sich zerdryen,

15 die hochgelobten fryen

sint ein gantz war volleist.

wer sie hat in sym hertzen,

der lept on allen smertzen,

hie uff der erd und ymm hochsten trone.

III

[517rb] Got sant zu Marien in dyse quele

den engel Gabriele,

sie solte sin bereit.

einr wolt ${ }^{94}$ sich by ir jungen,

5 der solte wyder bringen

menschliches heil on alle missewende.

Maria meit, du lichte hymel rose,

Got hett dich in der close

siner dryvaltikeit.

10 von dym son Jesu Criste

der sog an diner brüste,

all dyse welt stunt gar in siner hende.

Der wart enzunt vom heilgen geist bei dir in hoher art. ich man dich, maget, daz du in enpfinge

15 und menschlich mit ym ginge.

Jesus der was so zart,

da du in so gebere

und dannoch maget were,

dez bistu tochter, muter, meyit ein ende.

${ }^{1} \mathrm{Wartb} / 2 / 511$

k 697vb-698ra

Ein anders von syben künsten

I

Nu grüsz ich alle senger güt, mit meynstersang ${ }^{95}$ darnach mir stet sin unde müt, daz helffen mir geselliclichen pflegen.

94 wolt von Schreiber A (Redaktor) aus solt gebessert.

95 meynstersang von Schreiber A (Redaktor) aus meynsterschafft gebessert. 
[24r] Ich bit euch durch geselschaff,

5 al die mit meinster gesang sein behafft, dass sie mirsz zu dem ergsten nit enwegen.

$\mathrm{Ob}$ ich mich seum an meinstergesang mit worten oder weysheyt, meinster gesang ist so vill, ich bit euch sten ich hiemitt zu dem rechten zill,

10 das mich wolt mit euren kunsten speysen.

II

Uff ${ }^{96}$ philosophey stet mir mein gir, doch kunt dy kunst loyca nit werden mir, das macht ich bin nit vil gegangen $z$ u schull.

Kein arczet macht nit gutten getranck,

5 und dem die kunst visica im ist zu kranck, wie kont ich siczen uff der meinster stull?

Geomatry die ist mir teur, wie kont ich zelen und messen, und eben wegen in die wog.

kein stern seher noch rechter worheyt nit enfrag,

10 er sey dan mit astromey besessen.

III

Kont ${ }^{97}$ ich erginnen, merckt mich, an kupfer wolt ich goldesz werden also reich. kunt ich die kunst gramatica durchgerwen,

Swolt ich machen worter clug,

5 het ich die kunst retorica, das wer mein sanck gedeylt, die wolt ich hoffelichen ferben.

[24v] Kont ich die kunst auch musica, ir stim ausz sussen done kont ich der siben konsten pflegen, dennoch wolt ich mich desz hie nit uberwegen, dor an gedencket ir meinster, entphahet mich gar schone.

96 Uff] ffy.

97 Kont] ont y. 
Ich bit uch durch geselleschaff,

$5 \quad$ alle die hie mit meynsterschefte sind behaft,

also daz sie mir zum hertzsten nit enwegen.

Ob ich mich sum an meynsterkunst an worten und an wysen

Sit meynstersanges ist so vil,

Ich bitt ob ich nit eben stande zu dem zil

10 daz ir mit uwer kunst $t^{98}$ mich furbaz wysen.

\section{II}

Uff phylosophe ${ }^{99}$ stat myn gir,

[698ra] do kund die kunste loyca nie werden mir, daz macht ich bin nit gangen vil zu schulen.

Keyn artzet macht nit guten tranck,

5 dem auch die kunste visica nie wart bekant, wie mocht ich sitzen uff der kunste stulen?

Jeomatry die ist mir tür, wie kund ich zelen, messen und eben wegen in der wag. ein sterrenseher nach der warheit nit sol frag,

10 er sydann mit astronomy besessen.

III

Kund ich mit alchemye mich, von kupfer wolt ich goldes werden also rich. kund ich die kunst gramatika durchgerwen,

So wolt ich machen worten tüg.

$5 \quad$ kund ich die kunst rethorika, wer mir gefüg gedichtes, wolt ich hofelichen werden.

Kund ich die kunste muisica, gestymm usz suszem tone, kund ich der syben kunste pflegen, sehent dannoch so wolt ich mich mir uberwegen, darumb enpfaht, ir meinster, mich vil schone.

98 kunst] kust y.

99 phylosophe] phlosophe $\mathrm{k}$. 
${ }^{1}$ Ehrb/2/2 (Schallweise)

y $8 \mathrm{rv}$

Im küpffer don ernpot

I

Wer seinen arcz betreüget, wie sol der machen in gesunt, und seinen peichtiger leüget, und wirt dem sel und leib ernert,

5 die hann gelückes vil.

Fursprechen vor gerichte, wer dem tut falsche sache künt, wirt er mit rechter slichte bewart, das er nit meinet swert,

10 da prüfich selden spil.

Welch here hat getrewen rat versucht mit falscher frage, wie sol in der

15 [8v] mit ern wer ernern vor schanden wage? wie sol ich argen, poszen wicht ausz schanden pful erwegen? mit lob ich han volge nicht,

20 er lig da er hab gelegen.

II

Ich müsz vil dicke sweigen, den die zu recht mir wol swigen, ich müsz vil manigem neygen dick mer durch sein wart

5 wann durch sein adelickeit.

Ich leyd auch maniges straffen der mich sein pillich het verzygen, gen dem mein recht musz slaffen. also jag ich die wider fart, so manger pey mir seyt.

Sein lüg fur war, damit er gar der warheit mein gesweiget. manck arger wicht 
${ }^{1}$ Ehrb/2/2 (Schallweise)

k 727vab

Ein anders in dysem ton

I

Wer sinen artzet truget, wie sol der machen in gesunt, und sinen bichter luget, wirt dysen sel und lip ernert

5 die hant geluckes vil.

Fürsprechen für gerichte, wer den tut falsche sache kunt, wirt er mit rechter slichte bewert, daz er nit meinig swert,

10 da briffich selden spyl.

Welch herre hat getruwen rat versucht mit valscher frage wie sol in der

15 mit eren wer ernern von schanden wage? wie sol ich argen, bösen wicht usz schanden pful gewegen? mit lob ich han de volge nicht, $20 \quad$ lyg da er hab gelegen.

II

Ich misz vil dicke swygen, den die zu recht mir billich swiegen, ich musz auch mangem nygen vil dicke me dorch sin wart

5 dan durch sin edelkeit.

Ich lid auch manges straffen der billicher hute der zygen, gein dem min recht müsz slaffen. alsus jag ich die wyder fat,

10 so manger by mir seyt.

Sin lìg fur war, da mit er gar die warheit myn gesweyget. mang arger wicht 
15 mirfreuntschaff gicht,

der mir doch falsch erzeiget.

sunst müsz ich manigem han fur gut,

wie er mir miszehagt.

welch tümer gast des nicht entut,

20 des seld in zweyffel wagt.

III

Ein falscher freünt untreu,

der nent sich freünt und ist sein nit,

das musz mich ymer rewen.

und ob ich den nun wiszen lasz,

5

die meinen heimlickeit.

Ging es mir wol nach güte,

das wer im leyt

stet ye sein syt, betrübt wurd im sein müte,

und kund er es nit unter stan,

10 so wer es im doch leyt.

Das weisz ich wol,

wan er ist vol

neydes in allen sachen.

er gen mir gat,

15

er sich nun plat,

das kann der neyt wol machen,

das mir keines guten gann,

es sey spat oder frü,

wann er neyt mich allczeit an,

sein hercz hat selten rü. 
15 mir fruntschaft gicht,

der mir doch falsch erzeuget.

Susz můsz ich mangen han vergüt,

[727vb] der mir susz myssehat.

wa tummer gast dez nit entüt,

20 dez seld in zwyfel waget.

III

Ein valscher frunt untruwe,

der nent sich frunt und ist sin nit,

daz musz mich ymmer ruwen

ob ich die selben wyssen lan,

5 die myne heymlicheit.

Ging es mir wol nach gute,

daz wer ym leit.

stet ie sin sytt, betrubt word ym sin mute,

und kund er daz nit understan,

10 so wer es ym gar leyt.

Daz weysz ich wol,

wann er ist vol

nydes in allen sachen.

er gein mir gat

15 und sich zerblat,

daz kan der nyd wol machen,

daz er mir auch keins guten gan,

es sy spat oder frü,

wann er nydet mich alzyt an,

sin hertz hat selten rü. 
${ }^{1} \mathrm{Hardr} / 3 / 20$

$\mathrm{y} 2 \mathrm{v}-3 \mathrm{r}$

harders senften donn

I

A $l l^{100}$ hie han ich den meister funden, dem ich so lange zeit nachgangen pin.

und zwar er wirt mir doch zu teyl, in fur der posz dann hin.

Wan er singt doch zu allen stunden und weisz doch nit wo es hangt oder leit. nun wer dich, krancke meisterschaff!! wan es ist an der zeit.

Dein falsches singen soltu gen mir laszen, piszt nit im hausz? - ich find dich auf der straszen! dein uppickeit solt maszen. und wo du kümst zu fremden meistern ein, so soltu geben in enpfor und untertenick sein.

\section{II}

Ich ${ }^{101}$ han dir also lang gesungen, ja erst, so will ichs mit dir heben an. es zymt nit wol, der sich vil rümt und doch der künst nit kann.

Dir ist doch auch nit wol gelungen all an der kunst, und du pey dir hast. mich dunck, du dust ir nit gar recht, wo du zun leuten gast.

Er fürcht, er find unter in vil leicht ein gescheyden, 10 und der in umb sein gesanck werd sere neyden, er musz auch von in leyden und das er spricht: „meister, wo kumst du her? von parysz ausz der hohen schull? dein kunstu hie bewer!“ 
III

Ain ${ }^{102}$ singer sasz in einem hole,

der ticht und het doch keinen guten gesanck.

ir mercker, mercket alle eben!

und wie im da gelanck,

Er dau [ch] mich ${ }^{103}$ doch gar vil zu vole, das er mich singes wolt all hie bestann und zwar er mocht sein nicht gedun, er must es farn lan.

Er forch, er wurd von mir gar ser gescholten,

10 so het ers gen den meistern ye dick entgolten, im geschach, als er nun wolte:

er sang und west der reimen nit gar eben, dar umb ward im weder lob noch preisz all seine ${ }^{104}$ kunst geben.

102 Ain] in.

103 mich über der Zeile nachgetragen.

104 seiner] sein. 



\title{
Felix Prautzsch
}

\section{Die Meisterschaft des Laien? \\ Zum ästhetischen und theologischen Anspruch im Meistergesang}

\begin{abstract}
Taking Karl Stackmann's dictum of the 'mastery of laymen' as a starting point, the article looks onto the connection of art and theology, especially how they are represented in the Colmar Liederhandschrift. The songs in the manuscripts are analyzed according to aspects of lay theology and to how the institutional framework and theological contents fit into the performative action. It is concluded that the Meistersänger of the 14th and 15th century employed a concept of lay theology that was a precursor for the later Meistergesang during the Reformation. In the Colmar manuscript, several texts employ the motif of divine inspiration as the predominant way to legitimize this form of art.
\end{abstract}

Die Rede von der ,Meisterschaft des Laien' ist keine neue, sondern steht gewissermaßen am Anfang der jüngeren Meistergesangsforschung: Schon 1958, im Schlusswort seiner Studien zu Heinrich von Mügeln, fasste Karl Stackmann unter diesem Schlagwort den geistlichen, explizit ,laientheologischen Anspruch, ${ }^{1}$ der sich in der Entwicklung von der Sangspruchdichtung bis zum zünftigen Meistergesang mit der zunehmenden Konzentration auf geistliche Themen fortschreitend verstärke, bis er gewissermaßen in die Reformation münde und zum zentralen Movens des Meistergesangs werde:

Da ist vor allem an einen impliziten Vorgang zu erinnern. Nachdem die Spruchdichtung in die Hände der Meistersänger übergegangen ist, mehren sich rasch Gedichte mit biblischen Themen, die man recht gut als versifizierte Laienpredigten ansprechen kann. Nach dem Übertritt der Meistersänger zu Luthers Lehre bleibt dies der einzige geistliche Gegenstand, der in den Meisterliedern behandelt werden darf. ${ }^{2}$

Vor dem Hintergrund dieser Entwicklung regte Stackmann künftige Forschungen mit dem Thema „Spruchdichtung und vorreformatorische Laienbildung“3 an, die danach fragen sollten, inwieweit die meister des 14. und 15. Jahrhunderts

1 Vgl. Karl Stackmann: Der Spruchdichter Heinrich von Mügeln. Vorstudien zur Erkenntnis seiner Individualität. Heidelberg 1958 (Probleme der Dichtung. Studien zur deutschen Literaturgeschichte 3), S. 179.

2 Ebd., S. 177.

3 Ebd., S. 181. 
"durch ihre kunst, deren Resultat letzten Endes in der Erwerbung des Mitspracherechts von Laien in theologischen Fragen bestand, der Reformation an einem entscheidenden Punkt den Weg geebnet haben“, nämlich in der „Bildung einer breiten, geistig mündigen Laienschicht, die imstande war, die Reformideen einer kleinen theologischen Minderheit aufzunehmen“. ${ }^{4}$

Die Relevanz der Frage nach einer so verstandenen ,Meisterschaft des Laien für das bemerkenswerte gattungsgeschichtliche Kontinuum, das von der Sangspruchdichtung bis zum Meistergesang reicht, ${ }^{5}$ lässt sich dabei von beiden Enden der Entwicklung her akzentuieren: erstens von den Anfängen her, denn die Beschäftigung mit geistlichen Themen und biblischen Stoffen bildet fraglos eine wichtige, wenn nicht gar die bestimmende inhaltliche Linie in der Entwicklung von der Sangspruchdichtung zum Meistergesang - beziehungsweise stellt sie den entscheidenden Aspekt in der Rezeption der älteren Liedkunst durch die meister des 15. Jahrhunderts dar, die nicht nur zur Tradierung der Gattung, sondern überhaupt erst zur Formierung des zünftigen Meistergesangs führt; ${ }^{6}$ zweitens sozusagen vom Ergebnis her, nämlich von der Bedeutung des Meistergesangs für die Durchsetzung und Verbreitung der lutherischen Lehre vor allem in den süddeutschen Städten des 16. Jahrhunderts, wo er seit seiner Umgestaltung und Neubegründung durch Hans Sachs „zum Wegbegleiter oder gar zum Schrittmacher der Reformation" ${ }^{\text {“7 }}$ wird. Der Meistergesang fungiert in

4 Ebd., S. 180.

5 Vgl. dazu die Einleitung zum Repertorium der Sangsprüche und Meisterlieder des 12. bis 18. Jahrhunderts (RSM). Hg. von Horst Brunner und Burghart Wachinger. 16 Bde. Tübingen 1986-2009, Bd. 1, S. 1-7.

6 Vgl. Stefan Rosmer: Die Tradition des geistlichen Sangspruchs und seine Gestalt um 1300. In: Sangspruchdichtung um 1300. Akten der Tagung in Basel vom 7. bis 9. November 2013. Hg. von Gert Hübner. Hildesheim 2015 (Spolia Berolinensia 33), S. 307-330, hier S. 310, der die Dominanz geistlicher Themen in den frühen Meisterlied-Sammlungen des 15. Jahrhunderts und gerade auch in der Kolmarer Liederhandschrift betont, die sich in der Gesamtheit der bis zur Mitte des 14. Jahrhunderts überlieferten Sangsprüche so nicht feststellen lässt. Zur religiösen Unterweisung als einem zentralen ,thematischen Kern' der Sangspruchdichtung vgl. neuerdings auch Stefan Rosmer: Religiöse Unterweisung - Gebet - Gottes- und Marienpreis. In: Sangspruch/Spruchsang. Ein Handbuch. Hg. von Dorothea Klein, Jens Haustein und Horst Brunner. In Gemeinschaft mit Holger Runow. Berlin/Boston 2019, S. 205-223.

7 Karl Mitterschiffthaler: Meistersang in Oberösterreich. In: Streifzüge 1. Beiträge zur oberösterreichischen Musikgeschichte. Hg. von Klaus Petermayr und Erich Wolfgang Partsch. Linz 2007, S. 25-60, hier S. 33. Vgl. dazu meine Darstellung in 
diesem Zusammenhang als ein Kommunikationsmedium, das den eigenständigen Umgang mit der Bibel wie die allgemeine Auseinandersetzung mit Fragen eines gottgefälligen Lebens befördert, ${ }^{8}$ dabei außerdem die "geistliche und weltliche Bildung der Zeit vom Zustand der Lesbarkeit in den für alle offenen Zustand der Hörbarkeit überführt“.9

Beide Blickrichtungen gewinnen ihr eigentliches Gewicht angesichts des poetologisch wie kommunikativ-funktional bedeutsamen Umstands, dass es sich bei der Liedkunst der sogenannten und sich als solche verstehenden meister um eine dezidiert volkssprachig-laikale Kunstform handelt. Das gilt schon für die Sangspruchdichtung als Element höfischer Repräsentation und Auftragsdichtung fahrender Berufsdichter, die von der Gunst ihrer vor allem weltlichen Herren und Gönner abhängig sind, und umso mehr gilt das für den Meistergesang, dessen Träger nunmehr - literaturpragmatisch betrachtet - keine Berufsdichter, sondern stadtbürgerliche Dilettanten und als solche eben auch - im kirchlich-theologischen Verständnis - Laien sind. Mit der Institutionalisierung des Meistergesangs in entsprechenden Meistersingergesellschaften wird die ,meisterliche Liedkunst ${ }^{10} \mathrm{zu}$ einer Kunstübung, die auf

Felix Prautzsch: Von der Märtyrerlegende zum kirchengeschichtlichen Exempel. Die Transformation legendarischen Erzählens im nachreformatorischen Meistergesang. In: Zeitschrift für deutsche Philologie 136/1 (2017), S. 1-20, hier S. 11-12, sowie die Hinweise in meinem Beitrag Felix Prautzsch: Die Wittenbergisch Nachtigall gegen den Löwen in Rom. Lutherstilisierung, antirömische Invektiven und Reformation bei Hans Sachs. In: Beiträge zur Geschichte der deutschen Sprache und Literatur 143/2 (2021), S. 239-271, hier S. 246-247.

8 Vgl. Uta Dehnert: Freiheit, Ordnung und Gemeinwohl. Reformatorische Einflüsse im Meisterlied von Hans Sachs. Tübingen 2017 (Spätmittelalter, Humanismus, Reformation/Studies in the Late Middle Ages, Humanism, and the Reformation 102), S. 134-135, außerdem Horst Brunner: Meistergesang und Reformation. Die Meistergesangbücher 1 und 2 des Hans Sachs. In: Ders.: Literarisches Leben. Studien zur deutschen Literatur. Berlin 2018 (Philologische Studien und Quellen 266), S. 276-290 [zuerst 1984].

9 Einleitung des RSM, Bd. 1, S. 6.

10 Dieser Terminus ist von Schanze eingeführt worden, um die hinsichtlich der institutionellen Gebrauchssituation der Lieder und dem sozialen Status der Autoren schwer fassbare Übergangsphase zwischen „nicht mehr Sangspruchdichtung und noch nicht ausschließlich Meistergesang “ zu bezeichnen, die mit dem Übergang zur Mehrstrophigkeit aber formale Innovationen aufweise. Frieder Schanze: Meisterliche Liedkunst zwischen Heinrich von Mügeln und Hans Sachs. Bd. 1: Untersuchungen. München 1983 (MTU 82), S. 10. Vgl. dazu auch Dietlind Gade: Wissen Glaube - Dichtung. Kosmologie und Astronomie in der meisterlichen Lieddichtung 
einen klar bestimmten städtisch-bürgerlichen Interaktions- und Kommunikationszusammenhang bezogen zu denken ist, auf die Singschule als Ort der gemeinschaftlichen Kunstausübung, also der öffentlichen Repräsentation und Aneignung, Transformation und Vermittlung nicht zuletzt geistlicher Wissensbestände. ${ }^{11}$ Dieser spezifische soziokulturelle Zusammenhang und seine institutionelle Ausformung sind im Kontext der im späten Mittelalter stetig zunehmenden laikalen Heilssorge und der Ausprägung spezifischer religiöser Formen zu sehen, in denen Laien als selbstverantwortliche Subjekte ihrer Frömmigkeit hervortreten, während der Gegensatz zum gelehrten Klerus in den Hintergrund tritt. ${ }^{12}$

des vierzehnten und fünfzehnten Jahrhunderts. Tübingen 2005 (MTU 130), S. 2 , sowie neuerdings vor allem Michael Baldzuhn: Der Sangspruch im 14. und 15. Jahrhundert. In: Sangspruch/Spruchsang. Ein Handbuch. Hg. von Dorothea Klein, Jens Haustein und Horst Brunner. In Gemeinschaft mit Holger Runow. Berlin/Boston 2019, S. 485-500.

11 Vgl. Erich Kleinschmidt: Literatur und städtische Gemeinschaft. Aspekte einer literarischen Stadtkultur in der Frühen Neuzeit. In: Literatur in der Stadt. Bedingungen und Beispiele städtischer Literatur des 15. bis 17. Jahrhunderts. Hg. von Horst Brunner. Göppingen 1982 (GAG 343), S. 73-93, hier S. 77f., außerdem die aktuellste und derzeit umfassendste Darstellung zum Meistergesang des 16. Jahrhunderts bei Dehnert 2017 (Anm. 8), S. 93-148.

12 Es ist hier nicht der Platz, das breite Feld der spätmittelalterlichen Laienfrömmigkeit, zumal in der verwickelten Dialektik der Abgrenzung von Klerikern und Laien, genauer zu beleuchten. Es sei dazu auf die umfassenden Beiträge von Klaus Schreiner verwiesen und festgehalten, „daß die zwischen Klerus und Laientum, zwischen clerici litterati und laici illiterati festgeschriebenen Grenzen im späten Mittelalter an Trennschärfe verloren, sich verwischten und überschnitten“, was sich vor allem daran zeigt, „daß in wachsendem Maße Laien als legitime Leser von muttersprachlichem religiösem Schrifttum angesprochen und genannt werden“. Klaus Schreiner: Laienfrömmigkeit - Frömmigkeit von Eliten oder Frömmigkeit des Volkes? Zur sozialen Verfaßtheit laikaler Frömmigkeitspraxis im späten Mittelalter. In: Laienfrömmigkeit im späten Mittelalter. Formen, Funktionen, politisch-soziale Zusammenhänge. Hg. von dems. München 1992 (Schriften des Historischen Kollegs. Kolloquien 20), S. 178, hier S. 27. Vgl. dazu auch Klaus Schreiner: Grenzen literarischer Kommunikation. Bemerkungen zur religiösen und sozialen Dialektik der Laienbildung im Spätmittelalter und in der Reformation. In: Literatur und Laienbildung im Spätmittelalter und in der Reformationszeit. Symposion Wolfenbüttel 1981. Hg. von Ludger Grenzmann und Karl Stackmann. Stuttgart 1984 (Germanistische Symposien. Berichtsbände 5), S. $1-20$. 
Es handelt sich bei der meisterlichen Liedkunst des 14. und 15. Jahrhunderts also, so ließe sich pointieren, um eine spezifisch laikale Literatur beziehungsweise Kunstübung, und das gilt - mit Blick auf ihren ,Sitz im Leben' - letztlich auch da, wo sich klerikal Gebildete unter ihren Förderern oder auch Trägern befinden sollten, eine Unterscheidung, die mit der reformatorischen Betonung des Priestertums aller Gläubigen und der Kompetenz der Laien zur Schriftauslegung schließlich vollends ihre Bedeutung verlieren wird. ${ }^{13}$ Als „Literatur von Laien für Laien“ entwickelte sich der nachreformatorische Meistergesang jedenfalls zu einem „nicht zu unterschätzenden Mittel der protestantischen Volksbildung “. ${ }^{14}$ Von daher ist die Frage nach dem geistlichen, möglicherweise bewusst laientheologischen Charakter und Anspruch schon der spätmittelalterlichen meister und ihrer Liedkunst eine, die den Kern dieser Kunstform und ihren Funktionszusammenhang betrifft und von daher ihre Aufnahme und Transformation im ,eigentlichen', dem zünftigen und schulmäßigen Meistergesang vor und dann besonders nach der Reformation erhellt.

Dieser frömmigkeitsgeschichtliche Aspekt des Meistergesangs ist indessen - wie seine kulturgeschichtliche Pragmatik überhaupt - bis heute nicht systematisch untersucht worden. Da dahingehende Rezeptionszeugnisse fehlen, stellt sich die Frage, worin sich der laientheologische Anspruch der meister des 15. Jahrhunderts und der von ihnen tradierten Lieder der Sangspruchdichter in den Texten selbst niederschlägt, worin also die ,Meisterschaft des Laien' in der Liedkunst selbst grundsätzlich auszumachen wäre: inhaltlich-thematisch in der adäquaten Vermittlung geistlich-theologischer Inhalte an ein volkssprachiglaikales Publikum beziehungsweise einer tatsächlich laikalen Theologie, als Theologie von Laien für Laien; legitimatorisch-kommunikativ in einem in den Liedern greifbaren dezidiert laikalen Selbstbewusstsein, theologische Themen behandeln zu können und zu dürfen, in ,erbitterter Rivalität ${ }^{`}$ - deren Spuren Stackmann in den Liedern der meister des 14. Jahrhunderts zu zeigen können glaubte $^{15}$ - zum Klerus oder gar in dezidiert kritischer Haltung zu ihm? Und

13 Vgl. Johannes Rettelbach: Die geistlichen Meisterlieder des Jahres 1548 von Hans Sachs. Laientheologie nach der Reformation? In: Grenzmann/Stackmann 1981 (Anm. 12), S. 745-759, hier S. 756.

14 Werner Williams Krapp: Literatur und Standesgefüge in der Stadt. Nürnberg im 15. und frühen 16. Jahrhundert. In: Zeitschrift für deutsche Philologie 134/Sonderheft (2015), S. 9-23, hier S. 20.

15 Vgl. Stackmann 1958 (Anm. 1), S. 173f. Auf Stackmann beruft sich Marie E. Müller, wenn sie in den „laientheologischen Ambitionen des zünftigen Meistergesangs eine fortschreitende Loslösung von kirchlichen Bindungen“ beschreibt. Marie 
wie verhalten sich diese institutionellen Rahmenbedingungen und inhaltlichen Aspekte zum spezifischen literarisch-ästhetischen Medium gesungener Dichtung, eben der kunst der meister?

Das Textkorpus der Kolmarer Liederhandschrift scheint dabei in besonderem Maße geeignet, diese Fragen in eine umfassendere Perspektive einzubinden, weil sie wie keine andere eine Kontinuität von den Anfängen in der höfischen Sangspruchdichtung des späten 12. Jahrhunderts über die meisterliche Liedkunst bis zum städtischen Meistergesang des 15. Jahrhunderts entwirft. Wenn es sich bei ihr, wie in der Forschung angenommen, um eine programmatische Sammlung der Töne und Lieder der berühmten , alten Meister handelt ${ }^{16}{ }^{6}$ m eine „Kodifizierung des Kanons meisterlicher Sanges-

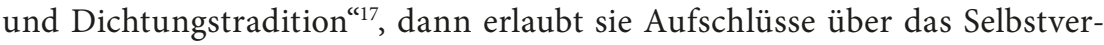
ständnis der meisterlichen Autoren ihrer Entstehungszeit. Diese wird in die Mitte beziehungsweise die zweite Hälfte des 15. Jahrhunderts datiert, fällt also einerseits mit der Phase der zunft- und schulmäßigen Institutionalisierung des Meistergangs, andererseits mentalitätsgeschichtlich mit dem ,Vorabend' der Reformation zusammen. Aber nicht nur ihre Entstehungszeit ist signifikant, sondern auch ihre Rezeption, denn tatsächlich gilt sie den Meistersingern des 16. Jahrhunderts als „Gründungsdokument des Meistergesangs ${ }^{\text {“18 }}$, als legitimatorischer und traditionsbildender Bezugspunkt für die

E. Müller: Bürgerliche Emanzipation und protestantische Ethik. In: Hans Sachs. Studien zur frühbürgerlichen Literatur im 16. Jahrhundert. Hg. von Thomas Cramer und Erika Kartschoke. Bern u. a. 1978 (Beiträge zur älteren Literaturgeschichte 3), S. 11-40, hier S. 21. Diese teleologische Zuschreibung entspringt Müllers erkennbar zeitbedingtem Paradigma einer frühbürgerlichen Emanzipationsbewegung. Die meisterliche Liedkunst des 14. und 15. Jahrhunderts dürfte sich in ihren Tendenzen deutlich vielschichtiger darstellen; dazu will ich im Folgenden einige Hinweise bieten.

16 Vgl. Volker Zapf: Kolmarer Liederhandschrift. In: Deutsches Literatur-Lexikon. Das Mittelalter. Bd. 4: Lyrik und Dramatik. Hg. von Wolfgang Achnitz. Berlin, Boston 2012, Sp. 834-842, hier Sp. 834.

17 Burghart Wachinger: Kolmarer Liederhandschrift. In: ${ }^{2}$ VL 5 (1985), Sp. 27-39, hier Sp. 36.

18 Friedrich Malm: Meisterliederhandschriften. In: Achnitz 2012 (Anm. 16), Sp. $742-$ 749, hier Sp. 744. Zur Rezeption der Kolmarer Handschrift im 16. Jahrhundert vgl. Horst Brunner: Die alten Meister. Studien zu Überlieferung und Rezeption der mittelhochdeutschen Sangspruchdichter im Spätmittelalter und in der frühen Neuzeit. München 1975 (MTU 54), S. 68-80, sowie Horst Brunner und Johannes Rettelbach: Der vrsprvng des maystergesangs. Eine Schulkunst aus dem frühen 
eigene Kunstübung. Gattungstheoretisch gesehen ist die Kolmarer Liederhandschrift damit ein entscheidender Zeuge für die Phase des Übergangs von der Sangspruchdichtung zum städtischen Meistergesang.

In diesem Sinne behandle ich die Kolmarer Liederhandschrift im Folgenden als gewissermaßen historisch-synchrones Gesamtkorpus, ohne hinsichtlich der diachronen Schichtung innerhalb der verschiedenen und in sich inkonsistenten Tonkorpora zu differenzieren, die bekanntlich über 900 Texte zumeist unbekannter Autoren aus drei verschiedenen Jahrhunderten unvermittelt nebeneinanderstellen. Mein Zugang bleibt dabei schon angesichts dieser schieren Textmenge notwendigerweise ein kursorischer beziehungsweise punktuellexemplarischer. ${ }^{19}$ Es kann im Rahmen dieses Beitrages aber auch konzeptionell nicht um eine erschöpfende Beantwortung der Frage nach dem laientheologischen Anspruch der meisterlichen Liedkunst im erwähnten gattungsgeschichtlichen Kontinuum vom 12. bis 15. Jahrhundert gehen. Vielmehr hoffe ich, mit meinen Überlegungen einige Bausteine zu einer noch ausstehenden umfassenden Gattungspoetik und -pragmatik des sich seit dem 15. Jahrhundert formierenden schulmäßigen Meistergesangs herausarbeiten zu können, die dem Aspekt der ,Meisterschaft des Laien' in noch stärkerem Maße Rechnung tragen müsste. ${ }^{20}$

16. Jahrhundert und die Kolmarer Liederhandschrift. In: Zeitschrift für deutsches Altertum und deutsche Literatur 114/3 (1985), S. 221-240.

19 Dank des Digitalisierungsprojekts Bavarikon der Bayerischen Staatsbibliothek München ist der Cgm 4997 seit Kurzem als farbiges Volldigitalisat allgemein zugänglich. Eine interpretatorische Erschließung des Gesamtkorpus steht indes noch aus; der Arbeit von Christoph Petzsch (Die Kolmarer Liederhandschrift. Entstehung und Geschichte. München 1978), auf die ich mich argumentativ unter anderem beziehe, liegt in weiten Teilen die alte von Karl Bartsch besorgte Auswahl (Meisterlieder der Kolmarer Handschrift. Unveränderter reprografischer Nachdruck der Ausgabe Stuttgart 1862. Hildesheim 1962) zugrunde - insofern wären auch meine Ausführungen durch eine breitere Textbasis aus der Handschrift selbst zu akzentuieren. Zur Kritik an der Auswahl von Bartsch vgl. Schanze 1983 (Anm. 10), S. 59.

20 Vgl. dazu die nach dem Abschluss des RSM formulierten Forschungsaufgaben, darunter vor allem die Frage nach der kommunikativen Funktion, der Rezeption sowie der Performanz der Sangsprüche und Meisterlieder, bei Johannes Janota: Und jetzt? Forschungsaufgaben auf dem Gebiet der Sangspruchdichtung und des Meistersangs nach Abschluß des ,Repertoriums der Sangsprüche und Meisterlieder. In: Sangspruchdichtung. Gattungskonstitution und Gattungsinterferenzen im europäischen Kontext. Internationales Symposium Würzburg, 15. bis 18. Februar 2006. Hg. von 
Worin ließe sich also der laientheologische Anspruch der meisterlichen Liedkunst ausmachen? Ich beginne mit der Frage, ob dieser inhaltlich-thematisch zu bestimmen wäre, im Sinne einer Theologie von und für Laien. Der Begriff der Laientheologie kann dabei grundsätzlich zweierlei meinen: erstens eine Theologie, die für Laien bestimmt ist, also von diesen verstanden werden kann, weil sie in ihrer Sprache und unter Berücksichtigung ihrer Erfahrungswelt verfasst ist; und zweitens eine Theologie, die von Laien selbst entwickelt wird und damit unmittelbar von deren spezifischen religiösen Bedürfnissen, Möglichkeiten und Voraussetzungen ausgeht. Beides kann sich natürlich überlagern, und beides impliziert je auf seine Weise ein Selbstbewusstsein der Laien, die nach einer ihnen verständlichen und ihrer Lebenssituation angemessenen theologischen Bildung verlangen, weil sie sich als Subjekte religiösen Lebens verstehen, ob nun als Adressaten oder selbst Träger theologischer Unterweisung. Laientheologie suggeriert dabei eine gewisse Absetzbewegung, nicht schon unbedingt gegenüber dem Anspruch der kirchlichen Hierarchie, über das Monopol in der Verkündigung der christlichen Lehre und der Unterweisung im Glauben zu verfügen, sondern vor allem von der Sprache und den Mustern des klerikalen Diskurses.

Beispiele für die Vermittlung von Glaubenswissen und christlicher Lebenslehre an ein volkssprachig-laikales Publikum, in seiner Sprache und auf seine religiösen Bedürfnisse hin, lassen sich in der Kolmarer Liederhandschrift ohne Frage etliche finden. Denn auch hier findet sich jene „Vorrangstellung des geistlichen Liedes in seinen verschiedenen Spielarten "21, die für das thematische Spektrum der Meisterliederhandschriften insgesamt charakteristisch ist:

Lob und Anrufung Gottes und Marias, die Geheimnisse der Trinität und der Eucharistie, die einzelnen Momente der Heilsgeschichte vom Sein Gottes vor der Schöpfung über Inkarnation und Erlösung bis zum jüngsten Gericht, dies und viel mehr ist es, was immer wieder Interesse findet, oft mit gelehrtem Anspruch verbunden. ${ }^{22}$

Dieser laikal-gelehrte Anspruch geht bis zu spitzfindigen theologischen Spekulationen, so der mehrfach diskutierten Frage, wo Gott gewesen sei, bevor er

Dorothea Klein u. a. Tübingen 2007, S. 3-16, hier S. 10-12, außerdem Prautzsch 2017 (Anm. 7), S. 20.

21 Frieder Schanze: Meisterliederhandschriften. In: ${ }^{2}$ VL 6 (1987), Sp. 342-356, hier Sp. 344.

22 Ebd. 
Himmel und Erde erschaffen habe. ${ }^{23}$ Weit häufiger noch und allgemein deutlich ist das Bestreben, Glaubensinhalte zum besseren und tieferen Verständnis darzustellen, zur Bestärkung im Glauben und zur Anleitung in rechter Andacht. Das wird besonders deutlich in Liedern, die die Sakramente und die Messe erklären. Immer wieder finden sich in diesem Zusammenhang Verse, die die Gläubigen direkt ansprechen, damit sie verstehen und geistlichen Nutzen aus dem Dargestellten ziehen mögen. Symptomatisch für diese didaktischillustrative Funktion scheint der Eingang einer solchen Messerklärung, in der sich der meister als Lehrer und Mittler von Glaubenswahrheiten an sein laikales Publikum wendet, indem er dessen Blick auf das sichtbare Bild Gottes in Form einer Passionsdarstellung lenkt: Ir leien, nement war, ir hant vor üch ein buch, / das man üch an die wende malt und an die duch / gots martel bild [...] (I,1-3). ${ }^{24}$

Die eigentliche Frage im Hinblick auf die Implikationen des Begriffs ,Laientheologie' besteht nun aber vielmehr darin, ob die meisterliche Liedkunst auch auf dessen zweite Dimension ausgreift und sich hier also eine tatsächlich laikale Theologie artikuliert. Es ginge also darum zu entscheiden, ob es sich um eine ,bloße' Vermittlung von im klerikalen Diskurs vorgeprägten theologischen Inhalten an ein volkssprachlich-laikales Publikum handelt, eine Vermittlung, deren Träger die meister wären, oder ob diese hier eine tatsächliche Theologie von Laien für Laien entwerfen. Das ist methodisch insofern problematisch das ist an anderer Stelle in der germanistisch-mediävistischen Forschung diskutiert worden ${ }^{25}$-, als dass sich die Inhalte einer möglichen Laientheologie

23 Vgl. den Hinweis bei Bartsch 1962 (Anm. 19), S. 154, der auf folgende Lieder verweist: ${ }^{1} \mathrm{Frau} / 18 / 2 \mathrm{a}$ : Man fragot hoch wo got sess der schoopfere; ${ }^{1} \mathrm{Frau} / 5 / 505 \mathrm{a}$ : Man fragt wo got behüset wer; ${ }^{1}$ WaltV/24/3a: Wer rotet wo got were; ${ }^{1} \mathrm{Rum} / 1$ : Man fraget hoch wo got behuset were. Bei Bartsch sind nur die letzten beiden, unter Nr. 158 und 161, abgedruckt.

24 'Bop/1/527, Cgm 4997, fol. 577r, abgedruckt bei Petzsch 1978 (Anm. 19), S. 76, vgl. dort insgesamt die Ausführungen und abgedruckten Lieder S. 73-83.

25 Vgl. Manuel Braun: Verdeckte Voraussetzungen oder: Versuch über die Grenzen der Hermeneutik. Einige Vorüberlegungen zur Erfassung ,literarischer Säkularisierung. In: Literarische Säkularisierung im Mittelalter. Hg. von Susanne Köbele und Bruno Quast. Berlin 2014 (Literatur - Theorie - Geschichte 4), S. 409-425, hier S. 424, in Kritik am ,Bayreuther Ansatz' von Susanne Knaeble und Silvan Wagner, der die volkssprachige Literatur des hohen Mittelalters als Ausdruck einer, von der kirchlichen Hochtheologie konsequent zu trennenden, höfischen Laientheologie verstehen will, dabei aber letztlich jedem Text eine eigene Theologie zuspricht. Vgl. Susanne Knaeble, Silvan Wagner und Viola Wittmann: Gott und Tod in der höfischen Kultur des Mittelalters. Einleitung. In: Gott und Tod. Tod und Sterben in der 
immer nur in den Texten selbst ausmachen lassen, die als Ausdruck einer solchen verstanden werden: Worin bestünde also eine Laientheologie und wie wäre sie zu erkennen?

Wenn beispielsweise in einem 13-strophigen Lied in Regenbogens Tageweise, ${ }^{26}$ das die Inkarnation und Passion Christi behandelt, am Ende jeder Strophe ein wahtor adressiert wird mit dem Aufruf: $n u$ sich [teilweise auch: luog] zem venster $\hat{u} z, o b d u$ iht sehest des tages schîn (I-XIII,18), dann ist diese geistliche Kontrafaktur der weltlichen Liedform des Tagelieds, die den anbrechenden Tag auf Christus beziehen kann, motivisch sicherlich interessant und aufschlussreich. Dem ließen sich auch andere Lieder an die Seite stellen, beispielsweise das in Peter von Arbergs Tagweise II, in dem die Wächter den Sünder aus seinen Sünden wecken und aufschrecken sollen, weil der Morgen naht, an dem Gottes Todespein begann, und die Zeit zur Reue verrinnt. ${ }^{27}$ Allerdings entspricht der geistliche Gehalt dem sonstiger Laienunterweisungen im Typus der Bußpredigt, der exhortatio, die zu Reue und Umkehr aufruft. Der Sänger konkurriert hier „mit dem Bußprediger, nicht mit dem Theologen“, wie Klaus Grubmüller es mit Blick auf die Spruchdichter des 13. Jahrhunderts auf eine Formel gebracht hat, weil „ihm eine prinzipiell nicht begründungsbedürftige (wenn auch nicht selten durch begründete Verweise gestützte) Autorität zu geistlicher Mahnung und Belehrung zur Verfügung" steht. ${ }^{28}$ Ich zitiere exemplarisch aus der letzten Strophe des erstgenannten Liedes:

höfischen Kultur des Mittelalters. Hg. von Susanne Knaeble, Silvan Wagner und Viola Wittmann. Berlin 2011 (bayreuther forum TRANSIT 10), S. 9-32, hier S. 24.

$26{ }^{1}$ Regb/9/1a, Bartsch Nr. 75.

$27{ }^{1}$ PeterA/3/1a, Bartsch Nr. 180.

28 Klaus Grubmüller: Autorität und meisterschaft. Zur Fundierung geistlicher Rede in der deutschen Spruchdichtung des 13. Jahrhunderts. In: Literarische und religiöse Kommunikation in Mittelalter und Früher Neuzeit. DFG-Symposium 2006. Hg. von Peter Strohschneider. Berlin 2009, S. 689-711, hier S. 703. Vgl. ergänzend dazu Stefan Rosmer: Geistliche Meisterlieder zwischen Heinrich von Mügeln und der Kolmarer Liederhandschrift. In: Sangspruchdichtung zwischen Reinmar von Zweter, Oswald von Wolkenstein und Michel Beheim. Beiträge der internationalen und interdisziplinären Tagung vom 30. September bis 3. Oktober 2015 in Brixen, veranstaltet von der Oswald-von-Wolkenstein-Gesellschaft in Verbindung mit dem Lehrstuhl für Deutsche Sprache und Literatur des Mittelalters der Universität Augsburg. Hg. von Horst Brunner und Freimut Löser. Wiesbaden 2017 (Jahrbuch der Oswaldvon-Wolkenstein-Gesellschaft 21), S. 319-333, der für einige städtische meisterliche Autoren zwischen ca. 1380 und 1450 beobachten kann, dass gegenüber älteren Autoren wie Frauenlob und Heinrich von Mügeln der „rhetorisch-elokutionäre wie der 


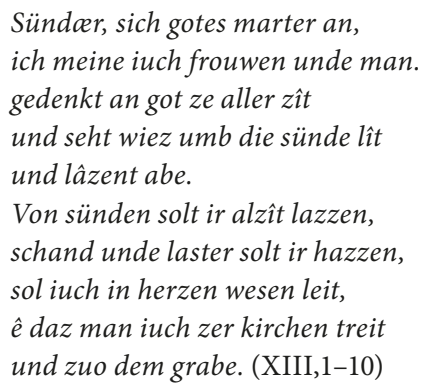

Die Strophe scheint völlig konventionell. Von Laientheologie ließe sich hier allenfalls im ersten Sinn sprechen, insofern damit nämlich gemeint ist, dass Glaubensinhalte sprachlich und didaktisch adäquat aufbereitet und vermittelt werden, und Ähnliches ließe sich für viele andere geistliche Themen und die Beispiele von Bibelversifikationen in der Kolmarer Liederhandschrift zeigen. ${ }^{29}$

Eine dezidiert laikale Theologie in Absetzung von einem klerikalen Diskurs wird hier kaum erkennbar, wie ja überhaupt kein eindimensionaler Gegensatz zwischen beiden Sphären anzunehmen ist. So hält gerade Stackmann zu Beginn seiner Überlegungen zur ,Meisterschaft des Laien' mit einigem Pathos fest, dass „die Wahrheit, von welcher die meister sangen, bis in die Tage der beginnenden Reformation hinein die einige und unteilbare Wahrheit des Dogmas" geblieben sei: „Der Kirche drohte demnach aus diesem Lager keine Gefahr; im Gegenteil, man sollte erwarten, sie hätte sich des meisters als eines willkommenen

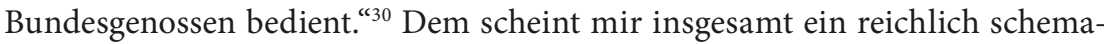
tisches Verständnis des Verhältnisses von Laien beziehungsweise meistern und Klerus zugrunde zu liegen, ${ }^{31}$ was dann auch dazu führt, dass Stackmann im

theologisch-spekulative Aufwand reduziert" ist und „Glaubenstatsachen schlicht referiert" (S. 328) werden.

29 Vgl. in diesem Zusammenhang auch den Beitrag von Johannes Janota in diesem Band (S. 313-337). Inwiefern in der Erhebung Mariens zu einer, vierten Person' der Trinität, die in der meisterlichen Liedkunst mitunter begegnet, möglicherweise ein Freiraum für eigensinnige, undogmatischen Formulierungen erkennbar wird, diskutiert, in anderen handschriftlichen Zusammenhängen, Eva Rothenberger: Die Stellung der Gottesmutter Maria in Regenbogens ,Langem Ton'. Ein thematischer Querschnitt. In: Die Edition mittelalterlicher deutscher Texte. Festkolloquium aus Anlass des 80. Geburtstags von Rudolf Bentzinger am 22.8.2016. Hg. von ders., Martin Schubert und Elke Zinsmeister. Erfurt 2019 (Akademie gemeinnütziger Wissenschaften zu Erfurt 50), S. 161-188.

30 Stackmann 1958 (Anm. 1) S. 173.

31 Vgl. dazu oben Anm. 12. 
Anschluss an diese inhaltlich-thematische Beobachtung den vermeintlichen Gegensatz konstatiert, „[i]n Wirklichkeit aber [seien] immer wieder Spuren einer erbitterten Rivalität zwischen dem Klerus und den Spruchdichtern festzustellen“. ${ }^{32}$ Diese entzünde sich am geistlichen Anspruch der Spruchdichter, „mit der Selbstverständlichkeit des Gleichberechtigten in theologischen Fragen“ Stellung beziehen zu können und, „bei allem schuldigen Respekt vor der Würde des einen rechten Glaubens, ein Lehrer dieses Glaubens zu sein so gut wie der von der Kirche verordnete Priester“. ${ }^{33}$

\section{II}

Damit komme ich zum legitimatorisch-kommunikativen Aspekt, also der Frage, ob sich in Beschäftigung der meister mit geistlich-theologischen Themen ein laikales Selbstbewusstsein in Absetzung vom Klerus ausmachen lässt. Eine latente bis offen erklärte Rivalität zwischen ,Liedautoren und Geistlichkeit' hat, im Anschluss an Stackmann und anhand der Kolmarer Liederhandschrift, Christoph Petzsch herauszuarbeiten versucht, der damit seine These untermauern wollte, die Handschrift sei im Auftrag der kirchlichen Zensurbehörde entstanden, die auf dieser Grundlage die laientheologischen Tendenzen der Meistersinger überwachen wollte ${ }^{34}$ - eine These, die in der folgenden Forschung freilich auf keine große Gegenliebe gestoßen ist. ${ }^{35}$

Fraglos findet sich im Textkorpus der Kolmarer Liederhandschrift eine ganze Reihe von Liedern, die von einem kritischen Umgang mit dem Klerus zeugen, der sogar bis zum Angriff auf den Papst reichen kann, zum Beispiel, wenn das Problem der Simonie gegeißelt wird. ${ }^{36}$ Zentrales Thema der Kleruskritik aber ist die Klage über moralisch verderbte Priester beziehungsweise die Schelte solcher unwürdiger Vertreter ihres Standes, und es scheint mir höchst fraglich, ob daraus tatsächlich auf einen fundamentalen Gegensatz zwischen meistern und Klerikern zu schließen ist. In einem Lied in Regenbogens Briefweise beispielsweise werden unter der Überschrift Ein anderz, der pfaffen strâfe ${ }^{37}$ die Bestechlichkeit und moralische Korrumpierbarkeit von Priestern angeprangert, die in ihrer Selbstüberhebung den Gläubigen die richtige Lehre

32 Stackmann 1958 (Anm. 1) S. 173.

33 Ebd., S. 179 und S. 176-177.

34 Vgl. Petzsch 1978 (Anm. 19), S. 48-49.

35 Vgl. Brunner/Rettelbach 1985 (Anm. 18), S. 235.

36 Vgl. Petzsch 1978 (Anm. 19), S. 58-69.

$37{ }^{1}$ Regb/1/504, Bartsch Nr. 56. 
schuldig bleiben. Die Behauptung, in der Hölle finde man deshalb mehr Kleriker als Kriegsleute, klingt nach harter Schelte, ja fast Blasphemie angesichts des gottgewollten Priesteramtes:

Unrehtes vil bringt uns der pfaffen übermuot, sie gebent selten rehte lêre, deist niht guot. des siht man zhelle maniger blate den îsenhuot. (I,1-3)

Der Modus dieser Vorwürfe ist aber nicht eigentlich der einer Schelte oder ,Strafe', sondern der einer Klage des Gläubigen, der sich in seinen geistlichen Bedürfnissen allein gelassen sieht und sich in dieser Not allein an Gott wenden kann:

ach herre got, ich klagez dir, sie strûchent manige stunde.

Der in dâ gît, den sagent sie von sünden frî,

er sî ein diep, ein morder oder swer er sî̀,

ach herre got, nu stant den armen etwan bî! (I,4-6)

Mit diesem Seufzer schwingt sich der Sänger zum Anwalt des, einfachen Mannes', des einfachen Gläubigen auf, der nicht einmal mehr beichten kann, weil der pfaffe auch dann die hant [reckt] und luogt wer im den pfennic gebe $(\mathrm{I}, 10)$. Damit wird der Klerikerstand aber nicht als solcher für obsolet erklärt, vielmehr besteht der Kern der Klage darin, dass die Priester ihrem Amt und ihrer Würde nicht gerecht würden und sich nicht am Heiligen, an Gott, ausrichteten, den sie doch - mit der eucharistischen Wandlung - in den eigenen Händen trügen:

Wunder nimet mich ouch, daz wil ich iu sagen,

daz die pfaffen alsô sêr nâch guote jagen

und sie den wâren got doch in den henden tragen.

daz sie niht bilde nement, daz ist von bose gedinge. (II,1-4)

Der Vorwurf der Gottvergessenheit gerät aber nicht zur grundsätzlichen Klerus- und Kirchenkritik, im Gegenteil fordert der laikale meister hier explizit, der Priester möge seinem Amt und seiner Weihe gerecht werden, weil sonst die Gläubigen ohne Hilfe zurückblieben:

swanne sich got von himmel lât, sô kumet er in sîn hende:

Sô sol er reiner sîn wan ie kein engel was.

war umb bistu dan gîtic? sage mir, priester, daz,

wan toetstu reht, so wore uns allen deste baz.

swenn nu der herre in flühten vert, daz gsinde enweiz war wenden. (III,4-8)

Das lässt sich einerseits als klagender Abgesang auf das an seiner eigentlichen Bestimmung scheiternde reale Priestertum verstehen, andererseits wird 
im Modus der Klage und damit der negativen Kontrastierung gerade dessen Funktion und sakramentale Würde, die den Priester reiner sein lasse als die Engel, betont. Auch den Schluss des Liedes darf man keinesfalls als tatsächliche Absage an den Glauben missverstehen, sondern muss ihn als rhetorischen Topos begreifen:

Daz selbe mac mir mînen glouben toeten, daz nu die priesterschaft nieman ervüllen kan glîch als ein wolf der louft mit hunden in den tan. sie welnt sich mit der gotes gâbe niht gnüegen lân. Wol hin dem sîge swie ez well, got helfe uns ûzer noeten. (III,9-13)

Das Bild von den an ihrem Anspruch scheiternden Priestern, die einem Wolf gleichen, der sich trotz seiner animalischen Wildheit unter seine domestizierten Artgenossen mischt, ist zwar fraglos ein sehr starkes und verstärkt den invektiv-distanzierenden Ton auf den Vorwurf der Boshaftigkeit und bewussten Täuschung; zu denken wäre an die benachbarte Metapher vom Wolf im Schafspelz. Aber auch diese Kritik an einer gierigen Priesterschaft, die sich mit der gotes gâbe niht gnüegen lân (III,12) will, mündet in die affirmativ-geistliche Haltung des einfachen Gläubigen, der sich in seiner Not wiederum Gott anbefiehlt.

Dem ließen sich Lieder an die Seite stellen, in denen die pfaffen noch viel deutlicher ermahnt werden, ihrer Aufgabe gerecht zu werden, wie die drei pare von der priesterschaft ${ }^{38}$, die an die Würde des Priesters als eines hôchgelopte[ $\left.n\right]$ gotes knecht $(\mathrm{I}, 1)$ gemahnen, die vor allem in seiner Kraft gründet, die Wandlung der eucharistischen Gaben zu bewirken - [...] du kanst mit worten machen / daz sich got in die hende dîn drivalticlîchen sliuzet. / Du twingest got her lebendic, des will ich jehen (I,5-7) - und damit Heilsmittler für die nach der Vergebung ihrer Sünden suchenden Gläubigen zu sein:

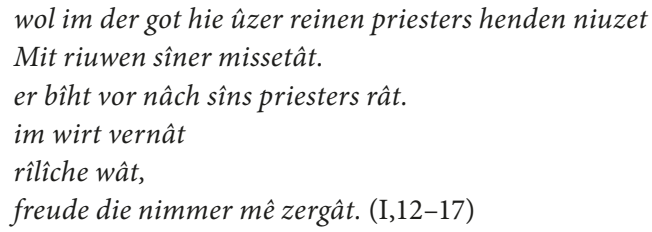

Das mündet in der dritten Strophe in einen direkten Appell an den einzelnen Priester, in seinem Lebenswandel der Würde und Funktion der Priesterschaft gerecht zu werden: Priester, wiltu vür alle dinc gehœhet sîn, / [...] / in dînes

$38{ }^{1}$ Frau/2/75-79b, Bartsch Nr. 10. 
herzen grunde bedenke wie dich gotes güete / vür alle dinc hât $\hat{u} z e r k o r n$, und halt dich wirdeclîche (III,1-6). Auch Petzsch urteilt:

Ungeachtet ihres strafens der Priester lassen auch die meister erkennen, daß die Priester unentbehrlich sind bei wichtigen Aufgaben der Seelsorge. Den meistern, denen es um möglichst ausreichende Hilfe für den Laien geht, kann der gute Geistliche nur recht sein. Priorität hat jene Hilfe. Da die lere Amt des Priesters, hat er sie auch zu leisten. Dann verdient er Anerkennung, ist andernfalls zu strafen..$^{39}$

Nicht nur in der kultischen Funktion des Priesteramtes, sondern auch in ihrer theologischen Kompetenz bleiben die pfaffen für die Gläubigen unentbehrlich; ich zitiere ein weiteres Lied, im Langen Ton Regenbogens, in dem der meister geradezu als Mahner gegenüber dem gelerte $[n]$ priester $(\mathrm{I}, 1)$ auftritt, dieser möge seinem Lehr- und Hirtenamt nachkommen, also die Gläubigen unterweisen und ihnen ein Vorbild sein:

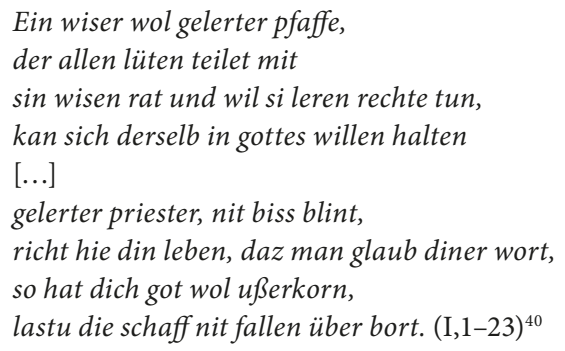

Anders als Petzsch, der das oben zuerst untersuchte Lied von der pfaffen strâfe so verstehen will, dass die kirchlichen Missstände „den meister veranlassen, sich zu engagieren, sich in der Funktion von Laienpriestern der Bevölkerung anzunehmen $^{\text {“41 }}$, würde ich die Kleruskritik im Kontext der meisterlichen Liedkunst und des frühen Meistergesangs des 15. Jahrhunderts daher weniger auf die möglichen Bezüge zur historischen Realität hin befragen, sondern zunächst

39 Petzsch 1978 (Anm. 19), S. 65.

$40{ }^{1}$ Regb/4/545a, Cgm 4997, fol. 375rv, abgedruckt bei Petzsch 1978 (Anm. 19), S. 65.

41 Petzsch 1978 (Anm. 19), S. 63. Vgl. in diesem Zusammenhang auch den Forschungsabriss und die Texthinweise bei Rosmer 2019 (Anm. 6), der betont, „dass Sangspruchdichter nur in der Lehre, nicht aber in der Heilsvermittlung in den Kompetenzbereich der Kleriker eindringen konnten, denn nur Kleriker waren für den Vollzug der Sakramente geweiht“, und resümiert: „Wenige Texte setzen meister und Priester in direkte Konkurrenz" (ebd, S. 207). 
und vor allem ihre rhetorisch-funktionale Qualität hervorheben. ${ }^{42}$ Elemente der Kleruskritik, die überdies stark topischen Charakter hat und Gemeinplätze aufgreift, die so alt sind wie die Kirche überhaupt, oder doch zumindest so alt wie die Herausbildung des Klerus als einer elitären Führungsschicht im Gegensatz zu den Laien, wären dann zu verstehen als Teil der laikalen Selbstermächtigung der meister. Die primär rhetorische Funktion der ,Pfaffenschelte ließe sich auch damit belegen, dass sie mitunter dezidiert im Rahmen einer allgemeinen Zeit- und Ständeklage steht, so in einem Lied in Muskatbluts Hofton, überschrieben mit Ein anders von der welt lauff..$^{43}$ Die sechste Strophe beklagt, dass die Priester nicht gemäß der Schrift lebten, sondern in Hass und Zuchtlosigkeit - so wie auch die in den anderen Strophen verhandelten Stände: Fürsten, Grafen, Ritter, Richter und Bürger ihrer eigentlichen Funktion und Berufung in einer gottgewollten Ordnung nicht gerecht würden. ${ }^{44}$

42 Auch Petzschs Deutung der Schlussbitte als „fromme Ergebenheit“ und die Lesart, das Lied offenbare "die Wirklichkeit der Not unter schlichten Menschen damals“ (ebd., S. 64), unterschneiden die Eigenlogiken der Kleruskritik, bei der der Priester unentbehrlich bleibt, wie überhaupt die literarisch-ästhetische Qualität einer solchen Darstellung im Medium meisterlicher Liedkunst. Zum topischen Charakter der spätmittelalterlichen Kirchen- und Kleruskritik vgl. Albrecht Dröse: Die Anfänge der Reformation. In: Die Literatur im Übergang vom Mittelalter zur Neuzeit. Hg. von Werner Röcke und Marina Münkler. München 2004 (Hanser Sozialgeschichte der deutschen Literaur vom 16. Jahrhundert bis zur Gegenwart 1), S. 198-241, hier S. 203-204, sowie speziell für die Sangspruchdichtung Ders.: Antikuriale Polemik in der nachwaltherschen Sangspruchdichtung: Reinmar von Zweter, der Marner, Frauenlob. In: Sangspruchdichtung zwischen Reinmar von Zweter, Oswald von Wolkenstein und Michel Beheim. Hg. von Horst Brunner und Freimut Löser. Wiesbaden 2017 (Jahrbuch der Oswald von Wolkenstein-Gesellschaft 21 [2016/2017]), S. 31-46, hier S. 31-33.

$43{ }^{1}$ Musk/1/54b, Cgm 4997, fol. 87r-88v. Die sechste Strophe war ursprünglich mit einer eigenen Überschrift: Ein anders von priestern versehen, diese wurde jedoch später gestrichen.

44 Vgl. dazu wie für die „stereotype, oft topische Pfaffenschelte im traditionellen Rahmen“, deren Beispiele Petzsch (Anm. 19) zusammengetragen hat, Hannes Kästner: Pfaffenhaß und Pfaffenschelte in der politischen Ereignisdichtung und im meisterlichen Spruchlied um 1400. In: Würzburg. Der Große Löwenhof und die deutsche Literatur des Spätmittelalters. Hg. von Horst Brunner. Wiesbaden 2004 (Imagines medii aevi 17), S. 359-370, bes. S. 364-365, Zitat S. 365, der für den Zeitraum um 1400 allerdings in einigen Liedern eine gewisse Verschärfung im Ton beobachtet und daraus „eine Hinwendung zu einer radikaleren Haltung gegenüber dem Klerus“ (S. 366) ableitet. 
Stackmanns vermeintliche „Spuren einer verbitterten Rivalität zwischen dem Klerus und den Spruchdichtern" ${ }^{\text {"45 }}$ wären damit vor allem Ausdruck des Anspruchs der Spruchdichter, über geistlich-theologische Themen sprechen zu können und zu dürfen, dabei als Wortführer der Laien agieren und geistliche Bedürfnisse artikulieren, ja gegenüber den Priestern selbstbewusst einfordern zu können. ${ }^{46}$ Denn ein laientheologischer Anspruch in diesem Sinne wird fraglos an verschiedenen Stellen mehr oder weniger deutlich formuliert. Ein Lied in der Schallweise des Ehrenboten ${ }^{47}$ beginnt mit der programmatischen Frage: Waz ist daz beste getihte / der welde, weme ist daz kunt? (I,1-2) Die Antwort ist klar: das ist der gesanc (I,4), und im Folgenden wird dessen Legitimation vom himmlischen Gesang der Engel über den liturgischen der Priester bis zu den meisterlichen Liedautoren entworfen. In der dritten Strophe werden dazu schließlich klerikale Bildung und laikale Dichtkunst gegenübergestellt:
Man sagt von meisterpfaffen, wie daz die kunden tihten wol. alsô ist ez geschaffen daz in ist in den buochen kunt swaz got gewundert hât. In wâge in himel $\hat{u} f$ erden

45 Stackmann 1958 (Anm. 1), S. 173.

46 Keinesfalls negieren möchte ich mit meiner Betonung der rhetorischen Funktion der Kleruskritik die in der Forschung formulierte These von einer Konkurrenz zwischen fahrenden Sangspruchdichtern und Klerikern um sozioökonomische Ressourcen, die im 13. Jahrhundert durch die neu aufkommenden und ebenfalls mobilen Mendikantenprediger besondere Relevanz erhalten haben könnte, so Hannes Kästner: Sermo Vulgaris oder Hövischer Sanc. Der Wettstreit zwischen Mendikantenpredigern und Wanderdichtern um die Gunst des Laienpublikums und seine Folgen für die mittelhochdeutsche Sangspruchdichtung des 13. Jahrhunderts (Am Beispiel Bertholds von Regensburg und Friedrichs von Sonnenburg). In: Wechselspiele. Kommunikationsformen und Gattungsinterferenzen mittelhochdeutscher Lyrik. Hg. von Michael Schilling. Heidelberg 1996 (Beihefte zur Germanisch-romanischen Monatsschrift 13), S. 209-243. Allerdings scheint es mir problematisch, diese Rivalität thematisch-inhaltlich und mit Blick auf den geistlichen Anspruch der Sangspruchdichter als gewissermaßen gattungskonstitutiv betrachten zu wollen. So fasst Rosmer 2015 (Anm. 6), S. 314, zusammen: „Die Polemik der Kleriker bleibt zumeist unspezifisch, sie richtet sich nicht gegen mangelndes oder angemaßtes Wissen von Sangspruchdichtern, so dass es bei der Annahme eines allgemeinen Gegensatzes bleiben muss, der von Zeit zu Zeit und von Ort zu Ort eine gewisse Schärfe haben konnte.“

$47{ }^{1}$ Ehrb/2/4, Bartsch Nr. 153. Vgl. Petzsch 1978 (Anm. 19), S. 71-72. 


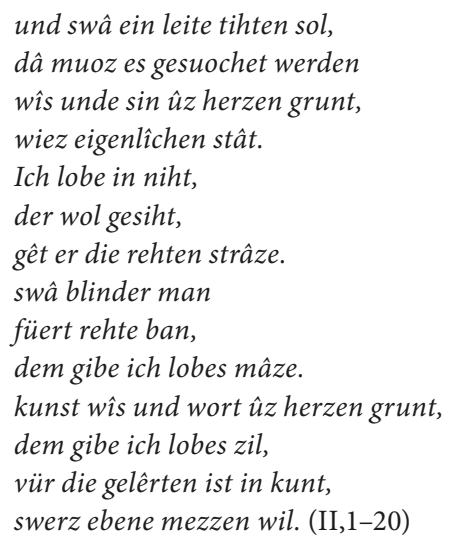

Die meisterpfaffen (III,1) verdienen dieser Argumentation zufolge weniger Lohn für ihr tihten (III,2) als die leien (III,7) - gemeint sind damit die meister, die keine theologische Bildung besitzen und diese wohl auch nicht brauchen, weil sie die Wunder Gottes nicht aus den Büchern kennen, sondern aus der Anschauung der Natur und $\hat{u} z$ herzen grunt (III,9) erkennen, wie es mit den Dingen eigenlîchen stât (III,10). Die volkssprachig-laikale Erkenntnis und Lehre gilt daher in nicht zu überhörendem Selbstbewusstsein als anerkennenswerter als die der gelêrten meisterpfaffen: „[N]icht derjenige ist zu loben, der die rehten strâze mit guten, das heißt hier mit theologisch geschulten Augen führt, sondern der ,Blinde', der dazu ohne jede Schulung gleicher Art imstande ist", so schon Petzsch. ${ }^{48}$ Allerdings geht es hier nicht allein um den Vorrang volkssprachiger lêre gegenüber dem der gelêrten, den Petzsch fokussiert. Vielmehr wird hier ein laientheologischer Anspruch greifbar, als Laie über geistliche Dinge sprechen zu dürfen, ja dazu qua Inspiration geradezu berufen zu sein und diese dabei in adäquater Form darbieten zu können. Denn der Diskurs über Gelehrtheit und Inspiration wird ergänzt und entscheidend akzentuiert durch den des künstlerischen Anspruchs, wenn die Formel von wîs und sin der Erkenntnis aufgegriffen wird als kunst wîs und wort $\hat{u} z$ herzen grunt, welchen allein vollkommenes Lob zukomme.

\section{III}

Damit komme ich $\mathrm{zu}$ meinem letzten Punkt und argumentativen Ziel. Denn wenn der laientheologische Anspruch der meister weder in der

48 Petzsch 1978 (Anm. 19), S. 72. 
inhaltlich-thematischen Qualität noch im bloßen laikalen Selbstbewusstsein einer Absetzung vom Klerus aufgeht, dann liegt es nahe, ihn im spezifischen literarisch-ästhetischen Medium der meisterlichen Liedkunst zu suchen, und damit in der Verbindung von geistlichem und ästhetischem Anspruch im Meisterschaftsdiskurs. ${ }^{49}$ Dieser reicht zurück bis weit in die Entstehung der Sangspruchdichtung, ließe sich folglich mit zahlreichen Beispielen belegen und in seiner diachronen Entwicklung herleiten. ${ }^{50}$ So resümiert Stackmann für Heinrich von Mügeln: „Die meister sind Freunde der wîsheit; Meisterschaft bedeutet [...] den Besitz der gesicherten wârheit und das Vermögen diese wârheit in Versen vorzutragen. ${ }^{\text {"51 }}$ Lehrhafter Anspruch und die Demonstration der eigenen Gelehrtheit gelten als Grundlage wahrer meisterschaft, die die meister vom ungelehrten leien trennt, und werden in der meisterlichen Liedkunst des 14. und 15. Jahrhunderts entsprechend poetologisch reflektiert. ${ }^{52}$

49 Die ,Kunstauffassung der frühen Meistersinger hat 1936 schon Heinz Otto Burger anhand der Kolmarer Liederhandschrift untersucht und „die Verflochtenheit meistersingerischer Poetik und Poesie nicht allein mit den Rhetoriken, die schon für die klassische Dichtung Geltung gehabt hatten, sondern mehr noch mit der Scholastik" konstatiert, insgesamt aber mehr die Parallelisierung des Meister-Titels mit den Handwerksmeistern fokussiert. Heinz Otto Burger: Die Kunstauffassung der frühen Meistersinger. Eine Untersuchung über die Kolmarer Handschrift. Berlin 1936 (Neue Deutsche Forschungen. Abteilung Deutsche Philologie 2), S. 75.

50 Vgl. Schanze 1983 (Anm. 10), S. 9. Aufschlussreich sind in diesem Zusammenhang auch die Lemmata ,Meister' und ,Meisterschaft' im Wörterbuch zur Göttinger Frauenlob-Ausgabe. Unter Mitarbeit von Jens Haustein redigiert von Karl Stackmann. Göttingen 1990 (Abhandlungen der Akademie der Wissenschaften zu Göttingen, Philologisch-Historische Klasse, Folge 3, 186), S. 235.

51 Stackmann 1958 (Anm. 1), S. 173.

52 So in Bezug auf Heinrich von Mügeln und die Rezeption kosmologischastronomischen Wissens in der meisterlichen Liedkunst des 14. und 15. Jahrhunderts Gade 2005 (Anm. 10), S. 181 und insbesondere S. 189-197. Gade zeigt aber auch (S. 181), dass das „Hochhalten eines auf Gelehrtheit und Belesenheit gegründeten Meister-Ideals“ in einer unaufgelösten Spannung zu einer „ausgeprägten Erkenntnisskepsis“ steht, die theologisch-geistlich begründet ist, wenn „[d]as Streben, die Wunder des Kosmos ergründen und begreifen zu wollen, [...] als gotteslästerliche superbia und als Häresie verurteilt“ werden kann. Diese ambivalente Haltung versteht sie als konstitutiv für die spätere Sangspruchdichtung und meisterliche Liedkunst, die immanentes Weltwissen mit transzendenten Wahrheiten verknüpfe und konfrontiere: „Gelehrtheit und Erkenntnisskepsis sind immer zugleich präsent, das eine bedingt das andere, und häufig dient die Demonstration der Wissensskepsis gerade dem Nachweis eigenen Wissens" (S. 182). 
Die Traditionskette vom Sangspruch über die meisterliche Liedkunst zum Meistergesang zeichnet sich durch ein ausgeprägtes Traditionsbewusstsein aus, das in der Berufung auf die alten Meister konstitutiv wird. In diesem Zusammenhang wäre auf die Ursprungssage zu verweisen, wie sie für den institutionalisierten Meistergesang seit dem 16. Jahrhundert greifbar wird und die diesen legitimatorisch-funktional bestimmt. Sie dreht sich in ihren verschiedenen Fassungen stets um die Frage, ob die Kunst der zwölf ,alten Meister, die vollkommen anachronistisch ins 10 . Jahrhundert datiert werden, eine häretisch-sektiererische oder eben eine gottgefällige und durch Gott selbst inspirierte ist, die der theologisch-gelehrten Überprüfung standhält und von Kaiser Otto I. und Papst Leo VIII. im Jahre 962, also im Gründungsjahr des Heiligen Römischen Reiches deutscher Nation, legitimiert wird. Stackmann hat diese Sage nicht als eine ätiologische, sondern als apologetische verstanden, die der Polemik des Klerus gegen die laientheologische Selbstermächtigung der meister wehren sollte. ${ }^{53}$ Diese mögliche Funktion ist sicher nicht ganz von der Hand zu weisen, doch lässt sich die Sage mit Brunner umfassender, und trotz ihrer historischen Ungereimtheiten im Einzelnen, als eine „wohldurchdachte dichterische Fiktion mit dem Anspruch der eigenen historischen Kontextualisierung und literarischen Konzeptionalisierung" und damit als „selbstreflexive Inszenierung" der Meistersinger verstehen, die ihre Kunst zur Traditionspflege wie zum Lob Gottes auszuüben beanspruchen. ${ }^{54}$ In ihrem Kunstbewusstsein stellen sich die Meistersinger jedenfalls bewusst in die Kontinuität der vorangegangenen Gattungstradition:

Selbst den Namen ihrer Kunstübung haben die Meistersinger geerbt: schon die Sangspruchdichter des 13. Jahrhunderts wurden ihrer Gelehrsamkeit und ihres Kunstanspruchs wegen in ihrer Zeit als meister (von lat. magister) gerühmt, und sie selbst sprachen schon gelegentlich von meistersanc, Gesang der meister ${ }^{55}$

Der Meisterschaftsdiskurs ist also entscheidend für den Traditionszusammenhang insgesamt, bestimmt konzeptionell und legitimatorisch aber vor allem den Kommunikations- und Interaktionszusammenhang des zunftmäßigen Meistergesangs als den einer gemeinschaftlichen Kunstübung in der

53 Stackmann 1958 (Anm. 1), S. 174.

54 Dehnert 2017 (Anm. 8), S. 106, in Bezug auf Brunner 1975 (Anm. 18), S. 24f. Zur Ursprungssage und ihrer Funktion im 16. Jahrhundert, auch im Zusammenhang mit der Kolmarer Liederhandschrift vgl. außerdem Brunner/Rettelbach 1985 (Anm. 18).

55 Einleitung des RSM, Bd. 1, S. 6. 
Singschule. Hier kreuzen sich schließlich, so möchte ich die bisherige Argumentation zusammenführen, der nun in den Tabulaturen kodifizierte ästhetische Anspruch regelkonformer Dichtung und fehlerfreier Darbietung mit der theologischen Selbstermächtigung, als Laie über geistliche Themen sprechen zu dürfen und zu können. Mit der künstlerisch bestimmten „Meisterschaft im Formalen der Strophenkunst" verknüpft sich im Meistergesang ein Geltungsanspruch, der auf die Bearbeitung und Vermittlung theologischer Inhalte ausgreift und dabei über die „Laiengelehrtheit und demonstrative Wissenssouveränität“ der Sangspruchdichtung hinausgeht, ${ }^{56}$ insofern er nicht nur die situativen Legitimationsstrategien der jeweiligen Autoren, sondern vor allem deren Funktionszuschreibung an ihren Gesang selbst meint - eine Zuschreibung und selbstreflexive Inszenierung, die nun nicht erst in den Singschulen der zunftmäßigen Meistersinger entsteht, sondern in der meisterlichen Liedkunst des 15. Jahrhunderts vorbereitet wird.

Vor diesem Hintergrund ist mein Ansatz also jener, die theologischen Inhalte beziehungsweise den Akt des Sprechens über religiöse Themen mit der Selbstreflexion und Selbstlegitimation meisterlicher Kunstauffassung zu überblenden beziehungsweise nach solchen Überblendungen in den Texten selbst zu suchen. Im Meisterschaftsdiskurs müsste solchermaßen eine Auseinandersetzung um die ästhetische wie (laien-)theologische,Geltung des Sanges ${ }^{57} \mathrm{zu}$ beschreiben sein, hinsichtlich der Autorisierung von Sprecherrollen und Redeordnungen,

56 Volker Mertens: Meistergesang und Predigt. Formen der Performanz und Legitimationsstrategien im späten Mittelalter. In: Sangspruchtradition: Aufführung, Geltungsstrategien, Spannungsfelder. Hg. von Margreth Egidi, Volker Mertens und Nine Miedema. Frankfurt am Main 2004 (Kultur, Wissenschaft, Literatur 5), S. 125-142, hier S. 128. Mertens bezieht die formale Meisterschaft auf die Institution der Meistersingergesellschaft, die sich im Liedvortrag aktualisiere. Der nachreformatorische Meistergesang rückt damit in seiner Performanz, die in der Bewährung der formalen Fähigkeiten im regelkonformen und fehlerfreien Meisterliedvortrag zugleich die intensive Betrachtung des Bibeltextes und damit theologische Kompetenz einschließt, in Parallele zur Predigt und ihren Legitimationsstrategien. Vgl. ebd., S. 136. Ob man angesichts der für die Bibelversifikationen des nachreformatorischen Meistergesangs fraglos konstitutiven ,demonstrativaneignenden' Performanz die ,kommunikativ-verkündigende' tatsächlich als sekundär betrachten muss, wie Mertens (S. 137) will, scheint mir indes fraglich. Beides ergänzt sich im Hinblick auf Geltungsbedingungen und Geltungsstrategien im meistersingerlichen Liedvortrag.

57 Die Frage nach der, Geltung des Sangs' ist für den Sangspruch in den letzten Jahren intensiv verhandelt worden, vgl. den konzisen Abriss bei Rosmer 2015 (vgl. Anm. 6), S. $312 f$. 
die über die Konstitution der jeweiligen Sängerrolle des einzelnen Liedes und die bloß konventionelle Topik einer Legitimation laikalen Sprechens über geistliche Themen hinausgeht. Zu solchen topischen Elementen würde ich auch Inspirationsbitten im Eingang von Liedern mit geistlichem Inhalt zählen, beispielsweise ein Gebet des Sängers an den Heiligen Geist im Eingang eines Liedes In meister Ankers dône ${ }^{58}$, auch wenn der theologische Anspruch hier nun explizit nicht nur die wissensmäßige Erkenntnis, sondern in poetologischer Ausdeutung der navigatio vitae gleichzeitig das richtige Dichten umfasst:

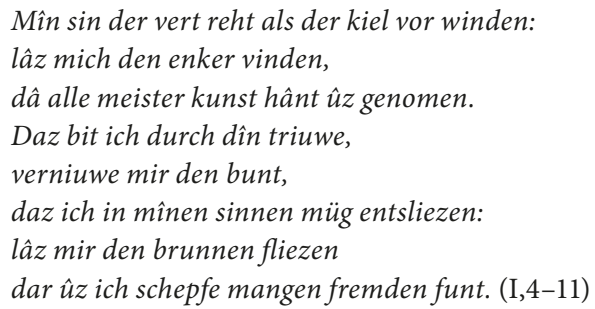

$\mathrm{Zu}$ einer solchen Legitimitationsstragie qua göttlicher Inspiration würde auch die Beteuerung des eigenen, sowohl geistlichen wie künstlerischen Unvermögens zählen, aus dem heraus Gott vil der wunder schaffen (III,6) möge, wie es in einem $[d]$ en guoten sengern $(\mathrm{I}, 1)$ gewidmeten Lied $^{59}$ heißt, das freilich gleich einen ganzen Geltungszusammenhang meisterlichen Dichtens entwirft, der sich auf die zitierte Inspirationsbitte in der dritten Strophe hin verdichtet. Inszeniert ist es nämlich als Bitte eines Sängers um Aufnahme in die Gemeinschaft der adressierten Sänger: sô daz sie mich geselleclîch in ire zunft enpfâhen (I,3). Für den Fall, dass es ihm an rehter kunst $(\mathrm{I}, 7)$ fehle, wolle er alrêrst $[. .$.$] geleites gern (\mathrm{I}, 8)$, meint damit aber ausdrücklich nur [...] die meister die dâ künnent mezzen, / ob ich mich $\hat{u}$ fder künste ban mit rîmen iht vergezzen (I,10-11). Der Anspruch formaler Meisterschaft wird in der zweiten Strophe vertieft, wenn sich der Sänger der Kritik derjenigen erwehrt, die ihn vil dicke durch die strâfemüln gehen lassen wollen, obwohl sie gar nicht wissen, wie man der künste mülen sol betreiben und berihten (II,2-3). Vielmehr übergibt er sich dem Urteil und Geleit der meister (II,7):

den gibe ich mich hie ûf ir müln daz sie mich sülen machen,

58 Bartsch Nr. 162. Der Name des Tonautors ist wegen des Ankermotivs vermutlich aus dem Tonnamen hypostasiert, daher ${ }^{1}$ Ank $/ 1$, eigentlich wohl ${ }^{1}$ Steinh/1b, um 1400 (?). Vgl. RSM, Bd. 3, S. 8 und Bd. 5, S. 391.

$59{ }^{1} \mathrm{Ehrb} / 1 / 507$, Bartsch Nr. 151. 
vil cleine malen gerwen unde griezen

alsô daz mîns gesanges mel die wîsen mügen niezen

daz ich vor künstelôser diet belîbe ân allez swachen. (II,8-12)

Dieser Diskurs um die ästhetische Meisterschaft der meisterlichen Dichtkunst wird nun in der dritten Strophe ergänzt um denjenigen theologischer Gelehrsamkeit und geistlicher Inspiration: kein bâbest nie sô wîse wart ern müeste sîn schuolore, / die bischove und die cardinâl, dar zuo die wîsen pfaffen (III,2-3). Aus dem Kontrast zur zwar zugestandenen, aber eben auch nie vollkommenen theologischen Gelehrsamkeit der Kleriker zieht das Sänger-Ich argumentative Kraft für seine Selbstlegitimation, denn da Gott auch im Unscheinbaren und Ungestalten wirke, könne es sich seiner Gnade und ,Schule‘ anbefehlen:

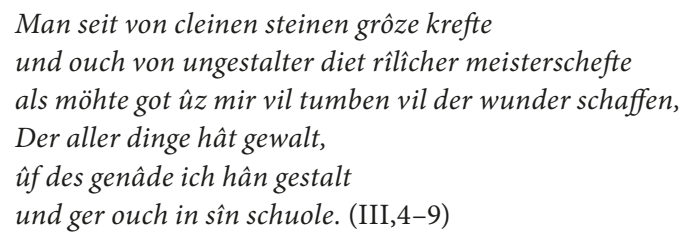

Damit ist auch der Bogen zu den guoten meistern (III,10) gezogen, denen sich das Sänger-Ich verpflichtet, sie zu êren und daz sie mich sülen lêren (III,10 und 11).

Vollends zum poetologischen Programm meisterlicher Dicht- und Sangeskunst wird eine solche Verschränkung ästhetisch-formaler Meisterschaft mit der geistlichen Legitimation durch Inspiration gegenüber bloßer Gelehrsamkeit in einem fürwurf, der sich nicht nur in der dritten Person an die Gemeinschaft der meisterlichen Sänger wendet, sondern direkt die gesanges gsellen $(\mathrm{I}, 1)$ anspricht. ${ }^{60}$ Es scheint mir hier nun kein Zufall, dass der Sprechmodus nicht derjenige theologischer Argumentation ist, sondern der des Lobpreises Gottes und vor allem Mariens sowie des Gebets - ein theologisches Sprechen, das den Laien ja von jeher erlaubt war und auch einen Großteil der Meisterlieder durchzieht. Der Sänger begrüßt seine Mitsänger als Teil einer Gemeinschaft, die in ihrem Gesang von Gott her legitimiert ist und in der Übung ihrer meisterschefte $(\mathrm{I}, 3)$ auf ihn verpflichtet bleibt:

\footnotetext{
Sint gote wilkumen, ir gesanges gsellen guot: der zarte got der habe uns allen in siner huot. swer nu mit meisterschefte daz beste tuot, dem sol man geben lop und brîs, gelücke und heil uns allen.
}

$60{ }^{1}$ Regb/1/549, Bartsch Nr. 76. 
Die sollen tûsentveltic gote wilkomen sîn die edeln meistersanc hie singen clâr und vîn gote ze lobe und Mariên der künigin, und swer des pfliget alle zît, der mac wohl frôlîch schallen. (I,1-8)

Im Vollzug des gemeinsamen Singens, Rühmens und Betens als Medium kollektiver Heilssorge konstituiert sich also eine quasi kultische Gemeinschaft, und der Gesang meint hier nicht nur die formale Kunstbeherrschung des Singens - clâr und vîn $(\mathrm{I}, 6)$-, sondern auch die Worte. Form und Inhalt, beides zeichnet die hier schon ausdrücklich als meistersanc (I,6) apostrophierte meisterliche Kunstübung aus:

Guot edel sanc ûf erde in himelrîche ist wol ob aller kunst ein êren swêbender hort.

Dâ von sô lobe ich edel sanc und guote wort: swer diu zwei $\hat{u} z$ probieret $\hat{u} f$ ein ganzes ort, daz wort und wîs bring rîchen sin, daz lobe ich sicherlîche. (I,9-13)

Ästhetischer und geistlicher Anspruch - der ein laientheologischer im Sinne eines theologischen Sprechens unter beziehungsweise von Laien für Laien ist bedingen sich hier gegenseitig. Die zweite Strophe ruft die gesanges gesellen (II,1) dazu auf, den edeln sanc (II,2) stets und überall zu pflegen und zu verbreiten, nachdem er lange zît geslâfen (II,5) habe: guot edel sanc der gît vernunft und wîse lêr / dâ von sol man gesanges baner wît in der welt ûf stecken (II,7-8), betont der Sänger hier den geistlichen Anspruch des Gesangs, und in dessen eindringlich wiederholter, wiewohl topischer Attribuierung als edel überschneiden sich ästhetischer Wohlklang und Gottgefälligkeit. Die Legitimität, ja Notwendigkeit eines solchen laientheologischen Sprechens und Singens erweist sich in der Inszenierung dieses Liedes schließlich in ihrer die Gemeinschaft der Sänger in die himmlische Sphäre transzendierenden Wirkung:

Ir frumen gesanges gsellen, ir solt nicht enlân,

ir solt mit edelsange ze himelrîche gân.

Got wil gesanc in sînem hohsten himel hân.

mit edelm sanc nu nieman kêr ern welle dâ mit schallen.

Mit edelm sange sô tet got sîn himelvart,

mit edelm sange ouch Marîa sîn muoter zart,

mit edelm sange im niunden kôre enpfangen wart.

guot edelsanc ist ie und immer gote wol gevallen. (III,1-8)

Mit edelsange (III,2), so unterstreicht die an kultische Rezitationsweisen gemahnende eindringliche Wiederholung, sollen die gesanges gsellen (III,1) ins Himmelreich voranschreiten, weil Gott ihn ebendort hören wolle. Da zudem seine wie seiner Mutter Himmelfahrt durch ebensolchen begleitet gewesen sei, 
erhalten die Sänger Anteil an der göttlichen ascensio. ${ }^{61}$ Geistliche Erkenntnis und Erlösung liegen dabei im Gesang als Einheit von kunstvollem Dichten und Singen und der Wahl der richtigen Worte: Guot edelsanc mit worte und ouch mit wîse / wol zieret und bekronet allez daz dâ ist (III,9-10) beginnt der Abgesang. Und so mündet das Lied, wie sollte es anders sein, in ein Gebet, das Gott selbst zum Urheber des kollektiven meisterlichen Singens erklärt: ${ }^{62}$

êwiger vater got, sun herre Jhês $\hat{u}$ Crist, ich bite dich, herre, nu tuo uns dîner wîsheit list, daz wir dîn lop und ouch dîn êr mit allem sange brîsen. (III,11-13)

Wenn in dieser poetologischen Selbstreflexion und Selbstlegitimation meisterlichen Singens im Spannungsfeld von ästhetischem und geistlichem Anspruch die (laien-)theologische Relevanz und Legitimität des Gesangs über den Kunstanspruch und die Ästhetisierung religiösen Sprechens über göttliche Inspiration eingeholt werden, dann stellt sich die ,Meisterschaft des Laien', nach der ich eingangs fragte, als eine gleichermaßen ästhetische wie theologische dar. Der laientheologische Anspruch der meisterlichen Liedkunst reiht sich damit fraglos ein in das breite Feld ,vorreformatorischer Laienbildung', die Laien als Subjekte ihrer Frömmigkeit hervortreten und sie nach eigenen Formen und eben auch literarisch-künstlerischen Ausdrucksmitteln suchen lässt.

Auf diese Weise haben die meister des 14. und 15. Jahrhunderts mit ihrer kunst, wenn vielleicht nicht unmittelbar der Reformation ,den Weg geebnet',

61 Als gewissermaßen gegenläufige, aber ergänzende Legitimationsstrategie erweist sich der von Miedema beschriebene Anspruch der Meistersinger, „dass sie den [...] Gesang des Himmels auf Erden zu imitieren wussten oder zumindest einen Vorgeschmack der himmlischen Musik bieten konnten“. Nine Miedema: Himmlischer Gesang auf Erden. Die Meistersinger und ihre Kunst. In: Himmel auf Erden. Heaven on Earth. Hg. von Rudolf Suntrup und Jan R. Veenstra. Frankfurt am Main 2009 (Medieval to Early Modern Culture/Kultureller Wandel vom Mittelalter zur Frühen Neuzeit 12), S. 57-88, hier S. 65-66.

62 Freilich ist diese Zuschreibung für das meisterliche Kunstverständnis konstitutiv: „Die im Cgm 4997 [k] und den weiteren großen Liederhandschriften versammelten anonymen Dichter sind sich einig, dass der Ursprung aller ,rechten Kunst' ein göttlicher ist." Judith Lange: Wettstreit um die rehte kunst - Fürwurf und Straflied im Meistergesang des 15. Jahrhunderts. In: Die Edition mittelalterlicher deutscher Texte. Festkolloquium aus Anlass des 80. Geburtstags von Rudolf Bentzinger am 22.8.2016. Hg. von Eva Rothenberger, Martin Schubert und Elke Zinsmeister. Erfurt 2019 (Akademie gemeinnütziger Wissenschaften zu Erfurt. Sonderschriften 50), S. 113-137, hier S. 116-117. Anrufungen an Gott, er möge die Dichter mit Weisheit und Kunstfertigkeit versehen, und Gebete sind daher topisch, vgl. die Belege ebd., S. 117. 
so aber doch zumindest die Grundlagen für den späteren Meistergesang gelegt. Denn die hier im letzten Lied herausgearbeitete poetologische Reflexion und Legitimation setzt sich in den Schulkünsten des nachreformatorischen Meistergesangs konsequent fort, die allerdings den geistlichen Anspruch noch stärker betonen, wie sich am Beispiel eines Liedes von Adam Puschmanns vom 1. Januar 1571 zeigen lässt. ${ }^{63}$ Zweck und Inhalt dieses Liedes sind in seiner Überschrift benannt: Einn schulkunst, vorher zu singen, wenn man schul helt, darinnen angezeigt der vrsprung dieser kunst, wer, wie, wenn vnd warumb sie erfunden, und auch die herausgestellte künstlerische Qualität unterstreicht diesen legitimatorischen wie gemeinschaftsstiftenden Anspruch über die Rückbindung der konkreten Singschulveranstaltung an die Gattungstradition, denn es handelt sich, wie es weiter heißt, um ein gefünfft lied in den 4 gekrönten hauptthönen der 4 gekrönten meister. Die meisterliche Sangeskunst wird hier nun letztlich auf keinen Geringeren als König David zurückgeführt, der vns $(\mathrm{I}, 10)$, also die Gläubigen allgemein wie die Meistersinger im Besonderen, mit seinen Psalmen aufgefordert habe, Gott mit Gesang zu loben:

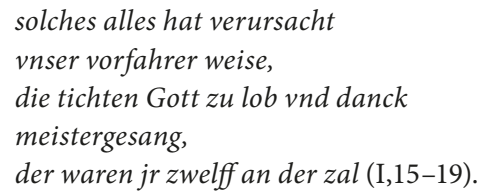

Die Legitimation über den Psalmisten als Ahnherren der Dichter und Patron der Meistersinger verbindet sich hier mit der klaren und letztlich allein geistlichen Funktionalisierung des Meistergesangs, wenn der Sänger - nach seinen Ausführungen über die Gründungssage, die Entstehung der Tabulaturen mit ihren inhaltlichen wie formalen Regeln, die damit verbundenen Strafen sowie das im Wettstreit zu ersingende Schulkleinod - seinen Mitsängern zusingt: $n u$ fanget an vnd singt Gottes wort rein (V,29). Die Aufgabe des Gesangs ist mit der lutherischen Reformation schließlich die Verbreitung der viva vox geworden, des lebendigen Wortes Gottes selbst, ${ }^{64}$ das aus der Schrift heraus im mündlichen Vortrag der Meistersinger immer wieder zur Sprache kommen muss.

$63{ }^{2} \mathrm{Pus} / 13 \mathrm{a}$, abgedruckt in Meisterlieder des 16. bis 18. Jahrhunderts. Hg. von Horst Brunner und Eva Klesatschke. Tübingen 1993 (Frühe Neuzeit 17), S. 233-237.

64 Vgl. Volker Mertens: Lebendige Stimme und tote Schrift. Erscheinungsform und Selbstverständnis von Luthers Predigt. In: Predigt im Kontext. Hg. von Volker Mertens, Hans-Jochen Schiewer und Regina Dorothea Schiewer. Berlin 2013, S. 257-280, hier S. $260 f$. 


\title{
Johannes Janota
}

\section{Die Bibelversifikationen in der Kolmarer Liederhandschrift}

\begin{abstract}
The versification of biblical texts is a genre that had a growing impact since the Reformation and was very much shaped by Hans Sachs. Yet, the Colmar Liederhandschrift contains seven such, more or less prototypical, versifications. The article analyses the poetical facture of these songs and the possibilities to sort them into groups. For this, the melodies employed ("Töne") have to be acknowledged, because they transport a certain range of artificiality, and the correspondence with the biblical text has to be studied. The seven songs turn out to display a broad spectre from meticulous translations to abbreviated paraphrases. Encompassing this spectre, the early versifications can be seen as a fixed type that builds a basis for the later forms.
\end{abstract}

Angesichts der wenigen vorreformatorischen Bibelversifikationen in Sangsprüchen und frühen Meisterliedern ${ }^{1}$ erscheint es nicht als verwunderlich, dass eine systematische Sichtung dieser Überlieferung bislang fehlt. Eine Ausnahme macht nur Michel Beheim, der letzte professionelle Spruchsänger, von dem zwar 68 der 90 vorreformatorischen Versifikationen stammen, ${ }^{2}$ der aber trotz seines eindrucksvollen Werks keine erkennbare Wirkung auf den Meistergesang vor und nach der Reformation ausübte. Sieht man von diesem nicht nur

1 Vgl. dazu das Verzeichnis der Bibelstellen in: Repertorium der Sangsprüche und Meisterlieder des 12. bis 18. Jahrhunderts [RSM]. 16 Bde. Hg. von Horst Brunner und Burghart Wachinger. Tübingen 1994-2009; hier Bd. 16, S. 261-330. Die textnahen Versifikationen (aus dem Älteren und Jüngeren Teil des Repertoriums) sind mit einem Asteriskus $\left(^{\star}\right)$ gekennzeichnet. Die Liedsiglen entsprechen nachfolgend dem RSM.

2 Vgl. Burghart Wachinger: Michel Beheim. Prosabuchquellen - Liedvortrag - Buchüberlieferung. In: Poesie und Gebrauchsliteratur im deutschen Mittelalter. Hg. von Volker Honemann, Kurt Ruh u. a. Tübingen 1979, S. 37-74. Zitiert wird nach dem ergänzten Wiederabdruck in Burghart Wachinger: Lieder und Liederbücher. Gesammelte Aufsätze zur mittelhochdeutschen Lyrik. Berlin, New York 2011, S. 363-393, und Johannes Fournier: Die gute Nachricht in wechselnden Formen. Vers und Prosa im ,St. Pauler Evangelienreimwerk', im Evangelienbuch für Matthias Beheim und in Michel Beheims Liedern. In: Metamorphosen der Bibel. Hg. von Ralf Plate und Andrea Rapp. Frankfurt a. M. 2004 (Vestigia Bibliae 24/25), S. 189-207. 
quantitativ erstaunlichen Korpus ab, dann verbleiben ganze 22 Versifikationen aus vorreformatorischer Zeit, die im Vergleich zur sonstigen Überlieferung an Sangsprüchen und frühen Meisterliedern kaum ins Auge fallen. Dieser Sachverhalt begründet Burghart Wachingers Urteil, dass vor der Reformation ein fest ausgebildeter Typus der 18 Bibelversifikation bei den Sangspruchdichtern und Meistersingern fehlt. ${ }^{3}$

Allerdings ist mit dem numerischen Argument nichts über die poetische Faktur der 22 Versifikationen gesagt. Besteht ihre Gemeinsamkeit allein in der Versifikation ausgewählter Bibelabschnitte? ${ }^{4}$ Oder gibt es über diesen materiellen Kern hinaus trotz aller Unterschiede im Einzelnen zumindest ein verbindendes Kennzeichen struktureller Art? Lassen sich innerhalb eines solchen verbindenden Rahmens Ansätze zu Gruppenbildungen erkennen? Zwar wird man bei Merkmalen dieser Art wegen der bescheidenen Anzahl an Bibelversifikationen auch weiterhin von keinem ,festen Typ' sprechen, wohl aber von einem Prototyp. Er wäre ein fester Vergleichspunkt, von dem aus spezifische Unterschiede, aber auch Übereinstimmungen mit den Bibelversifikationen der Reformationszeit bestimmt werden könnten, der vielleicht sogar nahelegt, in ihm ein Modell zu sehen, von dem sich Hans Sachs anregen ließ, als er mit

3 Wachinger 2011 (Anm. 2), S. 387: „Als festen Typ gibt es die Bibelversifikation außer bei Beheim nur im nachreformatorischen Meistergesang, wo die Lutherbibel zur verbindlichen Grundlage der reinen Lehre geworden war und beim Liedvortrag von den Merkern hinterm Vorhang zur Kontrolle mitgelesen wurde.“

4 Von den selbständigen Versifikationen von Bibelabschnitten zu unterscheiden sind kurze Bibelzitate, die zu argumentativen Zwecken (also ohne selbständigen Status) in geistliche oder weltliche Sangsprüche und Meisterlieder eingelagert sind. Unberücksichtigt bleiben im vorliegenden Zusammenhang natürlich auch die versifizierten Überblicke über die Bücher der Bibel, die in der Kolmarer Liederhandschrift mit einer Inhaltsangabe der Bücher in der Hebräischen Bibel durch Heinrich von Mügeln ( $\left.{ }^{1} \mathrm{Hei} / \mathrm{Mü} / 71-109 \mathrm{~b}\right)$ vertreten sind; vgl. dazu auch die Versifikation Michel Beheims ('Beh/148). Aus der Reformationszeit zu nennen sind Hans Sachs ( ${ }^{2} S / 185$ : Übersicht über die Bücher der Hebräischen und der Christlichen Bibel auf der Grundlage der Lutherbibel), Adam Puschmann ( ${ }^{2} \mathrm{Pus} / 172$ : unvollständiger Überblick über die Geschichtsbücher der Hebräischen Bibel) und ein Anonymus ( ${ }^{2} \mathrm{~A} / 392$ : gedruckte 82-strophige Übersicht über die Bücher der Hebräischen Bibel im Herzog-Ernst-Ton, der im Meistergesang als volkstümlicher, auch im Druck überlieferter Ton nicht erlaubt war, und als eigener Teil eine 29-strophige Übersicht über die Bücher der Christlichen Bibel). Zur Ablehnung des Herzog-Ernst-Tons im Meistergesang vgl. Horst Brunner: Epenmelodien. In: Formen mittelalterlicher Literatur. Festschrift Siegfried Beyschlag. Hg. von Otmar Werner und Bernd Naumann. Göppingen 1970 (GAG 25), S. 149-178, hierzu S. 154. 
seinen Bibelversifikationen ( $\mathrm{ab}$ 1526) den Grundstein für diesen dann zentralen Typ des reformatorischen und nachreformatorischen Meisterlieds schuf. Immerhin enthält sein Berliner Autograph (Berlin, Mgq 414) ${ }^{5}$ von 1517/18 nicht weniger als 10 vorreformatorische Bibelversifikationen, ${ }^{6}$ mit denen sich der Nürnberger Meistersinger auseinandersetzen konnte, bevor er seine Versifikationen aus dem Geist der Reformation schuf.

Ein Blick auf die Überlieferung stützt den Vorschlag, in vorreformatorischen Bibelversifikationen eine feste Größe zu sehen. Denn trotz ihrer geringen Anzahl treten sie in spätmittelalterlichen Sammelhandschriften mit mehreren Belegen auf: in der Kolmarer Liederhandschrift (um 1460) mit 7 Versifikationen, ${ }^{7}$ in der aus Augsburg stammenden, um 1500 entstandenen Heidelberger Meisterliederhandschrift (Heidelberg, Cpg 392) mit 4 und in der ersten Meisterliedersammlung (1517/18) des Hans Sachs (Berlin, Mgq 414), wie erwähnt, sogar mit 10 Versifikationen (einschließlich einer Parallelüberlieferung zur Kolmarer Liederhandschrift). ${ }^{8}$ Allerdings bilden die Bibelversifikationen in diesen Handschriften keine geschlossenen Gruppen, sondern sind über die Sammlungen verteilt, wobei in der Kolmarer Liederhandschrift (ähnlich wie im Berliner Sachs-Autograph) eine Anordnung nach Tonautoren und Tönen bekanntlich das leitende Prinzip ist.

Wenn man die vorreformatorischen Bibelversifikationen genauer beschreiben will, dann versprechen zwei Aspekte genauere Aufschlüsse: zum einen der Blick auf die verwendeten Töne, nicht nur weil die kompetente Verwendung der Töne (seien es eigene, seien es fremde) bei den Meistersingern eine vorrangige Rolle spielte, sondern weil die Wahl eines mehr oder weniger artifiziellen Tons Auswirkungen auf die Textgestalt der Versifikation hat; zum andern

5 Vgl. RSM 1, S. 84-86.

6 Vgl. Johannes Janota: Kanonische Texte in poetischer Form. Zur Versifikation von Evangelienabschnitten im Berliner Hans Sachs-Autograph. In: Geistliche Liederdichter zwischen Liturgie und Volkssprache. Übertragungen, Bearbeitungen, Neuschöpfungen in Mittelalter und Früher Neuzeit. Hg. von Andreas Kraß und Matthias Standke. Berlin/Boston 2020 (Liturgie und Volkssprache 5), S. 161-178.

7 Dabei ist wie im RSM der Hort des Peter von Reichenbach in die Zählung einbezogen, obwohl es sich dabei um einen Leich handelt (s. u.).

8 Dazu kommt ein einzelner Beleg in der Augsburger Sammlung Heidelberg, Cpg 680, die zwar erst 1532/33 aufgezeichnet wurde, die aber im ersten Teil 53 vorreformatorische Lieder enthält. Bei einem weiteren Beleg in der Wiltener Handschrift (München Cgm 5198, um 1500) handelt es sich um eine Parallelüberlieferung zur Kolmarer Liederhandschrift. 
der Vergleich zwischen dem Bibeltext und seiner Versifikation, weil sich hier zwischen intendierter Textnähe und raffender Paraphrase ein breites Spektrum an Gestaltungsmöglichkeiten eröffnet, die vielleicht Ansätze für typische Textmuster zeigen. Dieser Differenzierungsversuch soll nachfolgend für die Bibelversifikationen in der Kolmarer Liederhandschrift als der hierfür ältesten Überlieferung ${ }^{9}$ unternommen werden. Die Ergebnisse lassen sich dann in Untersuchungen zu den übrigen vorreformatorischen Versifikationen vertiefen, um schließlich einen verlässlichen Vergleich mit den seit Hans Sachs aufblühenden Bibelversifikationen in der Reformationszeit zu ermöglichen.

Sieht man vom Hort Peters von Reichenbach ( ${ }^{1}$ PeterR/2/1) ab, dann verwenden die durchweg anonymen Textautoren für die sechs Versifikationen ( ${ }^{1}$ Marn/ 7/540, ${ }^{1}$ KonrW/10/2, ${ }^{1}$ Frau/23/6a, ${ }^{1}$ Regb/4/557a, ${ }^{1}$ Regb/4/592 und ${ }^{1}$ Lesch/6/2) fünf Sangspruchtöne: Marners Langen Ton ( $\left.{ }^{1} \mathrm{Marn} / 7 / 540\right)$, die Konrad von Würzburg zugeschriebene Nachtweise ( ${ }^{1}$ KonrW/10/2), die Frauenlob zugeschriebene Ritterweise ( $\left.{ }^{1} \mathrm{Frau} / 23 / 6 \mathrm{a}\right)$, Regenbogens Langen Ton $\left({ }^{1} \mathrm{Regb} / 4 / 557 \mathrm{a},{ }^{1} \mathrm{Regb} / 4 / 592\right)$ und Albrecht Leschs Gesangweise ( ${ }^{1}$ Lesch/6/2). Die Bezeichnung ,Langer Ton bei drei Versifikationen lässt vermuten, dass bei der Wahl des Tons auch quantitative Gesichtspunkte eine Rolle spielten. Immerhin konnte man in einer umfangreichen Strophenform einen vorgegebenen Text leichter unterbringen als auf engbemessenem Raum - falls man die Strophenzahl in Grenzen halten wollte. Die quantitativen Aspekte und Relationen sollen daher zunächst verdeutlicht werden.

Beim Strophenumfang zeichnet sich eine Trennlinie ab, die bei 20 Zeilen verläuft. Die fünf Töne liegen deutlich über oder unter dieser Marke:

Marner, Langer Ton: 27 Zeilen

Regenbogen, Langer Ton: 23 Zeilen

Albrecht Lesch, Gesangweise: 22 Zeilen

Frauenlob, Ritterweise: 16 Zeilen

Konrad von Würzburg, Nachtweise: 13 Zeilen

Bezieht man die sprachliche Füllung (die Silbenzahl) der Strophen und die Strophenzahl der sechs Versifikationen in die Rechnung ein, dann verschiebt sich das Bild etwas:

9 Der einzige noch ältere Beleg für eine Bibelversifikation steht laut RSM in der Jenaer Liederhandschrift (um 1330) - ein zweistrophiger Sangspruch Des Meißners ( $\left.{ }^{1} \mathrm{Mei} / 10 / 2-3\right)$, der bei genauerem Hinsehen aus dem Korpus der textnahen Bibelversifikationen zu streichen ist, weil die ausgewählten Bibelverse nur als Teil einer typologischen Deutung, aber nicht für sich verständlich sind. 
Regenbogen, Langer Ton: 174 Silben

Marner, Langer Ton: 158 Silben

Albrecht Lesch, Gesangweise: 96 Silben

Frauenlob, Ritterweise: 87 Silben

Konrad von Würzburg, Nachtweise: 77 Silben
${ }^{1} \operatorname{Regb} / 4 / 592: 7$ Strophen $=1218$ Silben

${ }^{1}$ Regb/4/557a: 5 Strophen $=870$ Silben

${ }^{1}$ Marn/7/540: 5 Strophen $=790$ Silben

${ }^{1}$ Lesch/6/2: 5 Strophen $=480$ Silben

${ }^{1}$ Frau/23/6a: 3 Strophen $=261$ Silben

${ }^{1}$ KonrW/10/2: 3 Strophen = 231 Silben

Hier verläuft die Trennlinie bei etwa 500 Silben. Entsprechend wandert Albrecht Leschs Gesangweise zu Frauenlobs Ritterweise und zu Konrads von Würzburg Nachtweise, so dass die Langen Töne (Marner, Regenbogen) quantitativ tatsächlich eine Einheit bilden.

Eine größere Herausforderung als die quantitativen Vorgaben waren bei einer textnahen Bibelversifikation die formalen Ansprüche der Strophenstruktur, die sich mit der Wahl eines Tones stellten. Hier reichte die Bandbreite von konventionellen bis zu artifiziellen Formmustern. Der Schwierigkeitsgrad, der dabei zu bewältigen ist, wächst, je geringer der Strophenumfang und je ambitionierter die Strophenstruktur ist (etwa die Nachtweise Konrads von Würzburg), sie vermindert sich bei ausladenden Strophen und geringen formalen Vorgaben (so Regenbogens Langer Ton). Andererseits finden sich auch schmal gebaute Strophen mit konventionellem Tonschema (etwa Frauenlobs Ritterweise) wie füllige Strophen mit artifizieller Struktur (so Marners Langer Ton). Über den jeweiligen Grad der formalen Ansprüche informiert der folgende Überblick.

Töne mit konventioneller Strophenstruktur:

Frauenlob, Ritterweise ${ }^{10}$

$\begin{array}{llllllllllll}8 & 7 & 8 & 6 & 8 & 7 & 8 & 7 & 8 & 6 & 8 & 6 \\ 4 & 3^{\prime} & 4 & 3 & 4 & 3^{\prime} & 4 & 3^{\prime} & 4 & 3 & 4 & 3 \\ \text { a } & \text { b } & c & \text { d } & \text { e } & f_{10} & \text { e } & \text { f } & \text { g } & \text { h } & g_{15} & \text { h } \\ a_{5} & \text { b } & \text { c } & \text { d } & & & & & & & & \end{array}$

10 Vgl. RSM 2/1, S. 61 und Johannes Rettelbach: Variation - Derivation - Imitation. Untersuchungen zu den Tönen der Sangspruchdichter und Meistersinger. Tübingen 1993 (Frühe Neuzeit 14), S. 203-212; Melodie bei Spruchsang. Die Melodien der Sangspruchdichter des 12. bis 15. Jahrhunderts. Hg. von Horst Brunner und KarlGünther Hartmann. Kassel u. a. 2010 (Monumenta Monodica Medii Aevi 6), S. 97f. 
Dieses Tonschema zeigt folgende Strukturmerkmale:

AA/B - 6 bis 8 Silben - 8 Reimklänge - konventionelle Reimformen

Regenbogen, Langer Ton ${ }^{11}$

\begin{tabular}{|c|c|c|c|c|c|c|c|c|c|c|c|c|c|c|c|c|c|}
\hline $\begin{array}{ll}9 & 12\end{array}$ & 8 & 11 & 8 & 11 & 8 & 11 & 8 & 6 & 10 & 8 & 10 & 8 & 10 & 8 & 10 & 8 & 10 \\
\hline 4' 6 & 4 & 5 & 4 & $5^{\prime}$ & 4 & $5^{\prime}$ & 4 & 3 & 5 & 4 & 5 & 4 & 5 & 4 & 5 & 4 & \\
\hline $\mathrm{a} \quad \mathrm{b}$ & $c$ & $\mathrm{~d}$ & $\mathrm{e}$ & $\mathrm{f}_{10}$ & $\mathrm{e}$ & $\mathrm{f}$ & $\mathrm{g}$ & $\mathrm{h}$ & $\mathrm{h}_{15}$ & $\mathrm{i}$ & $\mathrm{k}$ & $\mathrm{i}$ & $\mathrm{k}$ & $\mathrm{x}_{20}$ & $\mathrm{~h}$ & g & \\
\hline
\end{tabular}

Dieses Tonschema zeigt folgende Strukturmerkmale:

AA/B - 6 bis 12 Silben - 10 Reimklänge - Waise (Z. 20) - konventionelle Reimformen

Töne mit artifizieller Strophenstruktur

Konrad von Würzburg, Nachtweise ${ }^{12}$

$\begin{array}{lllllllll}8 & 8 & 8 & 7 & 15 & 8 & 8 & 8 & 7 \\ 4 & 4 & 4 & 3^{\mathrm{c}} & 7^{\mathrm{c}} & 4 & 4 & 4 & 3^{\mathrm{c}} \\ \mathrm{a} & \mathrm{a} & \mathrm{a} & \mathrm{b} & \mathrm{d} & \mathrm{e}_{10} & \mathrm{e} & \mathrm{e} & \mathrm{d} \\ \mathrm{c}_{5} & \mathrm{c} & \mathrm{c} & \mathrm{b} & & & & \end{array}$

Das Tonschema zeigt folgende Strukturmerkmale:

AA/B - 7 bis 15 Silben (15: Z. 9) - 5 Reimklänge - Kaskadenreim (Z. 1-3, 5-7, $10-12)^{13}$

11 Vgl. RSM 2/1, S. 221 und Horst Brunner: Formgeschichte der Sangspruchdichtung des 12. bis 15. Jahrhunderts. Wiesbaden 2013 (Imagines Medii Aevi 34), S. 142; Melodie bei Brunner/Hartmann 2010 (Anm. 10), S. 320-326.

12 Vgl. RSM 2/1, S. 111 und Rettelbach 1993 (Anm. 10), S. 213-220, 279; Melodie bei Brunner/Hartmann 2010 (Anm. 10), S. 188.

13 Der ambitionierte Formanspruch ist im streng symmetrischen Bau begründet: Die vierzeilige Strophenstruktur wiederholt sich - durch einen einzeiligen Steg mit längerer Zeile - als dritter Stollen im Abgesang, wobei die Stollen mit Dreireim gebildet sind. 
Marner, Langer Ton (Form 3) ${ }^{14}$

$\begin{array}{lllllllllllllllllllll}8 & 6 & 8 & 8 & 8 & 8 & 8 & 6 & 12 & 6 & 8 & 8 & 8 & 6 & 4 & 6 & 8 & 8 & 8 & 8 & 8 \\ 4 & 3 & 4 & 4 & 4 & 4 & 4 & 3 & 6 & 3 & 4 & 4 & 4 & 3 & 2 & 3 & 4 & 4 & 4 & 4 & 4 \\ \mathrm{a} & \mathrm{b} & \mathrm{a} & \mathrm{b} & \mathrm{c}_{5} & \mathrm{~d} & \mathrm{x} & \mathrm{e} & \mathrm{e}_{15} & \mathrm{f} & \mathrm{x} & \mathrm{f} & \mathrm{x} & \mathrm{g}_{20} & \mathrm{~g} & \mathrm{~g} & \mathrm{~g} & \mathrm{x} & \mathrm{g}_{25} & \mathrm{c} & \mathrm{d} \\ \mathrm{a} & \mathrm{b} & \mathrm{a} & \mathrm{b}_{10} & \mathrm{c} & \mathrm{d} & & & & & & & & & & & & & & & \end{array}$

Das Tonschema zeigt folgende Strukturmerkmale:

AA/B - 4 bis 12 Silben (4: Z. 21) - 7 Reimklänge - Tiradenreim (Z. 20-23), Waise (Z. 13, 17, 19, 24)

Albrecht Lesch, Gesangweise ${ }^{15}$

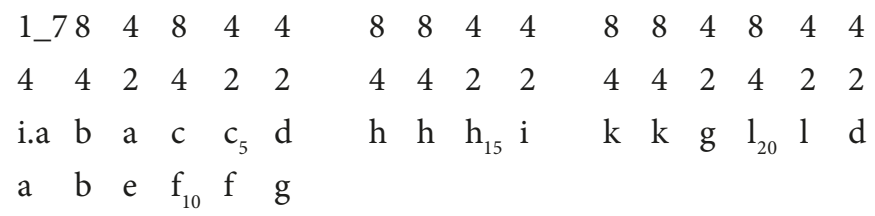

Das führt zu folgenden Strukturmerkmalen:

AA/B - 4 bis 8 Silben - 11 Reimklänge - Anreim (Z. 1: 16) - Tiradenreim (Z. 13-15)

Angesichts solcher formaler Vorgaben stellt sich unweigerlich die Frage, wie textnahe ein Bibelabschnitt - in der Kolmarer Liederhandschrift beträgt der Umfang 12 bis 16 Bibelverse $^{16}$ - überhaupt sein kann. Der Begriff ,textnahe', den auch das RSM als Merkmal bei der Klassifikation eines Sangspruchs oder Meisterliedes als Bibelversifikation verwendet, ${ }^{17}$ gibt mit dem Wortelement ,-nahe zu erkennen, dass eine wortgetreue Wiedergabe des Bibeltextes im Rahmen auch einfacher Strophenformen unmöglich ist. (Als Referenztext kann nur die Vulgata beigezogen werden, da wir - außer vereinzelt bei Beheim bislang keine konkreten Vorlagen für die Versifikationen kennen.) Wenn man den Begriff der Textnähe zur Kennzeichnung einer Bibelversifikation dennoch verwendet, wird man den Autoren größere Lizenzen bei syntaktischen Veränderungen, bei Füllwörtern und -versen zugestehen müssen, die aber weitgehend

14 Vgl. RSM 2/1, S. 129.

15 Vgl. RSM 2/1, S. 119, Brunner 2013 (Anm. 11), S. 178f.; Melodie bei Brunner/Hartmann 2010 (Anm. 10), S. 191-193.

16 Eine Ausnahme bilden lediglich die 7 Bibelverse als Grundlage von ${ }^{1}$ KonrW/10/2.

17 Vgl. RSM 16, S. 261. 
bedeutungsneutral bleiben. Davon abzugrenzen sind die Fälle, die nicht auf eine textnahe, sondern bloß paraphrasierende Versifikation zielen oder aber in eine bibelnahe Versifikation erklärende oder deutende Zusätze inserieren, die den versifizierten Bibeltext mit rahmenden Autortexten so verzahnen, dass die Grenzen zwischen den beiden Textebenen verschwimmen u. a. m. Verwendet man (wie im Älteren Teil des RSM geschehen) auch in diesen Fällen, bei denen die Versifikationen nach Art der Predigt- und der Traktatliteratur oder der Plenarien mit einem deutenden Netz überzogen sind, den Begriff der Textnähe, dann fehlt ihm die notwendige Trennschärfe, die es erlaubt, zwischen verschiedenen Textstrategien zu unterscheiden. Das Kriterium der Textnähe sollte daher nur solchen Versifikationen vorbehalten bleiben, die sich von deutenden und das Verstehen lenkenden Autortexten nach Möglichkeit freihalten oder aber beide Ebenen strikt trennen. Selbstredend versteht sich diese Abgrenzung nicht als Werturteil über das Unvermögen von Autoren, eine Bibelstelle textnahe zu versifizieren, sondern als Hinweis auf unterschiedliche Textfunktionen der Versifikation. Schließlich muss nicht eigens betont werden, dass auch bei dem vorgeschlagenen Abgrenzungsversuch Grenzfälle möglich sind.

Wie sinnvoll ein penibler Umgang mit dem Merkmal der Textnähe ist, zeigt exemplarisch das dreistrophige Lied ${ }^{1} \mathrm{KonrW} / 10 / 2,{ }^{18}$ das im RSM als textnahe Bibelversifikation eingestuft wird. Die ambitionierte Strophenstruktur bereitete dem Anonymus keinerlei Schwierigkeiten, dennoch beschränkte er sich in den Strophen II und III bei der Wiedergabe des biblischen Gleichnisses vom reichen Mann und vom armen Lazarus (Lk 16,19-31) auf eine stark raffende Nacherzählung des ersten, handlungsorientierten Teils (Lk 16,19-25). Allein dieser Befund stellt die Einordnung des Liedes in das Korpus der textnahen Bibelversifikationen in Frage. Dazu tritt ein weiterer Aspekt: Die Wiedergabe des biblischen Gleichnisses hat keinen Eigenwert, ihr kommt lediglich eine dienende Funktion zu, denn die Nacherzählung sollte das Liedthema mit der Autorität der Bibel absichern. Das zeigt ein Blick auf die Eingangsstrophe. In ihr warnt der Autor vor maßloser Habgier (gytikeit), die bereits ein cleynes kint ergriffen hatte (I,11: mir ist so we nach gytikeit), und versieht damit die Paraphrase des nachfolgenden Bibeltextes mit dem verständnisleitenden Vorzeichen der Didaxe. Das ist ein Konzept, das an keiner textnahen Wiedergabe des Bibeltextes interessiert, sondern der Unterweisung in einem lebensweltlichen Kontext verpflichtet ist. Entsprechend steht am Ende der Eingangsstrophe ein

18 München, Cgm 4997, Bl. 526rb/va. Digitalisat des Liedes unter: http://daten.digitalesammlungen.de/bsb00105055/image_1057. 
wys man und keine göttliche Instanz (I,12f:: der wys man sprach, mir ist geseit: / schacz fugt nit cleynen kinden). Eine solche Anbindung an eine Maxime der richtigen Kindererziehung und nicht an ein religiöses Deutungsmuster weicht von allen Bibelversifikationen in der Kolmarer Liederhandschrift ab. Daraus leitet sich neben dem sorglosen Umgang mit dem Text der Bibel ein zusätzliches Argument für die Entscheidung ab, ${ }^{1}$ KonrW/10/2 aus dem Korpus der textnahen Bibelversifikationen zu streichen.

Einem ähnlichen Muster folgt auch das dreistrophige Lied ${ }^{1} \mathrm{Frau} / 23 / 6 \mathrm{a},{ }^{19}$ für das der Anonymus mit Frauenlobs Ritterweise zwar einen konventionell gebauten Ton, mit dem Prolog des Johannes-Evangeliums (Joh 1,1-13) jedoch eine anspruchsvolle Perikope gewählt hat. Bei diesem schwierigen Text drängt sich die Notwendigkeit von Erklärungen und Deutungen geradezu auf. Diesem Ziel folgt die Paraphrase jedoch nicht, vielmehr steht auch sie im Dienst eines vorrangigen - hier nicht lebensweltlichen, sondern religiösen - Anliegens, das diesmal dem Evangelientext nicht vorausgeht, sondern ihm in der dritten Strophe folgt und aus ihm abgeleitet ist. In ihr verfolgt der Anonymus mit der Marienverehrung ein pastorales Anliegen. Entsprechend werden die Aussagen über die Menschwerdung des Gottessohnes, abweichend vom Johannes-Prolog, auf Maria hin ausgefaltet, deren Hilfe am Schluss gebethaft erfleht und mit einem Amen bekräftigt wird (III,9-16):

By ir [i.e. Maria] wart fleisch und auch zü blüt

10

megtlich daz wort beslossen.

an wandel was ir küscher müt,

an demüt unverdrossen.

sie zwang die gotheit zü ir her,

do mit herwarb sie uns hüld.

15 Maria, nu wiss unser wer, verslicht uns unser schüld. ${ }^{20}$ AMEN

Eine Parallelüberlieferung im Berliner Sachs-Autograph ( $\left.{ }^{1} \mathrm{Frau} / 23 / 6 \mathrm{~b}\right)$ nimmt hingegen die Aussagen über die Inkarnation zum Anlass, um bereits in der zweiten Strophe auf die Realpräsenz in der Eucharistie hinzuweisen und in der

19 München, Cgm 4997, Bl. 230va-231ra. Digitalisat des Liedes unter: http://daten. digitale-sammlungen.de/bsb00105055/image_466; Abdruck bei Michael Baldzuhn: Vom Sangspruch zum Meisterlied. Untersuchungen zu einem literarischen Traditionszusammenhang auf der Grundlage der Kolmarer Liederhandschrift. Tübingen 2002 (MTU 120), S. 213f. (danach zitiert).

20 Hs.: schülde. 
dritten Strophe die Gläubigen zu ermahnen, das Altarsakrament würdig zu empfangen (II,9-16 und III,1-4): ${ }^{21}$

10

Das ist sein reines fleisch und plüt

10

in dem fron sacramente

(wer empfahet das hochste güt

und das warlich der kente),

das uns Cristus zw lecze lis

vor seinem grimen dot

15

und sein dar pey gedencken his

sein marter und not.

Dar umb enpfahet wirdikleich

das frone sacramente,

auf das ir in der himel dron

got eimer nyssen seit.

Bei dieser Austauschbarkeit der Textauslegung bedarf es keiner textnahen Versifikation der Bibelstelle, es genügt eine raffende Paraphrase ${ }^{22}$ (wiebei ${ }^{1} \mathrm{KonrW} / 10 / 2$ ) und ein Thema (im vorliegenden Fall eine Zentrierung auf die Inkarnation), von der aus dann die jeweilige Textauslegung erfolgen kann. Mit diesem Verfahren, bei dem der Bibeltext ebenfalls nur eine dienende Funktion einnimmt, darf dieses Lied nicht zu den textnahen Bibelversifikationen gerechnet werden.

Beim dritten Beleg, dem siebenstrophigen Lied ${ }^{1}$ Marn/7/540, ${ }^{23}$ wählt ein Anonymus mit Marners Langem Ton (Form 3) eine artifizielle Strophenform, um den Beginn der schwer zugänglichen Johannes-Offenbarung (Offb 1,12,11) zu versifizieren. Gleichzeitig verzichtet er auf eine erläuternde Einführung und auf einen deutenden Schluss, aber die Herausforderungen der Textquelle

21 Abdruck des abweichenden Liedschlusses bei Baldzuhn 2002 (Anm. 19), S. 214 (zitiert); zu den beiden unterschiedlichen Schlussstrophen vgl. S. $215 f$.

22 Zur Veranschaulichung werden das Zeugnis des Johannes Baptista im Evangelium und in der Versifikation gegenübergestellt. Joh 1,6-8: Fuit homo missus a Deo, cui nomen erat Ioannes. Hic venit in testimonium, ut testimonium perhiberet de lumine, ut omnes crederent per illum. Non erat ille lux, sed ut testimonium perhiberet de lumine. ${ }^{1}$ Frau/23/6a, I,13-16: Johannes der wart uss gesant, daz er dem waren schin

15 gezügnüß geb mit seiner hant und zeügt der finger syn.

23 München, Cgm 4997, fol. 482va-483vb. Digitalisat des Liedes unter: http://daten. digitale-sammlungen.de/bsb00105055/image_970. 
erfordern neben Auslassungen erklärende und deutende Zusätze in der Form der Glossierung. Sie müssten nicht im Widerspruch zur Textnähe stehen, wenn diese Glossen formal vom Bibeltext getrennt wären (etwa Bibelversifikation im ersten, Glossierung im zweiten Stollen bzw. im Abgesang oder Bibeltext im ersten Stollen und Erläuterungen im zweiten Stollen und im Abgesang - eine Form, die Hans Folz bei seiner siebenstrophigen Versifikation des JohannesPrologs für sein Meisterlied ${ }^{1} \mathrm{Folz} / 33^{24}$ gewählt hat). Eine solche Differenzierung fehlt in ${ }^{1}$ Marn/7/540, so dass Bibeltext und Glosse ineinander verwoben sind. An einem Beispiel sollen die fatalen Folgen einer solchen Textklitterung verdeutlicht werden.

In Offb 1,13b-14a berichtet der Seher Johannes, er habe inmitten der sieben Leuchter jemanden gesehen, der dem Menschensohn ähnlich war, bekleidet mit einem Gewand, das bis zu den Füßen reichte, um die Brust einen goldenen Gürtel; sein Haupt aber und die Haare waren weiß wie Wolle und wie Schnee. ${ }^{25}$ An diese Beschreibung der Kleidung knüpft der Liedautor an, um im Abgesang der dritten Strophe das liturgische Gewand des Diakons (die Dalmatik) biblisch zu verorten (III,13-23):

All mitten in den luchtern sach

er glich eins mentschen kint,

15 gecleydet mit eim wyssen cleyde, wol durch schint, biss uff sins enckel fuß./, daz waz glich eim dalmatico, die an treit ein dyaconüs, der da gecleydet ist zu der

20 heiligen messe schon,/. und umb getan sin brust, gegurtet fron./, sin heupt, sin har wy $\beta$, schnees glan, [...]

Dabei kann zu Beginn von Vers 17 die Formulierung daz waz glich als sprachliches Signal für den Beginn eines Autorkommentars verstanden werden, aber bei V. 21f. ist offen, ob sich das Verspaar auf die Stola des Diakons bezieht oder

24 Die Meisterlieder des Hans Folz. Aus der Münchener Originalhandschrift und der Weimarer Handschrift Q. 566 mit Ergänzungen aus anderen Quellen. Hg. von August L. Mayer. Berlin 1908 (DTM 12), S. 136-141.

25 Offb 1,13b-14a: et [vidi] in medio septem candelabrorum similem filio hominis, vestitum podere et praecinctum ad mamillas zona aurea. Caput autem eius et capilli erant candidi tamquam lana alba et tamquam nix. 
ob es an V. 16 anschließt. Entsprechend ändert sich die Interpunktion an den Zeilenenden bei V. 16, 20 und 22 (auch wenn man die kommentierende Einfügung alternativ als Parenthese in Klammern oder zwischen Gedankenstriche setzt).

Andererseits versteht es der Versifikator, eine schwierige Textstelle mit eigenen Formulierungen wiederzugeben und dennoch zwischen biblischer Quelle und Autorkommentar zu unterscheiden. Das zeigt sich besonders deutlich bei der Wiedergabe von Offb 2,6f. Hier bestätigt der Engel in seinem Sendschreiben an die Gemeinde von Ephesus, sie habe Buße getan, weil auch sie die häretische Gruppierung der Nikolaiten gehasst habe. Man solle auf den Geist in den Gemeinden hören, der sage: Dem Sieger im Kampf werde ich vom Baum des Lebens zu essen geben, der im Paradies Gottes steht. ${ }^{26}$ Bei der deutenden Umsetzung dieser Bibelstelle in den beiden Stollen der sechsten Strophe stand der Autor vor dem Problem, ${ }^{27}$ dass er selbst (V. 9) und Christus bei der Versifikation in einer Ich-Rolle auftreten. Um die beiden Ebenen zu trennen und um sie auch gegenüber Johannes als Schreiber abzugrenzen, führt der Textautor gegen die Quelle eine Sprecherrolle (Christus) mit der - aus der Offenbarung des Johannes bekannten - Umschreibung ein: der in der sonnen stunt (V. 2). Ihm werden quellennahe die Verse 5 bis 7 in den Mund gelegt. Danach (V. 912) wendet der Autor in einer Ich-Aussage die Lohnverheißung der Quelle deutend ins Heilsgeschichtliche. Nach diesen Transformationen präsentiert sich Offb 2,6f. in folgender Textgestalt (VI,1-12):

Johannes aber horte daz.

der in der sonnen stunt, sprach zu der kirchen. mercke ${ }^{28}$ bas,

Johannes schrib den waren grunt:

$5 d u$ hassest ${ }^{29}$ die torechten diet, die ich auch ie gehasset han.

Wer hab oren, der ${ }^{30}$ höre was

hie spricht der warheit munt.

26 Offb 2,6f.: Sed hoc [i.e. poenitentiam agere] habes, quia odisti facta Nicolaitarum, quae et ego odi. Qui habet aurem, audiat, quid Spiritus dicat ecclesiis: Vincenti dabo edere de ligno vitae, quod est in paradiso Dei mei.

27 Zudem musste er Nennungen der Nikolaiten aussparen, die auch in einer modernen Bibelübersetzung einer Erklärung bedürfen.

28 Hs.: mecke.

29 Hs.: hasset.

30 Hs.: de. 
10

den gib ich hie daz ewig maß:

fleisch, blut, wart an dem holcz verwünt.

daz selbe holcz der slang verniet, ${ }^{31}$

daz wir zur helle musten gan.

Zwar fließen hier der Bibel- und der Autortext nicht ununterscheidbar wie in der dritten Strophe ineinander, aber von einer textnahen Versifikation kann auch beim vorliegenden Lied nicht gesprochen werden. Es hat jedoch im Vergleich mit den beiden ersten Beispielen ( ${ }^{1} \mathrm{KonrW} / 10 / 2$ und $\left.{ }^{1} \mathrm{Frau} / 23 / 6\right)$, deren Paraphrasen der gewählten Bibelstellen von einem übergeordneten Interesse geleitet werden, die am Beginn oder am Ende des Liedes formuliert sind, einen anderen Duktus, weil es die Autorkommentare in die Paraphrase inseriert.

Es wäre also auch zu fragen, ob sich Untergruppen bei den nicht textnahen Bibelversifikationen bilden lassen.

Von den drei bisher vorgestellten Fällen unterscheidet sich das fünfstrophige Lied ${ }^{1}$ Lesch/6/2, ${ }^{32}$ bei dem einem artifiziellen Ton (der Gesangweise Albrecht Leschs) mit Mt 2,1-12 (Anbetung der drei Weisen aus dem Morgenland) ein einfach strukturierter Text gegenübersteht. Zwar folgt - wie bei den beiden ersten Liedern - auf die Versifikation eines Anonymus in der Schlussstrophe ein Autortext, aber er steht hier ohne direkte Bezüge zum Bibeltext: Es wird zum Lob des Schöpfergottes aufgerufen und dafür der Beistand der Gottesmutter erfleht. Mit dieser klaren Trennung von Bibel- und Autortext wären die Voraussetzungen für eine textnahe Übersetzung geschaffen, der auch der ziemlich genau eingehaltene Handlungsverlauf der Perikope entspricht. Allerdings sind bei der Versifikation neben der Textnähe auch Ausschmückungen gegenüber der biblischen Erzählung nicht zu übersehen. Diese Schwankungen mögen mit der ambitionierten Strophenstruktur des gewählten Tons zusammenhängen, doch scheint hinter den Ausschmückungen nicht immer ein formaler Zwang zu stehen. Besonders augenfällig zeigt sich das bei der vierten Strophe in den beiden Stollen des Aufgesangs, in denen die Verse Mt 2,11b- $\mathrm{c}^{33}$ versifiziert sind (IV,1-12):

31 Hs.: vernet.

32 München, Cgm 4997, Bl. 840rb-841ra. Digitalisat des Liedes unter: http://daten. digitale-sammlungen.de/bsb00105055/image_1687; Abdruck in: Die kleineren Liederdichter des 14. und 15. Jahrhunderts. 4 Bde. Hg. von Thomas Cramer. München 1977-1985, hier Bd. IV, S. 118-212 (Text; danach zitiert), 403f. (Kommentar).

33 Mt 2,11b-12: invenerunt puerum cum Maria matre eius, et procidentes adoraverunt eum, et apertis thesauris suis obtulerunt ei munera, aurum thus et myrrham. 
Gach waz in zu der maget rein, da sie sahen daz kint loblich

vfyrem bein.

sie smuckt es fruntlich an ir brust,

5 schon sies gelust.

all da zuhant

Sie vielen nyder vff ir knie, sie brachen vff ir schetze rich vnd gaben ie

10 ir opfer: golt, wirauch vnd mer. daz nam der herr vnd auch die meit.

Dabei wird die Textstelle invenerunt puerum cum Maria matre eius ${ }^{34}$ in den Versen 3 bis $5 \mathrm{zu}$ einer Art von Andachtsbild ausgeschmückt, was freilich auch möglich war, weil der 22-zeilige Strophenumfang Raum für solche Ausschmückungen gewährte.

Neben solchen inhaltlichen gibt es aber auch rein formale Ergänzungen, die in der artifiziellen Strophenform begründet sind. Dazu gehören der Anreim Gach (V. 1) und die Reimwörter zuhant (V. 6) und meit (V. 12), die erst im Abgesang ihre Entsprechungen finden. Solche formalen Ergänzungen ziehen jedoch meist auch inhaltliche Zusätze nach sich, weil die Reimwörter syntagmatisch eingebunden werden müssen. Dabei verwischen sich - wie besonders deutlich an V. 11f. zu erkennen ist - zuweilen die formale und inhaltliche Ebene. Auslöser für diese Erweiterung war die Suche nach einem Reimwort zur biblischen Myrrhe, wobei das Strophenschema männliche Versschlüsse verlangte. Diese Vorgabe ließ sich durch Apokope leicht erfüllen (mhd./frühnhd. mirre $>$ mirr), die Operation löste aber die Suche nach einem Reimwort aus, das eine inhaltliche Ergänzung erlaubte, die offenkundig quellennahe bleiben sollte. Der Textautor entschied sich für herr und aus Gründen der Reimreinheit zur sprachlichen Ummodelung von mirr zu mer. Das Reimwort herr wurde zur sprachlichen Füllung des viersilbigen Verses mit der Phrase daz nam der ergänzt. Weiterhin löste das Reimwort der herr als Pendant die meit $t^{35}$ mit der Phrase und auch zur Füllung der noch offenen Zeile (V. 12) aus. Auf diese Weise

34 Alle lateinischen Bibelzitate entstammen der Biblia sacra. Iuxta Vulgatam versionem. Recensuit et brevi apparatu critico instruxit Robertus Weber. 5., verbesserte Auflage, bearbeitet von Roger Gryson. Stuttgart 2007.

35 Das Reimwort dazu steht nach Vorgabe des Reimbandes in V. 19 (hier: leit). 
greifen - was hier an einem Fall beispielhaft gezeigt werden sollte - formal bedingte und inhaltliche Textergänzungen ineinander über.

So offenkundig diese Ergänzungen sind, so deutlich unterscheiden sie sich allerdings von den Zusätzen der drei zuvor besprochenen Lieder. Deren Erweiterungen dienen zur Erläuterung und zur Deutung, während hier die Vorlage lediglich ausgeschmückt wird. Andererseits fließen auch in ${ }^{1}$ Lesch/6/2 Bibelund Autortext ineinander. Fasst man alle genannten Aspekte (auch die Nähe zum Handlungsverlauf der Perikope und die klare Trennung zwischen Bibelversifikation in den Strophen I-IV und davon getrennt der Autortext in Strophe V) zusammen, dann fällt eine eindeutige Entscheidung zwischen textnaher und textferner Versifikation schwer. Am angemessensten scheint mir die Einordnung als Grenzfall, mit dem bei dieser binären Kategorisierung natürlich immer gerechnet werden muss.

Textnahe Bibelversifikationen zeichnen sich dagegen dadurch aus, dass ihre Auslassungen und Ergänzungen gegenüber dem Bibeltext im Rahmen des Möglichen sinnneutral bleiben. Dieses Bemühen dokumentieren in der Kolmarer Liederhandschrift insgesamt drei Versifikationen. Zwei anonym überlieferte Lieder versifizieren den Stammbaum Jesu (Mt 1,1-16) und wählen dazu mit Regenbogens Langem Ton ( ${ }^{1} \mathrm{Regb} / 4 / 557 \mathrm{a}$ und $\left.{ }^{1} \mathrm{Regb} / 4 / 592\right)$ dieselbe konventionell gebaute Strophenform.

Das eine Lied ( ${ }^{1}$ Regb/4/557a) ${ }^{36}$ das auch in der Wiltener Handschrift (um 1500, Tirol? $)^{37}$ überliefert ist, verortet die Perikope in der Überschrift liturgisch. In der Kolmarer Liederhandschrift heißt es zwar nur [...] von unser fraüwen geburt liber generacionis, aber die Wiltener Handschrift präzisiert zu: [...] von unser lieben frawen das ewangelium das da haisset liber Generacionis. Gemeint ist damit das Tagesevangelium, das man zum Fest Mariä Geburt (8. September) im Gottesdienst liest. Entsprechend hat der Anonymus die Versifikation der Perikope marianisch gerahmt: Das fünfstrophige Lied nimmt in der Eingangsstrophe eine allegorische Deutung des anschließend versifizierten Stammbaumes vor, die auf Maria zuläuft. So heißt es zu Beginn des Abgesangs der ersten Strophe (I,9-17):

36 München, Cgm 4997, Bl. 384va-385va. Digitalisat des Liedes unter: http://daten. digitale-sammlungen.de/bsb00105055/image_774.

37 München, Cgm 5198, Bl. 157v-159r. Digitalisat des Liedes unter: http://daten. digitale-sammlungen.de/bsb00069128/image_320. 
Der stam daz ist die war gotheit.

die edeln est, die nenn ich uch mit rechte,

vom stamm in großer wirdikeit,

vernemment mich, daz ist das hoch geslechte,

dar uss die edel frucht so clar

nam ire reine art.

15

daz ist Mary, die kusche junckfraw zart.

der kern daz ist daz ewig wort,

daz sich versloss in irem balsam schrin.

Entsprechend allegorisiert die Schlussstrophe mit einem Lobpreis Marias das Wunder der Inkarnation: Ave, du bist daz zucker vach / dar in sich senckt der guldin ancker schone (V,9f.). Diese vom Anonymus geschaffene Rahmung greift jedoch nicht auf die Versifikation der Perikope über, sie ist vielmehr auffallend textnahe gestaltet, was teilweise durch die Registerform des Liber Generationis gefördert wurde. Das zeigen etwa die beiden Stollen der dritten Strophe, die Mt $1,5 f .{ }^{38}$ versifizieren (III,1-8):

Salmon in siner tugend wise

gebar Boos von Raab, tüt die schrifft bekant,

Boos gebar Obeth uss Rüth,

Obeth gebar her Yesse usserkoren,

5

Yesse so gar in hohem prise

gebar den lieben künig David hoch genant,

als uns die warheit wissen tüt,

von David wart her Salomon geboren.

Die zweite Versifikation des Stammbaumes Jesu erfolgt in dem siebenstrophigen Lied ${ }^{1}$ Regb/4/592. ${ }^{39}$ Sie umfasst dort die dritte und einen Teil der vierten Strophe, wird also im Vergleich zum eben vorgestellten fünfstrophigen Lied $\left({ }^{1} \mathrm{Regb} / 4 / 557 \mathrm{a}\right)$ von einem erheblich breiteren Rahmen umgeben, der zudem eine völlig andere Funktion hat. Im fünfstrophigen Lied bildet die Versifikation der liturgisch verorteten Perikope den Liedkern. $\mathrm{Zu}$ seinem Verständnis führt in der Eingangsstrophe eine allegorische Deutung hin, und in der Schlussstrophe wird mit dem Hinweis auf das unfassbare Wunder der Inkarnation und mit dem Lob der Gottesmutter die religiöse Bedeutung der Perikope

38 Mt 1,5f.: Salmon autem genuit Booz de Rachab, Booz autem genuit Obed ex Ruth, Obed autem genuit Iesse, Iesse autem genuit David regem, David autem rex genuit Salomonem.

39 München, Cgm 4997, Bl. 423va-425rb. Digitalisat des Liedes unter: http://daten. digitale-sammlungen.de/bsb00105055/image_853. 
hervorgehoben. Im siebenstrophigen Lied hingegen bildet der Stammbaum Jesu lediglich ein Segment in einem weitgespannten heilsgeschichtlichen Abriss, der von der Schöpfung über den Sündenfall bis zur Geburt und den Kreuzestod des Erlösers reicht, um schließlich wie ein Gebet in der Bitte zu enden: wann unser sel von hynnen fert, / so halt uns, lieber herr, in dyner hüt (VII,22f.). Diese Liedstruktur, die der Bibelversifikation nur einen Abschnitt in einem weiträumigen Gefüge einräumt, hinderte den Anonymus allerdings nicht, die Bibelstelle textnahe zu versifizieren. Zur Veranschaulichung folgt die Wiedergabe von Mt 1,5f., die bereits bei ${ }^{1}$ Regb/4/557a als Beispiel herangezogen wurde. In ${ }^{1} \mathrm{Regb} / 4 / 592$ steht die Versifikation am Beginn des Abgesangs der dritten Strophe (III,9-14):

[Aminadap Nason so clar,

10 Nason Salmon,] Salmon Boos in gưte,

Boos Obeth uss Ruth gebar,

Obeth Jesse gebar in hohem muite,

Jesse David, der Salomon

gebar in wirdikeit.

Ein Vergleich beider Versifikationen zeigt sogar, dass der Autor des siebenstrophigen Liedes deutlich textnäher versifiziert als dies im fünfstrophigen Lied geschieht. Zum Vergleich folgt nochmals die Versifikation von Mt 1,5f. in ${ }^{1} \operatorname{Regb} / 4 / 557 \mathrm{a}(\mathrm{III}, 1-8)$ :

Salmon in siner tugend wise

gebar Boos von Raab, tüt die schrifft bekant,

Boos gebar Obeth uss Rüth,

Obeth gebar her Yesse usserkoren,

$5 \quad$ Yesse so gar in hohem prise

gebar den lieben künig David hoch genant,

als uns die warheit wissen tüt,

von David wart her Salomon geboren.

Trotz der augenfälligen Unterschiede zwischen den beiden Versifikationen kann an der Textnähe beider Wiedergaben zur entsprechenden Bibelstelle nicht gezweifelt werden. Das zeigt zugleich, dass weder eine Einordnung der Versifikation in ein thematisch weiter gefasstes Konzept noch eine breite Kontextualisierung einer textnahen Versifikation der ausgewählten Bibelstelle im Wege stehen muss. Sie wäre also unter diesen Gesichtspunkten auch bei den drei erstgenannten Liedern prinzipiell möglich gewesen, wenn das Autorinteresse auf eine textnahe Versifikation gezielt hätte. 
Darüber hinaus braucht selbst eine komplexe Bauform kein Hinderungsgrund für eine textnahe Versifikation zu sein. Das belegt schließlich als letztes Zeugnis für Bibelversifikationen in der Kolmarer Liederhandschrift der Hort des Peter von Reichenbach ( ${ }^{1}$ PeterR/2/1). Zum besseren Verständnis sollen einige Vorbemerkungen dienen. ${ }^{40}$ Den Namen dieses Autors, der vielleicht in die erste Hälfte des 14. Jahrhunderts zu datieren ist, kennen wir nur aus der Kolmarer Liederhandschrift. Von ihm stammt ein geistliches Tagelied und ein religiöser Leich mit einem heilsgeschichtlichen Abriss, der von der Schöpfung bis zur Verkündigung des Engels an Maria reicht. Beide Werke sind ebenfalls nur in der Kolmarer Liederhandschrift überliefert. ${ }^{41}$ Dort hat sie der Schreiber als Einheit aufgefasst und als Hort bezeichnet (vgl. Abb. 1-3). Im RSM, das beide Dichtungen ohne Begründung in den Älteren Teil aufgenommen hat, werden das Tagelied und der Leich ${ }^{42}$ getrennt behandelt.

Im letzten (10.) Doppelversikel des Leichs, der einen weiten heilsgeschichtlichen Bogen von der Trinität über den Sündenfall und den Erlösungsratschluss bis zu Mariä Verkündigung spannt, steht die innerhalb der deutschsprachigen Überlieferung älteste textnahe Bibelversifikation in musikalischer Form. Sie hat Lk 1,28-38 zur Grundlage, also den größten Teil des Evangeliums zum Fest Mariä Verkündigung (25. März). Die hohen formalen Ansprüche der Leichstruktur und der beschränkte Umfang des Doppelversikels mit 34 Zeilen erzwang größere Lizenzen bei der Perikope, die in der Liturgie bereits mit Lk 1,26f. einsetzt. ${ }^{43}$ Die Auslassung dieser beiden Bibelverse ergab sich aus der inhaltlichen Anknüpfung mit dem vorausgehenden (9.) Doppelversikel, in dem Maria bereits eingeführt wurde. Er berichtet davon, dass Maria bei Jesaja von der Jungfrauengeburt liest (Jes 7,14) und über diese Prophezeiung nachsinnt, womit dann der 10. Doppelversikel einsetzt $(10,1-6)$ :

In den gedencken so zu hant

stunt vor ir sunder hone

da zwor ein engel schone,

40 Vgl. dazu ${ }^{2}$ VL 7, Sp. 448-451 (Horst Brunner).

41 München, Cgm 4997, Bl. 60ra-62va (Tagelied), 62va-68va (Leich). Digitalisat beider Texte unter: http://daten.digitale-sammlungen.de/bsb00105055/image_125.

42 Digitalisat des Leichs unter: http://daten.digitale-sammlungen.de/bsb00105055/ image_130; Abdruck bei Cramer (wie Anm. 32), Bd. 2, S. 469-479 (Text; danach zitiert) und S. 543-545 (metrisches Schema).

43 Lk 1,26f.: In mense autem sexto missus est angelus Gabrihel a Deo in civitatem Galilaeae, cui nomen Nazareth, ad virginem desponsatam viro, cui nomen erat Ioseph, de domo David, et nomen virginis Maria. 
die ${ }^{44}$ grußte $\mathrm{er}^{45}$ mit dem nuwen grů $\beta$ :

daz hieß „ave“, ein wort so suß,

"genaden vol", des sie herschrack.

Zu Beginn der Versifikation wird der Gruß des Engels (Lk 1,28) ${ }^{46}$ verkürzt wiedergegeben ${ }^{47}$ Marias Erschrecken und Nachdenken über die Bedeutung des Grußes ${ }^{48}$ sind übergangen. ${ }^{49}$ Danach ist die Perikope trotz kurzer Auslassungen und Zusätze aber erstaunlich textnahe wiedergegeben. Das zeigt die Fortsetzung des Engelgrußes mit der Verkündigung ${ }^{50}(10,7-17)$ :

der engel furbaz rede pflag:

„Maria, vorcht dich nit, du rein,

die gnade hast du funden ein:

10

sich, du enpfehst, gebirst on quel

ein kint, Jhesum Emanuel,

dez oberisten sun genant.

und got der herr ym gyt vor war

den stul David, sins vater.

15

in Jacobs huse richset clar

sin rich on ende gatter,

gelaube mir der mere."

Bereits dieses älteste Beispiel einer Bibelversifikation in musikalischer Form belegt, dass man im Umkreis der Sangspruchdichter von Anfang an eine feste Vorstellung von einer textnahen Versifikation hatte und dass man - bis hin zu den frühen Meistersingern - diesem Anspruch auch gerecht werden konnte. Innerhalb der Kolmarer Liederhandschrift zeigen das neben ${ }^{1}$ PeterR/2/1

44 Hs.: die maget.

45 Hs.: er fehlt.

46 Lk 1,28: Et ingressus angelus ad eam dixit: Ave, gratia plena. Dominus tecum. Benedicta tu in mulieribus.

47 Mit Textstörung bei der Versifikation der Inquit-Formel.

48 Lk 1,29: Quae cum vidisset/audisset, turbata est in sermone eius et cogitabat, qualis esset ista salutatio.

49 Vielleicht hängt das Übergehen von Marias Nachdenken auch damit zusammen, dass eine semantische Dublette zum gedencken in 10,1 nach nur wenigen Versen vermieden werden sollte.

50 Lk 1,30-33: ${ }^{30}$ Et ait angelus ei: Ne timeas, Maria, invenisti enim gratiam apud Deum: ${ }^{31}$ Ecce concipies in utero et paries filium et vocabis nomen eius Iesum. ${ }^{32}$ Hic erit magnus et filius altissimi vocabitur. Et dabit illi dominus Deus sedem David patris eius ${ }^{33}$ et regnabit in domo Iacob in aeternum et regni eius non erit finis. 
die beiden Lieder ${ }^{1} \operatorname{Regb} / 4 / 557 \mathrm{a}$ und ${ }^{1} \operatorname{Regb} / 4 / 592 .{ }^{51}$ Sieht man von ${ }^{1} \mathrm{Lesch} / 6 / 2$ als Grenzfall ab, ${ }^{52}$ dann haben ${ }^{1}$ Marn/7/540, ${ }^{1}$ KonrW/10/2, ${ }^{1} \mathrm{Frau} / 23 / 6 \mathrm{a}$ dagegen keine textnahe Versifikation im Blick, wobei formale Vorgaben dafür keine Rolle spielten. ${ }^{53}$ Bereits die Kolmarer Liederhandschrift lässt also bei den Bibelversifikationen im Blick auf deren Textnähe eine Untergliederung in zwei Teilgruppen (textnahe - nicht textnahe) erkennen, die für die gesamte vorreformatorische Überlieferung - sieht man von vereinzelten Grenzfällen ab ihre Gültigkeit behält.

Beide Teilgruppen verbindet ein Merkmal, das über die Kolmarer Liederhandschrift hinaus wiederum für alle vorreformatorischen Versifikationen gilt: Sie werden ausnahmslos von Autortexten begleitet, welche die versifizierte Bibelstelle kommentieren und deuten oder sie in einen weitergespannten Kontext stellen. Diese feste Verbindung von Bibel- und Autortext führt wohl auf die Tradition der Predigt- und Traktatliteratur zurück, aus der die Autoren für die Kontexte ihrer Bibelversifikationen unmittelbar oder doch mittelbar geschöpft haben dürften. ${ }^{54}$

Im Blick auf das Verhältnis zwischen Bibel- und Autortext wurden bei den Bibelversifikationen der Kolmarer Liederhandschrift wiederum zwei Teilkorpora sichtbar, deren Differenzierung ebenfalls für die anderen vorreformatorischen Versifikationen Gültigkeit hat. Die eine Gruppe bilden die Lieder, bei

51 Dazu kommen außerhalb der Kolmarer Liederhandschrift noch fünf weitere textnahe Versifikationen: ${ }^{1} \mathrm{Folz} / 33,{ }^{1} \mathrm{Fol} / \mathrm{k} / \mathrm{32},{ }^{1} \mathrm{Regb} / 4 / 633,{ }^{1} \mathrm{Regb} / 4 / 652$ und ${ }^{1} \mathrm{Regb} / 4 / 653$. Zusammen mit den Belegen aus der Kolmarer Liederhandschrift wird für die textnahen Versifikationen mit insgesamt fünf (von acht) Belegen auffällig häufig Regenbogens Langer Ton mit seiner konventionellen Strophenstruktur verwendet. Dazu stellt sich ${ }^{1} \mathrm{Folz} / 33$ in Fritz Zorns Zugweise. Einen artifiziellen Formanspruch erhebt hingegen neben Peter von Reichenbach ( $\left.{ }^{1} \mathrm{PeterR} / 2 / 1\right)$ bei den vorreformatorischen textnahen Versifikationen nur Hans Folz mit seinem Hohen Ton in ${ }^{1}$ Folz/132.

52 Mit Albrecht Leschs Gesangweise verwendet auch ${ }^{1}$ Lesch/6/2 einen artifiziell strukturierten Ton.

53 Zwei dieser drei Lieder verwenden artifizielle Strophenmuster: Marners Langen Ton, Form 3 ( ${ }^{1}$ Marn/7/540) und die Konrad von Würzburg zugeschriebene Nachtweise $\left({ }^{1} \mathrm{KonrW} / 10 / 2\right) ;{ }^{1} \mathrm{Frau} / 23 / 6 a$ wählt hingegen mit der Frauenlob zugeschriebenen Ritterweise ein konventionelles Strophenmuster.

54 Genauere Aussagen hierzu sind beim gegenwärtigen Forschungsstand nicht zu treffen, weil - mit Ausnahme von Michel Beheim - intensive Quellenuntersuchungen zu den Bibelversifikationen wie überhaupt zu den geistlichen Sangsprüchen und Meisterliedern des 14. und 15. Jahrhunderts fehlen. 
denen die versifizierte Bibelstelle im Dienst eines übergeordneten Interesses steht, das in Autortexten am Anfang und/oder Ende des Liedes formuliert ist; weiterhin gehören zu dieser Gruppe die Lieder, bei denen kommentierende und deutende Autortexte in die Bibelversifikation inseriert sind. Bei der zweiten Gruppe stehen die Versifikationen nicht im Dienst eines übergeordneten Interesses der rahmenden Autortexte, sie trennen Bibel- und Autortext und in den Versifikationen bleiben Auslassungen und Ergänzungen gegenüber dem Bibeltext weitgehend sinnneutral. Bei den Bibelversifikationen in der Kolmarer Liederhandschrift korrespondiert das Kriterium der Textnähe und -ferne in auffälliger Weise mit diesen beiden Gruppen: Deren erste ist an einer textnahen Wiedergabe der Bibelstelle nicht interessiert und begnügt sich mit deren Paraphrase; dagegen ist die zweite Gruppe um eine textnahe Versifikation bemüht.

Diese Korrespondenzen verdeutlicht ein kurzer zusammenfassender Blick auf die Versifikationen in der Kolmarer Liederhandschrift. ${ }^{1}$ KonrW/10/2 und ${ }^{1} \mathrm{Frau} / 23 / 6$ a stellen die ausgewählten Bibeltexte in den Dienst eines vorrangigen Interesses ( ${ }^{1} \mathrm{KonrW} / 10 / 2$ : Kindererziehung als weltliches Anliegen; ${ }^{1} \mathrm{Frau} / 23 / 6 \mathrm{a}$ : Marienverehrung als pastorales Anliegen); bei ${ }^{1}$ Marn/7/540 hat der Autortext zwar eine dienende Funktion, aber die Kommentierungen und Deutungen sind in die Versifikation inseriert. In diesen drei Beispielen beschränken sich die Autoren auf eine Paraphrase der Bibelstelle. Ein Grenzfall liegt bei ${ }^{1}$ Lesch/6/2 vor, wo Bibel- (I-IV) und Autortext (V) zwar strikt getrennt sind, die teils textnahe Versifikation jedoch auch inhaltlich ausgeschmückt wird. Anders präsentieren sich die textnahen Bibelversifikationen. Hier bleiben die Ergänzungen und Auslassungen durch den Autor, die nicht selten formal bedingt sind, weitgehend sinnneutral; insgesamt bleiben Bibel- und Autortext getrennt $\left({ }^{1}\right.$ Regb/4/557a mit Autortext als Rahmen der Versifikation). Auch steht der versifizierte Bibeltext nicht im Dienst eines ihm übergeordneten Anliegens, aber er kann durchaus in einen umfangreichen Kontext eingebettet sein. In ihm nimmt der versifizierte Bibeltext keine untergeordnete Rolle innerhalb einer weitausholenden Thematik ein (heilsgeschichtlicher Abriss, der bei ${ }^{1}$ PeterR/2/1 in eine Versifikation der Perikope von Mariä Empfängnis mündet, bei ${ }^{1}$ Regb/4/592 mit der Versifikation des Stammbaumes Jesu als Teil der Heilsgeschichte), sondern stellt innerhalb des Themas ein selbständiges Segment dar, das sich nicht mit einer Paraphrase der Bibelstelle begnügt, sondern auf den Rang einer textnahen Bibelversifikation zielt.

Fasst man alle diese Beobachtungen zusammen, dann erscheinen die sieben Bibelversifikationen in der Kolmarer Liederhandschrift in einer zweifachen Beleuchtung. Einerseits bestätigt die strukturelle Vielfalt dieser Versifikationen, die ein Kennzeichen auch aller anderen vorreformatorischen Belege ist, 
dass es die Bibelversifikation im Sangspruch und Meisterlied erst nach der Reformation, speziell ab Hans Sachs, als einen ,festen Typ (vgl. Anm. 3) gibt. Andererseits lassen bereits die wenigen Versifikationen in der Kolmarer Liederhandschrift erkennen, dass sie in dem schmalen Korpus anhand verschiedener Merkmale als eine feste Größe beschrieben werden können, die sogar Ansätze $\mathrm{zu}$ einer Untergliederung zeigt. Auch dieser Befund wird durch alle anderen vorreformatorischen Befunde gestützt, so dass man bei ihnen von einem Prototyp sprechen kann, den schon die Kolmarer Liederhandschrift präsentiert. Bei diesen Beobachtungen geht es nicht um belanglose Begriffsklaubereien, es soll vielmehr damit einsichtig gemacht werden, dass die Bibelversifikation als fester Typ in der Reformationszeit nicht gleichsam vom Himmel gefallen ist, sondern dass Hans Sachs und seine Nachfolger neben Luthers Bibelübersetzung als einheitlichem Bezugstext (den es im Mittelalter volkssprachlich nicht gab) auf eine vorreformatorische Tradition zurückgreifen konnten, um in Zustimmung wie Ablehnung der überlieferten Muster den Typ der Bibelversifikation im Meisterlied auszubilden. Die Aufzeichnungen vorreformatorischer Versifikationen in seinem Berliner Autograph (vgl. Anm. 6) belegen Kenntnisse jener Tradition für Hans Sachs. Dieser prospektive Ertrag der vorliegenden Studie gründet auf Ergebnissen einer rückschauenden Analyse: Die Aufzeichnungen in der Kolmarer Liederhandschrift als ältester Sammelhandschrift dieser Tradition belegen, dass es sich bei den vorreformatorischen Bibelversifikationen im Sangspruch wie im Meisterlied nicht um ein amorphes Phänomen handelt, sondern um eine feste Größe mit distinkten Merkmalen, mit denen man als Textautor vor und nach der Reformation operieren konnte. 


\section{Abbildungen}

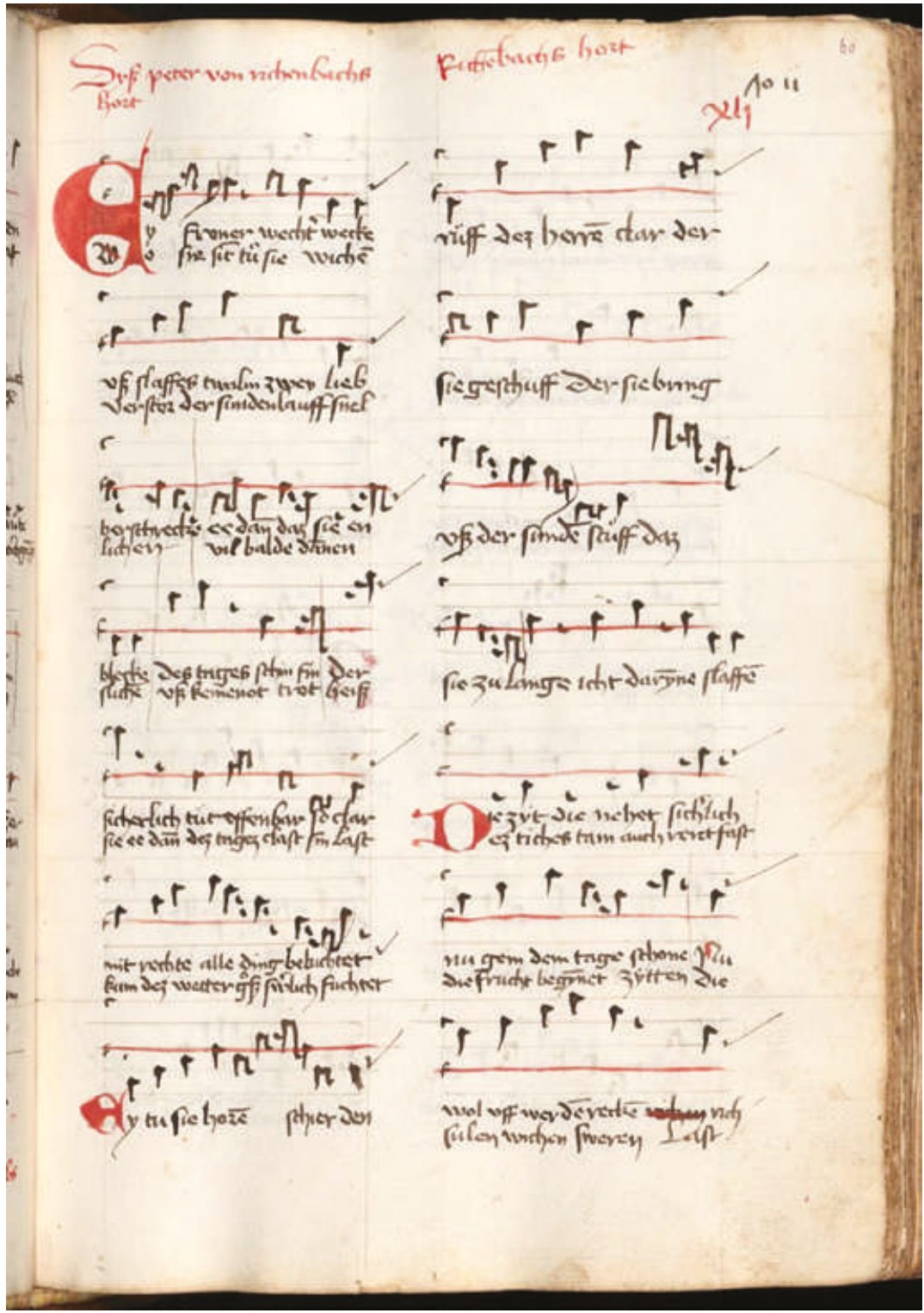

Abb. 1: Kolmarer Liederhandschrift, Bl. 60r: Peters von Reichenbach Hort: Überschrift und Kolumnentitel am Beginn der Aufzeichnung. 


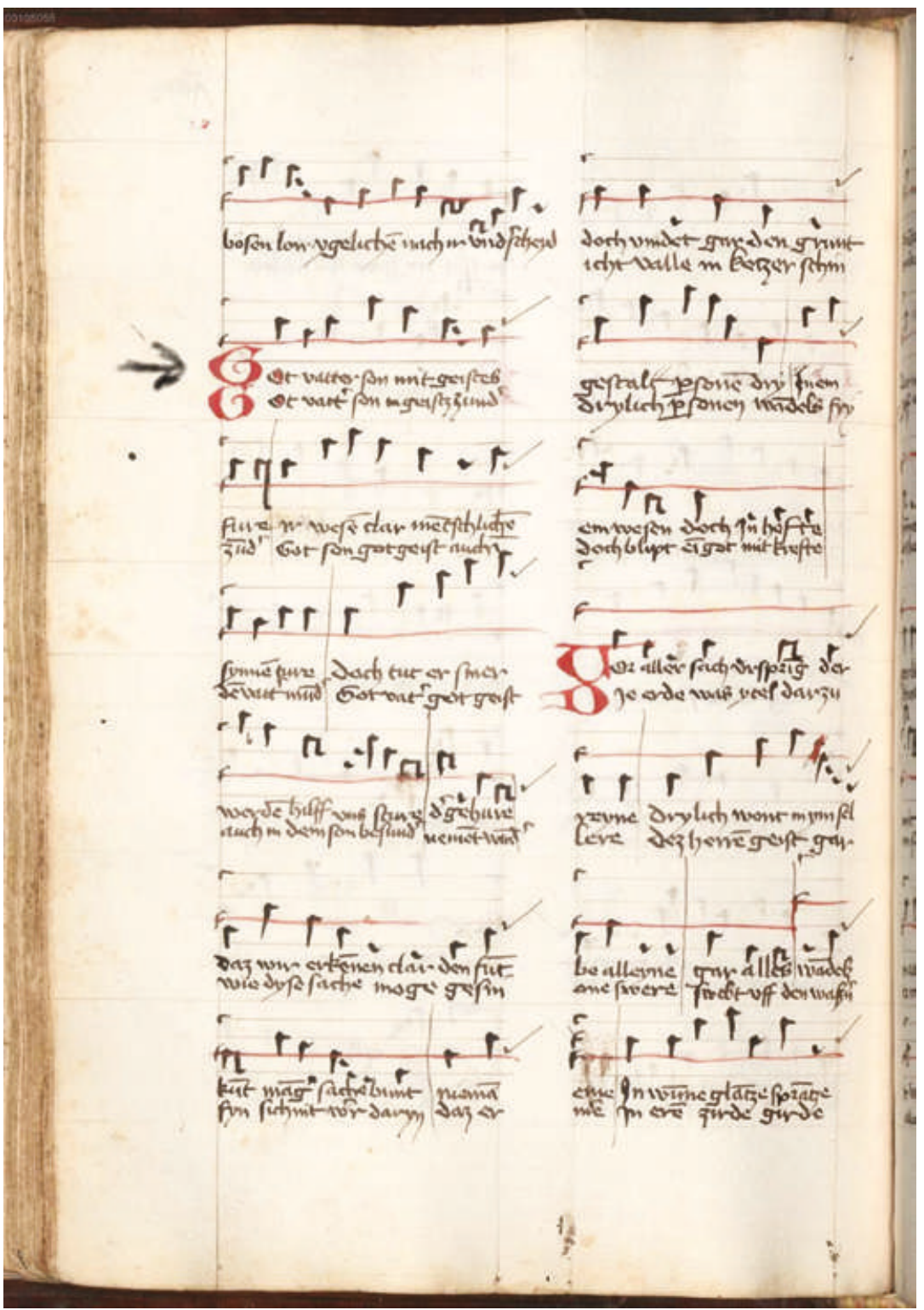

Abb. 2: Kolmarer Liederhandschrift, Bl. 62v: Übergangsloser Wechsel vom Tagelied zum Leich. 


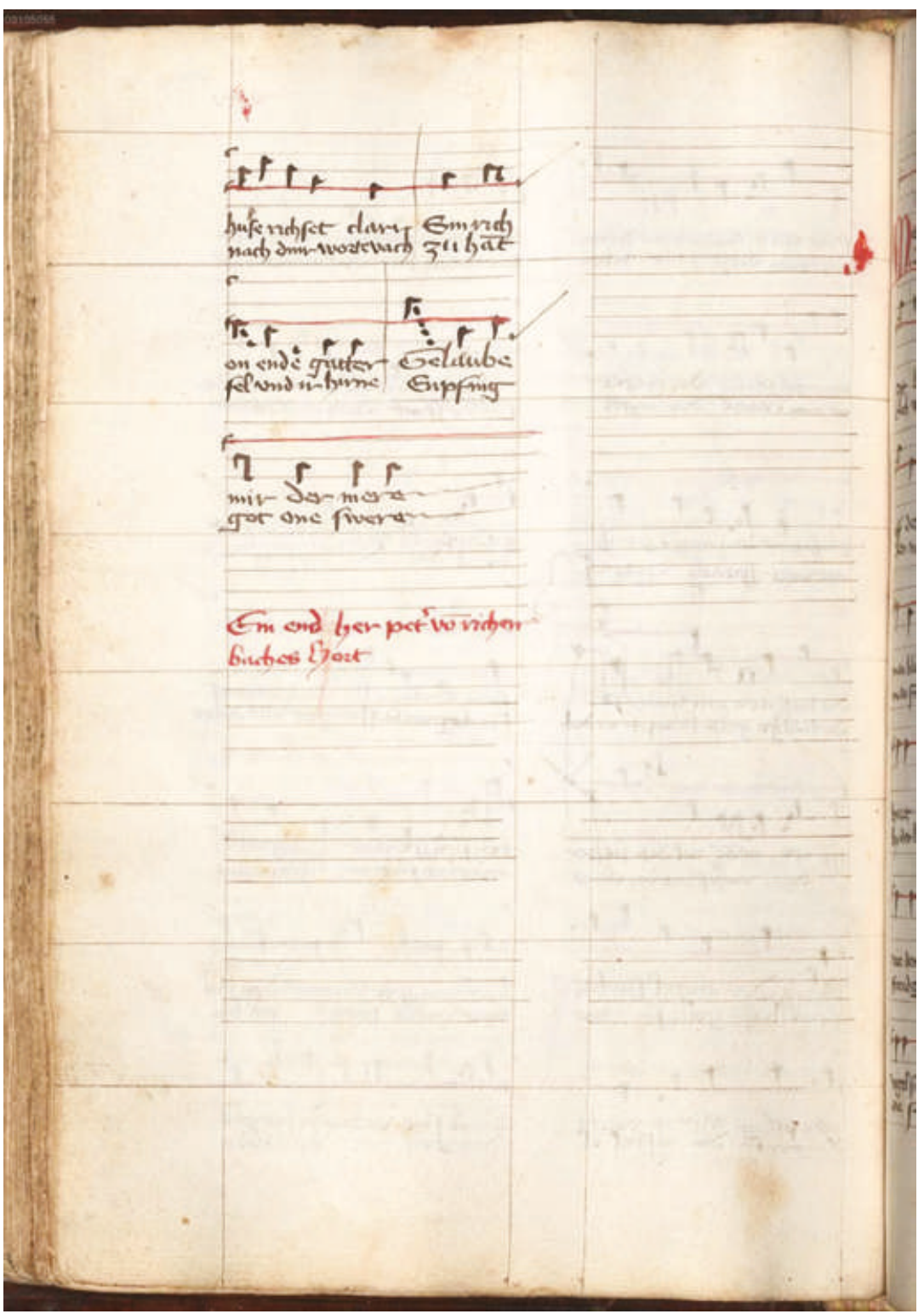

Abb. 3: Kolmarer Liederhandschrift, Bl. 68v: Peters von Reichenbach Hort: Explicit des Schreibers. 



\title{
Simone Loleit
}

\section{neyn, da zweyent sich die mer - Zum Zusammenhang von Antijudaismus, christologischer Schriftauslegung und Allegorese in Regenbogens Der juden krieg}

\begin{abstract}
The Colmar Liederhandschrift contains two versions of the 'Judenkrieg', a song in Regenbogen's Long Tone ("Langer Ton"); these versions differ notably in regard to the number and the succession of the stanzas. The song demonstrates, in the form of a religious disputation between a Christian main speaker and a Jewish character, the controversial debate about the divine status of Jesus Christ. The article focuses on the aggressive rhetorical strategy, on the attempt of maintaining Christian dominance and the modes of establishing a collective spirit for Christian recipients. An edition of the ten stanza version is attached.
\end{abstract}

\section{Einstieg}

1950er Jahre: Die Produktion eines sogenannten Sandalenfilms, einer Monumentalverfilmung des Leben Jesu, ist bereits angelaufen, und der Produzent Eddie Mannix will nichts unterlassen, um dem kostspieligen Film schon im Vorfeld eine breite und durchweg positive Resonanz zu sichern. Vor allem soll sich niemand durch die Jesus-Darstellung des Films in seinen religiösen Gefühlen verletzt fühlen: Wen könnte er diesbezüglich besser um Rat fragen als eine kleine, aus Geistlichen gebildete Expertengruppe: einen orthodoxen Patriarchen, einen katholischen Priester, einen protestantischen Geistlichen sowie einen Rabbiner?

EDDIE

Now Hail, Cæsar! is a prestige picture, our biggest release of the year, and we are devoting huge resources to its production in order to make it first-class in every respect. Gentlemen, given its enormous expense, we don't want to send it to market except in the certainty that it will not offend any reasonable American, regardless of faith or creed. Now that's where you come in. You've read the script; I wanna know if the theological elements of the story are up to snuff. ${ }^{1}$

1 Joel und Ethan Coen: HAIL, CÆSAR! [Originaldrehbuch]. O. O. 2014; online abrufbar unter: http://www.cinefile.biz/script/avecesare.pdf, S. 19-21; Hervorhebungen hier und im Folgenden, soweit nicht anders vermerkt, i. Orig. 
Wie die Geistlichen dem zunehmend verwirrter wirkenden Produzenten daraufhin gemeinschaftlich zu erläutern versuchen, verhalte es sich mit der Natur Christi nicht ganz so einfach, wie es in dem Film dargestellt werde. ${ }^{2}$ Allerdings herrscht selbst bei den christlichen Vertretern nur begrenzt Einigkeit, wie sich am besten erklären lässt, warum Gott und Christus nicht einfach in eins gesetzt werden dürfen und dass Christus sowohl Mensch als auch Gott ist. Die ganze trinitarische Problematik beginnt das Fassungsvermögen des, übrigens selbst streng katholischen, Produzenten sichtlich zu übersteigen:

EDDIE

So God is ... split?

PRIEST

Yes.

(Eddie nods.)

... And no! (Eddie frowns.)

PATRIARCH

There is unity in division.

MINISTER

And division in unity.

EDDIE

Not sure I follow, Padre.

RABBI

Young man, you don't follow for a very simple reason: these man [sic!]

are screwballs.

(to the others)

God has children? What, and a dog? A collie maybe? God doesn't have children. He's

a bachelor. And very angry.

PRIEST

He used to be angry!

RABBI

What, he got over it?

MINISTER

You worship the god of another age! $!^{3}$

2 „PRIEST: The nature of the Christ is not quite as simple as your photoplay would have it." (ebd.)

3 Ebd., S. 20f.; die Regieanweisungen sind, anders als in dem Drehbuch, einheitlich durch Klammern und Kursivierung gekennzeichnet. 
Anders als der um den guten Ton bemühte fiktive Produzent legen die CoenBrüder in ihrem Film Hail, Cosar! aus dem Jahr 2016 mit dieser Szene den Finger in die Wunde des christlich-jüdischen Dialogs. Die hier mit rhetorischen Volten und Spitzen geführte Debatte um die Menschennatur Gottes ist die Wiederauflage eines alten Problems: der Versuch einer Verständigung von Christen und Juden über die messianische Frage.

Es ist bekannt, dass dieses Problem in der Geschichte des christlich-jüdischen Dialogs oft, und leider nicht selten mit Eifer und Zorn, verhandelt wurde. Funkenstein bezeichnet Judentum und Christentum als „Konfrontationskulturen im genauen Sinne des Wortes. Die bewußte und stete Ablehnung von Werten und Ansprüchen des anderen war und blieb konstitutives Moment für den fortlaufenden Aufbau der Identität der eigenen Kulturen. ${ }^{\text {" }}$ Im Folgenden soll mit Regenbogens ,Judenkrieg' ein Beispiel für einen christlich-,jüdischen' Pseudo-Dialog behandelt werden, in dem der verbale Schlagabtausch permanent und einseitig die Grenze zur offenen, gewaltbereiten Aggression überschreitet und von einer Seite, der christlichen, beherrscht wird. Ähnlich wie der Rabbi, der sich fragt, ob Gott etwa auch noch einen Collie hätte, wenn er angeblich einen Sohn habe, wehrt auch die Figur des Juden in Regenbogens Lied die Vorstellung, dass Christus Gott sei, entschieden ab: ,neyn, da zweyent sich die mere. / noch nyeman mich zu bringen mag, / daz ich es gleub. der glaub ist ungehüre, / wie daz eine maget got gebere / uff erden hie und sie sin bürtig wurde.' (III,6-10)5 Betrachtet man diese Antwort, die der Figur des Juden innerhalb des christlich dominierten und in weiten Strecken eher monologischen Dialogs in den Mund gelegt wird, als Bestandteil einer Profilschärfung des christlichen Glaubens, so müsste man sie

4 Amos Funkenstein: Juden, Christen und Muslime. Religiöse Polemik im Mittelalter. In: Die Juden in der europäischen Geschichte. Sieben Vorlesungen. Hg. von Wolfgang Beck. München 1992, S. 33-49, hier S. 33.

5 Die Zitation des Lieds Der juden krieg zehen lieder ( $\mathrm{k}$ Reg/LangT 23-32 = RSM ${ }^{1} \mathrm{Regb} /$ 4/1b) erfolgt nach der am Ende des Beitrags abgedruckten Edition; die Erarbeitung erfolgte auf Basis der in einem DFG-Projekt an der Universität Duisburg-Essen entstehenden Edition der in Regenbogens Langem Ton überlieferten Lieder, die unter Leitung von Martin Schubert von Judith Lange und Eva Rothenberger erstellt wird und im Online-Editionsprojekt, Lyrik des deutschen Mittelalters online' (www. ldm-digital.de, hg. von Manuel Braun, Sonja Glauch und Florian Kragl) publiziert wird. Zitate aus anderen Strophen aus dem Regenbogen-Corpus in der Kolmarer Liederhandschrift und aus der Parallelüberlieferung des ,Judenkriegs' habe ich ohne Änderung nach dem mir zugänglichen aktuellen,work in progress'-Stand der Edition übernommen. Hiermit danke ich Judith Lange herzlich für die freundliche Erlaubnis, aus den Arbeitsfassungen zu zitieren. 
als christliche Autoprovokation unter billigender Inkaufnahme etwaiger Kollateralschäden interpretieren - was im Folgenden zu diskutieren sein wird.

\section{Der juden krieg in der Kolmarer Liederhandschrift}

Die Kolmarer Liederhandschrift (München, BSB, Cgm 4997) überliefert an zwei Stellen (Bl. 338r-340v und Bl. 422r-423v) ein mit Der juden krieg betiteltes Lied, einmal als zehnstrophige (k Reg/LangT 23-32 = RSM Regb/4/1b), einmal als sechsstrophige, aber vermutlich Fragment gebliebene Fassung (k Reg/LangT 408-413 = RSM Regb/4/1c). ${ }^{6}$ Die Überschrift verortet den Text im Genre des religiösen Streitgesprächs. ${ }^{7}$ Das zehnstrophige Lied, welches der folgenden Analyse zugrunde liegt, ist der vom Strophenbestand her umfangreichste Überlieferungszeuge dieser fiktiven disputatio.

Parallelüberlieferung mit Strophenbestands- und -folgevarianz findet sich in der sechsstrophigen Fassung D Namenl/65r $1-6^{8}$, der vierstrophigen Fassung $\mathrm{m}_{1}$ Namenl/232 $\mathrm{v} 1-4^{9}$ sowie im neunstrophigen Lied $\mathrm{m}_{1}$ Reg/LangT/199r $1-9^{10}$ und im dreistrophigen Lied $m_{2}$ Namenl/64v 36-

6 Die sechsstrophige Fassung wird über die Überschrift Der juden krieg vii lyder als siebenstrophiges Lied angekündigt; auf Bl. 423v ist nach dem Lied Raum freigelassen, auf dem womöglich eine oder mehrere weitere Strophen hätten eingetragen werden sollen. Der in roter Schrift geschriebene Vermerk such sie gantz da forn iij ${ }^{c}$ xiiij verweist auf Strophen der zehnstrophigen Fassung, aber es ist unklar auf welche Strophe(n) und, falls mehrere, in welcher Reihenfolge. Die Strophenzählung k Reg/ Lang T 23-32 entspricht der LDM-Zählung der Strophen/Lieder in Regenbogens Langem Ton in der Kolmarer Liederhs., Bl. 333ra-502va, hier 338rb-340va. Vgl. hierzu RSM 5, S. 92.

7 Bereits Berthold von Regensburg verwendet in seiner an christliche Laien gerichteten Warnung davor, mit Juden zu disputieren, den Ausdruck kriec. Vgl. den Beleg bei Manuela Niesner: Christliche Laien im Glaubensdisput mit Juden. Eine verbotene Gesprächssituation in literarischen Modellen des 15. Jahrhunderts. In: Zeitschrift für deutsches Altertum 136 (2007), S. 1-28, hier S. 3.

8 Heidelberg Cpg 350, Bl. 65rv-66r, Str. 382-387; RSM Regb/4/1a.

9 München Cgm 351, Bl. 232v-234r; RSM Regb/4/1e.

10 München Cgm 351, Bl. 199r-202r; RSM Regb/4/1d, s. Regb/4/603a. „Bei dem neunstrophigen Bar handelt es sich um eine Lied- und Strophenkompilation, die sich aus dem Strophenkonvolut von insgesamt vier weiteren Liedern bedient" (aus dem noch unveröffentlichten Liedkommentar der Regenbogen-Edition, vgl. Anm. 5). Die Strophen I-VII gehören thematisch nicht in den engeren Kontext des ,Judenkriegs', sondern behandeln allgemeine heilsgeschichtliche Themen. Dabei wird wiederholt auf die Johannesapokalypse Bezug genommen und Johannes dabei auch als 
$38^{11}$, welche jeweils zwei der in k Reg/LangT 23-32 überlieferten Strophen enthalten. Das achtstrophige Lied f Reg/Lang T/42v 1-8 12 überliefert drei aus k Reg/LangT 23-32 in Kombination mit fünf der sechs Strophen, die in $\mathrm{m}_{1} \mathrm{Reg} /$ LangT/239r $1-6^{13}$ als selbständiges Lied vorliegen und sich im Strophenbestand vollständig von dem zehnstrophigen Lied in der Kolmarer Liederhandschrift unterscheiden.

Das im Langen Ton komponierte Lied Der juden krieg nimmt in mehrfacher Hinsicht eine Sonderrolle im Regenbogen-Corpus der Kolmarer Liederhandschrift ein:

- Es wird, was aufgrund der in k recht häufig vorkommenden Dubletten allerdings nicht außergewöhnlich ist, an zwei Stellen überliefert.

- Es gehört - beide Anfangsstrophen von Der juden krieg bereits mit eingerechnet - zu den nur zehn der in der Kolmarer Liederhandschrift überlieferten Strophen in Regenbogens Langem Ton, die mit dem Wort ,Ich ' beginnen. ${ }^{14}$ Die zehnstrophige Fassung weist zudem mit zwei weiteren Strophen, in denen das Personal- bzw. Reflexivpronomen der 1. Person Singular direkt im

Gewährsmann für die vermeintlich von den Juden ausgehende Gefahr angeführt: So habe der Adler in seiner Vision u. a. darüber geklagt, das die welte strebt / gewaltecleich nach der judischen e (VI,16f.). Dies bildet eine Art Brücke zu den dann am Liedende (VIII-IX, Bl. 201r-202r) folgenden, Judenkrieg'-Strophen.

11 München Cgm 5198, Bl. 72-73r; RSM ${ }^{1}$ Regb/4/1f; wie die Überschrift Jm slecht langen don des Regenpogenn iii lied von Moyses vnd von künig Pharao bereits anzeigt, behandelt das Lied den Auszug der Israeliten aus Ägypten und kombiniert die „unikal“ (aus dem noch unveröffentlichten Liedkommentar der Regenbogen-Edition, vgl. Anm. 5) überlieferte Eingangsstrophe Gayst, vater, sun, ain got gehewr mit zwei ,Judenkrieg'-Strophen; da jedoch keine der Strophen einen Bezug zum Rahmenthema des Glaubensdisputs aufweist, sondern es sich um eine rein monologisch vorgetragene christologische Ausdeutung der mosaischen Erzählung handelt, kann das Lied m. E. nicht zum engeren Bestand des, Judenkriegs' gerechnet werden.

Weimar Q 564, Bl. 42v-44v; RSM Regb/4/1g.

13 München Cgm 351, Bl. 239r-241r; RSM Regb/4/1h.

14 Es handelt sich neben den Eingangsstrophen der beiden ,Judenkrieg'-Fassungen um die Strophen Ich wolt, daz kunst gekronet were (k Reg/LangT $34=\mathrm{RSM} \mathrm{Regb/4/}$ 507); Ich fraüw mich wan myn hertz betrahtet (k Reg/LangT 41 = RSM Regb/4/509); Ich wil von vier personen singen ( $\mathrm{k}$ Reg/LangT $84=\mathrm{RSM}$ Regb/4/516) (Liedanfang); Ich heb ans vatter persone ( $\mathrm{k}$ Reg/LangT $120=\mathrm{RSM}$ Regb/4/524a); Ich wil von hoher gotheit singen (k Reg/LangT 137 = RSM Regb/4/530); Ich bitt dich, herr, vor myne sünde (k Reg/LangT 144 = RSM Regb/4/532); Ich lob den vatter in dem trone (k Reg/ LangT 207 = RSM Regb/4/549a); Ich sprich es von den wisen pfaffen (k Reg/LangT $243=$ RSM Regb/4/559a). 
ersten Vers vorkommt (II, VI), eine gewisse Häufung von (affektiert) subjektiv eingeleiteten Strophen auf.

- Das Lied arbeitet bereits im Eingangsvers mit direktem Gefühlsausdruck, was - ob auf Strophen- bzw. Liedanfänge bezogen - in den Liedern des Langen Tons nicht allzu häufig vorkommt, und wenn doch, sind es nicht, wie hier, Hassgefühle, sondern das intellektuelle Gefühl von Verwunderung bzw. Staunen, ${ }^{15}$ religiös motivierte Angst, ${ }^{16}$ durch Liebessehnsucht verursachte Traurigkeit, ${ }^{17}$ in Minne und Frauenschönheit gründende Freude ${ }^{18}$ oder durch Armut verursachte Leiderfahrung. ${ }^{19}$ Nur im Fall von Der juden krieg erlaubt sich der Sprecher, ein Lied in der Pose des Hassers einzuleiten. Dieser aggressive, feindselige Ton trägt große Teile des Liedes und neutralisiert sich nur an den Stellen, in denen die Figur des Juden als Zielscheibe des Vorgetragenen aus dem Blick gerät.

\section{Leitfragen}

Es sind zwei aus diesen Vorüberlegungen abzuleitende Fragen, die ich im Speziellen an das Lied richten möchte:

1. Was verursacht einen solchen Hass, eine solche Aggression in dem Sprecher, und was veranlasst ihn, diese in unverhüllter und überforcierter Form zum Ausdruck zu bringen?

2. Warum verliert er den fingierten jüdischen Adressaten zwischenzeitlich (scheinbar) aus den Augen?

\section{Leitfrage 1: Gründe der Aggression}

Der Sprecher wählt die Form der disputatio bzw. des religiösen Kampfgesprächs, in dem er die Rolle des Herausforderers und des Fragenden innehat, der mittels systematisch vorgetragener Beweise versuchen will, den fingierten Juden zur Einsicht zu bringen. Nachdem er mit dem von Christen und Juden geteilten Glauben an Gott als Schöpfer eine Basis für den ,Dialog' geschaffen hat (I,9-11), spricht er den Punkt an, über den bekanntermaßen Dissens herrscht,

15 Ob mich daz wonder haben solte (k Reg/LangT 4 = RSM Regb/4/501a).

16 Wann ich betraht in myme sinne (k Reg/LangT 21 = RSM Regb/4/505a); Wann ich gedenck in mynem synne (k Reg/LangT 242 = RSM Regb/4/558a).

17 Mich wart myn munt so sere twingen (k Reg/LangT 22 = RSM Regb/4/505a); Mich wart myn mut so sere zwingen (k Reg/LangT 405 = RSM Regb/4/590a).

18 Mine freud ist groß, wann ich besynne (k Reg/LangT 39 = RSM Regb/4/509); Ich fraüw mich wann myn hertze betrahtet (k Reg/LangT $39=\mathrm{RSM}$ Regb/4/509).

19 Der habenit hat mich beraubet (k Reg/LangT 432 = RSM Regb/4/596). 
dass Jesus Christus mit dem Schöpfergott identisch und von einer Jungfrau geboren worden sei (I,16-20). Dies verneint der Jude erwartbarerweise (I,21) und soll nun durch allegorische und typologische Auslegungen einschlägiger Stellen überzeugt werden. Dabei geht der Sprecher davon aus, dass der Jude im Alten Testament gelehrt ist: Wol her an mich, wellch jud ist wise / uz der alten ee, den wil ich überkomen (II,1f.). Im Gefolge der Gerichtskampfmetaphorik der ersten Strophe kann dies als Abstecken des Kampfplatzes interpretiert werden; laut Müllerburg u. a. setzen mittelalterliche Religionsdialoge häufig damit ein, „die Regeln der Glaubenskontroverse zu definieren, gleich der Außengrenze eines Turnierplatzes, die in den Staub gezeichnet wird, um den Raum

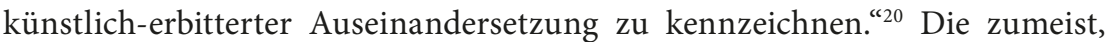
wie auch hier, aufgestellte Regel, sich auf das Alte Testament zu beschränken, werde von den christlichen Disputanten jedoch oft insoweit unterlaufen, als sie gemäß der typologischen Exegese auch Stellen aus dem Neuen Testament zur Erklärung einbeziehen: ${ }^{21}$ „Zwar wird das Neue Testament als Text aus der Debatte ausgeschlossen, aber die durch das Neue Testament legitimierte typologische Hermeneutik wird eben nicht ausgeschlossen. ${ }^{\text {"22 }}$ Dementsprechend dreht sich auch im ,Judenkrieg' der Streit um die richtige, nämlich christologische, mariologische bzw. trinitätsbezogene Auslegung der Bücher des Alten Testaments. ${ }^{23}$ Müllerburg u. a. erklären die sich daraus ergebende vertikale

20 Marcel Müllerburg, Britt Müller-Schauenburg und Henrik Wels: ,Und warum glaubst Du dann nicht?' Zur ambivalenten Funktion der Vernunft in Religionsdialogen des 12. Jahrhunderts. In: Integration und Desintegration der Kulturen im europäischen Mittelalter. Hg. von Michael Borgolte, Julia Dücker, Marcel Müllerburg und Bernd Schneidmüller. Berlin 2011 (Europa im Mittelalter 18), S. 261-324, hier S. 270.

21 Vgl. ebd., S. $272 \mathrm{f}$.

22 Ebd., S. 273.

23 Mit dieser Haltung bewegt sich der Sprecher des Lieds in einer Tradition, die bis heute innerhalb der katholischen Theologie eine Rolle spielt. So erläutert etwa Joseph Ratzinger bzw. Papst Benedikt XVI. in seinem umstrittenen Beitrag zum Traktat De Iudaeis zum Status des Neuen Testaments: „Diese Schriften stehen aber nicht in sich selbst, sondern beziehen sich durchweg auf das ,Alte Testament', das heißt auf die Bibel Israels. Ihr Sinn ist es, die authentische Auslegung der alttestamentlichen Schriften in den Ereignissen um Jesus Christus zu zeigen." Joseph Ratzinger/ Benedikt XVI: Gnade und Berufung ohne Reue. Anmerkungen zum Traktat ,De Judaeis'. In: Internationale katholische Zeitschrift Communio 47/4 (2018), S. 387406, hier S. 389. Dementsprechend seien die fünf Bücher Mose aus christlicher Sicht Prophetie, Tora und Propheten seien als vorausgenommene Christologie zu lesen (vgl. ebd., S. 391). Judentum und Christentum seien als zwei Antworten auf die 
Kommunikationssituation bezüglich der mittelalterlichen Religionsdialoge mit dem von den Dialogteilnehmern erhobenen „exklusiven Wahrheitsan-

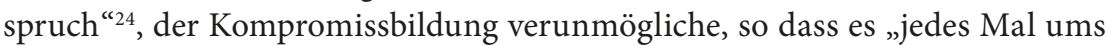
Ganze [gehe], wenn sie in die Diskussion eintreten. ${ }^{\text {"25 }}$ Für den im ,Judenkrieg fingierten Glaubensdisput gilt dabei, wie für die von Christen verfassten fiktiven religiösen Dialoge generell, dass die Niederlage des christlichen Sprechers „keine darstellerische Option“26 ist.

Der ,Judenkrieg' kann in den weiteren Umkreis der deutschsprachigen Rezeption der Adversus-Judaeos-Literatur eingereiht werden und richtete sich wohl kaum ,direkt' missionarisch an Juden, sondern sollte vielmehr innerhalb der christlichen Gemeinschaft glaubensstärkend wirken ${ }^{27}$ und, wie allgemein für diese Textgruppe angenommen, der „Bekämpfung judaisierender Zweifel am christlichen Glauben“28, d. h. im Speziellen „an der christologischen Exegese des Alten Testaments, der Messianität und den zwei Naturen Jesu und

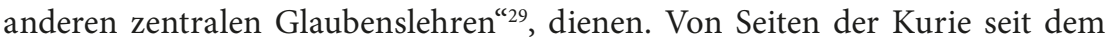
13. Jahrhundert verstärkt betriebene Versuche, den Kontakt zwischen Christen und Juden einzuschränken und insbesondere Gespräche über den Glauben zu unterbinden, ${ }^{30}$ sowie die von Mendikantenpredigern, wie z. B. dem Franziskaner Berthold von Regensburg, wiederholt ausgesprochenen Warnungen vor Kontakt und Gesprächen mit Juden ${ }^{31}$ spiegeln die „Furcht vor der religiösen

Zerstörung des Tempels im Jahr 70 n. Chr. anzusehen (vgl. ebd., S. 388). „Wie wir wissen, hat nur ein eher kleiner Teil Israels diese Antwort [= das Christentum, S. L.] anzunehmen vermocht, während der größere Teil sich ihr widersetzte und auf andere Weise eine Lösung suchen musste" (ebd.; Hervorhebungen von S. L.). Durch die Art der Formulierung wird deutlich unterstrichen, dass die christliche Position als der jüdischen überlegen anzusehen sei, und zwar in dem Sinne, dass sie nicht nur als ,richtigere' Meinung, sondern als wahre Erkenntnis hingestellt wird.

24 Müllerburg/Müller-Schauenburg/Wels 2011 (Anm. 20), S. 265.

25 Ebd.

26 Ebd., S. 268.

27 Siehe zu diesen beiden grundsätzlich in der Forschung diskutierten alternativen Wirkungsabsichten der Adversus-Judaeos-Literatur Manuela Niesner: Wer mit juden well disputiren. Deutschsprachige Adversus-Judaeos-Literatur des 14. Jahrhunderts. Tübingen 2005 (MTU 128), S. 43.

28 Ebd, S. 44.

29 Ebd.

30 Vgl. Niesner 2007 (Anm. 7), S. 2f.

31 Vgl. ebd., S. 3; Claudia Bendick: Daz übel ist daz si lebent. Antijudaismus in Predigten Bertholds von Regensburg (1210-1272). In: Judentum und Antijudaismus in der 
Beeinflussung von Christen durch Juden“32, welche insbesondere „als Gefahr für die analphabetische Bevölkerung "33 wahrgenommen wurde. Im Umkehrschluss gedacht, können judaisierende Zweifel dann eventuell auch als Indikator für christlich-jüdische Beziehungen gedeutet werden, ${ }^{34}$ wie Niesner in ihrer Kritik an einer vorschnellen Ineinssetzung der „Etiketten ,nicht missionarisch bzw. ,innerchristlich glaubensstärkend “ " 35 zu bedenken gibt. Ohnedies sei die Abgrenzung eines ,innerchristlichen' Bereichs innerhalb der Beziehungen der beiden Religionen „,immer nur graduell und willkürlich“" ${ }^{36}$ möglich, da „das Christentum aufgrund seiner Genese und seines Schriftkanons nicht ohne das Judentum denkbar ${ }^{\text {(37 }}$ sei.

Die, u. a. aufgrund des fiktiven Status der literarischen Glaubensdispute naheliegende Vorstellung eines, um eine Formulierung von Müllerburg u. a. aufzugreifen, ,inneren Außen ${ }^{38}$ impliziert eben auch die Vorstellung des ,Außen'. Krugers Überlegungen zum ,gespenstischen Juden' (spectral jew) folgend, bestünde dieses ,Außen' in einer ideologisch verzerrten und durch Stereotype und Phantasiekonstrukte gefilterten Wahrnehmung des zeitgenössischen Judentums und jüdischer Zeitgenossen durch ihre christlichen Mitmenschen. Einem streng zwischen gedanklichem Konstrukt und historischer Realität unterscheiden wollenden Beschreibungsansatz hält Kruger entgegen,

that „Jews and Judaism were living realities for the medieval Christian ${ }^{\star 39}$ - even the medieval English Christian post-1290 for whom "real“ Jews were absent - but that those „living realities" were experienced as much and as importantly through the constructions of fantasy and ideology as in any more purely experiential realm. ${ }^{40}$

deutschen Literatur im Mittelalter und an der Wende zur Neuzeit. Ein Studienbuch. Hg. von Arne Domrös, Thomas Bartoldus und Julian Voloj. Berlin 2002, S. 31-59, hier S. 45.

32 Niesner 2007 (Anm. 7), S. 3.

33 Bendick 2002 (Anm. 31), S. 45; vgl. Niesner 2007 (Anm. 7), S. 3.

34 Vgl. Niesner 2005 (Anm. 27), S. 44.

35 Ebd.

36 Ebd.

37 Ebd.

38 Müllerburg/Müller-Schauenburg/Wels 2011 (Anm. 20), S. 262.

39 Kruger (s. Anm. 40) reagiert hier auf eine Kritik, die Mary Dove gegenüber seiner schon früher geäußerten These zum ,spectral Jew' geäußert hat, und hebt einige Stellen als Zitate aus dieser Kritik in Anführungszeichen hervor.

40 Steven F. Kruger: The Spectral Jew. Conversion and Embodiment in Medieval Europe. Minneapolis u. a. 2006 (Medieval Cultures 40), S. XXI; dabei ist wohl von einer Vorgängigkeit des kirchlich geprägten, stereotypisierten Judenbilds vor der 
Exemplarisch für eine solche Wahrnehmung, realer Juden' durch Konstrukte kann Könnekers Analyse der Judendarstellung in den Passionsspielen angeführt werden: In diesen würden die biblischen Juden, die Jesus nicht als Messias anerkannten, durchweg mit den zeitgenössischen mittelalterlichen Juden gleichgesetzt, wohingegen die biblischen Jünger und jüdischen Anhänger Jesu $\mathrm{zu}$ christlichen Identifikationsfiguren würden. ${ }^{41}$ „Die Schuldigen am Leiden und Sterben des Gottessohnes waren daher im Geistlichen Spiel stets die Juden der zeitgenössischen Gegenwart, die auf der Bühne durch die ihnen seit dem 13. Jahrhundert vorgeschriebene Kleidung gekennzeichnet waren ". ${ }^{42}$ Diese anachronistische Deutung der Juden des Neuen Testaments lenke von dem Moment an, wo in den geistlichen Spielen die in den Evangelien „erzählten historischen Vorgänge zu einem immer neu sich realisierenden Gegenwartsgeschehen ${ }^{\text {"43 }}$ umgedeutet worden seien, die negativen Emotionen des christlichen Publikums auf die zeitgenössischen Juden. ${ }^{4}$

Auch wenn im Folgenden die Figur des Juden im ,Judenkrieg in erster Linie als Projektionsfläche einer innerchristlichen Selbstauseinandersetzung interpretiert wird, soll dabei nicht außer Acht gelassen werden, dass dieser Text antijüdische Einstellungen bei den christlichen Rezipienten befördert haben und somit zur Marginalisierung, Stereotypisierung und ggf. Verfolgung jüdischer Menschen beigetragen haben dürfte. Diese Frage soll jedoch nicht im Sinne eines realhistorischen Kontextualisierungsversuchs, sondern hinsichtlich der verwendeten argumentativen Strategien untersucht werden.

In dem Lied manifestiert sich das zentrale Problem, dass von christlicher Seite aus Deutungshoheit über das von Juden und Christen geteilte textuelle Erbe beansprucht wird; die allegorische Deutung wird im Text regelrecht als

Bekanntschaft mit real lebenden Juden auszugehen: „das Anderssein der Juden war allen evident, sie waren in Predigten und im Kirchenjahr quasi omnipräsent (viel präsenter als in der Wirklichkeit, und schon das Mittelalter kannte eine virulente Judenfeindschaft selbst ohne jegliche Anwesenheit realer Juden - z. B. in England), sie eigneten sich daher ganz vortrefflich zur Rolle eines allgegenwärtigen Widerparts der abstrakten Christenheit und zu einem universalen Sündenbock - eine solche Rolle beinhaltet zwangsläufig irrationale Züge" (František Graus: Die Juden in ihrer mittelalterlichen Umwelt. In: Die Juden in ihrer mittelalterlichen Umwelt. Hg. von Alfred Ebenbauer und Klaus Zatloukal. Wien u. a. 1991, S. 53-65, hier S. 64).

41 Vgl. Barbara Könneker: Das Donaueschinger Passionsspiel. In: Euphorion 79 (1985), S. 13-42, hier S. 19.

42 Ebd.

43 Ebd.

44 Vgl. ebd., S. 19f. 
,Waffe der Christen gegen die Juden eingesetzt; bereits den im zweiten Vers des Lieds verwendeten Ausdruck swert der kristen (I,2) könnte man in diese Richtung deuten. ${ }^{45}$ Die Vorstellung des Schwerts signalisiert auf der wörtlichen Bedeutungsebene eine Gewaltbereitschaft, die sich auch im Weiteren in der martialischen Sprache, mit der der christliche Sprecher seinen jüdischen Kontrahenten einzuschüchtern und abzuwerten versucht, abzeichnet: Er beschimpft ihn als blint mit (augen) angesicht (III,23; V,9), als Lügner (II,23), schalg jude (III,11), boses lasterfaß $(\mathrm{V}, 22)$, lasterbalg $(\mathrm{VI}, 22)$ und arge[n] wiht $(\mathrm{X}, 8)$; er bedroht und beleidigt ihn. ${ }^{46}$ Von derartigen Beschimpfungen unterscheidet sich die Schwertmetapher insoweit, als sie auf das Feld der Exegese und des mit Worten geführten Streits lenkt. Innerhalb dieses Redestreits nimmt sich der christliche Sprecher, wie es die Schwertmetapher bereits andeutet, jedoch die Lizenz, seinen Kontrahenten mit physischer Gewalt und Vernichtung zu bedrohen, wie folgender Passus nachdrücklich zeigt: schalg jude, ob ich dich des bewere, / wiltu dich lassen brennen uff eynre hurde? / , nit brenne mich, wanne du maht / mich sin beweren niht ' (III,11-14).

Diesem verbalen Schlagabtausch geht voran, dass der Jude die Lehre von der menschlichen Natur Gottes und der jungfräulichen Geburt des Messias ablehnt. Dies wird vom christlichen Sprecher offensichtlich als Provokation empfunden, denn er fordert daraufhin vom Juden ein, sich auf dem Scheiterhaufen verbrennen zu lassen, sollte er - der Sprecher - die nötigen Beweise vorlegen können. Diese höchst zynische Aufforderung impliziert die Option, die jüdische Position durch eine Feuerprobe, also ein (vermeintliches) Gottesurteil, zu bezeugen, und verbindet damit die Androhung der Todesstrafe für den Irrglauben. Wie Dinzelbacher ausführt, wurde in den eher seltenen Fällen, in denen Ordalien (Gottesurteile) gegen Häretiker angewandt wurden, anscheinend

45 Hier ist eine Ähnlichkeit zu einer Stelle aus dem Dialogus contra Iudaeos des Petrus Alfonsi zu erkennen: In diesem akzeptiert der christliche Disputant die Forderung des jüdischen Gegners, sich ausschließlich auf die hebräische Bibel zu beziehen, mit den Worten, dass er ihn mit, seinem eigenen Schwert' töten wolle, vgl. Müllerburg/ Müller-Schauenburg/Wels 2011 (Anm. 20), S. 272.

46 Zur verbalen Aggressivität und Bedrohlichkeit des christlichen Sprechers in dem Lied vgl. Helmut Birkhan: Die Juden in der deutschen Literatur des Mittelalters. In: Ders. (Hg.): Die Juden in ihrer mittelalterlichen Umwelt. Protokolle einer RingVorlesung gehalten im Sommersemester 1989 an der Universität Wien. Bern u. a. 1992 (Wiener Arbeiten zur germanischen Altertumskunde und Philologie 33), S. 143-178, hier S. 153. 
am häufigsten die Feuerprobe ausgewählt, „vielleicht in einer Art der Vorwegnahme, da Verbrennen die übliche Strafe für dieses Verbrechen war “" ${ }^{47}$

Der Sprecher rückt den Juden, was sich in spätmittelalterlicher Literatur, z. B. in Predigten Bertholds von Regensburg, wiederholt findet, hier also in die Nähe der Häretiker. ${ }^{48}$ An dieser Stelle wird die Grenze zwischen metaphorischer und eigentlicher Bedeutung sehr brüchig; die Rhetorik entgleitet dem Sprecher (scheinbar), so dass spätestens hier deutlich wird, dass diese disputatio ein Kampf auf Leben und Tod ist, in dem der Opponent ausgelöscht werden soll. Es ist der Jude, der mit der Antwort: ,nit brenne mich, wanne du maht / mich sin beweren niht' (III,13f.) den Wortwechsel wieder ins Rhetorische wendet und damit die Option des physischen Verbrennens durch Verneinung zurückhält. Verlängert man die Feuermetaphorik über die Dimensionen des Irdischen hinaus, so wird klar, dass es auch die Drohung des Höllenfeuers sein könnte, ${ }^{49}$ auf die der Sprecher hier anspielt. Diese Bedeutungen erschließen sich erst im Zusammenspiel von ,christlicher' Rede und, jüdischer' Gegenrede, was erneut verdeutlicht, dass es sich um ein Scheingefecht handelt, in dem der Jude vom christlichen Sprecher nur als Spielfigur aufgestellt wird. Ich werde zu dieser zentralen Stelle des Lieds später noch einmal zurückkommen, zunächst jedoch auf mögliche Gründe eingehen, warum der Sprecher in weiten Teilen des Textes aggressiv, zornig und hasserfüllt auftritt:

47 Peter Dinzelbacher: „Ordal (Gottesurteil).“ Übersetzung von Johannes Peisker, veröffentlicht am 5. 2. 2011 in historicum.net archiv; URL: https:/www.archiv.historicum. net/themen/hexenforschung/lexikon/alphabetisch/h-o/artikel/ordal-Gottesurteil/; letzter Zugriff am 26. 4. 2019.

48 Pryzbilski betont, „dass Juden, Muslime und Häretiker im Spätmittelalter in der Literatur oft zu einer unheiligen Trias wurden, die immer und überall die wahren Christen bedrohen" (Martin Przybilski: Jüdische Körper als Subjekte und Objekte des kulturellen Transfers in der Vormoderne. In: ,Rasse` und Raum. Topologien zwischen Kolonial-, Geo- und Biopolitik. Geschichte, Kunst, Erinnerung. Hg. von Claudia Bruns. Wiesbaden 2017 (Trierer Beiträge zu den historischen Kulturwissenschaften 17), S. 61-77, hier S. 66), siehe ebd., S. 66f. die Beispiele aus Predigten Bertholds. Dabei galten die Häretiker, laut Graus, als „,noch schlimmer [...] als die verstockten Juden oder die ungläubigen Heiden: Denn sie hatten ja den wahren Glauben gehabt, sie hatten ihn verlassen und verraten." (Graus 1991 [wie Anm. 40], S. 58).

49 Vgl. die explizite Drohung mit der Hölle in der Schlussstrophe (X,1-8). 
- Arbeit am eigenen Image: Er präsentiert sich als rechtschaffener Christ, indem er den vermeintlichen ,Christusmördern' und ,verstockten Juden' mit Hass begegnet.

- Imitation des zornigen Rachegottes ,der Juden: Sehr viele der angeführten Beispiele aus dem Alten Testament beziehen sich nämlich auf Rachehandlungen und Strafaktionen.

- Aufbau eines Feindbildes, von dem sich die ,guten' Christen absetzen sollen: Falsches Verhalten, judaisierende Zweifel werden mit Zorn geahndet und hierdurch nachdrücklich vor einer solchen Haltung gewarnt. Dies wäre dann letztlich ein innerchristlich intendierter Einschüchterungsversuch.

- Im Rahmen der weiteren Analyse ist zudem genauer zu prüfen, inwiefern Selbstzweifel bzw. Selbstunsicherheit, die sich aus den Paradoxien der christologischen Exegese ergeben und sich hier als latenter christlicher Selbsthass und Autoaggression äußern könnten, als ursächlich für die Aggression einzubeziehen sind.

Es ist nicht gesagt, dass hiermit alle möglichen Gründe bereits ausgelotet sind, in jedem Fall aber handelt es sich um ein Faktorenbündel, aus dem hier nur zwei Faktoren ausführlicher behandelt werden sollen, nämlich a) die RachegottImitation und b) die Autoaggression.

a) Mit der Rachegott-Imitation begegnet der Sprecher der von ihm entworfenen Figur des Juden nur scheinbar auf Augenhöhe, indem er dieser Figur das von ihr angeblich vertretene Gottesbild spiegelt. Denn mit dieser Rolle verbindet sich eine christliche Ermächtigungsgeste, die die Überlegenheit der christlichen gegenüber der jüdischen Schriftauslegung und somit der christlichen gegenüber der jüdischen Religion beansprucht. In Korrelation zu den Zornes- und Aggressionsbekundungen des Sprechers steht die Darstellung und Auslegung einer Reihe alttestamentarischer Rachehandlungen:

In Str. II greift der Sprecher mit dem Strafgericht durch die Chaldäer Versatzstücke aus dem ersten Buch Habakuk auf; in Str. V-VIII werden Ereignisse aus dem Buch Exodus nacherzählt, bei denen Gott an seinen Feinden Rache übt, zunächst an Pharao und den Ägyptern, die sich gegen den Auszug der Kinder Israel stellen, wobei die Tötung der ägyptischen Erstgeborenen sowie das Ertrinken Pharaos und des ägyptischen Heeres in den Fluten des Roten Meeres herausgegriffen werden. Der sich an die Episode um das Goldene Kalb anschließende Krieg zwischen den Anhängern Moses bzw. Gottes und den Abtrünnigen teilt dann bereits die Gruppe der Kinder Israel in zwei Lager. Mittels der 
typologischen Auslegung werden die geschilderten Ereignisse nicht als vergangene Geschichte des jüdischen Volkes ausgewiesen, sondern als Präfigurationen der Trennung von Gerechten und Verdammten im Jüngsten Gericht, ${ }^{50}$ was impliziert, dass sich ,die` Juden erneut für Gott, und zwar für Christus, entscheiden müssen, um gerettet zu werden. Das ,den' Juden aus der wörtlichen Auslegung des Alten Testaments bekannte Rachehandeln Gottes wird in die Gegenwart des Sprechens hinein verlängert, und zwar geschieht dies mittels der Typologie, die in Pharao den Teufel, in Mose gotes menscheit (VI,16), also Jesus, und im Blut des Lamms, mit dem jede israelische Familie ihre Türrahmen bestreicht (vgl. Ex 12,7), den geware[n] Crist (VI,9) als den Gekreuzigten $(\mathrm{VI}, 10)$ sieht. Diese als eschatologische Drohung im Raum stehende Rache sei abwendbar allein durch den Glauben daran, dass der Gekreuzigte der Messias ist.

b) Meine Überlegungen zum Aspekt der Autoaggression möchte ich mit Blick auf die zweite Leitfrage, nämlich, warum der adressierte Jude zwischenzeitlich aus dem Blick des Sprechers gerät, verbinden.

\section{Leitfrage 2: Die (Un-)Verzichtbarkeit der Figur des Juden als Adressat}

In Str. IX, in der der Sprecher das Ereignis des Durchzugs durch das Rote Meer auf die Taufe hin auslegt, scheint er seinen Blick von der Figur des Juden, mit der er doch eigentlich zu disputieren vorgibt, abgewendet zu haben; seine Worte richten sich an den innerchristlichen Zirkel, wie aus der pluralischen Anrede sehent $(\mathrm{IX}, 14)^{51}$, aber auch aus dem gemeinschaftsstiftenden wir (IX,13.20) und

50 Das Lied steht hiermit in der Auslegungstradition, die sich etwa im 41. Kapitel des ,Speculum humanae salvationis' findet, in dem die Höllenstrafen der Verdammten sowie die Trennung der Gerechten und der Verdammten in typologische Beziehung zu drei alttestamentarischen Rache-Erzählungen gesetzt werden, darunter zur Rache Gottes an Pharao und den Ägyptern, die er im Roten Meer ertrinken lässt. Vgl. Julia Hiller von Gaertringen: Das Speculum humanae salvationis der Badischen Landesbibliothek im Eigentum des Badischen Gemeinde-Versicherungs-Verbandes. Ehemals H 78 - jetzt K 3378. Mit Bildern von Beate Ehlig und Holger Kösel. Karlsruhe 2010, S. $90 \mathrm{f}$.

51 Zwar werden, die Juden im Eingangsvers pluralisch (Ich haß ̈̈̈ch juden, I,1) angeredet, in der Folge wird jedoch immer singularisch die exemplarische Figur des Juden angeredet (vgl. I,9.16, II,6.12.22, III,1.3.11.15.19.22, V,1.9.22, VI,5.22, X,1.9.17); die Kampfaufforderung in II,1f. adressiert einen aus einer Gruppe, was noch einmal verdeutlicht, dass der einzelne Jude im Lied als Repräsentant des Judentums fungieren 
uns (IX,16.19.23) sowie dem predigthaft an die Gemeinde gerichteten ir (IX,22) ersichtlich wird. Die Kinder Israel, die durch Gottes Hilfe sicher durch das Rote Meer gelangen und dabei zugleich die verhassten ägyptischen Feinde vernichtet zurücklassen können, sind Präfiguration der Christen, das Rote Meer weist auf die Taufe voraus (IX,19f.). Insofern wird das von den Kindern Israel im Alten Testament ausgesprochene wir (IX,13), mit dem sie das Lob Gottes einleiten, verlängerbar in die Gegenwart der christlichen Gemeinschaft: , wir sollen frolich loben got ${ }^{\prime}$ / sehent, als was ir wort [...] / der tauff uns daz alz ab geweschen hat: / wir sint hin dorch daz Rote Mer (IX,13f.19f.). Und von dieser Gemeinschaft - so könnte man die Abwendung des Sprechers von dem fingierten Juden interpretieren - bleiben die Juden eben ausgeschlossen, solange sie sich nicht bekehren. Die Abwendung von dem eingangs eigens eingesetzten jüdischen Adressaten entspricht einem Moment der ungestörten christianisierenden Aneignung der Bücher des Alten Testaments und ermöglicht es, ein sich typologisch vom Alten ins Neue Testament und bis in die Gegenwart der Kirche und der Sakramente hinein erstreckendes christliches, wir ${ }^{\text {' }}$ u konstruieren. Dieses ebenso einvernehmliche wie ahistorische ,wir ${ }^{`}$ wird durch die Hassfigur des ,verstockten' Juden gestört und zugleich stabilisiert; dementsprechend wird ,dem' Juden innerhalb des Lieds auch das Schlusswort überlassen. Nachdem der Sprecher die typologische Beziehung zwischen dem Wasser, das Mose mit Gottes Hilfe in der Wüste aus dem Felsen entspringen lässt (Ex 17,6), und dem Blut, das aus der von einem ,blinden Heiden' geschlagenen Seitenwunde Christi fließt (vgl. Io 19,34), aufgezeigt hat, entspinnt sich folgender kurzer Dialog:

vil arge jud, gedenckstu nit daran? / der jude sprach: ,ich han sin mut, / ich weiß wol, daz ich unrehte han getan. '/ sich, jud, warumb behaltest niht / die din gesetz, die unser her gebot? / der jude sprich:, ez were mir leit, / und solt ich an den tauff hie sterben dot.' $(\mathrm{X}, 17-23)$

Der Sprecher konfrontiert die Figur des Juden an dieser Stelle mit der von den Juden im Neuen Testament angeblich eingenommenen Rolle der ,Gottesmörder. Mit der Anspielung auf die mittelalterliche Longinuslegende ${ }^{52}$ in X,9-16

soll; die pluralische Anrede in VIII,15 ( $n u$ hort) beinhaltet eine an die christliche Zuhörerschaft gerichtete Publikumsapostrophe, uns in VII,2 könnte Juden und Christen gemeinschaftlich meinen.

52 „Eine Verlagerung der Blindheit und der Wunderheilung auf Longinus selbst findet erst im hohen Mittelalter Eingang in die Legende“. Carla Dauven-vanKnippenberg: ... einer von den Soldaten öffnete seine Seite ... Eine Untersuchung der Longinuslegende im deutschsprachigen geistlichen Spiel des Mittelalters. [zugl. Diss. phil.]. Amsterdam u. a. 1990, S. 48. 
wird dem Juden einerseits noch eine letzte Chance zur Bekehrung geboten, denn eine mit dieser Legende vertraute Zuhörerschaft ${ }^{53}$ weiß, dass der römische Soldat Longinus durch das Blut aus den Wunden Christi (im spirituellen Sinne) sehend wurde. Indem ein heyde blinde $(\mathrm{X}, 12)$ hier zum Vorbild des Juden wird, ${ }^{54}$ wird allerdings andererseits, entgegen der Darstellung in den Evangelien, auch die Beteiligung der Juden am Kreuzigungsgeschehen betont. ${ }^{55}$ Dass es auch in der Schlussstrophe um die Frage nach der, richtigen 'Auslegung der von Juden und Christen geteilten Bücher des Alten Testaments geht, wird nicht nur durch die Typologie,Wasser aus dem Felsen - Blut aus der Seitenwunde Christi ${ }^{\circ}$ deutlich, sondern auch durch Motiv und Metapher der Blindheit. Gemäß einer mit Mitteln der allegorischen Exegese arbeitenden christlichen Auslegungstradition werden die Verse Ies 6,9f. auf die ,Verstocktheit' der Juden, die Jesus Christus nicht als ihren Messias anerkennen wollen, hin gedeutet; diese vermeintliche ,Verstocktheit' wird als Verschließen der Sinne, auch des Gesichtssinns, ausgedrückt. Auch im Neuen Testament wird die ,Verstocktheit' mit einer Trübung, nämlich der Verschleierung des Gesichtssinns in Verbindung gebracht und dabei direkt auf die Auslegung der Bücher Mose bezogen: So wie Mose auf dem Berg Sinai stets mit einer Decke auf dem Gesicht zu Gott gesprochen habe, liege diese Decke bis zum heutigen Tag auf dem alten Bund und, solange sie sich nicht zum Herrn bekehrten, auf den Herzen der Juden, wenn diese die mosaischen Schriften läsen (vgl. II Cor 3,13-16). ${ }^{56}$ Wie Funkenstein ausführt, steht diese vermeintliche spirituelle ,Blindheit' im Zusammenhang mit der Stereotypisierung der Juden als, fleischlich`:

Die Kirche glaubte, daß der Status des auserwählten Volkes vom ,Israel im Fleischec auf, Israel im Geiste' verlagert worden war. [...] Secundum carnem bezog sich deshalb

53 Da die Longinusszene fester Bestandteil mittelalterlicher Passionsspiele war (vgl. ebd., S. 20), ist von einem hohen Bekanntheitsgrad auch bei Laien auszugehen.

54 Schreckenberg verzeichnet für die mittelalterliche Buchmalerei um 1200 eine „synchron zunehmende Tendenz, Longinus [...] mit dem konischen Judenhut auszustatten“. Heinz Schreckenberg: Die christlichen Adversus-Judaeos-Texte (11.-13. Jh.). Mit einer Ikonographie des Judenthemas bis zum 4. Laterankonzil. 3., erg. Aufl. Frankfurt a. M. u. a. 1997, S. 527f.

55 Eine solche ahistorische Tendenz, die Juden als an Marterung und Kreuzigung aktiv Beteiligte darzustellen, findet sich auch verschiedentlich in mittelalterlichen Passionsspielen, vgl. Könneker 1985 (Anm. 41), S. 35f.

56 Vgl. hierzu Heribert Schmid: Die christlich-jüdische Auseinandersetzung um das Alte Testament in hermeneutischer Sicht. Zürich 1971 (Schriften zur Judentumskunde 1), S. $12 \mathrm{f}$. 
auch auf die jüdische Mentalität: Demnach konnten Juden ihre Schriften nur im wortwörtlichen Sinne verstehen. Ihnen fehlte das tiefere Schriftverständnis, die spiritualis intelligentia, und sie galten deshalb als ,blind‘. ${ }^{57}$

Das Motiv der ,Blindheit' ist im Lied zudem mit den oben aufgezählten Beschimpfungen des Juden als moralisch verdorbene Gestalt assoziiert, denn „the trope of Jewish blindness physicalizes both the moral and intellectual errors of the Jews ${ }^{\text {“58 }}$. Im wörtlichen Sinne bezeichnet, Blindheit' ein physisches Defizit, welches mit einer ,den' Juden stereotypisch vorgeworfenen minderwertigen physischen Gestalt und Konstitution sowie einem Hang zum Körperlichen bis hin zu schweren Verbrechen assoziiert werden kann. ${ }^{59}$ Das Changieren zwischen Physis und Moral zeichnet sich auch an den Schimpfwörtern laster$f a ß(V, 22)$ und lasterbalg $(\mathrm{VI}, 22) \mathrm{ab}$, indem die Figur des Juden hier als mit Lastern angefülltes vaz (,Gefäß) und balc (Pejorativum für ,Körper') vorgestellt wird. Gemäß der psychoanalytischen Deutung Loewenbergs könnten diese Anschuldigungen als Teil eines sich im Judenhass entladenden, im Kern jedoch christlichen Schuldkomplexes interpretiert werden. Zwar arbeitet der Text nur latent mit der Bezichtigung der Juden als ,Christusmörder, weil die Glaubenslehre und exegetische Fragen im Zentrum stehen; gerade das Problem des rechten Glaubens und der richtigen Auslegung ist jedoch Teil des Schuldkomplexes, den Loewenberg, in Fortführung Freud'scher Theorien, analysiert, indem er die für die mittelalterliche Judenverfolgung virulenten Vorwürfe des Gottesmordes, des Hostienfrevels und des Ritualmords auf ihren „gemeinsamen unbewußten Inhalt" ${ }^{\text {60 }}$ hin befragt:

Es ist die Verleugnung von Christus. Diese muß symbolisch als Wiederholung des Christusmordes interpretiert werden. Der von Judenhaß besessene Christgläubige beschuldigt den Juden eines Verbrechens, das er durch seine Ambivalenz und Zweifel an der Göttlichkeit von Jesus selbst begeht. ${ }^{61}$

Die von Loewenberg in seinem Aufsatz beschriebene kollektive Psychodynamik liefert insofern einen Ansatz zur Erklärung der antijudaischen Aggressionen, die sich im ,Judenkrieg' manifestieren, dass dadurch die Irrationalität der wiederholt eruptiv hervorbrechenden verbalen Gewalttätigkeit als unbewusster

57 Funkenstein 1992 (Anm. 4), S. 36.

58 Kruger 2006 (Anm. 40), S. 95.

59 Vgl. ebd., S. XXIV und 95.

60 Peter Loewenberg: Die Psychodynamik des Antijudentums. In: Jahrbuch für deutsche Geschichte 1 (1972), S. 145-158, hier S. 154.

61 Ebd. 
Abwehrmechanismus deutbar wird. Loewenberg interpretiert, in Anlehnung an Freud, die vom christlichen Kollektiv formulierte Anklage gegen die Juden als ,Gottesmörder ' im Kontext des Ödipuskomplexes, d. h. der Todeswünsche und daraus erwachsenden Schuldgefühle gegenüber dem Vater. ${ }^{62}$ In diesem Zusammenhang spiele zudem eine Rolle, dass der Gott der Juden eine „Vergötterung des Überichs ${ }^{\text {“63 }}$ darstelle, woraus folgend ,der ' Jude von Nicht-Juden häufig als „Repräsentant eines starken Überich ${ }^{\text {“64 }}{ }^{4}$ wahrgenommen werde: „Für das Unbewußte symbolisiert er das Prinzip der Schuld: ,Du sollst nicht .... Auf diese Weise repräsentiert der Jude die archaischen Autoritäten des Unbewußten, die es nach Rache, Verstümmelung und Blutbad gelüstet. ${ }^{65}$ Ohne den ,Judenkrieg' einer psychoanalytischen Deutung unterziehen zu wollen, scheint es doch relevant, die ,unbewussten Kräfte', die generell im Judenhass zu Tage treten, und den ,irrationalen Kern' des Antijudaismus ${ }^{66}$ mitzubedenken. Für die Kombination aus vom Sprecher mehr oder weniger offen ausgesprochenen Gewalt- und Morddrohungen gegen seinen jüdischen Kontrahenten, ausgiebiger Bezugnahme auf das Rachehandeln des alttestamentarischen Gottes sowie dem wiederholten Vor-Augen-Stellen der Kreuzigung Christi, verbunden mit der Beschuldigung der Juden als Gottesmörder, wird hierdurch eine irrationale Bedeutungsebene fasslich, die durch die Rationalisierungen der typologischen Interpretation überlagert wird, wie etwa an den Versen VI,5-15 exemplarisch deutlich werden mag.

Im Folgenden soll die Aggression des christlichen Sprechers im ,Judenkrieg und die sich dahinter möglicherweise verbergende christliche Autoaggression jedoch vorrangig im Kontext der Frage nach der Deutungshoheit über das Alte Testament verfolgt werden. Schmid bezeichnet die christianisierende Umdeutung als eine christliche ,Usurpation' des Alten Testaments, die sich aus dem Selbstverständnis der Kirche als dem neuen Gottesvolk ergeben und das Rabbinat im Gegenzug gezwungen habe, den Literalsinn der Thora immer stärker herauszustellen. ${ }^{67}$ Wie oben dargelegt, repräsentiert die Figur des Juden in

62 Vgl. ebd., S. 147.

63 Ebd., S. 150.

64 Ebd.

65 Ebd., S. 151.

66 Vgl. ebd., S. $146 f$.

67 Vgl. Schmid 1971 (Anm. 56), S. 20; vgl. zur Konkurrenz der heidenchristlichen Kirche zum nachbiblischen Judentum und zu den Judenchristen um die Rolle des erwählten Gottesvolkes in der Nachfolge Israel ebd., S. 10f. und Funkenstein 1992 (Anm. 4), S. 34f. 
dem Lied die wörtliche Schriftauslegung und die Verweigerung der typologischen und christologischen Deutung des Alten Testaments. Wenn der Sprecher gegenüber dieser Stellvertreterfigur der vorchristlichen, jüdischen' Auslegung der Bücher des Alten Testaments in zorniger und bedrohlicher Weise nachzuweisen versucht, dass das Alte Testament nur mittels der allegorischen und typologischen Auslegung richtig verstanden werde, kaschiert er damit zugleich das exegetische Angewiesensein des Neuen auf das Alte Testament. Die Zustimmung zu einer anderen als der christlichen Auslegung des Alten Testaments würde Zweifeln an der Priorität des Neuen Testaments Raum geben, weswegen derartige ,judaisierende Zweifel' (Niesner) ausgeräumt werden müssen. Die ,Lautstärke und Aggressivität, mit der dies in dem vorliegenden Lied geschieht, könnte demnach auch als kollektiv-christliche Selbstunsicherheit gedeutet werden, die nur durch den Aufbau und die Abgrenzung von einem Fremd- bzw. Feindbild in Schach gehalten werden kann. Lotman betont die Ambivalenz des Begriffs der Grenze:

Einerseits trennt sie, andererseits verbindet sie. Eine Grenze grenzt immer an etwas und gehört folglich gleichzeitig zu beiden benachbarten Kulturen, zu beiden aneinandergrenzenden Semiosphären. Die Grenze ist immer zwei- oder mehrsprachig. Sie ist ein Übersetzungsmechanismus, der Texte aus einer fremden Semiotik in die Sprache ,unserer eigenen' Semiotik überträgt; sie ist der Ort, wo das , ̈̈ußere' zum ,Inneren ‘ wird, eine filternde Membran, die die fremden Texte so stark transformiert, dass sie sich in die interne Semiotik der Semiosphäre einfügen, ohne doch ihre Fremdartigkeit zu verlieren. ${ }^{68}$

Davon ausgehend, dass in einer bestimmten Ausprägung des christlichen Diskurses der ,Jude' als grenzsichernde Figur unverzichtbar ist, gewinnt die paradoxale Logik eines Bekehrungsversuchs unter der festen Voraussetzung der Nicht-Bekehrbarkeit ,der' Juden zum christlichen Glauben eine gewisse Plausibilität. Die Relation zwischen den Sätzen ,Die Juden müssen bekehrt werden' und ,Sie sind nicht bekehrbar' wäre dann weniger das konzessive obwohl, sondern eher das kausale denn. Ihre Nicht-Bekehrbarkeit macht ,die' Juden zu einer Art Wächterfigur der Grenze, die von christlicher Seite aus einerseits nicht übertreten werden darf und andererseits, aufgrund des postulierten intrinsischen Zusammenhangs zwischen Altem und Neuem Testament

68 Jurij M. Lotmann: Die Innenwelt des Denkens. Eine semiotische Theorie der Kultur. Aus dem Russischen von Gabriele Leupold und Olga Radetzkaja. Hg. und mit einem Nachwort von Susi K. Frank, Cornelia Ruhe und Alexander Schmitz. Berlin 2010, S. 182. 
und zwischen Literalsinn und Allegorie/Typologie, permanent passiert werden muss. Es ist der Vorgang des Passierens, also die Transferbewegung, zwischen den Büchern des Alten und Neuen Testaments und zwischen den Sinnebenen, die dem Juden in dem Lied verwehrt bleibt bzw. die er verweigert. Damit sichert er aber den Bestand des Alten Testaments gegen eine vollständige christianisierende Umdeutung, welche Schmid als eine potentielle Gefahr der allegorischen Deutung benennt:

Philologisch gesehen erhebt sich die kritische Frage, ob die Nichtbeachtung des Wortsinnes, den die typologische Erklärung wahren will, vor allem durch die Allegorese auf eine Aufhebung des Alten Testamentes hinausläuft. [...] auch das Schema Weissagung bzw. Verheißung und Erfüllung birgt in sich die Gefahr, daß der alttestamentliche Text im Sinne der Erfüllung umgedeutet und die Umdeutung selbst gar nicht mehr erfaßt wird. ${ }^{69}$

Im ,Judenkrieg wird die typologische und allegorische Deutungsweise des Alten Testaments an verschiedenen Beispielen explizit eingeübt. Darüber hinaus spinnt der Text selbst ein Bedeutungsnetz, das einer solchen Ausdeutung unterzogen werden muss, um die verschiedenen Sinnebenen aufzuschließen. Ein Beispiel hierfür sind die bereits zitierten Verse III,11f.: schalg jude, ob ich dich des bewere, / wiltu dich lassen brennen uff eynre hurde? Während die Antwort des Juden auf den Literalsinn dieser Verse bezogen ist, legt die vorangehende Strophe eine auch allegorische Bedeutung dieser Verse nahe. Hier verweist der Sprecher, um den Juden davon zu überzeugen, dass Jesus Christus, der Mariensohn, mit dem Schöpfergott identisch sei, auf das erste Buch Habakuk, in dem der Prophet die Ankunft der Chaldäer weissagt. ${ }^{70}$ In den Versen er hort da die gehorde sin / mit grosser krafft (II,9f.) bezieht sich (ge)horde wohl auf das heranreitende Volk der Chaldäer; der zwei Mal verwendete Ausdruck krafft (III,10.14) verweist auf den Bibelvers haec est fortitudo eius dei sui (Hab 1,11). Gemäß der Auslegung des Sprechers sei mit krafft Christus, der am Kreuz für die Sünden der Menschen die Marter erleiden musste, gemeint (vgl. II,1419); horde wird in II,20f. mit dem brennenden Dornbusch in eins gesetzt, was sich aus der Homonymie von mhd. horde (stf.) = ,Schar, Menge ${ }^{61}$ und horde (stf.) $=$ hurt ,Flechtwerk ${ }^{72}$ erklären ließe. Der brennende Dornbusch wird in der

69 Schmid 1971 (Anm. 56), S. 15.

70 Diese würden auf Pferden, die schneller als Leoparden und Wölfe seien und auf denen die Reiter wie Adler daherfliegen, herannahen und alles im Sturm erobern (vgl. Hab 1,8).

71 BMZ, Bd. 1, Sp. 717b.

72 Lexer, Bd. 1, Sp. 1338 und 1397. 
christlichen Exegese häufig als Typus Mariens interpretiert, ${ }^{73}$ was in der Strophe allerdings nicht explizit dargelegt wird, sondern dies würde als von Autor und Rezipienten des Liedes bzw. als vom Sprecher und dem adressierten Juden geteiltes Wissen vorausgesetzt. ${ }^{74}$ Für das zeitgenössische christliche Publikum könnte daher die harsche Drohung, den Juden auf einer hurde zu verbrennen, durch den Rückbezug auf den zuvor mit der horde assoziierten Dornbusch als Gleichzeitigkeit von Brennen, aber Nicht-Verbrennen gedeutet werden - dies würde zumindest die für eine mittelalterliche Zuhörerschaft wohl als bekannt vorauszusetzende typologische Deutung nahelegen:

So wie der Busch brannte, aber nicht verbrannte, empfing Maria den Sohn und blieb doch unversehrt. So wie Gott den Dornbusch in Besitz nahm, nahm er auch von Mariens Körper Besitz. Und so wie Gott die Erscheinung im Dornbusch nutzte, um das Volk Israel aus Ägypten zu befreien, so nutzte er seine Verkörperung in Maria, um die Menschheit zu erlösen. ${ }^{75}$

Die provokante Frage könnte dann im übertragenen Sinne (auch) darauf zielen, ob der Jude sich vom göttlichen Geist entzünden lassen werde, wenn der Sprecher ihm beweise, dass Jesus Christus der Messias sei. Auch dies ließe sich auf den paulinischen Gegensatz von tötendem Buchstaben und lebendigem Geist (vgl. II Cor 3,6) beziehen, welcher auch für die von der mosaischen bzw. synagogalen ,Decke` befreiten Lektüre des Alten Testaments entscheidend ist (vgl. II Cor 3,17). ${ }^{76}$ Auf die Verse II,20f. und III,11-14 der hier behandelten Fassung des ,Judenkriegs' im Zusammenhang bezogen, entspräche das ,richtige messianische Verständnis des Alten Testaments aus christlicher Sicht einem ,Brennen' im positiven Sinne, nämlich einem geistigen Entflammtwerden des Herzens, wohingegen das buchstäbliche Verständnis zur ewigen Verdammnis, zum ,Brennen' in der Hölle führt. Explizit wird dem ,verstockten' Juden über das mahnende Exempel des Judas in den Versen X,5-9 die ewige Höllenstrafe angedroht. In Str. II wird dem Juden hingegen eine, vom christlichen Sprecher aus gedacht, positive Identifikationsfigur vor Augen gestellt:

73 Beispielsweise werden im ,Speculum humanae salvationis' im siebten Kapitel die Darstellung der Empfängnis (oben) und des brennenden Dornbuschs (unten) auf einer Seite abgebildet, vgl. Hiller von Gaertringen 2010 (Anm. 50), S. 28.

74 Niesner verortet die Verteidigung der jungfräulichen Geburt mit der Vision, die Mose im brennenden Dornbusch hatte, im Rahmen der Adversus-Iudaeos-Literatur im laikalen Kontext (vgl. Niesner 2007 [Anm. 7], S. 12f.) und führt als Beispiel eine Stelle aus dem anonymen Spruch Von dem juden vnd dem cristen an (vgl. ebd., S. 9).

75 Hiller von Gaertringen 2010 (Anm. 50), S. 28.

76 Vgl. Schmid 1971 (Anm. 56), S. 12f. 
Das Wort (ge)horde ist im Vers II,9 er hort da die gehorde sin über die Lautähnlichkeit eng an das Wort hort gebunden und inszeniert den Propheten Habakuk als Hörenden und durch das Gehörte Erschrockenen, also Bewegten. Diese Figur des Alten Testaments wird damit zum Vorbild der ,richtigen' Rezeptions- und Interpretationshaltung: Das Gehörte soll den Hörenden innerlich bewegen, und es soll als messianische Prophetie verstanden werden. Die im Vers sprichestu, jude, ,des nit enist' (II,22) antizipierte Verweigerungshaltung des Juden wird interessanterweise an die Haltung des Sprechens und nicht des Hörens gebunden. Dies korreliert damit, dass dem Juden im Text kaum Raum zur Rede geboten, sondern er überwiegend in die Rolle des Zuhörenden gedrängt wird. Die Positionen und Argumente, die der Jude vorbringen könnte, stehen nicht zur Diskussion. Was von jüdischer Seite aus Wertvolles gesagt werden konnte, so könnte man dies weiterführend deuten, wurde von jüdischen Figuren des Alten Testaments ${ }^{77}$ bereits gesagt, so dass der Jude in dem Lied, wenn er sich der christlich-messianischen Umdeutung dieser Figuren anschließen würde, damit zugleich zum Schweigen gebracht würde.

Die Figur des Juden wird in dem Lied nicht nur durch eine höchst asymmetrische Verteilung der Redeanteile marginalisiert, sondern in Str. VII-IX sogar als Zuhörender regelrecht zum Verschwinden gebracht, indem sich der Sprecher hier gänzlich an eine christliche Zuhörerschaft wendet (s. o.). Aufschlussreich bezüglich der Redeanteile erscheint auch Str. V, in der der christliche Sprecher dem Juden Fragen zum Verständnis alttestamentlicher Stellen vorlegt, diesen aber nicht zu Wort kommen lässt, ${ }^{78}$ sondern das Unverständnis und die ,Blindheit ' des Juden voraussetzt und diesen, statt dass er selbst eine Antwort geben dürfte, dafür anklagt. Laut Kruger besteht zwischen dem Stereotyp jüdischer Fleischlichkeit und einer anhand mittelalterlicher Quellen parallel belegbaren Tendenz, Juden im realen Leben wie in der Fiktion zu ,entkörperlichen', ein Zusammenhang. ${ }^{79}$ In fingierten Disputationen, in denen die Juden nur über die Stimme eines jüdischen Sprechers heraufbeschworen

77 Birkhan betont für das mittelalterliche Judenbild eine sich aus dem Präfigurationsdenken ergebende „unerhörte Hochschätzung der Juden des Alten Testaments, als auserwähltes Volk, aus dem der Messias als Sohn Gottes geboren werden sollte.“ Birkhan 1992 (Anm. 46), S. 143.

78 Eine ähnliche Konstellation von Frage ohne Antwortoption beschreibt Kruger am Beispiel eines Auszugs aus einem antijüdischen Brief Peter Damians, vgl. Kruger 2006 (Anm. 40), S. 15.

79 Vgl. ebd., S. XXIV. 
würden, diene dies hauptsächlich dazu, um die Juden zum Verschwinden zu bringen. ${ }^{80}$

Dass der Jude in dem Lied zwar wenig spricht, aber wenn er spricht, zumeist widerspricht, wäre im Sinne ausgelagerter christlicher Selbstzweifel zu erklären, von denen der Sprecher sich und sein Publikum befreien will, indem er sie in den Figurationen der Lüge, des Leugnens und des Trotzes an die Figur des Juden heftet und dessen Einstellungen damit als indiskutabel hinstellt. Wie Müllerburg u. a. bezüglich der Tradition des gelehrten, lateinischen Religionsdialogs konstatieren, bedürfe dieser

der Zustimmung des Juden, denn die Validität der vorgetragenen Argumente erweist sich nicht nur darin, dass der Leser von den vermittelten Inhalten überzeugt wird. Stattdessen tritt mit dem Juden eine weitere, innertextliche Instanz in das Spiel ein, an der sich die christliche Wahrheit bewähren muss. ${ }^{81}$

Auch die Schlussworte (X,22f.) des Juden im ,Judenkrieg' lassen sich als Zustimmung interpretieren, wenn man von der Übersetzung ,Ich wäre betrübt, wenn ich hier ungetauft sterben würde ausgeht. ${ }^{82}$ Diesem Sinneswandel voraus geht, dass der jüdische Kontrahent, womöglich auch unter dem Eindruck der Höllenandrohung, sein Unrecht einräumt (X,18f.), als der christliche Sprecher ihm das Longinus-Exempel vorhält. Daraufhin wird er vom Christen durch eine rhetorische Frage dazu ermahnt, sich an die din gesetz, die unser her gebot $(X, 21)$ zu halten. Hiermit könnte zum einen das fünfte Gebot (,Du sollst nicht töten') gemeint sein, gegen welches die Juden als vermeintliche, Gottesmörder verstoßen hätten; für den nicht-biblischen Juden, an den sich der Sprecher wendet, müsste dies bedeuten, von der Leugnung der Messianität Jesu, insoweit diese als symbolische Wiederholung der Kreuzigung interpretiert wird, abzurücken. ${ }^{83}$ Zum anderen kann der Verweis auf das Gesetz auch als Bezugnahme auf den Talmud gedeutet werden. Wie Funkenstein darlegt, wurde mit dem Bekanntwerden nachbiblischer jüdischer Literatur, zuvorderst des Talmud, von christlich-theologischer Seite aus gegen die Juden argumentiert, dass sie der Bibel nicht wortwörtlich folgten, sondern ein neues, von Menschen erschaffenes

80 „The conjuring up of Jews in such a work [= dem antijüdischen Brief Peter Damians, S. L.] thus serves mainly to conjure them away“. Ebd., S. 13.

81 Müllerburg/Müller-Schauenburg/Wels 2011 (Anm. 20), S. 278.

82 Durch Inversionsstellung markierte Konditionalsätze werden im Mittelhochdeutschen nicht selten durch vorangestelltes ,und' eingeleitet, vgl. BMZ, Bd. 3, Sp. 184b.

83 Vgl. hierzu auch die Verse Moses, din leiter, dir nit prophiet / daz du den dinen schopfer soltest doten (VI,7f.). 
Gesetz an die Stelle der Bibel gesetzt hätten und somit unter Häresieverdacht stünden; ${ }^{84}$ diese Interpretation würde auch dadurch gestützt, dass, wie bereits dargelegt, durch die Aufforderung zur Feuerprobe in III,11-12 bereits ein Zusammenhang zwischen Juden und Häretikern hergestellt wurde.

Die Schlussworte des Juden können jedoch auch in eine genau konträre Richtung interpretiert werden, wenn folgende Übersetzungsvariante zugrunde gelegt wird: ,Es wäre mir zuwider - und wenn ich hier ungetauft sterben sollte.$^{85}$ Die Figur des Juden würde dann bis zum Schluss als Inbild der trotzigunverständigen Uneinsichtigkeit vorgeführt. Die Inszenierung des, verstockten' Juden korreliert mit dem Schluss der in der Heidelberger Handschrift Cpg 350 überlieferten sechsstrophigen, Judenkrieg'-Fassung, in der der Sprecher den Juden allerdings nicht zu Wort kommen lässt, sondern abschließend zu ihm sagt: sih, jud, du rehter lasterpalc, / noch sih, daz din gelaub uneben ste (D Namenl/65r, VI,22f.). Birkhan interpretiert diesen Schluss so, dass der Jude die präfigurierende Umdeutung des Passah-Opfers und des Auszugs aus Ägypten trotz ausführlicher Erläuterung nicht versteht bzw. nicht verstehen will. ${ }^{86}$ Auch in den mit der Schlussstrophe Du valscher jude, das bedrachte endenden Fassungen wird suggeriert, dass der Jude unbelehrbar und, verstockt' sei: jud, $d u$ pist mit deim rechten auge lam! ( $\left.\mathrm{m}_{1} \mathrm{Reg} / \mathrm{LangT} / 239 \mathrm{r}, \mathrm{VI}, 23\right)$, ach, jud, du pist an deinm gelauben lam! (f Reg/Lang T/42v, VIII,23).

Da die zehnstrophige ,Judenkrieg'-Fassung der Kolmarer Liederhandschrift allerdings mit einer Antwort des Juden endet, könnte auch das typische Schema

84 Vgl. Funkenstein 1992 (Anm. 4), S. 37; ders.: Basic Types of Christian Anti-Jewish Polemics in the Later Middle Ages. In: Viator. Medieval and Renaissance Studies 2 (1971), S. 373-382, hier S. 377 und 380f. Zwar argumentieren die in der Kolmarer Handschrift überlieferten Strophen, wie es seit der Patristik üblich war, ausschließlich mit Beweisen aus der Bibel und Verweisen auf Prophezeiungen und Präfigurationen; die in der Meisterliederhandschrift $m_{1}$ überlieferte sechsstrophige Variante des ,Judenkriegs' greift aber mit der zweifachen Erwähnung des jüdischen Talmud ( $\mathrm{m}_{1}$ Reg/LangT/239r, II,14; VI,9) und der einmaligen Bezeichnung der Juden als talmuten knechte (ebd., II,1) auf das diskursgeschichtlich neuere Argumentationsmuster zurück; vgl. zu den Argumentationsmustern mittelalterlicher antijudaischer Polemik Funkenstein 1971, S. $373 f$.

85 ez were mir leit wäre dann nicht gemäß der für das Adverb leide belegten Wendung mir ist leide / ,ich bin betrübt' (vgl. BMZ, Bd. 1, Sp. 980b) mit ,Ich wäre betrübt ${ }^{`} \mathrm{zu}$ übersetzen, sondern leit wäre adjektivisch i. S. von ,widerwärtig, unlieb, verhasst‘ aufzufassen (vgl. Lexer, Bd. 1, Sp. 1872) und $e z$ als Variante des Demonstrativpronomens daz (vgl. BMZ, Bd. 1, Sp. 312b).

Vgl. Birkhan 1992 (Anm. 46), S. 153. 
gelehrter religiöser Glaubensdispute zugrunde liegen, in denen, laut Müllerburg u. a., stets eine Einigung auf die christliche Position erzielt werde, ohne dass es dabei zur Konversion komme. ${ }^{87}$ Der in der o. g. Übersetzungsvariante ,Ich wäre betrübt, wenn ich hier ungetauft sterben würde' latent anklingende Taufwunsch findet sich auch in einem der von Niesner untersuchten spätmittelalterlichen volkssprachlichen Texte, die jeweils einen Glaubensdisput zwischen einem christlichen Laien und einem Juden fingieren. ${ }^{88}$ Zudem wäre der Schluss der vierstrophigen in der Meisterliederhandschrift $\mathrm{m}_{1}$ überlieferten ,Judenkrieg'-Fassung einzubeziehen, aus dem der indirekt formulierte Taufwunsch des Juden eindeutiger hervorgeht: des mustu ewicleich verderbin, / daz du niht heltest, was dir got gepot. / der jud der sprach. ,es wer mir lait, / daz ich scholt an den tauffe ligen tot ${ }^{\prime}\left(\mathrm{m}_{1} \mathrm{Namenl} / 232 \mathrm{v}, \mathrm{IV}, 20-23\right)$.

Für die hier diskutierte zehnstrophige, Judenkrieg'-Variante aus der Kolmarer Liederhandschrift ist aufgrund der grammatisch (möglicherweise sogar bewusst) uneindeutigen Formulierung nicht klar entscheidbar, ob der Jude einlenkt oder bei seiner Ausgangsposition verharrt. In beiden Fällen würde damit die Richtigkeit der christlichen Position bestätigt, denn auch die stereotype Vorstellung des Juden als unveränderlich, als ,lebender Anachronismus' diente als Zeugnis der Wahrheit des Christentums. ${ }^{89}$

Interessant in Bezug auf das Aggressionspotential des christlichen Sprechers erscheint, dass in der Schlussstrophe mit dem sper des Longinus ein Rückbezug auf die Schwertmetapher der Eingangsstrophe hergestellt und somit eine Art Rahmen erzeugt wird. Anders als das gezückte Schwert wird der Speer aber nicht vom Sprecher selbst geführt, sondern von einer Exempelfigur, und ist auch nicht bedrohlich auf den Juden gerichtet, sondern hat im Rahmen des Passionsgeschehens den leblosen Körper des Gekreuzigten verletzt. Dabei erscheint auffällig, dass der ,blinde Heide' im Lied, abweichend vom Evangelienbericht (Io 19,34), auf das Herz - statt auf die Seite - Jesu zielt und dieses durchschneidet $(\mathrm{X}, 13)$, was, unter Berücksichtigung der apokryph-mittelalterlichen Legendenbildung über die Bekehrung der nun als Longinus benannten Figur, als Anspielung auf die paulinische Beschneidung des Herzens (Rm 2,29) zu deuten wäre. Zudem knüpft der Vers erneut an die Schwertmetapher der Eingangsstrophe an, in der der Sprecher betont, das ,Schwert ' der Christen im Herzen (und in

87 Vgl. Müllerburg/Müller-Schauenburg/Wels 2011 (Anm. 20), S. 279.

88 Der anonyme Spruch Von dem juden vnd dem cristen endet mit Einsicht und Taufwunsch des Juden, vgl. Niesner 2007 (Anm. 7), S. 11 und 17.

Vgl. Funkenstein 1992 (Anm. 4), S. 36. 
der Hand) zu tragen (I,2f.). Rhetorisch betrachtet, wechselt das Lied mit dem Longinus-Exempel von einer direkten Konfrontations- und Bedrohungstaktik zur Pathoserzeugung: Der Jude soll Mitleid mit dem Gekreuzigten empfinden, der für die Sünden der Menschen gestorben sei, und sich hierfür mit der Figur des blinden heidnischen Speer- bzw. Lanzenstechers identifizieren und an dessen Stelle zum Sinneswandel bewegt werden. Damit gibt der christliche Sprecher dem Juden eine Waffe, nämlich den Speer, in die Hand, ohne allerdings seine eigene Waffe, das Schwert, abzulegen. Dieses führt er, indem er Ex 17,6 als Präfiguration von Io 19,34 auslegt, ja weiterhin; über die Verschaltung der Figur des ,blinden Heiden' mit dem jüdischen Kontrahenten wird noch einmal deutlich, dass dieser kein ebenbürtiger Disputant, sondern eine Spiel- und vor allem auch Rezeptionsfigur des Sprechers ist, denn er soll den Speer letztlich gegen seine eigene, Uneinsichtigkeit' führen. Der Jude soll dabei durch das ,Schwert' des Sprechers, nämlich die christologische Deutung des Alten Testaments, dahin gelenkt werden, den mosaischen Stab gegen die Longinuslanze zu tauschen und, indem er an die Stelle des von Blindheit geheilten Longinus tritt, seine jüdische Identität auszulöschen.

\section{Textgrundlage:}

\section{Der juden krieg zehen lieder (k Lang/T Reg 23-32)}

I

Ich haß üch juden sondir maße

umb einen glauben, swert der kristen drage ich bar

in hertzen, hant, die wil ich lebe.

fryde uß gein uch! züch us den boum, grießwarter!

5 den kamp $\mathrm{f}^{90}$ ich nieman sonen laße, sit daz mir got so starcken schilt und auch die jar von sinen gnaden hat gegeben, der für uns an deme krütze leyt die marter.

nu sag an, jud, wer ist din got?

10 ,daz ist der got, der laup, graß hat geschaffen.'

ist auch der myne, sondern spot, nu ger ich baumes urteil wiser pfaffen.

würff für die baum, grießwarte, ich getar nit juden slan 
15 umb einen glauben, den ich gein yn han.

nu sag an, jud, daz ist myn ger, ${ }^{91}$

glaubestu, daz sin eyn magt genaß,

den ir da nennent zu schopfer, ${ }^{92}$

daz ist der got, der schufflaup und graß

$20 \quad$ und hie die martel für uns leit?

,neyn', sprich der jud, ,dez glauben nie ich gewan.

so balde uz, baum! und were dich

der judescheyt, nieman dich gefristen kan.

II

Wol her an mich, wellch jud ist wise

$u z$ der alten ee, den wil ich überkomen.

eyne reine magt ein kint gebar

zu Bethleem, der was gewor schepfere;

5 des stat sie ewiclich zu prise.

jude, hast icht Abekucks rede vernomen,

der seit vor vil manigem jar,

wie daz eyne magt Mary ein kint gebere?

er hort da die gehorde sin

10 mit grosser kraff, do von erschrack er here,

zwischen zwein dieren sonder pin

sprach Abekucks. sag fürbaz, jude, mere:

die krafft was der gewore Crist,

der hie zu einre stunt

15 für manichen sonder sere wart ferwont.

do er die bitter martel leyt

an dem frone krütze sicherlich

und yn ein krone, ein sper versneit,

$z$ u hant sind menscheit da ferkerte sich.

20 die horde was ein brennend bosch,

einsmols wart mit gotlichem geist entzünt.

sprichestu, jude, ,des nit enist!',

so lügestu schelcklichen durch dinen munt.

III

Geleubestu, jud, daz hymmel, erde

gemachet got hat? ,ich glaub es und ist myn ger.'

91 Hs.: got.

92 Hs.: schopfere 
daz ist gut! glaubestu, ${ }^{93}$ daz ich sag, daz got ist schopper aller creatüre, und er ein mensche wolt werden von einer magt? ,neyn, da zweyent sich die mere. noch nyeman mich zu bringen mag, daz ich es gleub. der glaub ist ungehüre, wie daz eine maget got gebere ufferden hie und sie sind bürtig wurde. ${ }^{64}$ schalg jude, ob ich dich des bewere, wiltu dich lassen brennen uff eynre hurde? ,nit brenne mich, wanne du maht mich sin beweren niht',

15 er sprach. ich dun, du schalck, du bosewicht: Ysaias vor manicher zit laß, daz $\mathrm{z}^{95}$ von eynr magt worde got geboren, da von so la $\beta d u$ dinen strit, du boser jude, ee daz mir werde zorn.

20 ezwart geborn ein kindelin von eynre magt, ist ware die geschicht. jude, bose und ungeslaht, des bistu blint mit augen angesicht.

IV

Da kong Faron nit lassen wolte die gottes israhelschen in Egipten lant, ein lamp zu schlahen yn got gebot, daz blut ieglichem juden zu einr friste man an daz dürstell strichen solde. da es nit geschach, da wart ein engel hin gesant, der slug den erstgebornen dot, da er daz blut an dem dürstelle fermiste.

si furen eines morgens hin,

10 Moyses und der bruder sin, Arone, sie furten richeit und gewin so vil, daz es was leyt dem konig Farone. sie furen durch daz Rote Mer, daz ist endlichen war,

15 Faron erdrang und alle die sinen gar.

93 Hs.: glaübestu.

94 Hs.: worde.

95 Hs.: daz zu dar gebessert. 
die ysrahelschen zogen hyn

in ein wüsten, do sie hunger überdrabet.

die engel schar von Seraphin

brahtent yn, daz sie sich hungers erlabet.

20 noch mannabrot sie dürsten wart.

got der ließ wasser fliessen, do nie kein zar

gefloß. da drang daz groß her ${ }^{96}$

und danckten got siner gnaden offenbar.

V

Weist, ${ }^{97}$ waz konig Pharo betüte ${ }^{98}$

oder auch waz betüten mag Egipten lant

und waz daz lamp betüten kan,

sin plut und daz dürstelle mit gemele?

5

wer sind die israhelschen ${ }^{99}$ lüte

und der erstgeborne ist dir bekant?

so wil ich werlich dir gestan,

daz der glaube din dar an yt fele.

du jude, blint mit angesicht,

10 weistu, waz Moyses, Aaron bezeichen?

der rechten glosen hastu nicht,

so we dir, daz dich nyeman kan erweichen!

und wiltu nit glauben, daz

Faron erdrencket wart

15 al in der sintflut uff der selben fart?

oder weist, waz betüten mag,

daz got den ysrahelschen ${ }^{100}$ gab manna

und er us hertem felse wag

lie fliessen, do noch nie gefloß wasser?

20 do ist dir bekant, daz mir auch hie

$z u$ wissende ist, alz da vor ist bekart.

sich, jud, ${ }^{101} d u$ boses lasterfaß,

die glose würt fürbaß geoffenbart.

96 Hs.: here.

97 Hs.: weistü.

98 Hs.: betude.

99 Hs.: Iserhelschen.

100 Hs.: yserhelschen.

101 Hs.: sich bekart sich. 
VI

Faron gelich ich Lucziferen,

so ist gelich Egipten lant der hellen pin,

so ist die ysrahelsche diet

unschuldig volk, den got halff usser noten.

5 schalck jude, laß dich baz beweren

vil schoner zeichen, die auch an dem lambe syn.

Moses, din leiter, dir nit prophiet, ${ }^{102}$

daz du den dinen schopfer soltest doten.

daz ist nu der geware Crist,

10 der an dem crütze hing so jemerliche.

daz selben lambs blut daz ist,

do du mit dyn dürstelle solt bestrichen.

du bist der irstgeborn schalck

und strebst wider di ee.

15 dich slecht der engel, der do,Ely!'schre.

gotes menscheit waz Moyses fron,

der fürt uz helle seln ein michel her.

so glich ich Luczifer Faron,

die $\mathrm{e}^{103}$ hell dem ungetrüwen Roten Mer.

20 got fürt die sinen in sin rich,

darinn spist er sie fürbaß yemerme.

daz ist die glose, lasterbalg,

nu wissest, daz din glaube unrecht stee.

VII

Got vatter, junger, alter, nüwer,

durch manig wonder uns geschuff, din hantgetat,

lange hie vor manicher stunt,

ee daz du Cristus santest uz dem throne.

5 er wag uns faste große trüwe,

biz er vertreib der falschen bosen slangen rat.

sich, jud, daz was Moyses kunt

lange, ob er yn sante zu Farone.

got sprach zu ym: ,Moyses, gang hin,

10 heiß Faron mir die mynen faren laßen!"

Moses der sprach: ,o herre, ich bin

102 Hs.: piet; prophiet ist wohl aus Reimgründen vorgenommene Verkürzung von prophetiert/propheziert.

103 Hs.: der. 
in sin aht, ich getar nit uff die strassen.

er forht Farone me dan got,

daz rauwe yn auch hie syder,

15

doch hup er sich gar snelleclichen wider.

er sprach: ,Faron, dir büttet got,

daz du ym syn irahelschen laßest farn.

daz nam Faron für einen spot.

wie alle wasser eben blutig woren,

20 die not wert uff den sesten dag,

biz daz sich konig Faron neigte nider.

wie sie behielten gotes gebot,

daz fonden sicher gar wol ir gelider.

VIII

Moyses ging, als es got wolde,

uff einen berg. da was er follig fierzig dag,

da wordent ym die zeen gebot,

die er her nider broht an eyme steyne.

5 da zwischen wart von rotem golde

ein kalp gegossen, daz was Aron ein groze klag, ${ }^{104}$

daz bettens an für einen got

etliche do und auch nit alle gemeyne.

do Moyses do wider kam

10 und er die dofel brohte in siner hende

und die mere vom kalbe vernam,

in zorne wart sich sin gemut da wenden.

er slug die tafel an daz kalp

also, daz sie zurbrach.

15 nu hort, waz großes wonders da geschach:

daz kalp gar schiere gesmeltzet wart

und wart gegossen in des meres flut.

daz kam vil manichem in den bart,

also got noch vil grosser wunder dut;

20 die rechten wordent da erkant,

der wider got lebt, folgt dem düfel noch.

da wart ein mort der schulden halp,

daz man ein jemerliches sterben sah.

104 Hs.: klage. 
IX

Die israhelschen durch die flüte,

zwelff strassen dorch daz mere zogten, ${ }^{105}$ alz es wolte got.

Moyses mit sinr ruten slug,

daz sich daz mer uff leynet als eine mure,

$5 \quad$ in halff die wore gottes güte.

daz nam Pharon für schympf und auch vor einen spot,

dez sinem volkes was genug,

er zoch hin nach, daz wart ym wol zu sure.

die ersten zogen durch daz mer,

10 so krefteclich mit wol bedochten synnen

aht tage zoch daz selbe her;

Faron ertranck und alz sin volk darynne.

, wir sollen frolich loben got',

sehent, als was ir wort,

15 ,er hatt sin helffe wol zu uns gekort:

waz nu betütet uns Faron?

daz ist der tüfel und sin arger rat,

der falsche stricke legen kan.

der tauff uns daz alz ab geweschen hat:

20 wir sint hin dorch daz Rote Mer,

gar kreffteclich hin durch die rehte furt.

ir fraüwent üch an allen spot,

got der wil bii uns wesen hie und dort.

X

Ach jude, wiltu nit bedencken

manicher dinge, der ich dich bescheiden kan,

so mustu ewig liden pin

und wirst gescheiden von dem hymmelriche.

$5 d u$ wilt dich selber gar versencken

in hell apgründe, reht als Judas hat getan,

do er verreit den herren sin.

sich, arger wiht, dem wiltu dich gelichen.

jud, waz betütet uns die bach,

10 die uß dem felse lieff so rehte swinde?

durch manigen sonder daz geschach,

daz er ferhing, daz yn ein heyde blinde

ein sper ym durch sin hertze sneit,

105 Hs.: zogten fehlt. 
unt stunt in großer not.

15 die bach die was sin blut so rot, daz ym uz siner syten wut.

vil arge jud, gedenckstu nit daran?

der jude sprach: ,ich han sin mut, ich weiß wol, daz ich unrehte han getan.'

20 sich, jud, warumb behaltest niht die din gesetz, die unser her gebot? der jude sprich: ,ez were mir leit, und solt ich an den tauff hie sterben dot.' 



\title{
Johannes Rettelbach
}

\section{Ist imandt hie der mit mir singen welle? Überblick über die Elemente metapoetischer Meisterlieder 1430 bis 1520}

\begin{abstract}
Under the vast amount of Meisterlieder of the $15^{\text {th }}$ century, one of the most interesting segments consists of songs with a metapoetic content, meaning songs that deal with the requirements, rules, history and effects of singing or that provide information about the course of events in which several singers sing successively. For this article, the more than 190 texts fitting this definition have been sorted according to their type. Some of them are monothematic, but the majority mixes a manageable number of elements. Only a few songs include independent elements that do not recur elsewhere. The article attempts a systematic overview of the most common elements of metapoetic texts and tries to give some conclusions for the production process of Meistergesang during the $15^{\text {th }}$ century.
\end{abstract}

Eine Sichtung der in Meisterliederhandschriften des 15. Jahrhunderts entstandenen Lieder mit metapoetischen Inhalten fördert einen Bestand von über 190 Texten zutage. Dabei verstehe ich als metapoetisch solche Lieder, die sich mit Voraussetzungen, Regeln, Geschichte und Wirkungen des Gesanges auseinandersetzen, ferner Aufschluss über den Ablauf von Veranstaltungen geben, bei denen mehrere Singer zugegen sind und nacheinander singen. Bloße subjektive Ich-Aussagen zähle ich nicht dazu, auch nicht Anrufungen Gottes oder der Heiligen um Hilfe beim Dichten und Singen. Eine Armutsklage wäre nur einschlägig, wenn sie mit Heische verbunden auf das Schicksal von Sängern allgemein hinweist. Lieder, deren Ich fiktional die Rolle eines alten Meisters einnimmt betrachte ich als Grenzfälle, zumal sie nicht sauber von nachträglichen Fehlzuschreibungen zu trennen sind. Sprachspiele, bei denen Grammatik und Wortwitz den Gesamtsinn dominieren, das sind so genannte loica, durchgängige equivoca ${ }^{1}$ und Priameln, werden nicht einbezogen. Sie spielen mit den Regeln des Singens, aber stellen sie nicht dar. Ausdrücklich beschränke ich

1 Vgl. dazu Eva Klesatschke / Brian Taylor: Der Reiz des Verbotenen. Loica und Equivoca im Meistergesang. In: Vom Mittelalter zur Neuzeit. Festschrift Horst Brunner. Hg. von Dorothea Klein u. a. Wiesbaden 2000. 
mich nicht auf die Kolmarer Liederhandschrift (k), ${ }^{2}$ sondern erfasse Strophen und Bare, die zwischen 1430 und 1520 in Handschriften eingetragen wurden. Einige Texte sind mit Sicherheit oder möglicherweise älter.

Unter den Liedern finden sich klar einem bestimmten Typ zugehörige, die sich eindeutig thematisch umreißen lassen. Die Mehrzahl der Bare aber mischt eine überschaubare Zahl von Elementen: unterschiedliche Appelle etwa, Erklärungen oder Kurzerzählungen in freier Variation (vgl. die Gliederungssystematik). Nur einige bringen Originelles, also Elemente, die sonst nicht wiederkehren. „Ein Feld“ von Elementen und neuen Fachbegriffen „formiert sich“ so im Lauf des 15. Jahrhunderts. ${ }^{3}$ Einige Begriffe, die in diesem Zusammenhang auftauchen, entstammen bereits den zwei Jahrhunderten zuvor, doch nur gelegentlich erscheinen sie in alten Texten an der Oberfläche der Schriftlichkeit. Die Elemente der Metapoesie sind zahlreich und lassen sich nicht auf eine Ebene bringen. Zeitgenössische Bezeichnungen für ganze Lieder decken kein einheitliches Motivgeflecht ab. Der Generalbegriff fürwurf steht für Lieder, die als Einleitung eines wie auch immer gearteten Wettsingens dienen können. Schulkunst, ein Wort, das alles einschließt, was metapoetisch genannt werden kann, erscheint erstmals in der frühen Hans Sachs-Handschrift q bei einem anonymen Lied in Kettners Frauenton $\left({ }^{1} \mathrm{Ketn} / 5 / 1\right)^{4}$, dann erst wieder bei Hans Sachs im Jahr 1540 für ein Lied ( ${ }^{2}$ S/1907). Von da an übertrug Sachs den Begriff schulkunst in jüngeren Abschriften auch auf seine früheren und vorreformatorisch einschlägigen Dichtungen und setzte insbesondere in seinem Generalregister, in dem er die Themen in Gruppen geordnet eintrug, alle metapoetischen Texte, auch die vorreformatorischen, unter die Rubrik schulkünst. ${ }^{5}$ Der Begriff ,Schulkunst' wird auch als moderner Terminus alternativ zu der Bezeichnung

2 Die verwendeten Handschriftensiglen sowie Textausgaben sind im Anhang aufgelistet (s. auch Anm. 7).

3 Michael Baldzuhn: Ein Wortfeld formiert sich. Beobachtungen zur poetologischen Begrifflichkeit in den Tabulaturen der Meistersinger. In: Im Wortfeld des Textes. Hg. von Gerd Dicke. Berlin 2011, S. 165-186.

4 Die Liednummerierung dieses Beitrags ohne weitere Kennzeichnung bezieht sich auf Horst Brunner / Burghart Wachinger (Hrsg.): Repertorium der Sangsprüche und Meisterlieder des 12. bis 18. Jahrhunderts. 16 Bde. Tübingen 1986-2009 [RSM].

5 Entgegen meiner Entscheidung, loica und equivoca auszuschließen, bezeichnet Sachs auch einen Teil dieser Texte als Schulkünste. 
,metapoetisches Meisterlied ${ }^{` 6}$ gebraucht und ist problemlos auf Lieder des 15. Jahrhunderts anwendbar.

In meinem Beitrag möchte ich die häufigsten Elemente dieser metapoetischen Texte im Überblick darstellen. Am Schluss gehe ich auf einige Folgerungen für den Betrieb des Meistergesangs ein.

\section{Freundliche Begrüßungen (als Liedtyp empfahung, grues, meistergrues)}

Eine Schulkunst in Marners Langem Ton ( ${ }^{1}$ Marn/7/539) ruft die singer, tichter, mercker auf, zum Lob Gottes zu singen.

Ir singer, tichter, mercker gut, habt ir üch hie vereint, so lobent got in rechtem mut, als es mang wiser meister meint, die gut gesang hant ufgericht (Str. 1, V. 1-5).?

Ihr guten Dichter, Singer und Merker, habt ihr euch hier zusammengefunden, so lobt Gott in rechter Gesinnung, wie es viele kluge Meister vormachten, die den guten Gesang geschaffen haben.

In immer neuen Wendungen wird in den fünf langen Strophen zu Bescheidenheit und Demut aufgerufen. Das Lied endet mit den Versen:

Wer kunst recht übt on bös $\beta$ gefer,

der wirt von got begabet wol.

daz merck, du hoher kunstener,

vorwar du got hie schuldig bist!

die schrift dir daz vor lang gebot. (Str. 5, V. 23-27)

Wer Kunst auf richtige Art ohne bösartige Hinterlist ausübt, wird von Gott gut unterstützt. Daran denke, du hoher Künstler, du stehst Gott gegenüber in Verantwortung! Die Heilige Schrift gebietet das schon immer.

6 Der Begriff ist weniger umfassend als , autopoetisch'. Das würde auch Lieder umfassen wie ${ }^{1}$ Lesch/9/9, das vor der Mitteilung mehrerer Erzählbruchstücke in Länge von den Schwierigkeiten berichtet, bei seinem Publikum Interesse zu finden.

7 Die Textzitate der Autoren Beheim, Frauenlob, Folz und Sachs nach den maßgeblichen Editionen. Alle anderen Texte sind nach den Handschriften wörtlich zitiert, doch mit Auflösung geläufiger Kürzel, bereinigter Worttrennung, regulierter Großschreibung, abgesetzten Versen und ergänzter Interpunktion. An wenigen Stellen ist im Interesse der Verständlichkeit bei offensichtlichen Fehlern gekennzeichnet eingegriffen. In « stehen Ergänzungen bzw. Austausch (dieser ist jeweils in Anm. erklärt), in () stehen sinnentstellende Zutaten. 
Ganz ähnlich beginnt auch ein Lied in der Schallweise des Ehrenboten ( ${ }^{1} \mathrm{Ehrb} /$ $2 / 3)$.

\author{
$\mathrm{Nu}$ sint mir got wilkomen, \\ ir mercker und ir senger gut. \\ ich hab es wol vernumen, \\ wer singen wil umb einen crancz \\ der trett her an den 〈ring〉 (Str. 1, V. 1-5). ${ }^{8}$
}

Nun seid mir mit Gott willkommen, ihr Merker und lieben Sänger. Ich habe es genau gehört: Wer um den Kranz singen will, der trete in diesen Kreis.

Die folgenden Verse passen zur Eröffnung, indem sie die Einhaltung von Reim und Silbenzahl fordern. In p steht ein paralleles Lied mit den gleichen Elementen $\left({ }^{1} \mathrm{Ehrb} / 2 / 11\right)$ und im gleichen Ton, der hier als Frauenlobs Kupferton bezeichnet wird. Weitere Bestimmungen für die Kunstausübung werden genannt, ferner wird auf die Notwendigkeit verwiesen, Philosophie und die freien Künste zu beherrschen, nur mit deren Kenntnis könne man den Kranz gewinnen. Es werden auch Merker begrüßt; dennoch ist möglich, dass der Sänger selbst ein Merker ist, vorausgesetzt, dass es wenigstens drei von ihnen gibt. In anderen Liedern wird auch rechtes Verhalten angemahnt, oder man erfährt etwas über die Themen der Singschule. Das Element der Begrüßung steuert zum Teil die Kombination folgender Elemente: so wird die Begrüßung zum eigenen Liedtyp, der gerne als empfahung oder (meister-)gruß überschrieben wird. Gelegentlich können unerfahrene Sänger den Part der Einleitung übernehmen. Der Sänger von ${ }^{1}$ Ungl/1/9 grüßt die meister allesant, um kurz darauf zu gestehen: ich pin gesanges gar ein kint, | des muß ich preis entperen (Str. 1, V. 1 und 6f.). Möglicherweise darf der Anfänger noch gar nicht am Wettbewerb teilnehmen; im nachreformatorischen Meistergesang sind solche Praktiken gesichert.

In wenigen Fällen werden auch einzelne zum freundlichen Wettkampf aufgefordert, was funktional nicht ohne weiteres zu verstehen ist, vor allem wenn die Antwort im gleichen Ton erwartet wird. Ein solches Bar findet man beispielsweise in der Froschweise Frauenlobs ( $\left.{ }^{1} \mathrm{Frau} / 14 / 2\right)$.

Gesang den wil ich heben an

und für mich nemen einen man,

gesanges wil ich in bestan,

den man zelt fur den besten.

wann er sich dann bereytet hat

und gein mir singet snell und trat [...] (Str. 1, V. 1-6)

8 Im Text steht tancz, die Konjektur erfolgte nach dem zugehörigen Reimwort vrspring in V. 10. $\operatorname{tancz}$ ist das Reimwort zu V. 4, das in 9 nochmals richtig steht. 
Ich will mit Singen beginnen und einem Mann gegenübertreten, den man zu den besten zählt und den ich im Gesang besiegen will. Sobald er sich dann vorbereitet hat und gegen mich sogleich antritt,

dann soll dieser andere im gleichen Ton antworten. Zuhören sollen weitere Meister und auch eine Mehrzahl von Merkern. Einmal finden sich Herausforderung und Antwort sogar im gleichen Bar ( ${ }^{1}$ Bop/1/588). Ein gut abgestimmtes Frage- und Antwortspiel überliefert der Mgq 414. Das Eingangslied begrüßt ausdrücklich einen neu angekommenen einzelnen Sänger ( ${ }^{1} \mathrm{Tanh} / 1$ / 501) und der antwortet im gleichen Ton (1/502). Die Texte rühren offensichtlich vom selben Verfasser her, wohl einem Mitglied der Versammlung. In einem zuvor abgesprochenen Ablauf führen sie den Neuling ein und bezeugen (wenn alles gut geht) seine Befähigung zur Teilnahme. Der Meistergesang ist offenbar dem Neuling nicht ganz fremd, doch er ist eben kein Dichter. Beim Liederpaar ${ }^{1}$ Beh/63 und 64 ist Verfassereinheit durch die Überlieferung eindeutig. ${ }^{9}$ Einen weiteren Aspekt eröffnet ein Bar ( $\left.{ }^{1} \mathrm{Frau} / 2 / 517\right)$, das gezielt nur von einem Bestimmten Antwort erwartet, trotz der Anwesenheit mehrerer Personen, darunter lüte und Merker; doch auch gernde, herschaft und die ungezogen hovediet werden angesprochen. Selbst wenn die beiden letzten Gruppen nur gesungene Staffage wären, dürfte das Lied deutlich älter sein als die Überlieferung in k. Durchgängig ironisches Lob von einem oder mehreren Gegenüber kommt nur in Liedern von Folz und Sachs vor. Solche Texte gehören zur nächsten Gruppe (2.).

Das Begrüßungselement allein, wie schon erwähnt, reicht niemals aus, um ein drei- oder gar fünfstrophiges Bar zu füllen. Es schränkt aber die folgenden Elemente ein. Typische Folgeabschnitte sind Lob des Meistergesangs, Lob des Gesanges, Lob der Kunst, Nennung der sieben freien Künste oder Aufzählung von Anforderungen an den Gesang bzw. von Fehlern, die vermieden werden müssen. Schließlich ist es möglich, zum Lob Gottes in der beginnenden Veranstaltung aufzufordern. Ausgeschlossen ist dagegen, von der freundlichen Begrüßung zu irgendwelchen Negativaussagen über Konkurrenten überzugehen. Eine Ausnahme macht das Lied ,Grues im Gulden Zwinger' ('Zwing/1/2) in p. Der Gruß an die anwesenden Sänger beschränkt sich auf den Aufgesang,

9 Vgl. auch Judith Lange: Wettstreit um die rechte Kunst - Fürwurf und Straflied im Meistergesang des 15. Jahrhunderts. In: Editionen deutscher Texte des Mittelalters. Aktuelle Projekte. Beiträge des Festkolloquiums zum 80. Geburtstag von Rudolf Bentzinger am 22. August 2016. Hg. von Eva Rothenberger, Martin Schubert und Elke Zinsmeister. Erfurt 2019, S. 113-137, hier S. 120 mit Anm. 27. 
um dann sogleich die Eigenschaften Gottes und der Trinität zu beschreiben in diesem Fall in einer im Kreis der Meistersinger wenig qualifizierten Weise. Ungewöhnlich auch das Bar ${ }^{1}$ Folz/51: es warnt - wie durchaus üblich - in seiner Begrüßung vor Streit, jedoch indem er den Zustand des geistlichen Standes als warnendes Beispiel anführt.

\section{Aggressive Aufforderung zum Gesang und Beschimpfung (als Liedtyp schendung, reizer, reizunge)}

Das weitaus häufigste Thema der Schulkünste ist die kämpferische Auseinandersetzung mit einem namentlich nicht genannten Gegner. Man fordert ihn zum Wettstreit im Gesang, indem man seine Fähigkeiten zur Meisterschaft anzweifelt und häufig gleichzeitig die großspurigen Selbstrühmungen des Gegners kritisiert. Der beginnende Angriff schränkt die folgenden Elemente noch stärker ein als die der freundlichen Begrüßung und verändert sie durch die Negativwendung. Nicht immer ist die Beschimpfung mit der Aufforderung zur Antwort verbunden. In einem Teil der Texte wird man informiert, dass weitere Sänger oder ein passives Publikum zuhören. Ein Lied in Boppes Hofton ( ${ }^{1} \mathrm{Bop} /$ 1/547) setzt folgendermaßen ein:

Ach junger man, wie dunckest dich so synnentrich!

du wenst, man vind uff erden nirgent din gelich.

mit singen und mit hubschen worten schone

lest du nit ab und wilt erzaigen meisterschafft,

mit mym gesang«e bring(en) ich dich von diner krafft.

mit miner kunst wil ich dich spannen tönen.

ich setz dir esels oren an

als einem, der nit wysen synn kann walden.

ich glich dich einem tumen man

der da von all wysheit ist geschalten.

ich setz dich auf den narren stul,

durch myn gesang so mustu werden swytzen (Str. 1, V. 1-12).

Ach junger Mann, wie sinnreich glaubst du dich! Du meinst, man fände auf Erden keinen, der dir im Singen und im Setzen zierlich höfischer Worte gleicht. Lässt du nicht davon ab, deine angebliche Meisterschaft zu zeigen, nehme ich dir mit meinem Gesang deine Kraft. Mit meiner Kunst werde ich dich zum Singen reizen. Ich verpasse dir Eselsohren wie einem, der nicht über kluge Gedanken verfügt. Ich halte dich für einen Einfaltspinsel, der von jeglicher Vernunft abgesondert ist. Ich setze dich auf den Narrenthron, durch meinen Gesang wirst du ins Schwitzen geraten. 
Ein weiteres Beispiel ist ein Lied im Kurzen Ton Konrads von Würzburg. Der Meister dort wird aufgefordert, das Singen zu unterlassen, verstehe er doch nicht, maß unde zal einzuhalten ( $\left.{ }^{1} \mathrm{KonrW} / 9 / 2\right)$.

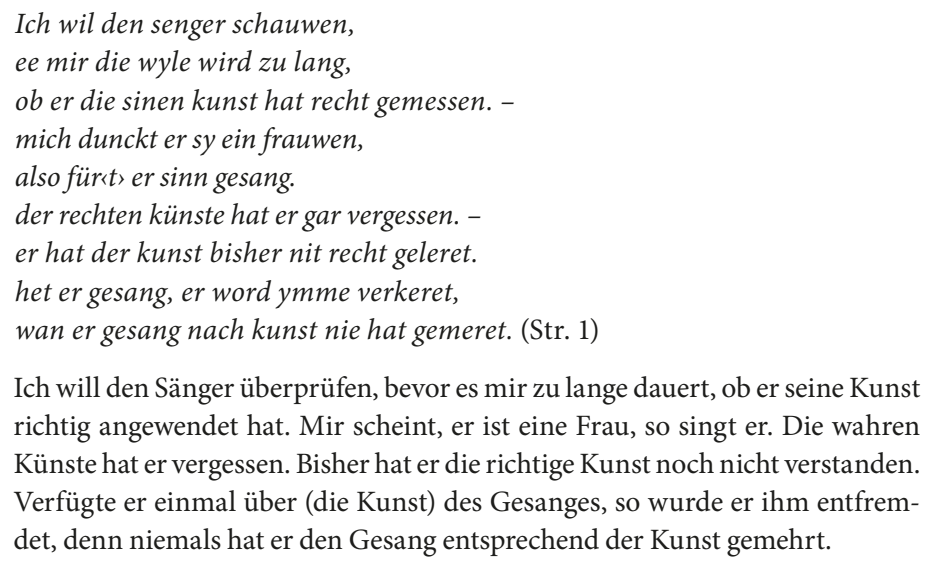
richtig angewendet hat. Mir scheint, er ist eine Frau, so singt er. Die wahren Künste hat er vergessen. Bisher hat er die richtige Kunst noch nicht verstanden. Verfügte er einmal über (die Kunst) des Gesanges, so wurde er ihm entfremdet, denn niemals hat er den Gesang entsprechend der Kunst gemehrt.

Er solle lieber mit den Pferden hinterm Pflug gehen, sein Gesang gleiche dem einer Gans oder Krähe, wie es weiter heißt. Tiervergleiche sind besonders beliebt, beispielsweise Esel, Kalb, Schaf und Geiß in Regenbogens Blauem Ton $\left({ }^{1} \mathrm{KonrW} / 8 / 17\right) .{ }^{10}$ In Konrads Morgenweise wird ironisch ein Studium in Paris oder Prag empfohlen, oder eine Reise ins Heilige Land ('KonrW/6/524). Paris als höchsten Ort des Studiums empfiehlt auch ein Lied im Sanften Ton des Harders $\left({ }^{1} \mathrm{Hardr} / 3 / 20\right)$. In einem Lied in Konrads von Würzburg Kurzem Ton ist der Ort der Auseinandersetzung ausdrücklich das Wirtshaus bzw. die Gesellenherberge ( ${ }^{1}$ KonrW/9/1). Der Wirt soll die Tür verschließen, damit der Gegner nicht entweichen kann. Metaphorisch wird das Repertoire der Heldenepik eingesetzt: Schwert und Speer des Gesanges vernichten den Gegner. In Klingsors Schwarzem Ton fordert einer in bösartiger Weise den Besten einer Gruppe zum Gesangswettstreit heraus und polemisiert dabei auch gegen einen Merker ('Wartb/2/519).

Es stellt sich die Frage nach den Anlässen bzw. der Funktion dieses ausgeprägten Liedtyps, der in unterschiedlichen Spielarten auf mehr als 30 Texte in den untersuchten Handschriften kommt. Als offizielle Einleitungen für

10 Weitere Beispiele: ${ }^{1}$ Beh/67; ${ }^{1}$ Bop $/ 1 / 547 ;{ }^{1}$ Folz/2 und 9; ${ }^{1}$ Frau/23/10; ${ }^{1} \mathrm{Hardr} / 3 / 20$; ${ }^{1} \mathrm{Hülz} / 1 / 3 ;{ }^{1} \mathrm{KonrW} / 6 / 522$ und 524; 7/509; 9/1; ${ }^{1} \mathrm{Regb} / 1 / 524 ; 4 / 632 ;{ }^{2} \mathrm{~S} / 60,63$ und 80; ${ }^{1}$ Wartb/2/515, 518; ${ }^{1}$ Zwing/3/16. 
Singschulen ${ }^{11}$ können sie schwerlich gedient haben. Spontanes oder abgesprochenes Gegeneinander im öffentlichen Raum der Wirtsstube scheint denkbar. Wie ernst sind solche bösartigen Fürwürfe gemeint? Darüber geben einige vorreformatorische Lieder von Sachs Aufschluss. Im Jahr 1520 löste sich die Nürnberger Meistersingergesellschaft im Streit auf, nicht für immer, wie wir wissen. Zuvor, und zwar bereits ab 1518, dichtete Sachs eine Reihe bitterböser Lieder, die offensichtlich ernst gemeint waren. Das Lied-Ich, berichtet eines der beiden letzten Bare, sei in eine Grube mit fünf Wölfen gefallen. Da er nicht mit ihnen heulen wollte, habe er Meistergesang angestimmt, doch gerade deshalb seien die fünf über ihn hergefallen. Dank des Jägers, der ihn herauszog, habe er entkommen können ( $\left.{ }^{2} S / 75\right)$. Das andere Lied handelt von dummen Merkern und vergleicht sie mit Fischern, die wegen engmaschiger Netze mit großen Löchern viele kleine Fische fangen, wogegen die großen entkommen können. So würden die Merker bei der Fehlersuche im Meistergesang arbeiten ( ${ }^{2}$ S/69). Im Jahr 1517 hatte Sachs etwas zahmere, zugleich witzigere Spottlieder verfasst ${ }^{2} \mathrm{~S} / 53$ und 55). ${ }^{12}$ Aus anderen Gegebenheiten können wir schließen, dass er sich zu dieser Zeit nach der Rückkehr von der Wanderschaft in die heimische Singergesellschaft zu integrieren bemühte. Die Scherze halten sich offenbar im gestatteten Bereich.

Einige höchst bösartige verunglimpfende Lieder von Folz darf man ebenfalls für durchaus ernst gemeint halten. Sie passen überwiegend zu der glaubwürdigen Auseinandersetzung um den Versuch, das Tonrepertoire in der Nürnberger Gesellschaft auf zwölf Meister einzuschränken. Doch in der Mehrzahl der sonstigen Texte geht es wohl um das, was der Bayer ,derblecken' nennt, ein Ausreizen des Humors des Gegenübers. Bei Menschen mit Humor löst es Lachen aus, selbst wenn tatsächliche Schwächen offenbart werden; von manchen werden die Bosheiten nur mühsam oder nicht ertragen.

Den Beschimpfungseinleitungen stehen nur wenige Antwortlieder gegenüber, die mit gleicher Münze zurückzahlen. Besonders hinterhältig reagiert ein Sänger auf eine gutartige Begrüßung ( ${ }^{1}$ Regb/3/4). Im gleichen Ton, der Grundweise Regenbogens ( ${ }^{1}$ Regb/3/5) beginnt seine Antwort:

11 Zum Verwendungshorizont des Wortes singschul, insbesondere zur Doppelbedeutung ,Singergesellschaft' und ,Konzertveranstaltung vgl. Horst Brunner: Die alten Meister. Studien zur Überlieferung und Rezeption der mittelhochdeutschen Sangspruchdichter. München 1975 (MTU 54), S. 14-18.

$12 \mathrm{Zu}$ den vorreformatorischen Schulkünsten von Hans Sachs vgl. Johannes Rettelbach: Die nicht-dramatischen Dichtungen des Hans Sachs. Wiesbaden 2019, S. 78 86. 


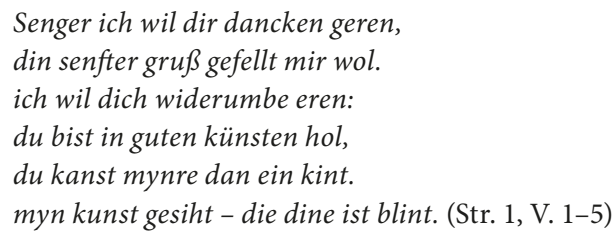

Sänger, ich will dir gerne danken, dein sanfter Gruß gefällt mir durchaus. Ich möchte dich ebenfalls ehren: Was Kunst betrifft, da bist du hohl, du kannst weniger als ein Kind. Meine Kunst kann sehen - deine ist blind!

Die hohe Zahl an Liedern dieses Typs ist erstaunlich. Vielleicht waren sie zum Teil überhaupt nicht für Aufführungen geplant; man dichtete sie aus Vergnügen am Genre, führte sie vielleicht lachend einander vor. Gerade das letzte Beispiel mit der bösartigen Antwort verlangt zur Aufführung eine vorherige Übereinkunft der Beteiligten.

\section{Lob und Voraussetzungen der Kunst}

Das Lob der Kunst ist ein ständig wiederkehrendes Motiv. Ganz allgemein und mündend in das Lob der Kunst des Schöpfers spricht es ein Lied im Vergessenen Ton Frauenlobs aus ( $\left.{ }^{1} \mathrm{Frau} / 7 / 501\right)$, das bereits vor $\mathrm{k}$ als einziges Lied in einem meisterlichen Ton in der Heidelberger Handschrift Cpg $638 \mathrm{zu}$ finden ist. Speziell auf die meisterliche Liedkunst zielt ${ }^{1}$ Regb/4/539, begleitet wird das Lob häufig von der Klage über die Missachtung des Gesangs ( ${ }^{1} \mathrm{KonrW} / 6 / 508$; $\left.{ }^{1} \mathrm{Frau} / 7 / 514\right)$. Ihrerseits werten die Meister die Instrumentalmusik rüde ab im Himmel und in der Kirche habe sie nichts zu suchen ( ${ }^{1} \mathrm{Frau} / 5 / 504$; ferner ${ }^{1}$ KonrW/7/510).

Zahlreiche Lieder beschäftigen sich mit den Sieben freien Künsten als Voraussetzung der Sangeskunst ( ${ }^{1}$ Marn/7/535, 7/561, ${ }^{1}$ Regb/4/518 und 4/521). Einige rechnen darunter auch die Philosophie (z. B. $\left.{ }^{1} \mathrm{Frau} / 9 / 523\right)$. Die meisten Bare indes stellen die freien Künste treffender als von der Philosophie abhängig dar; ein Text erfasst sie im Bild eines Brunnens mit sieben Röhren ('KonrW/6/519). Ein höchst anspruchsvolles Exemplar liefert Hans Folz für den Gebrauch durch Jacob Bernhaubt, genannt Schwennter ( $\left.{ }^{1} \mathrm{Folz} / 76\right)$, der es in einer Singschule vortrug. ${ }^{13}$

13 Das gesibent par / ist durch Hannsen Foltzen von Wormbs Barbierern zu Nurmberg gemacht unnd gedichtet Jacoben Bernhaubt Schwennter benannt / jme in grosser gunst unnd liebe zugestellt / doch umb sein darbezalung und ist im 1496 Jarnn gesunngen durch angezaigtenn Schwentern auff der singeschul umb ain klainoth / es ist jm unbekannten thon und saget von den siben fryen kunsten jtlicher ir erfinder / planeth / farb / methall (Überschrift zu $\left.{ }^{2} \mathrm{Folz} / 76 \mathrm{~b}\right)$. 
Den sieben freien Künsten ordnete er jeweils einen Planeten, ein Metall, eine Farbe und einen antiken meister zu. Auch in zwei Tannhäuser-Tönen wird ihr Lob gesungen: im unterschobenen Hauptton ( $\left.{ }^{1} \mathrm{Tanh} / 6 / 5\right)$ bereits in $\mathrm{m}$ von ca. 1530. Ein Lob der Gesangeskunst, das auf antike Traditionen zurückgreift, wie es im jüngeren Meistergesang gelegentlich vorkommt, fehlt. Einzig die alttestamentlichen ,primi inventores' der Musik, Jubal und Thubal-Kain, nennt ein Lied in Kettners Frauenton ( $\left.{ }^{1} \mathrm{Ketn} / 5 / 1\right)$. Entgegen Genesis 4,21f. sind sie hier auch die Erfinder des Gesanges. Der Nürnberger Autor Fritz Kettner selbst (um 1400) könnte der Autor sein. In einem Ehrenboten-Ton ( $\left.{ }^{1} \mathrm{Ehrb} / 2 / 4\right)$ wird festgestellt, dass Gesang aus dem Himmel stammt und vielen Seelen die Himmelfahrt ermögliche. Kunst stehe noch über Gelehrsamkeit. Das Lied, in k überliefert, spricht auch vom Lob der gernden für die Edlen und dürfte ebenfalls älteren Datums sein.

\section{Regeln der Gesangskunst}

Zahlreiche Lieder beschäftigen sich mit speziellen Regeln des Meistergesangs. Für die aus der Zeit vor 1500 ist charakteristisch, dass sie sich nur mit der Produktion, nicht mit dem Vortrag des Gesanges beschäftigen. In einem Bar im Grünen Ton Heinrichs von Mügeln ( ${ }^{1} \mathrm{HeiMü/542)} \mathrm{kündigt} \mathrm{ein} \mathrm{Sänger} \mathrm{an,} \mathrm{sowohl}$ in alten als auch in neuen Tönen fechten zu wollen. Als wesentliche Punkte, die beim Dichten zu beachten sind, nennt er Metrum, Reim und Melodie. ${ }^{14}$

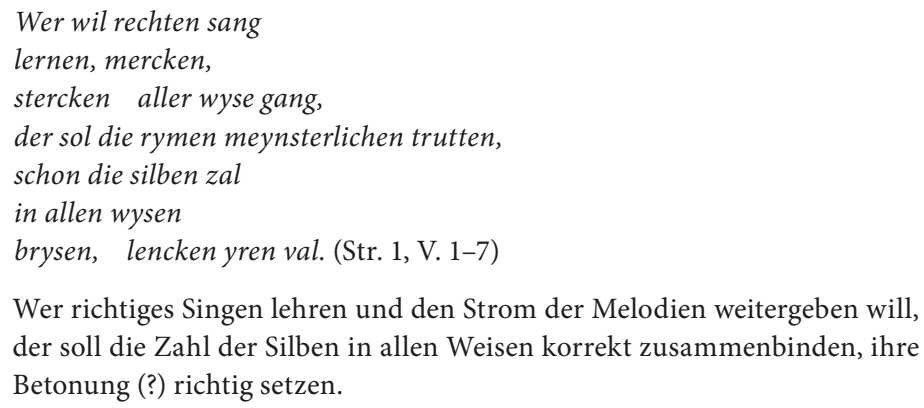

Wer richtiges Singen lehren und den Strom der Melodien weitergeben will, der soll die Zahl der Silben in allen Weisen korrekt zusammenbinden, ihre Betonung (?) richtig setzen.

Die Formulierung lencken yren val scheint die Forderung nach Alternation anzusprechen, die zur Zeit der Niederschrift nicht mehr galt, doch erwähnt auch Michel Beheim noch diesen Begriff (und [du] weist doch weder mauss ${ }^{15}$ nach

14 Im Weiteren polemisiert der Autor auch gegen Stümper und erklärt, dass er sowohl in alten als auch in neuen Tönen dichte.

15 au ist häufige schwäbisch-alemannische Graphie für ā. 
val (Maß noch Betonung) ( ${ }^{1}$ Beh/420 Str. 1, V. 3). Zuvor werden die Beachtung der unveränderten Melodie und die Einhaltung der Verslängen angemahnt. In sehr vielen ähnlichen Aussagen fordern die Autoren außerdem Einhaltung richtiger Reime. Das sind Regeln, die gelegentlich aus den Sieben freien Künsten abgeleitet werden: Melodie entspringt der musica, richtige Silbenzahl der arithmetica ${ }^{16}$ Forderungen an den Reim der grammatica. Die älteste Warnung vor $z u$ kurz, zu lanc (vermutlich bezogen auf die Silbenzahl einzelner Verse) fand ich in der Frauenlobstrophe GA V, ${ }^{\star} 122\left({ }^{1} \mathrm{Frau} / 2 / 17\right)$ aus der ,Jenaer Liederhandschrift' im Dialog mit einem Schüler: swa du den sanc zu kurz, zu lanc erverst, den soltu smehen (V. 12). ${ }^{17}$

In b (also um 1530; ${ }^{1} \mathrm{Regb} / 4 / 613$ ) nennt ein fünfstrophiges Bar in der ersten Strophe einige Begriffe, betreffend die erlaubte und verbotene Gestalt von Strophen. Anders als in späteren Tabulaturen fehlen viele diffizile Vorschriften und Wörter für kleine technische Verstöße und die zugehörigen Strafzumessungen, die in Silben gezählt werden; leider fehlen, wie in den anderen älteren Texten, vor allem praktische Beispiele, die die Forderung oder den Verstoß auch für heutige Leser erklären würden. Neben den bereits genannten Forderungen bezüglich Reim und Silbenzahl und nach guter Kenntnis der musica wird hier ein einziges Mal eine Stimme wie ein orgelbrumm als Voraussetzung für erfolgreichen Gesang genannt (Str. 1, V. 18); das meint in diesem Zusammenhang offenbar eine tiefe und volle Stimme (vgl. den Spott über eine weiblich klingende Stimme im Zitat von ${ }^{1} \mathrm{KonrW} / 9 / 2$ oben, S. 379). Dass man die melody notieren können sollte, fordert einzig ${ }^{1}$ Ungl/1/1 (Str. 1, V. 18) in der Fassung von k. Ferner findet man die Begriffe centrum, differenz, underschaid und equivoca. Von diesen erscheint equivoca (als Plural, aber auch feminin Singular), auch quivic genannt, sehr häufig und auch in jüngeren Tabulaturen. Ursprünglich bezeichnete der Begriff ein besonderes Reimspiel, nämlich eine Reimfolge aus phonemisch gleichen, doch semantisch unterschiedlichen Wörtern, was schon in der Lyrik des 13. Jahrhunderts ein beliebtes Kunststück war. In $\mathrm{f}$ ist es mit einem fünfstrophigen Bar $\left({ }^{1} \mathrm{Regb} /\right.$ 4/618) noch einmal vertreten, allerdings in einer Mischung aus rührenden und identischen Reimen; in ${ }^{1}$ Regb/3/4 ist die Beherrschung von equivocaReimen noch gefordert, in allen anderen Belegen sind sie ausdrücklich verboten. In letzteren Fällen ist davon auszugehen, dass mit dem Wort nur noch

16 In manchen Nennungen zu arsmetrica o. ä. verändert.

17 GA (Göttinger Ausgabe) = Frauenlob (Heinrich von Meissen): Leichs, Sangsprüche, Lieder. Hg. von Karl Stackmann und Karl Bertau. 2 Bde. Göttingen 1982, GA V, ${ }^{\star} 122$. 
identische Reime gemeint sind, ${ }^{18}$ denn rührende Reime (also mit unterschiedlicher Bedeutung) werden bis hinein in den jüngeren Meistergesang ungestraft gebraucht.

Michel Beheim ('Beh/420) schilt einen Sänger, dass der von silmen zal (Str. 1, V. 1) und quivic (Str. 2, V. 1) spricht, ohne diesbezüglich oder überhaupt richtig $\mathrm{zu}$ dichten. In $\mathrm{k}$ fallen vor allem in zwei Liedern regulierende Begriffe auf, eines im Schwarzen Ton des Ungelehrten ( $\left.{ }^{1} \mathrm{Ungl} / 1 / 1\right)$, das andere in der Schallweise des Ehrenboten ( $\left.{ }^{1} \mathrm{Ehrb} / 2 / 3\right)$.

Der Begriff differenz wechselte vermutlich seine Bedeutung. In älteren Liedern stehen oft in der Nähe die Begriffe melody oder musica. In Str. 2 von ${ }^{1}$ Marn/6/505 lautet die Fassung in k:

Ein meister von nature,

der git vns singer einen sin,

wie daz wir sollen mezzen wort vnd melody,

silben, rymen, differencz ein minsten underscheit. (Str, 2, V. 1-4) ${ }^{19}$

Ein natürlicher Meister (dem die Meisterschaft angeboren ist), empfiehlt uns Singern Worte und Melodie auszumessen, die Silben(zahl), die Reime, in der Differenz den kleinsten Unterschied (?).

Dazu passt eine scheinbar gegenteilige die Aussage in ${ }^{1} \mathrm{Regb} / 4 / 613$ : man möge beachten, das differencz ist nit ze kleesin (Str.1, V. 7), also groß genug. Ein exaktes Verständnis des Begriffs lassen die Formulierungen nicht zu. Doch passen sie am ehesten zu einer Deutung, dass Melodien unterschiedlicher Töne nicht über längere Strecken zu ähnlich sein sollen, und bezögen sich damit auf die Neuerfindung von Tönen. Adam Puschman formuliert eine solche Regel in seinem 3. Traktat über den Meistergesang, allerdings ohne einen speziellen Terminus dafür zu gebrauchen. ${ }^{20}$ Das Wort differenz dagegen hat bei Puschman eine völlig andere Bedeutung im Rahmen der Fehler, die beim Merken eine Rolle spielen; als Beispiel setzt er an: schreib statt schrieb. ${ }^{21}$ Noch eine andere Bedeutung lässt

18 In ${ }^{1}$ Regb/4/539 ist mit dem Verbot möglicherweise die Kunstform der durchgehenden equivoca gemeint.

19 Einen unverstandenen Kauderwelsch bietet b an: wie daz sie sollent messen | wort und melody in mischen sunderscheit.

20 Adam Puschman: Gründlicher Bericht des deutschen Meistergesangs (Die drei Fassungen von 1571, 1584, 1596). Texte in Abbildung mit Anhang und einleitendem Kommentar. Band 2: Texte und Anhang. Hg. von Brian Taylor. Göppingen 1984. Die Erläuterung steht in PI, S. 13, in PII, S. 91 und in PIII, S. 33f.

21 Dieses Beispiel betrifft den Unterschied zwischen Oberdt. und Mitteldt. bei den starken Verben, Klasse I. Wie oder ob es auszuweiten ist, bleibt unklar. Ed. Puschman 
sich bei einem Bar in Konrads von Würzburg Aspiston ( ${ }^{1}$ KonrW/5/507) vermuten, nämlich dass weiblicher Schlagreim mit dem Begriff gemeint ist, was im Beleg zugleich vorgeführt wurde. Dort heißt eine Forderung an den Dichter: er sol mit dyfferentzen krentzen. (Str. 1, V. 13). Es geht hier möglicherweise um den im Aspiston vorgeschriebenen weiblichen Schlagreim, den man demnach auch als Schmuck in eigene Töne einbauen kann. Er steht damit in Konkurrenz mit einer Bedeutung des Wortes centrum.

centrum, den dritten häufig genannten Begriff erklärt Hans Nochbur $\left({ }^{2}\right.$ Nochb/2) als Wort für weiblichen Schlagreim. Nochburs Meistergruß im Grünen Ton Frauenlobs stellt in den Strophen 4 und 5 vermutlich die Regeln seiner Heimatsingschule dar, am wahrscheinlichsten Colmar oder Straßburg. ${ }^{22}$ Im Anschluss an andere Regeln heißt es dort:

schlegreym sich darnach finden

und sich an mittel treffen,

darzwischen stet auch blos ein wort,

heysset der centrum, wy ich hort

von meinem meyster, last sich auch nicht effen. (Str. 4, V. 15-19)

Auch [so ist darnach an dieser Stelle zu verstehen] gibt es Schlagreime, die unmittelbar (nach dem jeweils vorangegangenen Reimwort) folgen, (sie stehen) allein (und sie bestehen) nur aus einem Wort dazwischen (zwischen

1984 (Anm. 20), PI, S. 9; PII, S. 90. In PIII, S. 28 gibt Puschman eine abweichende Definition: nämlich zwei gleiche Wörter hintereinander, Beispiel ist das das. Eine ähnliche Bedeutung erwähnt Brian Taylor: Prolegomena to a history of the Tabulatur of the German Meistersinger from its 14th Century Metapoetic Antecedents to its Treatment in Richard Wagner's Opera. In: Journal of the Australasian Universities Language and Literature Association 54 (1980), S. 201-219, hier S. 205f. Er bezeichnet dort den unbeabsichtigten Reim vom Versende zum ersten Wort des nächsten Verses als Differenz.

$22{ }^{2} \mathrm{Nochb} / 2$ ist in der von Georg Wickram geschriebenen Handschrift München cgm 4998 überliefert, ferner in der Handschrift des Klosters Göttweig Cod. 1033 und in den kleinen losen Faszikeln des cgm 6249; Provenienz aus dem Bestand des Nürnberger Meistersingerarchivs. Die lose Sammlung besteht hauptsächlich aus Faszikeln des 17. Jahrhunderts, Faszikel 13 jedoch ist nach dem Schrifttyp und entsprechend Prosaaufzeichnungen zu den Jahren 1524/25 zu dieser Zeit geschrieben. Vermutlich sahen sich die Nürnberger Meister, namentlich Hans Sachs, vor der Wiederbegründung die Regeln anderer Singergesellschaften an. Der sogenannte ,Urschulzettel' der Nürnberger findet sich im gleichen Faszikel. [Nochburs Lied ist aufgrund einer früheren Einordnung auch im älteren Teil des RSM unter ${ }^{1} \mathrm{Frau} / 4$ / 535 verzeichnet.] 
zwei Versen). Die nennt man centrum, wie ich bei meinem Meister lernte, der sich auch nicht in die Irre führen lässt.

Die Verbindung von zweisilbig weiblichem Schlagreimen - nur um diese geht es - mit der Umgebung fordert Sonderbedingungen. Normalerweise enden geradsilbige Verse im Meistergesang männlich, ungeradsilbige weiblich. Dies entspricht in einer älteren Stufe der Reimpaar- und gesungenen Dichtung alternierenden Versen mit Auftakt, die auf betonter Silbe (gerade Silbenzahl) bzw. unbetonter Silbe (ungerade Silbenzahl) enden. Die Sonderverhältnisse bei weiblichem Schlagreim lassen sich am Aspiston Konrads am Beispiel einer Strophe aus b zeigen. Im Lob des Tons ( $\left.{ }^{1} \mathrm{KonrW} / 5 / 508\right)$ klagt ein Sänger: agspiss ist mir zu zéhe, spérhè, wénn ich dichten schol ${ }^{23}$ (Str. 1, V. 13). Ohne Pausen gelesen ergibt sich ein alternierender Siebenheber. Der Vorderteil endet weiblich, der Schlagreim beginnt auf betonter Silbe und ebenso der folgende Dreiheber, der mit fünf Silben männlich endet. ${ }^{24}$ Auch später kennt man die Regel, sie wird z. B. in Puschmans Traktat erklärt, doch das Wort wird einzig durch Nochbur gesichert in dieser Bedeutung verwendet. ${ }^{25}$ Offensichtlich liegt auch hier eine komplette Bedeutungsänderung vor. Ein nach der ganzen Faktur älteres generelles Lob der Kunst ( ${ }^{1}$ KonrW/5/508) mündet in das Lob der Kunst des Schöpfergottes:

Got hat mit kunst gemacht siben planeten

sun(d) vnde man, der engel schar, propheten,

was czenterum mag bringen:

vier element nach gottes gunst [...].

Gott hat mit Kunst sieben Planeten erzeugt, Sonne und Mond, die Schar der Engel, die Propheten, (und?) was das centrum hervorbringen kann: vier Elemente nach Gottes Gunst [...].

Zwar kann centrum hier nicht klar verstanden werden, doch der formorientierte Begriff Nochburs ist sicher nicht gemeint. Noch deutlicher in seiner Undeutbarkeit formuliert ein Bar in Leschs Hofton ( ${ }^{1}$ Lesch/7/3):

er [der Sänger] sol rimen messen manicherlei(e),

wie er silben und zale recht bringet.

gut dütsch er spreche gehofet und slecht, geblümet worheit vol.

23 Handschrift spech statt spehe.

24 Ein Beispiel für die Verwendung des weiblichen Schlagreims in einem anderen Ton oben S. 382 in dem Zitat aus ${ }^{1}$ HeiMü/542.

25 Weitere vorreformatorische Nennungen: ${ }^{1}$ Lesch/7/3; ${ }^{1}$ KonrW/5/507; ${ }^{1} \operatorname{Regb} / 4 / 613$; ${ }^{1}$ Tanh/1/501. 
bunt wider bunt das bindet enzwey,

wa differencz ufdringet.

das centrum yeder sache

sol er in siner cirkelmoß nit brechen,

hoch bi der dieffe machen,

lenge by der breite, equifoca zu sprechen. (Str. 3, V. 3-12)

Er soll unterschiedliche Verse so bemessen, dass die richtige Zahl der Silben entsteht. Er soll gutes Deutsch nach höfischer Art, doch einfach setzen, doch voll geblümter Wahrheit. Bundreim bindet mit Bundreim zwei zusammen, wo Differenz entsteht. [Hier auch Differenz in einer weiteren, unerklärbaren Bedeutung.] Das Centrum jeder (dargestellten?) Sache soll er in seiner Kreisform nicht zerstören, (nicht?) Hohes neben Tiefes setzen, (nicht?) Länge neben Breite, nicht äquivoc reimen.

Die Bedeutung von ,Centrum jeder Sache' ist nicht zu sichern, doch ist wohl auszuschließen, dass es ,Zentrum eines Verses' im oben beschriebenen Sinn meint. Möglich scheint ,Zentrum einer Aussage, einer Darstellung, eines Sachverhalts', wozu dann cirkelmaß als ,Umkreis' passen würde. Dazu fügt sich ein weiterer Beleg: er sol vff künstenricher strass | keinn centrum nit verrücken ('Ungl/1/1 Str. 2, V. 3f.). Wenig Erklärendes zeigt sich in dem viermal überlieferten Text ${ }^{1}$ Marn/6/505, aus dem ich zum Beleg drei Verse nach drei verschiedenen Handschriften zitiere (Str. 2, V. 3-5):

$\begin{array}{ll}\text { vnd mergkh ain weyser disenn gesangk } & b \\ \text { nu mercka wise diesen sang } & k \\ \text { ein wißer der mercket den gesancke } & x \\ \text { er muoz ouch loyc wesen auf gesanges chur } & \\ \text { so muss er loycus sin in gesanges kur } & \\ \text { er muß auch loyca wißen uf gesanges kur } & \\ \text { dazwischen hin leg er daz zentrom } & \\ \text { vnd auch mit dryn (mittendrin) das zentrum } & \\ \text { hie zwischen ein zenttere nemen. }\end{array}$

Spezielle Tabulaturlieder, die die Gesamtheit oder wenigstens einen Großteil örtlich gebundener Verstöße gegen die Regeln des Gesanges in Reimen auflisten, gibt es erst zu Beginn des 16. Jahrhunderts. Und dank der Forschungen von Brian Taylor, ${ }^{26}$ die durch weitere Funde bestätigt werden

26 Brian Taylor: Der Beitrag des Hans Sachs und seiner Nürnberger Vorgänger zu der Entwicklung der Meistersinger-Tabulatur. In: Hans Sachs und Nürnberg. Bedingungen und Probleme reichsstädtischer Literatur. Hans Sachs zum 400. Todestag. Hg. von Horst Brunner u. a. Nürnberg 1976, S. 265-274. 
können, ${ }^{27}$ lassen sich diese Lieder auch bestimmten Singschulen zuordnen. Die Tabulatur in Liedform von Jeronimus Drabolt gehört nach München ( ${ }^{1}$ Drabolt/ 1/1), einschlägige Bare von Hans Folz $\left({ }^{1} \mathrm{Folz} / 46\right)$ und Lienhart Nunnenbeck ( $\left.{ }^{1} \mathrm{Nun} / 32\right)$ beleuchten Nürnberger Verhältnisse, je ein Lied von Caspar Singer ( ${ }^{1}$ Singer/1/1) und von Hans Sachs $\left({ }^{2} S / 45\right)$ waren für Frankfurt bestimmt. Für die ältere Zeit bleibt sehr zweifelhaft, ob die diffizilen Regeln bereits in fester Form bestanden und nur Zeugnisse fehlen oder ob die Merker aufgrund ihrer Erfahrung quasi frei über die Vergabe von Preisen verfügten. In jedem Fall zeigen die mehrfachen Bedeutungsverschiebungen zwischen älteren und jüngeren Regularien deutliche Brüche in der meisterlichen Tradition gegen Ende des 15. Jahrhunderts an.

\section{Stofflich geprägte Formen und Themen}

Mit Formen meine ich die verschiedenen teils formal, teils inhaltlich bestimmten Liedtypen, deren Beherrschung z. B. in b ( ${ }^{1}$ Marn/6/505) den Meistern anempfohlen wird: Nachtweisen, Leichs, Reihen, Zugweisen, Hofweisen und Baranttöne, andere Lieder fordern noch die Kenntnis von Schallweisen und Tänzen ( ${ }^{1} \mathrm{Frau} / 2 / 510 ;{ }^{1} \mathrm{Frau} / 2 / 544 ;{ }^{1} \mathrm{KonrW} / 5 / 507 ;{ }^{1} \mathrm{KonrW} / 7 / 514 ;{ }^{1} \mathrm{Marn} / 6 / 505$; $\left.{ }^{1} \mathrm{Pfalz} / 1 / 2 ;{ }^{1} \mathrm{Regb} / 1 / 531\right) .{ }^{28}$ Einen Katalog von Themen nennt das anonym in $\mathrm{q}$ überlieferte Lied ${ }^{1}$ KonrW/7/514: Kampfspiele; Tiere; Metalle und Steine; vier Elemente; Laien und Pfaffen; Frauen; Hölle und Paradies; Kälte und Hitze; Himmel mit Engeln, Gott und Maria. Der Schreiber Sachs ließ sich wohl dadurch zu einer eigenen umfassenden, Unterweisung was zu singen sey anregen $\left({ }^{2} S / 34\right)$. Er richtet seinen Themenkatalog publikumsbezogen aus: Nur vor Meistersingern solle man über Kunst und Kunstregeln singen, vor Priestern von Gott und Heiliger Schrift; vor Adeligen von Kampf, Turnieren und Jagd; weitere Themen empfiehlt er für das Singen vor weiblichem Publikum, vor Kriegs- und Kaufleuten; und schließlich gibt er Vorschläge für Gesang vor Trinkern, Spielern und Buhlern. Spätestens hier wird der spielerische Charakter deutlich: Meistersinger singen in der Regel nur noch vor Ihresgleichen und einem ständisch gemischten stadtbürgerlichen Publikum. Einige Eingangslieder stecken spezielle Themenbereiche ab, z. B. Weihnachten oder Christus und Maria.

27 Johannes Rettelbach: Fünfmal ,Salve Regina'. In: Ingrid Bennewitz (Hrsg.): Von Heiligen, Rittern und Narren. Festschrift Hans-Joachim Behr. Wiesbaden 2014, S. 41-52.

28 Genaueres mit weiterer Literatur bei Walter Röll: Vom Hof zur Singschule: Überlieferung und Rezeption eines Tones im 14.-17. Jahrhundert. Heidelberg 1976, S. 129-131. 


\section{Lob und Erklärungen einzelner Töne}

Einige Lieder beschäftigen sich mit dem Ton, in dem sie verfasst sind. Es geht dabei ausschließlich um echte Töne alter Meister: Frauenlob, Goldener Ton ( $\left.{ }^{1} \mathrm{Frau} / 9 / 520\right)$; Konrad von Würzburg, Aspiston ( $\left.{ }^{1} \mathrm{KonrW} / 5 / 508\right)$; Marner, Kurzer Ton ( ${ }^{1}$ Marn/6/510), Regenbogen, Grauer ( $\left.{ }^{1} \mathrm{Regb} / 2 / 19\right)$ und Langer Ton ( $\left.{ }^{1} \mathrm{Regb} / 4 / 510\right)$. Die Autoren der Bare nennen die Silbenzahlen der einzelnen Verse und/oder klären das Reimschema. Gelobt wird zum Beispiel auch der Überlange Ton Regenbogens wegen seiner zahlreichen und für spätere Tonerfinder vorbildlichen Besonderheiten ( $\left.{ }^{1} \mathrm{Regb} / 13 / 2\right)$.

Frauenlobs Goldener Ton existiert in mehreren Versionen. Ob die in der $\mathrm{GA}^{29}$ aufgestellte „Urform“ tatsächlich die vom Tonautor gebrauchte ist, ist nicht zu sichern. Sie ist in keiner einzigen Strophe belegt. Die hier mitgeteilte mit doppeltem Anreim im zweiten Vers ist häufig (es reimen also die erste und in V. 3 zusätzlich die zweite Silbe auf jeweils andere Anreime, beim Wechsel von Auf- zu Abgesang allerdings der Endreim k auf den Beginn des Abgesangs, V. 10 auf 11). Das Bar, von dem ich spreche, ist in $k$ und $q$ vertreten, dort aber in jeweils unterschiedlichen Versionen. Handschrift $k$ benutzt in diesem Fall folgendes Schema: ${ }^{30}$

$$
\begin{array}{llllllllllll|llllllllll}
7 & 7 & 7 & 7 & 6 & & 7 & 7 & 7 & 7 & 6 & 7 & 7 & 7 & 7 & 7 & 7 & 7 & 6 & 7 & 6 \\
\mathrm{~A} & \mathrm{~A} & \mathrm{BA} & \mathrm{A} & \mathrm{C} & \mathrm{C} & \mathrm{C} & \mathrm{D} & \mathrm{D} & \mathrm{E} & \mathrm{F} & \mathrm{k} & & \mathrm{F} & \mathrm{E} & & & \mathrm{B} & & \mathrm{G} & \mathrm{G} \\
\mathrm{a} & \mathrm{b} & \mathrm{c} & \mathrm{d} & \mathrm{e} & \mathrm{f} & \mathrm{g} & \mathrm{h} & \mathrm{i} & \mathrm{k} & \mathrm{c} & \mathrm{g} & \mathrm{a} & \mathrm{i} & \mathrm{f} & \mathrm{h} & \mathrm{b} & \mathrm{d} & \mathrm{e} & \mathrm{k} \\
& & & & 5 & & & & & & 10 & & & 13 & & & 17 & & & 20
\end{array}
$$

Allerdings passt eine Stelle im Text der Reimanweisung nicht dazu. Die nämlich behauptet, Anreim F solle die Verse 10 und 17 verbinden, was dem Schema widerspricht. Denn V. 17 ist durch den Anreim B besetzt, und F aus V. 10 fand schon in 13 seinen Partner. In der Textfassung der Handschrift q dagegen korrespondieren dank anderer Reimwörter die Reime so, wie es der Text behauptet. q vertritt die ältere Version der Reimanweisung, denn dort stimmen Aussage und Schema überein. In $\mathrm{k}$ aber ist ein Teil der Bare in dieser abweichenden Weise mit Anreimen versehen; offenbar wurde die Umstellung auch in diesem Lied getroffen, ohne den Text der Strophe überhaupt zu beachten.

29 GA, Bd. 2, S. 985.

30 Oberste Reihe Silbenzahlen, zweite Anreime, dritte Endreime. 
Die erste Strophe eines Bars im Aspiston Konrads von Würzburg ( ${ }^{1} \mathrm{KonnW} / 5 /$ 508) hebt die Schwierigkeiten dieses Tons hervor. Lob verdiene, wer ihn beherrsche. Offensichtlich spielt der Autor auf die verlangten vierfachen Reime in den Stollen und im Abgesang des Tons an: a b b c c d |a b b c c d | e effgg ffd. Ein knappes Lob gilt dem Kurzen Ton Marners in b: Ich lob den maister Marner | vnd brisen (preise ihn) hie in sinem don (Str.1, V. 1f.), danach folgt Polemik gegen einen nicht genannten Sänger ( ${ }^{1}$ Marn/6/510). Kurz wird auch die Briefweise im ,Krieg von Wirczburg' ('Regb/1/512) gelobt. Ein weiteres Lied liefert eine Analyse der Silbenzahlen von Regenbogens Grauem Ton ( ${ }^{1}$ Regb/2/19). Die stimmige Erklärung des Tons verzichtet auf eine Darstellung der Reimverhältnisse. Auch der Überlange Ton Regenbogens erhält ein kurzes Lob im Rahmen eines Gebets ( ${ }^{1}$ Regb/13/2). Dieser Ton wird im späten Meistergesang mehrfach als Muster für alle erlaubten Reimarten genannt: stumpf - klingend (entspricht männlich - weiblich), Pausenreim ${ }^{31}$ (einsilbiger An- oder Schlagreim) und doppelter Pausenreim, weiblicher Schlagreim mit Reimgeschlechtsumkehr des Folgeverses. Am Ende wird für Regenbogens Seele gebetet. ${ }^{32}$

Besonderes Lob für vier Töne verbreitet ein Bar in vier Langen Tönen der Meister Boppe, Frauenlob, Marner und Regenbogen ( ${ }^{1} \mathrm{Bop} / 1 / 563$ in q). Sie werden als einheitliches Bar strophenweise wechselnd gesungen. Die 5. und letzte Strophe wechselt in gleicher Reihenfolge die Strophenteile 1. und 2. Stollen (die also ausnahmsweise ungleich sind), und 1. und 2. Hälfte des Abgesangs. Der Text preist Walther und alle meisterlichen Töne und Tonerfinder. Im jüngeren Meistergesang wird dieses auffällige Schema weiter verwendet, der Ton Boppes indes durch den im Strophenschema gleichen, doch musikalisch unterschiedlichen Ton Mügelns ersetzt. Die Töne heißen nun die ,vier gekrönten Töné.

\section{Meister und Schüler}

Nicht wenige Gedichte beziehen sich auf das Thema Schülerschaft. Um ein singerlin, also um den Schüler eines Meisters, geht es schon in einer Strophe in Rumelants von Sachsen Ton VI ( $\left.{ }^{1} \mathrm{RumS} / 6 / 12\right)$. In der Strophe GA V, ${ }^{*} 122^{33}$ $\left({ }^{1} \mathrm{Frau} / 2 / 17\right)$ wird die feierliche Zeremonie der Aufnahme eines solchen schülers

31 Der Name rührt daher, dass der Singer auch nach dem einsilbigen Reimwort Luft holen darf und muss. Pausenreime sind oft mit einer reichen Melismatik geziert.

32 „Ob es sich um eine Fürbitte für Regenbogen handelt oder ob der Text insgesamt Regenbogen in den Mund gelegt ist, ist schwer zu entscheiden." RSM, Bd. 5, S. 200 zur Stelle.

33 S. Anm. 17. 
durch den Meister im Dialog vorgeführt. In den Schulkünsten des 15. Jahrhunderts spielen Schüler des Öfteren eine Rolle. Wohl an einen Schüler gerichtet ist eine Aufforderung zum Gesang in der Froschweise Frauenlobs, nicht nur weil der Sänger Hilfe verspricht, sondern auch der Tonname (,Frosch') scheint darauf zu zielen ( $\left.{ }^{1} \mathrm{Frau} / 14 / 2\right)$. In der Spiegelweise des Ehrenboten bittet ein Anfänger, als Mitsinger aufgenommen zu werden ( $\left.{ }^{1} \mathrm{Ehrb} / 1 / 507\right)$. Soweit er noch nicht ausreichend vorbereitet sei, bittet er um Unterweisung durch geeignete meister. Ganz bescheiden treten zwei junge Sänger auf, die programmatisch den Schwarzen Ton und den Fremden Ton des Ungelehrten gewählt haben: Ist imandt hie der mit mir singen welle? (Str. $1, \mathrm{~V} .1$ ) fragt der eine ( $\left.{ }^{1} \mathrm{Ungl} / 2 / 1\right)$, und der andere erklärt unter zahlreichen Bescheidenheitsfloskeln, wie er zum Meistergesang gekommen sei ( $\left.{ }^{1} U n g 1 / 1 / 9\right)$. Aufschlussreich für die Realität der Schülerschaft ist ein Bar in Regenbogens Grauem Ton ( $\left.{ }^{1} \mathrm{Regb} / 2 / 19\right)$. Das Ich dieses Liedes tritt durchaus selbstbewusst auf. Es tadelt singer, die sich vom schulmeister, der hier an Stelle des Merkers steht, nicht belehren lassen wollen. Früher, steht da, was (war) ich auch üppig (überheblich) (Str. 3, V. 15), doch nun sagt er: ya meister myn, ir habt mir recht gesait (V. 18). Bezogen auf den Unbelehrbaren heißt es: er [der Meister] nympt yme gelt und lat ym sinen sin (er nimmt sein Geld und lässt ihm seine Meinung) (Str. 2, V. 7). Meistergesang war, was sich auch sonst zeigt, zwar Freizeitbeschäftigung, doch keineswegs ohne finanzielle Aspekte. Anknüpfend daran erwähne ich hier noch, dass in der Höhnweise Wolframs ein Sänger in einer offensichtlich ganz normalen Singschule um seinen Pfennig singen will ( ${ }^{1}$ Wolfr/3/1).

\section{8. Über alte Meister}

Die Traditionsbildung der Sangspruchdichter wechselt nach und nach in die der städtisch-meisterlichen Freizeitkünstler, die sich selbstverständlich und gefühlt bruchlos in die Nachfolge der Sangspruchdichter stellen. Dies zeigt sich am deutlichsten in der Bewahrung von meisterlichen Namen. 81 Vorläufer fand der Nürnberger Meistersinger Konrad Nachtigall am Ende des 15. Jahrhunderts für ein Lied ( $\left.{ }^{1} \mathrm{NachtK} / 5 / 2\right)$, und Hans Folz ( $\left.{ }^{1} \mathrm{Folz} / 82\right)$, der vermutlich dieselbe Quelle benutzt, fast ebenso viele. Etliche sind nur bei ihnen überhaupt belegt und bleiben so „Dichter ohne Werk“ ${ }^{34}$ Die man kennt, stammen nicht alle aus

34 Vgl. die ausführliche Darstellung bei Horst Brunner: Dichter ohne Werk. In: Kleine Editionen und überlieferungsgeschichtliche Studien zur mittelalterlichen deutschen Literatur. Hg. von Konrad Kunze und Bernhard Schnell. Tübingen 1989 (Philologische Studien und Quellen 210), S. 1-31. 
dem Bereich der Sangspruchdichtung. In manchen Schulkünsten werden einige Namen lobend erwähnt: immer wieder Frauenlob und Regenbogen, Konrad von Würzburg, Heinrich von Mügeln, Walther von der Vogelweide, Wolfram von Eschenbach, Ehrenbote. Als seine Vorbilder nennt dagegen Michel Beheim die Namen Muskatblut, Harder, Lesch und Hülzing, ausdrücklich keine, die zum Zwölf-Meister-Kreis (s. u.) gezählt werden können, sondern beinahe Zeitgenossen, denen er konkret als weiterer nachmaister nacheifern will ( ${ }^{1} \mathrm{Beh} / 358$ und 425). Hans Folz ( ${ }^{1}$ Folz/81) lobt in einem Lied Neidhart, allerdings aus dem spezifischen Grund, dass er jedes Lied in einem eigenen Ton sang. Es gibt freilich auch eine Gegenstimme, die in der Morgenweise Konrads von Würzburg $\left({ }^{1} \mathrm{KonrW} / 6 / 508\right)$ beklagt, dass Lieder über Gederuden vnd Künzelmannen (Str. 2, V. 7), sprich Neitharte, gut edel gesang (V. 13 und öfter) verdrängen würden.

Außergewöhnlich ist die Erwähnung Heinrichs von Veldeke in einem Lied in Frauenlobs Langem Ton ( $\left.{ }^{1} \mathrm{Frau} / 2 / 544\right)$. Auch diesen Text halte ich für älter, doch ist er eindeutig als Dreierbar gedichtet. Er bietet die genauesten metrischmusikalischen Angaben zur Komposition von Sangspruchtönen, die wir kennen, und will vielleicht Veldeke für die Kanzonenform, das heißt für deren Übernahme in Deutschland, verantwortlich machen. Ebenso isoliert begegnet in einem Lied in Albrecht Leschs Hofton ( ${ }^{1}$ Lesch/7/3) der Ortsname Nifen. ${ }^{35}$ Der hat dort keine größere Bedeutung und steht wohl eher des Reimes wegen. Doch dürfte er dem Dichter gleichwohl als Herkunftsname eines uralten Kollegen bekannt geworden sein. Auffällig ist ein Lied in Regenbogens Langem Ton $\left({ }^{1} \mathrm{Regb} / 4 / 510\right)$, das Frauenlob, Klingsor, Wolfram, Ehrenbote, Marner, Boppe und Konrad in dieser Reihenfolge aufzählt, sie alle Mitglieder der Zwölfervereinigung. Regenbogen ist nur durch seinen Ton vertreten. Über die Auswahl gibt der Text keine Rechenschaft. Ein eindeutiger Zusammenhang mit den zwölf Meistern wird nicht hergestellt. Neben der puren Benennung der gelobten Meister gibt es auch Rollen- und Unterschiebungsdichtungen. Die wenigsten sind metapoetisch ausgerichtet (s. unter 9.).

Die Zwölfzahl von alten Meistern wird immer wieder einmal beschworen. In einigen Singschulen durfte einzig in den Tönen dieser alten Meister gesungen werden, wogegen Hans Folz in seinen so genannten "Reformliedern“ ('Folz/ 77-82) heftig polemisiert (s. u.). Aber keine Handschrift des 15. Jahrhunderts listet sie auf. Erst Sachs' früheste Sammlung q und die Handschrift Augsburger Provenienz p überliefern eine gesungene Zwölf-Meister-Liste ('Liebe/1/

35 wer beyde wise vnd wort $\mid$ wol dichtet, dem gibe ich danckes vil, | keme er dort her von Nyffen. ,... selbst wenn er aus Neifen kommt.' (Str. 1, V. 6-8). 
7): Frauenlob, Regenbogen, Klingsor, Walther von der Weit (Vogelweide), Konrad von Würzburg, Wolfram, Kanzler, Stolle, Boppe, Römer von Zwickau, ${ }^{36}$ Heinrich von Eferding (Ofterdingen). Das Bar zementiert die Zwölfzahl ausdrücklich, indem es noch fünf Nachmeister nennt, um sie auszuschließen. Die Meister Ungelehrter, Tannhäuser, Meißner, Neidhart, Ehrenbote waren ein wenig zlange, kamen also zu spät (Str. 4, V. 14). Die ausdrückliche Abqualifizierung der fünf erklärt sich vielleicht aus der Tatsache, dass einzelne von ihnen manchen Singschulen oder Meistern durchaus als Kandidaten galten. Die Liste kann allerdings in dieser Form nicht zur Begründung für das ausschließliche Singen von Baren in den Tönen der Zwölf alten Meister herangezogen worden sein, denn der Tonautor Liebe von Giengen gehört ja nicht einmal zu den genannten Nachmeistern. Ausdrücklich aber verweist ein Lied in h in Regenbogens Blauem Ton, wahrscheinlich Augsburger Provenienz wie die Handschrift, auf die Notwendigkeit, einzig in den Tönen der zwölf alten Meister zu singen ('KonrW/8/9). Singt er vns uz zwelf meister guot, | so mag im wol gelingen. (Str. 3, V. 15f.), resümieren die letzten Verszeilen. Das späte Erscheinen einer verbindlich geltenden Liste ist möglicherweise erst eine Reaktion auf die Angriffe von Hans Folz, der mit seiner Kritik an der Möglichkeit, eine solche Liste aufzustellen, ins Herz derjenigen Singschulen getroffen hatte, die nur die Töne der alten Meister beim Singen zulassen wollten, doch sich möglicherweise nie auf eine verbindliche Liste einigen konnten. Bei späteren Listen gibt es weitere Änderungen, die vor allem regionalen Wünschen entsprachen. Doch sind sie alle letztlich abhängig von der Liste, die das Lied im Ton des Lieben präsentiert. Auslöser für Änderungen war vor allem die Hereinnahme Müglings (Heinrichs von Mügeln), für den Heinrich von Eferding (Ofterdingen) oder Klingsor weichen mussten.

In Augsburg kam wohl erst im ersten Drittel des 16. Jahrhunderts die Sage mit der Begründung des Meistergesangs zu Kaiser Ottos Zeiten im 10. Jahrhundert dazu, ${ }^{37}$ während ein Lied im Langen Ton Marners ( ${ }^{1}$ Marn/7/570) mit einer ebenfalls unmöglichen Konstellation den Marner 1207 vor Otto IV. singen lässt und damit eine nicht ganz so absurde ältere Zeitvorstellung dokumentiert.

36 Er vertritt von nun an Reinmar von Zweter. Vgl. Horst Brunner: Römer von Zwickau. In: ${ }^{2}$ VL 10, Sp. $158-160$.

37 Vgl. dazu ausführlich Horst Brunner/Johannes Rettelbach: Der vrsprung des maystergesangs. Eine Schulkunst aus dem frühen 16. Jahrhundert und die Kolmarer Liederhandschrift. In: ZfdA 114 (1985), S. 221-240. 


\section{Unterschiebung oder Rolle}

Das Singen in Tönen früherer Meister ist schon im 14. Jahrhundert eine selbstverständliche Praxis. Deswegen sind Texte mit Ich-Nennung nicht als Lieder des Tonautors zu werten und im Normalfall nicht einmal als unterschobene Texte, wenngleich der Übergang zur Unterschiebung durchaus fließend und daher interpretationsbedürftig ist. Rollen und Unterschiebungen sind nur zu diskutieren, wenn im Text der Name eines Dichter-Ichs oder der eines Zeitgenossen als Adressat genannt wird, unter Umständen, wenn auf andere Weise historische Zeiten evoziert werden. Fiktionale Streitgedichte zwischen existierenden und fiktionalen Sangspruchverfassern sind bereits im Rahmen des, Wartburgkrieges' bald nach 1250 belegt. Das bekannteste Beispiel im Rahmen der meisterlichen Überlieferung sind die Schmiedegedichte Regenbogens. In einer Strophe im Grauen Ton Regenbogens beklagt ein Berufssänger ohne Namensnennung, seinen erlernten Schmiedeberuf aufgegeben zu haben (Str. 1 von ${ }^{1}$ Regb/2/30 und 2/50). Sie wird von mehreren Forschern sogar für möglicherweise echt gehalten. Sicher aber ist die Strophe Ich Regenbog ich was ein smyt ( $\left.{ }^{1} \mathrm{Regb} / 2 / 39\right)$ unecht, auch wenn dort nicht nur der Sänger sich selbst nennt, sondern auch die Konkurrenz zum ebenfalls genannten Meister Frauenlob angesprochen wird. ${ }^{38}$ Sicher spätere Dichtungen sind auch die Streitgedichte zwischen Frauenlob und Regenbogen, ${ }^{39}$ der Rätselstreit zwischen Fritz Kettner und dem Marner ( $\left.{ }^{1} \mathrm{Frau} / 26 / 2\right)$, der Segen des Starken Boppe in der Briefweise Regenbogens (!), Marners und Regenbogens Sterbelieder ( ${ }^{1}$ Marn/7/573 und ${ }^{1}$ Frau/33/2) oder Regenbogens Selbstrühmung $\left({ }^{1} \operatorname{Regb} / 2 / 68\right)$.

\section{Veranstaltungen und Gesellschaften}

Alles spricht dafür, dass in der Jahrhundertmitte in mehreren Städten Süddeutschlands mehr oder minder regelmäßig Gesangsveranstaltungen von Stadtbürgern stattfanden, die in Sangspruch- oder Meistertönen, also in

38 Vgl. Reinhold Schröder: Die Regenbogen zugeschriebenen Schmiedegedichte. In: Literatur und Laienbildung im Spätmittelalter und in der Reformationszeit. Hg. von Ludger Grenzmann und Karl Stackmann. Stuttgart 1984 (Germanistische Symposien. Berichtsbände 5), S. 289-313; Frieder Schanze: Regenbogen. In: ${ }^{2}$ VL 7 , Sp. 1077-1087, hier 1079.

39 Vgl. Burghart Wachinger: Sängerkrieg: Untersuchungen zur Spruchdichtung des 13. Jahrhunderts. München 1973 (MTU 42), S. 280-298. 
Kanzonenform, Lieder um die Wette sangen. ${ }^{40}$ In einigen Veranstaltungen gab es eine Beschränkung auf Töne von zwölf alten Meistern, die vielleicht nicht überall dieselben waren. Die Gesangsleistungen wurden von Merkern, besonders befähigten meistern, beurteilt. Die Zahl der formulierten Regeln für das Singen scheint nach der einschlägigen Liedüberlieferung zu dieser Zeit noch recht begrenzt gewesen zu sein und hebt vor allem bestimmte Sonderformen hervor. Der Sieger wurde durch einen Kranz geehrt (z. B. ${ }^{1} \mathrm{Ehrb} / 2 / 3$; ${ }^{1} \mathrm{Frau} / 2 /$ 548; ${ }^{1}$ KonrW/8/9; $\left.{ }^{1} \mathrm{Mönch} / 5 / 7 ;{ }^{1} \mathrm{Regb} / 1 / 526\right)$, in manchen Texten genauer als Rosenkranz bezeichnet:

und welcher nu die rosen schon

wil brechen zeinem crancze, der sol an dysz geselschaft gan, villicht felt ym ein schancze, er brech der rosen wolgemut zu einem krenczelin. das schenck ich uch gesellen gut und auch den sengern vin. ( ${ }^{1} \mathrm{Frau} / 23 / 10 ;$ Str. 3, V. 9-16)

Und wer nun die schönen Rosen für einen Kranz brechen will, der möge in diese Versammlung kommen (vermutlich so zu verstehen, nicht zwingend als Eintritt in die Gesellschaft), vielleicht hat er eine Chance, dass er fröhlich die Rosen für einen Kranz brechen kann. Den schenke ich euch Gesellen und auch den guten Sängern (Gesellen und Sänger wohl Zwillingsformel).

In ${ }^{1} \mathrm{Frau} / 7 / 508$ heißt es: wir hencken uß ein krenczelin (Str. 1, V. 3), was sich vermutlich jedoch nicht auf das Aufhängen im öffentlichen Raum als Einladung an die Bürger bezieht, sondern ebenfalls auf das Aussetzen des Preises. Einzelheiten steuert ein Lied in Frauenlobs Spiegelweise aus x bei ( ${ }^{1} \mathrm{Frau} / 26 / 5$, Str. 3, V. 6f.): wer in gewint, dem sol man in hofflichen vffseczen, | wer in verlust, der sol in zakn〉. Aus dem Zusammenhang ist nicht erschließbar, ob ein Verlierer aus der aktuellen Veranstaltung gemeint ist oder der Sieger der vorangegangenen Singschule. Das Singen eigener oder übernommener Texte war erlaubt, doch deuten einige Texte auf eine ungleiche Stellung von Dichtern und Sängern. ${ }^{41}$ Wenige Hinweise lassen auf ein geistliches oder geistlich-moralisches Repertoire schließen, ein Bezug auf die kirchlichen Hochfeste ist wahrscheinlich (Gott und Maria in ${ }^{1}$ Ungl/1/7; Weihnachten in ${ }^{1}$ Regb/4/521).

40 Neben den oben besprochenen Belegen vgl. auch die Zitate aus ${ }^{1} \mathrm{Frau} / 7 / 511,{ }^{1} \mathrm{Frau} / 7 /$ 508 und ${ }^{1} \mathrm{Frau} / 7 / 510$ bei Brunner 1975 (Anm. 11), S. 19.

41 Ganz deutlich erst in ${ }^{2} \mathrm{~S} / 55$. 
Einen klaren Beweis für die Existenz von festen Gesellschaften zur Zeit der Abfassung von $\mathrm{k}$ gibt ein Lied in der Spiegelweise des Ehrenboten ( ${ }^{1} \mathrm{Ehrb} / 1 /$ 507). Es beginnt:

Den guten sengern wil ich des getruwen

ob ich in ir geselleschafft sol husen oder buwen

so das sie mich geselleclich in yre zunft enpfhahen. (Str. 1, V. 1-3)

Den wohlwollenden Sängern will ich anheimstellen, ob ich in ihrer Gesellschaft Mitglied werden darf, indem sie mich als Gesellen in ihre Zunft aufnehmen.

Im weiteren Text bittet der Antragsteller zunächst um Unterricht. Den begehrt er aber ausdrücklich nicht von allen Mitgliedern, sondern einzig von den meinstern. Man unterscheidet in diesem Beleg zwischen verschiedenen Rängen der Mitglieder. Das Wort Zunft schließt Nürnberger Provenienz aus, die Tonwahl, Ehrenbote, lässt an rheinische Städte denken. ${ }^{42}$ In anderen Liedern bestätigt sich diese Vorstellung insoweit, als etwa ein junger Mann von den Sängern in einer bestimmten Stadt gehört hat und sich ihnen anschließen will, und auch andere Lieder, in denen Anfänger um Aufnahme oder Unterricht bitten, bestätigen die Existenz von dauerhaften Strukturen, die wohl in manchen Fällen auch von Einzelpersonen dominiert sein können.

Die Tatsache, dass man in den Veranstaltungen bestimmter Gesellschaften nur aus zwelf meistern singen kann, setzt ebenfalls eine regulierende Macht hinter den einzelnen Konzerten voraus.

Anders verhält es sich mit den aggressiven Aufforderungen an einen einzelnen Gegner, vor allem wenn auch von Wein oder von einem Wirt die Rede ist, wie dargestellt. Solche Wettkämpfe im Wirtshaus mögen spontan oder geplant stattgefunden haben, sie bereiten das meisterliche Zechsingen des 16. Jahrhunderts vor. Von merkern ist meist nicht die Rede, manchmal von mehreren Sängern. Eine übergeordnete Organisation ist dafür nicht zwingend nötig.

\section{Rückblick}

Zurück bis etwa 1450 ist durch die hohe Zahl der Lieder, die unter unterschiedlichsten Aspekten von gemeinsamem Singen, von Wettbewerb, Konkurrenz, Preis und Anforderungen singen, an vermutlich mehreren Orten, wahrscheinlich sogar an zahlreichen, ein geordneter Singschulbetrieb gesichert.

42 Selbstverständlich lässt sich nicht klar beweisen, dass das Lied jemals gesungen wurde. Aber es zu dichten, ohne dass eine geschlossene Gesellschaft und entsprechende Rituale existieren, wäre wohl sinnlos. 
Als solchen verstehe ich im Mindeststandard: Es sind Autoritäten da, die über eine Versammlung von singern wachen und ihren Wettbewerb kontrollieren. Sie heißen meist merker, ein Begriff, der schon in mittelhochdeutscher Zeit für Kontrolleure in den unterschiedlichsten Bereichen gebraucht wird und deshalb für sich alleine keine Verbindlichkeit besitzt. Ihr Urteil führt zu einem Preis, der wohl bereits als Wanderpreis zu denken ist, meist ein Kranz. Die Zusammenkünfte erfolgen regelmäßig.

An einigen Standorten sind Singer formelle Mitglieder, aber Neulinge oder Gäste sind besonders gut bezeugt. Schüler werden systematisch an den Gesang und seine Regeln herangeführt. Doch Schülerschaft ist auch ohne feste Gesellschaft bei einzelnen Meistern möglich. Was war vorher?

Es gibt mit m, b und Wien s. n. 3344 (,Liebhard Eghenfelders Liederbuch') drei Handschriften mit einschlägigen Texten aus den frühen Dreißigerjahren des 15. Jahrhunderts. $m$ tradiert aus dem Bereich Metapoesie einen Rätselstreit zwischen Regenbogen und Frauenlob in dessen Grünem Ton ( $\left.{ }^{1} \mathrm{Frau} / 4 / 516\right)$ und ein Bar über die Sieben freien Künste in Tannhäusers Hauptton ('Tanh/6/5). In Hülzings Weißem Ton lässt der Autor, wahrscheinlich Hülzing selbst, einen Trunkenbold ein Lied über die schuol mehrerer Tiere singen ( $\left.{ }^{1} \mathrm{Hülz} / 1 / 2\right)$; der Bär will gekrönt werden. In s. n. 3344 findet sich eine bösartige Herausforderung zum Wettsingen an einen einzelnen Gegner $\left({ }^{1} \mathrm{Wartb} / 2 / 515\right)$. Beim zweiten Bar scheint an eine alte Einzelstrophe im Rohrton des Pfalz' von Straßburg ${ }^{43}$ eine Aufforderung zum Wettsingen angehängt zu sein: Bol [wohl] her an mich,/ wer singen wel mit mir in schönen züchten (Str. 2, V. 1f.). Der Dichter kennt Zugweise, Parat, Meistertanz, Leich und Hofweise ( $\left.{ }^{1} \mathrm{Pfalz} / 1 / 2\right)$. Der Kurzweil soll das Singen dienen, und ein Preis ist zu vergeben, wenn man nach der meister tichte (Str. 3, V. 5) singt, was auch durch die silben vnd reimen (Str. 2, V. 16) näher ausgeführt wird. Als Zuhörer, Mitsinger oder Beurteilende werden herren genannt (Str. 2, V. 11).

In b stehen fünf Schulkünste. Leider scheint der Schreiber wenig Kenntnis von den Fachausdrücken und ihrer Bedeutung gehabt zu haben, viel möglicherweise Aufschlussreiches ist recht verderbt aufgezeichnet. Von den fünf metapoetischen Liedern in b lobt und erklärt eines den verwendeten Aspiston ( ${ }^{1}$ KonrW/5/508), eines gibt ausführliche Erklärungen über den Zusammenhang der Sieben freien Künste mit den Kunstregeln des Gesangs, wie es auch ähnlich

43 Str. 1 lobt die Kunst eines Meisters, der mehr als 30 Röhren (eine Orgel) zum Klingen bringt. Sie gab dem Ton den Namen. Vgl. Gisela Kornrumpf: Mülich von Prag, Pfalz von Straßburg, Albrecht Lesch. In: ZfdA 106 (1977), S. 121-137. 
einige nur später überlieferte Lieder tun ( ${ }^{1}$ Marn/6/505). Lob des verwendeten Kurzen Tons verbindet ${ }^{1}$ Marn/6/510 mit üblen Verunglimpfungen eines Gegners. Ein Berufsdichter fordert Gesangsverbot für alle Freizeitsänger, bevor er priamelartig Berufe und andere Stände aufzählt, für die jeweils das Verbot gilt ( ${ }^{1}$ Regb/1/ 559). Es ist besonders zu vermerken, dass wir hier einem Berufsdichter begegnen, der ausdrücklich fremde Töne verwendet, was nur selten nachweisbar ist. Regeln des Dichtens nennt ${ }^{1}$ Regb/4/613 und fordert Meister, die unterrichten wollen, auf, sie selbst zu beachten. Mit zahlreichen Tiervergleichen wird gegen besserwisserische Schüler, Gegner und Leute, die die Falschen loben, polemisiert.

Auch im Beheim-Corpus werden typische Begriffe des Meistergesangs verwendet. Besonders aufschlussreich ist sein frühestes Lied im Langen Ton ( ${ }^{1} \mathrm{Beh} /$ 425), das nach Schanze wohl zwischen 1440 und 1442 verfasst ist. ${ }^{44}$ Es heißt darin, dass er seine Töne und Dichtungen vor allen singern und den merkern vortragen könne.

\author{
Mein silmen zal \\ die sein dach wol verseczet, \\ nach rechter prait und nit zu schmal. \\ und was ich tichtens hie begynne, \\ das darff ich mich nit schemen \\ vor allen singern überal. \\ ich tar wal kumen fur die merker. (Nr. 425, V. 37-42)
}

Die Zahl meiner Silben ist genau gesetzt, in richtiger Erstreckung, weder zu kurz noch zu lang. Und was ich hier beginne zu dichten, dafür muss ich mich nicht schämen vor überhaupt allen Sängern. Ich wage (erfolgreich) vor die Merker zu treten.

Das aber sei nicht sein Ziel, er wolle zwar nicht zu den Zwölf Meistern, aber doch zu den Nachmeistern gehören. Das Lied, das von einem Gegensatz zwischen Berufs- und Freizeitsängern ausgeht, legt die Existenz organisierter Gesellschaften nahe, selbst wenn es fiktional zu verstehen wäre. Es fixiert ferner die Tatsache von Wettbewerb zwischen mehreren und die Beurteilung durch Merker als bestehenden Brauch.

Der Gesamtbefund bei den älteren Liedern bleibt insgesamt schmal, was feste Strukturen betrifft, bestätigt aber den schon länger bestehenden Brauch

44 Frieder Schanze: Meisterliche Liedkunst zwischen Heinrich von Mügeln und Hans Sachs. Band 1: Untersuchungen. München 1983 (MTU 82), S. 217 und 220. In der Überschrift zum Lied heißt es: ... das hat Michel Peham gemacht als er von erst an vieng zu tichten. 
Singschulen abzuhalten. Ein Lied lässt das vor herren ( ${ }^{1} \mathrm{Pfalz} / 1 / 2$ Str. 2, V. 11) geschehen, was auf Teilnahme höherer städtischer Kreise (und Regulierung durch sie?) verweist, wenn nicht sogar noch höfisches Publikum gemeint ist, die edel herschaft wird als Publikum in ${ }^{1}$ JungMei/1/508 angesprochen (Str. 1, V. 5). Niemals kommen die Einzelbestimmungen oder gar Strafpunkte für Wertungen der späteren Tabulaturen zur Sprache; diese Entwicklung ist erst um die Wende zum 16. Jahrhundert nachweisbar. Die Merker urteilten ursprünglich vielleicht aufgrund von Erfahrung und Autorität nach dem Gesamteindruck, mit nur wenigen fixierten Größen (Silbenzahl, Reim an der richtigen Stelle). Die Korrektheit der Melodie blieb bis ins 16. Jahrhundert und vielleicht darüber hinaus der unkontrollierbaren Kompetenz der Merker überlassen.

Die deutlich abweichenden Lieder der Handschriften aus der Zeit vor 1450 deuten an, dass die Gesellschaften in der ersten Jahrhunderthälfte wohl erst im Entstehen begriffen waren. Neben den Gesellschaften lehrten auch einzelne Meister das meisterliche Singen und traten wohl als Veranstalter von Singschulen auf, möglicherweise sind hier die Vorformen zu suchen. Die Zunahme der einschlägigen Handschriften ab der Jahrhundertmitte zeigt den Siegeszug des Meistergesangs an. Der war zwar dilettierende Nebenbeschäftigung, gleichwohl jedoch selbst im 16. und 17. Jahrhundert nicht ohne finanzielle Aspekte.

Die meisten polemischen Aufforderungen zum Gesang zielen auf den spontanen Zweikampf im Wirtshaus und wurden wohl in einer semiprofessionellen Sängerschicht entwickelt und gerne weitergeführt und weitertradiert. Erst um 1500 vermehren sich die Hinweise auf eine bis in Einzelheiten festgelegte und schließlich auch festgeschriebene Tabulatur, die auf die Aufführung von vorwiegend präexistenten Liedern im Wettbewerb zielt.

\section{Anhang: Liste der berücksichtigten Texte}

Ich habe versucht, alle metapoetischen Texte der Meisterliederhandschriften bis 1530 möglichst vollständig zu erfassen, kann aber nicht ausschließen, dass ich einzelne übersehen habe. Bei der Darstellung der Elemente sind im Darstellungsteil immer nur Beispiele genannt, so dass in der folgenden Liste auch zahlreiche Nummern auftauchen, die in der Darstellung nicht genannt sind, obgleich sie dort genannte Elemente enthalten. Siglen der Handschriften, die den jeweiligen Text überliefern, und Editionen sind angeben. Die Reihenfolge richtet sich bei den anonymen Texten nach dem Alphabet der Tonautoren und Tonnamen. Textautoren, soweit sicher bekannt, sind am alphabetischen Ort eingereiht und durch Fettdruck hervorgehoben. 


\section{Auflösung der verwendeten Handschriftensiglen}

$\mathrm{b}=$ Basel UB Cod. O IV 28

d = Dresden Sächsische LB Cod. M 13

$\mathrm{f}=$,Weimarer Handschrift' Weimar Anna Amalia Bibliothek Q 564

k = ,Kolmarer Liederhandschrift' München SB cgm 4997

$\mathrm{h}=$ Heidelberg UB cpg 392

$\mathrm{m}=$ München SB cgm 351

$\mathrm{p}=$ Heidelberg UB cpg 680

$\mathrm{q}=$ Berlin SBPK mgq 414

$\mathrm{u}=$,Donaueschinger Liederhandschrift' Karlsruhe Badische LB Donaueschingen 120

$\mathrm{w}=$,Wiltener Handschrift' cgm 5198

$\mathrm{x}=$ München SB cgm 1018

$\mathrm{y}=$ München SB cgm 1019

\section{Auflösung der abgekürzt angegebenen Editionen}

Eleanor M. Barnes: Georg Wickram's Anthology from Colmar: Ms. Cgm. 4998. Diss. Los Angeles 1969.

Karl Bartsch (Hrsg.): Meisterlieder der Kolmarer Handschrift. Stuttgart 1862.

Karl Bartsch: Beiträge zur Quellenkunde der altdeutschen Literatur. Straßburg 1886.

Thomas Cramer (Hrsg.): Die kleineren Liederdichter des 14. und 15. Jahrhunderts. 4 Bde. München 1985.

Frances H. Ellis (Hrsg.): The early Meisterlieder of Hans Sachs (1514-1518). Bloomington 1974.

Fritz Frauchiger (Hrsg.): Dresden M 13. A Fifteenth-Century Collection of Religious Meisterlieder. Diss. Chicago 1938.

Karl Goedeke (Hrsg.): Dichtungen von Hans Sachs, Bd. 1. Leipzig 1870.

August Hartmann: Deutsche Meisterliederhandschriften in Ungarn. München 1894.

Jens Haustein / Karl Stackmann (Hrsg.): Sangsprüche in Tönen Frauenlobs. 2 Bde. Göttingen 2000. 
HMS = Friedrich Heinrich von der Hagen (Hrsg.): Minnesinger. 4 Bde. Leipzig 1838.

Adolf Holtzmann (Hrsg.): Meistergesänge des XV. Jahrhunderts. In: Germania 3 (1858), S. 307-328.

Adolf Holtzmann (Hrsg.): Meistergesänge des XV. Jahrhunderts. In: Germania 5 (1860), S. 210-219.

Eva und Hansjürgen Kiepe (Hrsg.): Epochen der deutschen Lyrik 1300-1500. München 1972.

Eva Klesatschke (Hrsg.): Lienhard Nunnenbeck: Die Meisterlieder und der Spruch. Göppingen 1984.

Judith Lange: Wettstreit um die rechte Kunst - Fürwurf und Straflied im Meistergesang des 15. Jahrhunderts. In: Editionen deutscher Texte des Mittelalters. Aktuelle Projekte. Beiträge des Festkolloquiums zum 80. Geburtstag von Rudolf Bentzinger am 22. August 2016. Hg. von Eva Rothenberger, Martin Schubert und Elke Zinsmeister. Erfurt 2019.

August L. Mayer (Hrsg.): Die Meisterlieder des Hans Folz. Berlin 1908.

Gustav Roethe (Hrsg.): Die Gedichte Reinmars von Zweter. Leipzig 1887.

Johannes Siebert (Hrsg.): Der Dichter Tannhäuser: Leben - Gedichte - Sage. Halle/S. 1934.

Philipp Strauch (Hrsg.): Der Marner. Straßburg 1876.

Brian Taylor: Die verschollene Straßburger Meistersinger-Tabulatur von 1494 und eine bisher übersehene Kolmarer Tabulatur von $1546 \mathrm{im}$ Cgm 4997. In: ZfdA 105 (1976), S. 304-310.

Durward S. Poynter (Hrsg.): The Poetics of the early Meistersänger as reflected in the Kolmarer Handschrift [Cgm 4997]. Diss. Los Angeles 1965.

Franziska Wenzel: Meisterschaft im Prozess: der Lange Ton Frauenlobs. Berlin 2012.

WKL = Philipp Wackernagel (Hrsg.): Das deutsche Kirchenlied: von der ältesten Zeit bis zum Anfang des XVII. Jahrhunderts. 4 Bde. Hildesheim 1864-1877.

Elisabeth Wunderle (Hrsg.): Die Sammlung von Meisterliedern in der Heidelberger Handschrift cpg 680. Edition und Kommentar. Göppingen 1993.

Ignatz Zingerle: Bericht über die Wiltener Meistersänger-Handschrift. WSB, Phil.-hist. Classe 37 (1861). 


\section{Beheim, Michel}

(die angegebenen Werknummern entsprechen den Nummern der Edition bei Gille / Spriewald)

Kurze Weise (Bd. 1)

${ }^{1}$ Beh/63 - Holtzmann (1858), S. 327; Lange, Texte, Nr. 1

${ }^{1}$ Beh/64 - Holtzmann (1858), S. 327f.; Lange, Texte, Nr. 2

${ }^{1} \mathrm{Beh} / 65$

${ }^{1} \mathrm{Beh} / 66$

${ }^{1} \mathrm{Beh} / 67$

Lange Weise (Bd. 3)

${ }^{1}$ Beh/425 - Holtzmann (1858), S. 327

Slegweise (Bd. 3)

${ }^{1} \mathrm{Beh} / 358$

${ }^{1} \mathrm{Beh} / 418$

${ }^{1} \mathrm{Beh} / 419$

${ }^{1}$ Beh/420 - Holtzmann (1858), S. 311; Lange, Texte, Nr. 4

${ }^{1}$ Beh/425 - Holtzmann (1858), S. 309f.

Trummetenweise (Bd. 2)

${ }^{1}$ Beh $/ 250$

Zugweise (Bd. 1)

${ }^{1}$ Beh/24 - Kiepe, S. 269-272

Boppe Hofton/Langer Ton

${ }^{1}$ Bop/1/547 k - Poynter, S. 405-407

${ }^{1}$ Bop/1/549 h p - HMS III, S. 407; WKL II, Nr. 321; Wunderle Nr. 6

${ }^{1}$ Bop/1/558 w - Bartsch, Meisterlieder, Nr. 203

Boppe Hofton, Frauenlob Langer Ton, Marner Langer Ton, Regenbogen Langer Ton (strophenweise wechselnd)

${ }^{1}$ Bop $/ 1 / 563 \mathrm{q}$

\section{Drabolt, Jeronimus}

Goldene Tagreise

${ }^{1}$ Drab/1/1 q - Taylor, Beitrag des Hans Sachs, S. 270-272; Cramer I, S. 158163

Schlechter Ton

${ }^{1}$ Drab/2/1 q - Cramer IV, S. 32

Ehrenbote Schallweise

${ }^{1}$ Ehrb/2/3 k - Poynter, S. 489-491; Lange, Texte, Nr. 3

${ }^{1} \mathrm{Ehrb} / 2 / 4 \mathrm{k}$ - Bartsch, Meisterlieder, Nr. 153; Poynter, S. 491-494

${ }^{1}$ Ehrb/2/9 (Kupferton) h - Holtzmann (1858), S. $317 f$.

${ }^{1}$ Ehrb/2/11 (Kupferton) p - Wunderle, Nr. 28 
Ehrenbote Spiegelweise

${ }^{1}$ Ehrb/1/507 k - Bartsch, Meisterlieder, Nr. 151; Roethe, S. 564f.; Poynter, S. $487-489$

\section{Folz, Hans}

Zorn Verborgener Ton München cgm 6353 p

${ }^{1}$ Folz/2 - Mayer Nr. 2

${ }^{1}$ Folz/9 - Mayer Nr. 9

Mügling Kurzer Ton München cgm 6353

${ }^{1}$ Folz/39 - Mayer Nr. 39

${ }^{1}$ Folz/40 - Mayer Nr. 40

${ }^{1}$ Folz/41 - Mayer Nr. 41

${ }^{1}$ Folz/42 - Mayer Nr. 42

${ }^{1}$ Folz/43 - Mayer Nr. 43

${ }^{1}$ Folz/44 - Mayer Nr. 44

${ }^{1}$ Folz/45 - Mayer Nr. 45

${ }^{1}$ Folz/46 - Mayer Nr. 46

${ }^{1}$ Folz/47 - Mayer Nr. 47

${ }^{1}$ Folz/48 - Mayer Nr. 48

${ }^{1}$ Folz/49 - Mayer Nr. 49

Wolfram, Goldener Ton

${ }^{1}$ Folz/51 Weimar Q 566 - Mayer Nr. 52

Nestler von Speyer Unerkannter Ton

${ }^{1}$ Folz/76 q - Frances H. Ellis: The Solution for the Enigmatic Concluding lines of the Munich codex Germanicus 6353. In: PMLA 67 (1952), S. 446-472 ${ }^{1}$ Folz/77 - Mayer Nr. 89

${ }^{1}$ Folz/78 - Mayer Nr. 90

${ }^{1}$ Folz/79 - Mayer Nr. 91

${ }^{1}$ Folz/80 - Mayer Nr. 92

${ }^{1}$ Folz/81 - Mayer Nr. 93

${ }^{1}$ Folz/82 - Mayer Nr. 94

Frauenlob Froschweise

${ }^{1}$ Frau/14/2 (Str. 1) k - Poynter, S. 195-199

Frauenlob Goldener Ton

${ }^{1}$ Frau/9/501 k - Bartsch, Meisterlieder, Nr. 31; Poynter, S. 199-201

${ }^{1} \mathrm{Frau} / 9 / 516 \mathrm{k}$ - Bartsch, Meisterlieder, Nr. 32; Poynter, S. 206-210

${ }^{1}$ Frau/9/519 k q - Poynter, S. 206-210; Haustein/Stackmann XII,209

${ }^{1} \mathrm{Frau} / 9 / 520 \mathrm{k} \mathrm{q}$ - Bartsch, Meisterlieder, Nr. 33; Poynter, S. 210-214; Kiepe, S. 306-309; Haustein/Stackmann XII,210

${ }^{1}$ Frau/9/521 k - Poynter, S. 214-217 
${ }^{1}$ Frau/9/523 k - Poynter, S. 195-199

Frauenlob Grüner Ton

${ }^{1} \mathrm{Frau} / 4 / 516 \mathrm{~m} \mathrm{k}$ - Bartsch, Meisterlieder, Nr. 53; Poynter, S. 243-246

${ }^{1} \mathrm{Frau} / 4 / 535$ s. Nochbur, Hans

Frauenlob Langer Ton

${ }^{1}$ Frau/2/513 k - Bartsch, Meisterlieder, Nr. 14; Poynter, S. 171-174; Wenzel, S. $448-450$

${ }^{1}$ Frau/2/517 k u - Bartsch, Meisterlieder, Nr. 17; Poynter, S. 180-184; Haustein/Stackmann V,233; Wenzel, S. 459-462

${ }^{1}$ Frau/2/544 k - Bartsch, Meisterlieder, Nr. 24; Poynter, S. 185-187; Wenzel, S. $520 \mathrm{f}$

${ }^{1} \mathrm{Frau} / 2 / 548$ k - Bartsch, Meisterlieder, Nr. 27; Poynter, S. 187-190; Wenzel, S. $528-530$

${ }^{1}$ Frau/2/552 k - Bartsch, Meisterlieder, Nr. 29; Poynter, S 190-193; Wenzel, S. $544 f$.

Frauenlob Leidton

${ }^{1} \mathrm{Frau} / 21 / 6 \mathrm{q}$

Frauenlob Neuer Ton

${ }^{1}$ Frau/8/509 k - Bartsch, Meisterlieder, S. 20 (Str. 1); Poynter, S. 233-235

Frauenlob Ritterweise

23/10 k p - Poynter, S. 246-248; Wunderle, Nr. 31

Frauenlob Spiegelweise

${ }^{1} \mathrm{Frau} / 26 / 2 \mathrm{~b}$ und $11 \mathrm{k} \mathrm{q}$ - Cramer II, S. $118 f$.

${ }^{1} \mathrm{Frau} / 26 / 5 \mathrm{x}$

Frauenlob Vergessener Ton

${ }^{1} \mathrm{Frau} / 7 / 501$ Heidelberg cpg 638 k - Poynter, S. 219-221; Haustein/Stackmann VIII,201

${ }^{1} \mathrm{Frau} / 7 / 505 \mathrm{k}$ - Poynter, S. 230-233

${ }^{1} \mathrm{Frau} / 7 / 508 \mathrm{k}$ - Bartsch, Meisterlieder, Nr. 41; Poynter, S. 221-223

${ }^{1} \mathrm{Frau} / 7 / 510 \mathrm{k}$ - Bartsch, Meisterlieder, Nr. 42; Poynter, S. 223-225

${ }^{1} \mathrm{Frau} / 7 / 511 \mathrm{k}$ - Bartsch, Meisterlieder, Nr. 43; Poynter, S. 225-227

${ }^{1}$ Frau/7/514 k - Poynter, S. 227-229

Frauenlob Zarter Ton

${ }^{1}$ Frau/5/504 k u - Bartsch, Meisterlieder, Nr. 46; Poynter, S. 235-239

${ }^{1} \mathrm{Frau} / 5 / 511 \mathrm{k} \mathrm{u}$ - Bartsch, Meisterlieder, Nr. 47; Poynter, S. 239-243; Haustein/Stackmann VIII,214

Frauenlob Zugweise

${ }^{1}$ Frau/33/2 k - HMS III, S. 354; WKL Nr. 429

${ }^{1} \mathrm{Frau} / 33 / 12 \mathrm{q}$ 
Harder Sanfter Ton

${ }^{1} \mathrm{Hardr} / 3 / 14 \mathrm{k}$ - Bartsch, Meisterlieder, Nr. 186; Poynter, S. 571f.

${ }^{1} \mathrm{Hardr} / 3 / 19 \mathrm{y}$

${ }^{1} \mathrm{Hardr} / 3 / 20$ y

Heinrich von Mügeln Grüner Ton

${ }^{1}$ HeiMü/542 k - Bartsch, Meisterlieder, Nr. 185; Poynter, S. 446-448

Hülzing Hofton/Weißer Ton

${ }^{1}$ Hülz/1/2 m - Bartsch, Meisterlieder, Nr. 196; Cramer II, S. 69-71

${ }^{1}$ Hülz/1/3 h - Holtzmann (1858), S. 314f.; Cramer II, S. 71f.

Hülzing Holzweise/Hagelweise

${ }^{1}$ Hülz/3/1 q - Cramer IV, S. 144-147

Junger Meißner Ton I

${ }^{1} J u n g M e i / 1 / 508$ k - Poynter, S. 551-553; Peperkorn, Günter: Der Junge Meiß-

ner. Sangsprüche, Minnelieder, Meisterlieder. München 1982, S. 93-95

Kanzler Goldener Ton

${ }^{1}$ Kanzl/2/516 Trier StB Ms. 1032/1943

Kettner Frauenton

${ }^{1}$ Ketn/5/1 q - Cramer IV, S. 57f.

Klingsor Schwarzer Ton

${ }^{1}$ Wartb/2/511 k y - Poynter, S. 480f.

${ }^{1}$ Wartb/2/515 Wien ÖNB s. n. 3344 h - Holtzmann (1858), S. 318.

${ }^{1}$ Wartb/2/518 h Anna Amalia Bibliothek Fol 418 - Holtzmann (1858), S. $315 f$.

${ }^{1}$ Wartb/2/519 h - Holtzmann (1858), S. 316f.

Konrad von Würzburg Aspiston

${ }^{1}$ KonrW/5/507 k w - Poynter, S. 371-373; Röll, S. 129-131

${ }^{1}$ KonrW/5/508 b - Bartsch, Quellenkunde, S. 290

Konrad von Würzburg Blauer Ton s. Regenbogen, Blauer Ton

Konrad von Würzburg Hofton

${ }^{1}$ KonrW/7/509 k - Bartsch, Meisterlieder, Nr. 119; Poynter, S. 378-381

${ }^{1}$ KonrW/7/510 k w - Zingerle, S. 367f.; Bartsch, Meisterlieder, Nr. 120; Poynter, S. 381-383f.

${ }^{1}$ KonrW/7/514 q

Konrad von Würzburg Kurzer Ton

${ }^{1}$ KonrW/9/1 k - Weimar Anna Amalia Bibliothek Fol 421 Fasz. 32 (Str. 1) Bartsch, Meisterlieder, Nr. 73; Poynter, S. 376f.

${ }^{1}$ KonrW/9/2 k - Bartsch, Meisterlieder, Nr. 113; Poynter, S. $377 f$.

Konrad von Würzburg Morgenweise

${ }^{1}$ KonrW/6/508 k w - Zingerle, S. 369f. (Str. 1 und 2); Bartsch, Meisterlieder,

Nr. 109; Poynter, S. 374-376. 
${ }^{1} \mathrm{KonrW} / 6 / 519 \mathrm{w}$

${ }^{1}$ KonrW/6/522 q - Nürnberg StB Solg 56.2

${ }^{1}$ KonrW/6/524 p - Holtzmann (1858), S. 321f.; Wunderle, Nr. 10

Lesch Gesangweise

${ }^{1}$ Lesch/6/6 w - Koester, S. 111-113; Cramer II, S. 231-233

Lesch Hofton

${ }^{1}$ Lesch/7/3 k - Koester, S. 154-156; Poynter, S. 562-564; Cramer IV, S. 131f. Lesch Zirkelweise

${ }^{1}$ Lesch/9/7 k - Koester, S. 167-169; Cramer IV, S. 69f.

${ }^{1}$ Lesch/9/9 k q p - Holtzmann (1858), S. 314; Bartsch, Meisterlieder, Nr. 183;

Poynter, S. 558-562; Cramer IV, S. 74-82; Wunderle, Nr. 40

Liebe von Giengen Radweise

${ }^{1}$ Liebe/1/7 q p Berlin SBPK Mgq 510 - HMS IV, S. 117f.; Holtzmann (1858),

S. 317-319; Cramer IV, S. 144-147; Wunderle, Nr. 30

Marner Kurzer Ton

${ }^{1}$ Marn/6/505 b k x w - Bartsch, Meisterlieder, Nr. 188 (nach w); Poynter,

S. $367-371$

${ }^{1}$ Marn/6/510 b - Bartsch, Quellenkunde, S. 300f. (Str. 1)

Marner Langer Ton

${ }^{1}$ Marn/7/502 k y - Bartsch, Meisterlieder, Nr. 94 (Str.1-3); Poynter, S. 320322 (Str.4-5)

${ }^{1}$ Marn/7/535 k Wien ÖNB Cod. 2856 - Poynter, S. 342-351

${ }^{1}$ Marn/7/538 k - Bartsch, Meisterlieder, Nr. 100; Strauch, S. 140f.; Poynter,

S. $351-353$

${ }^{1}$ Marn/7/539 k - Poynter, S. 354-359

${ }^{1}$ Marn/7/556 h - HMS IV, S. 533f.; Holtzmann (1858), S. 319f.

${ }^{1} \mathrm{Marn} / 7 / 561 \mathrm{w}$

${ }^{1}$ Marn/7/564 w - Zingerle, S. 387 (Str. 2)

${ }^{1}$ Marn/7/570 q

${ }^{1}$ Marn/7/573 q - WKL II, Nr. 187

Meffrid Ton

${ }^{1}$ Meffr/6 k - Bartsch, Meisterlieder, Nr. 168; Poynter, S. 549-551; Cramer II, S. $29 \mathrm{f}$.

Mönch Langer Ton

${ }^{1}$ Mönch/5/7 h p - Wunderle, Nr. 46

Muskatblut Hofton

${ }^{1}$ Musk/1/69 h - Lieder Muskatblut's. Hg. von Eberhard von Groote. Cöln 1852, S. 255-257 


\section{Nachtigall, Konrad}

Abendton

${ }^{1} \mathrm{NachtK} / 1 / 2 \mathrm{q}$ - Cramer IV, S. $227 \mathrm{f}$.

Leidton

${ }^{1}$ NachtK/5/2 q - WKL II, Nr. 1311; Cramer II, S. 384-391; Brunner, Dichter ohne Werk, S. 15-19

\section{Nochbur, Hans}

Frauenlob Langer Ton

${ }^{2} \mathrm{Nochb} / 2\left(={ }^{1} \mathrm{Frau} / 4 / 535\right)$ München cgm $6249 \mathrm{cgm} 4998$ Göttweig StiftsB

Cod. 1033 - Hartmann, S. 71-73; Barnes, S. 285-290

\section{Nunnenbeck, Lienhard}

Frauenlob Überkrönter Ton

${ }^{1}$ Nun/32 q - Taylor, Beitrag des Hans Sachs, S. 268f.; Klesatschke, Nr. 46 Pfalz von Straßburg Rohrweise

${ }^{1}$ Pfalz/1/2 Wien ÖNB s. n. 3344 w - Bartsch, Meisterlieder, S. 114f. (Str. 1);

Cramer IV, S. 270-275 (2 Fassungen)

Regenbogen Blauer Ton ${ }^{45}$

${ }^{1}$ KonrW/8/5 h - Holtzmann (1858), S. $307 f$.

${ }^{1}$ KonrW/8/7 h - HMS IV, S. 837f. Fn. 1

${ }^{1}$ KonrW/8/9 h - HMS III, S. 350

${ }^{1}$ KonrW/8/17 p - Wunderle, Nr. 32

${ }^{1} \operatorname{Regb} / 5 / 2 \mathrm{q}$

Regenbogen Briefweise

${ }^{1}$ Regb/1/507 k - Bartsch, Meisterlieder, Nr. 57; Poynter, S. 253-255

${ }^{1}$ Regb/1/512 k w - Bartsch, Meisterlieder, Nr. 61; Poynter, S. 255-269

${ }^{1}$ Regb/1/513 k - Bartsch, Meisterlieder, Nr. 62; Poynter, S. 269-271

${ }^{1}$ Regb/1/522 k - Bartsch, Meisterlieder, Nr. 66; Poynter, S. 271-274

${ }^{1}$ Regb/1/524 k - Bartsch, Meisterlieder, Nr. 67; Poynter, S. 274-276

${ }^{1}$ Regb/1/526 k - Poynter, S. $276 f$.

${ }^{1}$ Regb/1/531 k - Bartsch, Meisterlieder, Nr. 70; Poynter, S. 278

${ }^{1}$ Regb/1/545 k Druck 67b (VD16 S 3527 und S 3528) - Bartsch, Meisterlieder, Nr. 74; Poynter, S. 279-281

${ }^{1}$ Regb/1/549 k - Bartsch, Meisterlieder, Nr. 76; Poynter, S. 279-281

45 Die Texte im RSM unter den Nummern ${ }^{1}$ KonrW/8/5-19 gehören zum metrisch und melodisch anders gebauten Blauen Ton Regenbogens. Sie stimmen metrisch (doch nicht melodisch) mit Frauenlobs Ritterweise überein und sind in einigen Belegen dieser zugewiesen. 
${ }^{1}$ Regb/1/559 b - Bartsch, Quellenkunde, S. 295-297

${ }^{1}$ Regb/1/564 p - Wunderle, Nr. 52

Regenbogen Goldener Ton

${ }^{1}$ Regb/7/6 k Sterzing StA Hs. I; Druck Nr. 140/I (VD16 ZV 16083) - Bartsch,

Meisterlieder, Nr. 92

Regenbogen Grauer Ton

${ }^{1}$ Regb/2/19 k - Poynter, S. 283-285

${ }^{1}$ Regb/2/30 k - Bartsch, Meisterlieder, Nr. 80; Schröder, S. $291 f$.

${ }^{1}$ Regb/2/39 k w Trier UB 1032/1943 - HMS III, S. 346f.; Schröder, S. $292 f$.

${ }^{1} \mathrm{Regb} / 2 / 59 \mathrm{k}$ - Wachinger, S. $293 \mathrm{f}$.

${ }^{1}$ Regb/2/68 Weimar Anna Amalia Bibliothek Fol 418 - Wachinger, S. 296f.;

Schröder, S. 294

Regenbogen Grundton

${ }^{1}$ Regb/3/3 k - Bartsch, Meisterlieder, Nr. 89; Poynter, S. 315f.

${ }^{1}$ Regb/3/4 k - Bartsch, Meisterlieder, Nr. 90; Poynter, S. $316 f$.

${ }^{1} \mathrm{Regb} / 3 / 5 \mathrm{k}$ - Bartsch, Meisterlieder, Nr. 91; Poynter, S. $317 f$.

Regenbogen Langer Ton

${ }^{1}$ Regb/4/507 k - Poynter, S. 288-290

${ }^{1}$ Regb/4/510 k Berlin SBPK Mgq 510 Weimar Anna Amalia Bibliothek Fol 418 - Holtzmann (1860), S. 444 (Str. 1); Bartsch, Meisterlieder, Nr. 82; Poynter, S. 290-293

${ }^{1}$ Regb/4/521 m k - Poynter, S. 293-296

${ }^{1}$ Regb/4/539 k - Bartsch, Meisterlieder, Nr. 83; Poynter, S. 296-299

${ }^{1}$ Regb/4/588 k Berlin SBPK 410 - Bartsch, Meisterlieder, Nr. 86; Poynter,

S. $312-315$

${ }^{1}$ Regb/4/613 b - Lange, Texte Nr. 5

${ }^{1}$ Regb/4/618 f - HMS III, S. 468k-m

${ }^{1}$ Regb/4/622 w - Bartsch, Meisterlieder, S. 670f.

${ }^{1} \mathrm{Regb} / 4 / 632 \mathrm{~h}$ - Holtzmann (1858), S. 320f.

Regenbogen Überlanger Ton

${ }^{1}$ Regb/13/2 d - Frauchiger, S. 29-31

Reinmar von Brennenberg

${ }^{1}$ ReiBr/501 k - Bartsch, Meisterlieder, Nr. 133

\section{Sachs, Hans}

${ }^{2} \mathrm{~S} / 34$ q Unterweisung was zu singen sey - Ellis, Nr. 30; weitere Überlieferungen und Abdrucke s. RSM, Bd. 9

${ }^{2} \mathrm{~S} / 35$ q Das schuel register der straff - Ellis, Nr. 30

${ }^{2} \mathrm{~S} / 36 \mathrm{q}$ Warumb gesang unwert ist - Ellis, Nr. 32

${ }^{2} \mathrm{~S} / 38$ q Ein maister grues aller ding - Ellis, Nr. 33 
${ }^{2} \mathrm{~S} / 45$ q Furwurff aller straff - Ellis, Nr. 31

${ }^{2} \mathrm{~S} / 53$ q Ein plosen maister grues - Ellis, Nr. 34

${ }^{2} \mathrm{~S} / 55 \mathrm{q}$ Ein dichter lob - Ellis, Nr. 35

${ }^{2} \mathrm{~S} / 60 \mathrm{q}$ Loica wider ain groben singer - Ellis, Nr. 37

${ }^{2} \mathrm{~S} / 63$ q Ein maister straff - Ellis, Nr. 38

${ }^{2} \mathrm{~S} / 66$ q Die falsch geselschaft - Ellis, Nr. 39

${ }^{2}$ S/69 q Straff der unfleisigen mercker - Ellis, Nr. 40

${ }^{2} \mathrm{~S} / 75$ q Verporgen straff der mercker - Goedeke, Nr. 12

${ }^{2} \mathrm{~S} / 80$ q Loica wider ain hoffertigen singer - Ellis, Nr. 36

Sighart Sanfter Ton

${ }^{1}$ Sigh/2/1 k - WKL II, Nr. 1307; Cramer IV, S. 316-318

\section{Singer, Caspar}

Freier Ton

${ }^{1}$ Singer/1/1 q - Cramer IV, S. $322 \mathrm{f}$.

Tannhäuser Hofton

${ }^{1} \mathrm{Tanh} / 1 / 501 \mathrm{q}-$ Siebert, S. $232 \mathrm{f}$.

${ }^{1}$ Tanh/1/502 q - Siebert, S. 233-235

Tannhäuser Hauptton

${ }^{1} \mathrm{Tanh} / 6 / 5 \mathrm{~m}$

Ungelehrter Schwarzer Ton

${ }^{1}$ Ungl/1/1 k w - Poynter, S. 494-496; Cramer IV, S. 336-339 (2 Fassungen)

${ }^{1}$ Ungl/1/7 x - Cramer IV, S. 354-356

${ }^{1}$ Ungl/1/9 q - Cramer IV, S. 360-364

Ungelehrter Fremder Ton

${ }^{1}$ Ungl/2/1 p - Wunderle, Nr. 37

Wolfram Höhnweise

${ }^{1}$ Wolfr/3/1 q

Zwinger Goldener Ton

${ }^{1}$ Zwing/1/1 q - Cramer IV, S. 390

${ }^{1}$ Zwing/1/2 p - Holtzmann (1858), S. 324 (Str. 1); Cramer IV, S. 391; Wunderle, Nr. 29

Zwinger Roter Ton

${ }^{1}$ Zwing/3/5 h - Bartsch, Meisterlieder, Nr. 9; Holtzmann (1860), S. 210; Cramer III, S. 529f.

${ }^{1}$ Zwing/3/7 k - Holtzmann (1860), S. 210-212; Poynter, S. 158-160; Kiepe II, 130-132; Cramer III, S. 533-535

${ }^{1}$ Zwing/3/15 q - Cramer IV, S. 382f.

${ }^{1}$ Zwing/3/16 p - Holtzmann (1858), S. 323f.; Cramer IV, 384f.; Wunderle, Nr. 27 



\section{Register}

\section{Personen mit zugeordneten Tönen und Werken}

A

Alblin 140, 144, $146 f$.

Anker

- Meister Ankers Ton 42, 132,308

Ave Maria $\rightarrow$ Konrad von

Würzburg

B

Beheim, Michel 69, 313, 314 Anm. 3, 319, 332 Anm. 54, 375 Anm. 7, 382, 384, 392, 398, 402

- Gekrönte Weise 69

- Hohe guldin Weise 69

- Sleht guldin Weise 69

- Trummetenweise 402

Bernhaubt, Jacob 381

Boppe 42, 144, 153, 156f., 157, 159, 161f., 178, 181f., 220, 221 Anm. 24, 392-394

- Hofton 26 Anm. 58, 132, 140, 157, $218,378,402$

- Langer Ton 390, 402

C

Chaucer, Geoffrey 94

- House of Fame 93, 96

D

Damen, Herman 56

Drabolt, Jeronimus 388, 402

E

Ebenreutter, Martin 60
Eghenvelder, Liebhard

- Liederbuch 153, 155, 170, 171

Anm. 93, 397

Ehrenbote 42, 378, 382, $392 \mathrm{f}$.

- küpffer don ernpot 264, 280, 402

- Schallweise 131, 264f., 280f., 303, 376, 384, 402

- Spiegelweise 132, 218, 264f., 391, 396, 403

Engel, Samuel 251 Anm. 21

F

Frauenlob (Heinrich von Meissen) 10f., 38, 42, 68, 105 Anm. 4, 136 Anm. 3, 140, 144, 146f., 148, 153, 156f., 163, 169-177, 179-186, 188, 190, 194, 196f., 200, 203-205, 209, 210 Anm. 93, 212 Anm. 97, 220, 258f., 261-263, 273, 296 Anm. 28, 375 Anm. 7, 383, 392-394

- Ankelweise 132

- Froschweise 131, 140, 146, 269, 376, 391, 403

- Gekrönter Ton 71, 74, 77, 131

- Geschwinder Ton 133

- Goldener Ton 132, 141, 170f., 389, 403

- Grüner Ton 132, 141, 174, 193, 196, 218, 254 Anm. 29, 385, 397, 404

- Hundweise 132, 218

- Kreuzleich (Diß ist Regenbogen geticht dez heiligen cruczes leich) 54, 56, 116, 184 Anm. 5

- Kupferton 131, 376

- Kurzer Ton 141, 170, 207 
- Langer Ton 20, 38, 41 Anm. 156, 43f., 116, 132, 140, 184 Anm. 5, 185, 190f., 200, 218, 390, 392, 402, 404, 407

- Leidton 123, 127f., 132, 404

- Marienleich (Diß ist unser frauwen leich oder der guldin flügel) 26 Anm. 58, 38, 54-56, $116,184,263$

- Neuer Ton 132, 141, 172, 404

- Ritterweise vgl. Ps. Frauenlob

- Spiegelweise 132, 188, 395, 404

- Süßer Ton 66 Anm. 32, 132

- Tannton 43, 132

- Tougenhort 54-56, 74

- Überkrönter Ton 407

- Überzarter Ton 26 Anm. 58, 38, 42 Anm. 161, 54, 116, 129, 132, 184

- Vergessener Ton 132, 141, 173, 381, 404

- Verhohlener Ton 117 Anm. 43, 131

- Würgendrüssel 41, 44, 132, 141, 171

- Zarter Ton 132, 141, 170f., 191, 203, 205, 210 Anm. 92, 212 Anm. $97,218,404$

- Zugweise 132, 269, 404

Folz, Hans 146, 247, 323, 375 Anm. 7, 377, 380f., 388, 391-393, 403

- Hoher Ton 332 Anm. 51

Fraß $\rightarrow$ Ps.-Neidhart

Friedrich von Sonnenburg

- Süßer Ton 131

G

Gast 141, 144, 147

Goldenes ABC $\rightarrow$ Mönch von Salzburg

Guillaume de Machaut

- Le livre dou voir dit 95-100
$\mathrm{H}$

Hardegger 141, 144, 150f., 177, 180

Harder 42, 63f., 179 Anm. 116, 392

- Goldener Reihen 55, 62-64, 71f., 74, 77

- Goldener Schilling in der Chorweise 55, 57, 71f., 74

- Hofweise 132

- Sanfter Ton 38, 269f., 404

Heinrich von Mügeln 17, 20, 41f., 129, 144, 148f., 248, 287, 296 Anm. 28, 305, 314 Anm. 4, 390, $392 f$.

- Grüner Ton 132, 382, 405

- Kurzer Ton 131

- Langer Ton 132, 142, 148

- Marienpreis (Dom/Tuom) 58

- Traumton 132

Heinrich von Ofterdingen 42, 393

- Gekaufter oder Fürstenton 133

Heinrich von Veldeke 392

Hornburg, Lupold 164

Hugo von Montfort

- Frau-Welt-Lied 78, 91

Hülzing 392

- Holzweise/Hagelweise 405

- Weißer Ton 397, 405

J

Junger Meißner 42, 115 Anm. 35

- Ton I 133, 218, 405

Junger Spervogel $\rightarrow$ Junger Stolle

Junger Stolle 42

- Junger Spervogel 133

- Ton I 133, 218

K

Kanzler 42, 393

- Goldener Ton 115 Anm. 37, 127, 133, 405

- Hohe Goldene Weise 133

- Langer Ton 133 
- Süßer Ton 131

- Ton II 265

Kebitz, Jacob, Liederbuch $\rightarrow$ München, BSB, Cgm 811

Kelin 144, 147f.

- Ton III 132, 142, 148

Kettner, Fritz, 382, 394

- Frauenton 374, 405

- Osterweise 117 Anm. 43, 131

- Prophetentanz 67f.

Klingsor 392f.

- Schwarzer Ton (vgl. ,Wartburgkrieg' Ton II) 17 Anm. 16, 38, 133, 266, 272f., 405

Koberger, Anton

- Biblia deutsch 76

Konrad von Würzburg 10f., 24, 42, $56,64,71,74,132,142,144,153$, 156f., 162-165, 169, 177f., 180, 182, 217f., 220-222, 224-227, 241, 243, 392f.

- Aspiston 103, 129, 131, 142, 162, 218, 385f., 389f., 405

- Ave Maria 43, 181 Anm. 117, 220 Anm. 18, 222 Anm. 25, 233

- Blauer Ton 131, 405

- Hofton 49, 133, 142, 163, 218, 220 Anm. 18, 222 Anm. 25, 228, 405

- Kurzer Ton/Werter Ton 131, 379, 405

- Mariengruß 224

- Morgenweise 43, 131, 142, 162, 218, 379, 392, 405

- Nachtweise 91, 131, 316-318, 332 Anm. 53

Krafft, Raymund 251 Anm. 21

Kreuzleich $\rightarrow$ Frauenlob, in k unter $\rightarrow$ Regenbogen

Krieg von Wirczburg 184 Anm. 5, 390

Kröll, Simprecht

- Hausbuch $\rightarrow$ Heidelberg, Universitätsbibliothek, Cpg 109
L

Lesch, Albrecht 10, 42, 64f., 65 Anm. 30, 129 mit Anm. 58, 392

- Feuerweise 91

- Gekrönter Reihen 64, 71, 74

- Gesangweise 316f., 319, 325, 332 Anm. 52, 406

- Goldener Reihen 55, 64, 71f., 74, 78-80

- Hofton/Hofweise 103, 129, 133, 386, 392, 406

- Kurzer Reihen 64, 74

- Sangweise 131

- Tag(e)weise 64, 132

- Zirkelweise 131, 406

Liebe von Giengen 42, 117 Anm. $43,131,393$

- Jahrweise/Radweise 131, 406

- Sanfter Ton $\rightarrow$ Nachtigall, Konrad, Sanfter Ton ,Ludeleich' $\rightarrow$ Tannhäuser

Lusch, Hans 117 Anm. 42

Luther, Martin 76, 85, 287, 334

Lydgate, John 94-96

- Reson and Sensuallyte 94

M

Magister sc. scriptor huius libri 22, $35,50 \rightarrow$ Nestler von Speyer

Magdeburger Chronik 92 Anm. 33

Mariengruß $\rightarrow$ Konrad von Würzburg

Marienleich $\rightarrow$ Frauenlob, in k unter $\rightarrow$ Regenbogen

Marienpreis (Dom/Tuom) $\rightarrow$ Heinrich von Mügeln

Marner (der) 29, 42, 67, 142, 144, 153, 156f., 165-170, 177, 180, 260, 272, 392-394

- Goldener Ton 115 Anm. 36, 133, $135,142,218$

- Hofton 133 
- Kurzer Ton 133, 142, 218, 389f., 406

- Langer Ton 41, 49, 133, 143, 168, 218, 260, 316f., 319, 322, 332 Anm. $53,375,390,393,402,406$

- Sterbelied 394

Meffrid 42

- Gedicht(weise) 131

- Meffrid-Ton 406

Michael de Leone 164

Mönch von Salzburg 42, 58, 115f., 261, 271

- Barantton 72, 74

- Goldenes ABC 33, 54, 57

- Langer Ton 260, 406

- Tag- und Nachthorn 54, 88

Mühlenrätsel (Aber iij die mül ein rat + Aber iij der vff rat der mül)

$\rightarrow$ Regenbogen

Mülich von Prag 42, 63

- Langer Ton 132

- Reihen 55, 71, $73 \mathrm{f}$.

Muskatblut 39 Anm. 142, 46, 55, 392

- Alter Ton 116 Anm. 41

- Fröhlicher Ton 48f.

- Hofton 44f., 302, 406

$\mathbf{N}$

Nachtigall, Konrad 146, 391

- Abendton 407

- Leidton 407

- Sanfter Ton 117 Anm. 43, 131

Neidhart von Reuenthal 61, 82-89, 91-93, 100, 108f., 138, 392f.

- Sommerlied 91

Nestler von Speyer 16, 19f., 26, 29, $54,131,186$

- Magister sc. scriptor huius libri 16, 29, 131, 186

- Schreiber A 10, 17f., 20, 21 mit Anm. 34, 22, 26, 28f., 30, 33 mit Anm. 117, 34f., 51, 54, 115, 185f., 188-191, 192 mit Anm. 33, 193, $232 \mathrm{f}$.

- Unbekannter Ton 131, 403
Nochbur, Hans 385f., 407

- Meistergruß 385 mit Anm. 22

Nunnenbeck, Lienhart 388, 407

O

Oswald von Wolkenstein 58, 78, 91, 112 Anm. 22, 118 Anm. 45

$\mathbf{P}$

Peter von Arberg 42, $115 f$.

- Tagweise II 54, 296

Peter von Reichenbach 56, 332 Anm. 51

- Hort (Tagelied + Leich) 54f., 315 Anm. 7, 316, 330, 335, 337

Peter von Sachs $\rightarrow$ Peter von Sachsen

Peter von Sachsen 58, 115

- Barantton 55, 58, 61, 72, 74, 116 Anm. 42

Petrus Alfonsi

- Dialogus contra Iudaeos 349 Anm. 45

Pfalz von Straßburg

- Rohrton/Rohrweise 397, 407

Ps.-Frauenlob

- Gekrönter Reihen 55, 65f., 68, 71, 74,77

- Ritterweise 131, 316f., 321, 332 Anm. 53, 404, 407 Anm. 45

- Schloßhort 55

- Tougenhort 54-56

Ps.-Konrad von Würzburg

- Ave Maria 180 Anm. 117

- Goldenes Reihel 55, 64

- Reihen 55, 65f., 68

Ps.-Neidhart

- Fraß (Dys ist herr nythartz ffras) 55, 60, 65, 115, 116 Anm. 42

Ps. Marner

- Prophetentanz 67f., 116 Anm. 39, 132

Puschman(n), Adam 27, 312, 314 


\section{$\mathbf{R}$}

Regenbogen 24 Anm. 49, 42, 54, 56, 66, 77, 91, 116, 139, 143f., 152, 169, 181-183, 184 Anm. 5, 259-261, 317, 341 mit Anm. 5, 342 Anm. 10, 343, 390 mit Anm. 32, 392f., 394, 397

- Blauer Ton 379, 393, 405, 407 mit Anm. 45

- Goldener Ton 131, 408

- Briefweise 25 Anm. 49, 41 Anm. 156, 91, 133, 143, 152, 184 Anm. 5, 218, 259, 261 Anm. 51, 298, 390, 394, 407

- Goldener Ton 131, 408

- Grauer Ton 25 Anm. 49, 41, 133, 143, 152, 178 Anm. 114, 248, 261 mit Anm. 51, 262, 271, 389-391, 394, 408

- Grundweise 25 Anm. 49, 132, 261 Anm. 51, 380, 408

- ,Judenkrieg' 12f., 341 mit Anm. 5, 342-343 mit Anm. 10, 344-346, 348, 355f., 358f., 361f., 362 Anm. 84, 363-371

- Kreuzleich 116

- Langer Ton 13, 25 Anm. 49, 41, 66 Anm. 32, 133, 218, 254 Anm. 29, 261 mit Anm. 51, 263, 269, 301, 316-318, 327, 332 Anm. 51, 341 Anm. 5, 342 Anm. 6, 343 mit Anm. 11, 344, 389f., 392, 402, 408

- Leidton/Blühende Weise 118f., 121-123, 125 mit Anm. 52, 126-128, 131

- Mühlenrätsel 261,271

- Sterbelied 394

- Tageweise 296

- Tagweise 132, 296

- Torenweise 66 mit Anm. 31, 71, 74, 75 Anm. 5, 91, 132

- Überlanger Ton 389f., 408
Reinmar von Brennenberg 42, 143f., 153f., 155f., 177f., 408

- Hofton 143, 218

- Ton IV 133

Reinmar von Zweter 42, 56, 135, 143f., 147, 148 mit Anm. 13, 393 Anm. 36

- Frau-Ehren-Ton 133, 143, 218, 220, 265

Römer von Zwickau 393

Rumsland

- Geschwinder Ton 129, 133

\section{$S$}

Sachs, Hans 13, 16, 20, 54, 61, 153, 247 mit Anm. 6, 255, 288, 314 mit Anm. 4, 315 mit Anm. 6, 316, 321, 334, 374 mit Anm. 5, 375 Anm. 7, 377, 380, 385 Anm. 22, 388, 392, 408

Schiller, Jörg 68

Schreiber A der Kolmarer Liederhandschrift $\rightarrow$ Nestler von Speyer

Schreiber B der Kolmarer Liederhandschrift 10, 28, 29 Anm. 78, 30 Anm. 88, 33 mit Anm. 114, 34, 45, 47, 185, 188-191, 192 mit Anm. 33, 193-194, 195 Anm. 38

Schulmeister von Esslingen 151

,Segen des Starken Boppe 394

$\rightarrow$ Regenbogens Briefweise

Singer, Caspar 388, 409

Speculum humanae salvationis 352 Anm. 50, 359 Anm. 73

Steinmar 61

Stolle 42, 139, 150f., $151 \mathrm{mit}$ Anm. 26, 177, 180, 393

- Alment 38-40, 133, 141, 144, 150, 218

- vgl. Junger Stolle

Suchendank, Konrad 255-257

Suchensinn 23 Anm. 43, 40, 42, 47, 132,269 
T

Tannhäuser 42, 56, 144, 148f., 154f., $177,382,393$

- Hauptton/Goldener Ton 131, 382, 397, 409

- Hofton 144, 156, 409

- ,Ludeleich` 55, 57, 144, 149, 155

- Ton IX 218

Tugendhafter Schreiber 42

- Grußweise 132, 218

$\mathrm{U}$

Ulrich von Liechtenstein 82

- Frauendienst 81

Ungelehrter 42, 393

- Fremder Ton 391, 409

- Schwarzer Ton 131, 384, 409

V

Voigt, Valentin 146

W

Walther von der Vogelweide 42, 56, 68, 144, 150-152, 181 Anm. 117, 218, 221, 390, 392f.

- Gespaltene Weise 144

- Goldene Weise 133

- Hofweise/Wendelweise 133, 269
- König-Friedrichs-Ton 218

,Wartburgkrieg 39 Anm. 142, 219f., 221 Anm. 22, 266f., 273, 394

- Ton I (Fürstenton) 133, 218

- Ton II (Schwarzer Ton, vgl. Klingsor: Schwarzer Ton) 133, 218, 266, 272

Wickram, Jörg 21, 26 Anm. 62, 27, 385 Anm. 22

- Freudenton 117 Anm. 42

Wilder Alexander 56

Winsbecke 45-47, 132, 218, 220

Wolfram von Eschenbach 42, $147,392 f$.

- Geschwinder Ton 129f., 133

- Goldener Ton 133, 218, 403

- Höhnweise 391, 409

- Vergoldete Weise 133

$\mathbf{Z}$

Zorn, Fritz

- Verborgener Ton 403

- Zugweise 332 Anm. 51

Zwinger 56 Anm. 4

- Goldener Ton 67, 377, 409

- Hort 55, 57

- Roter Ton 48, 55, 57, 116 Anm. 41, 409f. 


\section{Handschriften}

A

Augsburg, Staats- und Stadtbibliothek, $2^{\circ}$ Cod. 197: 77

\section{B}

Basel, Universitätsbibliothek

- Cod. B XI 8: 224, 232, 242

- Cod. N I 6, 50: 224, 242

- Cod. O IV 28 (Baseler Meisterliederhandschrift b): 203 Anm. 71, 246, 250, 400

Berlin, Staatsbibliothek

- Mgf 24: 77

- Mgf 488 (Liederhandschrift des Martin Ebenreutter): 60

- Mgf 779: 86f.

- Mgq 414 (q): 16, 54, 61, 247, 255 Anm. 32, 315, 377, 400

- Mgq 510: 406, 408

- Mgq 719: 153

- Ms. mus. 40.613: 92

,Buxheimer Orgelbuch ' $\rightarrow$

München, Bayerische

Staatsbibliothek, Mus. ms. 3725

D

Dresden, Sächsische Landesbibliothek

- Mscr. M9: 257 Anm. 36

- Mscr. M 13 (Meisterliederhandschrift d): 64, 246, 250f., 400

- Ms. Oc 66: 95 Anm. 38

E

Erfurt, Universitätsbibliothek, Cod. Ampl. Q 56: 77
G

Göttweig, Stiftsbibliothek, Cod. 1033: 385 Anm. 22, 407

$\mathbf{H}$

Heidelberg, Universitätsbibliothek

- Cpg 109 (Hausbuch Simprecht $\rightarrow$ Krölls): 255 Anm. 31

- Cpg 329: 78

- Cpg 350 (D, Faszikel R): 11, 148 Anm. 13, 160, 168f., 177, 180, 181 Anm. 117, 199 Anm. 58, 217, 222 Anm. 25, 223f., 233, 235, 237, 240, 243, 342 Anm. 8, 362

- Cpg 392 (h): 247 mit Anm. 7, 261, 315, 400

- Cpg 638: 381, 404

- Cpg 680: 24, 246 Anm. 5, 264, 315 Anm. 8, 400

- Cpg 848 (Große Heidelberger Liederhandschrift C): 11, 217, 223f., 242

J

Jena, Thüringer Universitäts- und Landesbibliothek, Ms. El. f. 101 (Jenaer Liederhandschrift J): 107 Anm. 7, 108 Anm. 8, 109 Anm. 11, 112, 123 Anm. 51, 128, 130, 179, 224, 243, 316 Anm. 9, 383

K

Karlsruhe, Landesbibliothek, Cod. 408: 175, 199 Anm. 60

- Cod. Donaueschingen 120: 15, 27, 189 Anm. 22, 191 mit Anm. 30, 192, 199 Anm. 60, 258 mit Anm. 37, 263 Anm. 59, 400

,Königsteiner Liederbuch ' $\rightarrow$ Berlin, Staatsbibliothek, Mgq 719 
L

,Liebhard Eghenfelders Liederbuch ‘

$\rightarrow$ Wien, ÖNB, Cod. Ser. nova 3344

,Liederbuch der Clara Hätzlerin`

$\rightarrow$ Prag, Nationalmuseum, Cod.

$\mathrm{X}$ A 12

,Liederhandschrift des Martin

Ebenreutter $\rightarrow$ Berlin,

Staatsbibliothek, Mgf 488

,Lochamer Liederbuch' $\rightarrow$ Berlin,

Staatsbibliothek, Ms. mus. 40.613

M

,Mondsee-Wiener

Liederhandschrift $\rightarrow$ Wien,

Österr. Nationalbibliothek,

Cod. 2856

München, Bayerische

Staatsbibliothek

- Cgm 351 (m): 67, 191 Anm. 31, 247, 254 Anm. 30, 257 Anm. 36, 261, 342 Anm. 9 und 10, 400

- Cgm 810: 92

- Cgm 811: 152

- Cgm 1018 (x): 247, 251-255, 270f., 400

- Cgm 1019 (y): 11f., 245, 247, 251-253, 255 Anm. 33, 256f., 260, 263-267, 269-273, 400

- Cgm 1020: 252, 255 mit Anm. 33

- Cgm 4997 (k): 14, 25ff., 71, 79 (Abb.), 103, 162, 183 Anm. 1, 243, 247, 249, 251, 263, 266, 270, 293 Anm. 19, 295 Anm. 24, 301 Anm. 40, 302 Anm. 43, 311 Anm. 62, 320 Anm. 18, 321 Anm. 19, 322 Anm. 23, 325 Anm. 32, 327 Anm. 36, 328 Anm. 39, 330 Anm. 41, 342,400

- Cgm 4998: 16 Anm. 12, 385 Anm. 22, 407
- Cgm 4999: 16 Anm. 12, 28

- Cgm 5198 (Wiltener Handschrift w): 62, 77, 247f., 315 Anm. 8, 327 mit Anm. 37, 343 Anm. 11 und 13, 400

- Cgm 6249: 385 Anm. 22, 407

- Cgm 6353: 247, 403

- Clm 27329: 224, 243

- Mus. ms. 3725 (Buxheimer Orgelbuch): 92

$\mathbf{N}$

Nürnberg, Landeskirchliches Archiv, Fen. $4^{\circ}$ V 182: 77 Nürnberg, Stadtbibliothek, Solg. Ms. $56.2^{\circ}: 406$

$\mathbf{P}$

Prag, Nationalmuseum, Cod. X A 12 (Liederbuch der Clara Hätzlerin): 60

S

Salzburg, Universitätsbibliothek, Cod. M III 3: 21 mit Anm. 34, 26, 30 Anm. 93, 187

,Schedelsches Liederbuch

$\rightarrow$ München, Bayerische

Staatsbibliothek, Cgm 810

Sterzing, Stadtarchiv

- Hs. I: 408

- ohne Signatur (Sterzinger Miszellaneenhandschrift): 60

,Sterzinger Miszellaneenhandschrift $\rightarrow$ Sterzing, Stadtarchiv, ohne Signatur

Straßburg, National- und Universitätsbibliothek, Cod. 1995: 164 
T

Trier, Stadtbibliothek, Ms 1032/1943

(Trierer Meisterliederhandschrift $\mathrm{t}$ ): 195 Anm. 41, 247f., 405, 408

\section{W}

Weimar, Herzogin Anna Amalia Bibliothek

- Cod. Fol. 418: 257 Anm. 36, 405, 408

- Cod. Fol. 421: 19, 77f., 405

- Cod. Quart 564 (Weimarer Liederhandschrift): 171, 175, 179 Anm. 116, 199 Anm. 60, 343 Anm. 12, 400
- Cod. Quart 566: 247, 403

- Cod. Quart 572: 257 Anm. 36

- Cod. Oct. 145: 255 mit Anm. 34, 256

Wien, Österreichische

Nationalbibliothek

- Cod. 2856 (Mondsee-Wiener Liederhandschrift): 88,261 , 281, 406

- Cod. Ser. nova 3344 (Liebhard Eghenfelders Liederbuch): 397, 405, 407

Wiltener Liederhandschrift $\rightarrow$ München, BSB, Cgm 5198 


\section{Liedverzeichnis nach RSM-Nummern}

\section{(Hauptnummern ohne Kleinbuchstaben)}

${ }^{1}$ Albl/1 258, 263 Anm. 59

${ }^{1}$ Ank/1 308 Anm. 58

${ }^{1} \mathrm{Beh} / 24402$

- ${ }^{1}$ Beh/63 377, 402

- ${ }^{1} \mathrm{Beh} / 64402$

- ${ }^{1} \mathrm{Beh} / 65402$

- ${ }^{1} \mathrm{Beh} / 66402$

- ${ }^{1}$ Beh/67 379 Anm. 10, 402

$-{ }^{1} \mathrm{Beh} / 250402$

$-{ }^{1} \mathrm{Beh} / 28369$

- ${ }^{1} \mathrm{Beh} / 28469$

- ${ }^{1} \mathrm{Beh} / 358$ 392, 402

- ${ }^{1} \mathrm{Beh} / 418402$

$-{ }^{1} \mathrm{Beh} / 419402$

- ${ }^{1}$ Beh/420 383f., 402

- ${ }^{1} \mathrm{Beh} / 425$ 398, 402

${ }^{1}$ Bop/1/500 140

- ${ }^{1}$ Bop/1/504 140

- ${ }^{1}$ Bop/1/507 140

- ${ }^{1}$ Bop/1/510 140

- ${ }^{1}$ Bop/1/517 140

- ${ }^{1}$ Bop/1/520 140

- ${ }^{1}$ Bop/1/527 295 Anm. 24

- ${ }^{1}$ Bop/1/531 140

- ${ }^{1}$ Bop/1/541 140

- ${ }^{1}$ Bop/1/547 378, 379 Anm. 10, 402

$-{ }^{1}$ Bop/1/549 402

$-{ }^{1}$ Bop/1/558 402

- ${ }^{1}$ Bop/1/563 390, 402

- ${ }^{1}$ Bop/1/588 377

${ }^{1} \mathrm{Drab} / 1 / 1402$

$-{ }^{1} \mathrm{Drab} / 2 / 1402$

${ }^{1}$ Ehrb/1/507 308 Anm. 59, 391, 396, 403

- ${ }^{1} \mathrm{Ehrb} / 2 / 2$ 257-259, 264, $280 f$.

- ${ }^{1} \mathrm{Ehrb} / 2 / 3$ 376, 384, 395, 402

- ${ }^{1} \mathrm{Ehrb} / 2 / 4303$ Anm. 47, 382, 402
$-{ }^{1} \mathrm{Ehrb} / 2 / 9402$

- ${ }^{1} \mathrm{Ehrb} / 2 / 11$ 376, 402

${ }^{1}$ Folz/2 379 Anm. 10, 403

- ${ }^{1}$ Folz/9 403

- ${ }^{1}$ Folz/39 403

- ${ }^{1}$ Folz/40 403

- ${ }^{1}$ Folz/41 403

- ${ }^{1}$ Folz/42 403

- ${ }^{1}$ Folz/43 403

- ${ }^{1}$ Folz/44 403

- ${ }^{1}$ Folz/45 403

- ${ }^{1}$ Folz/46 388, 403

- ${ }^{1}$ Folz/47 403

- ${ }^{1}$ Folz/48 403

- ${ }^{1}$ Folz/49 403

- ${ }^{1}$ Folz/51 378, 403

- ${ }^{1}$ Folz/76 381, 403

- ${ }^{1}$ Folz/77 392, 403

- ${ }^{1}$ Folz/78 392, 403

- ${ }^{1}$ Folz/79 392, 403

- ${ }^{1}$ Folz/80 392, 403

- ${ }^{1}$ Folz/81 392, 403

$-{ }^{1}$ Folz/82 391f., 403

${ }^{1} \mathrm{Frau} / 2 / 17 \quad 383,390$

- ${ }^{1} \mathrm{Frau} / 2 / 24198$ Anm. 53

- ${ }^{1} \mathrm{Frau} / 2 / 54198$ Anm. 53

- ${ }^{1}$ Frau/2/67 201 Anm. 64

- ${ }^{1} \mathrm{Frau} / 2 / 68199$ Anm. 58 und 60

- ${ }^{1} \mathrm{Frau} / 2 / 69199$ Anm. 60

- ${ }^{1} \mathrm{Frau} / 2 / 70199$ Anm. 60

- ${ }^{1} \mathrm{Frau} / 2 / 75-79300$ Anm. 38

- ${ }^{1} \mathrm{Frau} / 2 / 103199$ Anm. 60

- ${ }^{1} \mathrm{Frau} / 2 / 104199$ Anm. 60

- ${ }^{1} \mathrm{Frau} / 2 / 113140$

- ${ }^{1} \mathrm{Frau} / 2 / 501198$ Anm. 52 und 55

- ${ }^{1}$ Frau/2/502 190

- ${ }^{1} \mathrm{Frau} / 2 / 505$ 140, 198 Anm. 52

- ${ }^{1} \mathrm{Frau} / 2 / 510388$

- ${ }^{1}$ Frau/2/513 404

- ${ }^{1}$ Frau/2/514 197 Anm. 51, 198 Anm. 52, 200

- ${ }^{1} \mathrm{Frau} / 2 / 516254$ 
- ${ }^{1} \mathrm{Frau} / 2 / 517$ 191, 377, 404

- ${ }^{1} \mathrm{Frau} / 2 / 519140$

- ${ }^{1} \mathrm{Frau} / 2 / 520190$

- ${ }^{1} \mathrm{Frau} / 2 / 522$ 140, 198 Anm. 53

- ${ }^{1} \mathrm{Frau} / 2 / 524198$ Anm. 54, 199

- ${ }^{1} \mathrm{Frau} / 2 / 537197$ Anm. 51, 198 Anm. 55, 200

- ${ }^{1}$ Frau/2/540 197 Anm. 51, 198 Anm. 52 und 54

- ${ }^{1} \mathrm{Frau} / 2 / 541140$

- ${ }^{1} \mathrm{Frau} / 2 / 544$ 388, 392, 404

- ${ }^{1} \mathrm{Frau} / 2 / 545254$

- ${ }^{1} \mathrm{Frau} / 2 / 54844$ Anm. 175, 395, 404

- ${ }^{1} \mathrm{Frau} / 2 / 552$ 140, 197 Anm. 51, 199, 404

- ${ }^{1} \mathrm{Frau} / 2 / 554198$ Anm. 52 und 55

- ${ }^{1} \mathrm{Frau} / 2 / 557201$ Anm. 64

- ${ }^{1} \mathrm{Frau} / 2 / 562$ 140, 199

- ${ }^{1} \mathrm{Frau} / 4 / 100141$

- ${ }^{1} \mathrm{Frau} / 4 / 101141$

- ${ }^{1}$ Frau/4/502 141, 254, 254 Anm 29

- ${ }^{1}$ Frau/4/503 193

- ${ }^{1} \mathrm{Frau} / 4 / 511141$

- ${ }^{1} \mathrm{Frau} / 4 / 514$ 195, 198 Anm. 55

- ${ }^{1} \mathrm{Frau} / 4 / 516$ 397, 404

- ${ }^{1}$ Frau/4/518 254

- ${ }^{1} \mathrm{Frau} / 4 / 519141$

- ${ }^{1} \mathrm{Frau} / 4 / 522$ 253, 255 Anm. 32

- ${ }^{1}$ Frau/4/523 254

- ${ }^{1} \mathrm{Frau} / 4 / 532195$ Anm. 41

- ${ }^{1} \mathrm{Frau} / 4 / 535385$ Anm. 22, 404, 407

- ${ }^{1}$ Frau/5/10 198 Anm. 53, 206, 210 Anm. 92

- ${ }^{1}$ Frau/5/12 210 Anm. 92

- ${ }^{1} \mathrm{Frau} / 5 / 13210 \mathrm{Anm} .92$

- ${ }^{1} \mathrm{Frau} / 5 / 14210$ Anm. 92

- ${ }^{1} \mathrm{Frau} / 5 / 501$ 257f., 263, 273

- ${ }^{1} \mathrm{Frau} / 5 / 504$ 381, 404

- ${ }^{1} \mathrm{Frau} / 5 / 505295$ Anm. 23

- ${ }^{1} \mathrm{Frau} / 5 / 511404$

- ${ }^{1} \mathrm{Frau} / 5 / 512$ 141, 197 Anm. 51, 198 Anm. 52 und 53, 205f., 208

- ${ }^{1} \mathrm{Frau} / 5 / 514198 \mathrm{Anm} .52$ und 55,203
$-{ }^{1} \mathrm{Frau} / 5 / 518191$

- ${ }^{1} \mathrm{Frau} / 5 / 520198$ Anm. 52 und 55, 205, 208

- ${ }^{1}$ Frau/5/521 210 Anm. 92

$-{ }^{1} \mathrm{Frau} / 6 / 104141$

- ${ }^{1} \mathrm{Frau} / 6 / 502141$

- ${ }^{1}$ Frau/6/507 253

- ${ }^{1} \mathrm{Frau} / 7 / 101141$

- ${ }^{1} \mathrm{Frau} / 7 / 500$ 257f., 263f., 264

- ${ }^{1} \mathrm{Frau} / 7 / 501381,404$

$-{ }^{1} \mathrm{Frau} / 7 / 502$ 141, 173

- ${ }^{1}$ Frau/7/505 404

- ${ }^{1} \mathrm{Frau} / 7 / 508$ 395, 395 Anm. 40, 404

- ${ }^{1} \mathrm{Frau} / 7 / 510395$ Anm. 40, 404

- ${ }^{1} \mathrm{Frau} / 7 / 511395$ Anm. 40, 404

- ${ }^{1} \mathrm{Frau} / 7 / 513198$ Anm. 52 und 55

- ${ }^{1} \mathrm{Frau} / 7 / 514$ 381, 404

- ${ }^{1} \mathrm{Frau} / 7 / 515198$ Anm. 52 und 55

- ${ }^{1} \mathrm{Frau} / 8 / 101141$

- ${ }^{1}$ Frau/8/501 188

- ${ }^{1}$ Frau/8/506 141

$-{ }^{1} \mathrm{Frau} / 8 / 50758$

- ${ }^{1} \mathrm{Frau} / 8 / 509404$

- ${ }^{1} \mathrm{Frau} / 8 / 512141$

- ${ }^{1} \mathrm{Frau} / 8 / 515141$

- ${ }^{1} \mathrm{Frau} / 9 / 100141$

- ${ }^{1} \mathrm{Frau} / 9 / 501198$ Anm. 52 und 55, 403

- ${ }^{1} \mathrm{Frau} / 9 / 504198$ Anm. 52 und 55

- ${ }^{1} \mathrm{Frau} / 9 / 506198$ Anm. 52 und 55

- ${ }^{1} \mathrm{Frau} / 9 / 509198$ Anm. 52 und 55

- ${ }^{1} \mathrm{Frau} / 9 / 516403$

- ${ }^{1}$ Frau/9/519 403

- ${ }^{1} \mathrm{Frau} / 9 / 520$ 389, 403

- ${ }^{1}$ Frau/9/521 403

- ${ }^{1} \mathrm{Frau} / 9 / 523$ 381, 404

- ${ }^{1}$ Frau/9/528 254

- ${ }^{1} \mathrm{Frau} / 10 / 107197$ Anm. 51, 206, 207 Anm. 82

- ${ }^{1} \mathrm{Frau} / 10 / 500141$

$-{ }^{1} \mathrm{Frau} / 11 / 4254$

- ${ }^{1} \mathrm{Frau} / 14 / 1$ 140, 146, 256, 258, $262 f$. 
$-{ }^{1} \mathrm{Frau} / 14 / 2$ 376, 391, 403

- ${ }^{1} \mathrm{Frau} / 16 / 1$ 65, 74

- ${ }^{1} \mathrm{Frau} / 18 / 2295$ Anm. 23

- ${ }^{1} \mathrm{Frau} / 21 / 6404$

- ${ }^{1} \mathrm{Frau} / 23 / 2254$

- ${ }^{1} \mathrm{Frau} / 23 / 358$

- ${ }^{1} \mathrm{Frau} / 23 / 10379$ Anm. 10, 395

- ${ }^{1} \mathrm{Frau} / 23 / 12253$

- ${ }^{1}$ Frau/26/1 188 mit Anm. 18

- ${ }^{1} \mathrm{Frau} / 26 / 2$ 394, 404

- ${ }^{1} \mathrm{Frau} / 26 / 4253$

- ${ }^{1} \mathrm{Frau} / 26 / 5$ 253, 395, 404

- ${ }^{1}$ Frau/27/2 66 Anm. 32

- ${ }^{1} \mathrm{Frau} / 33 / 2$ 394, $403 \mathrm{f}$.

- ${ }^{1} \mathrm{Frau} / 33 / 8$ 257, 269

- ${ }^{1}$ Frau/33/12 404

${ }^{1}$ Gast/1 147

${ }^{1} \mathrm{Hardr} / 1 / 1 \quad$ 57, 74

- ${ }^{1} \mathrm{Hardr} / 1 / 274$

- ${ }^{1} \mathrm{Hardr} / 1 / 374$

- ${ }^{1} \mathrm{Hardr} / 2 / 1$ 62, 74

- ${ }^{1} \mathrm{Hardr} / 3 / 14405$

- ${ }^{1} \mathrm{Hardr} / 3 / 19$ 256, 269-271, 269 Anm. 78, 405

- ${ }^{1} \mathrm{Hardr} / 3 / 20$ 256, 269-271, 284, 379, 379 Anm. 10, 405

- ${ }^{1} \mathrm{Hardr} / 3 / 21 \quad 257,269$

${ }^{1}$ HeiMü/56-70 142, 149

- ${ }^{1}$ HeiMü/110-181 58

- ${ }^{1}$ HeiMü/516 142

- ${ }^{1}$ HeiMü/542 382, 386 Anm. 24,405

${ }^{1} \mathrm{Hülz} / 1 / 2 \quad 397,405$

- ${ }^{1} \mathrm{Hülz} / 1 / 3379$ Anm. 10, 405

- ${ }^{1} \mathrm{Hülz} / 3 / 1405$

${ }^{1} J u n g M e i / 1 / 508$ 399, 405

${ }^{1} \mathrm{Kanzl} / 2 / 500253$

- ${ }^{1} \mathrm{Kanzl} / 2 / 516405$

${ }^{1} \mathrm{Kel} / 3 / 501142$

${ }^{1} \mathrm{Ket} / 2 / 1 \quad 67$

${ }^{1} \mathrm{Ketn} / 5 / 1$ 374, 382, 405

${ }^{1}$ KonrW/5/1 223-225

- ${ }^{1}$ KonrW/5/2 223f., 225
- ${ }^{1}$ KonrW/5/3 223

- ${ }^{1}$ KonrW/5/4 223

- ${ }^{1}$ KonrW/5/5 223

- ${ }^{1}$ KonrW/5/6 223

- ${ }^{1}$ KonrW/5/7 223

- ${ }^{1}$ KonrW/5/503 142, $223 \mathrm{f}$.

- ${ }^{1}$ KonrW/5/504 223-225

- ${ }^{1}$ KonrW/5/507 385, 386 mit Anm. 25, 388, 405

- ${ }^{1}$ KonrW/5/508 386, 389f., 397, 405

- ${ }^{1}$ KonrW/5/509 256

- ${ }^{1}$ KonrW/6/5 223

- ${ }^{1}$ KonrW/6/6 223

- ${ }^{1}$ KonrW/6/7

- ${ }^{1}$ KonrW/6/100 43 Anm. 170, 220 Anm. 18, 222 Anm. 25, 223 mit Anm. 28, 223f., 233-242, 238 Anm. 54

- ${ }^{1}$ KonrW/6/503 142, 223

- ${ }^{1}$ KonrW/6/508 381, 392, 405

- ${ }^{1}$ KonrW/6/509 257 mit Anm. 36, 258f., 264f., 274-276

- ${ }^{1}$ KonrW/6/515 142, 223

- ${ }^{1}$ KonrW/6/519 381, 406

- ${ }^{1}$ KonrW/6/522 379, 406

- ${ }^{1}$ KonrW/6/524 379, 406

- ${ }^{1}$ KonrW/7/1 224, 227, 231

- ${ }^{1}$ KonrW/7/2 224, 228, 230 f.

- ${ }^{1}$ KonrW/7/3 224, 229, 231

- ${ }^{1}$ KonrW/7/4 224, 231

- ${ }^{1}$ KonrW/7/7 224

- ${ }^{1} \mathrm{KonrW} / 7 / 18224$

- ${ }^{1} \mathrm{KonrW} / 7 / 19224$

- ${ }^{1}$ KonrW/7/21 224, 226

- ${ }^{1}$ KonrW/7/24 224

- ${ }^{1}$ KonrW/7/500 142, 224

- ${ }^{1}$ KonrW/7/502 142, 224, 231f., $241 f$.

- ${ }^{1} \mathrm{KonrW} / 7 / 503$ 49f. Anm. 205, 142,224

- ${ }^{1}$ KonrW/7/504 49 Anm. 203, 49-50 Anm. 204, 142, 224, 226, 232, $241 f$.

- ${ }^{1}$ KonrW/7/509 405 
- ${ }^{1}$ KonrW/7/510 142, 224, 226, 271f., 381, 405

- ${ }^{1}$ KonrW/7/514 388, 405

- ${ }^{1}$ KonrW/8/5-19 407 Anm. 45

- ${ }^{1} \mathrm{KonrW} / 8 / 5407$

- ${ }^{1} \mathrm{KonrW} / 8 / 7407$

- ${ }^{1}$ KonrW/8/9 393, 395, 407

- ${ }^{1}$ KonrW/8/17 379, 407

- ${ }^{1}$ KonrW/9/1 379, 405

- ${ }^{1}$ KonrW/9/2 379, 383, 405

- ${ }^{1}$ KonrW/10/1 91

- ${ }^{1}$ KonrW/10/2 316f., 319 Anm. 16, 320-322, 325, 332 mit Anm. 53,333

- ${ }^{1}$ KonrW/11/1 65, 74

- ${ }^{1}$ KonrW/12/1 74

${ }^{1}$ Lesch/1/1 64f.

$-{ }^{1}$ Lesch/2/1 64, 74

$-{ }^{1} \operatorname{Lesch} / 4 / 164$

- ${ }^{1} \operatorname{Lesch} / 5 / 591$

- ${ }^{1}$ Lesch/6/2 316f., 325, 327, 332 mit Anm. 52, 333

$-{ }^{1}$ Lesch/6/6 406

- ${ }^{1}$ Lesch/7/3 386 mit Anm. 25, 392, 406

- ${ }^{1}$ Lesch/9/7 406

- ${ }^{1}$ Lesch/9/9 375 Anm. 6, 406

- ${ }^{1}$ Lesch/10/1 64, 74

${ }^{1}$ Liebe/1/7 392f., 406

${ }^{1}$ Marn/1/500 136 Anm. 2, 142

- ${ }^{1}$ Marn/6/101 142

- ${ }^{1}$ Marn/6/500 142

- ${ }^{1}$ Marn/6/505 253, 254 Anm. 30, 384, 387f., 398, 406

- ${ }^{1}$ Marn/6/506 142

- ${ }^{1}$ Marn/6/508 142, 167

- ${ }^{1}$ Marn/6/509 142

- ${ }^{1}$ Marn/6/510 389f., 398, 406

- ${ }^{1}$ Marn/7/14 258, 259 Anm. 43

- ${ }^{1}$ Marn/7/55 256

- ${ }^{1}$ Marn/7/101 143

- ${ }^{1}$ Marn/7/102 143

- ${ }^{1}$ Marn/7/500 143
- ${ }^{1}$ Marn/7/501 143

- ${ }^{1}$ Marn/7/502 49 Anm. 201, 143, 257f., 259 Anm. 43, 260, 272, 406

- ${ }^{1}$ Marn/7/503 143

- ${ }^{1}$ Marn/7/504 49 Anm. 201

- ${ }^{1}$ Marn/7/505 253

- ${ }^{1}$ Marn/7/512 143

- ${ }^{1}$ Marn/7/518 253

- ${ }^{1}$ Marn/7/534 254

- ${ }^{1}$ Marn/7/535 381, 406

- ${ }^{1}$ Marn/7/538 406

- ${ }^{1}$ Marn/7/539 375, 406

- ${ }^{1}$ Marn/7/540 316f., 322f. $332 \mathrm{mit}$ Anm. 53, 333

- ${ }^{1}$ Marn/7/553 254

- ${ }^{1}$ Marn/7/554 257 Anm. 36

- ${ }^{1}$ Marn/7/556 406

- ${ }^{1}$ Marn/7/561 381, 406

- ${ }^{1}$ Marn/7/564 406

- ${ }^{1}$ Marn/7/570 393, 406

- ${ }^{1}$ Marn/7/573 394, 406

- ${ }^{1}$ Marn/11/1 67

${ }^{1}$ Meffr/6 406

${ }^{1}$ Mönch/5/3 257f., 260

- ${ }^{1}$ Mönch/5/4 254

- ${ }^{1}$ Mönch/5/7 395, 406

- ${ }^{1}$ Mönch/8/2 54

- ${ }^{1}$ Mönch/10/1 58, 74

${ }^{1}$ Mülich/1/1 63, 74

${ }^{1}$ Musk/1/11 44 Anm. 178

- ${ }^{1}$ Musk/1/54 302 Anm. 43

- ${ }^{1}$ Musk/1/69 406

- ${ }^{1}$ Musk/3/3 48 Anm. 197, 49 Anm. 199

- ${ }^{1}$ Musk/3/5 49 Anm. 198

${ }^{1} \mathrm{NachtK} / 1 / 2407$

- ${ }^{1}$ NachtK/5/2 391, 407

${ }^{1}$ Neidh/1 60

${ }^{1} \mathrm{Nun} / 32$ 388, 407

'PeterA/3/1 296 Anm. 27

${ }^{1}$ PeterS/1 58, 74

$-{ }^{1}$ PeterS/3 58, 74

${ }^{1} \mathrm{Pfalz} / 1 / 2$ 388, 397, 399, 407 
$-{ }^{1} \mathrm{Pfalz} / 4254$

${ }^{1} \operatorname{Regb} / 1 / 50091$

- ${ }^{1} \mathrm{Regb} / 1 / 504298$ Anm. 37

- ${ }^{1}$ Regb/1/507 407

- ${ }^{1}$ Regb/1/512 184 Anm. 5, 390

- ${ }^{1}$ Regb/1/513 407

- ${ }^{1} \operatorname{Regb} / 1 / 514253$

- ${ }^{1} \operatorname{Regb} / 1 / 522271$

- ${ }^{1}$ Regb/1/524 379 Anm. 10

- ${ }^{1} \operatorname{Regb} / 1 / 526395$

- ${ }^{1} \mathrm{Regb} / 1 / 531388$

- ${ }^{1} \mathrm{Regb} / 1 / 532136$ Anm. 2, 143

- ${ }^{1}$ Regb/1/545 407

- ${ }^{1}$ Regb/1/549 271, 309 Anm. 60

- ${ }^{1}$ Regb/1/559 389, 408

- ${ }^{1}$ Regb/1/564 408

- ${ }^{1} \mathrm{Regb} / 2 / 258$

- ${ }^{1}$ Regb/2/5 58, 257f., 271 Anm. 83

$-{ }^{1} \mathrm{Regb} / 2 / 658$

- ${ }^{1} \mathrm{Regb} / 2 / 17-18$ 257f., $260 \mathrm{f}$.

- ${ }^{1} \operatorname{Regb} / 2 / 19$ 389-391

- ${ }^{1} \operatorname{Regb} / 2 / 30$ 143, 394

- ${ }^{1}$ Regb/2/39 248, 394

- ${ }^{1} \mathrm{Regb} / 2 / 43$ 253, 254 Anm. 30

- ${ }^{1} \mathrm{Regb} / 2 / 50143$

- ${ }^{1} \mathrm{Regb} / 2 / 56253$

- ${ }^{1}$ Regb/2/57 253

$-{ }^{1} \operatorname{Regb} / 2 / 58253$

- ${ }^{1}$ Regb/2/19 408

- ${ }^{1} \operatorname{Regb} / 4 / 30408$

- ${ }^{1} \operatorname{Regb} / 4 / 39408$

- ${ }^{1} \operatorname{Regb} / 2 / 59408$

- ${ }^{1} \operatorname{Regb} / 2 / 68$ 394, 408

- ${ }^{1} \operatorname{Regb} / 3 / 3408$

$-{ }^{1} \mathrm{Regb} / 3 / 4$ 380, 383, 408

- ${ }^{1} \mathrm{Regb} / 3 / 5$ 380, 408

- ${ }^{1}$ Regb/4/501 344 Anm. 15

- ${ }^{1}$ Regb/4/505 344 Anm. 16 und 17

- ${ }^{1}$ Regb/4/507 343 Anm. 14, 408

- ${ }^{1}$ Regb/4/509 343 Anm. 14, 344 Anm. 18
- ${ }^{1} \operatorname{Regb} / 4 / 510194$ Anm. 37, 389, 392,408

- ${ }^{1} \operatorname{Regb} / 4 / 512407$

- ${ }^{1} \mathrm{Regb} / 4 / 513407$

- ${ }^{1} \mathrm{Regb} / 4 / 516343$ Anm. 14

- ${ }^{1} \mathrm{Regb} / 4 / 518$ 381, 383

- ${ }^{1}$ Regb/4/521 253, 395, 408

- ${ }^{1} \mathrm{Regb} / 4 / 522407$

- ${ }^{1}$ Regb/4/524 343 Anm. 14, 407

- ${ }^{1}$ Regb/4/526 407

- ${ }^{1} \mathrm{Regb} / 4 / 530343$ Anm. 14

- ${ }^{1} \operatorname{Regb} / 4 / 531407$

- ${ }^{1}$ Regb/4/532 343 Anm. 14

- ${ }^{1}$ Regb/4/539 381, 384 Anm. 18, 408

- ${ }^{1}$ Regb/4/545 301 Anm. 40, 407

- ${ }^{1}$ Regb/4/549 343 Anm. 14, 407

- ${ }^{1} \mathrm{Regb} / 4 / 550253$ mit Anm. 29

$-{ }^{1}$ Regb/4/557 316f., 327-329, $332 f$.

- ${ }^{1} \mathrm{Regb} / 4 / 558344$ Anm. 16

- ${ }^{1} \operatorname{Regb} / 4 / 526408$

- ${ }^{1} \mathrm{Regb} / 4 / 56466$ Anm. 32, 408

- ${ }^{1} \mathrm{Regb} / 4 / 588408$

$-{ }^{1} \mathrm{Regb} / 4 / 545$ 316f., 327-329, $332 \mathrm{f}$.

- ${ }^{1}$ Regb/4/559 343 Anm. 14, 398

- ${ }^{1} \mathrm{Regb} / 4 / 588408$

- ${ }^{1}$ Regb/4/590 344 Anm. 17

- ${ }^{1} \operatorname{Regb} / 4 / 595253$

- ${ }^{1}$ Regb/4/596 344 Anm. 19

- ${ }^{1}$ Regb/4/603 342 Anm. 10

- ${ }^{1} \operatorname{Regb} / 4 / 613$ 383f., 386 Anm. 25, 398, 408

- ${ }^{1}$ Regb/4/614 253, 255 Anm. 31

- ${ }^{1} \mathrm{Regb} / 4 / 615253$

- ${ }^{1} \operatorname{Regb} / 4 / 616$ 257, 269

- ${ }^{1} \mathrm{Regb} / 4 / 618$ 257, 408

- ${ }^{1} \mathrm{Regb} / 4 / 622408$

- ${ }^{1}$ Regb/4/632 408

- ${ }^{1}$ Regb/4/633 332 Anm. 51

- ${ }^{1}$ Regb/4/652 332 Anm. 51

- ${ }^{1}$ Regb/4/653 332 Anm. 51

- ${ }^{1} \operatorname{Regb} / 5 / 2407$

$-{ }^{1} \operatorname{Regb} / 7 / 6408$ 
- ${ }^{1} \operatorname{Regb} / 8 / 1$ 120, 121 Anm. 47

- ${ }^{1}$ Regb/9/1 296 Anm. 26

- ${ }^{1} \mathrm{Regb} / 11 / 166$

$-{ }^{1} \mathrm{Regb} / 13 / 2389 \mathrm{f}$.

$-{ }^{1} \operatorname{Regb} / 50091$

${ }^{1} \mathrm{ReiBr} / 501408$

- ${ }^{1} \operatorname{ReiBr} / 506143$

- ${ }^{1} \operatorname{ReiBr} / 507$ 143, 257f., 259 Anm. 44

- ${ }^{1} \operatorname{ReiBr} / 510143$

- ${ }^{1} \mathrm{ReiBr} / 514254$

- ${ }^{1} \mathrm{ReiBr} / 517$ 143, $154 \mathrm{f}$.

- ${ }^{1} \operatorname{ReiBr} / 520$ 143, 153

- ${ }^{1} \mathrm{ReiBr} / 524$ 143, 155

- ${ }^{1} \mathrm{ReiBr} / 526$ 143, 155

- ${ }^{1} \mathrm{ReiBr} / 527255$

- ${ }^{1} \mathrm{ReiBr} / 534143$

${ }^{1}$ ReiZw/1/242-245 148 Anm. 13

- ${ }^{1}$ ReiZw/1/508 143

- ${ }^{1}$ ReiZw/1/512 136 Anm. 2, 148 Anm. 13

${ }^{1}$ Rums/1 295 Anm. 23

- ${ }^{1}$ Rums/6/12 390

${ }^{1}$ Schil/3/1 68

- ${ }^{1}$ Schil/4/1 68

${ }^{1}$ Sigh/2/1 409

${ }^{1}$ Singer/1/1 388, 409

${ }^{1}$ Steinh/1 308

${ }^{1}$ Stol/34 151

- ${ }^{1}$ Stol/37 151

- ${ }^{1}$ Stol/500 141, 144

- ${ }^{1}$ Stol/507 141

- ${ }^{1}$ Stol/511 141, 144

- ${ }^{1}$ Stol/528 144

${ }^{1}$ Suchs/22 257, 269

${ }^{1}$ Tanh/1/500 144

- ${ }^{1}$ Tanh/1/501 377, 386 Anm. 25, 409

- ${ }^{1}$ Tanh/1/502 409

- ${ }^{1}$ Tanh/4/1 144, 149

- ${ }^{1}$ Tanh/6/5 382, 397, 409

${ }^{1}$ Ungl/1/1 383f., 387, 409
- ${ }^{1}$ Ungl/1/6 253

- ${ }^{1}$ Ungl/1/7 253, 395, 409

- ${ }^{1}$ Ungl/1/8 254

- ${ }^{1}$ Ungl/1/9 376, 391, 409

- ${ }^{1}$ Ungl/2/1 391, 409

${ }^{1}$ WaltV/8/500 144

- ${ }^{1}$ WaltV/8/501 144

- ${ }^{1}$ WaltV/8/502 144

- ${ }^{1}$ WaltV/7/501 256, 269

- ${ }^{1}$ WaltV/24/3 295 Anm. 23

- ${ }^{1} \mathrm{WaltV} / 24 / 6253$

${ }^{1}$ Wartb/1/502-504 58

- ${ }^{1}$ Wartb/2/511 257-259, 264, 266f., 276-278, 405

- ${ }^{1}$ Wartb/2/515 379 Anm. 10, 397, 405

- ${ }^{1}$ Wartb/2/518 405

- ${ }^{1} \mathrm{Wartb} / 2 / 519$ 379, 405

${ }^{1} \mathrm{Wolfr} / 2 / 1141$

- ${ }^{1}$ Wolfr/3/1 391, 409

${ }^{1}$ Zwing/1/1 409

- ${ }^{1}$ Zwing/1/2 377, 409

- ${ }^{1}$ Zwing/3/5 409

- ${ }^{1}$ Zwing/3/7 409

- ${ }^{1}$ Zwing/3/15 409

- ${ }^{1}$ Zwing/3/16 379 Anm. 10, 409

${ }^{2}$ Nochb/2 385 mit Anm. 22, 407

${ }^{2}$ Pus/13 312 Anm. 63

${ }^{2} \mathrm{~S} / 34 \quad 388,408$

$-{ }^{2} \mathrm{~S} / 35408$

$-{ }^{2} S / 36408$

$-{ }^{2} \mathrm{~S} / 38408$

$-{ }^{2} \mathrm{~S} / 45388,409$

$-{ }^{2} \mathrm{~S} / 53 \quad 380,409$

$-{ }^{2} \mathrm{~S} / 55395$ Anm. 41, 409

$-{ }^{2} \mathrm{~S} / 60379$ Anm. 10, 409

$-{ }^{2} \mathrm{~S} / 63409$

$-{ }^{2} S / 66409$

- ${ }^{2} S / 69380,409$

- ${ }^{2} \mathrm{~S} / 75380,409$

$-{ }^{2} \mathrm{~S} / 80409$

$-{ }^{2} \mathrm{~S} / 185314$

$-{ }^{2} \mathrm{~S} / 1907374$ 



\section{Abbildungsnachweis}

Die folgenden Abbildungen aus der Kolmarer Liederhandschrift wurden von der Bayerischen Staatsbibliothek München zur Verfügung gestellt (Lizenz: CC BY-NC-SA 4.0):

S. 79, Abb. 2: Bayerische Staatsbibliothek München, Cgm 4997, fol. 37rb

S. 335, Abb. 1: Bayerische Staatsbibliothek München, Cgm 4997, fol. 60r

S. 336, Abb. 2: Bayerische Staatsbibliothek München, Cgm 4997, fol. 62v

S. 337, Abb. 3: Bayerische Staatsbibliothek München, Cgm 4997, fol. 68v

Siehe:

www.digitale-sammlungen.de/de/view/bsb00105055

Alle anderen Graphiken, Tabellen und Notenbeispiele stammen von den Autorinnen und Autoren der jeweiligen Beiträge. 



\title{
Kultur, Wissenschaft, Literatur \\ Beiträge zur Mittelalterforschung
}

\author{
Herausgegeben von Thomas Bein
}

Band 1 Christa Baufeld (Hrsg.): Gesundheits- und Haushaltslehren des Mittelalters. Edition des $8^{\circ}$ Ms 875 der Universitätsbibliothek Greifswald mit Einführung, Kommentar und Glossar. 2002.

Band 2 Cornelia Schu: Vom erzählten Abenteuer zum Abenteuer des Erzählens. Überlegungen zur Romanhaftigkeit von Wolframs Parzival. 2002.

Band 3 Christoph Leuchter: Dichten im Uneigentlichen. Zur Metaphorik und Poetik Heinrichs von Morungen. 2003.

Band 4 Harald Saller: Ein neues Editionskonzept für die Schriften Notkers des Deutschen anhand von De interpretatione. 2003.

Band 5 Margreth Egidi / Volker Mertens / Nine Miedema (Hrsg.): Sangspruchtradition. Aufführung Geltungsstrategien - Spannungsfelder. 2004.

Band 6 Robert Scheuble: mannes manheit, vrouwen meister. Männliche Sozialisation und Formen der Gewalt gegen Frauen im Nibelungenlied und in Wolframs von Eschenbach Parzival. 2005.

Band 7 Detlef Goller: wan bî mînen tagen und ê hât man sô rehte wol geseit. Intertextuelle Verweise zu den Werken Hartmanns von Aue im Tristan Gottfrieds von Straßburg. 2005.

Band 8 Irmgard Gephart: Das Unbehagen des Helden. Schuld und Scham in Hartmanns von Aue Erec. 2005.

Band 9 Berenike Krause: Die milte-Thematik in der mittelhochdeutschen Sangspruchdichtung. Darstellungsweisen und Argumentationsstrategien. 2005.

Band 10 Ricarda Bauschke (Hrsg.): Die Burg im Minnesang und als Allegorie im deutschen Mittelalter. 2006.

Band 11 Alexandra Rink: Aristoteles in Sankt Gallen. Notkers des Deutschen Kategorien-Bearbeitung (Kapitel 1-17) auf Grundlage der Übersetzung und des Kommentars des Boethius. 2006.

Band 12 Barbara Nitsche: Die Signifikanz der Zeit im höfischen Roman. Kulturanthropologische Zugänge zur mittelalterlichen Literatur. 2006.

Band 13 Janina Drostel: des gerte diu edele herzoginne. Möglichkeiten und Voraussetzungen weiblicher Teilhabe am mittelalterlichen Literaturbetrieb unter besonderer Berücksichtigung von Mäzenatentum. 2006.

Band 14 Gabriele Klug: Wol ûf, wir sullen slâfen gân! Der Schlaf als Alltagserfahrung in der deutschsprachigen Dichtung des Hochmittelalters. 2007.

Band 15 Katja Rothstein: Der mittelhochdeutsche Prosa-Lancelot. Eine entstehungs- und überlieferungsgeschichtliche Untersuchung unter besonderer Berücksichtigung der Handschrift Ms. allem. 8017-8020. 2007.

Band 16 mit clebeworten underweben. Festschrift für Peter Kern zum 65. Geburtstag. Herausgegeben von Thomas Bein, Elke Brüggen, Lars Eschke, Susanne Flecken-Büttner, Tobias A. Kemper und Thomas Klein. 2007.

Band 17 Cord Meyer: Die deutsche Literatur im Umkreis König Heinrichs (VII.). Studien zur Lebenswelt spätstaufischer Dichter. 2007. 
Band 18 Martin Schubert / Jürgen Wolf / Annegret Haase (Hrsg.): Mittelalterliche Sprache und Literatur in Eisenach und Erfurt. Tagung anlässlich des 70. Geburtstags von Rudolf Bentzinger am 22.8.2006. 2007.

Band 19 Marianne Derron: Des Strickers ernsthafter König. Ein poetischer Lachtraktat des Mittelalters. Eine motivgeschichtliche Studie zur ersten Barlaam-Parabel. 2008.

Band 20 Christian Leibinnes: Die Problematik von Schuld und Läuterung in der Epik Hartmanns von Aue. 2008.

Band 21 Trude Ehlert (Hrsg.): Küchenmeisterei. Edition, Übersetzung und Kommentar zweier Kochbuch-Handschriften des 15. Jahrhunderts. Solothurn S 490 und Köln, Historisches Archiv GB $4^{\circ} 27$. Mit einem reprographischen Nachdruck der Kölner Handschrift. 2010.

Band 22 Stefan Erlei: ,Höfisch' im Mittelhochdeutschen. Die Verwendung eines Programmworts der höfischen Kultur in den deutschsprachigen Texten vor 1300. 2010.

Band 23 Robert Mohr: Präsenz und Macht. Eine Untersuchung zur Martina Hugos von Langenstein. 2010.

Band 24 Tobias Lüpges: Varianz. Studien zu einer kulturellen Verortung am Beispiel Walthers von der Vogelweide. 2011.

Band 25 Carola Susanne Fern: Seesturm im Mittelalter. Ein literarisches Motiv im Spannungsfeld zwischen Topik, Erfahrungswissen und Naturkunde. 2012.

Band 26 Nina Spangenberger: Liebe und Ehe in den erzählenden Werken Hartmanns von Aue. 2012.

Band 27 Judith Lange: Die Verslegende Veronica II. Hybridedition und Studien zur Überlieferung. 2014.

Band 28 Yücel Sivri: Mitteldeutsche Orientliteratur des 12. und 13. Jahrhunderts. 'Graf Rudolf' und 'Herzog Ernst'. Ein Beitrag zu interkulturellen Auseinandersetzungen im Hochmittelalter. 2016.

Band 29 Nicolas Mittler: Virtualität im Minnesang um 1200. Transdisziplinäre Analysen. 2017.

Band 30 Simone Loleit: Zeit- und Alterstopik im Minnesang. Eine Untersuchung zu Liedern Walthers von der Vogelweide, Reinmars, Neidharts und Oswalds von Wolkenstein. 2018.

Band 31 Magdalena Terhorst: Gottfrieds, Tristan' lesen: Prolog, Haupttext, Wortpaare. 2018.

Band 32 Florian Schmitz: Der Orient in Diskursen des Mittelalters und im „Willehalm“ Wolframs von Eschenbach. 2018.

Band 33 Yvonne Caroline Schauch: Parzivals Weg zum Artusritter. Über die Erringung höfischer Identität. 2018.

Band 34 Peter Göhler: Beiträge zu literaturgeschichtlichen Prozessen im 12. und 13. Jahrhundert. Zum Nibelungenlied, Walther von der Vogelweide und anderen Werken. 2019.

Band 35 Florian Führen: Poetische Vereinnahmung gelehrten Wissens bei Konrad von Würzburg, Frauenlob und Heinrich von Mügeln. 2019.

Band 36 Jennifer Koch: Interkulturelle Intertextualität im Widuwilt. Diskussion - Konzeption - Analyse. 2020

Band 37 Mirjam Geissbühler: Die Parzival-Handschrift L (Hamburg, Staats- und Universitätsbibliothek, Cod. germ. 6). Entstehungsprozess, Sammelkonzept und textgeschichtliche Stellung. 2021.

Band 38 Judith Lange / Eva Rothenberger / Martin Schubert (Hrsg.): Die Kolmarer Liederhandschrift und ihr Umfeld. Forschungsimpulse. 2021.

www.peterlang.com 


\section{DuEPublico}

\section{Duisburg-Essen Publications online}

UNIVERSITÄT

DE ${ }_{S} I_{S} S_{N} B_{N} U R G$

offen im Denken

$\mathbf{U b} \mid \begin{aligned} & \text { universitäts } \\ & \text { bibliothek }\end{aligned}$

Dieser Text wird via DuEPublico, dem Dokumenten- und Publikationsserver der Universität Duisburg-Essen, zur Verfügung gestellt. Die hier veröffentlichte Version der E-Publikation kann von einer eventuell ebenfalls veröffentlichten Verlagsversion abweichen.

DOI: $\quad 10.3726 / \mathrm{b} 18479$

URN: urn:nbn:de:hbz:464-20210920-111444-7

Dieses Werk kann unter einer Creative Commons Namensnennung 4.0 Lizenz (CC BY 4.0) genutzt werden. 